\title{
A INFLUÊNCIA ORGANIZACIONAL SOBRE A QUALIDADE DO PROJETO DO AMBIENTE CONSTRUÍDO
}

\author{
[Versão original]
}

Tese apresentada ao Programa de Pós-Graduação do Instituto de Arquitetura e Urbanismo da Universidade de São Paulo como parte dos requisitos para a obtenção do título de Doutor em Arquitetura e Urbanismo.

Área de concentração: Arquitetura, Urbanismo e Tecnologia Orientador: Prof. Dr. Márcio Minto Fabrício 
AUTORIZO A REPRODUCAO TOTAL OU PARCIAL DESTE TRABALHO, POR QUALQUER MEIO CONVENCIONAL OU ELETRONICO,

PARA FINS DE ESTUDO E PESQUISA, DESDE QUE CITADA A FONTE

Ficha catalográfica elaborada pela Biblioteca do Instituto de Arquitetura e Urbanismo com os dados fornecidos pelo(a) autor(a)

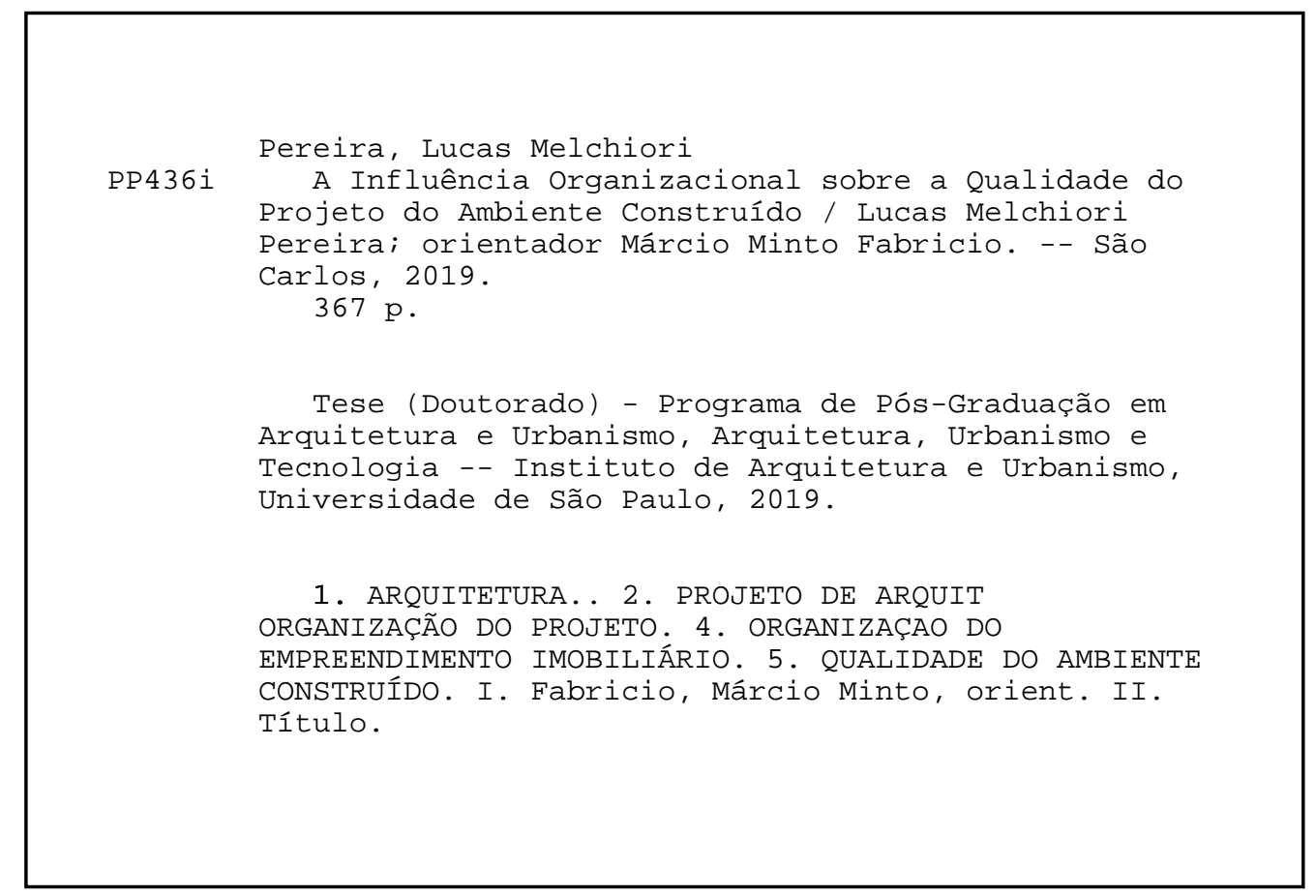

Bibliotecária responsável pela estrutura de catalogação da publicação de acordo com a AACR2: Brianda de Oliveira Ordonho Sígolo - CRB - 8/8229 
Ata de defesa de Tese do(a) Senhor(a) Lucas Melchiori Pereira no Programa: Arquitetura e Urbanismo, do(a) Instituto de Arquitetura e Urbanismo da Universidade de São Paulo.

Aos 02 dias do mês de julho de 2019, no(a) Auditório Paulo de Camargo realizou-se a Defesa da Tese do(a) Senhor(a) Lucas Melchiori Pereira, apresentada para a obtençăo do título de Doutor intitulada:

"A influência organizacional sobre a qualidade do projeto do ambiente construído"

Após declarada aberta a sessão, o(a) Sr(a) Presidente passa a palavra ao candidato para exposição e a seguir aos examinadores para as devidas arguiçōes que se desenvolvem nos termos regimentais. Em seguida, a Comissão Julgadora proclama o resultado:

\begin{tabular}{|c|c|c|c|}
\hline Nome dos Participantes da Banca & Função & Sigla da CPG & Resultado \\
\hline Márcio Minto Fabricio & Presidente & IAU - USP & Não Yotante \\
\hline Manoel Antonio Lopes Rodrigues Alves & Titular & IAU - USP & \\
\hline Sheila Walbe Ornstein & Titular & FAU - USP & Aprovedo \\
\hline Silvio Burrattino Melhado & Titular & EP - USP & MPRURTO \\
\hline Ercilia Hitomi Hirota & Titular & UEL - Externo & ADTEVADO \\
\hline José Carlos Paliari & Suplente & UFSCar - Externo & APROUAD \\
\hline
\end{tabular}

Resultado Final: APROV $\triangle D O$

Parecer da Comissão Julgadora *

Eu, Fávia Cavalianti Macambravavrei a presente ata, que assino juntamente com os(as) Senhores(as). São Carlos, aos 02 dias do mês de julho de 2019.
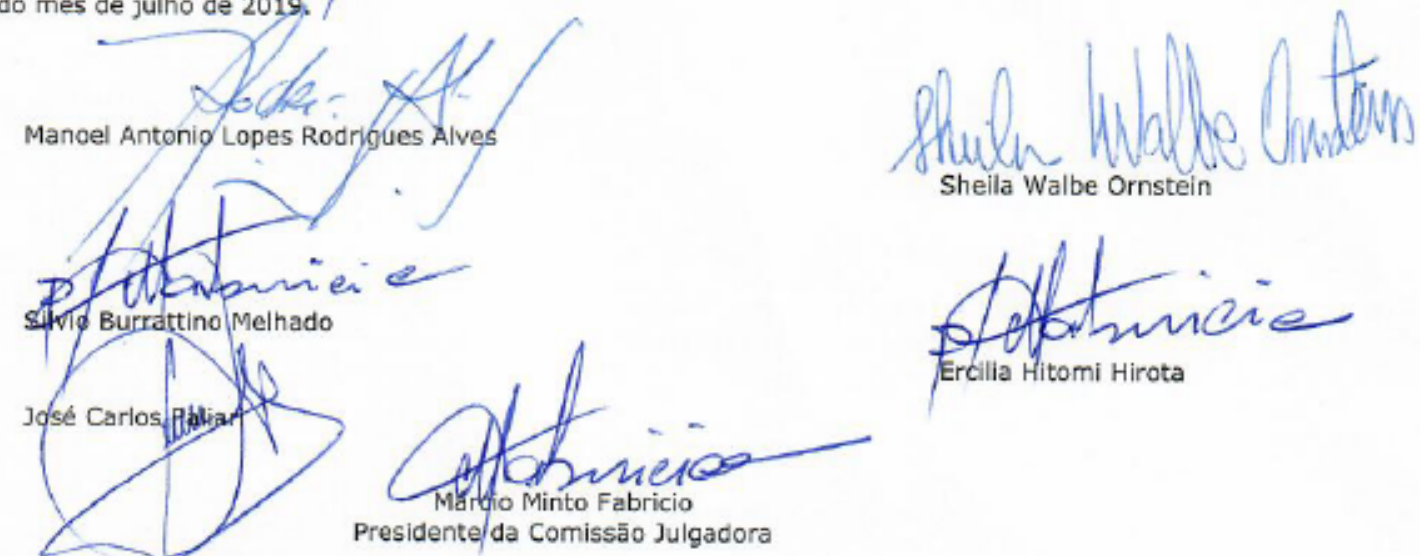

* Obs: Se o candidato fer reprovado por algtín das membros, o preenchimento do pareser é obrigatório.

A defesa foi homologada pela Comissão de Pós-Graduação em $0.3 / 07 / 2019$ e, portanto, o(a) aluno(a) _ f a z ao título de Doutor em Ciências obtido no Programa Arquitetura e Urbanismo - Área de concentração: Arquitetura, Urbanismo e Tecnologia.

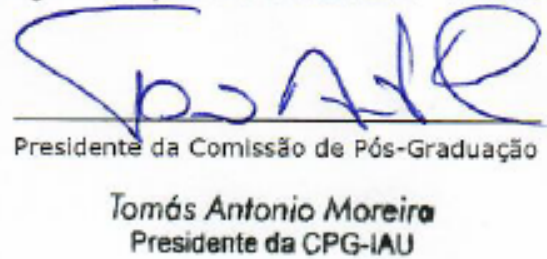



Agradeço ao professor Dr. Marcio Minto Fabricio, por orientar o trabalho da tese, bem como por colaborar em outros trabalhos de pesquisa e desenvolvimento valorosos para minha formação acadêmica.

Aos professores Dra. Ercilia Hitomi Hirota, Dra. Sheila Walbe Ornstein, Dr. José Carlos Paliari, Dr. Manoel Antonio Lopes Rodrigues Alves e Dr. Silvio Burrattino Melhado, pelas importantes contribuições à pesquisa e pelas reflexões sobre o valor dela e seus possíveis desdobramentos.

Agradeço a bolsa ofertada para esta pesquisa - Processo n 2015/06367-9, Fundação de Amparo à Pesquisa do Estado de São Paulo (Fapesp) - que viabilizou a realização do trabalho com a dedicação e as condições materiais necessárias.

Agradeço a todos os professores, funcionários e discentes do Instituto de Arquitetura e Urbanismo da Universidade de São Paulo (IAU/USP), que direta ou indiretamente ajudaram na realização da pesquisa.

Agradeço a minha família e amigos mais próximos, por todo o carinho e suporte que me dão, dia a dia. Em especial, agradeço à vó Maria e ao vô Osvaldo, que em vida me ofereceram inúmeros e valiosos ensinamentos, seja em conversas amorosas, seja pelo exemplo de vida.

A todos, obrigado. 



\section{COMO POIS INTERPRETAR \\ O QUE OS HERÓIS NÃO CONTAM? COMO VENCER O OCEANO SE É LIVRE A NAVEGAÇÃO \\ MAS PROIBIDO FAZER BARCOS?}



RESUMO

PEREIRA, L. M. A influência organizacional sobre a qualidade do projeto do ambiente construído. 2019. 367 f. Tese (Doutorado em Arquitetura e Urbanismo) Instituto de Arquitetura e Urbanismo, Universidade de São Paulo, São Carlos, 2019.

Propósito - A demanda por patamares mais elevados de qualidade do ambiente construído pressiona o setor de Arquitetura, Engenharia, Construção e Operação (AECO) a aumentar a eficiência e a eficácia com que os projetos criam e gerenciam valor para os clientes, para o negócio e para a sociedade. O proeminente desenvolvimento de novos conhecimentos, processos, práticas e ferramentas para promover tais objetivos, contudo, carece de condições organizacionais adequadas para uma aplicação bem-sucedida. Nesse sentido, oferecer subsídios para identificar, projetar, implementar e monitorar as mudanças organizacionais necessárias é uma questão-chave para consecução de projetos com a qualidade esperada. Método/Abordagem - A obtenção de subsídios teóricos e metodológicos para promover organizações de projetos mais eficientes e eficazes se iniciou com uma revisão sistemática da literatura (RSL), que identificou conceitos de teoria organizacional ligados a projetos complexos, isomorfismo, congruência e arquitetura organizacional, entre outros. A partir desse arcabouço teórico se estruturou um conjunto de estudos orientados à Design Science Research (DSR), que permitiram propor e simular uma arquitetura organizacional adequada a criar valor em projetos de empreendimentos imobiliários. Conclusões - A tese apresenta as implicações teóricas dos achados sobre a organização de projeto especificamente relacionadas ao tipo de empreendimento estudado e a outras formas de organização em AECO, ao estabelecer as relações de isomorfismo organizacional existentes e apontar a organização de rede de multiempresas orientada à criação de valor como uma alternativa mais congruente a práticas de projeto associadas à criação de valor, tais como autonomia para colaborar, gerenciamento de fluxo de informação e de valor, e BIM. Originalidade/Valor - $\mathrm{O}$ trabalho apresenta contribuições relevantes para a pesquisa e para a gestão em AECO ao estabelecer uma base metodológica e instrumental para a arquitetura organizacional mediante o mapeamento da congruência entre sistema, processo e organização de projeto de empreendimentos imobiliários, associado a diretrizes de realização e considerações acerca das condições de disseminação de mudanças organizacionais no setor.

Palavras-chave: Organização do projeto. Gerenciamento de valor. Qualidade do ambiente construído. Organização de empreendimentos imobiliários. 


\section{ABSTRACT}

\section{PEREIRA, L. M. The organizational influence on design quality of built environment. 2019. $367 \mathrm{f}$. Thesis (PhD in Architecture and Urbanism) - Institute of Architecture and Urbanism, University of São Paulo, São Carlos, 2019.}

Purpose - The demand for higher levels of built-environment quality requires from Architecture, Engineering, Construction and Operation sector (AECO) to increase the efficiency and effectiveness wherewith the projects create and manage value for customers, business and society. The development of knowledge, processes, practices and tools to promote these objectives, however, require an organizational condition appropriate for successful implementation. For this purpose, providing support to identify, design, implement, and monitor the organizational changes is a central point towards capacitating the projects to achieve the expected quality. Methodology/approach - The theoretical and methodological approach to promote more efficient and effective project organizations started with a Systematic Review of Literature which has identified a theorical frame from the organizations related to projects, isomorphism, congruence and organizational architecture, etc. From this theoretical framework a set of studies oriented to the Design Science Research (DSR) method was organized, supporting the development and simulation of an appropriate organizational architecture towards creating design value in real estate projects. Findings - Presents the theoretical implications of the design organization findings, specifically related to the approached organizational type and other organization forms from AECO, establishing the organizational isomorphism relationships and pointing the Multi-firm network organization as a more congruent alternative to the design practices associated with the creating value, as the autonomy to collaborate, information flow and value management, $B I M$, etc. Originality/value - The investigation contributions are relevant to AECO research and management, by establishing a methodological and instrumental basis to the organizational architecture by mapping the congruence among system, process and organization of real estate projects, associated with implementation guidelines and the context of organizational change spreading in the sector.

Keywords: Design organization. Value-design management. Builtenvironment quality. Real estate project organization. 


\section{LISTA DE ILUSTRAÇÕES}

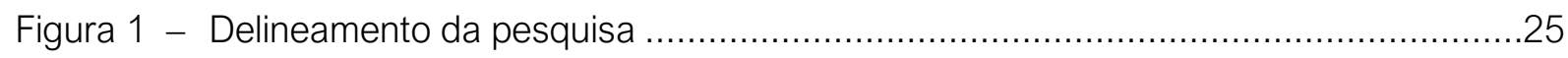

Figura 2 - Ciclo de atividades de avaliação em uma DSR .......................................... 31

Figura 3 - Fluxograma de como as matrizes se relacionam .....................................49

Figura 4 - Identificação e seleção dos trabalhos .................................................63

Figura 5 - Organização funcional e organização por produtos ..........................................71

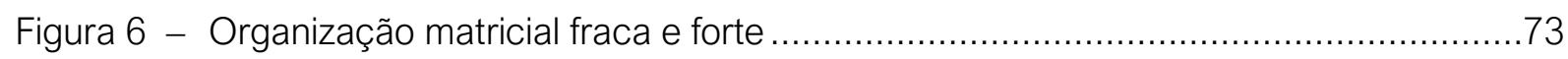

Figura 7 - Concepção do projeto - Primeiro estudo exploratório ....................................139

Figura 8 - Desenvolvimento do estudo preliminar da arquitetura da HIS...........................141

Figura 9 - Exemplo de duas opções de customização ..............................................142

Figura 10 - Exemplo de opções de fachada do estudo preliminar ...................................142

Figura 11 - Desenvolvimento do anteprojeto da arquitetura da HIS ................................144

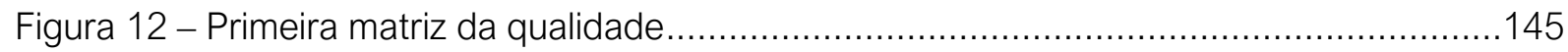

Figura 13 - Desenvolvimento do executivo da arquitetura da HIS .................................146

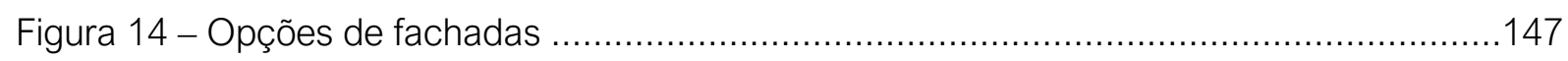

Figura 15 - Opções de customização de ambientes da HIS .........................................148

Figura 16 - Desenvolvimento dos processos de projeto da produção...............................149

Figura 17 - Processo de projeto baseado no plano de trabalho da SAVE ...........................162

Figura 18 - Atividades da fase informativa - Segundo estudo exploratório ..........................163

Figura 19 - Atividades da análise funcional - Segundo estudo exploratório ..........................164

Figura 20 - Diferença entre importância relativa da referência e do projeto ..........................166

Figura 21 - Consumo relativo de referência versus importância relativa ............................167

Figura 22 - Painel com as diretrizes para novas soluções ..........................................169

Figura 23 - Croqui de estudos preliminares realizado em mesa digital.............................169

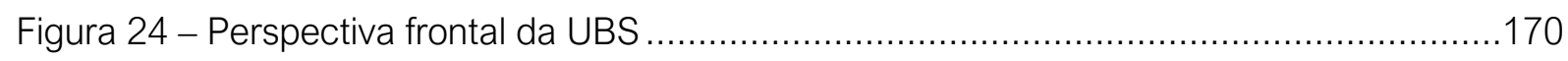

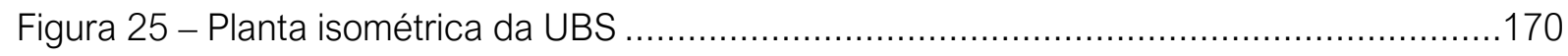

Figura 26 - Atividades da fase criativa - Segundo estudo exploratório .............................171

Figura 27 - Atividades da fase de avaliação - Segundo estudo exploratório .........................172 
Figura 28 - Gráfico Compare da proposta de UBS ................................................ 172

Figura 29 - Fluxo e processo de projeto do primeiro estudo exploratório ........................... 181

Figura 30 - Fluxo e processo de projeto do segundo estudo exploratório ............................ 181

Figura 31 - Fluxo do processo de projeto orientado ao valor ......................................... 182

Figura 32 - Perspectiva do empreendimento...................................................... 192

Figura 33 - Planta dos pavimentos do empreendimento ........................................ 193

Figura 34 - Matriz da arquitetura do sistema $\left(S_{n n}\right)$ - Empreendimento existente................... 201

Figura 35 - Matriz de interações reconhecidas $\left(R_{m m}\right)$ - Empreendimento existente ............... 202

Figura 36 - Matriz de filiação $\left(F_{m n}\right)$ - Empreendimento existente ...................................... 205

Figura 37 - Matriz de interações potenciais totais $\left(\mathrm{PT}_{\mathrm{mm}}\right)$ - Empreendimento existente .......... 206

Figura 38 - Matriz de interações potenciais fortes $\left(\mathrm{PF}_{\mathrm{mm}}\right)$ - Empreendimento existente.......... 207

Figura 39 - Matriz de congruência $\left(\mathrm{C}_{\mathrm{mm}}\right)$ - Empreendimento existente .......................... 208

Figura 40 - Correlação entre as atividades dos processos de projeto ............................... 217

Figura 41 - Reorganização das atividades da organização existente ............................... 218

Figura 42 - Iteração em espira entre anteprojeto e executivo arquitetônico ........................ 226

Figura 43 - Matriz de filiação $\left(F_{m n}\right)$ - Arquitetura organizacional ................................... 241

Figura 44 - Matriz de interações reconhecidas $\left(R_{m m}\right)$ - Arquitetura organizacional................ 242

Figura 45 - Matriz de interações potenciais fortes $\left(\mathrm{PF}_{\mathrm{mm}}\right)$ - Arquitetura organizacional .......... 243

Figura 46 - Matriz de congruência $\left(C_{m m}\right)$ - Arquitetura organizacional .............................. 244

Figura 47 - Comparação entre a matriz de congruência do empreendimento existente e a evolução da arquitetura organizacional proposta .......................... 251

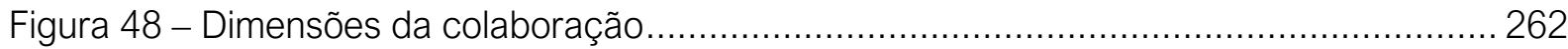

Figura 49 - Organização temporária do projeto e da obra versus organização permanente do chão de fábrica ........................................ 268

Figura 50 - Ciclo de vida do projeto de empreendimentos imobiliários............................. 325

Figura 51 - Estrutura básica da Casa da Qualidade ................................................... 334 


\section{LISTA DE QUADROS}

Quadro 1 - Síntese das dimensões estratégicas de avaliação em DSR .............................30

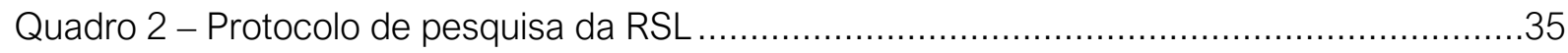

Quadro 3 - Formulário de avaliação da qualidade ....................................................36

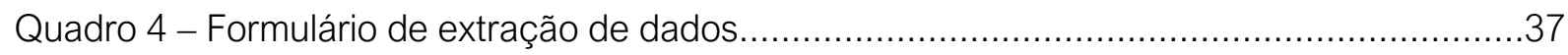

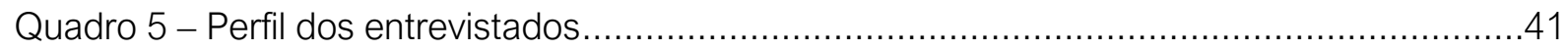

Quadro 6 - Perfil dos demais atores envolvidos no projeto .......................................42

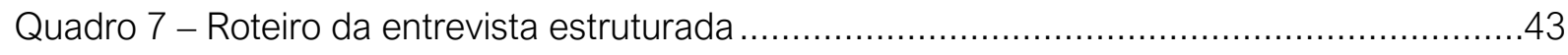

Quadro 8 - Agentes envolvidos no empreendimento............................................51

Quadro 9 - Exemplo de matriz da arquitetura do sistema $\left(S_{n, n}\right) \ldots \ldots \ldots \ldots \ldots \ldots \ldots \ldots \ldots \ldots \ldots \ldots . . .52$

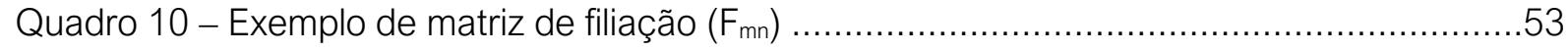

Quadro 11 - Exemplo de matriz de interações reconhecidas $\left(R_{m m}\right)$.................................54

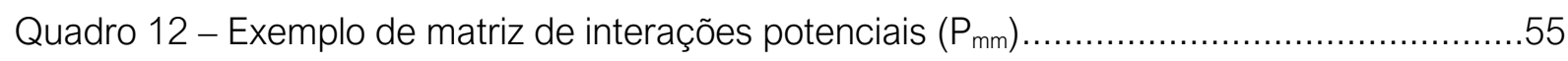

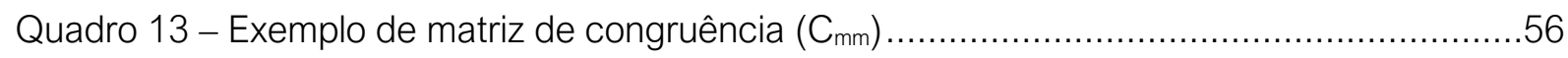

Quadro 14 - Número de ocorrência dos critérios de seleção .......................................64

Quadro 15 - Assuntos de interesse identificados na RSL por ordem de ocorrência ................65

Quadro 16 - Assuntos incidentais identificados na RSL por ordem de ocorrência ..................65

Quadro 17 - Referências mais citadas pela redação da RSL ........................................66

Quadro 18 - Diferenciação entre competência e capacidade..........................................84

Quadro 19 - Técnica de Mudge aplicada à UBS ...............................................166

Quadro 20 - Alocação de recursos na concepção da UBS ........................................173

Quadro 21 - Lista das atividades do processo de projeto orientado ao valor .......................189

Quadro 22 - Lista de componentes da arquitetura de um edifício....................................195

Quadro 23 - Lista das atividades levantadas na organização do empreendimento ................198

Quadro 24 - Lista das atividades combinadas para a arquitetura organizacional..................233

Quadro 25 - Comparação entre totais de interações observadas em cada cenário...............254

Quadro 26 - Lista de artigos muito importantes e importantes da TSL ............................340 

SUMÁRIO

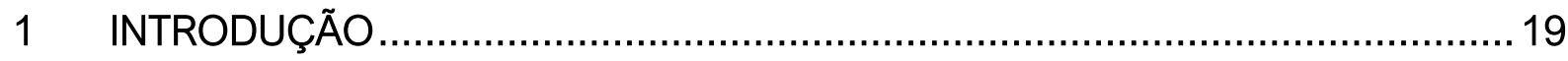

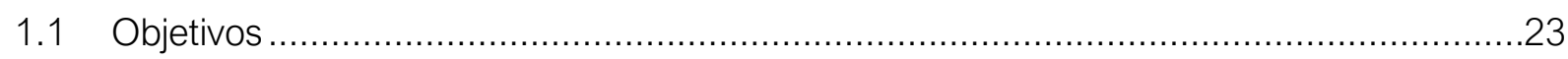

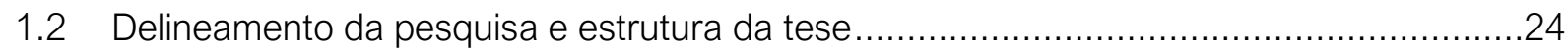

2 MÉTODO

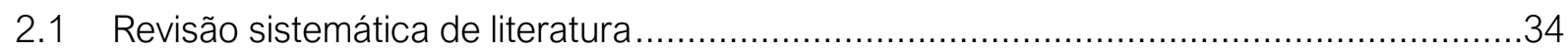

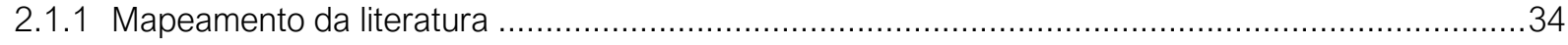

2.1.2 Avaliação e extração da literatura mapeada ..........................................................................36

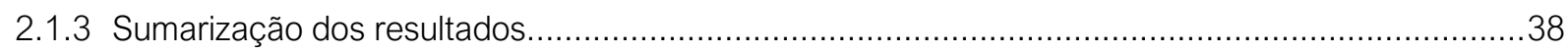

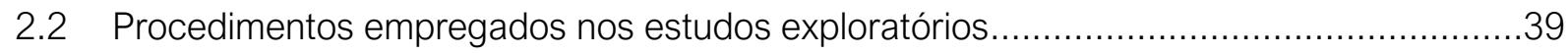

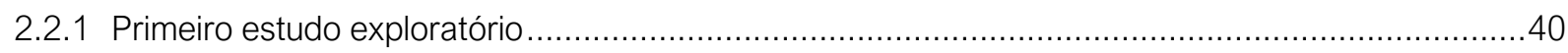

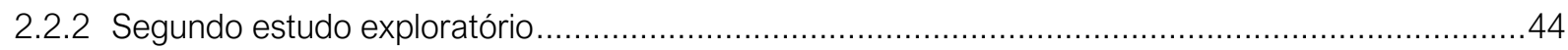

2.3 Diagramação do processo de projeto orientado ao valor..............................................48

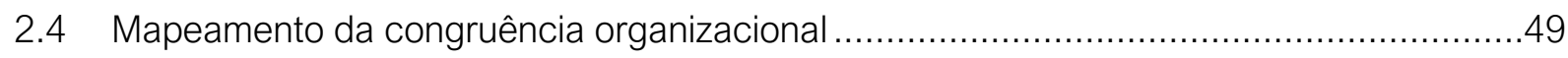

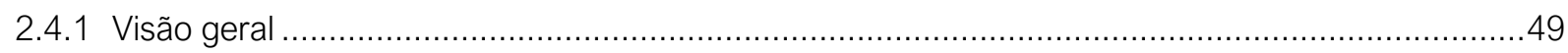

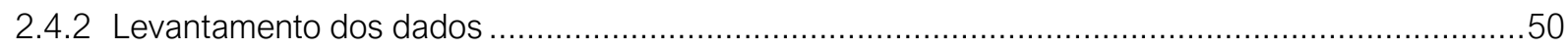

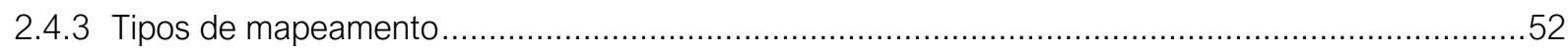

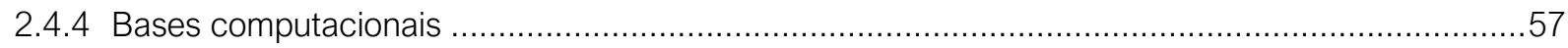

2.4.5 Interpretação do mapeamento ......................................................................................... 


\section{A INFLUÊNCIA ORGANIZACIONAL SOBRE A QUALIDADE DO PROJETO DE EMPRENDIMENTOS IMOBILIÁRIOS .....................................................61}

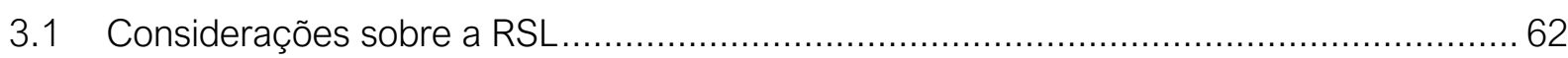

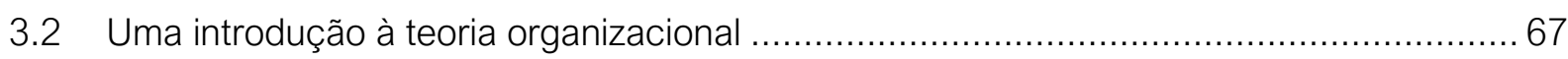

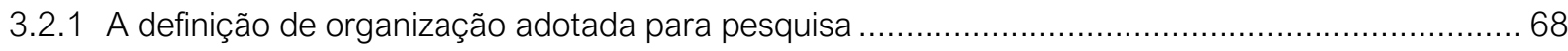

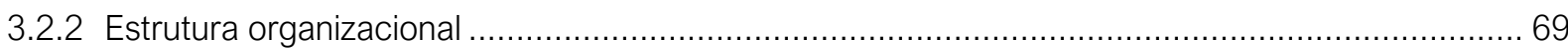

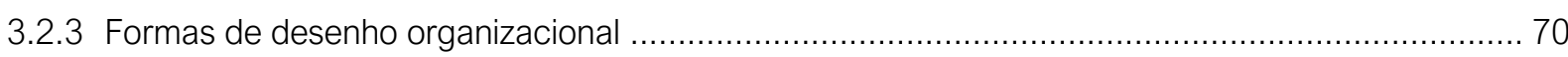

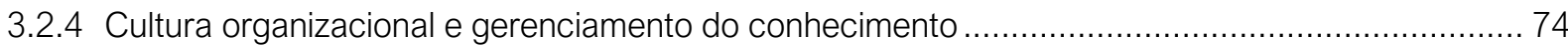

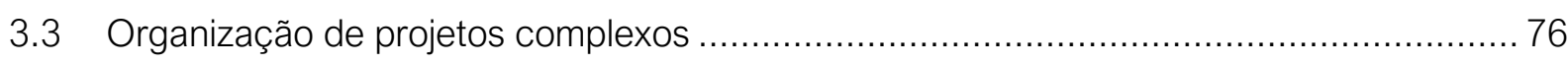

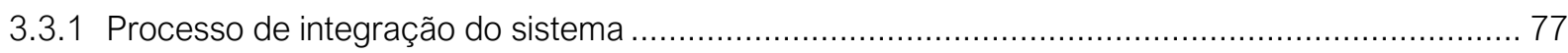

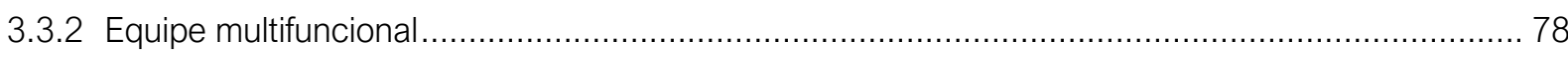

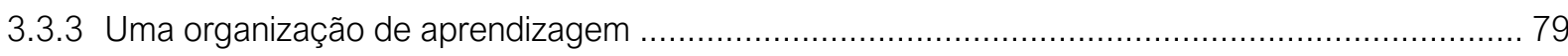

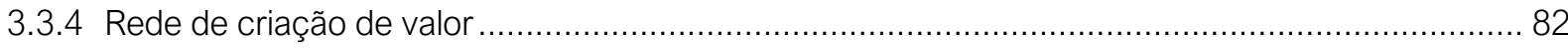

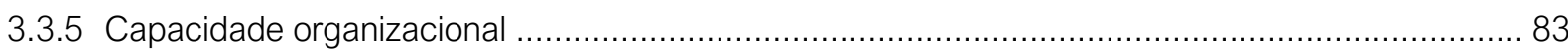

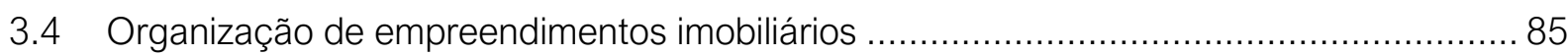

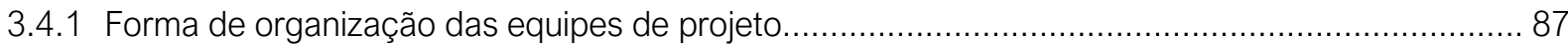

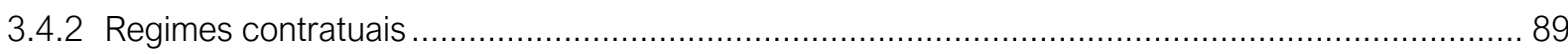

3.4.3 Gerenciamento do projeto e autonomia da equipe de projeto ................................................. 93

3.4.4 Integração informacional e integração organizacional........................................................... 95

3.4.5 Cadeia de suprimentos, gerenciamento predial e ciclo de vida do edifício .................................... 98

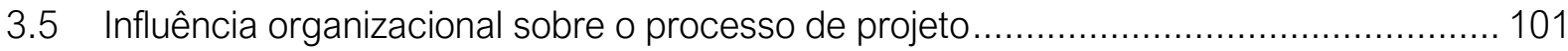

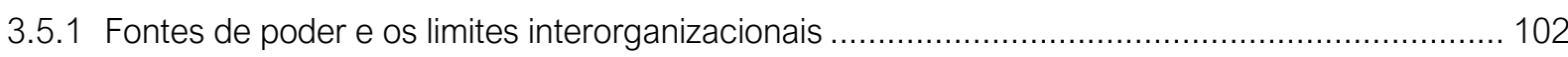

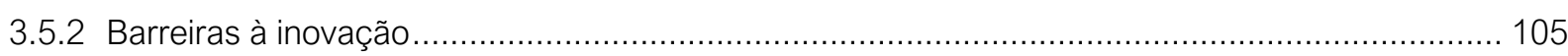

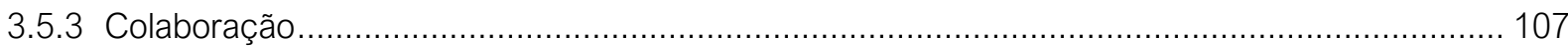

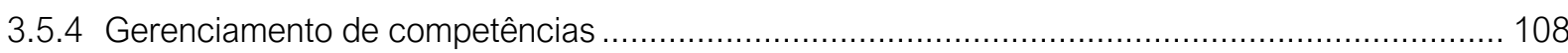

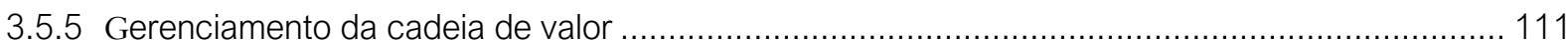

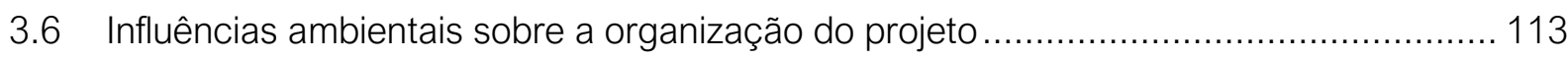

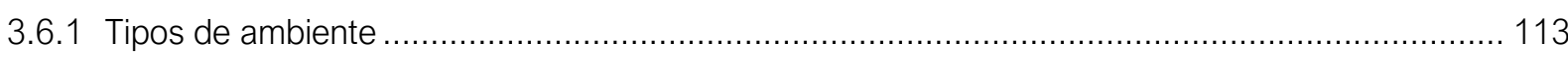

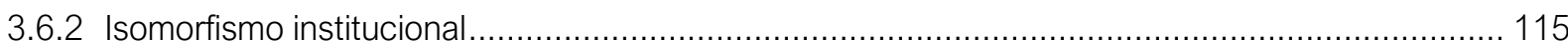

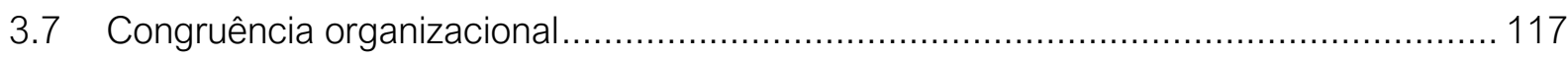

3.7.1 A congruência organizacional do isomorfismo arquitetônico ................................................. 118

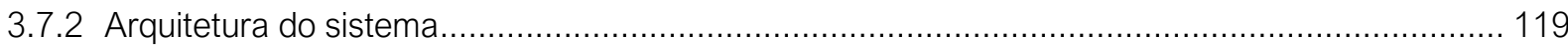

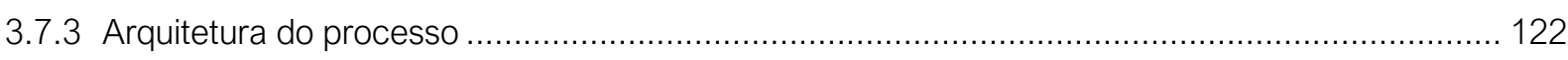

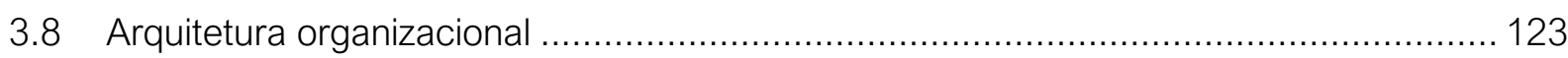

3.8.1 Alinhamento entre a arquitetura da organização e o ambiente.................................................. 124

3.8.2 Interfaces de interações do sistema, do processo e da organização........................................... 126

3.8.3 Modularização orientada pela competência organizacional .................................................. 128

3.8.4 Modelagem e simulação da arquitetura organizacional ....................................................... 130

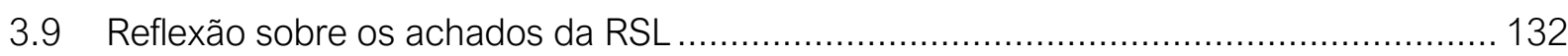




\section{ANÁLISE DAS CONDIÇÕES ORGANIZACIONAIS PARA GERENCIAR A CRIAÇÃO DE VALOR DURANTE O DESENVOLVIMENTO DO PROJETO ........137}

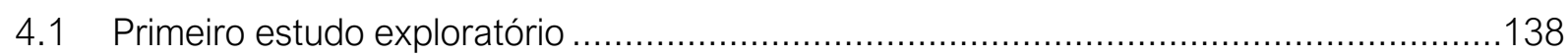

4.1.1 Caracterização do processo de projeto em um contexto de escassez.....................................138

4.1.2 Análise das entrevistas com profissionais da equipe de projeto ...........................................150

4.1.3 Discussão dos resultados da análise comparada das entrevistas ............................................158

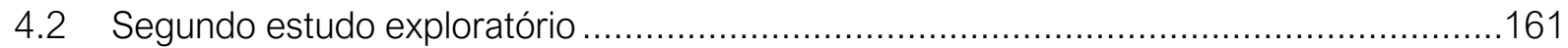

4.2.1 Caracterização das atividades de concepção orientadas ao valor ...........................................161

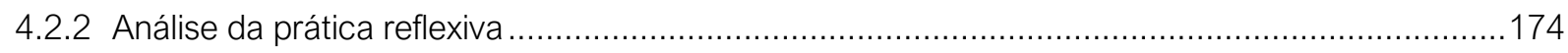

5 ARQUITETURA DO PROCESSO DE PROJETO ORIENTADO AO VALOR ........177

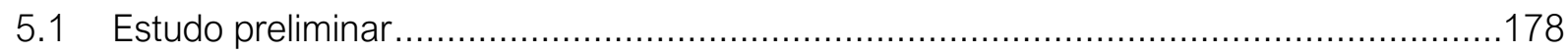

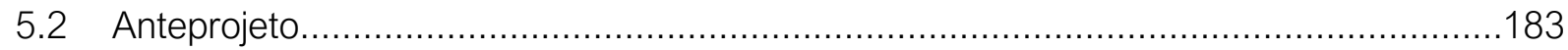

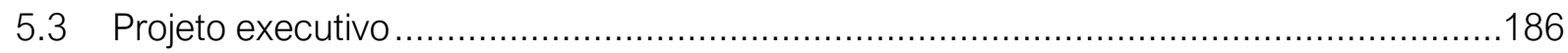

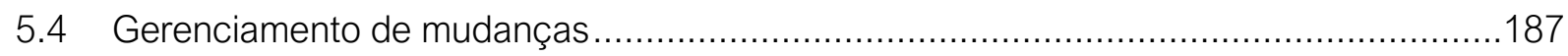

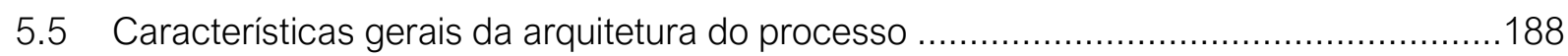

6 MAPEAMENTO DA CONGRUÊNCIA ORGANIZACIONAL DE UM EMPREENDIMENTO IMOBILIÁRIO ......................................................... 191

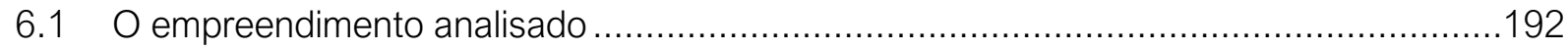

6.2 Análise da congruência organizacional de um empreendimento imobiliário existente ....194

6.2.1 Arquitetura do sistema: o caso da edificação de uma unidade residencial .................................194

6.2.2 Organização existente do empreendimento analisado .........................................................197

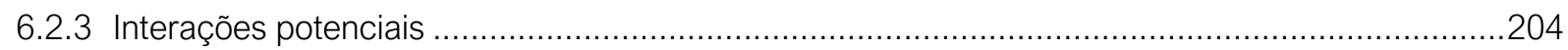

6.2.4 Comparações entre as interações reconhecidas e potenciais ...................................................209

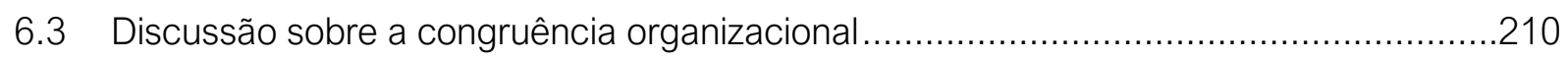

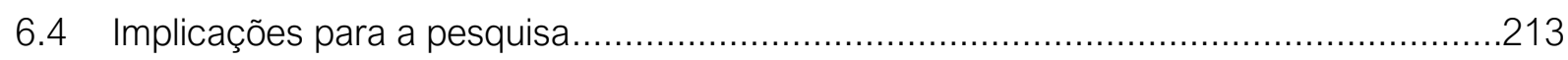

7 ARQUITETURA ORGANIZACIONAL PARA O PROCESSO DE PROJETO ORIENTADO AO VALOR......................................................................... 215

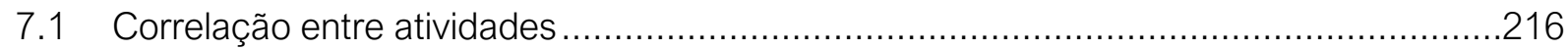

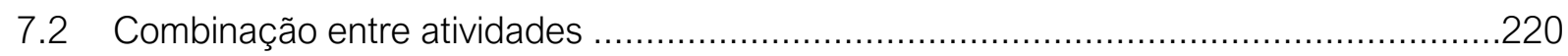

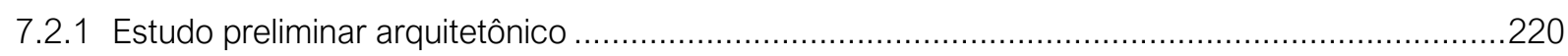

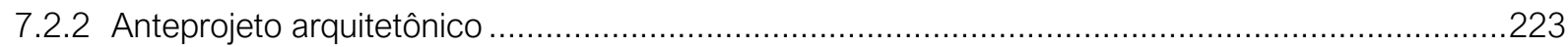

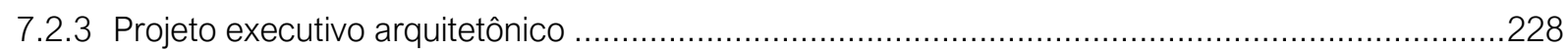

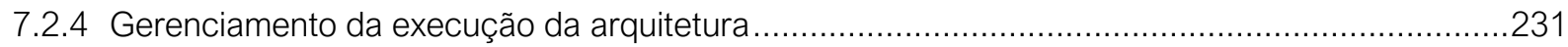

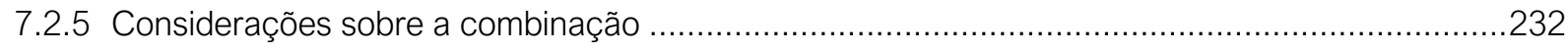

7.3 Análise da congruência organizacional da arquitetura organizacional proposta .............235 


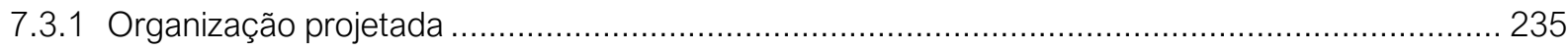

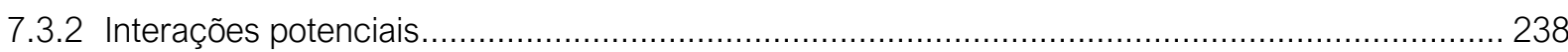

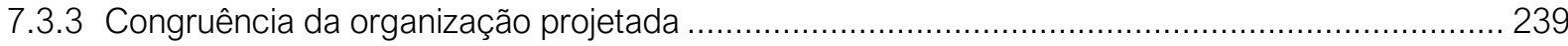

7.4 Discussão sobre a aplicação do mapeamento da congruência à arquitetura

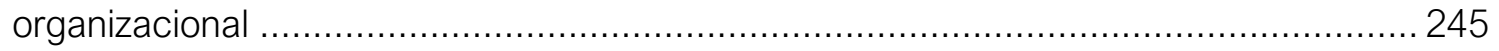

\section{ANÁLISE COMPARATIVA ENTRE A CONGRUÊNCIA DA ORGANIZAÇÃO EXISTENTE E A DA ARQUITETURA ORGANIZACIONAL PROPOSTA...............247}

8.1 Comparação entre os mapeamentos da congruência organizacional ......................... 248

8.2 Confrontação com a perspectiva das especialidades ........................................... 254

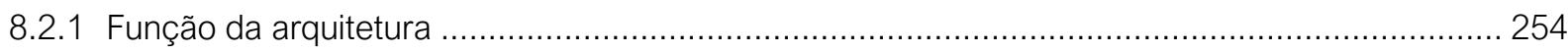

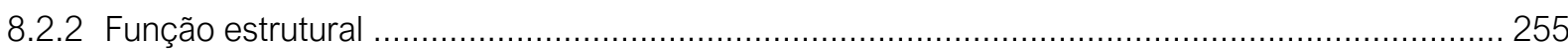

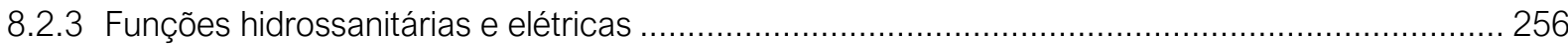

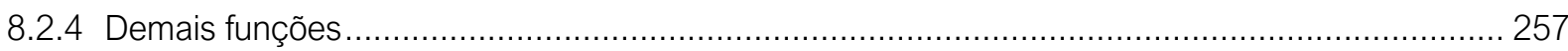

8.3 Considerações sobre a arquitetura organizaconal .............................................. 258

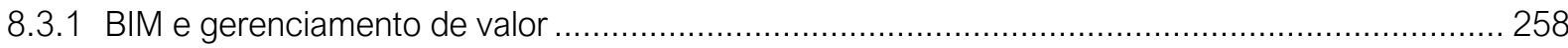

8.3.2 Cooperação entre as organizações do empreendimento ......................................................... 260

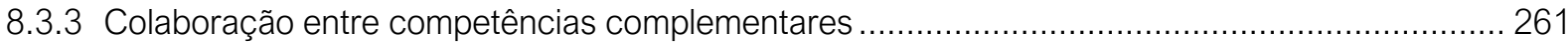

8.3.4 Organização matricial e orientada ao projeto ....................................................................... 263

8.3.5 Equipe de projeto autônoma e gerenciamento de mudanças .................................................. 264

8.3.6 Ciclos de melhoria contínua orientados à diferenciação, APO e gerenciamento predial .............. 265

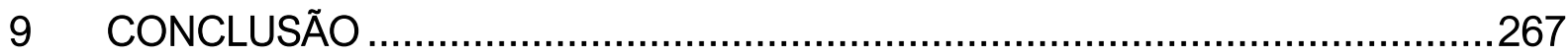

9.1 Implicações teóricas dos achados sobre a organização do projeto............................ 271

9.1.1 O empreendimento estudado e outras formas de organização em AECO................................. 271

9.1 .2 Isomorfismo institucional e congruência organizacional ...................................................... 273

9.1.3 Organização de rede de multiempresas orientada à criação de valor .......................................... 274

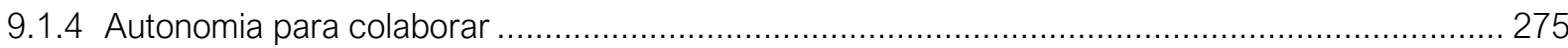

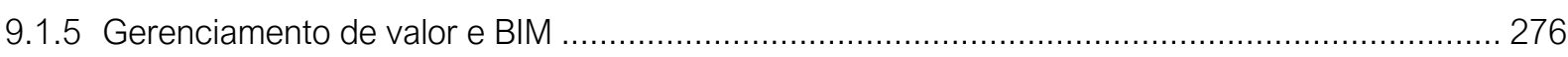

9.2 Mapeamento da congruência organizacional para pesquisa e gestão ...................... 277

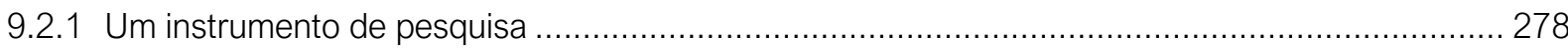

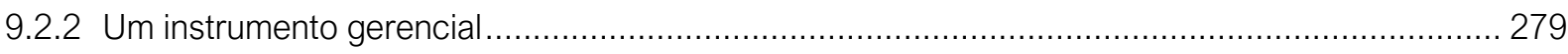

9.2.3 Diretrizes gerais da proposição de uma arquitetura organizacional ............................................. 279

9.3 Condições de disseminação de mudanças organizacionais....................................... 282

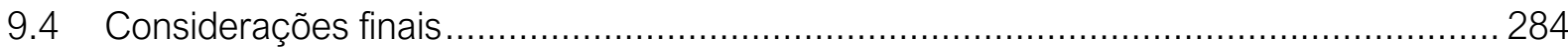

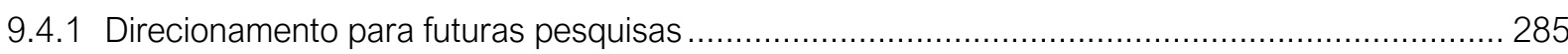

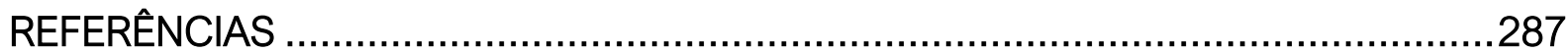


Apêndice A Acrônimos e glossário

Apêndice B Revisão sistemática da literatura (RSL)

Apêndice C Modelos de "Termo de consentimento informado" e de "Solicitação de informações documentais e entrevista"

Apêndice D Orientações para a realização do mapeamento da congruência organizacional.

Apêndice $E$ Matriz da arquitetura do sistema $\left(S_{n n}\right)$ - Edifício ...........................................357

Apêndice $F$ Matriz de interações reconhecidas $\left(R_{m m}\right)$ - Empreendimento existente ..............358

Apêndice $G$ Matriz de filiação $\left(F_{m n}\right)$ - Empreendimento existente .......................................359

Apêndice $\mathrm{H}$ Matriz de interações potenciais totais $\left(\mathrm{PT}_{\mathrm{mm}}\right)$ - Empreendimento existente........360

Apêndice I Matriz de interações potenciais fortes $\left(\mathrm{PF}_{\mathrm{mm}}\right)$ - Empreendimento existente ........361

Apêndice J Matriz de congruência $\left(\mathrm{C}_{\mathrm{mm}}\right)$ - Empreendimento existente...............................362

Apêndice K Matriz de interações reconhecidas $\left(R_{m m}\right)$ - Arquitetura proposta........................363

Apêndice $L$ Matriz de filiação $\left(F_{m n}\right)$ - Arquitetura proposta................................................364

Apêndice M Matriz de interações potenciais totais $\left(\mathrm{PT}_{\mathrm{mm}}\right)$ - Arquitetura proposta ..................365

Apêndice $\mathrm{N}$ Matriz de interações potenciais fortes $\left(\mathrm{PF}_{\mathrm{mm}}\right)$ - Arquitetura proposta .................366

Apêndice $O$ Matriz de congruência $\left(C_{m m}\right)$ - Arquitetura proposta......................................367 



\section{INTRODUÇÃO}

A epígrafe de uma tese é um tributo ou reverência a outro autor, que, por meio de suas palavras, às vezes de expressão não acadêmica, pode desvelar o sentido do trabalho e situar o leitor com mais síntese e beleza que o pesquisador. É uma possibilidade de exprimir as questões que nos impactam com estilo e talento. O fragmento do poema de Andrade (2012) é um alerta para o risco de interpretar os desafios que se apresentam a uma atividade humana sem compreender as limitações que determinadas condições impõem. O convite a vencer o oceano, no caso, responde pelas novas e crescentes expectativas acerca da qualidade do ambiente construído (AC), que pressionam os setores produtivos ligados à arquitetura, engenharia, construção e operação (AECO) a buscar patamares de eficiência e de eficácia inéditos.

Esse desafio apresenta grande complexidade e coleciona um conjunto de questões-chave ligadas a fatores econômicos, sociais, ambientais e tecnológicos, que demandam a adoção de uma abordagem multidisciplinar. Entre as questões que circundam a compreensão da qualidade do AC se destacam a discussão sobre como se dá o ciclo de vida do projeto do empreendimento e do próprio edificio, sobre como a percepção de valor é diferente para os diversos agentes envolvidos e sobre como o reconhecimento e a acomodação das expectativas e necessidades decorrentes dessas percepções de valor alteram a compreensão do que significa projetar o edificio de uma casa, de um comércio, de um hospital, de uma escola, de um parque e de toda a diversidade de fins para os quais empreendimentos imobiliários são concebidos, que constituem, na prática, os elementos do AC. 
As respostas para essas e outras questões correlatas estão atualmente dispersas, codificadas em conhecimentos, habilidades, procedimentos e ferramentas de um conjunto de disciplinas em franca evolução. A fim de listar alguns temas incidentais ao desenvolvimento da tese, podem-se destacar as estratégias e os procedimentos de gerenciamento e criação de valor, como captura e hierarquização de requisitos dos clientes (CONCEIÇÃO; IMAI; URBANO, 2015), Target Value Design (TVD) (BALLARD, 2012; MORAIS; FABRICIO; RUSCHEL, 2018; PEREIRA et al., 2018), Quality Function Deployment (QFD) (DIKMEN; TALAT BIRGONUL; KIZILTAS, 2005; RUIZ et al., 2010; ARAGÃO et al., 2016), Avaliação Pós-Ocupação (APO) (ORNSTEIN; ROMÉRO, 1992; MARQUES; BORGES, 2012; CONCEIÇÃO; IMAI; URBANO, 2015), etc.; análises de desempenho do ciclo de vida do edificio (KOHLER; LÜTZKENDORF, 2002; EADIE et al., 2013; BUENO; PEREIRA; FABRICIO, 2018), de eficiência energética, de desempenho térmico, lumínico e acústico (WEYTJENS; ATTIA; OTHERS, 2010) e de flexibilidade e customização em massa (BARLOW et al., 2014; CONCEIÇÃO, 2015; GUADANHIM et al., 2015; AZUMA, 2016), etc.

A tese também tangencia temas que abordam problemas do fluxo de trabalho e de informação e que articulam soluções tecnológicas e sociais para integrar os processos interdependentes de uma complexa e fragmentada rede de criação de valor. Trata-se de uma complexidade ligada ao fato de essa rede ser composta temporariamente de agentes de diferentes empresas, que estão envolvidos em apenas uma ou em poucas tarefas específicas e que estão comprometidos com interesses individuais, não necessariamente alinhados aos objetivos do projeto. A esse respeito se destacam as estratégias e procedimentos coordenação, cooperação e colaboração (KYNG, 1991; KLEINSMANN, 2006; AUSTIN et al., 2007; PEREIRA, 2014); de gerenciamento de mudanças de projeto (PMI, 2017), de gerenciamento de riscos (AKINTOYE; MACLEOD, 1997; ÖZTAŞ; ÖKMEN, 2004, 2005), de gerenciamento da cadeia de suprimentos (FIXSON, 2005; AZAMBUJA; O'BRIEN, 2009), de gerenciamento predial e de negócios imobiliários (JENSEN et al., 2013; NEIVA; FARIA; BIZELLO, 2014; HASTJARJO et al., 2015; VAN DER VOORDT, 2017); e de integração digital e BIM (SUCCAR; SHER; WILLIAMS, 2012, 2013; EASTMAN et al., 2014; VASS; KARRBOM; GUSTAVSSON, 2015; LINDGREN, 2016; ÇIDIK et al., 2017; ZHENG et al., 2017). 
É uma variedade considerável de assuntos que não poderiam ser adequadamente abordados sem tornar ainda mais extenso e enfadonho o texto desta tese, o que pode ser compensado com a leitura de autores aqui citados, que já o fizeram com mais desenvoltura e propriedade. Todavia, a fim de não tornar este texto ininteligível para quem não tenha familiaridade com alguns dos temas incidentais sem consultar as referências, é possível ter acesso a uma definição sintética dos principais itens abordados no glossário disponibilizado no Apêndice A .

Além disso, na prática profissional, tal variedade de assuntos implica tantas novas formas de conhecimento e habilidades para criar valor com a eficiência e a eficácia esperadas que nenhuma pessoa sozinha tem condições de deter todas as competências necessárias para realizar satisfatoriamente esse trabalho em um projeto de empreendimento imobiliário. Dessa forma, a livre navegação por este oceano de possibilidades depende da articulação de pessoas com competências específicas, complementares e interdependentes, em um novo arranjo do processo de projeto, que acomode adequadamente as atividades que se estendem sobre todo o ciclo de vida do projeto e do edificio, para criar e gerenciar o valor do projeto.

A articulação das competências e dos recursos necessários para se perseguir a qualidade esperada em empreendimentos imobiliários por meio do desenvolvimento de projetos orientados à criação de valor significa mudar a forma como o projeto se organiza. E, assim como são projetadas novas arquiteturas de edificios para responder às novas demandas e expectativas da sociedade, é preciso reconhecer a importância de se projetarem novas arquiteturas organizacionais para orientar o projeto a criar valor. $\mathrm{Ou}$ ainda, para recuperar a mensagem da epígrafe, pode-se afirmar que não reconhecer a necessidade de mudanças estruturais na organização do projeto, situando-o adequadamente no ciclo de vida do edifício, equivale a proibir a construção de barcos adequados para navegar o oceano de possibilidades.

A ideia de que exista resistência no setor de AECO a mudanças que aumentem a eficiência e a qualidade do projeto, ainda mais se essas mudanças também trazem beneficios à própria rede de empresas que compõem um empreendimento imobiliário, pode parecer descabida ou, pelo menos, contraintuitiva. Afinal se espera de uma organização produtiva uma postura racional em face da organização de seus processos e 
que essa racionalidade direcione a adequação do trabalho a ser realizado para reduzir custos e aumentar o valor de seus produtos e serviços.

O que se observa, porém, é o predomínio da reprodução de formas de organização já consagradas, ou seja, cujo desempenho seja historicamente reconhecido e legitimado pelo ambiente de negócios, independentemente da racionalidade. O resultado é que empresas tendem a se organizar de forma semelhante a outras empresas que atuam no mesmo mercado. As razões para esse isomorfismo organizacional podem estar relacionadas tanto ao conservadorismo de gestores diante de um cenário de incerteza e ao constrangimento de parceiros, clientes e instituições profissionais, empresariais e governamentais, que não reconhecem que outros arranjos possam equivaler ou se sobrepor aos já existentes, quanto ao fato de esse isomorfismo estar normativamente estabelecido, por força de lei, regulamento, edital, normas técnicas, etc. Em todos esses casos não é a racionalidade que determina a manutenção ou a mudança de alguma característica organizacional, mas, sim, a intuição de que uma forma de organização é melhor por estar difundida, legitimada.

Todavia, diante de um ambiente em evolução ou dinâmico - como o setor imobiliário tem se configurado diante das crescentes demandas sociais, econômicas e ambientais -, a emergência de mudanças organizacionais tem sido adotada como estratégia de diferenciação de mercado sustentável bem-sucedida, principalmente em setores que lidam com projetos complexos, como ocorrem em AECO. Assim como há na maioria dos empreendimentos imobiliários, os casos dessas organizações bem-sucedidas relatados pela literatura especializada são compostos de redes de empresas. Porém, diferentemente do que se observa em AECO, os relatos apontam que essas organizações em redes apresentam altos níveis de inovação e de criação de valor.

O que distingue as redes de empresas que compõem empreendimentos imobiliários das organizações de redes de empresas com alto desempenho parece ser a chave para compreender e discutir quais são as mudanças organizacionais que, implantadas, permitirão à AECO superar as limitações históricas e galgar novos níveis de eficiência e eficácia na criação de valor. 


\subsection{OBJETIVOS}

O reconhecimento da importância de promover mudanças nas organizações de projeto suscita um questionamento quanto à maneira como projetar novas arquiteturas organizacionais de forma a incorporar as competências e os recursos necessários para lidar com a emergência das novas expectativas do ambiente. Assim, a tese apresenta uma abordagem explicativa-propositiva, ao discutir por que e como promover uma arquitetura organizacional de projetos de empreendimento imobiliário orientada à criação de valor.

Trata-se de um objetivo ambivalente, que invoca um tipo de pesquisa construtiva e se traduz na multiplicidade de objetivos específicos, ligados tanto a questões ontológicas, para explicar o funcionamento do artefato proposto, como a questões epistemológicas do conhecimento abordado, a fim de acrescentar alguma contribuição teórica relevante ao conhecimento. Visando orientar o delineamento da pesquisa, o objetivo principal foi desdobrado em três objetivos específicos:

(1) discutir as condições organizacionais que influenciam a qualidade de projetos de empreendimentos imobiliários;

(2) propor uma arquitetura organizacional congruente para integrar o processo de projeto por meio do gerenciamento de valor como forma de promover maior qualidade arquitetônica a empreendimentos imobiliários; e

(3) apresentar as contribuições teóricas da pesquisa sobre a influência da congruência organizacional para a qualidade do projeto em empreendimentos imobiliários e quais são as implicações práticas da proposição de uma arquitetura organizacional para promover a congruência organizacional em um empreendimento existente.

Como é de se supor, a persecução desses objetivos depende do encadeamento de procedimentos, apoiados por uma abordagem multimétodos capaz de sistematizar dados, informações e conhecimentos de ordem teórica e prática. $\mathrm{O}$ encadeamento lógico entre os objetivos postos, os procedimentos e métodos empregados e os resultados alcançados são apresentados a seguir. 


\subsection{DELINEAMENTO DA PESQUISA E ESTRUTURA DA TESE}

O planejamento dos procedimentos realizados para atender aos objetivos da pesquisa originou da decomposição dos três objetivos específicos em 11 ações estruturadas conforme indicado no delineamento da pesquisa (Figura 1). A conformação dessas ações, embora apresente um sentido predominante indicado pelas setas, sugere um arranjo baseado em ciclos de independência e iteratividade que foram observados na prática.

As ações 1.1, 1.2 e 1.3 foram planejadas para oferecer as bases teóricas da pesquisa, abrangendo uma revisão de métodos de pesquisa e uma revisão sistemática ligada à organização do projeto e à arquitetura organizacional. As três ações constituem o primeiro ciclo de pesquisa, orientado a contextualizar o problema sob a perspectiva dos conhecimentos existentes, qualificando a discussão e subsidiando os passos seguintes da pesquisa.

O segundo ciclo é composto da combinação da ação 1.2 (ligada ao objetivo 1) com as ações 2.1 e 2.2 (ligadas ao objetivo 2). Juntas, essas ações foram planejadas para consolidar empiricamente o conhecimento sobre o processo de projeto, levantado pela revisão da literatura e aplicado a dois estudos exploratórios, e para subsidiar a concepção da arquitetura de um processo de projeto orientada ao valor.

A arquitetura do processo também pertence ao terceiro ciclo da pesquisa, que agrupa as ações 1.3, 2.2 e 2.4. Esse ciclo combina os conhecimentos e os procedimentos identificados na revisão da literatura para construir uma arquitetura organizacional de projeto orientada ao valor mediante o tratamento das informações recolhidas da arquitetura do processo de projeto e de uma organização existente.

O quarto ciclo corresponde à validação do artefato por meio da aplicação ou simulação em um contexto real. Enquanto a arquitetura organizacional de 2.4 pressupõe uma avaliação de congruência interna, a ação 2.5 compara a congruência mapeada da organização de um empreendimento imobiliário real, realizada em 2.3,com a congruência da arquitetura organizacional proposta para integrar as capacidades de criação de valor a essa organização de projeto existente. 

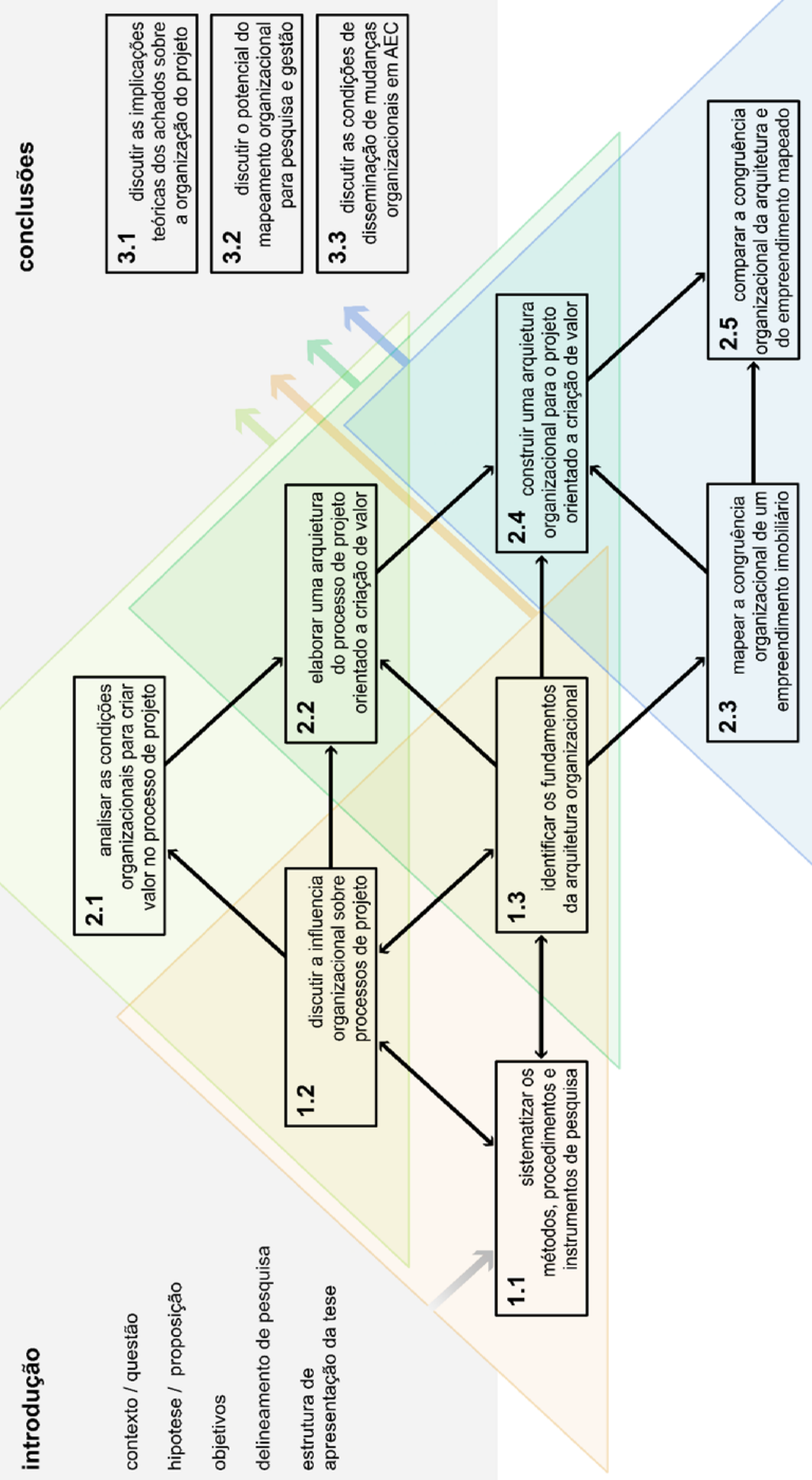

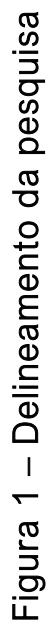




\section{Descrição individual das ações indicadas no delineamento da pesquisa: (Figura 1)}

(1.1) Identificar os métodos, procedimentos e instrumentos adequados para discutir de forma sistemática e propositiva a influência organizacional sobre a qualidade do projeto de empreendimentos imobiliários.

(1.2) Discutir os conceitos de organização e quais são as características particulares de organizações de projetos complexos e de empreendimentos imobiliários; qual é a influência da organização sobre a qualidade do projeto de empreendimentos imobiliários; qual é a influência ambiental sobre a organização do projeto; e quais são as características de uma organização de projeto orientada à criação de valor.

(1.3) Identificar os fundamentos para a proposição de arquiteturas organizacionais de projetos de ambiente construído que considerem as características discutidas em 1.2.

(2.1) A partir da teoria levantada em 1.2, analisar as condições para a criação de valor no processo de projeto de empreendimentos imobiliários, considerando os limites, facilitadores e barreiras observados na prática.

(2.2) Elaborar uma arquitetura do processo de projeto orientado a criação de valor, que considere as condições organizacionais discutidas em 1.2, 1.3 e 2.1.

(2.3) Mapear a congruência organizacional de um empreendimento imobiliário típico e analisar a relação entre organização, processo e sistema sob a perspectiva teórica levantada em 1.1, 1.2 e 1.3.

(2.4) Desenvolver uma arquitetura organizacional para incorporar o processo de projeto orientado ao valor, desenvolvido em 2.2, e à organização existente, mapeada em 2.3.

(2.5) Avaliar a congruência da arquitetura organizacional resultante, desenvolvida em 2.4, comparando o desempenho da organização proposta com a existente, mapeado em 2.3.

(3.1) Discutir a contribuição teórica dos achados sobre a organização do projeto de empreendimentos imobiliários.

(3.2) Discutir o potencial de adoção do mapeamento da congruência organizacional como um procedimento de pesquisa e de gerenciamento estratégico de empreendimentos imobiliários.

(3.3) Discutir as condições de disseminação de organização de projeto orientada à criação de valor e qual é a contribuição potencial dessa disseminação para empreendimentos imobiliários e para a qualidade do ambiente construído. 
A apresentação dos resultados obtidos com a execução de cada ação prevista está distribuída na redação da tese ao longo de nove capítulos, incluindo aí a introdução e a conclusão. Essa correlação entre delineamento da pesquisa e estrutura da tese é indicada a seguir.

O capítulo 1 introduz a discussão do problema de pesquisa e antecipa alguns conceitos discutidos em 1.1, 1.2 e 1.3.

O capítulo 2 apresenta as abordagens multimétodos empregadas para realizar a pesquisa e descreve os procedimentos adotados para cada estudo, conforme definido em 1.1.

O capítulo 3 aprofunda a discussão sobre a organização do projeto e as condições organizacionais para criar valor no processo do projeto, realizada em 1.2, apresentando os resultados de uma revisão sistemática da literatura que discute os conceitos, as formas de análises e os casos de organizações de projetos complexos e, mais especificamente, de empreendimentos imobiliários.

O capítulo 4 apresenta a análise das condições para a adoção do gerenciamento de valor em organizações de projeto, realizada em 2.1.

O capítulo 5 apresenta a proposição de uma arquitetura para o processo de projeto orientado ao valor conforme os resultados de 2.2 .

O capítulo 6 apresenta o mapeamento da congruência organizacional de um empreendimento imobiliário típico, realizado em 2.3.

O capítulo 7 apresenta a arquitetura organizacional desenvolvida em 2.4, construída a partir da combinação da organização mapeada com o processo de projeto orientado ao valor proposto.

O capítulo 8 apresenta a avaliação comparativa, proposta em 2.5, realizada entre a congruência mapeada no empreendimento existente e a congruência simulada na arquitetura organizacional.

O capítulo 9 apresenta a conclusão, que abrange a discussão teórica sobre a organização do projeto de empreendimentos imobiliários, feita em 3.1; a discussão sobre o potencial de adoção do mapeamento da congruência organizacional como um procedimento de pesquisa e de gerenciamento, em 3.2; e o debate sobre as condições de disseminação das práticas de gerenciamento de valor, delineadas em 3.3. Encerra-se com as recomendações para a continuidade da pesquisa. 
Uma particularidade dessa estrutura diz respeito à localização da revisão. Como o levantamento bibliográfico foi realizado sistematicamente, por meio de uma revisão sistemática da literatura (RSL), pareceu pertinente apresentar os procedimentos adotados para a RSL antes de seus resultados, o que antecipou todo o capítulo de métodos, em desacordo com a apresentação convencional da redação de uma tese.

Além dos capítulos descritos, os apêndices da tese foram disponibilizados após as referências bibliográficas. Estes abrangem um glossário, protocolos e matrizes que serviram de fonte de dados para a pesquisa. 


\section{MÉTODO}

O potencial prático e teórico que a Design Science Research (DSR) representa para os campos de desenvolvimento e pesquisa aplicada, como é o caso de arquitetura e engenharias, vem acompanhado de novos desafios metodológicos, principalmente acerca da validação dos artefatos propostos. Embora já haja um consistente arcabouço de estratégias para realizar a validação em DSR, é importante observar que determinado artefato apresenta limitações e condições específicas para avaliação, relacionadas às disciplinas e atividades envolvidas, que precisam ser consideradas para que a pesquisa seja adequadamente orientada.

Como é uma pesquisa construtiva, a DSR tem por objetivo fundamental construir e avaliar dado artefato prático/teórico. Assim, é comum aos métodos DSR que se separem explicitamente as atividades de diagnóstico, construção e avaliação, com o objetivo de atribuir maior rigor tecnológico aos instrumentos de avaliação da pesquisa. Essa característica é atribuída ao desenvolvimento de métodos pioneiros de DSR nas engenharias de sistemas, engenharias de operações e sistemas de informações, em que o desenvolvimento da validação instrumental de sistemas tecnológicos predominava sobre o desenvolvimento de métodos de validação epistêmica (SONNENBERG; VOM BROCKE, 2012).

As deficiências decorrentes desse modelo com orientação operacional foram identificadas e discutidas por Sein et al. (2011), que sugeriram um método de construção e avaliação simultânea que permitisse a reflexão e a aprendizagem imediata sobre o progresso alcançado, antecipando revisões de melhoria no contexto organizacional para a concepção do artefato. Embora menos comuns, as abordagens simultâneas trouxeram mais complexidade à definição das estratégias de DSR, que impulsionaram o desenvolvimento de critérios de avaliação dos artefatos orientados tanto à consolidação das teorias gerais do projeto como à relevância prática do artefato, segundo sua importância, adequação e acessibilidade (ROSEMANN; VESSEY, 2008; AIER; FISCHER, 2011). 
De forma mais pragmática, outras pesquisas visaram estabelecer diretrizes para identificar quais estratégias DSR adotar considerando o que se está avaliando e quando e como essa avaliação deve ocorrer (SONNENBERG; VOM BROCKE, 2012). O enquadramento proposto por Sonnenberg e Brocke (2012) confere uma correlação entre diferentes características de pesquisas, segundo as dimensões sugeridas por diferentes teóricos da DSR para o artefato (Quadro 1).

\section{Quadro 1 - Síntese das dimensões estratégicas de avaliação em DSR}

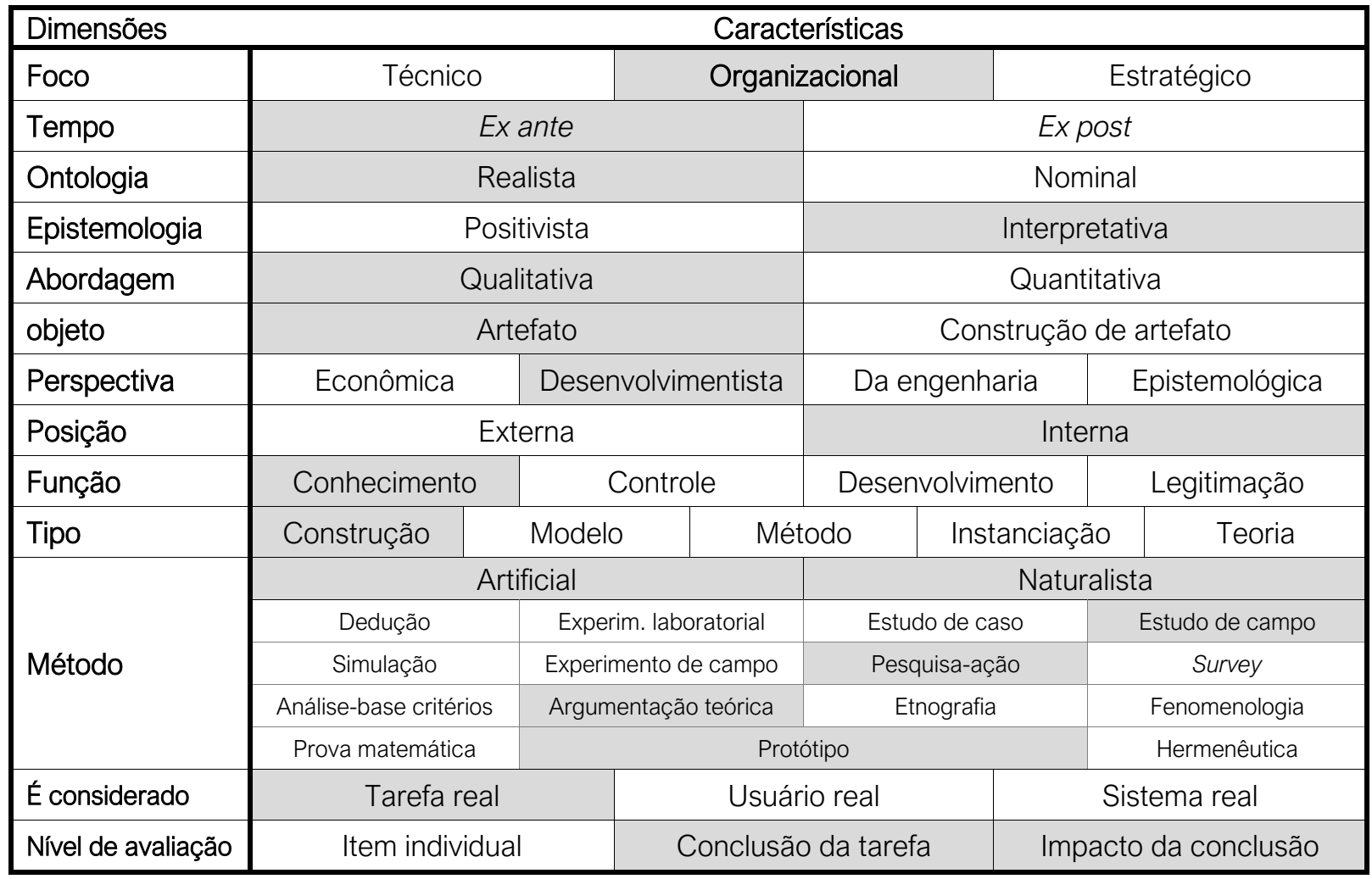

Fonte: adaptado de Sonnenberg e Vom Brocke (2012) e de Cleven, Gubler e Hüner (2009).

A indicação ex ante e ex post aponta o tempo em que o artefato é avaliado, se antes de sua adoção-construção ou se depois da concepção-construção dele (CLEVEN; GUBLER; HÜNER, 2009). Como se pode observar, as pesquisas com foco organizacional podem abranger ambos os tempos para avaliação. A Figura 2 mostra um esquema cíclico para o processo DSR coerente com a pesquisa realizada, composto de identificação do problema, concepção, construção e utilização do artefato, intercalados por atividades de avaliação simultâneas (SONNENBERG; VOM BROCKE, 2012). 
Figura 2 - Ciclo de atividades de avaliação em uma DSR

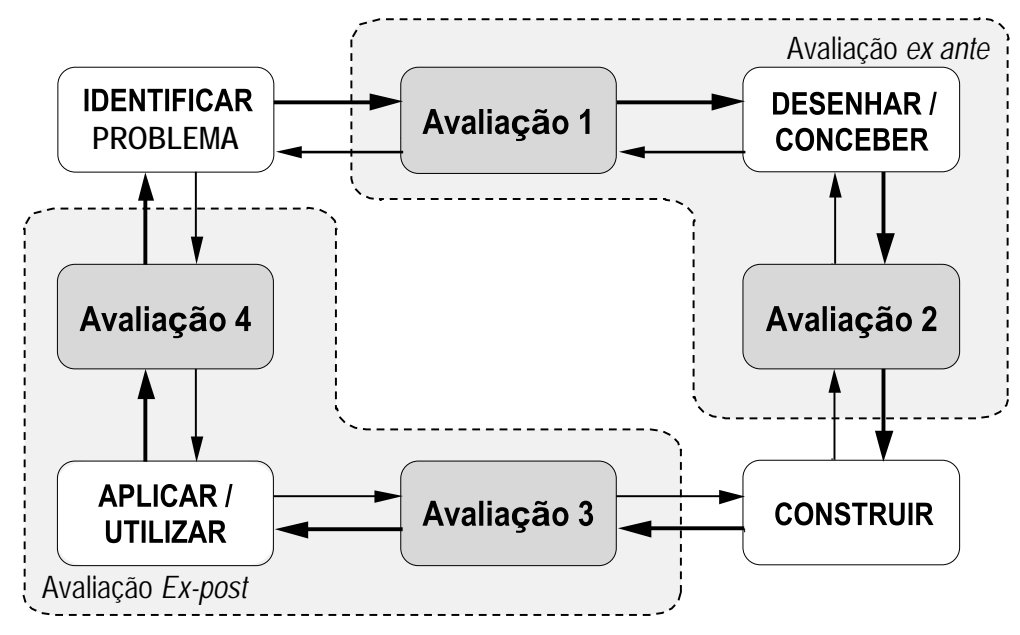

Fonte: baseada em Sonnenberg e Vom Brocke (2012).

Cabe uma ressalva sobre a admissão de certas limitações em pesquisas organizacionais largamente reconhecidas academicamente quanto à recorrente impossibilidade de implantar e avaliar o uso do artefato durante o período da pesquisa, o que implica a aceitação de uma validação parcial ou simulada. A compreensão das implicações práticas dessa condição é apresentada e discutida com mais clareza na descrição das etapas de desenvolvimento e avaliação, descritas a seguir.

A atividade de identificação e justificação do problema (Avaliação 1) visa assegurar a relevância prática e a novidade teórica do problema formulado. Para tanto se deve demonstrar que este representa uma lacuna do conhecimento que implique a inadequação ambiental/contextual do trabalho ou dos artefatos existentes. A aplicação de métodos de raciocínio dedutivo, como uma RSL, e de entrevistas com especialistas ou grupos de interesse é adequada à justificativa do problema de pesquisa em DSR (SONNENBERG; VOM BROCKE, 2012). Para o presente estudo foi adotada uma revisão da literatura sobre as práticas ligadas ao processo de projeto e feita uma RSL sobre arquitetura e desenho organizacional, que subsidiou um debate consistente das condições de projeção do artefato organizacional e de sua relevância para o campo do conhecimento.

A atividade de concepção e avaliação do desenho do artefato (Avaliação 2) deve demonstrar como o artefato apresenta uma resposta ao problema levantado. Trata-se de uma avaliação virtual, ou artificial, pois o artefato ainda não foi construído. O que são avaliados nesta fase são critérios de coerência e pertinência, que podem estar ligados a 
sua viabilidade, acessibilidade, facilidade de compreensão, simplicidade, estética, integridade ou nível de detalhamento. Para tanto é possível empregar métodos como raciocínio lógico ou dedutivo, prova matemática, demonstração ex ante, simulação, benchmarking, entrevista com especialistas ou grupos de interesse (SONNENBERG; VOM BROCKE, 2012).

Os estudos exploratórios sobre o processo de projeto orientado para o valor apresentam uma abordagem indutiva sobre as implicações da aplicação de práticas e instrumentos de gerenciamento de valor e do gerenciamento de informação orientada ao valor para o processo de projeto. As informações ligadas ao primeiro estudo foram obtidas por meio de entrevistas estruturadas aplicadas aos profissionais envolvidos no projeto. As informações do segundo estudo foram obtidas por meio de uma discussão semiestruturada que abordou a evolução da experiência de projeto vivenciada pela equipe de projeto que participou do segundo estudo, quando foi provocada a aplicar as lições aprendidas no primeiro estudo, promovendo mudanças no processo durante o decorrer do projeto. Essa etapa ofereceu uma base empírica para identificar na prática as dinâmicas previstas na teoria abordada sobre qualidades do processo de projeto orientado ao valor e propor uma arquitetura a esse processo.

A construção e experimentação do artefato (Avaliação 3) corresponde à transição entre o estágio ex ante e o ex post da pesquisa. Deve demonstrar preliminarmente se o artefato construído responde adequadamente ao problema e como se comporta ao interagir com elementos da organização existente. Nessa fase é possível inferir informações da iteração (real ou potencial) com o ambiente que permitam refletir sobre a utilidade do artefato e orientar um eventual redesenho (Avaliação 2). Tanto métodos artificiais como naturalistas de avaliação se aplicam, podendo assim abordar itens, tarefas e sistemas reais para verificar o desempenho segundo critérios de facilidade de uso, eficácia e eficiência, operacionalidade, robustez ou adequação ao mundo real. São empregados métodos como demonstração e experimento com protótipos, benchmarking, survey, entrevista com especialistas ou grupos de interesse (SONNENBERG; VOM BROCKE, 2012).

A abordagem dedutiva adotada nessa fase consiste em um estudo de campo em que o desempenho de uma organização existente foi analisado por meio do mapeamento da congruência organizacional. Sobre esse mapeamento foram desenvolvidas propostas de arquitetura organizacional para modificar a organização mapeada de forma a subsidiar o 
processo de projeto orientado ao valor. A formulação desses cenários com maior ou menor mudança na organização permite simular na fase seguinte a congruência organizacional de diferentes arranjos, de forma a validar ou revisar as orientações teóricas para a adoção do gerenciamento de valor no processo de projeto que ainda não foram verificadas sistematicamente na prática profissional em AECO.

O estudo da utilização (Avaliação 4) deve demonstrar a aplicabilidade e a utilidade do artefato na prática e, ao mesmo tempo, contribuir para a teoria, discutindo os princípios de projeto subjacentes ao artefato. São aplicadas avaliações naturalistas que lidem com critérios como a generalidade da aplicação do artefato, o impacto sobre o meio ambiente e o usuário, sua consistência interna ou externa. Para tanto são adotados métodos diversos, como estudo de caso, experimento de campo, survey, entrevista com especialistas ou grupos de interesse e simulação analítica (SONNENBERG; VOM BROCKE, 2012).

É comum em pesquisas ligadas à teoria organizacional que a validação externa de utilização não seja possível. Trata-se de uma limitação contingencial das pesquisas do tipo em que se observa pouca receptividade do mercado e dificuldade de mobilizar os atores necessários para realizar mudanças no nível estratégico da empresa. Todavia, é necessário que uma validação interna seja realizada, com a adoção de procedimentos de construção e avaliação consistentes, replicáveis e coincidentes com a teoria que embasou a pesquisa construtiva, para que a contribuição teórica resultante seja válida e relevante ao debate, uma vez que os achados podem revelar inconsistências entre a teoria-base e a realidade observada (LUKKA, 2003).

Para atender a essa condição de validação de utilização, a simulação da aplicação do artefato foi instrumentalizada adotando-se o mesmo método utilizado no estudo de campo da organização existente. O mapeamento de congruência organizacional se baseia em procedimentos consolidados pela teoria dos domínios, cuja adequação para analisar o desempenho organizacional por meio da correlação entre arquitetura do sistema, do processo e da organização foi demonstrada e já é aplicada no gerenciamento estratégico de empresas baseadas em projeto. Este e demais métodos utilizados na pesquisa são detalhados a seguir. 


\subsection{REVISÃO SISTEMÁTICA DE LITERATURA}

A revisão sistemática da literatura (RSL) é um método estruturado de levantamento, seleção e avaliação da literatura que visa reduzir a ocorrência de vieses de seleção e aferição ao tornar explícitas, verificáveis e reproduzíveis as condições de uma pesquisa para a definição do estado da arte e das lacunas do conhecimento (GOUGH; OLIVER; THOMAS, 2012).

A RSL envolve três etapas principais, ligadas (1) ao mapeamento das pesquisas existentes, (2) à avaliação da íntegra dos estudos de mapeamento e extração de informações pertinentes para revisão e (3) à sumarização das descobertas em uma síntese dos resultados da pesquisa.

\subsubsection{Mapeamento da literatura}

A realização do mapeamento envolve a definição das características de busca por meio da construção de um protocolo de pesquisa (1.1). O protocolo deve deixar explícito o objetivo e questões a serem respondidas, os keywords e possíveis sinônimos a serem combinados na busca, a definição de critérios de seleção dos estudos - como a identificação das fontes de busca, línguas e janela temporal consideradas - e critérios de exclusão dos trabalhos identificados (Quadro 2).

$\mathrm{Na}$ atividade de identificação dos estudos (1.2) os estudos primários e secundários foram recuperados por meio de mecanismos de busca de bancos de dados científicos. Além disso, trabalhos não indexados, mas referenciados pelos estudos recuperados foram identificados posteriormente, na extração dos dados, e incorporados à pesquisa diante da constatação de sua relevância e disponibilidade de acesso. Na identificação a pesquisa não discriminou tipos de objetivos ou métodos e se restringiu à identificação de publicações indexadas, recuperadas em portais de busca acadêmica por meio da combinação de palavras-chave. Também foi estabelecido um recorte temporal de até 12 anos, considerando o ano final o de 2019.

Considerou-se nesta pesquisa que a identificação de ao menos um critério de exclusão era suficiente para a não aceitação do trabalho. Já os itens de inclusão tiveram como objetivo apoiar a seleção e a organização dos trabalhos aceitos para extração, orientando a leitura segundo o interesse representado pelo critério. 
Quadro 2 - Protocolo de pesquisa da RSL

\begin{tabular}{|c|c|}
\hline ITEM & CONTEÚDO \\
\hline Pesquisadores & $\begin{array}{l}\text { Lucas Melchiori Pereira (desenvolvedor) } \\
\text { Márcio Minto Fabricio (revisor) }\end{array}$ \\
\hline \multicolumn{2}{|l|}{ PROPOSIÇÃO } \\
\hline Objetivo & $\begin{array}{l}\text { Caracterizar a organização do processo de projeto em AECO, } \\
\text { integrando conhecimentos, ambiente, práticas, competências, rotinas e } \\
\text { ferramentas disponíveis para promover a arquitetura organizacional. }\end{array}$ \\
\hline Questão principal & $\begin{array}{l}\text { Como organizar do processo de projeto visando a maior eficiência e } \\
\text { eficácia? }\end{array}$ \\
\hline Questões secundarias & $\begin{array}{l}\text { - O que é organização do processo de projeto? } \\
\text { - Quais são os principais tipos existentes de organização do processo } \\
\text { de projeto? } \\
\text { - Como analisar a organização do processo de projeto? }\end{array}$ \\
\hline \multicolumn{2}{|c|}{ CRITÉRIOS DE SELEÇÃO } \\
\hline Bases de dados & Scopus; Web of Science; Engineering Village; ACM \\
\hline $\begin{array}{l}\text { Critérios de admissão } \\
\text { de fontes }\end{array}$ & $\begin{array}{l}\text { - Disponibilidade digital on-line ou do acervo USP } \\
\text { - Base de dados indexadas } \\
\text { - Artigos de revistas e congressos, monografias } \\
\text { - Adição de fontes recomendadas por especialistas } \\
\text { - Adição de precedência dos trabalhos levantados }\end{array}$ \\
\hline Linguagens & Inglês e português (uso de keywords equivalentes) \\
\hline Keywords & $\begin{array}{l}\text { Organization; organizational design; design processes; project } \\
\text { processes; organizational architecture; built environment; BIM real } \\
\text { estate. }\end{array}$ \\
\hline Critérios de inclusão & $\begin{array}{l}\text { - Teoria da organização do projeto } \\
\text { - Teoria da organização de projetos complexos } \\
\text { - Método de análise organizacional } \\
\text { - Inovação em algum aspecto da organização do projeto } \\
\text { - Influência na organização do projeto em AECO } \\
\text { - Exemplo de organização do projeto em AECO } \\
\text { - Exemplo de organização de empreendimento em AECO }\end{array}$ \\
\hline Critérios de exclusão & $\begin{array}{l}\text { - Teoria ou exemplo de organização de atividade não ligada ao projeto } \\
\text { - Dubiedade das keywords, por não corresponder ao tema pesquisado } \\
\text { - Organização do projeto citada retoricamente } \\
\text { - Exemplo de organização de projeto não relacionado à AECO } \\
\text { - Metadados ou documento completo não acessíveis } \\
\text { - Não publicado entre } 2007 \text { e } 2019 \text { (12 anos) } \\
\text { - Artigo não científico; não atende aos critérios de qualidade }\end{array}$ \\
\hline \multicolumn{2}{|c|}{ FORMULÁRIOS DE AVALIAÇÃO E EXTRAÇÃO } \\
\hline Critérios de qualidade & Quadro 3 \\
\hline Critérios de extração & Quadro 4 \\
\hline
\end{tabular}




\subsubsection{Avaliação e extração da literatura mapeada}

A avaliação dos artigos selecionados se inicia com a avaliação da qualidade formal dos trabalhos (2.1). Os questionamentos sobre qualidade do trabalho respondem a critérios de clareza, estrutura e coerência conceitual e metodológica. Os arquivos que não atingiram a pontuação mínima de sete pontos nos critérios de avaliação da qualidade (Quadro 3) foram excluídos das atividades seguintes da RSL.

Quadro 3 - Formulário de avaliação da qualidade

\begin{tabular}{|l|l|}
\hline Questões de qualidade & Opções \\
\hline A introdução ao problema é clara? & Sim (1) \\
Não (0) \\
\hline A revisão da literatura condiz com o problema da pesquisa? & Sim (3) \\
Parcialmente (1) \\
Não (0)
\end{tabular}

A extração das informações de pesquisa (2.2) tem como objetivo subsidiar o processo de análise para a sumarização por meio da classificação e da organização do conteúdo dos estudos considerados adequados na avaliação da qualidade. $\mathrm{O}$ formulário de extração apresenta campos de respostas textuais e de múltipla escolha, de preenchimento obrigatório ou facultativo (Quadro 4).

Nesse formulário cabe destaque ao campo "Indique os assuntos abordados", em que, diferentemente das demais opções de múltipla escolha, as respostas foram complementadas ao longo do processo de avaliação e extração de forma a considerar a diversidade de assuntos abordados nos estudos. O campo de antecedências permite relacionar pesquisas citadas no trabalho cuja leitura é relevante à discussão. 
Quadro 4 - Formulário de extração de dados

EXTRAÇÃO DE INFORMAÇÕES

TIPO DE INFORMAÇÃO

\begin{tabular}{|l|l|}
\hline Descreva interesse identificado no texto & Texto \\
\hline Indique os assuntos abordados & Lista de múltipla escolha \\
\hline Lista aberta & Lista de múltipla escolha \\
\hline Classifique os assuntos de interesse &
\end{tabular}

Teoria organizacional, arquitetura organizacional, método de diagnóstico organizacional, congruência organizacional, organização do projeto, organização da AECO, influência organizacional sobre a qualidade do projeto, influências ambientais sobre a organização do projeto

Indique as áreas de estudo Lista de múltipla escolha

Geral, AECO, manufatura, serviços, projetos complexos, projetos simples, edifícios residenciais, edifícios comerciais, edifícios mistos, edifícios especiais, equipamentos urbanos, infraestrutura, público, privado

\begin{tabular}{|l|l|}
\hline Indique a localidade do estudo & Lista de múltipla escolha \\
\hline
\end{tabular}

Internacional, Brasil, EUA, Inglaterra

\begin{tabular}{|l|l|}
\hline Descreva o contexto abordado & Texto \\
\hline Abordagem da pesquisa & Lista de única escolha \\
\hline
\end{tabular}

Pesquisa qualitativa, pesquisa quantitativa, pesquisa quali-quanti

\begin{tabular}{|l|l}
\hline Natureza da pesquisa & Lista de única escolha \\
\hline
\end{tabular}

Pesquisa básica (hipótese - teoria), pesquisa aplicada (proposição - aplicação)

Objetivo da pesquisa Lista de única escolha

Pesquisa exploratória, pesquisa descritiva, pesquisa explicativa

Procedimentos de pesquisa Lista de múltipla escolha

Pesquisa experimental, pesquisa bibliográfica, pesquisa documental, pesquisa de campo, pesquisa ex-post-facto, pesquisa de levantamento, pesquisa com survey, estudo de caso, pesquisa construtiva, pesquisa participante, pesquisa-ação, pesquisa etnometodológica

Delimitação temporal da pesquisa Lista de única escolha

Estudos transversais, estudos longitudinais, estudos retrospectivos, estudos prospectivos

\begin{tabular}{|l|l|}
\hline Descreva a hipótese/proposição & Texto \\
\hline Caracterização das variáveis de pesquisa & Texto \\
\hline Contribuição dos resultados e conclusões & Texto \\
\hline Nota para pesquisa (facultativo) & Texto \\
\hline Antecedências (facultativo) & Texto \\
\hline
\end{tabular}


Os artigos avaliados primeiro foram aqueles classificados com importância "very high", seguidos de "high", "low" e "very low" (classificação do software). Conforme a pontuação na avaliação da qualidade, a importância foi alterada de forma a subsidiar o rigor das notações durante a extração. Objetivamente, para viabilizar a varredura completa dos trabalhos, os artigos cuja leitura foi classificada como mais importante tiveram uma extração de informações textuais detalhadas para viabilizar uma abordagem qualitativa, enquanto a extração e a sumarização dos dados dos trabalhos menos importantes foram tratadas apenas na abordagem quantitativa geral. Assim os últimos cinco pontos são destinados aos trabalhos mais importantes (Quadro 4).

Cabe destacar que, além da desclassificação decorrente de uma qualidade formal insuficiente, os trabalhos também foram desconsiderados quando algum critério de exclusão (Quadro 2) foi identificado durante a leitura do texto integral. O enquadramento tardio de um estudo por um desses critérios de exclusão, que a princípio deveriam ser detectados na fase 1.3, se deve a informações inadequadas ou insuficientes do título, resumo e keynotes, ou a um erro de interpretação dessas informações pelos pesquisadores.

\subsubsection{Sumarização dos resultados}

A interpretação dos resultados ocorre por uma via quantitativa e uma via qualitativa. Dados extraídos de todos os estudos selecionados são analisados quanto à origem dos trabalhos, o tipo de pesquisa realizada e quais as abordagens organizacionais neles discutidas (WANG et al., 2013). Os trabalhos mais relevantes, seja por sua proximidade com a organização de processos de AECO, seja pela relevância teórica da organização de projetos, foram confrontados qualitativamente, de forma a consolidar e a avançar a discussão sobre o estado da arte da arquitetura organizacional em AECO. O resultado desse trabalho deu origem ao capítulo 3 e embasou tanto a definição do método de mapeamento organizacional, descrito na seção 2.4 , como a discussão dos resultados do artefato desenvolvido e a conclusão, nos capítulos 8 e 9 . 


\subsection{PROCEDIMENTOS EMPREGADOS NOS ESTUDOS EXPLORATÓRIOS}

Os dois estudos exploratórios constituem a avaliação do desenho resultante da identificação e justificação do problema de pesquisa, identificado na revisão da literatura. Juntos compõem parte da pesquisa desenvolvida com uma abordagem indutiva, em que a experiência sensível, apoiada por procedimentos de controle e mediação da discussão, permite compreender de forma profunda e relacional o comportamento humano e as circunstâncias em torno do fenômeno estudado (CRESWELL, 2013), e assim fundamentar uma proposição teórica com o objetivo de expandir o domínio do conhecimento existente.

Cada estudo exploratório possui propósito, tempo e estratégia de levantamento de dados distintos. O primeiro corresponde a um estudo retrospectivo baseado em entrevistas semiestruturadas (CRESWELL, 2013), realizadas com o objetivo de identificar as características organizacionais que impactaram no trabalho realizado por uma equipe de projeto. Trata-se de um projeto de habitação de interesse social (HIS) que buscava atender às diferentes necessidades de uma população-alvo em um contexto de escassez de recursos financeiros. Para responder a esse problema, a equipe de projeto buscou associar a flexibilidade da arquitetura do edificio e a racionalidade possível com a produção em massa, adotando, para isso, estratégias de análise de requisito, custeio-meta, projeto colaborativo e customização em massa.

O segundo estudo corresponde a um tipo de investigação-ação (AVISON et al., 1999; DAVISON; MARTINSONS; KOCK, 2004; TRIPP, 2005) orientado para a melhoria do processo de projeto em que se adotou a prática reflexiva (SCHÖN, 1988; VALKENBURG, 2000; WAKS, 2001) como procedimento para aplicar as lições aprendidas com o primeiro estudo, mudando o processo de projeto proposto em um exercício de projeto orientado para o gerenciamento de valor, e assim monitorar os efeitos da mudança por meio da discussão dos resultados observados. Nesse estudo foi desenvolvido um projeto de unidade básica de saúde (UBS) em que o custeio-meta coincidia com o custo permissível, pois correspondia aos recursos públicos disponibilizados para um empreendimento real.

Embora cada estudo aborde um contexto e tipologia de edificios distintos, o objeto de análise corresponde aos procedimentos de gerenciamento de valor adotados, cujo conhecimento, práticas e ferramentas se aproximam e se alinham aos interesses de exploração teórica e prática para a pesquisa. 


\subsubsection{Primeiro estudo exploratório}

O primeiro estudo exploratório $\left(1^{\circ} \mathrm{EE}\right)$ realiza uma análise retrospectiva de um projeto de desenvolvimento e pesquisa (JÄRVINEN, 2007) ocorrido entre 2013 e 2014 por iniciativa dos Programas de Pós-Graduação em Arquitetura e em Engenharia Civil da Universidade Estadual de Londrina (UEL). O projeto tinha como objetivo desenvolver soluções criativas para um modelo de habitação de interesse social que atendesse aos requisitos dos usuários, de redução do consumo energético e de redução de custos de manutenção, respeitando-se o custo unitário e os parâmetros do programa Minha Casa, Minha Vida (MCMV) para a faixa 1, destinada a famílias com renda bruta de até R\$ 1.600,00 (equivalente a cerca de US\$500).

O foco do estudo, contudo, está na estratégia adotada pela equipe de projeto para desenvolver esse projeto. Com base em conhecimentos, práticas e ferramentas de gerenciamento de valor e de projeto colaborativo, o processo de concepção e desenvolvimento do projeto contou com parcerias estabelecidas com empresas da cadeia de suprimentos, que viabilizaram soluções inovadoras tanto no âmbito funcional quanto no de componentes.

A análise das implicações organizacionais da adoção de princípios de projeto colaborativo e de gerenciamento de valor pela equipe responsável pelos projetos foi realizada por meio da coleta de evidências mediante entrevistas e documentos complementares, como croquis e desenhos projetivos, atas de reunião e fluxogramas elaborados na época. Embora o pesquisador, autor da tese, tenha participado da equipe de projeto, então como mestrando, sua percepção não foi incorporada como conteúdo adicional à análise.

Assim, a discussão resultante se baseia na comparação da percepção apreendida de três membros da equipe sobre os temas previamente definidos em um roteiro de entrevista. Além disso, as impressões positivas e negativas recolhidas foram confrontadas com a teoria consultada, de forma a identificar pontos de convergência e divergência, e assim propor melhoras, seja no processo, nos instrumentos e nas competências, seja em determinados aspectos da teoria, a serem aplicadas e verificadas em outro ciclo de desenvolvimento e pesquisa (MOODY; SHANKS, 2003). 


\section{Caracterização dos entrevistados e demais intervenientes}

Os profissionais entrevistados integraram o núcleo principal da equipe de projeto durante o período inicial de concepção e desenvolvimento da arquitetura do sistema. O anonimato dos profissionais foi preservado, mas uma caracterização profissional associada a um codinome foi registrada para clarificar o perfil dos atores envolvidos no processo analisado (Quadro 5).

Quadro 5 - Perfil dos entrevistados

COD Descrição do entrevistado

P1 - Foi responsável pelo projeto arquitetônico, tendo promovido e coordenado a integração do projeto das especialidades técnicas de hidráulica, elétrica e estrutura no projeto arquitetônico. É arquiteto urbanista e professor universitário. Atuou regularmente como arquiteto por 10 anos e é docente há 20 anos. Leciona disciplinas sobre introdução à arquitetura, projeto e desenho arquitetônico, além de realizar esporadicamente projetos de arquitetura. Durante o trabalho, era pesquisador docente da instituição promotora do projeto.

P2 - Foi responsável pelo custeio-meta e análise dos atributos do projeto. Trabalhou na captação e hierarquização de requisitos do cliente. É arquiteto urbanista, formado há 6 anos, atuou profissionalmente em projetos de edificações de pequeno porte, projetos de reformas, execução de algumas obras de reformas e alguns projetos completos. Trabalhou em construtora e em escritório de maquete. Atualmente ministra aulas de gerenciamento de projetos e construção, tecnologia da construção e introdução à arquitetura. Durante o trabalho, era pesquisador mestrando na instituição promotora do projeto.

P3 - Foi responsável pela captação e hierarquização de requisitos dos usuários das HIS. É arquiteta urbanista, formada há 5 anos, atuou profissionalmente em projetos arquitetônicos residenciais e comerciais; orçamentação, compras, acompanhamento de obras; gestão de qualidade, manutenção, auditorias, vistorias de obras; e atendimento a clientes de empreendimentos residenciais verticais. Durante o trabalho, era pesquisadora mestranda na instituição promotora do projeto.

A caracterização dos projetistas entrevistados foi extraída da parte inicial do roteiro da entrevista estruturada, descrita a seguir. Já os demais profissionais envolvidos no projeto (Quadro 6) foram caracterizados apenas acerca de sua atuação no projeto. São profissionais com reconhecida experiência prática e acadêmica, que atuaram no projeto como colaboradores ou cooperaram como consultores externos. 
Quadro 6 - Perfil dos demais atores envolvidos no projeto

CA - Responsável pela coordenação acadêmica. Engenheira civil.

$A C$ - Atuou no apoio à coordenação, nas atividades convencionais de projeto e atividades de gerenciamento de valor. Arquiteto urbanista.

C1 - Cooperou como consultor e projetista de tecnologia de madeira.

C2 - Cooperou orientando o desenho do projeto hidráulico. Engenheiro civil.

C3 - Cooperou com um projeto pesquisa e desenvolvimento de esquadrias.

C4 - Atuou na integração da customização em massa ao processo de seleção da Cohab. Arquiteta.

C5 - Colaborou na análise de valor em atividades de custeio-meta.

C6 - Cooperou com o projeto da produção.

C7 - Cooperou com consultas e análises de conforto ambiental e eficiência energética.

E1 - Empresa especializada em construção de edificações utilizando tecnologia de light wood frame.

E2 - Uma das empresas construtoras do conjunto habitacional analisado para captação de requisitos e estabelecimento do custeio-meta

\section{Entrevista estruturada}

A captação das percepções dos profissionais sobre o processo de projeto foi realizada por meio de uma entrevista estruturada, composta de quatro partes principais (Quadro 7). Para orientar as respostas dos entrevistados sem induzi-los a uma interpretação enviesada, o entrevistador os convidou a responder ao roteiro sem apresentar a teoria envolvida na pesquisa, apenas recapitulando informações objetivas sobre o projeto, como qual recorte temporal estava sendo considerado e a lista dos intervenientes.

A primeira parte das questões se concentrou na caracterização profissional do entrevistado e seu papel no projeto; a segunda parte os questionou sobre a compreensão dos objetivos do projeto e como o trabalho deles se alinha a esses objetivos; a terceira parte focou a descrição do trabalho total e individualmente realizado, bem como a mudança na percepção de cada um no início, durante e depois do período analisado; por último, os entrevistados foram provocados a realizar uma reflexão sobre as barreiras enfrentadas e as potencialidades do trabalho realizado a serem exploradas para a melhoria do processo de projeto. 


\begin{tabular}{|c|}
\hline Caracterização do entrevistado \\
\hline $\begin{array}{l}\text { - } \quad \text { Profissão } \\
\text { - } \quad \text { Experiência profissional } \\
\text { - } \quad \text { Experiência de pesquisa } \\
\text { - } \quad \text { Papel no projeto de pesquisa e desenvolvimento (PeD) }\end{array}$ \\
\hline Compreensão dos objetivos do projeto de PeD \\
\hline
\end{tabular}

- Quais são as premissas do projeto de PeD?

- Em que consiste o objeto desenvolvido?

- Quais áreas do conhecimento foram envolvidas diretamente no projeto de PeD?

- Como seu trabalho se enquadrou no projeto?

\section{Percepção do trabalho realizado}

- Qual era a condição do trabalho inicial? Como foi o planejamento do processo de projeto?

- Havia clareza do trabalho a ser realizado no processo de projeto?

- Durante o desenvolvimento, o planejamento se confirmou?

- Como a equipe de projeto se organizou? (detalhar quem estava envolvido)

- Como foi a coordenação das atividades? (centralizada, documental, informal)

- Qual o grau de comprometimento dos envolvidos (individualizar avaliação)

o Colaboradores

o Demais intervenientes (consultores, parceiros, fornecedores)

- Aponte dificuldades na realização do trabalho
o Ambiente de trabalho
o Competência (conhecimento e habilidades necessárias)
o Processos (práticas e tarefas, coordenação e comunicação)
o Equipamentos, ferramentas e instrumentos
o Rede de cooperação (consultores, parceiros, fornecedores)

\section{Reflexão sobre a experiência}

- Considerando a descrição da percepção realizada

- Mudaria sua conduta na equipe?

o Sugeriria alguma mudança a algum colaborador?

o Mudaria algum aspecto ou ponto do processo de projeto? Qual(is)?

- Você considera positiva ou negativa a adoção de alguma das práticas do processo de projeto?

- Aponte quais e em quais condições?

o Quais são as potencialidades e desafios dessas práticas de projeto.

- Você considera que sua participação no processo de projeto enriqueceu sua experiência profissional? Como? 


\section{Forma de análise dos resultados}

Após a transcrição das entrevistas, os conjuntos de respostas foram confrontados um a um, considerando cada especialidade. Para tanto, as respostas às questões foram organizadas em um quadro que permitiu a comparação do conteúdo de cada conjunto de respostas (Erro! Fonte de referência não encontrada.). Um sistema de notação definiu as frases e expressões que apontavam as convergências entre dois ou mais entrevistados, e divergências e complementação do pensamento entre eles. Além disso, relatos de aspectos particulares realizados apenas por um participante também foram destacados de forma a diferenciar as singularidades derivadas de uma perspectiva específica.

A discussão dos resultados foi realizada mediante a confrontação dessa análise empírica com a teoria adotada na pesquisa de forma a enunciar as lições aprendidas para a realização de outro ciclo de projeto e subsidiar a elaboração de um desenho de processo adequado às práticas de projeto orientadas para a construção de valor. Sempre que possível parte da resposta do entrevistado foi transcrita dentro do contexto da exposição, evitando-se a aproximação de conceitos e termos.

Os resultados do estudo retrospectivo são descritos na primeira parte do capítulo 3, na seção 4.1, e as implicações para o desenho de processo são retomadas no decorrer do capítulo 5 .

\subsubsection{Segundo estudo exploratório}

A oportunidade de realização do segundo estudo exploratório ( $\left.2^{\circ} \mathrm{EE}\right)$ ocorreu em uma disciplina de pós-graduação em Arquitetura realizada em 2017 na forma de workshop de projeto. A proposta do trabalho era aliar a capacidade de gerar quantitativos por meio da modelagem de informação da construção para alimentar os instrumentos de custeiometa com agilidade suficiente para que estes fossem incorporados ao processo de concepção da solução.

A organização do processo foi estruturada com base em uma pesquisa de pós-doutorado que apresentou um método para utilização de BIM apoiando o Target Value Design (TVD) na concepção (MORAIS; FABRICIO; RUSCHEL, 2018). Tal método se baseia na modelagem da concepção em um template e famílias de objetos BIM 
previamente preparados para a extração adequada dos quantitativos de material, área, volume, etc. Tais dados são exportados em um arquivo de texto e importados para as planilhas de composição de custo. Os custos compostos são vinculados às funções do sistema por meio da análise funcional e da aplicação da Técnica de Mudge. Esses custos vinculados às funções são correlacionados ao atendimento dos requisitos hierarquizados dos clientes, revelando uma relação entre custo e beneficio pelo Gráfico Compare, que subsidia a avaliação da conveniência das soluções adotadas.

\section{Caracterização da estrutura do processo de projeto}

A realização do processo de projeto também seguiu uma estrutura predefinida, baseada nas recomendações propostas pela Sociedade Americana de Engenharia de Valor (SAVE, 2018), em que o desenvolvimento do projeto é dividido em fase informativa, fase da análise funcional, fase criativa e fase da avaliação (MORAIS; FABRICIO; RUSCHEL, 2018).

$\mathrm{Na}$ fase informativa, a captura de requisitos dos clientes/usuários contou com a consulta a profissionais de arquitetura e de saúde envolvidos no desenvolvimento, execução e uso de uma UBS existente, da qual também foram aproveitadas algumas das características do empreendimento, como terreno, programa e verba disponível. Com essas informações a equipe de projeto elaborou a caracterização dos usuários, estimativas de custo iniciais e diretrizes de projeto, baseadas nas normativas de saúde, "que levam em consideração as percepções de valor do usuário” (MORAIS; FABRICIO; RUSCHEL, 2018, p. 18). Na análise funcional, as funções da edificação são decompostas e classificadas como funções básicas, necessárias ou secundárias (DELL'ISOLA, 1997; MORAIS; GRANJA; RUSCHEL, 2015). As relações funcionais são então hierarquizadas em razão de sua importância para o usuário e comparadas com os custos-meta associados aos sistemas construtivos. Com a definição do custo-meta por meio do Gráfico Compare, inicia-se a fase criativa, com um brainstorming visando criar novas soluções e melhorias da proposta inicial, induzida com a análise funcional. Por fim, a fase da avaliação ocorre com a comparação entre as soluções alternativas, por meio do acompanhamento da variação entre necessidades relativas e consumo de recursos (MORAIS; FABRICIO; RUSCHEL, 2018). 
A realização dessas fases foi planejada para ser sequencial e multidisciplinar. A equipe contava com dois profissionais diretamente responsáveis pelo projeto, um profissional responsável pelo gerenciamento de custos e outro pelo gerenciamento de requisitos. Apesar da atribuição de funções, a responsabilidade pela concepção era partilhada por toda a equipe, caracterizando-se, assim, mais como uma orientação de competência do que como uma função com atividades predefinidas.

\section{Prática reflexiva e observação participante}

A equipe de projeto, da qual o pesquisador fez parte, acordou em alterar a estrutura predefinida do processo de projeto a partir das experiências aprendidas no estudo retrospectivo (PEREIRA; HIROTA; FABRICIO, 2017). Para tanto, os integrantes foram provocados a analisar o trabalho em curso sempre que um membro apontasse alguma condição limitadora ou oportunidade de ganho na eficiência e, com a reflexão apresentada, a discutir a pertinência de gerenciar mudanças no processo em curso e verificar a efetividade da mudança posta em ação (SCHÖN, 1988; VALKENBURG; DORST, 1998; WAKS, 2001).

O gerenciamento de mudanças do processo de projeto adotado pela equipe foi estruturado em quatro passos, baseados na "prática reflexiva” proposta por Schön (1988):

1. contextualizar as atividades a serem realizadas no processo de projeto;

2. discutir sua adequação aos objetivos do projeto enquanto realizavam essas tarefas;

3. propor mudanças na realização das tarefas ou na forma como as tarefas são organizadas no processo, visando melhor desempenho para atender aos objetivos do projeto; e

4. analisar se as mudanças implementadas atenderam a seu propósito e se ajustes eram necessários.

Após a conclusão da concepção, a estratégia adotada e os resultados alcançados no projeto foram discutidos com a equipe. Nessa atividade de pesquisa os indicadores dos instrumentos de gerenciamento de valor foram recuperados para embasar a discussão acerca das decisões de mudança, conforme relatado na seção 4.2.2. 


\section{Pesquisador-participante}

Como indicado, o pesquisador atuou neste estudo exploratório como um observador participante (FABIAN, 2001), ou seja, no $1^{\circ} \mathrm{EE}$, quando o pesquisador integrou a equipe de projeto, não havia a intencionalidade de analisar a organização do processo de projeto para a pesquisa, mas, sim, apenas uma preocupação gerencial, enquadrada dentro da estrutura de conhecimento existente. Já no $2^{\circ} \mathrm{EE}$ tal intenção investigativa era manifesta. Assim, diferentemente do primeiro caso, este estudo não era uma investigação sobre a atuação da equipe, mas, sim, um estudo realizado com essa equipe (GUNN; LØGSTRUP, 2014).

Trata-se de uma abordagem antropológica aplicada à pesquisa sobre o processo de projeto (GUNN; LØGSTRUP, 2014), instrumentalmente interessante para a DSR por permitir um diagnóstico dialógico, baseado na interação com as pessoas em ação, o que permite construir formas colaborativas emergentes e coanalisar materiais, em vez de apenas capturar e representar os pontos de vista dos outros (FABIAN, 2001).

\section{Forma de análise dos resultados}

Além do papel ativo na prática reflexiva para promover as mudanças no processo em curso, o pesquisador anotou observações sobre eventos de decisões a fim de registrar onde e quando tais mudanças ocorreram (GUNN; LØGSTRUP, 2014). A demarcação desses episódios permitiu que a equipe fosse provocada a dizer suas percepções e discutir as decisões de mudanças e suas consequências acerca de ao menos três pontos:

- $\quad$ nível de colaboração;

- adequação da organização predefinida; e

- sucesso na construção do entendimento compartilhado.

A discussão foi iniciada presencialmente, e as conclusões foram então anotadas e organizadas em uma redação preliminar. Esse texto foi revisado pela equipe de forma a fortalecer os argumentos com evidências empíricas e conexões com a teoria. Os resultados desse estudo exploratório são apresentados na seção 4.2. Além disso, as contribuições dos resultados para o desenho de processo são mencionadas no capítulo 5 . 


\subsection{DIAGRAMAÇÃO DO PROCESSO DE PROJETO ORIENTADO AO VALOR}

A diagramação dos fluxos dos processos de projeto analisados na pesquisa da tese foi realizada com base em um modelo simbólico de representação de atividades, de conexão/interação entre essas atividades e o acesso a dados do projeto. Tal modelo não tem como objetivo marcar o tempo necessário para a realização dessas tarefas, tampouco indica os insumos necessários para realizar a atividade. Assim, os modelos diagramados não são autoexplicativos, mas, sim, recursos acessórios à discussão apresentada nos resultados.

Os símbolos gráficos empregados foram:

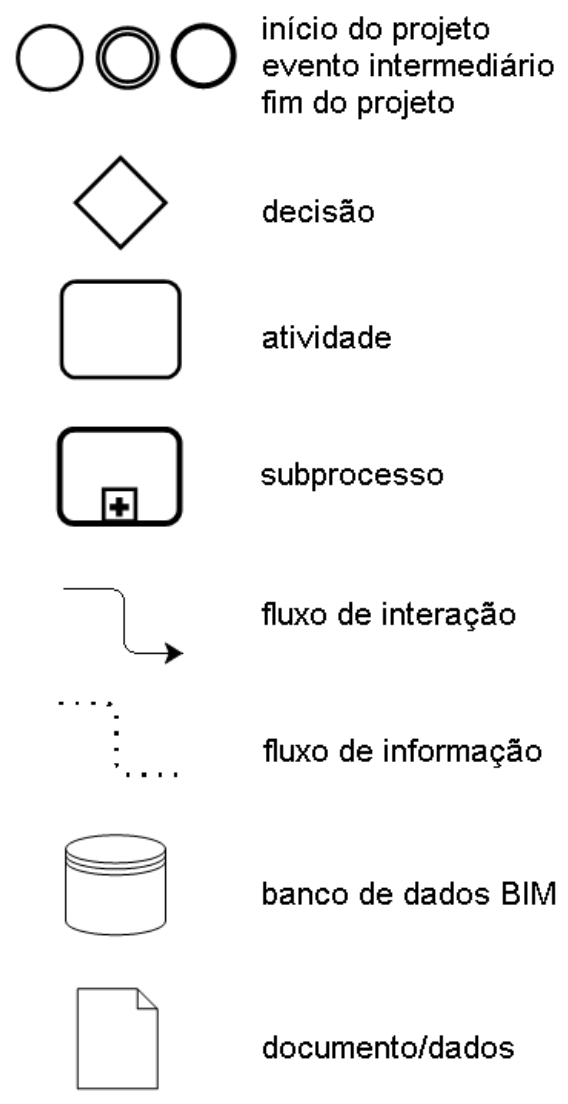

A diagramação dos processos apresentados teve como fonte de dados o levantamento realizado em bibliografia e mediante consulta a profissionais e pesquisadores no setor que cooperaram com a pesquisa por meio de ponderações e diálogos estabelecidos sobre os assuntos relacionados ao artefato modelado. 


\subsection{MAPEAMENTO DA CONGRUÊNCIA ORGANIZACIONAL}

O mapeamento da congruência organizacional permitiu identificar e caracterizar as interações fortes e fracas entre as diferentes atividades envolvidas na solução do projeto em organizações de empreendimentos imobiliários. Para tanto foi adaptado um conjunto de matrizes de domínio (EPPINGER; SALMINEN, 2001; SOSA, 2007) que captura e relaciona as informações referentes à arquitetura do sistema (a edificação) à arquitetura do processo (as atividades envolvidas no desenvolvimento da edificação) e à arquitetura organizacional (organização dos agentes envolvidos no empreendimento para viabilizar a realização das atividades).

\subsubsection{Visão geral}

O método é composto de cinco passos, que foram adequados ao contexto de projetos de AECO (Figura 3).

Figura 3 - Fluxograma de como as matrizes se relacionam

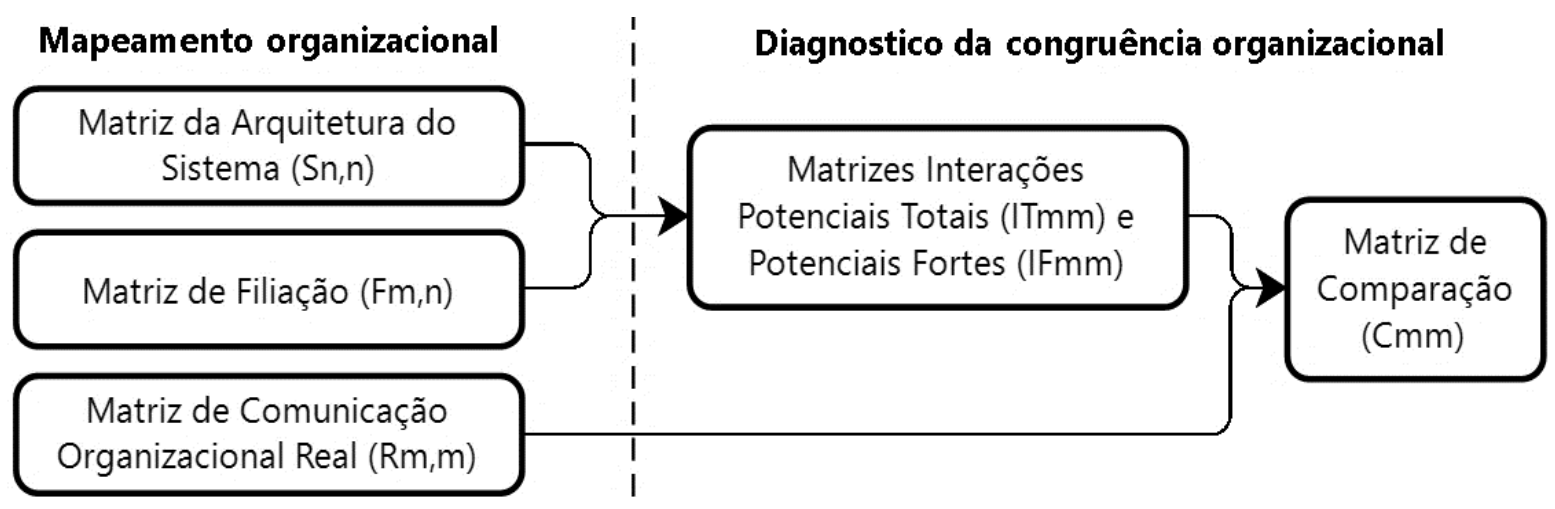

Os três primeiros correspondem a atividades de levantamento, formatação e processamento das informações da realidade analisada. Primeiramente, a arquitetura do sistema e as atividades do processo de projeto e execução são levantadas e correlacionadas para identificar quais são as interações das atividades de projeto que contribuem para a definição da arquitetura do sistema e em que grau isso ocorre. As atividades do processo são então relacionadas aos agentes responsáveis de forma a agrupar o conjunto de interações de responsabilidade de um mesmo agente na organização das atividades do empreendimento. 
Os dois passos consequentes correspondem ao mapeamento das interações totais e fortes, previstas com a combinação dos dados levantados e a combinação entre as interações potenciais e as interações reconhecidas da organização analisada. A seguir são detalhadas as condições para o levantamento dos dados primários e apresentados os tipos de matrizes utilizados. A descrição dos passos é apresentada suscintamente a seguir. Além disso, um guia mais detalhado pode ser consultado no Apêndice D

\subsubsection{Levantamento dos dados}

O caso apresentado no capítulo 6 mapeou um empreendimento habitacional unifamiliar construído na cidade de Londrina, Paraná, Brasil. O empreendimento foi uma iniciativa do cliente-proprietário, iniciada por meio da contratação de empresa de arquitetura e de uma empresa empreiteira da obra. Os projetistas da estrutura, instalações hidráulicas, instalações elétricas e telemáticas foram contratados posteriormente, com o acompanhamento do escritório responsável pela arquitetura.

A identificação, o levantamento e a análise do caso ocorreram entre outubro e dezembro de 2017 e contaram com a colaboração de representantes das empresas citadas. As demais empresas e agentes relacionadas no estudo derivam do levantamento realizado com esses intervenientes. A relação dos agentes envolvidos no empreendimento é apresentada no Quadro 8. Cabe destacar que cada agente apontado corresponde a uma responsabilidade específica, podendo ser realizada por uma ou mais pessoas que respondam em conjunto na organização do empreendimento. Assim, se a dinâmica de trabalho de dado profissional de projeto envolve o trabalho supervisionado de um estagiário ou funcionário, este não figura na lista. A anuência formal e o engajamento dos agentes responsáveis pelo gerenciamento das empresas envolvidas no empreendimento foram cruciais para o sucesso do levantamento.

A numeração apresentada nas listas de atividades (Quadro 21 e Quadro 23) e na lista de decomposição da arquitetura do sistema (Quadro 22) corresponde a uma sequência numérica simples, de progressão não linear. Tanto os nomes das atividades como os termos apresentados na decomposição do sistema são idênticos aos levantados no mapeamento. A opção por não adaptar a sequência e os nomes levantados a um modelo de tesauro e de classificação hierárquica ou facetada específico teve como objetivo evitar variabilidade adicional na interpretação dos dados decorrente de aproximações inexatas quando da análise comparativa entre a proposta de arquitetura organizacional e a organização de empreendimento existente. 
Quadro 8 - Agentes envolvidos no empreendimento

\begin{tabular}{|c|c|c|}
\hline GRUPO & COD & AGENTE \\
\hline \multirow{5}{*}{ clientes } & 1 & cliente final \\
\hline & 2 & prefeitura \\
\hline & 3 & condomínio fechado \\
\hline & 4 & CAU \\
\hline & 5 & CREA \\
\hline \multirow{7}{*}{ projetistas } & 6 & arquiteto projetista \\
\hline & 7 & arquiteto coordenador \\
\hline & 8 & projetista hidráulico \\
\hline & 9 & projetista elétrico \\
\hline & 10 & projetista estrutural \\
\hline & 11 & projeto de ar-condicionado \\
\hline & 12 & projetista paisagístico \\
\hline \multirow{7}{*}{$\begin{array}{l}\text { executores, fornecedores e } \\
\text { prestadores de serviços }\end{array}$} & 13 & topografia \\
\hline & 14 & empreiteira da obra \\
\hline & 15 & serviço de perfuração e estaqueamento \\
\hline & 16 & armador \\
\hline & 17 & concreteira \\
\hline & 18 & encanador \\
\hline & 19 & eletricista \\
\hline \multirow{19}{*}{$\begin{array}{l}\text { executores, fornecedores e } \\
\text { prestadores de serviços }\end{array}$} & 20 & serralheria \\
\hline & 21 & ar-condicionado \\
\hline & 22 & esquadria de alumínio \\
\hline & 23 & carpintaria \\
\hline & 24 & ferragens \\
\hline & 25 & marmorista \\
\hline & 26 & marcenaria \\
\hline & 27 & gesseiro \\
\hline & 28 & azulejista \\
\hline & 29 & pintor \\
\hline & 30 & sintecador \\
\hline & 31 & armários planejados \\
\hline & 32 & revestimentos cerâmicos \\
\hline & 33 & louças e metais \\
\hline & 34 & luminárias \\
\hline & 35 & serviço de paisagismo \\
\hline & 36 & serviços de limpeza \\
\hline & 37 & serviço de fornecimento de energia \\
\hline & 38 & serviço de fornecimento de água e esgoto \\
\hline
\end{tabular}




\subsubsection{Tipos de mapeamento}

Operacionalmente, o primeiro passo para o mapeamento da congruência organizacional envolve a captura e o mapeamento da arquitetura do edificio em uma matriz da arquitetura do sistema $\left(\mathrm{S}_{\mathrm{n}, \mathrm{n}}\right)$. Trata-se de uma matriz quadrada (Quadro 9) em que tanto as linhas como as colunas marcam as $n$ funções do sistema que constitui um produto, ordenando-as por subsistemas e componentes, além das funções integrativas, que garantem a adequação das interfaces existentes e o atendimento à função principal do sistema (seu uso). Tem como objetivo estabelecer a relação de restrições entre as partes, definindo os módulos fisicos a partir da identificação de interfaces fortemente interdependentes.

Quadro 9 - Exemplo de matriz da arquitetura do sistema $\left(S_{n, n}\right)$

\begin{tabular}{|c|c|c|c|c|c|c|c|c|c|c|c|c|}
\hline & \multicolumn{4}{|c|}{ Sistema 1} & \multicolumn{3}{|c|}{ Sistema 2} & \multicolumn{3}{|c|}{ Sistema 3} & \\
\hline & & 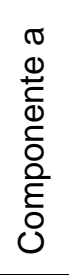 & 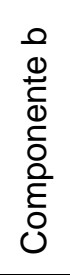 & 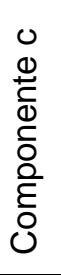 & 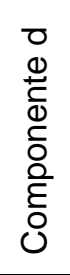 & 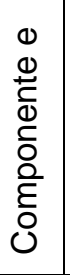 & 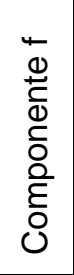 & 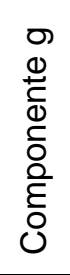 & 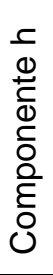 & 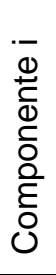 & 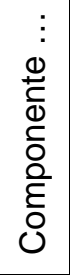 & 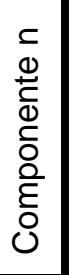 \\
\hline \multirow{4}{*}{ 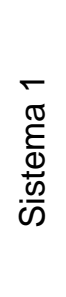 } & Componente a & & & & & & & & & & & \\
\hline & Componente b & & & & & & & & & & & \\
\hline & Componente c & & & & & & & & & & & \\
\hline & Componente d & & & & & & & & & & & \\
\hline \multirow{3}{*}{ 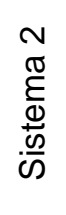 } & Componente e & & & & & & & & & & & \\
\hline & Componente f & & & & & & & & & & & \\
\hline & Componente $\mathrm{g}$ & & & & & & & & & & & \\
\hline \multirow{3}{*}{ 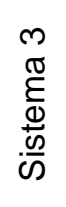 } & Componente $\mathrm{h}$ & & & & & & & & & & & \\
\hline & Componente i & & & & & & & & & & & \\
\hline & Componente ... & & & & & & & & & & & \\
\hline .. & Componente $\mathrm{n}$ & & & & & & & & & & & \\
\hline
\end{tabular}

Legenda: _ interfaces entre função, subsistemas e componentes. 
O segundo passo envolve a captura das relações entre as atividades e as funções do sistema. Para tanto, para cada etapa do processo de projeto é atribuído um grau de envolvimento na concepção de cada um dos subsistemas e componentes.

Esse mapeamento ocorre por meio da matriz de filiação $\left(F_{m n}\right)$, em que as linhas são rotuladas com as atividades do processo, enquanto as funções, subsistemas ou componentes são listados nas colunas (Quadro 10). Assim é possível relacionar o grau de envolvimento de cada atividade com o desenvolvimento de cada elemento do sistema. Entende-se que uma atividade é "diretamente envolvida" quando detém a responsabilidade exclusiva de concepção, execução ou instalação do componente; está "envolvida" quando essa responsabilidade é compartilhada por agentes de duas ou mais atividades que agem solidariamente sobre a concepção, execução ou instalação do componente; e é "indiretamente envolvida" quando o impacto de suas ações influencia características do componente sem que haja responsabilidade.

Quadro 10 - Exemplo de matriz de filiação $\left(F_{m n}\right)$

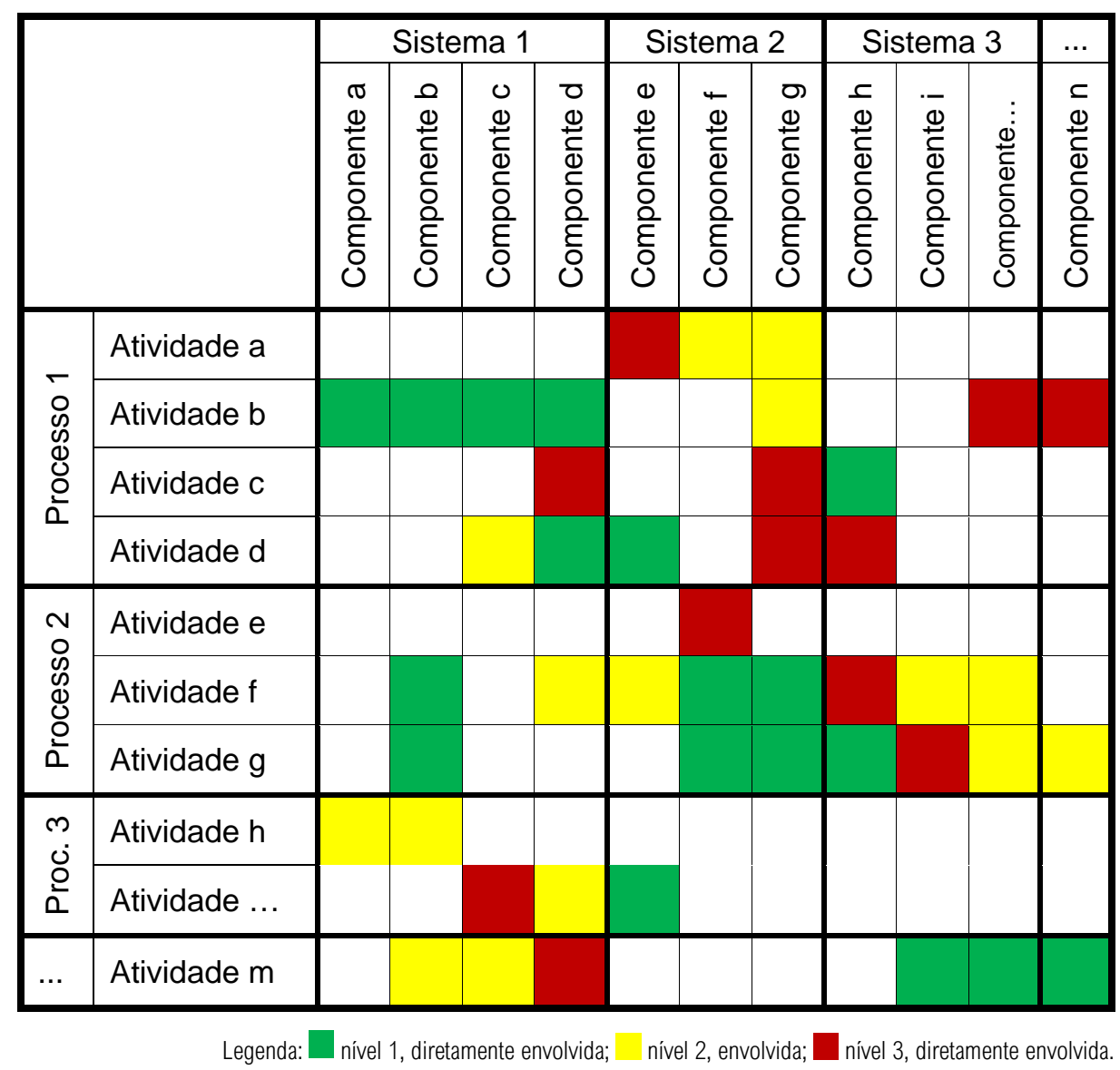


O terceiro passo envolve a captura das interações reconhecidas na organização existente.

Para tanto, as atividades do processo levantadas no segundo passo são correlacionadas entre si, mantendo-se a organização existente nas empresas ou departamentos que compõem o empreendimento imobiliário analisado, seguindo o escopo das responsabilidades previsto contratualmente.

O mapeamento é realizado por meio da matriz de interações reconhecidas $\left(R_{m, m}\right)$, em que a linha apresenta os fornecedores das informações relacionadas a um sistema, enquanto a coluna lista os receptores (Quadro 11). Assim, a célula de intersecção aponta as interações reais entre os atores envolvidos.

Quadro 11 - Exemplo de matriz de interações reconhecidas $\left(R_{m m}\right)$

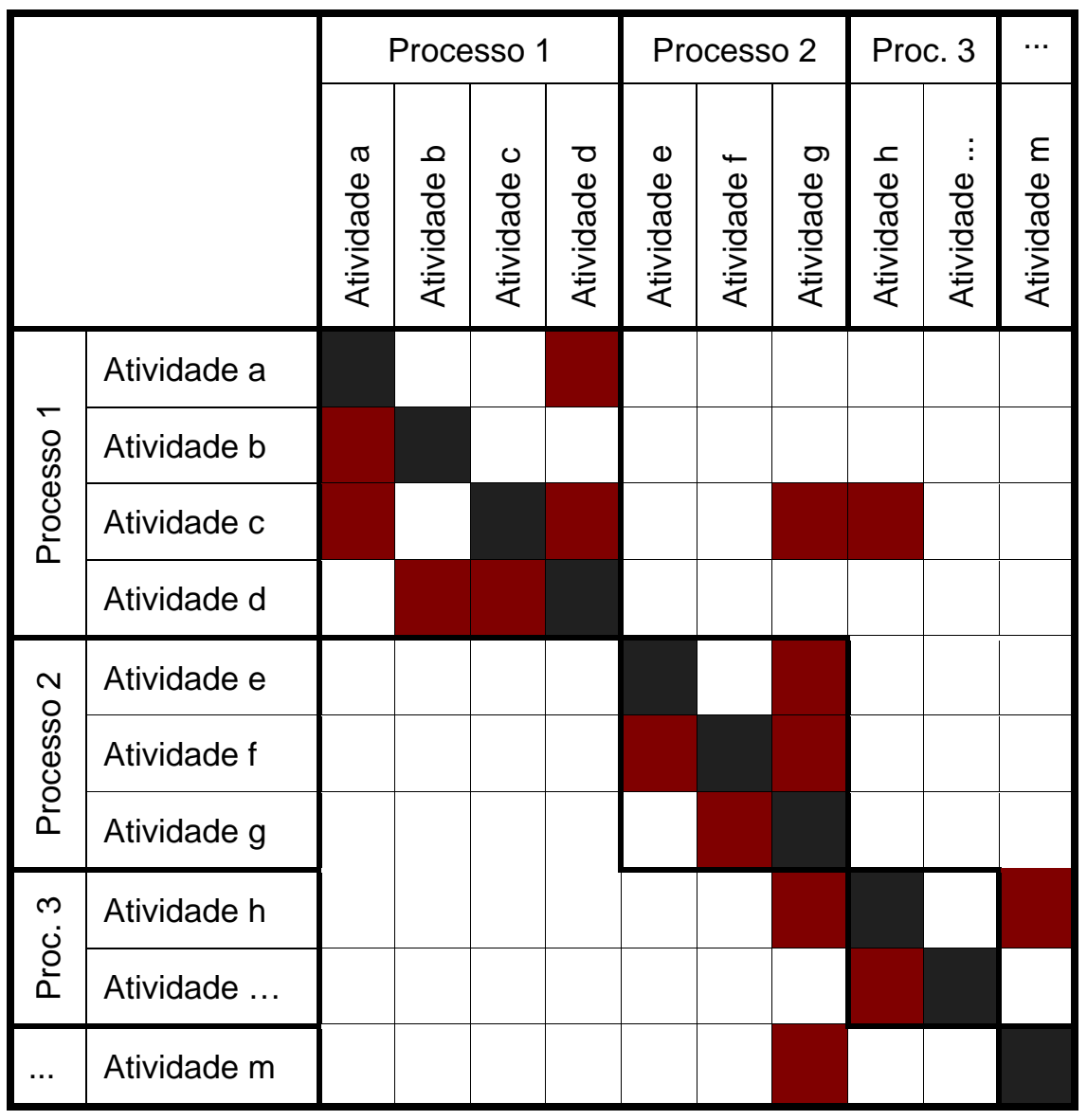

Legenda:__ i solicita informações relacionadas a j. 
O quarto passo envolve a determinação do potencial de interações entre as atividades para a resolução do projeto (SOSA, 2007). Para tanto, é construída uma matriz de interação potencial $\left(\mathrm{P}_{\mathrm{mm}}\right)$, diferente de zero, em que a célula indica a interação potencial de um ator i com o ator $\mathrm{j}$ por estarem envolvidos no desenvolvimento dos subsistemas e componentes do sistema (Quadro 12). A matriz é formada pela equação $\mathrm{P}_{\mathrm{mm}}=\mathrm{F}_{\mathrm{mn}}$. $\mathrm{S}_{\mathrm{nn}} \cdot \mathrm{F}^{\mathrm{T}}{ }_{\mathrm{nm}}$, em que os dados da matriz do sistema e da matriz de filiação são combinados.

Como resultado é possível extrair duas matrizes: ao considerar todos os graus de envolvimento sobre a arquitetura do sistema, tem-se como resultado uma matriz de interação potencial total $\left(\mathrm{PT}_{\mathrm{mm}}\right)$. Já ao filtrar apenas as atividades diretamente envolvidas, gera-se uma matriz de interação potencial forte $\left(\mathrm{PF}_{\mathrm{mm}}\right)$.

Quadro 12 - Exemplo de matriz de interações potenciais $\left(P_{\mathrm{mm}}\right)$

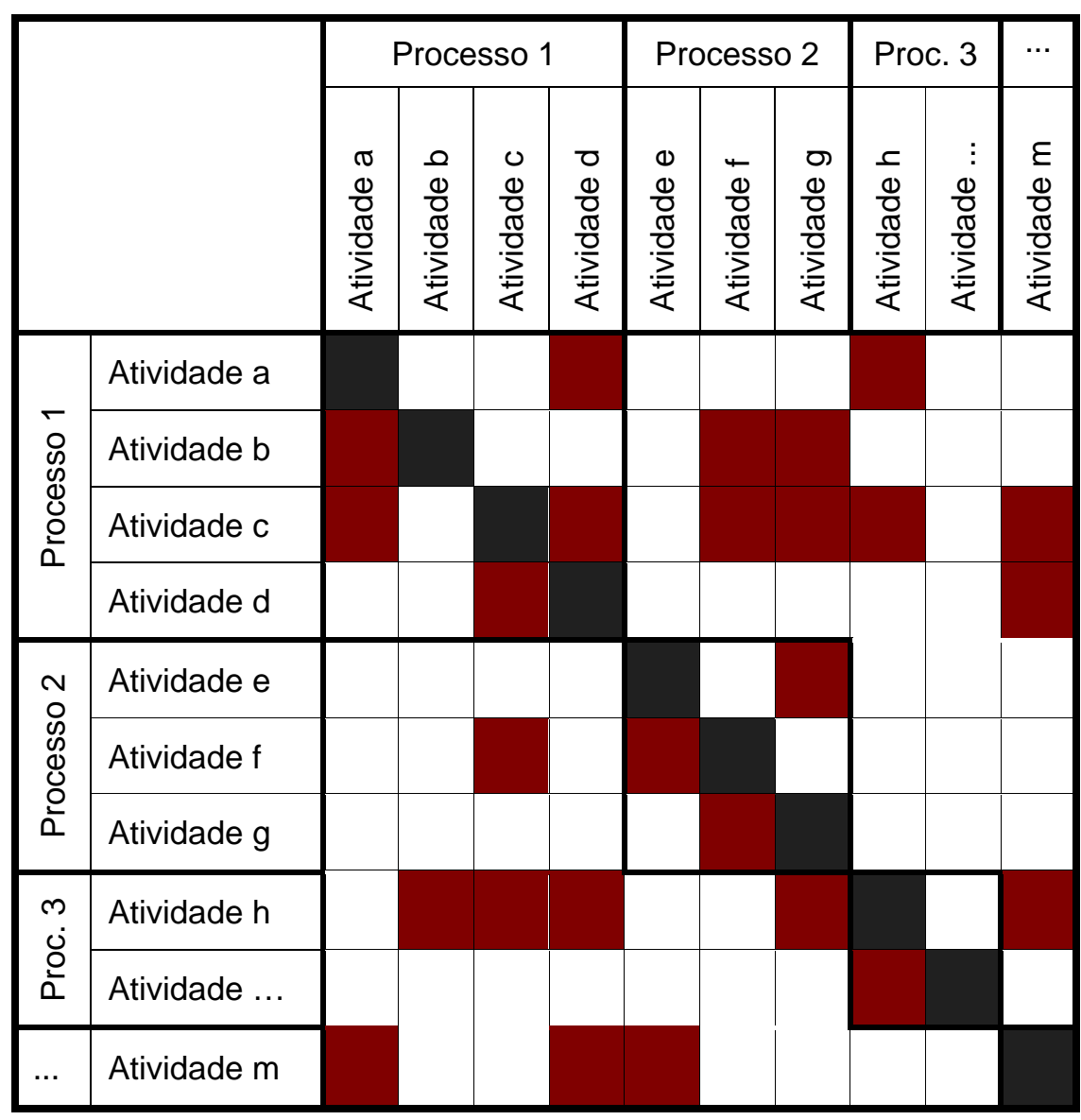


As interações fortes são definidas por intensa dependência entre processos diretamente ligados ao desenvolvimento de uma função do sistema. Essas dependências demandam colaboração e fluidez do fluxo de informações para integrar com eficiência as soluções de projeto. A matriz das relações totais apresenta todas as interações potenciais para o desenvolvimento do sistema do produto, e estas exigem comunicação informacional fluida. Ambas as matrizes permitem visualizar quão adequada é a divisão das atividades do processo analisado, o que permite gerenciar sua modulação e orientar as atividades de coordenação do projeto.

O quinto passo compara a interação potencial e a comunicação real ao sobrepor a matriz $\mathrm{R}_{\mathrm{m}, \mathrm{m}}$ às matrizes $\mathrm{PT}_{\mathrm{mm}}$ e $\mathrm{PF}_{\mathrm{mm}}$. Por meio dessa matriz de congruência $\left(\mathrm{C}_{\mathrm{mm}}\right)$ é possível observar os pontos de congruência da organização do processo existentes com a arquitetura do sistema (Quadro 13).

Quadro 13 - Exemplo de matriz de congruência $\left(C_{\mathrm{mm}}\right)$

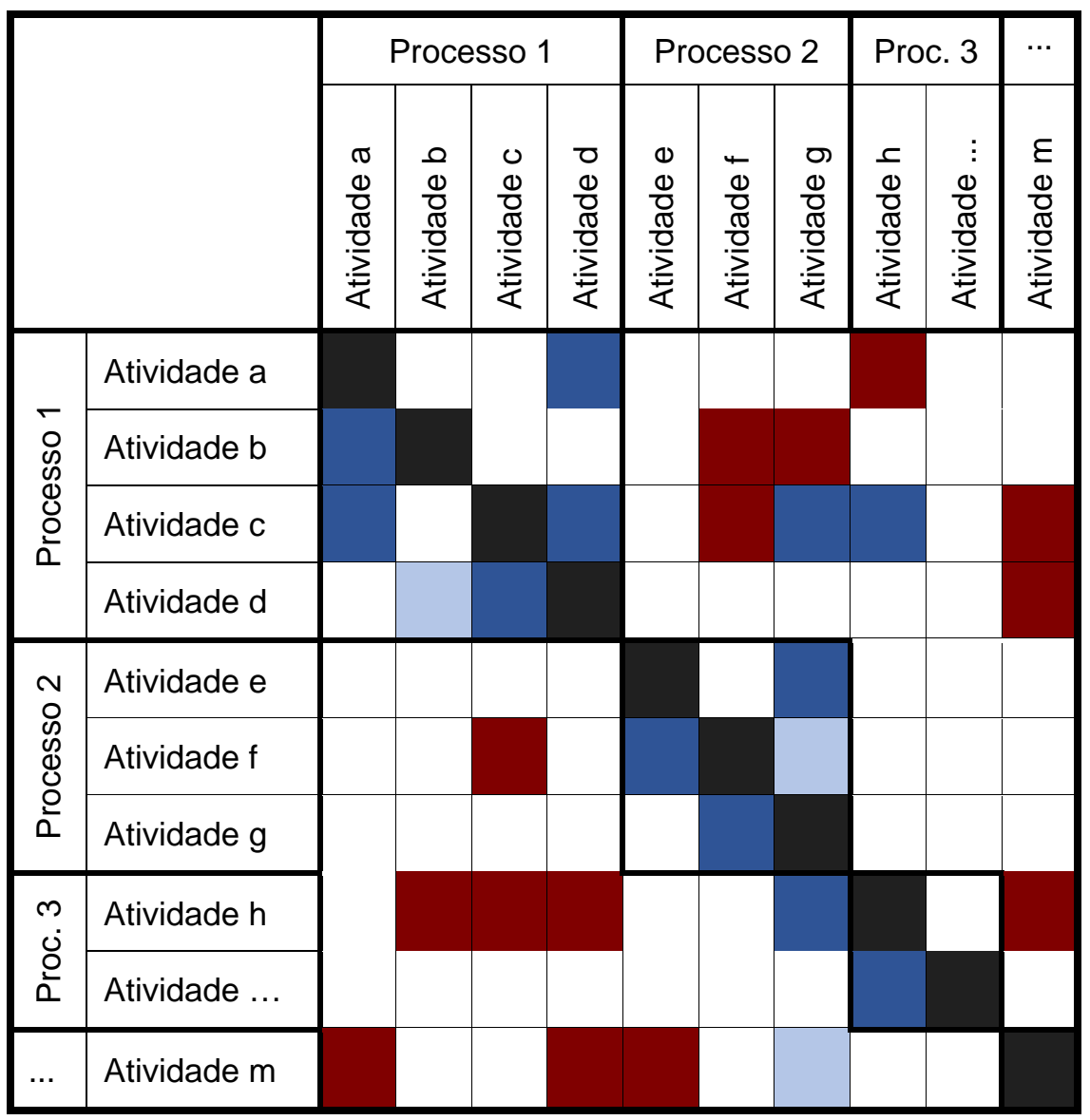

Legenda: $\square$ interações correspondentes, $\boldsymbol{\square}$ interações não atendidas, $\square$ interações não previstas. 
$\mathrm{Na}$ matriz $\mathrm{C}_{\mathrm{m}, \mathrm{m}}$ apontam-se três situações de sobreposição diferentes: (1) indica todas as "interações correspondentes" entre a comunicação real e a potenciais totais existentes; (2) as interações potenciais fortes "não atendidas" pela comunicação real; e (3) os casos em que a comunicação real apresenta "interações não previstas" no mapeamento das interações potenciais totais.

A maior ou menor coincidência das interações entre agentes responsáveis pelas atividades do projeto indicam o grau de congruência organizacional. Uma baixa coincidência aponta um processo pouco congruente. Isso implicaria custos adicionais, maior demora e até comprometimento da eficácia do processo, que impactam sobre a percepção de valor e a lucratividade do empreendimento.

Em uma análise detalhada da $\mathrm{C}_{\mathrm{mm}}$ associada à observação direta das idiossincrasias dos casos mapeados, é possível construir um diagnóstico consistente da organização orientada a projetos, como no geral são as organizações ligadas à construção. Por exemplo, é possível verificar se e como a necessidade de interações não atendidas estruturalmente é suprida por uma maior ou menor informalidade nas relações interorganizacionais; se os limites organizacionais existentes respeitam os vínculos fortes de interdependência e como são contornadas as barreiras eventualmente existentes; se as interações não previstas mas existentes na comunicação real entre os agentes envolvidos no projeto relacionamse a atividades que não agregam informação ao sistema ou se decorrem de uma compreensão inadequada de sua arquitetura por parte dos agentes envolvidos, etc.

\subsubsection{Bases computacionais}

Tanto a montagem das matrizes quanto o cálculo da equação apresentada na definição das matrizes de interação potencial foram operacionalizados computacionalmente de forma a viabilizar em tempo hábil o estabelecimento de todas as relações entre atividades, agentes e componentes do sistema. Como as interações existentes no processo de projeto apresentavam relações cíclicas, iterativas, uma estrutura de verificação de relações em estrutura de arvore não era adequada. Assim, empregou-se uma estrutura de dados baseada em grafo, que permite verificar as relações de ciclicidade, uma vez que as informações são abstraídas em dados registrados como entidades genéricas ou nós, que se relacionam por meio de arestas. 
No caso das interações de atividades, foi utilizado um grafo direcionado (dígrafo) em que se estabelece um sentido à relação entre entidades. No caso em questão, estabelece em uma entrada de dados em que a atividade $i$ depende da atividade $j$, mas não o contrário. Assim, para que a atividade $j$ apresente uma relação de dependência com a atividade $i$ é preciso que exista uma entrada assim indicando (CORMEN et al., 2009). Já as arestas de conexão entre as entidades da arquitetura do sistema, ou seja, dos componentes dos sistemas construtivos, não apresentam um grafo direcionado, havendo, assim, uma dependência mútua (CORMEN et al., 2009), adequada a uma relação de interfaces observadas na teoria. Dessa mesma forma, foram estabelecidas relações de filiação.

Os dados, levantados e registrados em formato textual adequado, são processados por estruturas auxiliares para leitura dos arquivos. Então, as matrizes são geradas pelo programa desenvolvido especificamente para a tese a partir das relações já indicadas. Para realizar a equação $\mathrm{P}_{\mathrm{mm}}=\mathrm{F}_{\mathrm{mn}} \cdot \mathrm{S}_{\mathrm{nn}} \cdot \mathrm{F}_{\mathrm{nm}}$, o programa utiliza como apoio uma biblioteca de operações de álgebra linear para estruturar a multiplicação das matrizes de filiação e da interface entre sistemas para obter a matriz de interações potenciais. As matrizes de interação potencial são então interseccionadas, elemento a elemento, com a matriz de interações reconhecidas, para identificar a congruência entre as matrizes.

O programa computa as atividades como se fossem pertencentes a um único processo, indicando onde pode ser "quebrado" quando as interações cíclicas e iterativas não são observadas; ou, do contrário, faz-se necessária alguma ação sobre as relações entre atividades existentes para alterar as relações de interações cíclicas e iterativas, e evitar perda de eficiência organizacional ao quebrar o processo em uma área previamente arbitrada por outros motivos que não aumentar a congruência.

\subsubsection{Interpretação do mapeamento}

O mapeamento da congruência organizacional estabelece as coordenadas das interações potenciais atendidas, não previsíveis e não atendidas em um processo de projeto e execução para dado edifício. Todavia, como uma lente especializada, o mapeamento não explicita todo o contexto de realização das tarefas pertencentes a esses processos. A 
interpretação de tais indicadores depende da verificação das características não mapeadas do empreendimento devido a não estarem contempladas em sua organização formal.

Por meio de discussões realizadas com os agentes envolvidos a partir da leitura do mapeamento, foi possível compreender como qualidades individuais responderam às condições organizacionais levantadas de forma a suprir as interações fortes não previstas. Também foram verificadas as circunstâncias para a ocorrência de interações não previstas, porque estas podem decorrer tanto de uma compreensão inadequada da arquitetura do sistema como de uma idiossincrasia organizacional ou devido a uma característica isomórfica do setor.

Após a leitura do mapeamento junto com os profissionais, discutiu-se acerca das responsabilidades nominais e reais de cada agente. Seguindo um protocolo de entrevistas semiestruturadas, os profissionais foram provocados a falar sobre o comprometimento com o sucesso do empreendimento; o envolvimento com as atividades em que não eram os responsáveis principais, mas cujas interações fortes não atendidas os conectavam; quais competências estavam vinculadas à realização das atividades; quais as condições fisicas, culturais e contratuais para a realização do trabalho; e se atribuíam a alguma competência ou prática a superação (ou não) das interações não atendidas.

Com o esclarecimento sobre a situação mapeada junto aos profissionais envolvidos, foi realizada a análise do mapeamento, considerando as circunstâncias da divisão do trabalho, especialização, hierarquia, distribuição da autoridade e da responsabilidade dos agentes. Os resultados foram discutidos fazendo-se relações entre, de um lado, os mapeamentos e a discussão realizada com os profissionais e, de outro, as implicações organizacionais analisadas com base na teoria. 


\section{A INFLUÊNCIA ORGANIZACIONAL SOBRE A QUALIDADE DO PROJETO DE EMPRENDIMENTOS IMOBILIÁRIOS}

A adoção de termos cujo significado é consolidado em uma área do conhecimento por outras disciplinas acontece frequentemente como um recurso narrativo para comunicar por meio de analogia conceitos fundamentais à discussão. O desenrolar desse debate acadêmico estabelece - ou deveria estabelecer - novos e embasados significados para os termos adquiridos, incorporando-se organicamente ao linguajar técnicos de uma área. Hoje, quando um estudante recém-formado de arquitetura sai em busca de emprego, em um primeiro momento será tomado por uma feliz e ilusória alegria ao verificar o número de oportunidades de emprego com bom salário destinado à função de “arquiteto". Entretanto, tão logo sua atenção for direcionada à lista dos requisitos profissionais a serem preenchidos, perceberá a ilusão, já que muitas dessas vagas são destinadas, na verdade, a profissionais aptos a realizar "arquitetura de sistemas".

Se existem casos de abuso de analogias não explicadas e validadas, como critica Alan Sokal (1999), em outras situações um aparente conflito epistemológico decorrente da apropriação interdisciplinar de determinados termos consolidados em uma área pode revelar uma convergência conceitual relevante entre campos distintos e mesmo ressignificar o termo original. É o caso, por exemplo, do termo arquitetura, que é empregado na teoria organizacional para designar o processo de criação de uma nova organização ou a modificação de uma organização existente. Arquitetura organizacional diz respeito tanto à construção do ambiente fisico adequado às realizações humanas como ao arranjo organizacional que estrutura essas realizações. Imediatamente, o primeiro sentido se conecta diretamente ao campo da arquitetura, enquanto o segundo remete aos processos, competências e formas de relações hierárquicas ligadas à organização.

O conhecimento associado a ambas as definições, contudo, interessa ao processo de projeto, uma vez que o campo da arquitetura abrange tanto o domínio sobre o artefato como o domínio sobre o trabalho necessário para sua construção. 


\subsection{CONSIDERAÇÕES SOBRE A RSL}

Pesquisas relacionadas às ciências aplicadas, como ocorrem nos campos ligados à AECO, apresentam bases diversas de conhecimento, o que dificulta consideravelmente a categorização e a recuperação das informações pertinentes a algumas questões de pesquisa com forte entrelaçamento interdisciplinar. O desafio expresso em consolidar o debate sobre tais questões limítrofes torna a elaboração de uma RSL particularmente desafiadora e necessária, pois o pesquisador que transita entre esses limites esbarra em barreiras ontológicas e etimológicas de teorias que se integram na prática. Uma das consequências da opacidade entre os limites do saber acadêmico e científico pode ser acrescida aos riscos de se promover uma pesquisa com viés de seleção ou confundimento.

RSL requer uma pesquisa aprofundada, objetiva e reprodutível, que considere a maior variedade de fontes possível dentro dos limites de recursos para identificar o maior número de estudos relevantes à pesquisa. Assim, para superar o viés de seleção, a busca de fontes em uma base de dados não é adequada. Foram exploradas as principais bases de dados indexados, desde bases mais abrangentes, como a Scopus e a Web of Science, até bases direcionadas às áreas tecnológicas, como a Engineering Village e a ACM. Por essas bases indexadas contarem com sistemas de buscas avançados, as combinações de palavras-chave (string de busca) puderam ser aplicadas com eficiência apenas nesses portais.

De um total de 1.593 resultados, o Scopus abrangeu mais de $67 \%$ do total de resultados recuperados (gráfico à esquerda da Figura 4), e entre todos os trabalhos identificados no levantamento das bases anteriormente citadas foi detectada uma incidência de $40 \%$ de redundância nos metadados, isto é, repetição da indexação de um mesmo trabalho em mais de um dos bancos consultados (gráfico à direita da Figura 4). Quando o volume de metadados de trabalhos duplicados atingiu os 40\%, assumiu-se que a saturação das fontes de busca tinha sido alcançada. Assim, entre artigos de revistas científicas, trabalhos publicados em anais e algumas teses e livros técnicos, foram identificados de fato 948 trabalhos para serem avaliados segundo os critérios de seleção apontados no protocolo da RSL. 


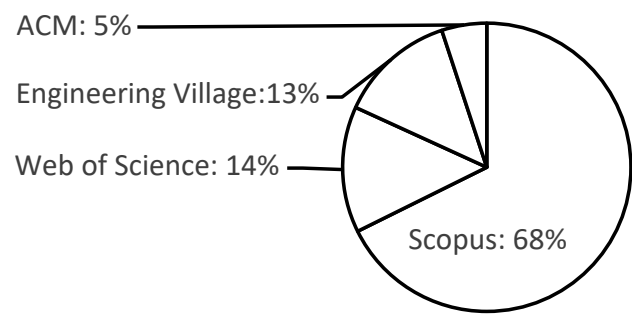

fontes dos trabalhos

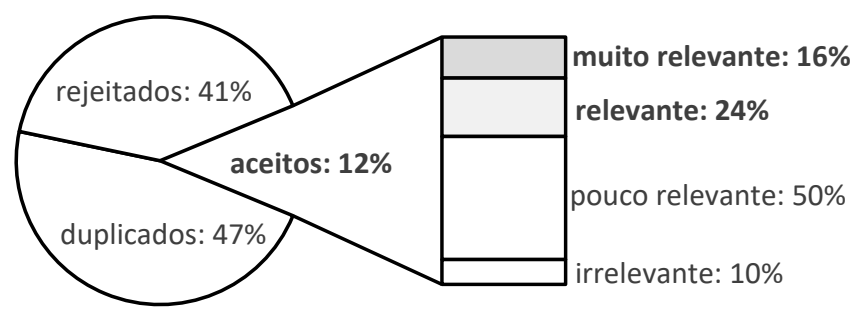

trabalhos selecionados

No decorrer do processo de seleção dos trabalhos identificados, constatou-se um problema ligado à falta ou insuficiência de coordenação interdisciplinar para que termos e estrutura da formação do título e do resumo adotados em diferentes campos do conhecimento ou mesmo em um mesmo assunto comunicassem com a menor redundância possível o conteúdo realmente publicado. Essa constatação é expressa pelo número de ocorrências em que foi detectado caso de dubiedade das keywords/palavraschave e por trabalhos que não correspondiam ao tema pesquisado (Quadro 14). Tratase de 329 casos, um número expressivo quando comparado ao resultado de dois outros critérios de exclusão mais recorrentes, a "teoria ou exemplo de organização de atividade não ligada ao projeto" e “exemplo de organização de projeto não relacionado à AECO”, que juntos atingiram 371 casos.

Entre as ocorrências de critérios de inclusão, prevaleceram trabalhos cuja contribuição para a discussão sobre a organização do projeto é indireta. São casos associados à “influência sobre a organização do projeto em AECO", com 100 casos, e "inovação em algum aspecto da organização do projeto", com 73 casos, que refletem a sobreposição interdisciplinar (Quadro 14). 
Quadro 14 - Número de ocorrência dos critérios de seleção

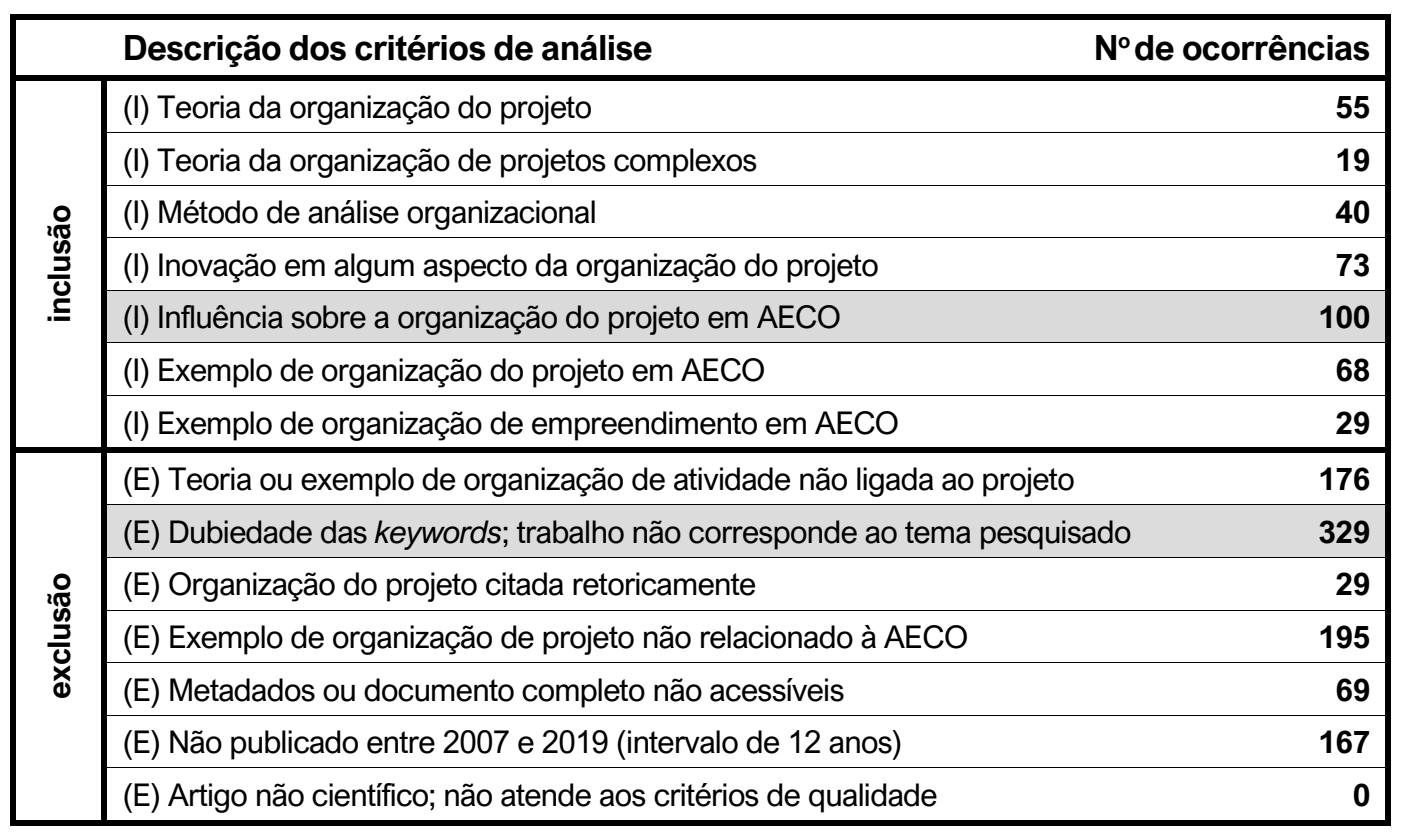

A análise das informações de título, resumo e palavras-chave nesses trabalhos aponta para baixa consciência sobre a intersecção do tema principal com a teoria organizacional. Assim, embora os trabalhos tangenciem temas que influenciam a organização do trabalho de projeto em AECO, salvo os trabalhos considerados muito relevantes para a pesquisa, não foi identificado um esforço consistente de relacionar e interpretar os achados de fundo organizacional com as teorias organizacionais existentes.

A análise do conteúdo integral de todos os trabalhos considerados relevantes e muito relevantes, realizada para extração das informações das pesquisas para revisão da literatura, deixou claro o predomínio de trabalhos que abordam a influência organizacional sobre a qualidade do projeto, a organização do projeto e a organização de empreendimentos imobiliários (Quadro 4 e Quadro 15). O predomínio de trabalhos que não estão diretamente relacionados à teoria, arquitetura e congruência organizacional sugere que as pesquisas desenvolvidas em AECO apresentam um debate embasado em conhecimentos ensimesmados, não relacionados à discussão mais ampla realizada pela teoria organizacional sobre a organização de projetos complexos e organizações de criação de valor. 
Quadro 15 - Assuntos de interesse identificados na RSL por ordem de ocorrência

\begin{tabular}{|lr|}
\hline Assunto de interesse & $\mathbf{N}^{\circ}$ de ocorrências \\
\hline Influência organizacional sobre a qualidade do projeto & 18 \\
\hline Organização do projeto & 16 \\
\hline Organização do AC & 16 \\
\hline Método de diagnóstico organizacional & 8 \\
\hline Teoria organizacional & 7 \\
\hline Arquitetura organizacional & 7 \\
\hline Influências ambientais sobre a organização do projeto & 7 \\
\hline Congruência organizacional & 3 \\
\hline
\end{tabular}

Já entre os assuntos incidentais, cuja lista era aberta para abranger a diversidade de temas ligados aos assuntos de interesse, o maior número de ocorrências está relacionado ao gerenciamento de projeto, BIM, barreiras organizacionais, arquitetura do sistema, inovação, colaboração, interação, sistemas complexos e aprendizado (Quadro 4 e Quadro 16). Menos recorrentes, temas reconhecidamente relevantes como capacidade organizacional e gerenciamento de competência trouxeram poucas, porém significativas contribuições para a discussão.

Quadro 16 - Assuntos incidentais identificados na RSL por ordem de ocorrência

\begin{tabular}{|lr|}
\hline Assuntos incidentais abordados & $\mathbf{N}^{\circ}$ de ocorrências \\
\hline Gerenciamento de projeto; BIM & 11 \\
\hline Barreiras organizacionais & 9 \\
\hline Arquitetura do sistema; Inovação & 8 \\
\hline Colaboração; Interação; Sistemas complexos & 6 \\
\hline Aprendizado & 5 \\
\hline $\begin{array}{l}\text { Capacidade organizacional; estrutura organizacional, fluxo de informações; } \\
\text { gerenciamento de competência; gerenciamento de valor; mudança; projeto } \\
\text { integrado; riscos; modelagem unificada }\end{array}$ & 4 \\
\hline Equipe & 3 \\
\hline $\begin{array}{l}\text { Design Structure Matrix (DSM); Domain Mapping Matrix (DMM); empresas virtuais; } \\
\text { gerenciamento estratégico; gerenciamento predial; isomorfismo; liderança; requisitos } \\
\text { funcionais; sustentabilidade }\end{array}$ & 2 \\
\hline $\begin{array}{l}\text { Conhecimento; contratos; especialização; fronteiras organizacionais; gerenciamento } \\
\text { de cadeia de suprimentos; gerenciamento de exceçães; incerteza; MEP; modulação; } \\
\text { negociação; qualidade; tecnologia digital; viabilidade organizacional; gerenciamento } \\
\text { de execução; integração de sistemas }\end{array}$ & 1 \\
\hline
\end{tabular}


Entre os textos classificados como muito relevantes, alguns permeiam toda a estrutura argumentativa principal apresentada na redação a seguir (Quadro 17). São artigos de revistas científicas, capítulos de livros e artigos publicados em periódicos de congressos que abordam principalmente temas ligados à arquitetura organizacional e competência, colaboração, BIM, gerenciamento de projeto, aprendizado, equipes de projeto multifuncionais, capacidades, inovação, etc. Com esses textos foram levantadas as precedências teóricas das referências em que se baseiam, configurando o encadeamento de citações que foram analisadas e consideradas na sumarização dos temas desenvolvidos com a RSL.

Quadro 17 - Referências mais citadas pela redação da RSL

\begin{tabular}{|c|c|c|}
\hline Título & Autor, data & Vezes \\
\hline Design core competence diagnosis & (BONJOUR; MICAELLI, 2010) & 48 \\
\hline $\begin{array}{l}\text { Architecting organizations: A dynamic } \\
\text { strategic contingency perspective }\end{array}$ & (SANCHEZ, 2012) & 33 \\
\hline BIM: In search of the organizational architect & (FORGUES; LEJEUNE, 2015) & 29 \\
\hline The architecture of collaboration & (FJELDSTAD et al., 2012) & 29 \\
\hline Organizational power in building design management & (KNOTTEN et al., 2015) & 28 \\
\hline $\begin{array}{l}\text { Systems architecture, procedural knowledge } \\
\text { and learning by using: Implications on systems } \\
\text { integration capabilities }\end{array}$ & (CHAGAS JR.; CAMPANÁRIO, 2014) & 26 \\
\hline $\begin{array}{l}\text { Practices for Designing Cross-Functional } \\
\text { Teams for Integrated Project Delivery }\end{array}$ & (LAURENT; LEICHT, 2019) & 26 \\
\hline $\begin{array}{l}\text { Design management of sustainability values: } \\
\text { A learning organization perspective }\end{array}$ & (NOVAK, 2014) & 23 \\
\hline $\begin{array}{l}\text { Inter-organizational context of the innovation } \\
\text { process and the role of architectural designers as } \\
\text { system integrators: Case evidence from Turkey }\end{array}$ & (ERBIL; AKINCITÜRK; ACAR, 2013) & 17 \\
\hline Integrated collaborative design & (AUSTIN et al., 2007) & 15 \\
\hline The implications of product architecture on the firm & (YASSINE; WISSMANN, 2007) & 15 \\
\hline $\begin{array}{l}\text { Beyond the BIM utopia: Approaches to the } \\
\text { development and implementation of building } \\
\text { information modeling }\end{array}$ & (MIETTINEN; PAAVOLA, 2014) & 14 \\
\hline $\begin{array}{l}\text { Talent management: Challenges of building cross-fun } \\
\text { capability in high-performance work systems environr }\end{array}$ & (LEVENSON, 2012) & 12 \\
\hline
\end{tabular}


A sumarização dos 67 trabalhos considerados muito relevantes e relevantes para a revisão (Apêndice B ) foi estruturada em sete subseções principais, que apresentam de forma concatenada uma introdução à teoria organizacional; as especificidades das organizações de projetos complexos e das organizações de empreendimentos imobiliários; a influência organizacional sobre o processo de projeto, assim como a influência ambiental sobre a organização do projeto; os conceitos de isomorfismo e de congruência organizacional; e as bases da arquitetura organizacional consideradas na tese.

\subsection{UMA INTRODUÇÃO À TEORIA ORGANIZACIONAL}

O estudo sobre a evolução da teoria e práticas das organizações apresenta um interessante percurso que se confunde com a história moderna e revela determinados aspectos das forças socioeconômicas que alteraram e alteram a percepção do que é o trabalho. De um pensamento inicialmente mecanicista, que reduzia a atividade e o corpo humano a apenas mais uma peça das máquinas modernas, até a valorização do conhecimento e a aceitação da subjetividade em uma interpretação das organizações como um sistema social complexo, observam-se subsequentes revisões dos paradigmas organizacionais, que resultaram, hoje, um cenário de incerteza em torno dos princípios gerais de administração da estrutura, pessoas e funcionamento organizacional (ARAUJO, 2011).

Enquanto as abordagens clássicas da teoria das organizações, baseadas na administração científica e na teoria da burocracia administrativa, enfatizavam principalmente as estruturas formais, a autoridade, o controle e a hierarquia (TAYLOR, 1919; WEBER, 1947), estudos posteriores defendiam que a análise das organizações precisava considerar a motivação e os valores sociais dos atores envolvidos na organização, que não se comportavam necessariamente de forma racional e econômica (MCGREGOR, 1957). Tal subjetividade exigiu uma interpretação estruturalista em que as organizações só poderiam ser compreendidas em relação a seu ambiente e, assim, comportavam-se como sistemas abertos, em que atividades interdependentes eram realizadas por atores com competências e valores distintos (DAVIS; SCOTT, 2007), que precisavam ser gerenciados.

O reconhecimento da influência de variáveis sociais e ambientais sobre a caracterização de organizações resultou no pressuposto fundamental de não uniformidade, ou melhor, de que podem variar significativamente a concepção de um desenho ótimo para alcançar os objetivos da organização, alcançado por meio da avaliação da natureza do trabalho e das condições para a realização das tarefas que se deve realizar (TOSI; ALDAG; STOREY, 1973). 


\subsubsection{A definição de organização adotada para pesquisa}

Uma organização pode ser compreendida de forma abrangente como um sistema de atividades realizadas com a intenção de alcançar determinados objetivos (ALDRICH; RUEF, 2006; FJELDSTAD et al., 2012). A eficácia de uma organização está relacionada a sua coerência interna e externa, isto é, depende do alinhamento entre sua estratégia e a estrutura interna, bem como do alinhamento entre essa estratégia e o ambiente em que se insere, em um processo dinâmico de ajustes ao longo do tempo (FJELDSTAD et al., 2012).

Sob a perspectiva dos negócios, uma empresa corresponde a uma entidade organizacional que tem como finalidade (objetivo) produzir um ou mais produtos ou serviços para um ou mais consumidores (YASSINE; WISSMANN, 2007). O sucesso do negócio depende da relação que há entre a própria empresa, os produtos ou serviços que ela produz ou disponibiliza e os clientes que serve, constituindo um sistema gerenciado de criação de valor que pode se basear em três tipos de ativos: de portfólio de conhecimento, de portfólio de produtos e de portfólio de marcas (YASSINE; WISSMANN, 2007).

A complexidade do sistema de negócio baseado em desenvolvimento de produto, como normalmente são enquadradas as atividades de AECO, pode ser gerenciada por meio das arquiteturas do produto, do processo e da organização (EPPINGER; SALMINEN, 2001; SOSA; EPPINGER; ROWLES, 2004; SOSA, 2007). Sob a perspectiva do sistema, a organização é entendida como um conjunto de estruturas e de processos que permitem a realização, a coordenação e o controle de atividades por meio da divisão e integração dos recursos disponíveis (PERROW, 1967; FJELDSTAD et al., 2012).

Fundamentalmente, para que um negócio seja viável, um projeto de sistema deve ser capaz de responder com eficácia a uma variedade de requisitos internos e externos, exigidos pelo ambiente (SCHILLING, 2000; SANCHEZ, 2012). Ou seja, uma organização não apenas projeta produtos como deve ser projetada para os produtos, uma vez que o modelo de organização determina em grande parte a forma como as atividades de desenvolvimento e execução do projeto do produto são coordenadas (SANCHEZ; MAHONEY, 1996; SANCHEZ, 2012). 
Na prática, os agentes responsáveis por uma organização muitas vezes optam por manter um desenho organizacional inadequado aos novos requisitos internos e ambientais, o que reduz sua capacidade de desenvolver e executar um novo projeto com eficiência (BRUSONI; PRENCIPE, 2006; SANCHEZ, 2012). A inadequação das organizações existentes exige dos agentes envolvidos esforços adicionais para cobrir as falhas estruturais. Em contrapartida, um desenho organizacional projetado de forma a se alinhar à arquitetura de um sistema e do processo de desenvolvimento e produção confere aos agentes melhores condições para realizar o trabalho (BURT, 1992; FJELDSTAD et al., 2012).

\subsubsection{Estrutura organizacional}

O sistema que integra todas as partes que constituem o trabalho em uma organização é denominado de estrutura organizacional (FJELDSTAD et al., 2012). Assim, estrutura organizacional de uma empresa corresponde à maneira como são agrupadas pessoas, com diferentes níveis de autoridade e diferentes áreas de atuação, para realizar atividades específicas possíveis em determinadas condições e competências. Sua constituição pode variar consideravelmente, segundo tipos de arranjos específicos, como estrutura linear, funcional, matricial, organizadas em rede ou em equipes (ARAUJO, 2011).

As formas como os subsistemas são interligados e subordinados em cada arranjo de estrutura organizacional determinam uma relação de hierarquia específica, que altera a forma como são definidos os objetivos e metas, como ocorre o controle e a coordenação do trabalho, como são alocados os recursos e como as relações de interdependências e conflitos são mediadas (PERROW, 1967; FJELDSTAD et al., 2012). Em um desenho organizacional hierarquicamente bem definido, as relações de interdependências dos subsistemas são resolvidas direta ou indiretamente por níveis hierárquicos mais elevados de gerenciamento, por meio de planejamento e padronização (MINTZBERG, 1992; MORGAN, 2006). Já em desenho menos hierárquico, a informalidade e a horizontalidade podem oferecer vantagem competitiva em situações específicas ao conferirem maior dinamismo para mudanças de rumo orientadas à adequação ao mercado, ao cliente e ao propósito final do empreendimento, obtendo daí suas recompensas econômicas (UZZI; SPIRO, 2005; FJELDSTAD et al., 2012). 
O desenho organizacional corresponde a um modelo representativo dos sistemas e processos do ciclo de vida que auxilia no processo de planejamento e análise da organização (CHIAVENATO, 2010; ARAUJO, 2011). O desenho expressa os padrões de integração, diferenciação, centralização e formalização que caracterizam a estrutura, os processos e a cultura organizacional. Normalmente é representado por organogramas estatísticos de sua constituição interna, que, entretanto, não mostram seu funcionamento ou sua dinâmica, embora ajudem a compreender como funcionam as relações de hierarquia (CHIAVENATO, 2010).

O reconhecimento dos diferentes arranjos organizacionais por meio de seus desenhos característicos pode clarificar algumas questões sobre a organização de empreendimentos imobiliários. Contudo, um estudo extensivo sobre todas as possibilidades de arranjo e as implicações em torno das diferentes possibilidades de estruturas ultrapassam o conhecimento que tangencia o presente debate. Portanto, em vez de uma longa digressão sobre cada tipo de organização existente, são abordadas aqui, de forma sintética, apenas as características de desenhos que impactam diretamente a tese.

\subsubsection{Formas de desenho organizacional}

Entre as diferentes formas de organização do trabalho produtivo relevantes para a presente discussão, algumas são apresentadas para estabelecer uma perspectiva histórica e outras como desdobramentos de estratégias para abordar a complexidade, o dinamismo e a indeterminação que as formas clássicas não podiam atender.

A organização linear corresponde à forma mais simples (e antiga) de organização do trabalho. Extremamente hierarquizada, a relação entre os agentes é única e direta entre as posições de comando e de operação. É representada pela estrutura piramidal típica de comandos militares, com decisão centralizada e linhas de comunicação formal bem definidas (CHIAVENATO, 2006). No campo de atuação da AECO, essa forma de organização aparece principalmente em organizações temporárias de empreendimentos independentes e em pequenas e médias empresas da construção civil, onde a cultura organizacional centralizadora confunde os objetivos e valores pessoais de seus proprietários com aqueles expressos pela empresa (VIVANCOS; CARDOSO, 1999; VIVANCOS, 2001). 
A organização funcional se desenvolveu originalmente nas indústrias das estradas de ferro e do aço do final de 1800. Apresenta uma estrutura baseada em diferenciação e especialização funcional, em que cada especialidade possui autoridade restrita a operações sequencialmente bem definidas em função de sua área de domínio (FJELDSTAD et al., 2012), o que descentraliza as decisões (representação à esquerda na Figura 5).

As atividades de cada agente são bem definidas e nelas predomina a comunicação direta entre os agentes de um mesmo departamento, o que favorece a promoção de conhecimento organizacional especializado sobre assuntos técnicos (CLARK; WHEELWRIGHT, 1992). As atividades são hierarquicamente controladas, e as interdependências sequenciais são previamente planejadas e geridas pelos níveis hierárquicos mais altos de decisão (FJELDSTAD et al., 2012). O principal problema está associado à dificuldade de coordenar as atividades dos departamentos (CHIAVENATO, 2006). Além disso, como a avaliação do desempenho de cada especialidade é individual, os objetivos e as metas de cada departamento se sobressaem ao resultado global (CLARK; WHEELWRIGHT, 1992).

Incorporadoras e construtoras de médio e grande porte apresentam características de organizações funcionais, evidentes na departamentalização recorrente, não apenas em áreas contáveis e administrativas, mas também observadas pela constituição de departamentos permanentes de marketing e de projeto, de orçamentação e aquisição, de operações e de RH, entre outros (VIVANCOS, 2001; GIBSON et al., 2006).

Figura 5 - Organização funcional e organização por produtos
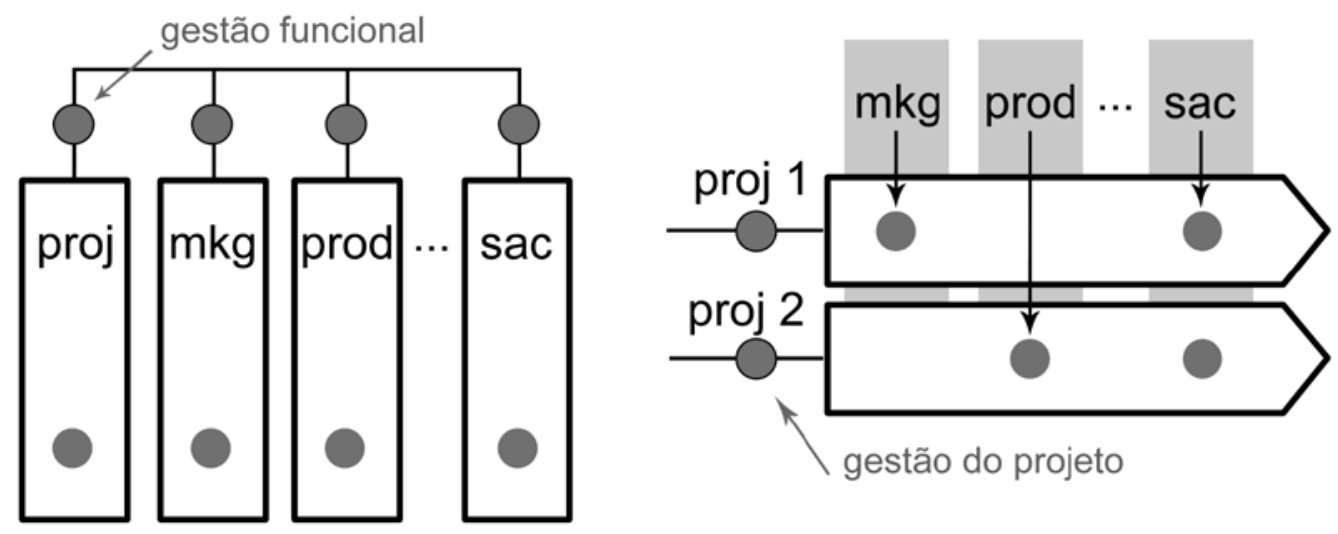

Fonte: adaptada de Clark e Wheelwright (1992). 
A organização baseada em projeto, ou organização orientada ao produto (à direita na Figura 5), se estrutura segundo as especificações dos clientes e enfatiza o negócio (CHIAVENATO, 2006). As equipes são constituídas temporariamente para realizar o projeto, e, após sua conclusão, os agentes especializados são deslocados para a constituição de outro projeto. Com a definição de um gerente responsável pelo projeto e o predomínio da comunicação informal e direta, a atuação dos integrantes da equipe de projeto não é limitada pelas barreiras departamentais ou pela burocracia da organização, o que confere maior flexibilidade e coordenação das especialidades. (CHIAVENATO, 2006). Entre os problemas observados, a falta de coesão entre agentes de uma mesma especialidade pode resultar na duplicação de trabalho, na disputa pela alocação de recursos e em conflito com a direção da empresa (CLARK; WHEELWRIGHT, 1992).

As organizações baseadas em projeto são frequentemente associadas a empresas desenvolvedoras de software, a instituições de pesquisa (SATO; DERGINT, 2014) e até mesmo a escritórios de projeto arquitetônico, estrutural, etc. (VIVANCOS, 2001).

A organização matricial combina características de organizações funcionais e de organizações por projeto (Figura 6), em que coexistem uma estrutura de departamentos funcional e uma de gerenciamento de produtos ou projetos (CHIAVENATO, 2006). Nessa organização a unidade de comando deixa de existir, e os agentes de um departamento possuem dupla subordinação, uma associada à especialização e outra à coordenação das especialidades (FJELDSTAD et al., 2012).

A disposição matricial pode ser leve ou pesada (MINTZBERG, 1992; FJELDSTAD et al., 2012). A organização matricial leve tem comportamento semelhante ao de uma organização funcional, porém apresenta melhores condições de comunicação interdepartamental e coordenação de projetos. Por outro lado, a coordenação ainda é limitada a algumas especialidades e a avaliação é individualizada, o que dificulta o gerenciamento do projeto (CLARK; WHEELWRIGHT, 1992). Já em uma organização matricial pesada a equipe de projeto abrange agentes de todas as especialidades, integrando os esforços para atender às expectativas dos clientes. Todavia, existe a possibilidade de haver conflitos com a organização funcional, aumento da complexidade e prejuízo da especialização do conhecimento técnico (CLARK; WHEELWRIGHT, 1992). 
Figura 6 - Organização matricial fraca e forte
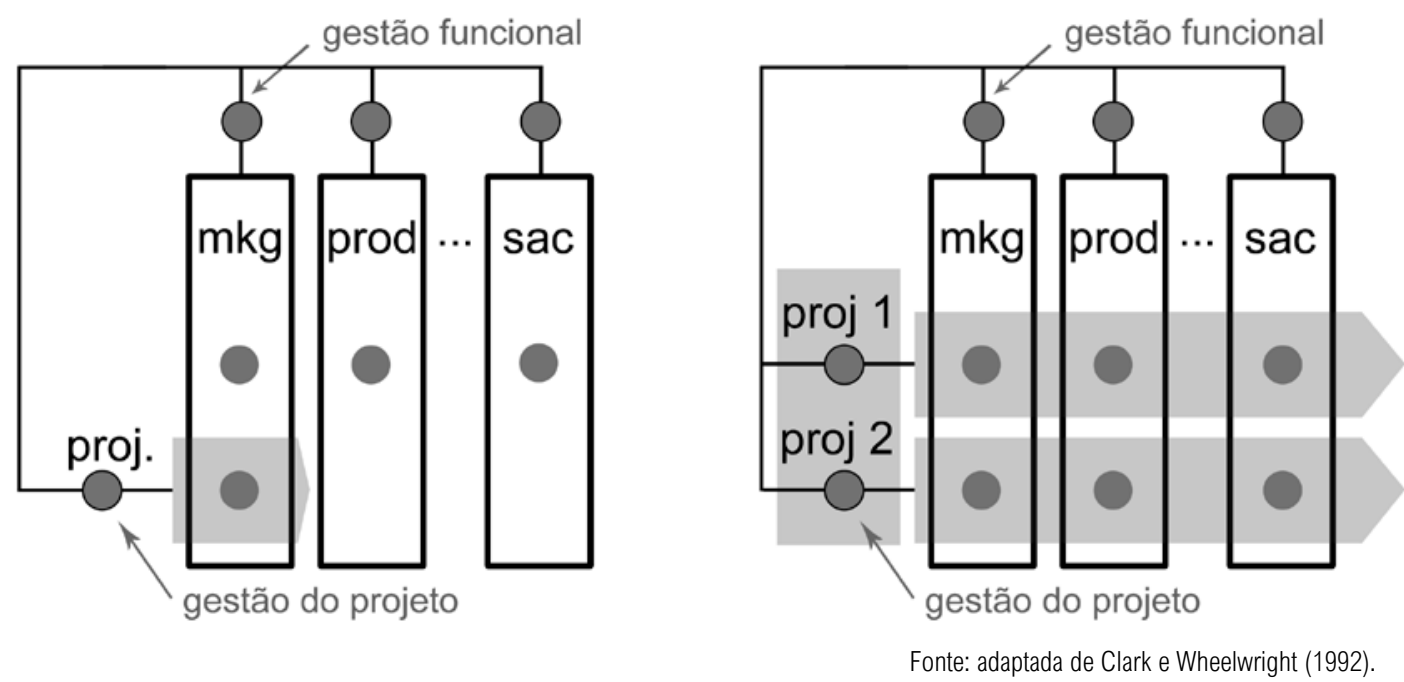

$\mathrm{Na}$ organização de redes de multiempresas uma empresa central concentra as atividades principais a seu negócio e terceiriza atividades não essenciais a prestadores externos. Assim como as organizações matriciais, as organizações de redes de multiempresas aumentam a capacidade de combinar competências de diferentes fontes (HEDLUND, 1994; GULATI, 2007; FJELDSTAD et al., 2012), estabelecendo uma relação hierárquica clara da empresa central, porém razoavelmente dinâmica, com os parceiros da rede para desenvolver, produzir e entregar seus produtos ou serviços (DYER; NOBEOKA, 2000; FJELDSTAD et al., 2012).

É uma forma de organização bastante comum em empreendimentos imobiliários organizados em torno de uma incorporadora/construtora forte, que concentra os meios de integração dos processos e produtos das empresas parceiras, com quem estabelece contratos de prestação de serviços e empreitas, caracterizados por escopos, custo e prazos predefinidos.

A organização orientada aos atores reduz a sobrecarga da burocracia e a hierarquia (GALBRAITH et al., 1974; FJELDSTAD et al., 2012) ao conceder aos agentes da organização autonomia e responsabilidade para promover mudanças visando superar incertezas ligadas à complexidade do sistema e do ambiente (CHAGAS JR.; CAMPANÁRIO, 2014). A redução dos mecanismos de controle e coordenação formais aumenta a agilidade para processar propriedades emergentes, analisar o ambiente e tomar decisões (FJELDSTAD et al., 2012). 
A interação direta entre os atores/agentes, em vez de uma subordinação hierárquica, é adequada para organizações que lidam com incertezas decorrentes de problemas mal estruturados, o que exige capacidade de adaptação e antecipação às mudanças do processo e do ambiente (FJELDSTAD et al., 2012).

As diferentes formas de organização apresentadas correspondem a sínteses de estratégias adotadas para estruturar uma organização, com focos específicos, seja para garantir a capacidade de planejamento prévio, para aumentar sua flexibilidade para se adaptar a sua incapacidade de planejar previamente, seja para garantir o controle reduzindo o desempenho, etc. (GALBRAITH et al., 1974). Cada desenho apresentado possui características formais bastante distintas quanto à relação de hierarquia dos agentes e à forma tanto de divisão do trabalho quanto de atribuição de autoridade e de responsabilidade. A complexa interação desse conjunto de variáveis insinuadas nos desenhos se expressa na real organização de estruturas organizacionais formais e informais. Uma estrutura formal corresponde àquela planejada e formalizada no desenho, enquanto a estrutura informal corresponde às relações de autoridade, de comunicação e de trabalho não regulamentadas, que suplementam a estrutura formal em suas deficiências, mas também podem prejudicar a organização (VIVANCOS, 2001; CHIAVENATO, 2010).

\subsubsection{Cultura organizacional e gerenciamento do conhecimento}

Para além das construções formais do desenho organizacional, um importante fator que influencia as interações entre os agentes decorre da cultura que se forma em uma estrutura organizacional real, onde componentes formais e informais, fisicos e humanos, influenciam e orientam em diferentes níveis o regime de crenças e o comportamento dos agentes que constituem a organização (ARGYRIS, 2010). A necessidade de promover mudanças organizacionais diante de novos paradigmas técnicos, sociais, mercadológicos e éticos evoca a importância de compreender comportamentos disfuncionais e, assim, projetar e implementar intervenções que reduzam essas barreiras organizacionais culturais, sob o risco de frustrar as mudanças (ARGYRIS, 2010). Esse universo de preocupações toma particular relevância em organizações que trabalham com o desenvolvimento de projetos, quando aprendizado e melhorias contínuas são condições para a competitividade e a diferenciação no mercado. 
A adaptação de um negócio às condições de competitividade também depende da capacidade de processamento de conhecimentos sobre o ambiente e os processos de trabalho em uso (STARY et al., 2007). Mais que uma decisão estratégica da direção da empresa, a promoção de mudanças organizacionais envolve a adequação tanto de tecnologias da informação e comunicação como das operações. Assim, melhorias e redesenhos devem ser compreendidos como um processo sociotécnico, que demanda mobilização dos agentes de gerenciamento e operação dos processos, de forma a participarem na formação do conhecimento organizacional (CARTER et al., 2013).

O movimento chamado aprendizagem organizacional requer a disponibilidade de recursos de comunicação e socialização do conhecimento aprendido individualmente e de anotação de representações desse conhecimento (NONAKA; TOYAMA, 2003; STARY et al., 2007). A decisão por implementar mudanças estruturais se baseia em descobertas conceituais e empíricas pessoais dos agentes da organização, que sociabilizam o aprendido por meio do entendimento compartilhado (DONG; KLEINSMANN; DEKEN, 2013). O aprendizado organizacional depende de um segundo ciclo, de processamento do conteúdo para afirmação do conhecimento, por meio de um sistema interativo de mediação da difusão dos processos e conhecimentos (STARY et al., 2007).

A estruturação de procedimentos de aprendizagem organizacional é importante para negócios que apresentam processos de reivindicação contínua do conhecimento do ambiente para a realização do trabalho (STARY et al., 2007). São organizações que obtêm vantagens competitivas devido a processos e resultados exclusivos, realizados com eficiência. Para tanto, a capacidade de mudança organizacional e de melhoria contínua assume relevância estratégica. Com o aumento de complexidade tecnológica e um ambiente de negócios mais competitivo e dinâmico, o aprendizado e a melhoria contínua são recursos eficazes para aumentar a eficiência organizacional na criação de valor (BETHA, 2007). A integração do projeto ao gerenciamento das operações ao longo da cadeia de valor permite articular requisitos do projeto, desempenho técnico e custos e prazos para alcançar os objetivos do empreendimento. Contudo, para que os processos de melhoria não sejam endógenos, mas, sim, orientados à criação de valor, é preciso uma forte interação com clientes e fornecedores (BETHA, 2007). 


\subsection{ORGANIZAÇÃO DE PROJETOS COMPLEXOS}

O projeto é normalmente descrito como um esforço temporário empreendido para alcançar determinado resultado exclusivo (PMI, 2017). Enquanto alguns projetos simples podem ser realizados por um indivíduo capacitado, projetos que dependem da organização do trabalho de vários agentes, com conhecimentos, competências e meios específicos, que compõem uma equipe de concepção e gestão do projeto, são entendidos como complexos (BONJOUR; MICAELLI, 2010). A organização desse tipo de projeto é comumente constituída por uma unidade de produção, uma empresa, uma associação de empresas ou uma organização temporária baseada em projetos (HOBDAY, 1998; ERBIL; AKINCITÜRK; ACAR, 2013) com capacidade de realizar o resultado esperado (PMI, 2017).

A capacidade de uma equipe de projeto influenciar variáveis de projeto tais como custo, cronograma, funcionalidade e qualidade material é maior no início do processo, durante a concepção, e se reduz com o decorrer do projeto. Inversamente, o custo para se fazerem mudanças no projeto aumenta com o tempo decorrido, o que sugere a colaboração entre agentes envolvidos em todas as etapas do projeto para a antecipação da tomada de decisão (MACLEAMY, 2004; HATTAB; HAMZEH, 2016). Cada vez mais gestores e pesquisadores das organizações têm reconhecido o potencial de criação de valor que confere importância estratégica do projeto para o negócio. Essa abordagem tem colocado a aquisição de competências associadas ao processo de projeto como uma das capacidades centrais para empresas obterem ganhos de competitividade significativos e sustentáveis (BONJOUR; MICAELLI, 2010).

Tanto a quantidade de componentes e subsistemas interdependentes como a maneira como são integrados e o grau de novidade tecnológica necessário para a realização das atividades ligadas a seu desenvolvimento e execução são indicadores da complexidade do produto (HOBDAY, 1998). A dificuldade de concepção e de realização de sistemas complexos exige esforços intensivos de integração da arquitetura e de especialização da engenharia. A perspectiva é a de que todos os componentes, subsistemas e suas interdependências tornam o sistema maior do que a soma de suas partes, o que implica o surgimento de propriedades emergentes, que tornam a integração da arquitetura um trabalho nada trivial (BONJOUR; MICAELLI, 2010; CHAGAS JR.; CAMPANÁRIO, 2014). 


\subsubsection{Processo de integração do sistema}

Pesquisas orientadas à prática gerencial têm reportado casos de subsistemas tecnicamente bem concebidos e executados que não conduzem a um bom produto final em razão de falhas de projeto do sistema de integração (CHAGAS JR.; CAMPANÁRIO, 2014). Parte das falhas de integração decorre da compreensão inadequada de sua natureza, que não se resume em equacionar as interdependências técnicas, mas, sim, precisa responder a requisitos externos, sociais e ambientais (BONJOUR; MICAELLI, 2010). Em alguns textos também chamada de engenharia de sistemas, a arquitetura de sistemas tem como objetivo organizar essas interações emergentes presentes em um projeto complexo de modo a coordenar os requisitos das diferentes partes interessadas e o ambiente em que se insere, considerando todo o ciclo de vida do projeto (BONJOUR; MICAELLI, 2010).

Com foco na relação entre produto e processo de concepção, a capacidade de desenvolver e gerenciar o sistema de integração corresponde a uma espécie de conhecimento processual (PAVITT, 2003; CHAGAS JR.; CAMPANÁRIO, 2014) que permite reduzir a incerteza sistêmica em riscos gerenciáveis por meio da decomposição em diferentes módulos inter-relacionados e coordenar os diferentes processos, ligados à negociação, à gestão, à técnica e ao suporte para o desenvolvimento do ciclo de vida dos módulos, primeiro em um movimento de concepção e especificação, seguido por um processo de integração e validação da arquitetura resultante (BONJOUR; MICAELLI, 2010).

Assim, além do trabalho criativo, o papel do arquiteto do sistema é coordenar as atividades de vários agentes envolvidos no desenvolvimento e execução do projeto para integrar componentes e subsistemas, competências e know-how de várias organizações em um produto coerente e único para satisfazer adequadamente às exigências específicas do cliente (RUTTEN; DORÉE; HALMAN, 2009; BONJOUR; MICAELLI, 2010; ERBIL; AKINCITÜRK; ACAR, 2013; CHAGAS JR.; CAMPANÁRIO, 2014). Esse papel de integrador de sistema pode ser identificado em ao menos quatro atividades distintas ao longo ciclo de vida do projeto: na fase inicial de "planejamento" do negócio ou empreendimento; no desenvolvimento da solução para o negócio; no gerenciamento da execução do projeto; e, por fim, no apoio ao operador do sistema já implementado. 
Na prática essas atividades se sobrepõem ao longo do ciclo de vida, o que permite a um único agente com competência técnica e social exercer todas elas (ERBIL; AKINCITÜRK; ACAR, 2013). Assim, embora seja possível que o papel de integrador do sistema seja realizado por um executivo administrativo, por um gerente de execução ou por um de operação, as condições mais favoráveis para a promoção da integração do sistema estão vinculadas à atividade de concepção do projeto em razão da capacidade de gerar valor com o menor custo operacional, ao combinar criativamente as informações, as experiências e os conhecimentos técnicos dispersos nas outras fases. Tal atribuição estende a influência da concepção do projeto sobre as atividades de planejamento do negócio, em razão da necessária relação com os clientes, e sobre a fase de execução, por ocasião do gerenciamento de mudanças do projeto (ERBIL; AKINCITÜRK; ACAR, 2013).

Para que o arquiteto do sistema realize adequadamente o papel de integrador, precisa colmatar a discrepância existente entre a perspectiva clássica do arquiteto estéticoholístico e a do coordenador de sistemas (NOVAK, 2014), comprometido, de um lado, com a organização dos processos relacionados à negociação com a rede de colaboradores e com a coordenação da equipe multifuncional de projeto, e, de outro, com o aprendizado possível durante a atividade de projeto e com a consolidação do conhecimento técnico e processual (HOBDAY, 2000; ERBIL; AKINCITÜRK; ACAR, 2013).

\subsubsection{Equipe multifuncional}

O agrupamento de agentes em uma organização baseada em projeto não significa automaticamente a constituição de uma equipe de projeto (KATZENBACH; SMITH, 2005; LAURENT; LEICHT, 2019). Não existe uma equipe quando cada indivíduo do grupo é responsável por seus próprios resultados e por eles responde. A formação de uma equipe depende de agentes com habilidades complementares, que compartilham objetos, meios, métricas de desempenho e a responsabilidade da entrega final (LAURENT; LEICHT, 2019).

Um dos principais benefícios da constituição de estruturas multifuncionais está na melhoria do processamento de informações entre fronteiras interdepartamentais, 
intersetoriais ou mesmo interorganizacionais (LAURENT; LEICHT, 2019). A colaboração facilita o compartilhamento de informações sem sobrecarregar os meios de comunicação formal de gerenciamento e aumenta o envolvimento, a interação e a comunicação entre os membros nas unidades de negócios dentro das organizações (FORD; RANDOLPH, 1992; LAURENT; LEICHT, 2019). O compartilhamento de informações e recursos aumenta a flexibilidade e acelera a adaptação tanto a oportunidades quanto a problemas críticos (KERZNER, 2017; LAURENT; LEICHT, 2019).

Fatores relacionados à composição da equipe e ao ambiente no qual se irá atuar impactam sobre a dinâmica de trabalho das equipes (AMMETER; DUKERICH, 2002; KATZENBACH; SMITH, 2005; LAURENT; LEICHT, 2019). Caso os membros da equipe multifuncional façam parte de diferentes setores de uma mesma organização, o aumento da interação significa também maior cooperação entre os setores da empresa a que pertencem; além disso, caso tenham autonomia suficiente, terão motivação para desenvolver soluções que respondam aos diferentes requisitos de cada especialidade de forma a equacionarem antecipadamente problemas que enfrentariam em seu trabalho de rotina (LAURENT; LEICHT, 2019). Ainda, dentro de uma equipe, fatores como colocalização, coesão, liderança e estímulos claros impulsionam o desempenho e a eficiência.

\subsubsection{Uma organização de aprendizagem}

Em processos de projeto convencionais, como observado em AECO, o sistema social que prevalece no desenvolvimento e execução do projeto está enraizado no reducionismo e na decomposição do todo em partes (KANTER; STEIN; JICK, 1992; NOVAK, 2014). A mudança dessa prática não é tão simples como a introdução de um novo procedimento de gestão, pois depende de mudanças de mentalidade - de um pensamento mecanicista para um pensamento sistêmico - que confiram agilidade à organização de projeto suficiente para coincidir a capacidade de aprendizado de sua equipe com a velocidade das mudanças no ambiente (NOVAK, 2014).

O modelo de criação do conhecimento tradicional proposto por Nonaka e Takeuchi (1997) não expressa uma abordagem adequada para a velocidade e a direção das 
mudanças técnicas e sociais em sistemas complexos (CHAGAS JR.; CAMPANÁRIO, 2014), por não considerar como a complexidade influencia a capacidade de gerenciamento do desenvolvimento, reutilização, retenção e compartilhamento do conhecimento (YASSINE; WISSMANN, 2007; ARGOTE, 2013). O conflito entre a teoria e a prática organizacional ocorre devido à inadequação entre a habilidade de aprender, conhecer e agir diante das propriedades emergentes do projeto e a forma como o conhecimento organizacional é gerenciado (NOVAK, 2014).

Modelos de inovação em sistemas complexos (ROSENBERG, 1982; CHAGAS JR.; CAMPANÁRIO, 2014) e modelos de resolução de problemas dificeis (NOVAK, 2014), como são os projetos complexos, são baseados em práticas iterativas e na dinâmica de modelagem dos sistemas sociais associados ao sistema do produto, que fomentam a aprendizagem contínua e o desenvolvimento pessoal como base para uma cultura de aprendizagem (CHINOWSKY; MOLENAAR; REALPH, 2007; NOVAK, 2014). Trata-se de uma organização de aprendizagem, que se distingue da aprendizagem organizacional porque, enquanto esta é entendida como a atividade gerencial de conversão da aprendizagem em si (ÖRTENBLAD, 2001), aquela corresponde a um processo contínuo de alinhamento e desenvolvimento das capacidades da equipe para reconhecer os requisitos e criar os resultados esperados (NOVAK, 2014).

A relevância da aprendizagem está vinculada à incerteza ou à ambiguidade sistêmica, que diminui a capacidade de prever o desempenho do sistema complexo com base apenas no estoque de conhecimento existente (ROSENBERG, 1982; CHAGAS JR.; CAMPANÁRIO, 2014). As propriedades emergentes do sistema fazem com que todo o conhecimento prévio seja dinâmico, iterativo e relacional ao contexto de aplicação, o que implica a aprendizagem iterativa derivada da ação prática e da resolução de problemas (HOBDAY, 2000; COOK; BROWN, 2008; CHAGAS JR.; CAMPANÁRIO, 2014).

Entendido como uma epistemologia orientada para a prática, o ciclo de aprendizagem iterativa entre o estoque anterior de conhecimento e o fluxo de conhecimentos concretos, derivados do aprendizado na ação prática (SNOWDEN, 2002; DEN OTTER; EMMITT, 2008; NOVAK, 2014), confere oportunidade de melhorias modulares e incrementais à organização do projeto (COOK; BROWN, 2008; CHAGAS JR.; CAMPANÁRIO, 2014; NOVAK, 2014). 
O processo de projeto de sistemas complexos exige uma extensão do ciclo de vida maior que o tradicional, de forma a influenciar as atividades estratégicas e de operações para a criação de valor econômico. De forma semelhante, modelos de ciclo de aprendizagem enfatizam a importância da aprendizagem por meio do uso, em que se ligam os processos de aprendizagem com a prestação de serviços para o usuário final (DAVIES; HOBDAY, 2005; CHAGAS JR.; CAMPANÁRIO, 2014).

O conhecimento processual que resulta de aprendizagem por meio da avaliação do uso e operações indica possíveis caminhos para a inovação, além de aumentar o refinamento nas interfaces e propriedades do sistema concebido. A extensão do ciclo de vida do projeto tradicional até a fase operacional cria condições para identificar, medir e gerenciar as propriedades emergentes imprevisíveis que coloquem em risco o desempenho dos sistemas (CHAGAS JR.; CAMPANÁRIO, 2014).

Para especialistas em organizações de aprendizado, a modularidade do sistema não implica modularidade organizacional, uma vez que as propriedades emergentes decorrentes das interfaces dos módulos exigem da equipe multidisciplinar o domínio de uma base de conhecimento dificil de ser formada. Um integrador dos sistemas tem que cuidar do conhecimento processual para aproveitar os beneficios da aprendizagem, integrando gerenciamento estratégico e operacional (CHAGAS JR.; CAMPANÁRIO, 2014).

Pesquisas sobre o aprendizado em equipe indicam que as técnicas de gerenciamento de projetos convencionais dificultam o aprendizado e a inovação (DRUSKAT; PESCOSOLIDO, 2002; FORGUES; LEJEUNE, 2015). Assim, além da necessidade de autonomia e de colocalização para que problemas de entendimento compartilhado da equipe de projeto não restrinjam as possibilidades de melhorias (SNOWDEN, 2002; NOVAK, 2014), as organizações de aprendizagem precisam projetar novos processos de gestão capazes de integrar novos recursos à concepção para promover a criação de valor e a melhoria contínua (USDIKEN et al., 1988; KARIM, 2006; KUSUNOKI; NONAKA; NAGATA, 2008; PARMIGIANI; MITCHELL, 2009; SANCHEZ, 2012). 


\subsubsection{Rede de criação de valor}

Além dos aspectos técnicos dos sistemas, o desenvolvimento de produtos e serviços deve responder aos requisitos das partes interessadas (BONJOUR; MICAELLI, 2010) de forma a satisfazer as expectativas distintas, muitas vezes contraditórias. A concepção e o desenvolvimento de um produto final ou de um processo é importante fase para que a criação de valor em um projeto seja bem-sucedida (HANSEN; OLSSON, 2011; EL. REIFI; EMMITT, 2013; KNOTTEN et al., 2015).

Quando no plural, valores corresponde a um conjunto de crenças fundamentais e subjetivas, de origem moral, que define a convicção sobre um comportamento ideal (PASQUIRE; SALVATIERRA-GARRIDO, 2011; NOVAK, 2014). No singular, valor corresponde a uma relação de custo-benefício, em que se estabelece uma relação entre a aquisição de um produto ou serviço e qual quantia monetária ou material a pessoa ou organização a que se destina está disposta a pagar. Essa relação, embora quantificável, não é objetiva, uma vez que envolve uma avaliação que não é financeira ou monetária, e, sim, pautada por valores como utilidade, importância, excelência e estima (VAN DER VOORDT, 2016).

O desafio de criar valor para satisfazer as expectativas de clientes finais e dos agentes envolvidos em uma organização multiempresas é uma tarefa dificil. Por um lado, as preferências do cliente estão sempre mudando ou são dificeis de determinar (YASSINE; WISSMANN, 2007) e, por outro, muitos atores na organização de um projeto possuem uma agenda própria e agem para promover essa agenda em detrimento do projeto (KNOTTEN et al., 2015).

O objetivo de construir uma rede de criação de valor para uma organização de projeto está em reunir os recursos necessários para construir uma oferta de mercado que ofereça alto valor ao cliente e, assim, em obter vantagens competitivas (KOTHANDARAMAN; WILSON, 2001). Nesse contexto, existe uma organização central, responsável por coordenar a integração da rede de criação de valor, que precisa alinhar os objetivos de um conjunto de empresas que desenvolvem e fornecem componentes de subsistemas ou módulos de construção do sistema projetado (BONJOUR; MICAELLI, 2010), para que estes cooperem entre si, coordenando seus 
subprocessos de desenvolvimento e execução e suas cadeias de suprimento (LAMMING et al., 2000; BONJOUR; MICAELLI, 2010).

Em setores de manufatura a análise da cadeia de valor de uma sistema complexo para construção de uma rede de valor está vinculada ao impacto da cooperação entre atores sobre três tipos de ativos, ligados a suas "carteiras" de conhecimento, de produtos e de marca (YASSINE; WISSMANN, 2007). Já em organizações de AECO as principais análises apontam para a necessidade de promover a entrega de valor focada no cliente por meio de equipes integradas (AUSTIN et al., 2007). Essa orientação é coerente com as bases do gerenciamento de competências, que aponta a integração da rede de colaboração de grupos especializados como a forma mais eficaz para criar valor à organização (DANILOVIC; LEISNER, 2007; BONJOUR; MICAELLI, 2010; LEVENSON, 2012).

\subsubsection{Capacidade organizacional}

A identificação de quais são as competências tecnológicas e processuais essenciais ao negócio permite organizar uma rede de valor que capacite um organização de projeto a se diferenciar e ganhar competitividade de mercado (KOTHANDARAMAN; WILSON, 2001; DANILOVIC; LEISNER, 2007). Assim, a capacidade organizacional é entendida como qualquer realização que uma organização é capaz de realizar com eficiência e eficácia suficiente para impulsionar significativamente seus resultados de negócios (AHUJA et al., 2016).

A capacidade organizacional decorre das habilidades e da experiência dos integrantes da organização (ULRICH; SMALLWOOD, 2004; AHUJA et al., 2016; AHUJA; SAWHNEY; ARIF, 2018). Isto é, decorre das competências profissionais que abrangem o domínio individual dos agentes, a comunicação de modelos mentais desses saberes, a construção de entendimento compartilhado e o aprendizado em equipe (AHUJA et al., 2016).

Embora alguns estudos empreguem uma diferenciação entre os termos competência e capacidade quanto à natureza técnica e social dos saberes envolvidos (ULRICH; SMALLWOOD, 2004; AHUJA; SAWHNEY; ARIF, 2018), essa distinção parece 
arbitrária epistemologicamente e pouco prática. Considerando que um projeto complexo é uma atividade coletiva, multidisciplinar, pode-se argumentar que capacidade é uma característica de uma empresa ou rede de empresas que compõe uma organização apta a realizar uma atividade, e que competência são as qualidades individuais, sejam técnicas ou sociais, dos indivíduos que atuam nessas organizações, de forma a capacitálas para a atividade.

O entendimento proposto (Quadro 18) estabelece uma clara distinção e dependência entre a capacidade da organização e o gerenciamento de competências, importante para orientar o gerenciamento da rede de criação de valor. Para aumentar a competitividade, as competências essenciais para a capacidade organizacional devem ser desenvolvidas pela organização junto à rede de criação de valor, e as demais, adquiridas por meio do gerenciamento da cadeia de suprimentos (FJELDSTAD et al., 2012).

Quadro 18 - Diferenciação entre competência e capacidade

\begin{tabular}{|l|l|l|}
\hline \multirow{2}{*}{$\begin{array}{l}\text { Competência } \\
\text { individual }\end{array}$} & Técnica & $\begin{array}{l}\text { Habilidades e experiência para o indivíduo realizar } \\
\text { o trabalho em determinada organização do } \\
\text { trabalho }\end{array}$ \\
\cline { 2 - 3 } & Social & $\begin{array}{l}\text { Comprometimento e domínio dos meios de } \\
\text { comunicação, colaboração e decisão } \\
\text { compartilhada }\end{array}$ \\
\hline \multirow{2}{*}{$\begin{array}{l}\text { Capacidade } \\
\text { organizacional }\end{array}$} & Técnica & $\begin{array}{l}\text { Núcleo de uma organização técnica capaz de } \\
\text { instrumentalizar a competência individual }\end{array}$ \\
\cline { 2 - 3 } & Social & $\begin{array}{l}\text { Transformação de conhecimento técnico em } \\
\text { resultados }\end{array}$ \\
\hline
\end{tabular}

Fonte: adaptado de quadro de Ulrich e Smallwood (2004) e Ahuja et al. (2018).

Os dois domínios relacionados à capacidade de uma organização (Quadro 18) podem ser entendidos como uma dimensão interna e outra externa de oferecer as condições de trabalho necessárias para a realização do projeto. Uma perspectiva técnica, interna, o desempenho dos agentes está diretamente condicionado aos procedimentos e tecnologias da prática profissional. Numa perspectiva social, externa, a capacidade está vinculada a critérios de mercado, como raridade e inimitabilidade, conformidade a regulamentações sociais, etc. (BONJOUR; MICAELLI, 2010). 
Os critérios de aquisição ou desenvolvimento das competências centrais e de terceirização das demais competências são balanceados pelos critérios de custo de manutenção dos ativos da capacidade organizacional (BONJOUR; MICAELLI, 2010). Como os custos globais de manutenção de todas as competências necessárias para a realização de um projeto são significativos, identificar, desenvolver e implementar melhorias para processos críticos do projeto são ações estratégicas para o melhor desempenho do negócio (AHUJA et al., 2016; AHUJA; SAWHNEY; ARIF, 2018).

A capacitação traz implicações à organização relacionadas ao custo de aquisição ou desenvolvimento, ao custo de contextualização das capacidades ao processo existente, ao custo de integração ao conhecimento existente e ao custo de capitalização (BONJOUR; MICAELLI, 2010). Embora seja relativamente caro tornar competências de projeto uma capacidade central sustentável para uma organização, os beneficios observados têm sido significativamente maiores e de grande valor estratégico, entendidos como principais ativos intangíveis (BONJOUR; MICAELLI, 2010; KNOTTEN et al., 2015; AHUJA et al., 2016).

\subsection{ORGANIZAÇÃO DE EMPREENDIMENTOS IMOBILIÁRIOS}

O setor de AECO sobreviveu durante décadas sem grandes mudanças organizacionais. Após um período de rearranjo para acomodar algumas práticas modernas da racionalidade da era industrial, não foi capaz de apresentar evoluções significativas no gerenciamento de projetos de empreendimentos imobiliários (FORGUES; LEJEUNE, 2015). Atualmente, a indústria de AECO apresenta dados preocupantes, com baixa produtividade e criação de valor-agregado, que a colocam pouco acima de setores agrícolas (EASTMAN et al., 2014; FORGUES; LEJEUNE, 2015).

Pesquisas que discutem problemas do setor apontam que o predomínio de processos sequenciais no desenvolvimento e execução, a fragmentação da cadeia produtiva, a ineficiência do gerenciamento com foco no controle de custos, prazos e escopo de entregas, e a falta de autonomia e de coesão da equipe de projeto são as principais causas para falhas recorrentes de orçamento, atrasos no cronograma e problemas de qualidade (FORGUES; LEJEUNE, 2015; FRANZ et al., 2017; LAURENT; LEICHT, 2019). 
Essas pesquisas sugerem que as práticas de projeto e construção de gestão não são apropriadas por serem orientadas para o gerenciamento dos processos de transformação, isto é, para a otimização de cada elemento de trabalho (KOSKELA, 2000; ROOKE et al., 2012; FORGUES; LEJEUNE, 2015).

A rede de projeto em AECO é considerada de baixo acoplamento, com o predomínio de pequenas empresas especializadas que cooperam temporariamente em um processo de projeto único, desmobilizadas em seguida (DUBOIS; GADDE, 2002; PAPADONIKOLAKI; VRIJHOEF; WAMELINK, 2015). As oportunidades de melhoria de processos para aumentar a capacidade de aprender e criar valor são reduzidas pela cultura de gerenciamento orientada à correção de erros (LOVE et al., 2004; NOVAK, 2014). Essa realidade é agravada pela falta de propósito compartilhado na atividade de entrega das empresas (AUSTIN et al., 2007; FORGUES; LEJEUNE, 2015). Cada empresa persegue sua própria estratégia de negócios, com foco nos melhores resultados individuais (TAYLOR; LEVITT, 2007; FORGUES; LEJEUNE, 2015).

O foco da produtividade do trabalho individual de cada especialidade tem como consequência prática a repartição do projeto em pacotes de trabalho que não abordam adequadamente a interdependência (FORGUES; LEJEUNE, 2015). A responsabilidade contratual nesses casos está limitada à regulação da entrega do trabalho técnico do projeto, não instrumentalizando mecanismos de gerenciamento visando à satisfação das necessidades e expectativas dos clientes. Sem o alinhamento dos interesses dos agentes, o gerente de projeto tem pouco poder para garantir um fluxo de informações adequado, o que provoca desperdício e perda de valor final (WINCH, 2010; FORGUES; LEJEUNE, 2015).

A adoção de uma abordagem baseada em sistemas oferece uma resposta para os problemas observados ao tornar explícita a interdependência técnica e social do trabalho e ao conscientizar a importância da colaboração e de ativos intangíveis como aprendizado e melhoria contínua para apoiar estratégias orientadas à criação de valor para o cliente (GARAVAN, 1997; AUSTIN et al., 2007; FORGUES; LEJEUNE, 2015). 
Sintomaticamente, as primeiras iniciativas nesse sentido foram dadas por pesquisadores e desenvolvedores de tecnologia da informação (TI) para construção. Eles constataram que a fragmentação causa problemas na gestão do fluxo de informação do projeto de ponta a ponta, isto é, da identificação dos requisitos do cliente ao atendimento destes com a conclusão da construção do edificio (FORGUES; LEJEUNE, 2015), e propuseram que era possível ligar os membros de uma rede de projeto, do estudo de viabilidade ao gerenciamento predial, por meio de um sistema robusto de gerenciamento de informações (HATTAB; HAMZEH, 2016).

Nesse sentido, a adoção de filosofias Lean associadas a tecnologias de modelagem da informação (BIM) é proposta como uma solução para o gerenciamento do ciclo de vida do edificio (HATTAB; HAMZEH, 2016). Contudo, pesquisas recentes têm reportado um desempenho abaixo do esperado devido à resistência em promover mudanças organizacionais adequadas aos desafios de integração que esses processos e tecnologias impõem (HARTY, 2005; WHYTE; LOBO, 2010; ÇIDIK et al., 2017).

\subsubsection{Forma de organização das equipes de projeto}

Um dos fatores estruturais mais importantes observado no setor de AECO, que distingue setores baseados em projeto, é o fato de que os membros da equipe de projeto são serviços terceirizados, desmobilizados ao fim de cada projeto (ECCLES, 1981; KNOTTEN et al., 2015; LAURENT; LEICHT, 2019). Isso aumenta a importância do regime de contratos e, principalmente, determina o compromisso dos agentes com os resultados e a estrutura da organização do empreendimento, normalmente centralizada em torno da empresa responsável pela construção, e não na responsável pela concepção e gestão de informações de projeto (FORGUES; LEJEUNE, 2015; KNOTTEN et al., 2015).

Equipes de projeto de empreendimento imobiliário são constituídas por muitos indivíduos que trabalham de forma dispersa em pequenas empresas, com diferentes sistemas sociais e diferentes habilidades, reunidas incidentalmente para entregar um projeto em tempo e com custo e informações limitados (ERBIL; AKINCITÜRK; ACAR, 2013; KNOTTEN et al., 2015; HATTAB; HAMZEH, 2016). A composição 
dessa equipe não é apenas dispersa física e organizacionalmente, como também muda ao longo do andamento do projeto, conforme são demandados conhecimentos específicos para resolver os desafios emergentes da melhor maneira possível (KNOTTEN et al., 2015). Tais características implicam que a organização da equipe multifuncional de projeto é muitas vezes mal formulada e desconhecida pelos agentes que a integram, o que reduz a capacidade de coalizão da equipe e prejudica o desempenho esperado (MORGAN, 2006; AUSTIN et al., 2007; KNOTTEN et al., 2015).

Em contraste com a realidade de fragmentação e temporariedade observada na composição das equipes multifuncionais de projeto de empreendimentos imobiliários (AUSTIN et al., 2007), existe grande homogeneidade cultural dentro das organizações de empresas que compõem o empreendimento. Essa homogeneidade decorre do agrupamento de profissionais com a mesma especialidade, o que estabelece uma estrutura rígida de modelo mental e valores, muitas vezes protegida e reforçada pelas associações profissionais (FORGUES; LEJEUNE, 2015).

Quando o escopo do produto é facilmente descrito, como ocorre nas atividades de execução, a coordenação das diferentes realidades e culturas é gerida contratualmente com eficácia. Contudo, durante a concepção do projeto - isto é, da parte do processo que é desenvolvida antes do início do trabalho fisico - o gerenciamento do escopo empregado no setor se mostra pouco eficaz para lidar com a complexidade das iterações de agentes com diferentes conhecimentos e valores (AUSTIN et al., 2007).

Como já observado, equipes multifuncionais são tipicamente moldadas em contextos de equipes internas em uma base de longo prazo (LAURENT; LEICHT, 2019). A aplicação do conhecimento gerencial a equipes temporárias, interorganizacionais, como frequentemente é observado em AECO (ECCLES, 1981), implica resultados que ainda não são amplamente conhecidos (ERBIL; AKINCITÜRK; ACAR, 2013; LAURENT; LEICHT, 2019). Contudo, a impossibilidade de gerir efetivamente o escopo do projeto sugere que essa etapa não possa ser terceirizada sem aumentar a variabilidade, o que impõe riscos ao negócio.

O gerenciamento do fluxo de informações e de criação de valor requer uma abordagem estratégica para o processo de concepção e desenvolvimento do projeto, integrando processos de gestão do empreendimento, como o gerenciamento de cadeia de 
suprimentos, às competências e responsabilidades da equipe de projeto. Tal mudança irá criar oportunidades tanto para melhorar a satisfação do cliente, ao orientar o processo para criação de valor, como para promover a sustentabilidade das empresas de AECO, por meio de regimes contratuais equilibrados e do desenvolvimento de novos ativos para o negócio (AUSTIN et al., 2007; BONJOUR; MICAELLI, 2010).

\subsubsection{Regimes contratuais}

Projetos de empreendimentos imobiliários normalmente são constituídos por milhares de processos, que envolvem relações entre muitas organizações mediadas por meio de acordos contratuais bem estabelecidos (AUSTIN et al., 2007). Parte da dificuldade do setor em inovar ou simplesmente em adotar melhores processos e tecnologias, mesmo quando se observam pressões ambientais consistentes (DOWSETT; HARTY, 2014), está relacionada às barreiras interorganizacionais decorrentes dessa estrutura fortemente pautada por regras contratuais que restringem o fluxo de informações ao isolar processos em etapas pouco articuladas entre si, limitando a retroalimentação e a melhoria contínua.

Como já observado, empreendimentos imobiliários normalmente são organizados sequencialmente. Essa condição é consolidada contratualmente com a subdivisão do processo de projeto de quatro partes fundamentais, assim identificadas: etapa de concepção, realizada pelo empreendedor e pelo arquiteto (BLYTH; WORTHINGTON, 2001; KNOTTEN et al., 2015); etapa de desenvolvimento, normalmente protagonizada por escritórios de projeto e por agentes responsáveis pelo gerenciamento e coordenação do projeto; etapa de execução, normalmente liderada por uma empresa construtora em associação com prestadores de serviços especializados em subempreitas e equipamentos da construção; e a etapa de operação, uso e manutenção, quando se observa o envolvimento entre os agentes responsáveis pela entrega do imóvel e os usuários e responsáveis pelo gerenciamento predial (MELHADO, 1994; ABAURRE, 2014).

Embora seja comum a ocorrência de conflitos entre os agentes responsabilizados por essas etapas (ABAURRE, 2014), observam-se poucas iniciativas para alterar as estratégias de organização baseadas em contratação de serviços e subempreitas que dominam os empreendimentos no setor. Em parte em razão de uma compreensão de que esses 
conflitos são inerentes ao trabalho realizado no setor, gestores frequentemente optam pela manutenção de organizações inadequadas, que não consideram outras possibilidades de organização para o projeto que não seja com base na segmentação sequencial, como, por exemplo, a partir da decomposição dos sistemas da arquitetura do edifício (SANCHEZ; MAHONEY, 1996; HOETKER, 2006).

Um dos aspectos que reafirmam o conservadorismo estratégico pode ser observado nos sistemas contratuais dominantes no setor. O modelo sequencial, ou Design Bid Build (DBB), é o contrato mais comum (GRILO; MELHADO, 2002; EL ASMAR; HANNA; LOH, 2013; ABAURRE, 2014; LAURENT; LEICHT, 2019). Nesse modelo as contratações dos agentes envolvidos em cada etapa é independente, realizada sequencialmente e orientada ao atendimento do escopo de trabalho específico à especialidade do contratado (ABAURRE, 2014). A definição detalhada de escopos de contratação orientados para entregas de subprodutos permite o controle formal e externo por parte do contratante, mas a falta de um alinhamento claro entre os escopos e os objetivos do empreendimento resulta em um processo lento, oneroso e conflituoso (GRILO; MELHADO, 2002; MUIANGA, 2018).

O modelo de projeto-construção, ou Design Build(DB), corresponde a uma alternativa ao modelo DBB mais adequada a processos simultâneos, quando as etapas posteriores à concepção são de responsabilidade de uma empresa, no caso, a construtora (ASHWORTH, 2012; EL ASMAR; HANNA; LOH, 2013; ABAURRE, 2014; LAURENT; LEICHT, 2019). O aumento de eficiência associado à coordenação dos contratos pela construtora, contudo, tem como consequência a redução da influência do cliente sobre o gerenciamento de mudanças de projeto durante o desenvolvimento e a construção do empreendimento, e o desequilíbrio na distribuição de riscos, entre outros aspectos associados a conflitos de interesses e avaliação de desempenho (ABAURRE, 2014).

Embora existam outros tipos de contrato, como o Build Own Operate Transfer (BOOT), o Construction Management (CM), o Project Management Contract (PMC), o Engineer Produce Construct (EPC) e o Construction Management as Risk (CMAR), 
entre outros formatos específicos (LUO; MAO; FU, 2016; LAURENT; LEICHT, 2019), pode-se afirmar que variações do DBB e do DB predominam ainda hoje na constituição de regimes contratuais de empreendimentos imobiliários (EL ASMAR; HANNA; LOH, 2013; NOVAK, 2014; LUO; MAO; FU, 2016; LAURENT; LEICHT, 2019).

Em comum, esses contratos não reconhecem a diferença entre a forma de gerenciamento de uma rede de suprimentos e a de uma rede multifuncional de desenvolvimento do projeto. Enquanto uma cadeia de suprimentos é facilmente gerida por meio do escopo de produtos e serviços, uma vez que a informação flui do cliente para o contratado e o produto ou serviço flui do contratado para o cliente (AUSTIN et al., 2007), uma rede de desenvolvimento do projeto apresenta fluxo de informações multidirecional e iterativo, que se dispersa por toda a cadeia de suprimentos e cujo valor não pode ser expresso adequadamente por um escopo contratualmente definido (AUSTIN et al., 2007). A tentativa de forçar o enquadramento do processo de projeto em estruturas rígidas de contratos como meio de controle das relações entre participantes é apontada como uma postura reducionista e protecionista, que não oferece o ambiente de confiança e o apoio psicossocial necessário para uma comunicação aberta, nem o comprometimento com os objetivos e métricas de desempenho do projeto (AUSTIN et al., 2007; NOVAK, 2014).

Nesse sentido, modelos relacionais como o Integrated Delivery Development (IPD) correspondem a um caso de inovação da forma contratual em que um acordo multilateral é firmado entre as partes de forma a compartilharem os riscos e recompensas associados ao empreendimento (LAURENT; LEICHT, 2019). Dessa forma, os interesses individuais são alinhados aos objetivos do empreendimento, estimulando a colaboração entre os agentes que atuam na concepção, no desenvolvimento, na construção e na operação do edificio (AIA, 2007; HARNESS, 2008; ILOZOR; KELLY, 2011). Contratos de modelo IPD são comumente relacionados ao BIM em decorrência dos ganhos globais advindos da integração das informações de projeto. Os 
beneficios são particularmente sentidos em atividades associadas ao planejamento e ao gerenciamento da execução, e, potencialmente, ao gerenciamento predial.

Todavia, a dificuldade observada na difusão dessas tecnologias sugere que a abordagem contratual e tecnológica recorrentemente adotada seja insuficiente e incompleta (ASHWORTH, 2012). O incentivo à colaboração por meio da partilha dos riscos e recompensas está claramente definido, mas falta consolidar o conhecimento e as experiências sobre como organizar as equipes de projeto para trabalhar com IPD (LAURENT; LEICHT, 2019) e superar barreiras relacionadas a outras dimensões das organizações de AECO (DOSSICK; NEFF, 2010).

Críticos alertam para uma abordagem fortemente retórica sobre os benefícios do BIM e do IPD em trabalhos acadêmicos e profissionais, que acenam com a promessa de solucionar problemas da fragmentação por meio de um sistema de integração das informações ao longo de todo o ciclo de vida do edificio, sem que, contudo, essa realidade seja organizacional e operacionalmente viabilizada (MIETTINEN; PAAVOLA, 2014). A principal crítica dos autores é que frequentemente o IPD - ou melhor, a entrega integrada de uma modelo virtual de desenvolvimento, construção e operação - tem sido apontado como o objetivo final da implementação de BIM (SUCCAR; SHER; WILLIAMS, 2012), desconsiderando que a excessiva generalidade dos termos contratuais adotados e da falta de suporte dos softwares BIM atuais para várias disciplinas de construção e operação compromete a segurança em torno da interoperabilidade ao longo do ciclo de vida do projeto (MIETTINEN; PAAVOLA, 2014).

A excessiva generalidade e ambiguidade observada nos termos contratuais do modelo IPD é expressa, por exemplo, na distinção entre o que é comunicação vertical e o que é tomada de decisão (LAURENT; LEICHT, 2019). Ela advém do entendimento de que uma mudança na cultura organizacional associada a um sistema interoperável é suficiente para promover a colaboração dos diferentes agentes para a integração dos processos que fazem parte do ciclo de vida da edificação, minimizando, assim, a necessidade de mudanças significativas na estrutura organizacional. Contudo, sem uma 
estrutura coerente com as práticas de colaboração, projetistas, gerentes de execução e operações, entre outros, veem com desconfiança o convite para adotar os princípios de confiança e transparência na partilha de informações abertas, de riscos e de benefícios entre os parceiros de um projeto para a equipe (ANDERSON et al., 2012; MIETTINEN; PAAVOLA, 2014).

Um dos principais desafios da aplicação de conceitos de contratação relacional e governança compartilhada dentro das equipes temporárias encontrados na construção está justamente na dificuldade em reorganizar o processo de projeto de forma a facilitar a comunicação vertical e, ao mesmo tempo, a colaboração da equipe multifuncional (LAURENT; LEICHT, 2019). Em vez de um formato único, é provável que se desenvolvam diferentes formas de organização viabilizadas pelo BIM, que respondam a estruturas e circunstâncias específicas em AECO (MIETTINEN; PAAVOLA, 2014), e que os contratos venham a apoiar esses novos arranjos organizacionais com a especificidade adequada.

\subsubsection{Gerenciamento do projeto e autonomia da equipe de projeto}

Os métodos de gerenciamento de projeto influenciam diretamente o desempenho da equipe de projeto ao definir como a equipe interage, compartilha informações, é gerida e recompensada pelo sucesso do projeto (MCGRAW HILL CONSTRUCTION, 2014; LAURENT; LEICHT, 2019). Problemas relacionados a aumento de custos e atrasos no cronograma de empreendimentos imobiliários são atribuídos à adoção de métodos de gerenciamento baseados em entregas, com ferramentas prescritivas, e à decorrente falta de integração, colaboração e inovação da equipe de projeto (HALL et al., 2014; FORGUES; LEJEUNE, 2015; FRANZ et al., 2017; LAURENT; LEICHT, 2019).

A filosofia gerencial tem tradicionalmente aliado um planejamento centralizado e uma execução descentralizada (LEVITT, 2011), que resultam em planos detalhados porém pouco realistas em razão da falta de envolvimento da equipe de projeto na definição dos objetivos e das metas de que serão cobrados, o que deixa de fora a criatividade e a 
experiência dos projetistas e dos gerentes de execução, geralmente mais bem informados sobre a realidade do trabalho a ser realizado (LAURENT; LEICHT, 2019).

Algumas abordagens do gerenciamento do projeto difundidas no setor visam superar essa condição de baixa eficiência e eficácia (KNOTTEN et al., 2015). Uma linha bastante difundida tem como base os princípios do Lean Construction, que fundamentalmente preconizam o planejamento e o gerenciamento de atividades paralelas e colaborativas como forma de reduzir os desperdícios e de promover valor (HAMZEH; BALLARD; TOMMELEIN, 2009; BØLVIKEN; GULLBREKKEN; NYSETH, 2013; FUNDLI; DREVLAND, 2014; KNOTTEN et al., 2015; HATTAB; HAMZEH, 2016). Outra abordagem ligada à modelagem de informação (BIM) e à construção virtual (VDC: Virtual Design and Construction) busca melhorar o gerenciamento de projeto ao integrar as informações de projeto e reduzir a latência das implicações das decisões, antecipando o envolvimento das partes interessadas na concepção da solução $(\mathrm{CHO}$; FISCHER, 2010; KUNZ; FISCHER, 2012; KNOTTEN et al., 2015).

Nesse contexto, o papel do gerente de projeto, que já era mal definido em um processo tradicional (MILLS; GLASS, 2009), torna-se ainda mais ambíguo com novos modelos de distribuição de responsabilidades, riscos e recompensas compartilhadas (LICHTIG, 2005; NOVAK, 2014). Os gerentes de projeto não detêm o poder nem os meios necessários para planejar e controlar projetos de forma eficaz (FORGUES; LEJEUNE, 2015), principalmente durante os processos de concepção e desenvolvimento, quando predomina uma dinâmica iteração para criar, inovar, testar e transformar ideias em produtos, serviços, instalações ou edificios, ou seja, em valor para clientes ou usuários (HATTAB; HAMZEH, 2016).

A concepção e o desenvolvimento de um projeto são processos abertos, criativos, de dificil controle (AUSTIN et al., 2007; KNOTTEN et al., 2015; HATTAB; HAMZEH, 2016), caracterizados por um alto nível de incertezas ligadas à natureza dos requisitos, que não podem ser completamente definidos com antecedência (HATTAB; HAMZEH, 2016). Contudo, esse controle é entendido como algo necessário, já que os projetistas não têm conhecimento suficiente das áreas de negócios ou de construção (FORGUES; LEJEUNE, 2015), o que pode implicar um desalinhamento entre uma resolução técnica bem elaborada e a solução efetiva para o projeto (HATTAB; HAMZEH, 2016). Críticas às teorias organizacionais e às teorias do gerenciamento de 
projeto baseadas em controle externo apontam que essa abordagem reduz a atividade de projeto a um processo de conversão, o que não exprime adequadamente a experiência prática real (TSOUKAS; CHIA, 2003; SANDBERG; TSOUKAS, 2011; ÇIDIK et al., 2017).

Com o reconhecimento da impossibilidade de gerenciamento externo, outra visão de gerenciamento orientada para a colaboração tem ganhado força. Para ser capaz de controlar o próprio desempenho, a equipe de projeto tem de desenvolver habilidades para gerenciar o fluxo de informações e a geração de valor (KOSKELA; HUOVILA; LEINONEN, 2002; NOVAK, 2014; FORGUES; LEJEUNE, 2015). Embora seja comum argumentos que defendam a manutenção da figura do gerente de projeto externo ao desenvolvimento da arquitetura do sistema (KNOTTEN et al., 2015), a combinação das atividades de desenvolvimento da arquitetura e de integração dos sistemas e processos do projeto tem como vantagem reduzir a complexidade do processo (ERBIL; AKINCITÜRK; ACAR, 2013).

A introdução de novos papéis, como o "arquiteto organizacional" (FORGUES; LEJEUNE, 2015), que se contrapõem ao papel do gerente de projeto, como um vetor de integração do sistema e do processo a partir da negociação constante entre estrategistas e tecnólogos, é, na verdade, reflexo da dificil transição entre o paradigma de gerenciamento de projetos, que favorece a fragmentação do trabalho, e o paradigma da coordenação, que incentiva a integração do trabalho em equipes autogerenciadas (FORGUES; LEJEUNE, 2015). A questão central para o sucesso dessa transição é capacitar as organizações para sustentar projetos colaborativos. Para tanto, os profissionais de projeto precisam desenvolver as competências necessárias para desempenhar em seu cotidiano as mudanças que conferem uma dimensão estratégica à equipe de projeto da arquitetura do sistema (ÇIDIK et al., 2017).

\subsubsection{Integração informacional e integração organizacional}

Uma equipe multidisciplinar de projeto em AECO normalmente tem seus integrantes dispersos fisica e organizacionalmente, distribuídos em diferentes empresas especializadas (AUSTIN et al., 2007). O desafio de integração nessa realidade é gerir as relações de interação entre esses agentes de forma a fornecer um projeto integrado (AUSTIN et al., 
2007), ou seja, a chave para a integração está no gerenciamento do fluxo de trabalho (HATTAB; HAMZEH, 2016). Como a organização do projeto tradicional tem como foco o processo de conversão, os fluxos de trabalho, de informação e de valor são reduzidos e subordinados ao gerenciamento de entregas (BALLARD; KOSKELA, 1998; BALLARD, 2012; HATTAB; HAMZEH, 2016).

Atualmente, uma abordagem recorrente em discussões sobre a integração do projeto em AECO está vinculada às plataformas BIM. É por meio de políticas de difusão dessas plataformas que as principais organizações públicas e privadas do setor têm se conscientizado da necessidade de promover práticas integradas da equipe de projeto facilitadas por BIM (MIETTINEN; PAAVOLA, 2014). O BIM promete ser o catalizador da evolução de um processo altamente fragmentado para um processo integrado de projeto, construção e gerenciamento predial (FORGUES; LEJEUNE, 2015).

Contudo, assim como já apresentado na seção de regimes contratuais, crescem as críticas à retórica da integração digital, por se entender que esta não fornece um quadro realista da profundidade das mudanças organizacionais necessárias para a implementação efetiva da integração informacional (MIETTINEN; PAAVOLA, 2014; ÇIDIK et al., 2017) e, o que pode ser mais grave, por se apontar o risco de banalização do problema ao se interpretarem casos de fracasso apenas como uma má aplicação da tecnologia (ÇIDIK et al., 2017). A evolução de uma realidade fragmentada para um cenário de integração entre redes de projeto e de suprimentos exige grandes mudanças nos padrões de trabalho e na coordenação da rede de projeto (FORGUES; LEJEUNE, 2015), que vão além da resolução do problema de interoperabilidade e de política de abertura de dados (FORGUES; LEJEUNE, 2015).

Como existe um movimento constante de expansão do entendimento do que afinal significa BIM (ÇIDIK et al., 2017), é importante delimitar conceitualmente seu alcance para evitar mistificações. Como toda tecnologia da informação, o BIM atua sobre conhecimento explícito, por meio da automatização, facilitação e integração do registro, simulação, comunicação e armazenamento das informações do projeto (FORGUES; LEJEUNE, 2015). A integração entre a rede e a cadeia de suprimentos depende dessa integração informacional, acompanhada de um movimento de quebra das fronteiras organizacionais por meio da colaboração e do compartilhamento dos recursos 
(SUCCAR, 2009; FOR GUES; LEJEUNE, 2015), o que corresponde a uma integração organizacional. Esse entendimento tem feito com que os estudos sobre integração do projeto, historicamente enraizados na teoria da difusão de TIC, apresentem agora trabalhos fundamentados na teoria das organizações, tais como Actor Network Theory (ANT), objeto de fronteira e arquitetura organizacional (GAL; LYYTINEN; YOO, 2008; JACOBSSON; LINDEROTH, 2010; MERSCHBROCK, 2012a).

Uma integração organizacional significa estabelecer as condições materiais, técnicas, sociais e psicológicas para a integração de fluxo de trabalho, informação e valor por meio de um processo ativo e contínuo de interações entre formas explícitas e tácitas de conhecimento compartilhado pela equipe de projeto (FORGUES; LEJEUNE, 2015). A integração informacional, possível com tecnologias digitais como o BIM, enfatiza e apoia aspectos da colaboração ligados ao compartilhamento do conhecimento explícito, mas não tem meios suficientes para subsidiar as interações entre os agentes e o aprendizado (PAPADONIKOLAKI; VRIJHOEF; WAMELINK, 2015).

Embora seja uma peça fundamental para superar os problemas causados pela fragmentação do setor, adotar a implementação do BIM como linha condutora para a integração do projeto pode levar a um viés na forma como o processo de projeto funciona (ÇIDIK et al., 2017), não acomodando o dinamismo das interações sociais de experimentação e aprendizagem necessárias (MIETTINEN; PAAVOLA, 2014).

Além de ajudar superar o alto nível de incertezas ligadas à natureza mal definida dos requisitos do projeto (MIETTINEN; PAAVOLA, 2014; HATTAB; HAMZEH, 2016), a aprendizagem tem papel central no gerenciamento da integração do sistema e do processo de projeto. Nesse caso, a aprendizagem contínua visa projetar melhorias e inovações no sistema de trabalho (MIETTINEN; PAAVOLA, 2014). Como se trata de um aprendizado realizado durante a atividade prática, a equipe de projeto deve desenvolver competência para gerenciar o conhecimento aprendido. Além disso, para que não negligenciem requisitos e valores não formalizados de atividades a jusante, a equipe de projeto depende de uma interação direta com agentes-chave da cadeia de suprimentos, bem como com os usuários ou responsáveis pelo gerenciamento predial (MIETTINEN; PAAVOLA, 2014; HATTAB; HAMZEH, 2016) 


\subsubsection{Cadeia de suprimentos, gerenciamento predial e ciclo de vida do edifício}

Ainda é incipiente o volume de pesquisas que relacionam aspectos organizacionais do processo de projeto e do gerenciamento da cadeia de suprimentos com o ciclo de vida do edifício. Os casos encontrados o fazem a partir de uma perspectiva da implementação de tecnologias da informação (VRIJHOEF, 2011; PAPADONIKOLAKI; VRIJHOEF; WAMELINK, 2015).

O gerenciamento da cadeia de suprimentos (Supply Chain Management-SCM) regula os fluxos de material, informações, capital, equipes de trabalho e equipamentos disponibilizados por conjunto de empresas associadas ao empreendimento (MENTZER et al., 2001; PAPADONIKOLAKI; VRIJHOEF; WAMELINK, 2015). A aquisição de componentes e de serviços terceirizados parece ser uma atividade relativamente simples, porém, diferentemente da compra de um componente, serviços terceirizados envolvem questões relacionadas ao desenvolvimento de capacidades e à integração de tarefas (LEVENSON, 2012).

Sob essa perspectiva, a cadeia de suprimentos constitui, na verdade, uma rede de organizações composta de múltiplos fluxos de informações (PAPADONIKOLAKI; VRIJHOEF; WAMELINK, 2015). Aqui também a fragmentação do processo, associada a problemas de compartilhamento de informações precisas, confiáveis e controláveis entre as organizações (AZAMBUJA; O’BRIEN, 2009), resulta em uma variedade de perdas, tais como atrasos, gastos acima do orçamento e problemas de qualidade (PAPADONIKOLAKI; VRIJHOEF; WAMELINK, 2015).

Algumas iniciativas em curso nos âmbitos nacional e internacional, como a aliança BuildingSMART (NBS, 2014; BUILDING SMART, 2018), criaram normas de intercâmbio de dados e informações de projeto, construção e operação. Uma dessas normas de intercâmbio é o Cobie (Construction Operations Building Information Exchange), cujo principal mérito está em não regular apenas quais informações foram trocadas, mas também o como, quando e onde essas informações foram trocadas (ANDERSON et al., 2012; NBS, 2014). Os avanços tecnológicos relacionados ao fluxo 
de informações, contudo, esbarram na dificuldade de coordenar a cadeia de suprimento para um projeto colaborativo (PAPADONIKOLAKI; VRIJHOEF; WAMELINK, 2015).

O alinhamento estratégico das empresas que formam a cadeia de suprimento com os objetivos do projeto é um importante ativo para o negócio, ainda pouco explorado no setor (AZAMBUJA; O’BRIEN, 2009). Um estudo sobre as interações entre os processos que compõem um empreendimento imobiliário mostrou que as interações entre a equipe de projeto e a de gerenciamento da cadeia de suprimentos eram bem intensas, maiores que o esperado (PAPADONIKOLAKI; VRIJHOEF; WAMELINK, 2015). A necessidade de envolver a perspectiva dos agentes de execução e uso para subsidiar as decisões da equipe de projeto estabelece uma relação de interdependência entre o processo de projeto e o gerenciamento da cadeia de suprimentos que ainda não foi reconhecida nem subsidiada pelas organizações de projeto de empreendimentos imobiliários (MACLEAMY, 2004; SEBASTIAN, 2011; PAPADONIKOLAKI; VRIJHOEF; WAMELINK, 2015; HATTAB; HAMZEH, 2016).

A pressão para promover a interação entre processos de projeto, de gerenciamento da cadeia de suprimentos e de gerenciamento predial, embora ainda seja pouco expressiva, tem raízes na mudança de percepção do valor ao longo do ciclo de vida do edifício (LOVE et al., 2014; ÇIDIK et al., 2017). Em uma organização de projeto de empreendimentos imobiliários preocupada com a criação de valor, a identificação dos requisitos dos clientes assume importância central. A simples identificação e balanceamento do valor percebido carrega complexidade ao processo. O que é importante para um cliente pode ter pouco ou nenhum valor para outros. Para um acionista interessa o crescimento de produtividade e receitas (LINDHOLM; GIBLER; LEVAINEN, 2006); para os usuários e gestores prediais interessam, por exemplo, as condições de conforto, segurança e economia na operação, uso e manutenção; e para a sociedade, valores globais de sustentabilidade socioambiental (JENSEN et al., 2013; NOVAK, 2014; VAN DER VOORDT, 2016). 
O gerenciamento predial tradicionalmente presta muita atenção na satisfação dos clientes finais e dos usuários. Para profissionais que trabalham nessa área, o valor corresponde ao balanceamento entre os benefícios para a operação, uso e manutenção do edifício, os custos de implementação desses benefícios e os riscos para alcançá-los (ANKER JENSEN et al., 2012; VAN DER VOORDT, 2016). Contudo, apesar da importância dada a valores orientados para as pessoas, como a satisfação do usuário final, ou a valores empresariais, tais como a produtividade e a inovação, altamente priorizadas, ainda predominam as preocupações com fatores considerados "duros", tais como redução de custos, flexibilidade e controle de riscos (VAN DER VOORDT, 2016).

Em relação ao fluxo de informações e de trabalho, o gerenciamento predial se baseia em uma rede de profissionais excepcionalmente qualificados para fornecer o tipo certo de serviços e de informações ligadas à compreensão tácita dos equipamentos prediais e do trabalho de operação ou manutenção a ser realizado (JAVERNICK-WILL; LEVITT, 2010; ANDERSON et al., 2012). Por outro lado, esses profissionais se mostram bastante conservadores quanto à utilização de sistemas de informação, com certo ceticismo em relação ao BIM (BECERIK-GERBER et al., 2011; MIETTINEN; PAAVOLA, 2014).

Com os avanços tecnológicos e normativos apresentados por iniciativas como o Cobie é possível organizar um sistema de trabalho que aproveite os pontos fortes de bancos de dados de informações para auxiliar o gerenciamento predial (ANDERSON et al., 2012). Para que esse uso potencial do BIM seja convertido em valor para o gerenciamento predial, é preciso que algum profissional tenha capacidade, tempo ou motivos suficientes para atualizar informações da execução e pós-ocupação em uma versão as-built do modelo do edificio (MIETTINEN; PAAVOLA, 2014).

Por outro lado, a perspectiva de se obter retroalimentação por meio da modelagem das informações de gerenciamento predial não supre a demanda por interação entre projetista e operadores dos edificios. É por meio de trocas sociais que as lacunas de conhecimento e os requisitos são identificados (ANDERSON et al., 2012). Uma abordagem compartimentalizada de projeto e gerenciamento predial dificulta a 
capacidade de atingir níveis mais elevados de desempenho econômico, funcional e ambiental. Para alcançar níveis mais elevados de qualidade é preciso adotar uma abordagem mais integrativa para o projeto, que redefina o arranjo organizacional do empreendimento para comportar práticas de aprendizagem (NOVAK, 2014).

Algumas pesquisas sugerem que a criação de valor é maior quando as decisões sobre o valor-alvo do projeto "puxem" informações e análises dos interessados em vez de simplesmente "empurrar" um pacote de especificações, da concepção para execução e uso (MAGENT et al., 2009; NOVAK, 2014). Para tanto, empreendimentos imobiliários precisam aumentar significativamente o envolvimento do cliente final e usuário nas fases iniciais do projeto (VICTOR; BOYNTON, 1998; MIETTINEN; PAAVOLA, 2014).

\subsection{INFLUÊNCIA ORGANIZACIONAL SOBRE O PROCESSO DE PROJETO}

Algumas organizações, por combinar uma grande interação entre diversos elementos, com diferentes níveis de acoplamento ou interdependência, com outros objetos e com o ambiente, são consideradas sistemas complexos (MACCORMACK; BALDWIN; RUSNAK, 2012), ou seja, são organizações cujo trabalho depende da mobilização de pessoas com diferentes competências e valores. Atuam em atividades interdependentes, em processos especializados e paralelos, cujo resultado desejado depende da coordenação para integração (FABRICIO; MESQUITA; MELHADO, 2002; ERBIL; AKINCITÜRK; ACAR, 2013).

A organização do projeto de empreendimentos imobiliários se tornou mais complexa em razão do crescente número de agentes, o que traz complexidade à cadeia de suprimentos; da manutenção da fragmentação e do gerenciamento baseado em entrega, que implica complexidade operacional; do aumento do número de desafios projetuais de construção, ou seja, maior complexidade técnica; e de fatores externos, como maior competitividade e regulamentação mais rigorosa, que acrescentam complexidade ambiental (WINCH, 2010; PAPADONIKOLAKI; VRIJHOEF; WAMELINK, 2015). 
Existem diferentes abordagens para superar aspectos específicos das complexidades observadas, que impactam sobre a qualidade do projeto. A dimensão organizacional tem grande influência sobre o processo de projeto e sobre a qualidade do resultado alcançado. Em certa medida, ela determina ou altera as relações de poder entre os agentes envolvidos no processo decisório (MORGAN, 2006); pode inviabilizar ou estabelecer as condições para a inovação e para a colaboração efetiva (FJELDSTAD et al., 2012; ERBIL; AKINCITÜRK; ACAR, 2013); e pode promover ou desarticular a integração dos processos de projeto por meio do gerenciamento de competência e do gerenciamento da rede de valor (PAPADONIKOLAKI; VRIJHOEF; WAMELINK, 2015).

\subsubsection{Fontes de poder e os limites interorganizacionais}

A teoria das organizações apresenta uma literatura vasta sobre o funcionamento de organizações baseadas em operações de rotina, como são observadas na indústria de manufatura, onde uma burocracia racional estabelece um sistema refinado de controle de poder. Contudo, esse conhecimento tem pouca serventia para um contexto de organizações de projeto em que as relações de poder são diretas e afetam o processo de projeto (KNOTTEN et al., 2015). De forma geral, poder é entendido como a ação de imposição de uma perspectiva ou de um resultado exercida por uma parte, sujeitando outra parte, que pode ser um indivíduo ou um grupo. Essa imposição se dá por meio de recursos, informações e autoridade para a tomada de decisão (PAMMER; KILLIAN, 2003; IVANCEVICH; MATTESON; KONOPASKE, 2013; KNOTTEN et al., 2015).

$\mathrm{Na}$ organização do trabalho em equipe, as fontes de poder podem ser consideradas como a força, um desafio ou uma ameaça, porque podem favorecer o gerenciamento, influenciar diretamente sobre o processo decisório e restringir a liberdade de atuação da equipe. Na organização de projeto, balancear o compartilhamento de poder e autoridade para aumentar a confiança e a eficácia da equipe é um grande desafio para a liderança, pois esse balanço tem grande impacto sobre o processo de concepção e de gestão do projeto de edificio (IVANCEVICH; MATTESON; KONOPASKE, 2013; KNOTTEN et al., 2015). 
Morgan (2006) descreve a principais fontes de poder nas organizações e lista 14 possíveis fatores que atribuem poder a um indivíduo ou grupo dentro da equipe de projeto (KNOTTEN et al., 2015). Essas 14 fontes de poder (f.p.) se organizam em três grupos principais, ligados a características formais e/ou institucionais, características gerenciais e de competência, e características socioculturais.

As fontes de poder formais e/ou institucionais (f.p.1) estão relacionadas à autoridade formal, atribuída pessoalmente pela estrutura organizacional por meio das atribuições de um cargo, ou são decorrentes do uso de regras, regulamentos e procedimentos dessa estrutura organizacional (f.p.2). Também podem estar relacionadas a fatores estruturais que definem o estágio de ação (f.p.3) ou à utilização do "poder que já possui" para se impor em outras instâncias (f.p.4) (MORGAN, 2006; KNOTTEN et al., 2015).

As fontes de poder gerencial, bem como aquelas relacionadas à competência, se impõem por meio do controle de recursos escassos (f.p.5), pelo controle do processo decisório (f.p.6), pelo controle do conhecimento e da informação (f.p.7), pelo controle de fronteiras (f.p.8), pelo controle da tecnologia (f.p.9) e pela habilidade para lidar com as incertezas de origem ambiental e operacional (f.p.10), seja por meio da prevenção, do controle ou da absorção (MORGAN, 2006; IVANCEVICH; MATTESON; KONOPASKE, 2013; KNOTTEN et al., 2015).

As fontes de origem socioculturais se manifestam por meio de alianças interpessoais, networks e controle de organizações informais (f.p.11), ou então pelo controle de organizações contrárias ao poder dominante (f.p.12), uma forma de poder reativo. Podem ainda ser resultado da articulação de valores morais e ideológicos, por meio do simbolismo e da gestão de significado (f.p.13), bem como do sexo e da gestão das relações de gênero (f.p.14) (MORGAN, 2006; BEHAM; STRAUB; SCHWALBACH, 2012; KNOTTEN et al., 2015).

Uma fonte de poder pode ter influência direta ou indireta sobre as outras fontes, e sua influência sobre o processo varia com o decorrer do projeto. A influência dessas variáveis é tão grande que é capaz de impor uma ordenação discreta à organização do projeto (uma reconfiguração), a ponto de alterar o desempenho do processo (KNOTTEN et al., 2015; ÇIDIK et al., 2017). 
O principal recurso escasso é o tempo. O curto espaço de tempo entre o início do projeto de um empreendimento e sua execução impõe uma pressão por resultados que pode ser utilizada pelo gerente do projeto para direcionar o processo decisório da equipe de projeto. Além disso, a falta de tempo para a realização do desenvolvimento do projeto também pode ser interpretada como uma carência de recursos disponíveis. Isto é, como a equipe de projeto não gerencia a composição do orçamento, frequentemente são atribuídos recursos insuficientes à concepção e ao desenvolvimento, resultando em subculturas e subequipes de projeto (KNOTTEN et al., 2015).

O controle da tecnologia é uma fonte de poder cada vez mais expressiva com o avanço das tecnologias digitais. Relatos de situações em que uma equipe de projeto é obrigada a se acomodar pela falta de resposta de determinada tecnologia apontam para um descolamento do processo decisório, de uma situação em que as interações interdisciplinares definem “o que pode ser feito”, para uma situação em que a decisão está limitada pelo "que pode ser representado" com a tecnologia digital (ÇIDIK et al., 2017).

O poder formal está presente na gerência de agentes externos sobre as decisões da equipe de projeto e pode prejudicar o processo de criação de valor na medida em que os mecanismos de interações interdisciplinares, de construção de entendimento compartilhado e de negociação não sejam respeitados. A adoção de uma visão simplista sobre o processo de projeto ou sobre uma solução de projeto, induzida pelo entendimento particular de um agente com poder não mediado, pode ocasionar a desorganização dos vínculos socioculturais que permitem a colaboração (KNIGHTS; VURDUBAKIS, 2005; LEVENSON, 2012; ÇIDIK et al., 2017).

A colaboração no processo de projeto visa estabelecer as condições para a equipe de projeto tomar as decisões certas no momento certo (KLEINSMANN, 2006). Permite ainda que essas decisões sejam deliberadas com os agentes interessados em toda a cadeia produtiva (KNOTTEN et al., 2015). Para que a equipe de projeto tenha condições de colaborar com os demais processos do empreendimento, ela precisa ter autonomia e gerência sobre o fluxo de informações do empreendimento (KNOTTEN et al., 2015).

Atualmente, em razão das barreiras organizacionais existentes entre as empresas que compõem um empreendimento, a integração das informações é feita pelos gerentes de 
projeto por meio da centralização dos meios de comunicação. Essa concentração de poder produz um excesso de determinação e inflexibilidade para a atividade criativa e dificulta a configuração de sínteses baseadas na troca de experiências práticas entre as disciplinas (DOSSICK; NEFF, 2010, 2011; NEFF; FIORE-SILFVAST; DOSSICK, 2010; SANDBERG; TSOUKAS, 2011; ÇIDIK et al., 2017).

O controle do fluxo de informações entre os limites interorganizacionais de um empreendimento imobiliário tem como objetivo preservar ativos do negócio. Por outro lado, esse controle diminui a transparência e a permeabilidade entre processos, o que reduz a construção de um entendimento compartilhado dos desafios, recursos e interfaces de cada sistema ou disciplina, o que, por sua vez, reduz o desempenho global do projeto. Essas barreiras organizacionais são muitas vezes superadas de maneira informal pelas equipes envolvidas. Contudo, o alcance dessas mudanças sutis nas comunicações informais entre profissionais é limitado, uma vez que são constrangidos a operar segundo a determinação de uma estrutura organizacional hierárquica e centralizada (KNOTTEN et al., 2015).

\subsubsection{Barreiras à inovação}

A inovação é apontada por profissionais e pesquisadores de gestão estratégica como um ativo raro e decisivo para uma diferenciação de mercado bem-sucedida, que garanta a sustentabilidade do negócio. Para isso, alguns fatores são considerados chave, tais como a colaboração efetiva entre os principais atores (CHAGAS JR.; CAMPANÁRIO, 2014), o gerenciamento das competências necessárias para promover o aprendizado, a melhoria contínua e a integração dos conhecimentos sobre o sistema e os processos (BONJOUR et al., 2010).

Uma empresa pode inovar tanto em seus produtos e serviços (BONJOUR; MICAELLI, 2010), para a obtenção de patentes, a personalização de produtos em massa ou a integração de sistemas (ERBIL; AKINCITÜRK; ACAR, 2013), como inovar em seus processos internos ou no posicionamento de mercado (CAO; LI; WANG, 2014), visando à obtenção de eficiência de custos e preços, a troca de expertise de alto nível, o ingresso em sistemas coletivos ou a resolução de problemas (ERBIL; AKINCITÜRK; ACAR, 2013). 
A manutenção de uma vantagem competitiva sustentável baseada em inovação, todavia, depende da capacidade de a empresa desenvolver e sustentar competências que não possam ser replicadas por seus concorrentes (MCDERMOTT; COATES, 2007; BONJOUR; MICAELLI, 2010). Essa capacidade de inovar não está limitada ao trabalho de determinado agente ou área de especialidade, pois abrange competências e processos que atravessam as fronteiras organizacionais convencionais (AHUJA et al., 2016).

Organizações de redes de multiempresas baseadas em sistemas abertos de colaboração são frequentemente apontadas como os arranjos mais adequados para sustentar o compartilhamento dos riscos e conhecimentos necessários para criar, desenvolver, difundir e capitalizar diferentes formas de inovações tecnológicas e sociais (RUTTEN; DORÉE; HALMAN, 2009; ERBIL; AKINCITÜRK; ACAR, 2013).

Assim, o problema central para sustentar a inovação contínua em sistemas complexos como os empreendimentos imobiliários está na forma como as especializações são segmentadas para obter ganhos de produtividade (CHAGAS JR.; CAMPANÁRIO, 2014). No caso de empresas de AECO esse problema é ainda mais evidente (KULATUNGA; AMARATUNGA; HAIGH, 2006). Salvo algumas exceções notáveis, predomina no setor uma política de absorção de inovações disponibilizadas por setores da cadeia de fornecimento de tecnológicas construtivas e materiais (KOSKELA, 2000), e fornecedores de softwares de projeto (CAO; LI; WANG, 2014; ÇIDIK et al., 2017). Só mais recentemente são observados ganhos incrementais ligados a melhorias nos processos de transformação (KOSKELA, 2000; ERBIL; AKINCITÜRK; ACAR, 2013).

Embora a conformação de empreendimentos imobiliários que hoje predomina no setor apresente uma aparentemente convergência com redes de multiempresas (ERBIL; AKINCITÜRK; ACAR, 2013), a realidade de baixa inovação observada no setor parece contrariar tal correlação. A chave para compreender um desempenho tão adverso está ligada ao papel do projeto em AECO e àquele desempenhado pelas equipes de projeto em um sistema aberto de colaboração (DYER; NOBEOKA, 2000; FJELDSTAD et al., 2012). 
O isolamento da equipe de projeto, deslocada na cadeia de suprimentos e reduzida a um conjunto de pequenas empresas especializadas que prestam serviços de consultoria técnica, suprime uma das mais influentes e criativas fontes de inovação da indústria (HARTMANN, 2006; ERBIL; AKINCITÜRK; ACAR, 2013). A capacidade de projetar inovação depende do reposicionamento da equipe de projeto para desempenhar o papel de "integrador do sistema" e assim articular informações e trabalho das rede de empresas mobilizadas ao longo ciclo de vida do empreendimento (SLAUGHTER; SLAUGHTER, 1998; SARAH SLAUGHTER; SHIMIZU, 2000; ERBIL; AKINCITÜRK; ACAR, 2013).

\subsubsection{Colaboração}

Em um processo de projeto complexo nenhuma pessoa sozinha tem competências para centralizar todas as decisões ou determinar quais são as demandas do projeto. Por essa razão projetar é uma atividade social, realizada em equipe (EISNER, 2008; CHAGAS JR.; CAMPANÁRIO, 2014).

A colaboração tem se mostrado uma alternativa mais eficiente que o gerenciamento formal e centralizado quando o objetivo é coordenar uma equipe multidisciplinar de projeto com vistas à realização de um conjunto de atividades interdependentes e iterativas, que envolvem componentes lógicos e criativos em um contexto ambíguo (VALKENBURG, 1998). Projetos colaborativos são frequentemente relacionados à redução de riscos e custos no desenvolvimento de sistemas complexos, à melhoria em processos e no tempo de resposta a inovações, à absorção de tecnologias e às demandas do mercado (FJELDSTAD et al., 2012; KNOTTEN et al., 2015).

Embora apresentem ganhos de eficiência e eficácia notáveis, processos colaborativos exigem o investimento em mudanças organizacionais e culturais profundas, de dificil aceitação por parte de empresários de um setor conservador como é a AECO. As formas de organização tradicionais empregam mecanismos hierárquicos como o principal meio de controle e coordenação, o que limita uma colaboração efetiva dentro da empresa (FJELDSTAD et al., 2012), e as tensões decorrentes dos interesses organizacionais conflitantes a tornam impraticável sem alteração nos processos de trabalho (OWEN et al., 2010; MERSCHBROCK, 2012b). 
Setores de ponta, como manufatura, alta tecnologia e computação, têm explorado o potencial de organizações menos hierárquicas em ambientes complexos e dinâmicos. Essas novas abordagens organizacionais representam um claro redirecionamento nos modelos tradicionais de governança, coordenação e liderança (MAJCHRZAK; JARVENPAA; HOLLINGSHEAD, 2007; STEWART; COURTRIGHT; MANZ, 2011; FJELDSTAD et al., 2012; MAHONY; FERRARO, 2016).

Uma organização de rede de multiempresas baseada em sistemas abertos de colaboração é orientada ao ator, isto é, busca aumentar a eficiência e a eficácia do projeto por meio da interação entre os atores, que são estimulados a se auto-organizar e compartilhar experiências, valores, recursos, processos e infraestrutura (FJELDSTAD et al., 2012). Essa forma de organização cria uma estrutura de trabalho flexível e transparente, com valores e recursos compartilhados, assim como uma cultura de não culpabilização e autorregulação social (FJELDSTAD et al., 2012; PAPADONIKOLAKI; VRIJHOEF; WAMELINK, 2015; BARNEY; HANSEN, 2016).

A organização deve capacitar a equipe de projeto a construir uma consciência situacional partilhada. A equipe precisa ter meios e competência para capturar informações de várias fontes e formatos, e então formular um entendimento compartilhado e corrente sobre a situação do negócio e do ambiente do negócio (FJELDSTAD et al., 2012). A equipe também precisa ser capaz de interpretar operacionalmente esse entendimento compartilhado por meio da combinação dos conhecimentos especializados, e assim se auto-organizar para definir os objetivos e gerenciar os recursos disponíveis, de maneira a lidar com a complexidade e a incerteza do processo, e a criar valor para seus clientes (FJELDSTAD et al., 2012; KNOTTEN et al., 2015).

\subsubsection{Gerenciamento de competências}

A capacidade de uma organização está diretamente relacionada aos meios que disponibiliza e às competências que seus integrantes detêm e desenvolvem. Diante da necessidade de se realizarem mudanças tão profundas na organização do projeto, como a discussão até aqui demonstrou, exige-se uma reestruturação de competências ampla, relacionadas aos conhecimentos e habilidades que o processo de projeto exige (FORGUES; LEJEUNE, 2015). 
A teoria de gestão baseada na competência caracteriza fundamentalmente as organizações como sistemas abertos tipos goal-seeking, isto é, sistemas orientados por metas (SANCHEZ, 2012). Nessa abordagem a estratégia é orientada a alcançar os objetivos por meio da mobilização de recursos humanos com as habilidades e experiências necessárias para alcançar os propósitos definidos no projeto (LEVENSON, 2012). Em um contexto em que a colaboração e o aprendizado são demandas fundamentais para superar os imprevistos emergentes, o gerenciamento de competências visa promover os conhecimentos, informações, ferramentas e valores necessários para que os atores definam metas e avaliem as consequências potenciais das ações propostas para alcançar os objetivos do projeto (FJELDSTAD et al., 2012). É preciso ter consciência dos recursos compartilhados disponíveis para reconhecer e lidar com os problemas e as oportunidades internas ou ambientais, bem como da disponibilidade atual de recursos para lidar com esses problemas e oportunidades (HESS; OSTROM, 2007).

No centro das preocupações com o gerenciamento de competências está o recrutamento e/ou o desenvolvimento de pessoas com o conhecimento, a habilidade e os valores necessários para atuar em uma especialidade e mobilizar os demais membros da equipe para colaborar quando necessário. O alcance e o conteúdo das competências são dinâmicos, estão sujeitos a mudanças tecnológicas, organizacionais e mercadológicas (MCDERMOTT; COATES, 2007; BONJOUR; MICAELLI, 2010). Antes de investir desenvolvendo um conjunto de competências complementares, é preciso identificar quais são exatamente as competências que precisam ser desenvolvidas para capacitar a organização (BONJOUR; MICAELLI, 2010). As capacidades essenciais de uma organização são ativos intangíveis e dinâmicos que promovem uma vantagem competitiva sustentável e duradoura (BONJOUR; MICAELLI, 2010).

O desenvolvimento de habilidades multifuncionais não é necessariamente uma tarefa dificil. Especialidades que apresentam alguma relação, tais como marketing e vendas, pesquisa e desenvolvimento, orçamentação e aquisições, etc., possuem tamanhas similaridades disciplinares que se observa uma sobreposição entre as experiências profissionais. Por isso são entendidas como atividades adjacentes (LEVENSON, 2012).

Contudo, outras atividades exigem habilidades e experiências tão distintas que a compreensão e a interação entre funções não são corriqueiras. Essas atividades não 
aderentes, não adjacentes ou distantes, podem se caracterizar pela falta de relação entre os domínios de formação e prática profissional, associada à dificuldade e demora em aprender suficientemente sobre a outra disciplina para compreender e cooperar, o que torna dificil encontrar pessoas com o capital humano necessário para se tornarem especialistas em ambas as disciplinas (LEVENSON, 2012; KÜHLMANN; HEINZ, 2017). Assim, enquanto é relativamente fácil para projetistas com formações complementares cooperarem, não ocorre o mesmo quando um encarregado por operações em canteiro de obra ou um operador de vendas precisa dialogar com esses mesmos projetistas.

As formas tradicionais de organização do trabalho e de desenvolvimento de habilidades deixam as organizações expostas a desafios de integração, pois oferecem impedimentos estruturais à formação de competências complementares em especialidades não aderentes, para que os envolvidos possam interagir e cooperar mutuamente. Além de impor barreiras ao aprendizado, organizações estruturadas sobre uma especialidade, como é comum em AECO, não costumam desenvolver e recompensar adequadamente as competências multifuncionais como fazem com as especialidades dominantes em sua cultura organizacional (LEVENSON, 2012; SUCCAR; SHER; WILLIAMS, 2013; OPARAOCHA, 2016; SHOU; WANG, 2017).

As interfaces organizacionais da construção são problemáticas (AUSTIN et al., 2007), e a estratégia de utilizar o gerenciamento para integrar o trabalho de ocupações não adjacentes frequentemente acarreta ineficiência e problemas de execução. Isso ocorre porque a falta de alinhamento de perspectivas e de repertorio técnico decorrente da disparidade ocupacional distorce a comunicação entre as duas funções, feita por meio de canais e processos formais (BALDWIN; CLARK, 2000; LEVENSON, 2012). A teoria que embasa o gerenciamento baseado em competências entende que a forma mais eficaz de superar a falta de alinhamento decorrente da disparidade ocupacional ocorre em um nível individual, com o equilíbrio entre capacidade técnica e social. Como são difíceis e caras de adquirir, o desenvolvimento das habilidades multifuncionais não adjacentes deve ser orientado àquelas atividades que juntas desempenham papéis fundamentais no processo de criação de valor (GOMES; DAHAB, 2010; LEVENSON, 2012; SHOU; WANG, 2017). 
Uma mudança organizacional deve ser capaz de estabelecer e de manter relações sociais, além de promover um regime de valores compartilhados que permitam a interação efetiva entre atividades não adjacentes (LEVENSON, 2012; OPARAOCHA, 2016). Para reconhecer quais dessas atividades precisam ser integradas organizacionalmente para gerar valor ao negócio e quais podem ser terceirizadas, é preciso identificar quais são os principais requisitos e interações para executar com sucesso determinada função do sistema projetado (BONJOUR; MICAELLI, 2010). Em outras palavras, precisa-se identificar quais são as atividades não adjacentes que se complementam e que, por isso, precisam ser integradas para desenvolver e executar cada sistema funcional da arquitetura de um edificio.

\subsubsection{Gerenciamento da cadeia de valor}

Por meio da discussão sobre o gerenciamento de competências foi possível delinear um princípio básico da teoria da admiração contemporânea, que convida as empresas a distinguir quais são as capacidades essenciais para criar valor, tanto para seus clientes como para o negócio, e quais atividades são terceirizáveis por meio de um regime contratual bem definido com empresas que compõem a cadeia de suprimentos da empresa.

Análises de mercados futuros apontam que organizações que acompanham seus clientes ao longo de todo o ciclo de vida do produto - que em AECO corresponde ao edificio, equipamentos e instalações - serão mais bem-sucedidas em satisfazer as exigências cada vez maiores e diversificadas dos clientes (JOCHEM; MENRATH; LANDGRAF, 2010). Essa projeção coaduna com a disposição de alinhar organizacionalmente as atividades não adjacentes de um processo de projeto que respondem a determinado requisito funcional com o desenvolvimento e a execução de um sistema que responda às expectativas e necessidades do cliente.

O conceito de valor normalmente é empregado em empreendimentos imobiliários sob a forma de objetivos associados à qualidade e ao impacto ambiental do projeto que se contrapõem a objetivos de tempo e custo no balanceamento entre cronograma e orçamento do empreendimento (FORMOSO et al., 2002; THOMSON et al., 2003; NOVAK, 2014; AHUJA et al., 2016). O gerenciamento de uma cadeia de valor deve ser capaz de conectar a organização do empreendimento à cadeia de suprimento e o 
ambiente para viabilizar esse balanceamento de forma a criar valor para o cliente e para o negócio (KELLY; MALE; GRAHAM, 2015).

A ênfase em criar o valor demanda maior dependência entre a equipe de projeto, o fluxo de informações e a articulação da cadeia de valor do projeto (NOVAK, 2014). Cada organização de projeto deve ser capaz de estimar os custos de desenvolvimento e execução para atender aos requisitos de projeto dentro das restrições orçamentárias (BALLARD; REISER, 2004; DO; BALLARD; TOMMELEIN, 2015; LAURENT; LEICHT, 2019). Esse balanceamento parte da definição de um valor-alvo para o projeto (Target Value Design - TVD), que deve ser perseguido pela equipe de projeto durante todo o ciclo de vida do empreendimento, de forma a assegurar que o resultado obtido atenda às necessidades operacionais e reproduza os valores dos usuários dentro do orçamento permitido (LICHTIG, 2005; MACOMBER; HOWELL; BARBERIO, 2007; LAURENT; LEICHT, 2019).

A prática de TVD se origina da convergência entre os princípios de custeio-meta (Target-Costing - TC), construção enxuta e IPD, com o objetivo de subsidiar o processo de tomada de decisão nas fases iniciais do projeto (AIA, 2007; MACOMBER; HOWELL; BARBERIO, 2007; PASQUIRE; SALVATIERRA-GARRIDO, 2011; NOVAK, 2014). Em outras palavras, o TVD fornece uma interface estruturadas para articular atividades criativas e iterativas do desenvolvimento com o controle de orçamento da construção (KESTLE; POTANGAROA; STOREY, 2011). A novidade dessa articulação pode ser explorada organizacionalmente para promover a melhoria contínua e a inovação nos processos da empresa (JOCHEM; MENRATH; LANDGRAF, 2010; NOVAK, 2014; LAURENT; LEICHT, 2019).

Os dados de TVD podem ser adotados como entrada para um sistema de medição de desempenho simplificado do desenvolvimento do projeto orientada ao valor-alvo (JOCHEM; MENRATH; LANDGRAF, 2010). O alinhamento dos indicadores de desempenho das operações críticas de concepção com os resultados obtidos mediante o gerenciamento da cadeia de valor pode resultar em um sistema de medição que reflete a estratégia e os objetivos gerais de uma organização de projeto baseada em sistemas abertos de colaboração (JOCHEM; MENRATH; LANDGRAF, 2010; WINCH, 2010; PAPADONIKOLAKI; VRIJHOEF; WAMELINK, 2015). 
Uma consequência da adoção de uma estratégia de projeto orientada à criação de valor é a maior integração entre o projeto e o gerenciamento da cadeia de suprimentos (FIXSON, 2005; BETHA, 2007). Na prática, o acesso às informações confiáveis para definir e perseguir o valor-alvo depende da negociação com um conjunto de empresas da cadeia de suprimentos sobre os detalhes contratuais, processuais e tecnológicos (ANDERSON et al., 2012) que viabilizarão o alinhamento estratégico dessas empresas em uma rede de criação de valor (MENTZER et al., 2001; PAPADONIKOLAKI; VRIJHOEF; WAMELINK, 2015).

\subsection{INFLUÊNCIAS AMBIENTAIS SOBRE A ORGANIZAÇÃO DO PROJETO}

O valor de determinada organização está intimamente vinculado às capacidades organizacionais que consegue capitalizar. Já se abordaram aqui aspectos internos que capacitam uma organização de projeto a alcançar os resultados esperados. O

posicionamento de mercado, todavia, depende de um desdobramento dessas capacidades, que dizem respeito à raridade e à inimitabilidade, entre outras qualidades de suas capacidades que garantem vantagem competitiva no ambiente em que a organização atua (JAY, 1991; BONJOUR; MICAELLI, 2010).

Assim, o gerenciamento de mudanças diante da oportunidade de negócio e pressões ambientais corresponde a uma capacidade essencial para a sustentação da vantagem competitiva. Para a teoria estratégica, as organizações devem possuir capacidades, isto é, recursos e habilidades para coordenar um alinhamento estratégico eficaz com o ambiente e absorver as oportunidades e ameaças (VENKATRAMAN; CAMILLUS, 1984; TEECE; DAVID JPISANO; SHUEN, 1997; SANCHEZ, 2012).

\subsubsection{Tipos de ambiente}

A definição de uma estratégia adequada para responder aos estímulos do mercado por meio do gerenciamento de mudanças das capacidades organizacionais depende de um mapeamento realista do ambiente em que a organização atua ou pretende atuar (SANCHEZ, 2012). 
Dependendo das características identificadas, o ambiente de negócio pode se enquadrar como um ambiente com demandas de mercado e requisitos de capacidade estáveis (a.1); um ambiente em que o crescimento das exigências de mercado pode ser satisfeito por meio de uma reconfiguração das capacidades existentes na organização (a.2); um ambiente em que a evolução das exigências de mercado impõe a mudança das capacidades da organização (a.3); e um ambiente em que ocorrem mudanças significativas das exigências de mercado e em que não há clareza quanto a quais mudanças de capacidades são necessárias para garantir sua posição (a.4) (SANCHEZ, 2012).

Nos ambientes estáveis (a.1) as pressões ambientais para que uma organização sustente sua competitividade resultam em estratégias para progressivamente reduzir os custos e melhorar os níveis de qualidade, por meio do refinamento das capacidades de rotina em seus processos de gerenciamento de recursos, $\mathrm{RH}$, produtividade, marketing, etc.

Os ambientes em evolução (a.2 e a.3) podem tanto exigir um ajuste na forma como a empresa atende a seu mercado como exigir que a empresa mude o que é capaz de oferecer ao mercado de forma a atender a sua demanda. No primeiro caso espera-se que a organização seja capaz de mudar a forma como coordena suas capacidades de forma a responder adequadamente à crescente expectativa do mercado. No segundo caso é preciso integrar novas capacidades aos processos de criação de valor para que a empresa mantenha competitividade.

Os ambientes dinâmicos (a.4) são aqueles em que não está claro quais são as mudanças adequadas nas capacidades organizacionais para responder às mudanças de exigências de mercado, o que exige um contínuo gerenciamento de cenários futuros alternativos para reduzir os riscos dessa indeterminação.

Com base nessas descrições, pode-se inferir que a indústria da construção transitou entre ambientes estáveis e ambientes em evolução, e mais recentemente a pressão por mudanças estruturais sugere um ambiente em evolução do tipo a.3, que exige a mudança de capacidades da organização do projeto de empreendimentos imobiliários a fim de atender às crescentes expectativas por qualidade e redução dos impactos econômicos e ambientais que o setor historicamente tem apresentado. 


\subsubsection{Isomorfismo institucional}

Para que seja capaz de manter o alinhamento estratégico eficaz com o ambiente em que atua, uma organização precisa promover mudanças organizacionais que ajustem ou alterem a forma de trabalhar e de entender qual é o valor de seu trabalho (SANCHEZ, 2012; MCCARTY; GOTTSCHALK, 2014). A teoria organizacional clássica apresentava um entendimento determinista para uma organização produtiva, em que os processos poderiam ser racionalmente projetados de forma a reduzir os custos de produção, transporte e transação, o que, em última análise, significaria um estado de isomorfismo racional entre as organizações que atuam sob condições análogas em um mesmo mercado (CAO; LI; WANG, 2014).

Em contraste com a teoria da racionalização dos custos de transação, a teoria institucional enfatiza o papel crítico do ambiente de negócios em reconhecer e institucionalizar determinada forma de organização em cada setor. Assim, as empresas que querem atuar nesse setor são pressionadas a se conformarem às normas e comportamentos institucionalizados a fim de obterem legitimidade social para atuar no ambiente de negócio desse setor (SCOTT, 1995; DIMAGGIO; POWELL, 2005; DAVIS; SCOTT, 2007; CAO; LI; WANG, 2014). Essas pressões de isomorfismo institucional podem se expressar de três formas distintas, como pressões isomórficas coercitivas, miméticas e normativas (DIMAGGIO; POWELL, 2005; CAO; LI; WANG, 2014).

As pressões isomórficas coercitivas correspondem às pressões formais e informais que uma organização sofre de outras organizações de que é dependente para que os vínculos comerciais sejam mantidos (DIMAGGIO; POWELL, 2005). As pressões isomórficas miméticas têm origem nas incertezas ante as tendências do mercado, que levam uma organização a imitar a realização bem-sucedida de outras organizações estruturalmente equivalentes (DIMAGGIO; POWELL, 2005). Sem conseguir quantificar exatamente quais são os riscos para seu negócio, empresas tendem a observar o comportamento de organizações pares e a imitar aquelas que aparecem legítimas e promissoras. Por fim, as pressões isomórficas normativas derivam principalmente da regulamentação de setores profissionais ou agências governamentais (DIMAGGIO; POWELL, 2005). O desenvolvimento tecnológico e corporativo de determinado setor pode pressionar as agências representativas e governamentais a formular normas, currículo mínimo de formação e obrigatoriedade de participação em associações que regulem os 
comportamentos profissionais esperados no setor (TEO; WE; BENBASAT, 2003; DIMAGGIO; POWELL, 2005; CAO; LI; WANG, 2014).

Os casos típicos de adoção de inovação em AECO apresentados na literatura são exemplos de mudanças decorrentes de pressões isomórficas. Embora essas mudanças ofereçam melhorias de eficiência dos processos internos, muitas vezes a decisão pela implementação de um processo ou tecnologia inovadora em uma empresa é fortemente influenciada por pressões de parceiros e do ambiente externo (MITROPOULOS; TATUM, 2000; BOSSINK, 2004; BHAKOO; CHOI, 2013; CAO; LI; WANG, 2014).

Como não existe nenhuma grande empresa que domine o setor de $\mathrm{AECO}$, a pressão por mudanças organizacionais tem origem na mudança de expectativas de grandes clientes (FORGUES; LEJEUNE, 2015). Como faltam casos de sucesso com potencial para promover espontaneamente casos de isomorfismo mimético, de modo geral os casos exemplares que existem vêm a reboque de isomorfismos de constrangimento de grandes clientes, quando estes se posicionam criticamente diante da estrutura existente, condicionando a contratação dos serviços de AECO a mudanças e à inovação (LING et al., 2007; CAO; LI; WANG, 2014).

\section{O exemplo da difusão de plataformas BIM}

A difusão de plataformas BIM é um exemplo de mudança organizacional em AECO impulsionada por pressões coercitivas e normativas bastante significativas. A implementação da tecnologia depende de mudanças significativas no processo e no comportamento de empresas do setor, o que impõe riscos de retornos sobre o investimento (ROI) dificeis de quantificar (TAYLOR; LEVITT, 2007; DOSSICK; NEFF, 2010; GIEL; ISSA, 2013; CAO; LI; WANG, 2014; DOWSETT; HARTY, 2014). Os riscos associados aos elevados custos de investimento de implementação têm inibido a difusão do BIM entre empresas de AECO que atuam em ambientes em que os clientes não exigem projetos BIM. Mais do que uma busca por ganhos de eficiência para os processos de cada empresa, observa-se uma relação direta entre o grau de difusão do BIM e os benefícios de legitimidade determinada pelo ambiente em que as empresas operam (EADIE et al., 2013; CAO; LI; WANG, 2014; DOWSETT; HARTY, 2014). 
De fato, as pressões isomórficas para difusão de plataformas BIM se manifestam de três formas, com um predomínio de pressões coercitivas. Essas pressões coercitivas ocorrem principalmente por meio de associações da indústria e agentes governamentais, quando, por exemplo, condicionam contratações de projeto à entrega de modelos de informação (CAO; LI; WANG, 2014). A pressões miméticas aparecem com a imitação das práticas de sucesso de projetos pares que foram pioneiros na implementação do BIM por pressão de grandes clientes. Uma vez que foram ao menos parcialmente mitigados pelas empresas pioneiras, os riscos remanescentes de adoção da tecnologia são menores que os riscos de perder legitimidade por não adotá-la (CAO; LI; WANG, 2014). Já as pressões normativas são bastante visíveis, protagonizadas por associações profissionais, universidades, etc. (CAO; LI; WANG, 2014).

Alguns estudos consideram que existe o interesse de empresas de software, de grupos acadêmicos e de representações setoriais em promover uma política de difusão da inovação baseada em BIM que não oferece necessariamente uma resposta adequada às demandas de racionalização de determinados processos de AECO (MIETTINEN; PAAVOLA, 2014). Os riscos relacionados à promoção de uma integração digital que não seja capaz de representar e integrar a complexidade decorrente da variedade social, material e organizacional, todavia, têm pouca repercussão diante do movimento de isomorfismo institucional observado (HARTY, 2005; WHYTE; LOBO, 2010; ÇIDIK et al., 2017). Não se pretende negar os ganhos potenciais expressos por uma tecnologia de grande alcance, mas orientar a mudança organizacional para que ela atenda aos interesses de criação de valor para o setor, evitando-se, assim, prejuízos significativos.

\subsection{CONGRUÊNCIA ORGANIZACIONAL}

Mudanças na arquitetura de um sistema ou de um processo, feitas em resposta a oportunidades e exigências competitivas advindas dos ambientes interno ou externo, requerem também mudanças organizacionais para que os recursos, as competências e a coordenação necessária para suportar as mudanças nas arquiteturas do sistema e dos processos sejam disponibilizados adequadamente. Na verdade, uma mudança na arquitetura do sistema, ou do processo ou da organização invariavelmente acarreta 
mudanças nas outras duas arquiteturas. O que se pode arbitrar é se essas mudanças serão incidentais ou projetadas (SANCHEZ, 2012).

Um caminho para que as organizações de AECO mantenham um alinhamento estratégico eficaz com seu ambiente de negócios e possam projetar novas capacidades para ganhar competitividade por meio da diferenciação e gerar valor é expresso pela teoria organizacional na forma de métodos de modelagem orientados à consecução de um isomorfismo arquitetônico por meio da congruência entre o projeto, seus processos e sua organização (HENDERSON; CLARK, 1990; SOSA; EPPINGER; ROWLES, 2004; SANCHEZ, 2012).

\subsubsection{A congruência organizacional do isomorfismo arquitetônico}

A racionalidade científica de que a teoria original do isomorfismo organizacional deriva pressupõe um mundo determinístico, composto de categorias e entidades distintas, fixas e bem definidas, tais como pessoas, competências, tecnologias, etc. Ela explica os fenômenos organizacionais segundo características gerais de causa e efeito entre essas categorias que ignoram as variáveis dinâmicas e relacionais das propriedades emergentes do sistema e das interações entre os agentes (SANDBERG; TSOUKAS, 2011; ÇIDIK et al., 2017).

A observação das inter-relações entre as entidades de uma organização, por outro lado, permite capturar os elementos constitutivos de uma racionalidade prática do sistema produtivo, que considera a dinâmica das interações e das rotinas de trabalho (SANDBERG; TSOUKAS, 2011; ÇIDIK et al., 2017). Diferentemente do que os modelos teóricos sugerem, as estruturas organizacionais não possuem existência própria, mas estão enraizadas e são continuamente (re)construídas na prática diária, por meio das interações entre agentes e eventos (MACKAY; CHIA, 2013; ÇIDIK et al., 2017).

Assim, para compreender uma organização é preciso identificar corretamente em qual tipo de ambiente externo a organização está, de forma a entender que tipo de capacidades “externas" o mercado espera identificar. Contextualizado o ambiente, é preciso compreender os desdobramentos das ações e interações das pessoas que atuam na organização, relacionando as atividades que executam aos resultados esperados, de forma 
a capturar a lógica contingente do trabalho (DE OLIVEIRA; CAVEDON, 2013; ÇIDIK et al., 2017).

A análise da congruência entre processo e sistema relaciona quais são as ações e as interações que influenciam o desenvolvimento e a execução do sistema. Assim, as implicações de um projeto de mudanças na arquitetura do sistema ou do processo considerado para responder aos estímulos do ambiente podem ser adequadamente avaliadas (SOSA; EPPINGER; ROWLES, 2004; SANCHEZ, 2012). A forma como a composição e a correlação das arquiteturas do sistema e do processo são entendidas, representadas e preconcebidas alteram a forma de avaliação da congruência. Assim, o alinhamento de conceitos que ofereçam um entendimento sobre cada tipo de arquitetura se faz necessário.

\subsubsection{Arquitetura do sistema}

A arquitetura de um sistema pode ser definida como um plano por meio do qual a função do sistema é atribuída aos elementos que o constituem (ULRICH, 1995; BONJOUR; MICAELLI, 2010). Um sistema como um edificio é composto de muitos elementos únicos e compartilhados, hierarquicamente estruturados por subsistemas de componentes, componentes, etc., que interagem mutuamente de maneira complexa e eventualmente inesperada (YASSINE; WISSMANN, 2007).

Uma arquitetura de sistema pode apresentar características integrativas e modulares. Hipoteticamente, em uma arquitetura estritamente integrativa os requisitos funcionais apresentariam múltiplas relações com todos os elementos e interfaces do sistema, tornando o mapeamento uma tarefa muito complexa. Já o mapeamento de uma arquitetura estritamente modular apresentaria uma relação de um para um entre os requisitos funcionais e os elementos do sistema (YASSINE; WISSMANN, 2007). É por essa razão que o projeto arquitetônico é precursor necessário para o desenvolvimento de projetos detalhados do sistema, subsistemas e componentes (PAHL; BADKESCHAUB; FRANKENBERGER, 1999; YASSINE; WISSMANN, 2007).

Sob essa perspectiva, um projeto de arquitetura deve ser capaz de definir quais são os requisitos funcionais do sistema, mapear quais elementos componentes do sistema atendem a esses requisitos funcionais e harmonizar as interfaces entre esses elementos de 
forma a impedir comportamentos não desejados (ULRICH, 1995; SHARMAN; YASSINE, 2004; YASSINE; WISSMANN, 2007; BONJOUR; MICAELLI, 2010; SANCHEZ, 2012; CHAGAS JR.; CAMPANÁRIO, 2014). Para reduzir a complexidade de um sistema, a divisão das tarefas deve respeitar a modulação da arquitetura definida pelo mapeamento um para um da relação entre os requisitos funcionais e os parâmetros do projeto (YASSINE; WISSMANN, 2007).

Os módulos de uma arquitetura são definidos por meio da identificação das interfaces entre os elementos constituintes e de qual é a extensão da interdependência dessas interfaces para atender a um ou mais requisitos de funcionalidade do projeto (ORTON; WEICK, 1990; BALDWIN; CLARK, 2000; YASSINE; WISSMANN, 2007; BONJOUR; MICAELLI, 2010). Convencionou-se dizer que dois elementos são fortemente acoplados quando apresentam grande interdependência funcional e que são fracamente acoplados quando essa interdependência não é fundamental para desempenhar a funcionalidade esperada (YASSINE; WISSMANN, 2007).

Um conjunto de elementos com interações fundamentais corresponde a um subsistema da arquitetura. Uma vez que o mapeamento demonstre interações entre os subsistemas bem definidas, é possível encapsular em um módulo as funcionalidades desse subsistema, reduzindo a complexidade do gerenciamento de integração do sistema (CHAGAS JR.; CAMPANÁRIO, 2014). Além dos elementos que compõem um módulo funcional, existem elementos integrativos, que interagem com os módulos sem pertencer a nenhum deles (BROWNING, 2001).

Sob uma perspectiva analítica e gerencial, um projeto dificilmente apresentará uma arquitetura estritamente modular, o que implica que grande parte do esforço criativo de uma equipe de projeto está em equilibrar características de arquitetura modular e integrada (SOSA; EPPINGER; ROWLES, 2000; YASSINE; WISSMANN, 2007; BONJOUR; MICAELLI, 2010). Uma arquitetura excessivamente integrada apresenta um emaranhado de relações entre requisitos funcionais e subsistemas cujas interfaces estão mal definidas, o que torna dificil precisar qual a contribuição de cada elemento para atender aos requisitos funcionais.

Em uma arquitetura do sistema modular, a definição das interfaces entre subsistemas torna possível definir parâmetros de projeto para que cada módulo possa ser projetado 
com certa independência (SANCHEZ, 2012). Por outro lado, o excesso de parâmetros pode ter implicações duradouras sobre a capacidade de inovar (BALDWIN; CLARK, 2000; YASSINE; WISSMANN, 2007). É preciso que a equipe de projeto gerencie a evolução dos parâmetros de projeto ao longo de todo o processo, comparando o desempenho real dos módulos com o desempenho esperado (BALDWIN; CLARK, 1997; YASSINE; WISSMANN, 2007), para que propriedades emergentes não comprometam os requisitos funcionais da arquitetura.

As propriedades que emergem da evolução do projeto normalmente são imprevisíveis, já que resultam da ambiguidade que existe nas interações entre atividades do processo de projeto e de problemas de interfaces entre o sistema e o ambiente (CHAGAS JR.; CAMPANÁRIO, 2014). Uma das soluções empregadas para reduzir o volume de propriedades emergentes é o desenvolvimento de arquiteturas de sistema baseadas em plataforma, isto é, quando um conjunto de projetos possui ao menos um tipo de ativo em comum. Esses ativos podem ser tanto componentes partilhados, como processos, redes de valor e conhecimentos (NELSON; PARKINSON; PAPALAMBROS, 2002; YASSINE; WISSMANN, 2007; MARTIN; ISHII, 2016). Outra abordagem empregada em projetos de arquiteturas altamente inovadoras está relacionada à constituição de organizações de aprendizagem (CHAGAS JR.; CAMPANÁRIO, 2014). Essa forma de organização já foi tratada em uma subseção específica e se caracteriza por fomentar a aprendizagem contínua sobre as dimensões técnicas e processuais do projeto, o que permite um gerenciamento adequado das propriedades emergentes (PAVITT, 2003; CHAGAS JR.; CAMPANÁRIO, 2014).

De fato, arquiteturas modulares oferecem maior clareza para a aprendizagem organizacional, pois segmentam as propriedades internas e especializadas de cada módulo funcional, e as propriedades relacionais entre módulos ligadas aos elementos integrativos (SANCHEZ, 2000; BONJOUR; MICAELLI, 2010). Além da oportunidade de promover o aprendizado organizacional, a arquitetura modular permite economia de escala e de escopo, gerenciamento dos riscos de introduzir novos processos e soluções inovadoras, e redução dos custos de negociação e coordenação (JIAO; SIMPSON; SIDDIQUE, 2007; PAN et al., 2007; BONJOUR; MICAELLI, 2010). 


\subsubsection{Arquitetura do processo}

O princípio do isomorfismo não apenas preconiza a importância estratégica em promover a congruência entre as arquiteturas do sistema, do processo e da organização, como estabelece uma equivalência na forma de analisá-las. Assim como a arquitetura de um sistema pode ser decomposta em módulos funcionais, a arquitetura de um processo de projeto pode ser decomposta em tantas tarefas quanto forem convenientes para cumprir os objetivos e metas do projeto e criar valor. Na prática, a arquitetura do processo de projeto compreende todos os atores que integram a organização do empreendimento, isto é, abrangem arquitetos, engenheiros, gerentes, clientes (ou alguém que os represente), empreiteiros e fornecedores.

De forma semelhante ao que acontece com os elementos do sistema, as atividades apresentam níveis distintos de interação e, dependendo do nível de interdependência entre elas, é possível agrupá-las e segmentá-las em subprocessos menores, adequados às capacidades disponíveis. A alocação de equipes e de recursos para a realização das tarefas de cada subprocesso do projeto é uma atividade gerencial importante e delicada para o sucesso do projeto (BONJOUR; MICAELLI, 2010), pois o equilíbrio entre as capacidades técnicas e sociais muda com a evolução do processo, o que gera custos de mobilização e desmobilização de contingentes.

Visando reduzir a complexidade gerencial, é comum que subprocessos sejam modularizados e terceirizados para organizações menores (SANCHEZ; MAHONEY, 1996). Contudo, como já discutido em seções anteriores, os limites organizacionais tendem a ser compactos, o que implica problemas de interação entre as interfaces desses subprocessos. A identificação dos conjuntos de atividades do processo de projeto com interações fortes e a coincidência desses conjuntos com a constituição dos subprocessos minimizam problemas de integração (SOSA; ROWLES, 2003).

As capacidades das equipes responsáveis pelos módulos funcionais são geralmente mais especializadas do que as capacidades das equipes de integração do sistema (BONJOUR; MICAELLI, 2010). Normalmente, a equipe de arquitetura é responsável por integrar o sistema, enquanto as equipes compostas de projetistas especializados, empreiteiros e fornecedores são responsáveis pelo desenvolvimento de módulos e componentes (BONJOUR; MICAELLI, 2010). A segmentação entre organizações de projeto técnico e execução é problemática por se tratar de atividades não adjacentes (LEVENSON, 2012). 
Algumas pesquisas sugerem que a correlação imediata entre um sistema modular e a modularização do processo e da organização do projeto, como proposto por Sanchez e Mahoney (1996), embora seja bastante explorada em várias organizações de projeto, pode não ser eficiente (CHAGAS JR.; CAMPANÁRIO, 2014). Na verdade, foram relatados casos em que o desenvolvimento de uma arquitetura modular do sistema levou à integração de processos e à desmodularização organizacional (BRUSONI; PRENCIPE, 2006; SANCHEZ, 2012). Diferentemente do que ocorre em indústrias de produção em massa, organizações de projetos de sistemas complexos dependem de ciclos de aprendizagem organizacional iterativos, que fluem do desenvolvimento à operação de sucessivos projetos para desenvolver novas capacidades, melhorar sistemas e processos, e inovar (ROSENBERG, 1982; CHAGAS JR.; CAMPANÁRIO, 2014).

O movimento de integração de processos em uma organização é condizente com as condições de implementação de ciclos de aprendizagem organizacional. Os esforços de converter conhecimento tácito em conhecimento codificado são importantes para o gerenciamento de informações entre organizações, mas não para a criação de conhecimentos relevantes para a organização (CHAGAS JR.; CAMPANÁRIO, 2014). A integração organizacional de atividades interdependentes não adjacentes permite que especialistas criem novos conhecimentos enquanto aprendem, ao socializarem e combinarem os conhecimentos tácitos com sua equipe (GOURLAY, 2006; CHAGAS JR.; CAMPANÁRIO, 2014).

\subsection{ARQUITETURA ORGANIZACIONAL}

Embora os termos "estrutura" (GULATI; EPPINGER, 1996; YIN; ZAJAC, 2004; KARIM, 2006) e "arquitetura" sejam muitas vezes empregados em pesquisas sobre organizações como conceitos equivalentes ou ao menos intercambiáveis (BONJOUR; MICAELLI, 2010; SANCHEZ, 2012), cabe aqui estabelecer uma distinção.

A estrutura organizacional é um arranjo dos recursos, processos, atores, infraestrutura, etc., que constituem uma organização de forma a orientar esse arranjo de elementos para a obtenção do propósito da organização. A arquitetura organizacional, por sua vez, corresponde a uma síntese da forma como a organização se estrutura para subsidiar uma discussão estratégica de projeto de mudanças organizacionais, ou seja, corresponde aos princípios orientadores da concepção e da evolução da organização fundamental de um 
sistema de elementos críticos e gerenciáveis, tais como recursos, tarefas, atores, etc., e a maneira como esses elementos interagem nos ambientes interno e externo (SULLIVAN, 1896; BONJOUR; MICAELLI, 2010; FJELDSTAD et al., 2012).

Na prática, a distinção decorre de uma mudança na visão estratégica, que passou de uma abordagem baseada no planejamento detalhado de toda a estrutura de uma organização para uma abordagem que reconhece domínios que são orientados a colaborar para promover a coerência, o crescimento e a adequação organizacional. Essa mudança de abordagem reduz a contingência de elementos a serem gerenciados, o que permite aos gestores estratégicos efetivamente projetar as organizações como sistemas de criação de valor sustentável (FJELDSTAD et al., 2012; SANCHEZ, 2012).

A estratégia baseada em domínios considera as implicações das várias inter-relações existentes entre as arquiteturas dos sistemas, dos processos e da organização para definir qual é a estrutura funcional adequada para um projeto de sistema complexo (BALDWIN; CLARK, 2000; SCHILLING, 2000; EOM, 2008; PURANAM, 2012; SANCHEZ, 2012).

\subsubsection{Alinhamento entre a arquitetura da organização e o ambiente}

Uma arquitetura organizacional precisa responder adequadamente às condicionantes ambientais em que a empresa ou a rede de empresas que está sendo criada ou modificada atua. A teoria do gerenciamento estratégico descreve orientações específicas para cada tipo de ambiente. Dos ambientes estáveis aos ambientes dinâmicos observa-se uma crescente demanda por modularização das atividades de criação de valor, orientadas para a consolidação e a melhoria contínua e para o acoplamento de novas capacidades à estrutura organizacional existente.

Em ambientes estáveis as pressões competitivas demandam o posicionamento de mercado por meio do aumento da qualidade e da redução de custos e de preço. Assim, uma arquitetura organizacional deve implementar processos de melhoria contínua das capacidades funcionais existentes e o aperfeiçoamento das interfaces entre os módulos funcionais, a fim de eliminar defeitos de entrega e reduzir o tempo de produção e de estoque (GARVIN, 1993; NONAKA; TAKEUCHI, 1997; SANCHEZ, 2012). 
Em ambientes onde se observa o crescimento das exigências de entrega, uma organização deve ser capaz de atender às novas demandas emergentes sem perder o posicionamento de mercado. Nesses casos, a arquitetura organizacional corresponde a um processo de rearranjo das capacidades funcionais existentes de forma a identificar e apoiar as atividades centrais para a criação de valor por meio da melhoria ou da substituição de recursos, competências e processos de suporte existentes (PRAHALAD; HAMEL, 1990; DANILOVIC; LEISNER, 2007; EDEN; ACKERMANN, 2010; SANCHEZ, 2012).

Além da reconfiguração das capacidades existentes, ambientes em evolução podem exigir que uma organização desenvolva continuamente novas capacidades. Para tanto, a organização deve ser capaz de identificar as novas demandas, criar ou adquirir as capacidades que respondam a essas demandas e, então, integrar as novas capacidades ao processo de criação de valor existente (KARIM, 2006; PARMIGIANI; MITCHELL, 2009; SANCHEZ, 2012). Para suportar essa evolução, a arquitetura de uma organização deve ser concebida modularmente para permitis acoplamentos fortes entre os módulos essenciais para a criação de valor, em que seja estimulada uma cultura de comprometimento com a persecução dos objetivos e autonomia para gerenciar as mudanças no processo. A partir desse núcleo, deve estabelecer interações fracas com os módulos funcionais de apoio, que podem ser acoplados, substituídos e eliminados livremente, sem desestruturar o processo de criação de valor (USDIKEN et al., 1988; ORTON; WEICK, 1990; EDEN; ACKERMANN, 2000; HANNAN; PÓLOS; CARROLL, 2003; SANCHEZ, 2012).

Ambientes dinâmicos apresentam uma variedade significativa de cenários possíveis, que tornam incerta qualquer prospecção sobre quais capacidades serão relevantes para a diferenciação de mercado. Essa realidade exige mudanças rápidas, que impactam sobre a capacidade de manter as atividades relativamente estáveis durante a configuração de arquiteturas inteiramente novas. Para tanto, uma arquitetura organizacional deve apresentar uma estrutura o mais frouxamente acoplada possível, no limite que permita subsidiar os processos de criação de valor, e interfaces modulares estáveis, codificadas, que sejam adequadas à coordenação de mudanças de acoplamento entre módulos essenciais para o processo de criação de valor (USDIKEN et al., 1988; GARUD; JAIN; TUERTSCHER, 1996; HANNAN; PÓLOS; CARROLL, 2003; HOETKER, 2006; SANCHEZ, 2012). 
Em partes anteriores da revisão, foi delineado um estado de mudança do tipo de ambiente em que AECO atuam, de um ambiente estável para um ambiente em evolução. A pressão por melhorias da qualidade do ambiente construído, bem como por comprometimento com a sustentabilidade econômica, social e ambiental, tem movimentado o setor a reorganizar o modo de produção (USDIKEN et al., 1988; PAPADONIKOLAKI; VRIJHOEF; WAMELINK, 2015). Numerosos diagnósticos apontam a fragmentação da cadeia de valor como um dos principais desafios a serem superados. Não acompanhadas de mudanças na estrutura organizacional dos empreendimentos imobiliários, as iniciativas de integração digital têm se restringido, na prática, à promoção de ilhas de automação (MERSCHBROCK, 2012b).

Casos de melhorias e de inovação ligados ao gerenciamento de requisitos, à simulação de desempenho da edificação, à modelagem das informações do edificio, à autonomia dos grupos de trabalho, etc., não adequadamente integrados à organização de empreendimento imobiliário são indícios de problemas de acoplamento e de modularização que isolam e reduzem o potencial de ganhos dessas novas capacidades.

\subsubsection{Interfaces de interações do sistema, do processo e da organização}

A organização de uma rede de criação de valor em módulos funcionais tem como um de seus principais beneficios substituir o gerenciamento baseado no controle de todo o processo por uma coordenação modular baseada no controle de resultados (TIWANA, 2008; SANCHEZ, 2012). Essa mudança de abordagem favorece a terceirização de todos os módulos cujas atividades não são essenciais para a criação de valor, reduzindo a complexidade (LESTER; PIORE, 2006; BONJOUR; MICAELLI, 2010).

Todavia, a definição estratégica entre “o que fazer" e "o que adquirir de outros" não é fácil porque depende de uma interpretação correta sobre quais são as capacidades essenciais para uma organização criar valor e como essas capacidades podem ser articuladas. As diferentes estratégias de articulação dos módulos - tais como colaboração, coordenação e negociação - alteram as condições e a intensidade de interação entre os agentes dos módulos (BONJOUR; MICAELLI, 2010). 
A identificação das interfaces entre módulos de uma organização tem início com a arquitetura do sistema, por meio da decomposição de um projeto do sistema em seus componentes e subsistemas (módulos funcionais). Para cada componente são então especificadas as interfaces com outros componentes, determinando como interagem para cumprir uma função no sistema (SANCHEZ; MAHONEY, 1996; BALDWIN; CLARK, 2000; SANCHEZ, 2012). Uma organização do projeto congruente apresenta uma estrutura composta de módulos de atividades que apresentam, um a um, a capacidade para executar o módulo funcional. Então, esse modulo de atividades deve conter todos os processos de criação de valor para a função em questão, incluindo, idealmente, a pesquisa básica, o desenvolvimento de tecnologias, projeto do módulo funcional, construção e, eventualmente, atividades relacionadas à distribuição, ao suporte e ao atendimento ao cliente (SINHA; VAN DE VEN, 2005; SANCHEZ, 2012; SINHA et al., 2012). Assim como os módulos funcionais apresentam interfaces de acoplamento, os módulos de atividade apresentam interfaces de interação, que se distinguem em razão do tipo de coordenação que exigem, podendo ser interfaces funcionais, interfaces de recursos, interfaces de informação, interfaces de governança, interfaces de compromisso e interfaces de redes sociais (GALBRAITH et al., 1974; GULATI; SINGH, 1998; SMYTH; THOMPSON, 1999; YIN; ZAJAC, 2004; GALBRAITH, 2012; GULATI; PURANAM; TUSHMAN, 2012; SANCHEZ, 2012).

No contexto das organizações de projeto de empreendimentos imobiliários se observa um expressivo desenvolvimento de objetos de fronteiras para a coordenação das interfaces de informação por meio de tecnologias digitais, que permitem a troca de informações entre diferentes disciplinas e diferentes organizações da rede de valor do empreendimento (ZAGER, 2002; TAYLOR, 2007; FORGUES; LEJEUNE, 2015). Sistemas de informação interorganizacionais, como o BIM (TAYLOR, 2007), conectam atores e atividades dos diferentes módulos do projeto e desempenham o papel de mediador entre esses módulos do processo, tais como clientes, escritórios de projeto técnico, construtores, etc. (TAYLOR, 2007; FORGUES; LEJEUNE, 2015). Cabe observar nesse ponto que os exemplos apresentados para os diferentes módulos do processo condizem com a prática atual, e não com uma modulação congruente ao sistema. 
A perspectiva de que uma arquitetura organizacional deve apresentar uma congruência com a arquitetura modular do sistema e do processo tem como objetivo alinhar as diferentes formas de interfaces existentes, de maneira a permitir que os componentes de uma arquitetura, seja de qual dimensão for, possam ser modificados modularmente sem aumentar a complexidade de forma indeterminável. Em outras palavras, a congruência da arquitetura organizacional determina a capacidade de projetar mudanças na arquitetura do processo ou do sistema para melhor atender aos objetivos do empreendimento (GARUD; JAIN; TUERTSCHER, 1996; SANCHEZ; MAHONEY, 1996; HANDLEY; LEVIS, 2003; SANCHEZ, 2012).

Assim, em um nível estratégico, a arquitetura organizacional deve se preocupar em articular as interfaces funcionais do sistema, as interfaces dos recursos e informações do processo, e as interfaces de governança, comprometimento e rede social da organização, definindo quais devem obter acoplamentos fortes ou acoplamentos fracos. A diferença entre acoplamentos para viabilizar as interações fortes e interações fracas impacta sobre a flexibilidade organizacional, isto é, sobre a capacidade de uma organização de adequar suas capacidades em resposta a mudanças ambientais estratégicas (SANCHEZ; MAHONEY, 1996; TEECE, DAVID JPISANO; SHUEN, 1997; SANCHEZ, 2012).

A definição dos módulos funcionais e das interfaces entre as funções do sistema permite identificar as relações de dependência e pertencimento que orientam a coordenação modular de forma a reduzir a complexidade e evidenciar os pontos críticos. Por exemplo, em uma arquitetura de edificio, a decisão por desenvolver a vedação e a superestrutura como sistemas independentes ou indissociáveis altera a maneira como o acoplamento dos sistemas hidráulicos e elétricos devem ser coordenados no projeto. Alguns sistemas de aberturas e fechamentos apresentam recursos de interface bem definidos, compostos de contramarco, requadro e prumo, que também são exemplos de interface funcional (SOSA; EPPINGER; ROWLES, 2000, 2004).

\subsubsection{Modularização orientada pela competência organizacional}

A definição das interfaces de recursos e de informação do processo dizem respeito à condição de interdependência para a realização do módulo funcional. As informações de um projeto podem ser desenvolvidas e comunicadas por diferentes meios, o que altera 
a compreensão das condições de execução e de monitoramento do desempenho funcional que se pretende obter. Em última análise, recursos dizem respeito tanto às condições materiais de realização do trabalho como à competência disponível para realizá-lo. Como já observado, a formação de competências multifuncionais é um fatorchave para viabilizar interações fortes entre atividades interdependentes e não adjacentes ligadas a um módulo do sistema; assim, a intensidade dessas interações devem orientar a modularização da arquitetura do processo de forma a integrar recursos, a facilitar o fluxo de informações e a estimular o aprendizado contínuo (SOSA; EPPINGER; ROWLES, 2004; KREIMEYER; EICHINGER; LINDEMANN, 2007).

Como os estudos sobre a racionalidade prática e as capacidades organizacionais sugerem, os recursos intangíveis associados às competências interpessoais e multifuncionais são os mais dificeis de se obter e aqueles que propiciam a diferenciação de mercado sustentável. Isso ocorre porque a competência central do projeto não corresponde a um pacote de habilidades, ferramentas e rotinas de projeto que capacitam a organização (BONJOUR; MICAELLI, 2010), mas, sim, à condição de articulação dos fluxos de informações e de recursos das atividades que uma organização do processo de projeto confere aos agentes, por meio da definição de interfaces de governança, de comprometimento e de rede social (JACOBIDES; BILLINGER, 2006; BONJOUR; MICAELLI, 2010; LEVENSON, 2012; SANCHEZ, 2012).

A partir da análise dos domínios no sistema, processo e organização, é possível diagnosticar as competências centrais ao projeto de cada módulo do sistema e destacar os pontos críticos da organização do projeto que requerem atenção gerencial especial. Dessa forma, organizações de projeto, como redes multiempresas, podem ser reestruturadas para acomodar novas capacidades tecnológicas e sociais para criar valor. Trata-se de uma mudança de paradigma em que a modulação baseada em competências substitui as tradicionais formas de segmentação organizacional por especializações funcionais e sequenciamento do processo (BONJOUR; MICAELLI, 2010).

A congruência entre os domínios da organização do projeto permite que os módulos de processos tenham autonomia suficiente para gerenciar as competências e recursos necessários para ter a capacidade de desenvolver e executar cada módulo funcional, todos coordenados por um sistema de integração, responsável pela arquitetura do sistema. Para que a autonomia modular não resulte em conflitos, entre os papéis de dentro das 
organizações que fazem parte do empreendimento são identificados os integrantes da equipe de projeto que serão responsáveis pela concepção compartilhada da arquitetura do sistema (BONJOUR; MICAELLI, 2010).

Os agentes designados para integrar a equipe de projeto da arquitetura respondem a um duplo papel. Para a arquitetura do sistema são os responsáveis técnicos pela negociação das condições de acoplamento e execução do subsistema que representam. Para o projeto do subsistema são os responsáveis pelo gerenciamento da execução segundo especificações acertadas e pelas validações técnicas e funcionais do subsistema. A perspectiva de terceirização de parte do processo é dada de acordo com o nível de interação exigido entre as atividades que exercem influência sobre a definição dos conjuntos de componentes dos sistemas, que permitem regras de acoplamento dos subsistemas modulares mais ou menos claras (BONJOUR; MICAELLI, 2010).

A organização responsável pela arquitetura do sistema deve desenvolver a capacidade de absorver os projetistas dos módulos na equipe de projeto da arquitetura e promover a integração do sistema para alcançar o desempenho esperado para a operação, uso e manutenção do sistema. Trata-se de uma organização leve, em que as competências centrais são fracas no nível dos componentes e bastante elevadas no nível da função (BONJOUR; MICAELLI, 2010). Os arquitetos do sistema de integração devem desenvolver a habilidade para aprender sobre os domínios modulares o suficiente para construir uma síntese das variáveis e interdependências existentes entre os subsistemas modulares, a habilidade social para coordenar a equipe multifuncional constituída para o projeto e a capacidade de gerenciar a rede de criação de valor por meio da negociação de integração das interfaces com as outras equipes funcionais (BONJOUR; MICAELLI, 2010).

\subsubsection{Modelagem e simulação da arquitetura organizacional}

Métodos de diagnóstico baseados em modelagem e simulação organizacional oferecem uma abordagem sistemática para a abstração de um sistema real em um modelo codificado e executável, realizada por meio de análises quantitativas baseadas em grafos e associadas a uma descrição qualitativa (PAPADONIKOLAKI; VRIJHOEF; WAMELINK, 2015). Geralmente ilustrados como gráficos ou redes, esses modelos 
podem ser adequados para explicar a complexidade organizacional de um empreendimento imobiliário em várias escalas diferentes, de uma escala setorial a determinada rede multiempresas, ou mesmo nas interações interpessoais de uma equipe de projeto (PAPADONIKOLAKI; VRIJHOEF; WAMELINK, 2015).

Diferentemente do que se observa nas modelagens de sistemas e de processos, as modelagens organizacionais apresentam relações entrelaçadas em redes que não podem ser representadas em uma base hierárquica ou linear única. Isso ocorre porque a representação de um modelo organizacional deve contemplar as relações de todas as ações e interações entre os atores de um processo e, muitas vezes, relacioná-las com as interfaces de acoplamento e com os componentes do sistema (PAPADONIKOLAKI; VRIJHOEF; WAMELINK, 2015). Algumas abordagens de diagnóstico e modelagem organizacional se destacam, tais como os métodos de análise de configuração, de topologia da rede social, de domínio funcional, de análise de comparências centrais à organização, etc. (BONJOUR et al., 2009; BONJOUR; MICAELLI, 2010; MERSCHBROCK, 2012a; HATTAB; HAMZEH, 2016).

A maioria dessas abordagens apresenta uma modelagem baseada em agente, em que as interações entre os agentes são mapeadas em um ambiente existente a fim de capturar os comportamentos emergentes de uma rede, que não poderiam ser identificados de outra forma, seja por meio da simples observação ou da dedução lógica de modelos estáticos. Os agentes, no caso, podem tanto ser as pessoas e os cargos em uma organização, como se relacionar a fontes de informações e de recursos, a empresas, núcleos ou departamentos, etc. (MACAL; NORTH, 2009; HATTAB; HAMZEH, 2016). As modelagens baseadas em agentes ajudam a entender como o fluxo de informações entre os agentes ocorre, e assim permitem delinear a influência da estrutura social na criação e na difusão de informações de projeto. Assim, nesse tipo de modelagem cada atividade do processo está vinculada a um ou mais agentes, que podem atuar como iniciadores, como facilitadores e/ou como executores da atividade (PAPADONIKOLAKI; VRIJHOEF; WAMELINK, 2015).

Outros métodos de modelagem organizacional partem da análise de dependência entre os módulos de um sistema complexo, as atividades do processo de projeto e as capacidades necessárias para executar a modularização organizacional (FELIN; FOSS, 2009; BONJOUR; MICAELLI, 2010). Nesses casos existem dois tipos principais de 
matrizes de dependência que podem ser utilizados para analisar formas de organizar um projeto, ligadas às relações interdomínios e intradomínios.

As matrizes de intradomínios, também conhecidas como Design Structure Matrix (DSM), mapeiam as relações de dependência entre elementos do mesmo domínio; por exemplo, mapeiam as interfaces entre componentes de um sistema ou, então, mapeiam as interações entre atividades do projeto (BROWNING, 2001; DANILOVIC; BROWNING, 2007; BONJOUR; MICAELLI, 2010). Já as matrizes interdomínios, também conhecidas como Domain Mapping Matrix (DMM), representam dependências incidentes entre dois domínios distintos, normalmente entre o domínio do sistema e o do processo (CHEN; CLOTHIER, 2003; BONJOUR et al., 2009; BONJOUR; MICAELLI, 2010).

Enquanto a DSM pode modelar as relações existentes entre os componentes do sistema ou a interdependência entre as atividades do processo de projeto, a DMM estabelece a relação entre sistema e processo. Juntas essas matrizes permitem identificar as relações de dependência que um projeto de arquitetura organizacional deve subsidiar para construir uma rede de criação de valor eficiente, de modo a integrar as atividades cujas capacidades são essenciais e terceirizar aquelas que são delegáveis (UFRGS, 2006; DANILOVIC; LEISNER, 2007; SOSA, 2007; REICHARDT et al., 2012).

A combinação dessas matrizes para a análise organizacional é uma descoberta ainda muito recente, o que implica que as poucas ferramentas propostas ainda não estão suficientemente desenvolvidas e testadas para o uso comercial (BONJOUR; MICAELLI, 2010). No entanto, casos de aplicação, aperfeiçoamento e informatização dos procedimentos de mapeamento da congruência entre domínios de uma organização estão atualmente em desenvolvimento (SOSA, 2007), e algumas considerações sobre a modularização organizacional podem ser extraídas dos resultados alcançados. Entre elas cabe destacar a perspectiva de relacionar a modelagem de domínios às variáveis ligadas aos agentes da organização.

\subsection{REFLEXÃO SOBRE OS ACHADOS DA RSL}

A revisão sistemática da literatura permitiu delinear uma trajetória entre a teoria organizacional, as especificidades de organizações de projetos complexos e as 
idiossincrasias presentes nas organizações de empreendimentos imobiliários. Essa transição entre teoria e situação existente apresentou o contexto para identificar as influências organizacionais e ambientais sobre a qualidade do projeto e apresentar uma perspectiva de promover mudanças significativas no setor de AECO por meio de projetos de arquitetura organizacional de empreendimentos imobiliários.

A introdução de alguns conceitos fundamentais sobre teoria das organizações permitiu caracterizar o que é organização para a pesquisa, o que é uma estrutura organizacional e quais são as formas de desenho organizacional de interesse para a discussão subsequente, introduzindo o problema associado à dimensão sociocultural da organização, que restringe o alcance de abordagens formais de concepção e gerenciamento de organizações, que não consideram a imprevisibilidade de contextos específicos de interação entre agentes e ambientes.

A discussão sobre projetos complexos permitiu delinear as características fundamentais para que organizações de projetos complexos sejam eficientes e eficazes em criar valor para o cliente e para o negócio. Destacou o protagonismo da arquitetura para a integração do sistema e a importância de subsidiar o aprendizado contínuo para lidar com as propriedades emergentes do projeto. Caracterizou a rede de criação de valor do projeto e demonstrou que a capacidade principal de uma organização orientada ao projeto é desenvolver e assimilar as competências necessárias para elaborar soluções de projeto únicas e, assim, se diferenciar no mercado, o que confere uma dimensão estratégica para o aprendizado suficiente para caracterizar a organização de projeto como uma organização de aprendizagem.

A identificação das características de organizações de empreendimentos imobiliários, por outro lado, ofereceu um cenário abrangente sobre o setor, confrontado com as condições de eficiência e de eficácia observadas na discussão sobre projetos complexos. Assim, discutiu-se a inadequação da forma como as equipes de projeto de empreendimentos imobiliários são organizadas, o que repercute sobre o regime de contratos e compromete o gerenciamento de projeto, e distinguiram-se os limites entre integração informacional e integração organizacional, evidenciando a necessidade de promover mudanças 
organizacionais para viabilizar organizacionalmente o processo de projeto e de gerenciamento da cadeia de valor ao longo do ciclo de vida do projeto.

Mediante a confrontação entre as características de uma organização para projetos complexos e a realidade experimentada em empreendimentos imobiliários foi possível pontuar diferentes aspectos organizacionais que influenciam o processo de projeto, tais como alterar o regime de poder, estimular ou oferecer barreiras ao aprendizado, à inovação e à colaboração, e subsidiar o desenvolvimento e a absorção de competências necessárias para gerenciar a cadeia de valor e responder adequadamente aos diferentes estímulos e demandas do ambiente de negócios do setor.

Com relação às influências ambientais sobre a organização do projeto foram apresentados os diferentes tipos de ambiente e as pressões por isomorfismo institucional que o ambiente de determinado setor exerce sobre as organizações que nele desejam atuar. Os argumentos em favor de se promover uma congruência entre sistema, processo e organização como uma resposta a essas pressões foram então apresentados como base do marco teórico para se promover uma arquitetura organizacional.

A opção por adotar o isomorfismo arquitetônico entre sistemas, processos e organização como abordagem para discutir a influência organizacional sobre a qualidade do projeto e, assim, orientar a arquitetura organizacional do projeto é motivada pelo sucesso com que a sistematização da arquitetura de sistemas tem sido demonstrada em casos de aplicações práticas. De fato, o desenvolvimento da arquitetura de sistemas e de processos realizado em diversos setores associados a projetos complexos tem se provado uma maneira economicamente viável de organizações satisfazerem as expectativas e as necessidades de seus clientes.

$\mathrm{Na}$ AECO, em que a cadeia de suprimentos fragmentada acrescenta complexidade ao projeto de empreendimentos imobiliários e em que o desenvolvimento do projeto não possui condições de promover uma arquitetura integrada, uma reorganização dos processos de desenvolvimento e da execução do projeto parece fundamental para realizar os ganhos de eficiência potencial que a adoção desarticulada de tecnologias, procedimentos e práticas de projeto inovadoras não obteve. Por isso, entende-se que é preciso identificar e incorporar ao processo de projeto as práticas, tecnologias e 
procedimentos de gerenciamento de requisitos e de modelagem da informação, de TVD e de gerenciamento da cadeia de suprimento, que capacitem a equipe de projeto a criar valor para os clientes e para o negócio.

Trata-se de um processo contínuo e em evolução, em que é mais importante compreender os mecanismos de promoção da arquitetura organizacional do que seu resultado, de forma a capacitar a organização a projetar novos arranjos mais congruentes, visando a maior eficiência e eficácia em satisfazer os níveis de qualidade esperados. As seções seguintes se debruçam sobre esse exercício de identificação das competências centrais para a equipe do projeto arquitetônico, de análise da congruência do empreendimento imobiliário de uma residência e, a partir desse caso, de proposição de uma arquitetura organizacional orientada à criação de valor, em conformidade com as bases teóricas identificadas nessa RSL. 


\section{ANÁLISE DAS CONDIÇÕES ORGANIZACIONAIS PARA GERENCIAR A CRIAÇÃO DE VALOR DURANTE O DESENVOLVIMENTO DO PROJETO}

A proposição de uma arquitetura organizacional congruente ao processo de projeto orientado ao valor depende da compreensão das variáveis organizacionais que impactam sobre as atividades desse processo. Como os processos de projeto existentes ainda não têm incorporado sistematicamente práticas de gerenciamento de valor visando à qualidade do projeto, é necessário modelar tais processos por meio de estudos exploratórios que se aproximem significativamente da realidade profissional.

Assim, foram realizados dois estudos sobre processos de projeto com objetivo de aplicar teoria, práticas e ferramentas levantadas sobre gerenciamento de valor no projeto e analisar as condições de operacionalização de tal conhecimento ainda predominantemente acadêmico. Os resultados desses estudos são apresentados a seguir.

O primeiro estudo aborda um processo mais abrangente de custeio-meta, em que as soluções de projeto foram negociadas com a cadeia de suprimentos do setor de forma a viabilizar soluções criativas no nível dos sistemas. Trata-se de um projeto de habitação social desenvolvido numa parceria entre empresas e academia que adotou uma estratégia de customização em massa para resolver o problema das demandas de diferentes perfis de moradores em um contexto com recursos financeiros bastante restritos.

O segundo estudo concentra-se na dinâmica de concepção baseada na análise de importância das soluções propostas para o atendimento dos requisitos dos clientes e seu ajuste ao custeio-meta do projeto. A viabilidade deste projeto dependeu da operacionalização de uma verificação rápida de quantitativos e custos, possível com uma modelagem de informação da construção adequada. Trata-se de um projeto de unidade de pronto atendimento (UPA) desenvolvido em uma disciplina de oficina com a colaboração de agentes de saúde responsáveis pelo desenvolvimento e uso de um empreendimento real, utilizado como referência. 


\subsection{PRIMEIRO ESTUDO EXPLORATÓRIO}

A necessidade de diminuir o impacto de variáveis de projeto não consideradas sobre o valor percebido em um contexto de escassez demanda a antecipação da resolução de problemas de projeto ainda nas fases iniciais de concepção do empreendimento, de forma a projetar os custos e as condições de execução na cadeia produtiva. Tal contexto, observado pela equipe de desenvolvimento e de pesquisa responsável pelo projeto, exigiu uma mudança processual de um modelo sequencial para processos simultâneos.

Também a interatividade exigiu a cooperação e a colaboração entre profissionais com diferentes competências. Entre as funções ligadas diretamente ao processo de projeto destacaram-se o gerenciamento dos requisitos dos usuários e o custeio-meta como respostas à gestão de valor no contexto de escassez de recursos associados a um projeto inovador para habitação de interesse social (HIS) no Brasil. A dinâmica entre requisitos, solução e custos do projeto assume particular relevância quando a necessidade de reduzir custos com a produção em massa entra em conflito com a diversidade de requisitos de moradores que tais programas atendem.

A gestão de requisitos e o custeio-meta instrumentalizaram a concepção de soluções de customização em massa, uma abordagem adotada pela equipe de projeto como prérequisito para garantir maior flexibilidade construtiva dentro dos limites de custos e produção em massa. Conforme se configurou, o projeto trouxe para o centro da discussão da equipe a necessidade e as condições de colaboração, gestão de requisitos e custeio-meta, conectando-se incidentalmente o processo de projeto ao debate geral aqui articulado.

\subsubsection{Caracterização do processo de projeto em um contexto de escassez}

A novidade experimentada pela equipe responsável pelo desenvolvimento do projeto não se restringia às características do produto. Um processo de viabilidade do empreendimento, aqui chamado de concepção do projeto, contou com o envolvimento de intervenientes do mercado, que contribuíram para a construção de um entendimento compartilhado sobre os objetivos do projeto e sobre o partido tecnológico e os desafios processuais. 


\section{Concepção do projeto}

As atividades de viabilidade mercadológica, programática e institucional do projeto ocorreram numa fase de prospecção e avaliação para a concepção do projeto de pesquisa e desenvolvimento (Figura 7), que antecedeu a concepção da arquitetura do edifício. Tal construção ocorreu por meio do envolvimento de profissionais da área de arquitetura, engenharia, assistência social e estatística, que participaram de reuniões, debates e workshops, em que soluções de tecnologia, de processo e de produto foram apresentadas, discutidas e negociadas.

Foram definidas as premissas de projeto, que alinharam os interesses dos diferentes intervenientes e os objetivos do projeto. Institucionalmente ficou definido que o projeto se basearia nas regras do programa habitacional Minha Casa, Minha Vida (MCMV) e na estrutura existente da Companhia de Habitação de Londrina (Cohab-LD), propondose aperfeiçoamentos incrementais a partir do desenvolvimento do projeto.

Diante das condições institucionais, a viabilização programática foi resolvida com a adoção de uma estratégia de customização em massa para o desenvolvimento de um modelo de HIS que alinhava a possibilidade de atender à demanda mediante diferentes arranjos espaciais e equipamentos específicos, em um contexto de escassez de recursos e produção em massa.

Figura 7 - Concepção do projeto - Primeiro estudo exploratório

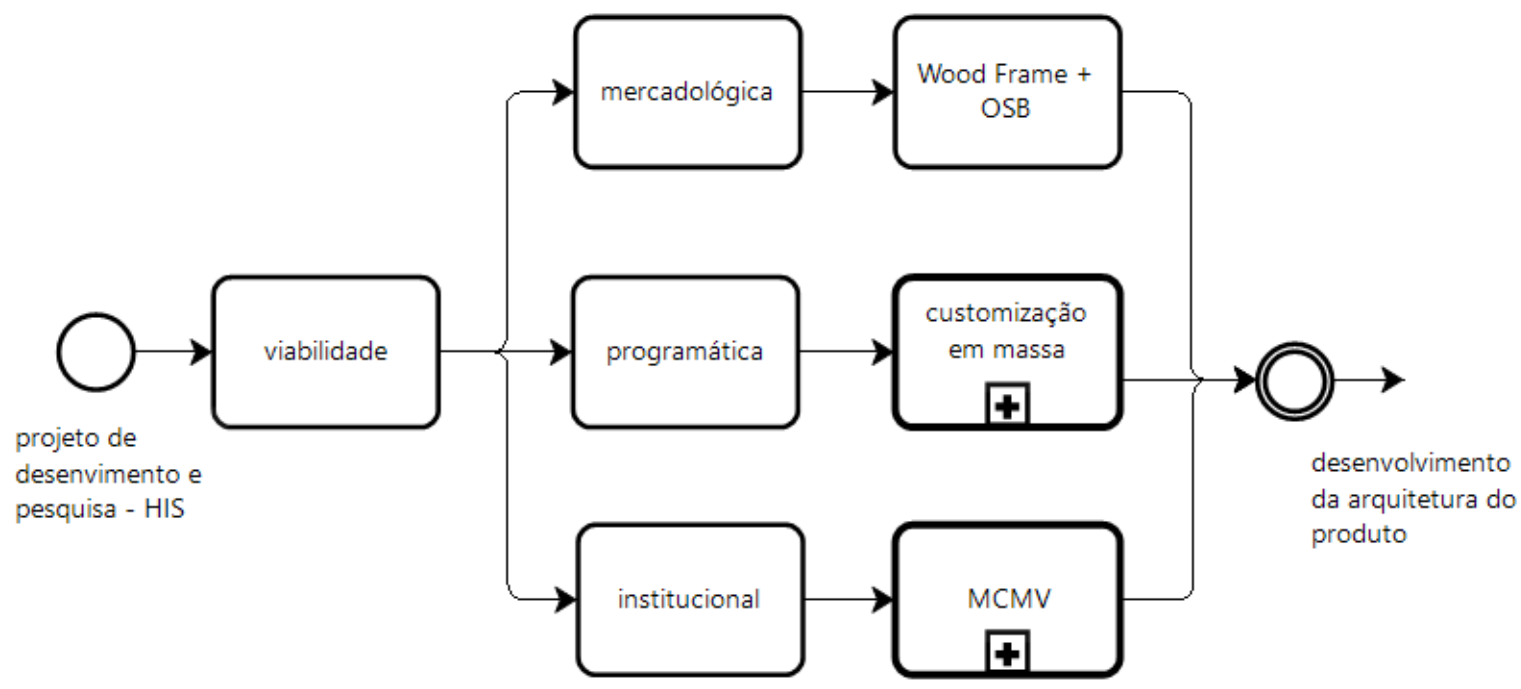


Tecnologicamente, as parcerias estabelecidas com as empresas do setor orientaram a pesquisa sobre soluções baseadas em estruturas de madeira (wood frame) e vedação em placas de OSB (oriented strand board). Tais parcerias se alinhavam à necessidade de flexibilidade modular e a um maior controle de produção que a customização em massa exige, ao mesmo tempo em que promoviam a difusão de tecnologias construtivas não convencionais dessas empresas parceiras.

Até esse momento, embora não houvesse uma proposta formal da HIS, várias características do produto haviam sido indiretamente definidas em decorrência do delineamento estabelecido acerca dos requisitos de projeto levantados. Tais definições estratégicas, anteriores à concepção de uma solução da arquitetura, foram decisivas para o trabalho de desenho, iniciado na etapa seguinte.

O condicionamento das definições estratégicas foi sentido pela equipe de desenvolvimento do projeto, pois alterou de forma significativa as bases tecnológicas e processuais de trabalho com que estava familiarizada. Todavia, cabe a ressalva de que, sem uma concepção do projeto como a descrita, as condições de mercado que prevalecem também condicionam e restringem a atividade criativa, porém seu impacto não é percebido igualmente, por terem sido naturalizadas na cultura profissional, o que contribui para a pouca inovação observada em projetos de AECO.

\section{Desenvolvimento do projeto do edifício}

Com a confirmação da viabilidade do projeto, a equipe de projeto, composta dos projetistas indicados no Quadro 5, iniciou o desenvolvimento da arquitetura do sistema com a elaboração de um estudo preliminar (Figura 8). Em um primeiro momento, esse estudo abrangeu as atividades de discriminação dos custos, a definição do partido tecnológico e o tratamento estatístico das atividades de avaliação pós-ocupação (APO) (CONCEIÇÃO, 2015). Para tanto, além das competências específicas de cada integrante, a equipe de projeto contou com a cooperação de profissionais especialistas, indicados no Quadro 6. 
Figura 8 - Desenvolvimento do estudo preliminar da arquitetura da HIS

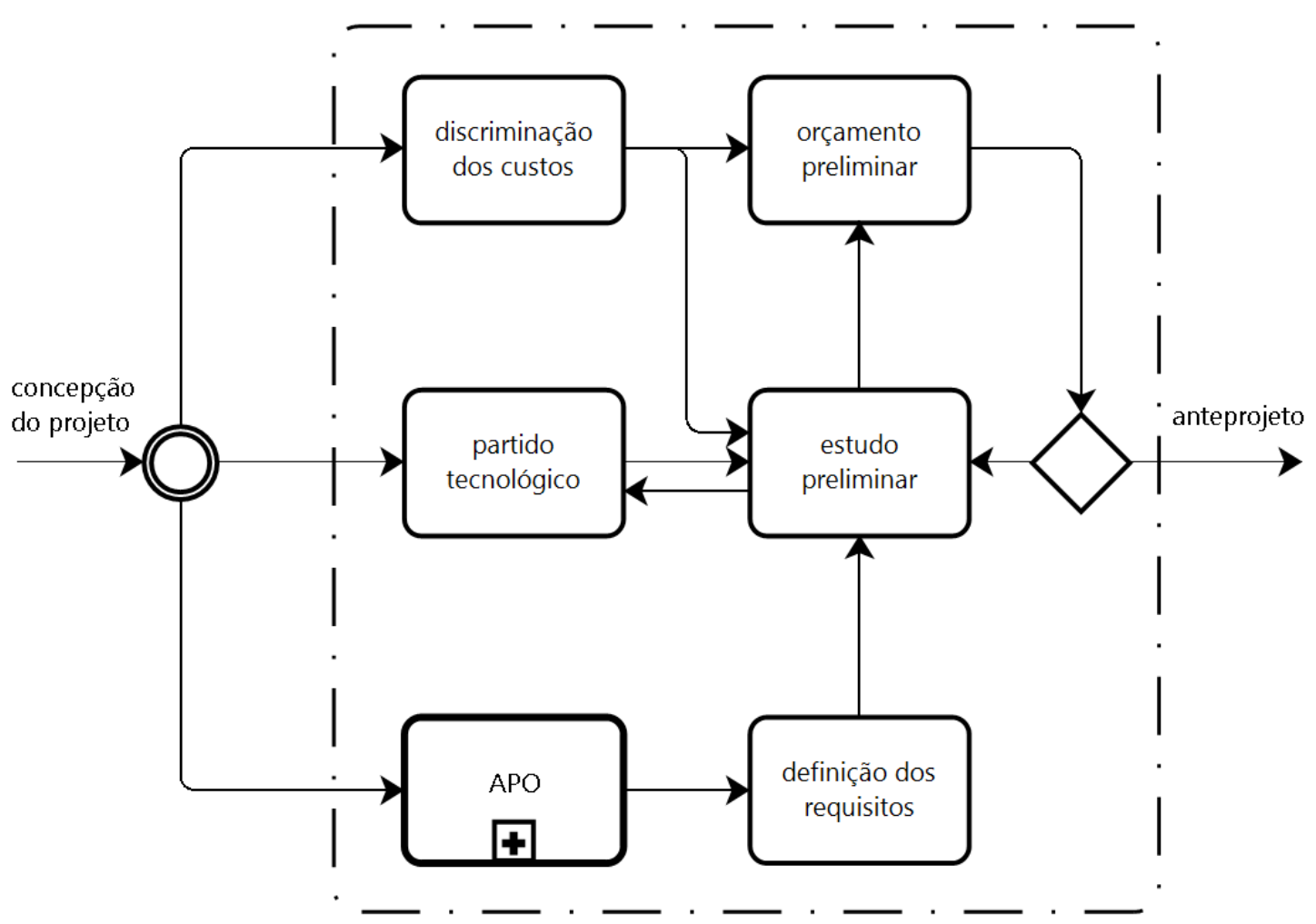

Na prática, o levantamento da APO foi executado antes do início dessa etapa, ocorrendo paralelamente o estudo de viabilidade do projeto. Além disso, embora o enfoque tenha sido a coordenação de soluções tecnológicas, a definição de partidos tecnológicos incluiu investigações formais e espaciais para a arquitetura. $\mathrm{O}$ envolvimento dos profissionais de projeto nas discussões sobre o partido tecnológico, a APO e a discriminação dos custos no nível funcional contribuiu significativamente para a proposição iterativa de soluções, que incrementavam a preocupação de custo, a execução e os requisitos em ciclos curtos de discussão e experimentação observadas no estudo preliminar.

Mediante a racionalização tecnológica baseada na discriminação de custo, a equipe de projeto conseguiu reduzir o custo unitário para execução de uma unidade de HIS o suficiente para garantir a configuração mínima exigida pelo programa MCMV e adicionar opções de ambientes e/ou de equipamentos que atendessem a requisitos de clientes levantados pela APO (Figura 9). 
Figura 9 - Exemplo de duas opções de customização

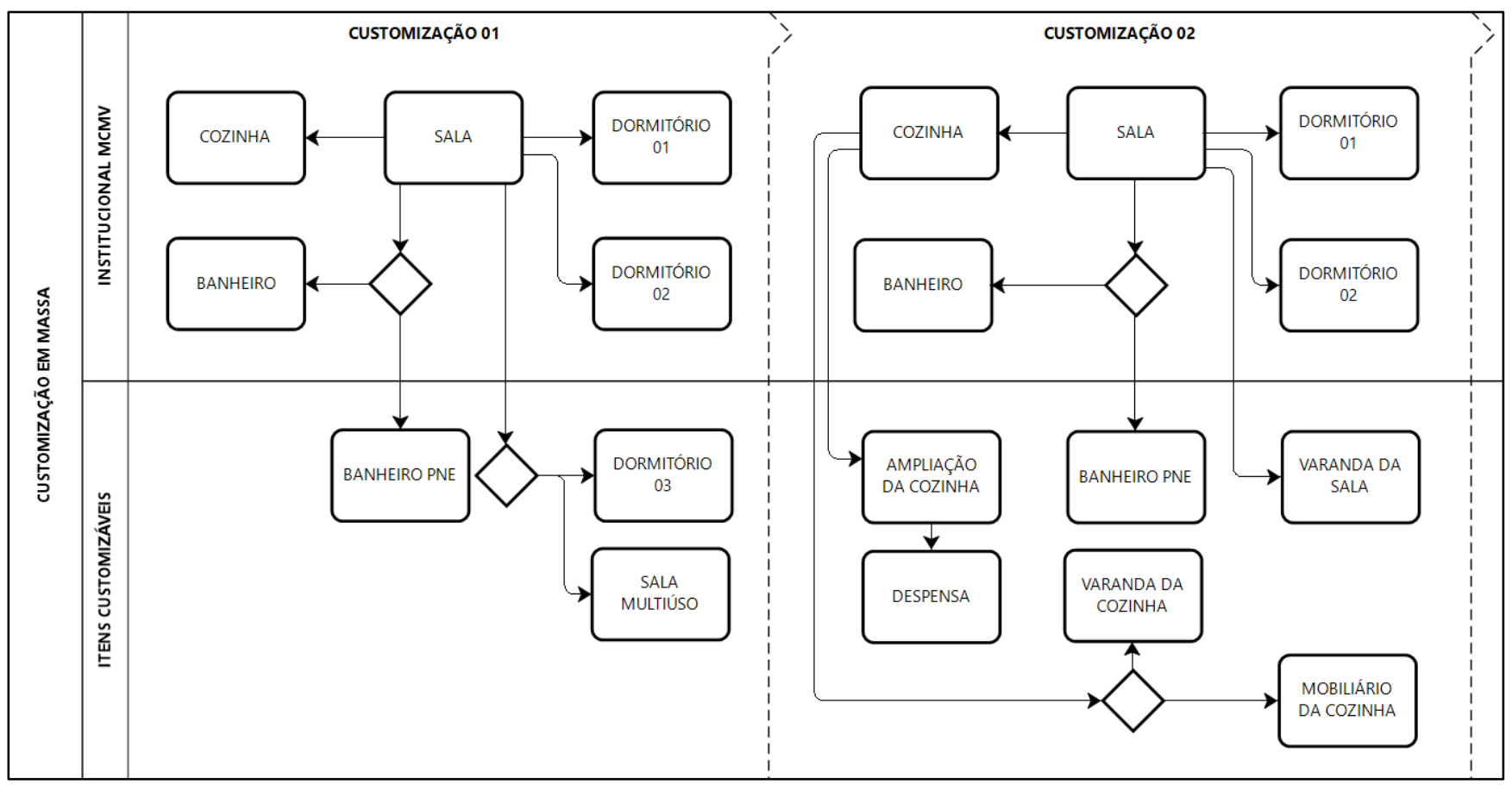

Para tanto, o custo de produção de uma unidade HIS com a configuração mínima exigida foi reduzido por meio da eliminação de custos desnecessários até viabilizar recursos suficientes para a construção de um dormitório adicional, ou seja, unidade padrão +1 dormitório. As demais opções de customização foram então desenvolvidas de forma a atender aos requisitos de clusters específicos que não demandavam um terceiro dormitório, agregando valor à edificação com a combinação de benefícios alternativos, como garagem coberta, extensão da cozinha, entre outros, até converter toda a economia obtida. Associadas ao estudo de plantas, soluções de customização também foram concebidas para a diversificação das fachadas e acabamentos internos (Figura 10).

Figura 10 - Exemplo de opções de fachada do estudo preliminar

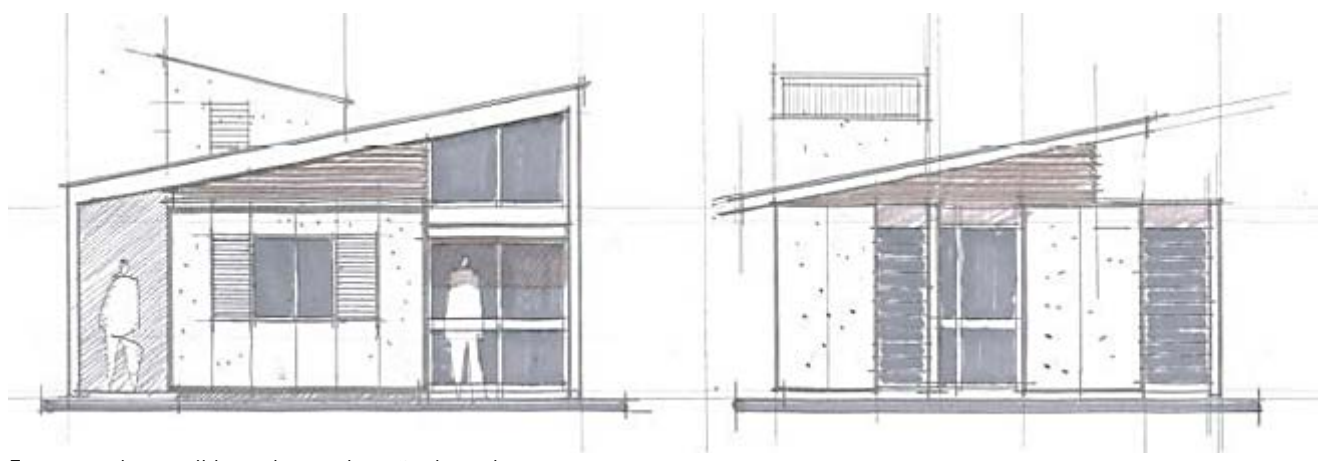

Fonte: arquivos cedidos pela coordenação do projeto. 
A adequação da proposta ao custo permissivo - no caso, o valor pago pelo programa por unidade habitacional menos os custos indiretos e os custos com infraestrutura urbana (ARAGÃO, 2014; SAITO, 2016) - foi adotada como variável da maturidade da proposta. Uma vez alcançada, a equipe decidiu iniciar o anteprojeto da arquitetura, quando um orçamento no nível de sistema poderia ser elaborado.

O anteprojeto se caracterizou pelo aprofundamento das atividades de custeio-meta, pela iteração de soluções tecnológicas para manter o orçamento abaixo do custo permissivo e pela hierarquização dos requisitos de cliente e valoração dos atributos funcionais da HIS, por meio da matriz da qualidade (Figura 11).

Com o detalhamento dos sistemas, a equipe de projeto observou que alguns custos estimados no estudo preliminar não se confirmavam, pois a capacidade de redução de custos baseada em melhorias do desenho técnico se mostrara limitada em um projeto com recursos escassos e restrições normativas bastante discricionárias, como é o caso de HIS do programa MCMV.

Novos estudos foram realizados, e aprimorou-se cada proposta até um nível de detalhamento dos sistemas exigido para o anteprojeto. Para acelerar o avanço dessas soluções, a equipe adotou como estratégia de atuação garantir o atendimento do custeiometa da unidade básica com o terceiro quarto, para só em um segundo momento retornar às alternativas de customização orientadas para os clusters.

Ciclos mais curtos e iterativos de proposição e avaliação foram realizados. Uma solução já era concebida e modelada em um software CAD obedecendo às características técnicas e materiais dos sistemas, o que permitia levantar os quantitativos necessários para um orçamento no nível do sistema a ser elaborado. Por meio da hierarquização dos requisitos em um índice geral de importância (IGI), os custos relativos a essas decisões de projeto eram avaliados. Para tanto, determinadas características do sistema proposto e orçado eram identificadas e relacionadas a atributos funcionais do produto, ${ }^{1}$ que responderiam a um ou mais requisitos dos clientes.

\footnotetext{
10 termo "atributos funcionais" foi utilizado em substituição ao termo "requisitos do projeto", empregado durante a realização do projeto pelos pesquisadores e projetistas então envolvidos. A razão para essa mudança se deve a uma interpretação diferente da atual pesquisa sobre o procedimento adotado. 0 anacronismo assim se justifica pela clareza na correlação entre processo analisado e proposto.
} 
Figura 11 - Desenvolvimento do anteprojeto da arquitetura da HIS

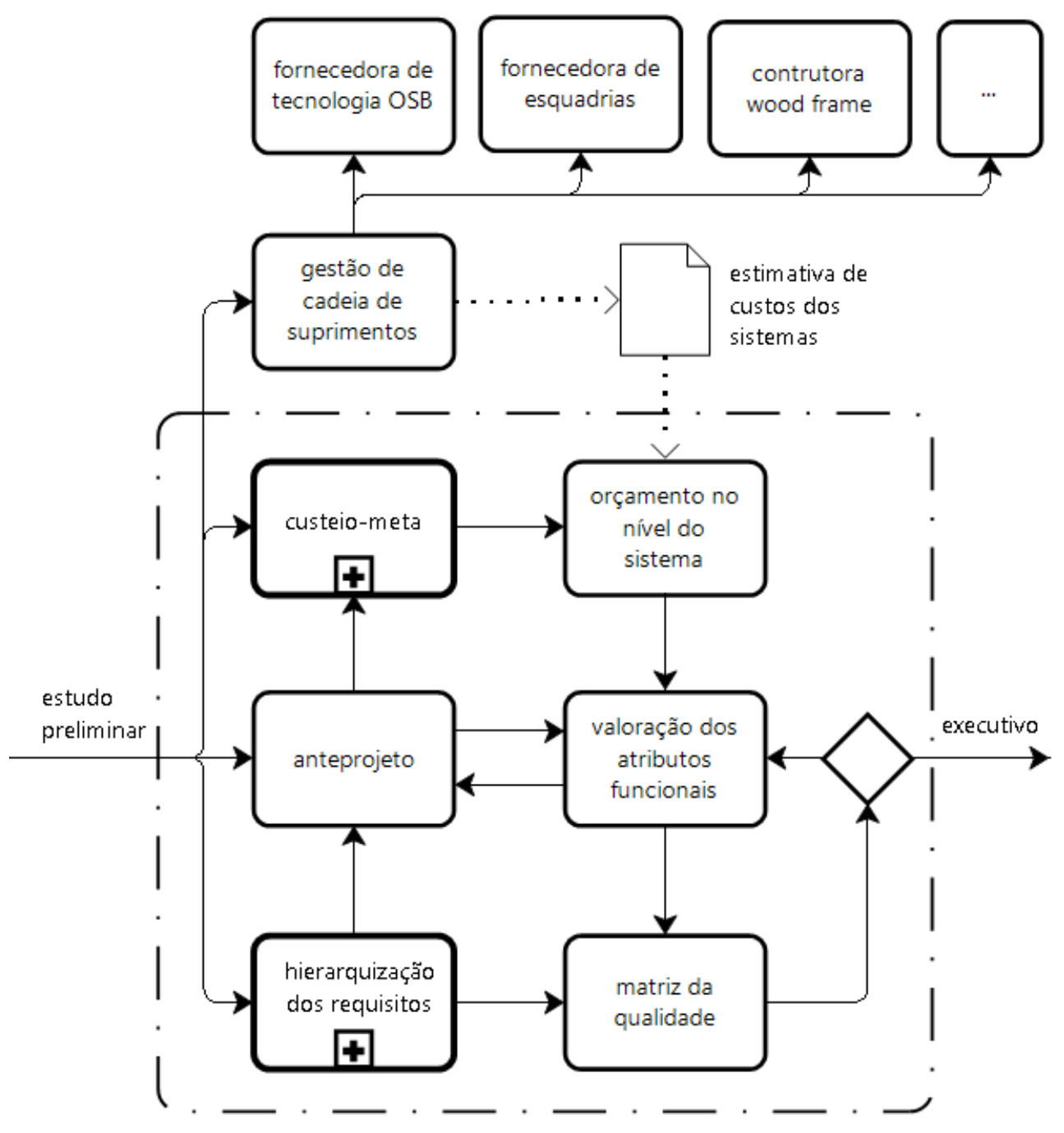

Os atributos do projeto eram então relacionados aos requisitos dos clientes na matriz da qualidade, conferindo-lhes um peso relativo ao IGI de cada requisito do cliente atendido (Figura 12). Quanto mais requisitos importantes um atributo do produto atendia, maior importância assumia. Assim, os custos de produção dos sistemas e componentes eram valorizados, auxiliando a equipe de projeto a avaliar as soluções com melhor relação custo-beneficio (ARAGÃO, 2014). 


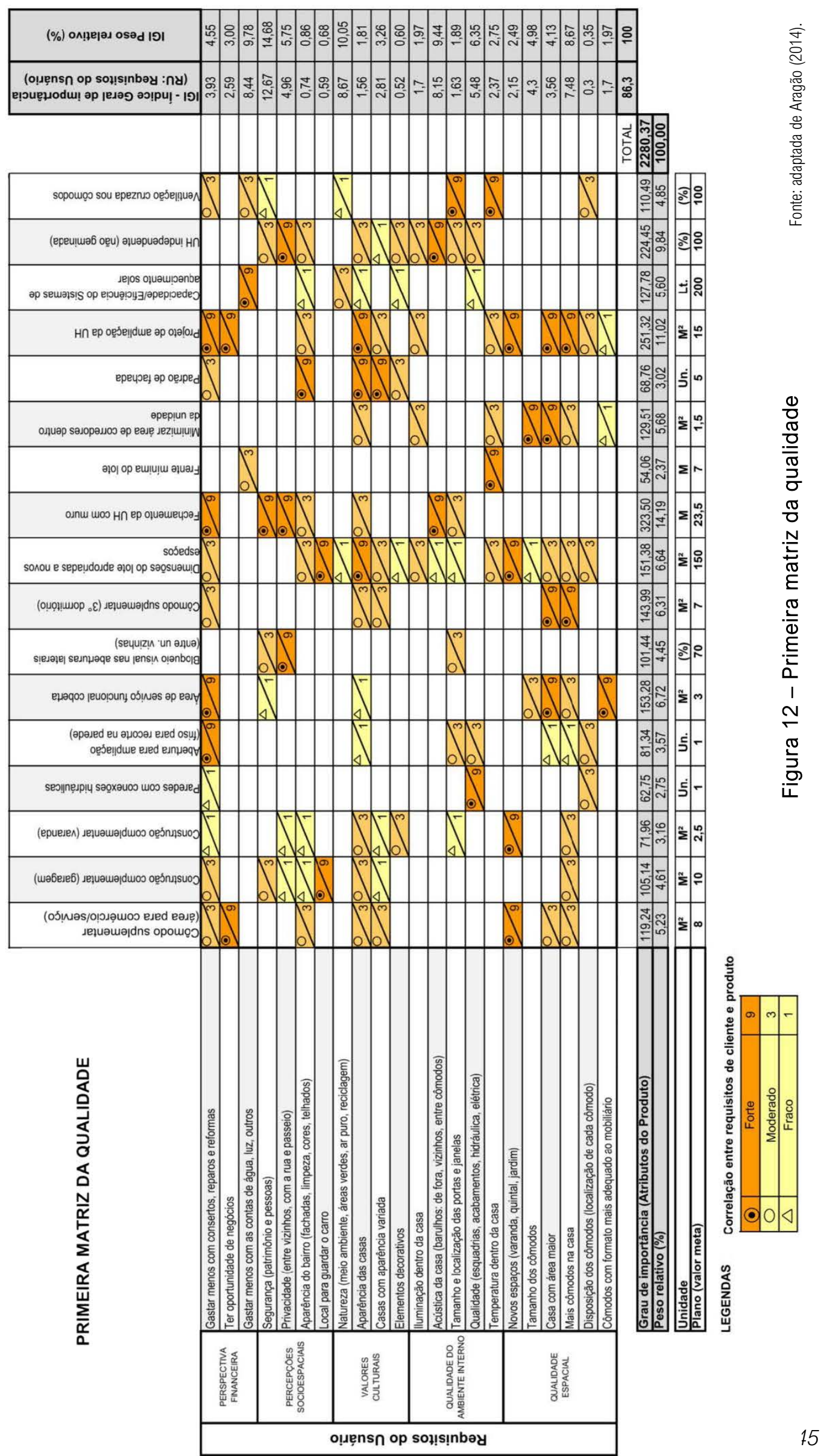


Cabe observar que o gerenciamento da cadeia de suprimentos associado às atividades de custeio-meta não foi expressivo durante o anteprojeto. De fato, a relação da equipe de projeto com os fornecedores de tecnologia parceiros era predominantemente consultiva, visando à maior exatidão na estimativa dos custos para os sistemas construtivos.

O início do executivo trouxe uma nova dinâmica ao relacionamento entre a equipe de projeto e a cadeia de suprimentos (Figura 13).

Figura 13 - Desenvolvimento do executivo da arquitetura da HIS

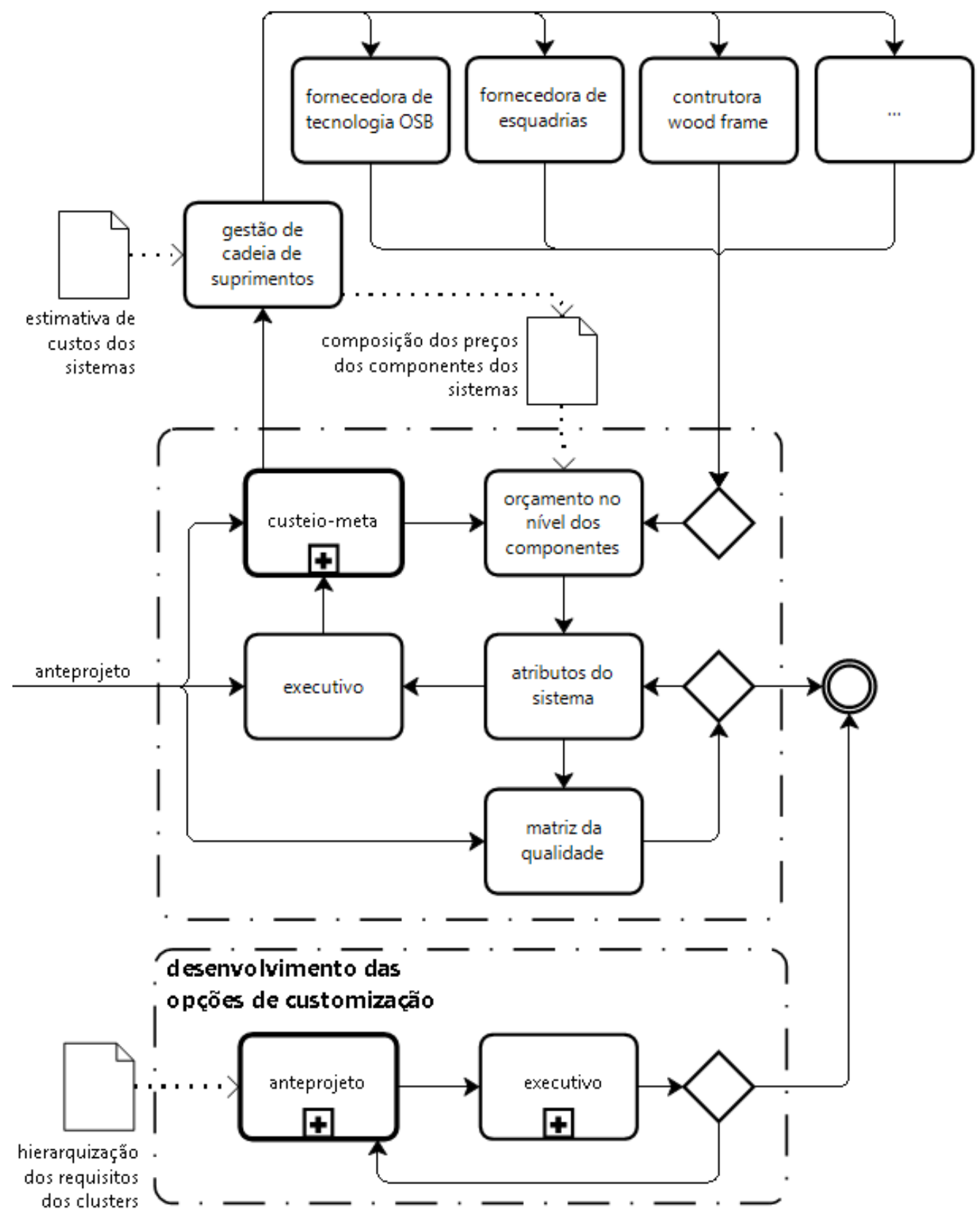


Além de compreender as condicionantes tecnológicas e de produção, as iniciativas de desenvolvimento de soluções técnicas inovadoras, ligadas à redução de perdas na produção em massa de painéis de vedação pré-fabricados (NOGUEIRA, 2016), soluções de estanqueidade de esquadrias de alumínio em painéis de vedação (TUMELERO, 2016) e de coberturas modulares pré-fabricadas customizáveis (GHOZ, 2017) permitiram que a equipe de projeto adotasse soluções baseadas em alternativas tecnológicas negociadas com as empresas parceiras.

$\mathrm{O}$ anteprojeto das opções de customização adicionais, desenvolvidas para atender aos requisitos específicos de determinados clusters de clientes (CONCEIÇÃO, 2015), foi realizado depois, simultaneamente ao executivo da unidade básica. Assim, apresentou um ritmo de resolução de problemas mais acelerado, por ter sido favorecido com informações sobre os detalhes e sobre os custos dos sistemas mais precisas e negociadas junto à cadeia de suprimentos, definidas até o nível dos componentes (Figura 14 e Figura 15).

Figura 14 - Opções de fachadas
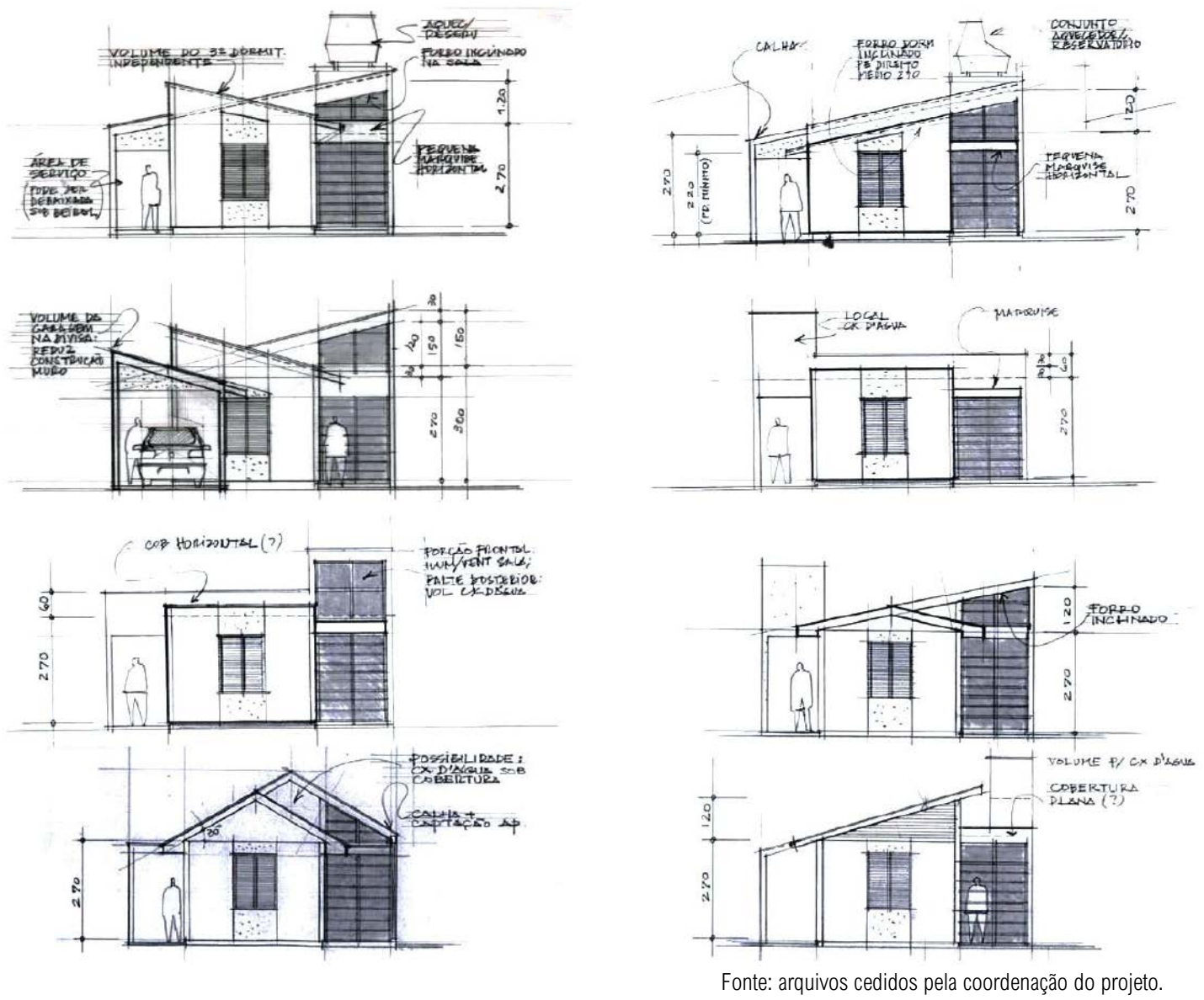
Figura 15 - Opções de customização de ambientes da HIS
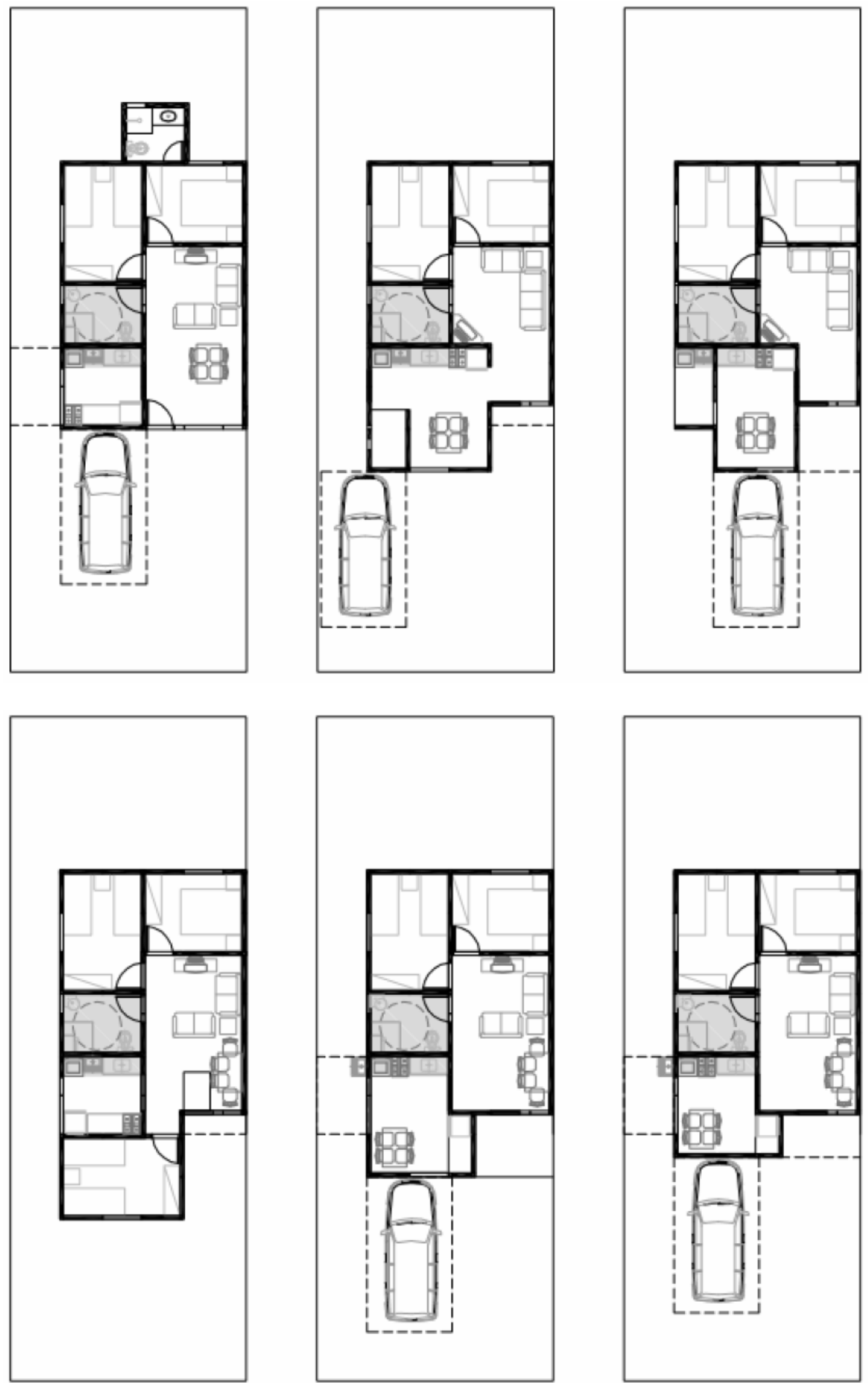

Fonte: arquivos cedidos pela coordenação do projeto. 


\section{Desenvolvimento do projeto para produção}

O executivo da unidade básica e das opções de customização apresentavam uma solução integrada de soluções tecnológicas inovadoras e custeio-meta, contudo questões ligadas à operacionalização de processos de captura das preferências de customização dos moradores e a confirmação das condições de produção sobre as quais o projeto foi concebido precisavam ser gerenciadas por meio da prototipagem de componentes e do projeto da produção (Figura 16).

Figura 16 - Desenvolvimento dos processos de projeto da produção

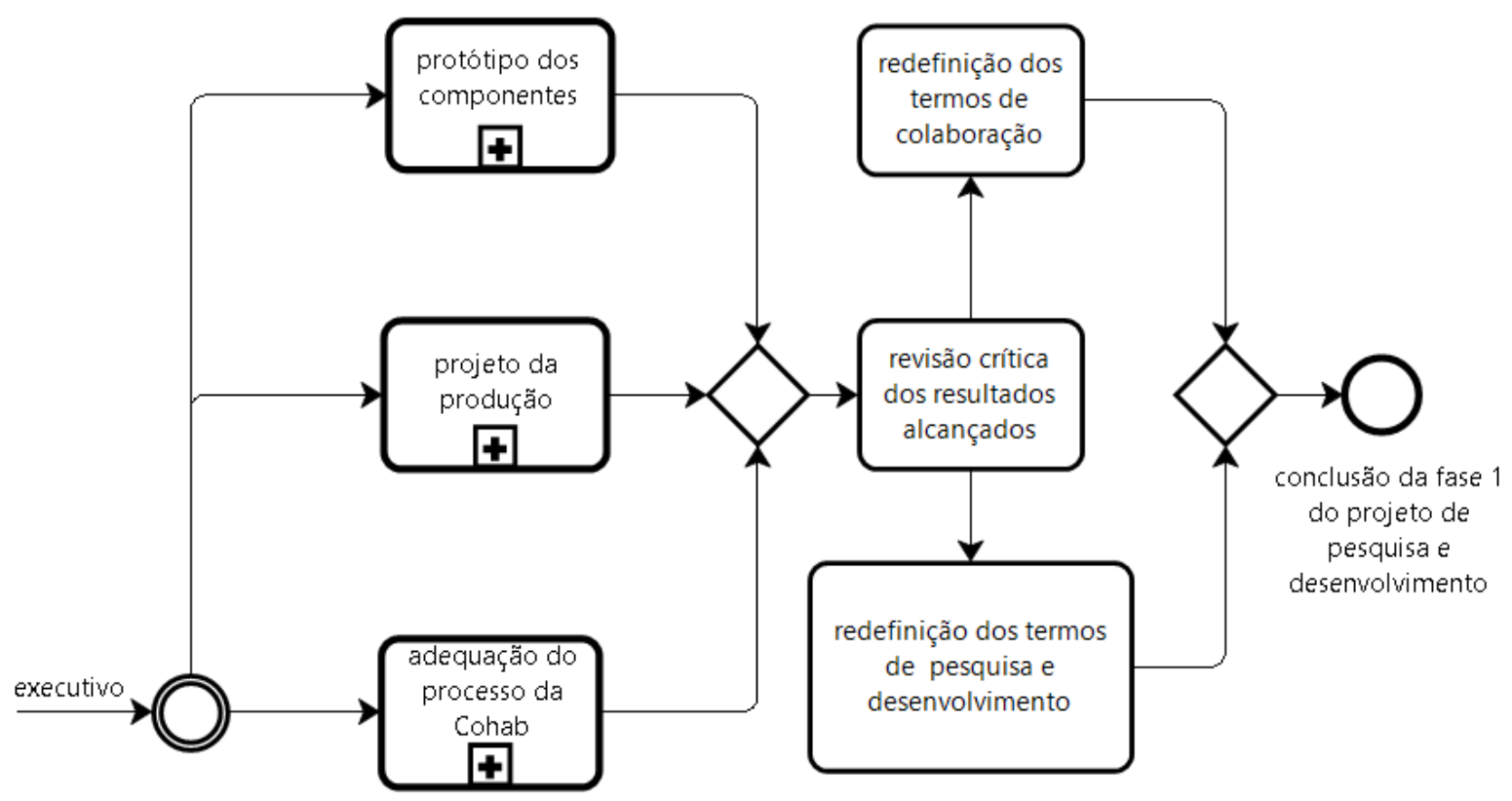

As atividades desses processos não são detalhadas aqui porque correspondem a processos cujo fluxos não foram acompanhados e documentados na época de sua realização. Além disso, alguns desses processos respondem a algumas especificidades do caso estudado, como o mapeamento do fluxo do processo de provisão de HIS realizado pela Cohab (LONDRINA; TAUBE, 2015), que pouco tem a contribuir para a generalização da discussão a que este trabalho se propõe.

Um debate aprofundado sobre as particularidades desse projeto de pesquisa e desenvolvimento foi realizado pela coordenação acadêmica e resultou na redefinição dos termos de pesquisa e de colaboração com organizações tanto da iniciativa privada quanto pública. 


\subsubsection{Análise das entrevistas com profissionais da equipe de projeto}

A caracterização dos processos de concepção do projeto e desenvolvimento do produto, descritos até aqui, teve como objetivo descrever o funcionamento do processo de projeto para instrumentalizar a arquitetura do processo apresentada no capítulo 5 . Contudo, tal descrição representa uma leitura esquemática e coerente de um processo marcado por variáveis sociais, tecnológicas e, principalmente, organizacionais. Assim, para qualificar o fluxo do processo desenhado é preciso reconhecer as variáveis culturais, ambientais e estruturais que determinaram a organização do trabalho realizado.

A compreensão da influência organizacional é importante para qualificar a discussão da arquitetura organizacional, e para tanto a pesquisa contou com a colaboração de três profissionais pesquisadores que integraram a equipe de projeto. Como participantes do processo descrito, suas percepções captadas por meio de uma entrevista semiestruturada oferecem subsídio empírico para compreender as condições de realização do trabalho. A discussão apresentada na seção 4.1 .3 baseou-se na confrontação da perspectiva de cada um desses profissionais, esquematicamente identificados como P1, projetista criativo; P2, projetista dos custos; e P3, projetista dos requisitos.

Os detalhes ligados à entrevista e aos entrevistados, bem como os demais intervenientes citados foram detalhados no capítulo de método, na seção 2.2.1. A análise apresentada a seguir foi publicada originalmente em um artigo nos anais do $4^{\circ}$ Congresso Internacional da Habitação no Espaço Lusófono (CIHEL) (PEREIRA; HIROTA; FABRICIO, 2017), como parte do esforço acadêmico de pesquisa e desenvolvimento do projeto. Os subtítulos que introduzem cada parte da análise das entrevistas, apresentados a seguir, correspondem ao tema tratado pelos profissionais. A estrutura de relato segue, portanto, a estrutura do questionário semiestruturado empregado nas entrevistas.

\section{Compreensão dos objetivos do projeto analisado}

Após responderem a questões relacionadas à caracterização dos entrevistados, em que aspectos de sua formação e atuação dentro da equipe de projeto foram clarificados, os entrevistados foram questionados sobre as premissas do projeto, objetivo, áreas do conhecimento envolvidas, etc. 
Os entrevistados demonstraram ter bom entendimento compartilhado sobre os objetivos e condicionantes do processo de pesquisa e desenvolvimento analisado, tendo indicado que o centro das preocupações associadas ao projeto era atender às expectativas e necessidades de moradia de uma população de baixa renda, considerando as restrições do programa habitacional de interesse social brasileiro, Minha Casa, Minha Vida. Concordaram também que a equipe de projeto dependia do gerenciamento ativo dos requisitos e custos do projeto para alcançar "um projeto de maior qualidade" ou "valor" diante de um "mesmo limite do montante financeiro a ser aplicado, que não muda" (P2). Além disso, P3 observou a importância da capacitação da equipe para a adoção de novas tecnologias, princípios de customização em massa e eficiência energética.

Ainda sobre o objeto projetado, cabe observar que, enquanto P3 referiu-se ao atendimento de requisitos de eficiência, P1 e P2 destacaram a tecnologia Light Wood Frame. P1 ainda associou essa escolha à experiência e aos recursos produtivos e logísticos de uma das empresas parceiras, a empresa E1 (ver Quadro 6). O envolvimento direto de P1 com a resolução arquitetônica do projeto destaca-se na preocupação em apresentar as dificuldades em trabalhar orientação em um terreno hipotético de 150,00 m², o que certamente resulta em problemas de implantação.

Quando questionados sobre as áreas do conhecimento envolvidas diretamente no projeto, $\mathrm{P} 2$ incluiu como participantes diretos do projeto os clientes promotores, no caso a assistente social da companhia habitacional local (Cohab). Os outros entrevistados não fizeram a mesma referência ao envolvimento direto dos clientes no projeto, reconhecendo, contudo, a importância da cooperação do cliente promotor em disponibilizar "pesquisas do grupo de serviço social" (P3) e, indiretamente, dos clientes finais com a participação nas entrevistas de avaliação pós-ocupação e técnica de preferência declarada. Por outro lado, embora P2 reconheça a importância da colaboração e coordenação para o projeto, ele parece se concentrar nas atividades diretamente relacionadas à gestão de custos e requisitos dos clientes, não explicitando os campos envolvidos no projeto, indicados por P1 e P3 como "projetos complementares", “customização em massa", técnicas de "eficiência energética" e "conforto ambiental", "técnicas construtivas, planejamento da produção" e "prototipagem fisica e virtual". 
Em seguida, os entrevistados foram questionados sobre a maneira como seu trabalho se enquadrava no projeto: P1 apontou a "geração, discussão e desenvolvimento das ideias" de projeto e a "coordenação da equipe" ligada ao projeto; P2 seria responsável por "mapear as necessidades do cliente e os custos, para auxiliar o processo de projeto, servindo como um meio de consulta para que os requisitos não se perdessem durante o processo de projeto"; e P3 apresentou um enquadramento menos sucinto, decorrente do envolvimento "na compreensão da percepção do usuário e as formas de comunicação com os mesmos" para a captação adequada dos requisitos do usuário por meio da “estruturação, aplicação e análise de resultados de uma avaliação pós-ocupação” e de uma "técnica de preferência declarada". P2 também esteve envolvido nessa atividade, mencionando isso mais à frente em sua entrevista. Posteriormente, P3 e P4 se envolveram no desenvolvimento de um classificador para customização em massa de HIS desejadas pelas famílias selecionadas pela Cohab. A exigência de antecipação das possíveis necessidades de grupos de clientes, por meio de uma pesquisa prévia, consistiu no principal fator de complexidade e diferenciação desse projeto de desenvolvimento, que conferiu novidade ao problema e exigiu soluções inovadoras de seus envolvidos.

\section{Percepção do trabalho realizado}

A novidade do trabalho era percebida pelos entrevistados, que compreendiam como o problema de projeto "não estava totalmente definido previamente" (P2), pois era "grande e complexo" (P3), propondo-se a obter contribuições de diversos profissionais e pesquisadores, de várias áreas envolvidas, em detrimento de um protagonismo inicial (P1). A decisão das "estratégias de pesquisa e desenvolvimento foram moldadas" (P2) ao longo da primeira fase do processo de projeto, o que impactou nas condições de trabalho.

Inicialmente, para P1, essa condição de incerteza tornou o "processo mais lento do que o desejado". Com uma opinião contrária, P2 aponta a intensa iteração ocorrida em reuniões durante o período, um dos aspectos mais ricos do processo. Essa diferença de percepção é compreensível se se considerarem os diferentes papéis desempenhados por cada um: enquanto P1 tinha por incumbência conceber e integrar uma solução técnica e socialmente adequada para o problema proposto, P2 e P3 tinham como objetivo final clarificar dois aspectos fundamentais do problema para garantir que as soluções apresentadas não se distanciassem dos requisitos captados do cliente ou do custo previsto. 
A percepção de que havia clareza do trabalho a ser realizado no processo de projeto, partilhada pelos três entrevistados, se restringia ao propósito do projeto. Porém, à medida que o trabalho se desenvolvia, "as variáveis e incertezas aumentaram” (P1). Essa visão se relaciona à preocupação de $\mathrm{P} 2$ ante a indefinição inicial de "como processar, sistematizar" os dados de APO e preferência declarada, o que ocasionou uma demora maior que a prevista nessa fase inicial e, na opinião de P3, pressionou algumas decisões de projeto antes de finalizar o detalhamento da captura de requisitos dos usuários. P1 reforça essa percepção quando considera que a preocupação com custos e atendimentos às regras do programa MCMV foi excessiva e prematura. Para ele tal grau de preocupação sufocou a experimentação de alternativas e desfocou a atenção de outros aspectos importantes do projeto, ligados à eficiência energética. Para P1 algumas especialidades, requisitos e restrições acabaram se sobressaindo em detrimento de melhores soluções. Como visto, a diferenciação entre os processos de captação de requisitos, custeio-meta e projeto se mostrou pouco evidente.

A origem para as dificuldades apontadas por P1 pode ser entendida com base nas respostas das questões seguintes. Ao responder como a equipe de projeto se organizou, P1 e P2 descreveram um desenho semelhante. Nele uma equipe menor, limitada a P1 e mais quatro ou cinco pessoas, reunia-se para trabalhar na elaboração do projeto. Eventualmente, uma reunião maior era convocada para apresentar, avaliar e validar as soluções projetadas. As reuniões maiores contavam com uma série de consultores técnicos e clientes do projeto, que compõem uma rede de apoio à tomada de decisão coordenada pelo coordenador acadêmico (CA) e pelo arquiteto coordenador (AC). Já P3 apresentou outra estrutura que abrangia equipes envolvidas em atividades e temáticas específicas, ligadas a "técnicas construtivas (com C1, C2 e C3), análise de valor (com C4 e C5), projeto da produção (com C6), modelagem de informações (com P1 e AC), eficiência energética (com C7)" (ver Quadro 6 para a identificação das siglas). Para P3 o projeto não ocorreria apenas naquele núcleo de desenho do projeto, mas dependia do trabalho coordenado das demais equipes elencadas. $\mathrm{O}$ que se observou no projeto, contudo, foi uma concentração da responsabilidade das decisões de projeto na figura do arquiteto coordenador $(\mathrm{P} 1)$, decorrente da fragmentação do processo de projeto.

A diferença na interpretação de P1 e P2 da apresentada por P3 explica ainda a divergência ao classificar a coordenação das atividades. Enquanto P1 e P2 a consideraram descentralizada e não sistemática, P3 apontou uma coordenação centralizada, uma vez 
que não "compreendíamos o projeto e atuação de todos como uma unidade". Principal responsável pela captação e hierarquização dos requisitos, P3 não se sentiu participante do projeto e, portanto, do processo decisório. P1 corrobora essa percepção ao comentar que, além dele e de outras duas pessoas, os demais participantes "não se envolviam diretamente no desenvolvimento do projeto", ou seja, a definição dos requisitos do cliente foi tratada como uma condição dada, que compunha o programa de necessidades a ser atendido, sem possibilidade de negociação e gerenciamento dos requisitos.

Quando questionados os entrevistados sobre o grau de comprometimento dos atores envolvidos, a percepção dominante é a de grande comprometimento com o projeto. Contudo, P1 comenta o caráter esporádico da participação de toda a equipe nas reuniões de trabalho, com exceção dele e de outras duas outras pessoas subordinadas a ele. P2 apresentou ressalvas com relação à baixa interação dos demais envolvidos também na atividade de análise de valor, realizada principalmente por P2, P3 e AC. Para ele o pouco envolvimento não se devia à falta de interesse, mas ao acúmulo de outras atividades profissionais e acadêmicas que impediam a participação assídua do restante da equipe nessas reuniões. De fato, durante o processo, AC assumiu um papel na coordenação quando atuou como um apoio ao trabalho de análise de requisitos e custeio-meta realizado pela equipe de análise de valor $(\mathrm{P} 3)$ e promoveu a integração deste trabalho ao processo de projeto. Com relação à integração dos trabalhos dessa equipe ao processo decisório no desenvolvimento de projeto, P3 considera que o envolvimento "deveria ser mais intensivo, para que a troca de informações fosse constante".

Ao falarem especificamente sobre os demais intervenientes, ficou evidente o maior envolvimento de P2 e P3 com consultores, parceiros e fornecedores. Considerando o tempo decorrido, estes relataram lembranças objetivas da cooperação, como o deslocamento do engenheiro da E1 de Curitiba a Londrina para discutir custo e dificuldades de produção sobre soluções técnicas, o auxílio da E2 na decomposição de custos e os diálogos constantes com a equipe da Cohab. Certamente P1 envolveu-se em reuniões semelhantes, mas não tem uma memória clara sobre esses acontecimentos como demonstra ter sobre os processos internos de projeto, o que transparece uma preferência por construir simbolicamente um problema e uma solução intrínseca ao processo de projeto. 
$\mathrm{Na}$ sequência das perguntas, um grupo de questões relacionadas à dificuldade na realização do trabalho foi tratado, iniciando-se por eventuais problemas no ambiente de trabalho. A falta de um "local adequado para se reunir em que as atividades se desenvolvessem de uma maneira mais organizada" (P2) interferiu na clareza (P3), "velocidade e ritmo dos trabalhos" (P1). A segmentação espacial observada nas atividades de projeto, principalmente ligadas ao desenho arquitetônico, prejudicou o "entendimento das pessoas, na comunicação direta" (P2) das alternativas exploradas para o atendimento aos requisitos do cliente e custos decorrentes, atrasando a avaliação, de forma a impossibilitar maior aprofundamento na investigação formal e técnica.

Quanto à percepção das competências envolvidas, P1 e P2 destacaram uma deficiência em lidar com custos durante o projeto, "não como resultante do processo de projeto, mas como uma de suas premissas, para que todas as decisões fossem tomadas, pautadas pelo valor inicial de investimento" (P2). Enquanto P2 credita essa condição a uma deficiência na formação de arquitetura, P3 considera algo inerente à novidade da atividade, que exigiu o desenvolvimento dos conhecimentos e habilidades durante o processo, mas que, com a continuidade das atividades, o mesmo trabalho transcorreria com facilidade.

Com relação aos equipamentos, ferramentas e instrumentos, observou-se tanto a subutilização de equipamentos e ferramentas disponíveis como a adoção experimental e o desenvolvimento de instrumentos como uma ferramenta de APO, aperfeiçoada e adaptada para "captar os requisitos e identificar as prioridades entre esses requisitos", e procedimentos para uso de QFD para a estruturação de requisitos para a tomada de decisões de projeto (P2). Embora seja verdade que a falta de equipamentos de informática tenha dificultado o uso de ferramentas de apoio ao desenvolvimento de projeto, como bem observaram os entrevistados, ocorreram casos excepcionais sempre que alguma pesquisa necessitava de determinada ferramenta. Esses casos bem-sucedidos evidenciam que a não adoção ou o abandono de ferramentas foram determinados principalmente pela eventual falta de esforços no desenvolvimento das competências necessárias para utilizar as ferramentas, ocasionada pela falta de tempo ou de interesse dos envolvidos.

O desinteresse por desenvolver competências em informática se estendeu, inclusive, às plataformas virtuais de trabalho colaborativo, que integram diversas ferramentas de desenvolvimento de projeto, como uma alternativa para a impossibilidade de se 
estruturar ambiente fisico para colaboração direta. Essa estrutura de informática não colaborativa restringiu a interatividade entre a equipe de projeto e a rede de cooperação, composta de consultores, parceiros e fornecedores. Reduzidas as oportunidades de encontro presencial e trocas de e-mail, a participação desses intervenientes foi descontínua e formal.

As condições estruturais apresentadas até aqui pelos entrevistados refletem-se na avaliação deles sobre o processo de projeto, que aponta para dois problemas principais: primeiro, a pouca organização e sistematicidade da equipe de projeto impediu a rastreabilidade das decisões (P1 e P3), normalmente circunscritas às conversações da equipe de desenho; segundo, não havia uma forma de mediação clara e explícita dos conflitos no processo decisório, o que resultava numa subjetividade que inibia a evolução das ideias de projeto (P3 e P2). Ambas as observações decorrem da inadequação organizacional do projeto, em que estrutura de suporte e processo de projeto não são congruentes. Na terceira parte da entrevista, descrita a seguir, os entrevistados foram provocados a refletir sobre a experiência relatada até aquele momento.

\section{Reflexão sobre a experiência de projeto}

Ao serem questionados se mudariam sua conduta na equipe em algum ponto, P1 comentou que "delegaria mais, evitaria centralizar o processo" de projeto e envolveria mais atores da rede de cooperação nas decisões; P2 atuaria mais intensamente na organização do projeto, junto com outros trabalhos da equipe, pois entende hoje que, uma vez amadurecida, essa organização do trabalho serviria para desenvolver outros produtos; P3 “seria mais ativa no desenvolvimento do projeto", embora reconheça que só depois de decorrido o trabalho teve uma noção completa das questões que nortearam o projeto. Diante do contexto apresentado, a conduta centralizadora que P1 reconhece era esperada.

O projeto colaborativo prescinde de uma organização de mediação para a tomada de decisão, e, não havendo, a equipe tende a se auto-organizar de forma hierárquica e concentradora, segundo a responsabilidade específica de cada ator, conforme ocorre nas práticas tradicionais de projeto. Essa barreira organizacional para colaboração se reflete também sobre P3, que se sentiu pouco ativo na elaboração projeto. Por outro lado, P2 identifica a origem organizacional nas dificuldades de colaboração e considera ser 
necessário estruturar o projeto como forma de amadurecer ou aperfeiçoar o processo "para desenvolver outros produtos". Só assim, a complexidade observada por P3 poderia ser reconhecida no início do projeto.

Quando questionados sobre mudanças que sugeririam a outros colaboradores, não obstante uma resistência inicial, todos apontaram questões alinhadas à autocrítica: P1 reconheceu que há uma grande diferença "quando um colaborador se debruça de fato sobre o problema de quando apenas participa de uma reunião maior e faz considerações de imediato". De fato, o primeiro caso evidencia um trabalho colaborativo, o segundo não. Nesse projeto, embora uma das premissas de desenvolvimento e pesquisa tenha sido o projeto colaborativo, sua realização foi incompleta e não sistemática.

Como destacou P3, fora o início do projeto, quando atores das demais equipes do projeto se envolveram no desenho e discussão de propostas concorrentes, todo o trabalho seguinte foi sequencial e concentrado na equipe liderada por P1, da qual não integravam diretamente P2 ou P3. Para P2, na mesma medida em que considera ter sido omisso em provocar as demais equipes do projeto a se envolverem no custeio, faltou à equipe de "projeto também buscar esse trabalho como apoio", porque o projeto se beneficiaria caso toda a equipe ligada ao desenho visse nos dados de custo e requisitos do cliente um respaldo para as decisões. Esse maior envolvimento propiciaria ainda “desenvolver a criatividade do grupo de projeto" (P3).

As definições de projeto pareceram excessivamente predeterminadas para P1, na conformação do terreno hipotético, na técnica construtiva e na tipologia. Em outras palavras, para ele faltou maior autonomia à equipe de desenho para explorar e discutir os termos do problema de projeto. P2 corrigiria a falta de uma conexão direta entre o trabalho de desenho do projeto e o levantamento de dados, que, no caso, foi intermediada pela coordenação. Para P2 o trabalho colaborativo entre ele, P1, P3 e AC em um mesmo espaço físico aumentaria os ganhos para o projeto, permitindo a negociação dos termos e definições de projeto com base no gerenciamento dos dados de requisitos e custos. Essa dinâmica seria acelerada com o desenvolvimento de projetos concorrentes entre equipes, em exercícios projetuais preocupados com um aspecto específico do problema, e assim se estabeleceria um entendimento compartilhado sobre o problema de projeto e os diferentes conhecimentos envolvidos em sua resolução (P3). 
Embora reconheçam a fragilidade da colaboração no projeto, devido ao modo “analógico, individual, limitado" (P1), a crença nas vantagens em adotar essa prática é consensual. Além da colaboração, o gerenciamento de requisitos, o custeio-meta (P2), a modelagem de informação e simulações de eficiência e conforto (P1) são práticas consideradas benéficas para a qualidade do projeto, porém dependem da consolidação de uma organização do processo de projeto diferente da atual, constituída pela cooperação entre escritórios de arquitetura e engenharia. Como os atores envolvidos nas práticas citadas são geralmente arquitetos urbanistas e engenheiros civis, todos são capacitados para se envolverem diretamente no desenvolvimento do projeto (P3).

A ausência de instrumentais adequados para aplicação do custeio-meta nas fases iniciais de projeto do ambiente construído se revela um desafio a ser vencido (P1), para auxiliar a equipe a lidar adequadamente com as restrições de projeto, de requisitos e custos ainda nessas fases. Embora a falta de um instrumental adequado ainda exista, P2 alerta que, para além de softwares, ferramentas e plataformas, "a espinha dorsal é o processo colaborativo, informatizado", associado ao desenvolvimento de pesquisas. De outra forma, não se constrói uma identidade organizacional que reconheça no resultado final, e não nos objetivos particulares a cada subprocesso, o sucesso do projeto (P3).

Profissionalmente cada entrevistado apontou um ganho particular: o trabalho colaborativo tem exigido de P1 “a revisão e mudança de hábitos arraigados”, um esforço recompensado pela "visão mais ampla do problema, a valorização de abordagens sistêmicas e holísticas”. Para P2 a principal mudança aconteceu na ideia do que é ser um profissional criativo: agora, para ele, a "criatividade é, na verdade, a resposta a um problema, e esse problema tem que ser claro, para ser respondido de maneira correta". P3 valoriza o contato mais próximo com novos campos do conhecimento ligados a tecnologias construtivas, gerenciamento, habitação, custos, entre outros, e como esse contato permitiu reconhecer o projeto sob vários pontos de vista.

\subsubsection{Discussão dos resultados da análise comparada das entrevistas}

Com base na confrontação das respostas dos entrevistados observou-se um entendimento compartilhado sobre as expectativas acerca do projeto, porém não sobre as estruturas de conhecimento da equipe, o que prejudicou uma articulação intensa entre os atores. Essa 
não articulação deriva, em parte, da novidade dos temas envolvidos, o que exigiu a capacitação durante o processo de projeto, mas também decorre da fragmentação de processos interdependentes, com a constituição de um grupo de trabalho ligado à gestão do valor, com foco no custeio-meta e nos requisitos de cliente, e de outro grupo, ligado ao desenho do projeto, que coordenou o desenvolvimento de soluções de eficiência energética, tecnologia e produção.

Em razão dessa divisão funcional, a colaboração se limitou, na prática, aos integrantes de cada grupo de trabalho, não havendo fluxo livre de informações ou a corresponsabilidade, por exemplo, entre as soluções de eficiência energética e de gerenciamento de valor. Da forma como ocorreu, a responsabilidade de articulação do conhecimento e, portanto, da tomada de decisão se concentrou na figura do coordenador.

A assincronicidade entre as atividades de concepção, integração e verificação de uma solução retardou todo o processo, inibindo a experimentação formal. A cooperação existente entre o grupo responsável pelo desenho do projeto e o grupo de gestão do valor não ofereceu as condições suficientes de autonomia e de entendimento compartilhado para integrar as práticas de investigação tecnológica, a criação de uma solução arquitetônica e a verificação de desempenho no atendimento aos requisitos de projeto. Ficou claro que o custeio-meta e o gerenciamento de requisitos são atividades colaborativas, instrumentais a um processo decisório iterativo. Caso contrário, os requisitos se tornam uma entrada para a concepção do projeto, e o projeto resultante, uma entrada para o custeio, o que caracteriza um processo sequencial, baseado em entregas ou subprodutos, cujo escopo e prazos precisam ser gerenciados formalmente.

A falta de um ambiente de trabalho adequado, tanto fisico quanto virtual, reforça essa fragmentação organizacional dos domínios de conhecimento disponíveis e do trabalho realizado, o que se reflete na falta de articulação de soluções criativas. Essa fragmentação aumenta desnecessariamente a complexidade da coordenação e exige mais tempo na elaboração de documentações expositivas, como entregas de desenho projetivo e registros de comunicação. A sincronicidade da comunicação, sobre a qual se fundamenta o processo colaborativo, visa corrigir essa lentidão, decorrente de deficiências da comunicação assíncrona, o que exige alto grau de comprometimento e transparência. 
Entretanto, um alto grau de comprometimento dos colaboradores e demais intervenientes, como foi observado pelos entrevistados, sem os meios adequados de comunicação síncrona se mostrou pouco efetivo para explorar o conhecimento disponível, tanto entre os profissionais que cooperavam com o projeto, quanto com as empresas parceiras. Eventos ocasionais de esforço pessoal reforçam essa deficiência estrutural do projeto, que não promovia a interação intensa. A estrutura matricial existente, quando os envolvidos acumulam outras atividades paralelas ao projeto, resultou em conflitos de agenda e interesses. O envolvimento interorganizacional estabeleceu um senso de responsabilidade maior aos projetistas quanto às restrições legais, técnicas e orçamentarias. Esse envolvimento revelou a necessidade de desenvolver novas competências na equipe de projeto.

A falta de condições para compreender e manipular variáveis dos custos foi a mais sentida durante o processo de concepção. Sem a habilidade de manipular iterativamente soluções técnicas e custos ainda nas fases iniciais de projeto, o gerenciamento de valor perde um dos instrumentos fundamentais para avaliar quais atributos de projeto melhor atendem aos requisitos do cliente.

\section{Implicações para a pesquisa}

A experiência observada com o caso do projeto de HIS estudado oferece uma contribuição relativa à discussão geral sobre o processo de projeto no ambiente construído, pois identificou empiricamente as barreiras estruturais à adoção de processos de gerenciamento dos requisitos dos usuários e custeio-meta como subsídios para as decisões do projeto em um contexto de escassez de recursos. Tal dinâmica de processos, que reflete essencialmente o gerenciamento de valor, se faz não apenas presente em um contexto de projetos de habitações de interesse social, mas também abrange a grande maioria dos empreendimentos imobiliários, cujo impacto econômico das demandas socioambientais se mostra um fator cada vez mais relevante para seu sucesso.

Ao constatar a natureza das dificuldades do projeto orientado ao valor ligadas à incompatibilidade de práticas colaborativas com a estrutura organizacional fragmentada e, mais especificamente, com a assincronicidade das atividades de concepção e identificação de atributos que atendem aos requisitos dos clientes, um estudo exploratório complementar foi realizado. 


\subsection{SEGUNDO ESTUDO EXPLORATÓRIO}

O segundo estudo explora o potencial de utilização de plataformas BIM disponíveis, associadas a um ambiente de projeto colaborativo, para promover a integração e o tratamento das informações do projeto orientado ao valor com a rapidez necessária para ser adotado durante as fases iniciais de desenvolvimento do projeto. Para tanto, o pesquisador participou avidamente como membro da equipe de projeto, conforme caracterizado na seção 2.2.2, de forma a aplicar as lições aprendidas com os resultados do primeiro estudo.

Com o presente estudo foi possível acompanhar o gerenciamento de mudanças no processo de projeto, que se assemelhava ao núcleo de atividades ligadas ao processo decisório, circunscrito por uma linha pontilhada na Figura 8. Foi nessa parte do desenvolvimento do projeto em que a dinâmica de gerenciamento de valor se mostrou menos eficaz, tendo exigido o redesenho da proposta da edificação nas etapas seguintes. De fato, observam-se neste estudo dois ciclos do desenvolvimento do projeto, equivalentes ao estudo preliminar e ao anteprojeto da solução arquitetônica. Diferentemente do ocorrido no caso anterior, a adequação da proposta desenvolvida no estudo preliminar ao custo permissivo se confirmou no anteprojeto graças à estratégia de ação acordada e aplicada pela equipe. Essas atividades são descritas a seguir.

\subsubsection{Caracterização das atividades de concepção orientadas ao valor}

O fluxo do processo de projeto predefinido para o projeto da UBS, desenvolvido no workshop, baseou-se no plano de trabalho da Sociedade Americana de Engenharia de Valor (Society American Value Engineering - SAVE), que, em linhas gerais, define as fases de criação e avaliação do valor de uma solução (MORAIS; FABRICIO; RUSCHEL, 2018). A Figura 17 ilustra uma adaptação aproximada do fluxo esquemático apresentado à equipe de projeto, em que algumas mudanças foram inseridas para evidenciar características específicas do processo em questão. Uma das mudanças foi a indicação das atividades efetivamente realizadas pela equipe de projeto por um grupo, delimitada mediante um campo de traços e pontos. Também foi corrigida a diferença observada entre alguns termos do fluxo geral e dos fluxos detalhados. Por exemplo, o termo "fase de apresentação" foi substituído pelo termo "otimizar custos". 
Figura 17 - Processo de projeto baseado no plano de trabalho da SAVE

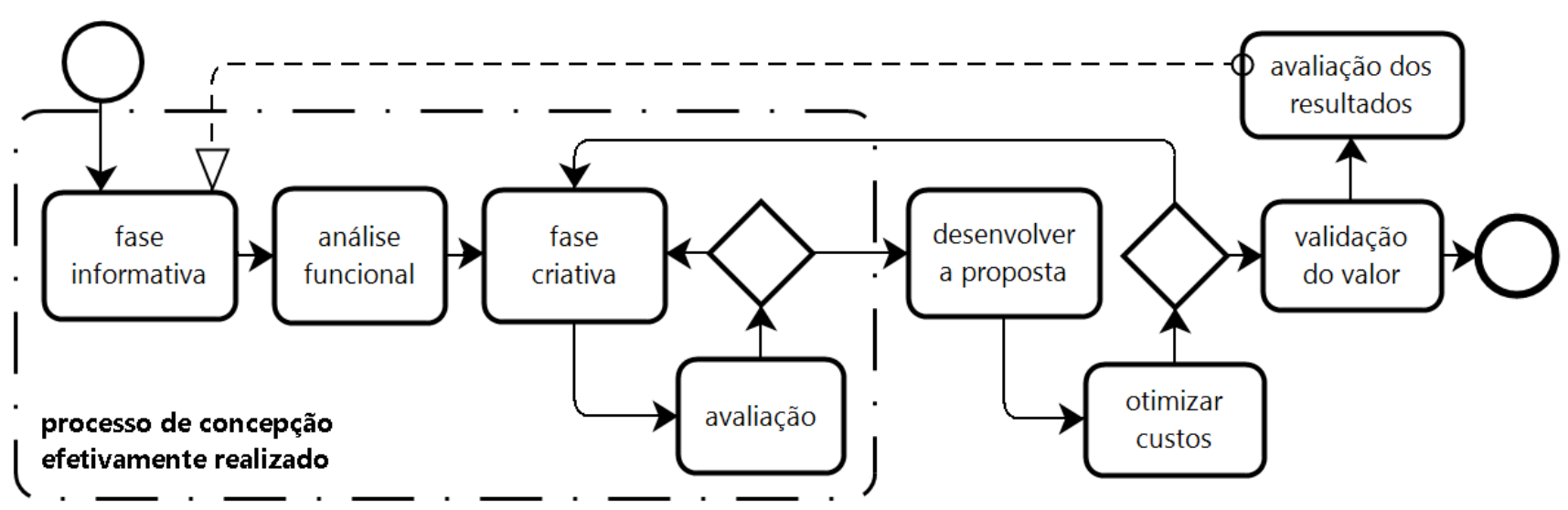

Fonte: adaptada de Save (2018) e Morais, Fabricio e Ruschel (2018).

A principal mudança, contudo, relaciona-se à indicação de uma seta tracejada conectando a "avaliação dos resultados" à "fase informativa". Embora não se adéque à representação do fluxo de processos convencional, a representação da seta indica a retroalimentação das atividades ligadas ao que se denominou "fase informativa" pelas informações e experiência acumulada na "avaliação dos resultados". Tal retroalimentação é sugerida pelo método sobre o qual o processo de projeto se baseia, em que as informações iniciais são capturadas da consulta aos requisitos dos clientes e do levantamento de um caso correlato.

\section{Fase informativa}

A fase informativa, semelhante à fase de "concepção do projeto" apresentada pelo $1^{\circ} \mathrm{EE}$, caracteriza-se pela participação intensa dos clientes do projeto (Figura 18), mais especificamente, de um enfermeiro-chefe, representante dos profissionais de saúde, e de uma arquiteta do departamento de projetos da prefeitura responsável pela UBS de referência. Além disso, a viabilização do projeto envolveu a preparação de um sistema de integração de ferramentas de apoio ao gerenciamento de valor baseado em software BIM e planilhas de cálculo, que permitiu acelerar a realização da análise funcional, a correlação entre custo e função, a Técnica de Mudge e o Gráfico Compare (MORAIS; FABRICIO; RUSCHEL, 2018). 
Figura 18 - Atividades da fase informativa - Segundo estudo exploratório

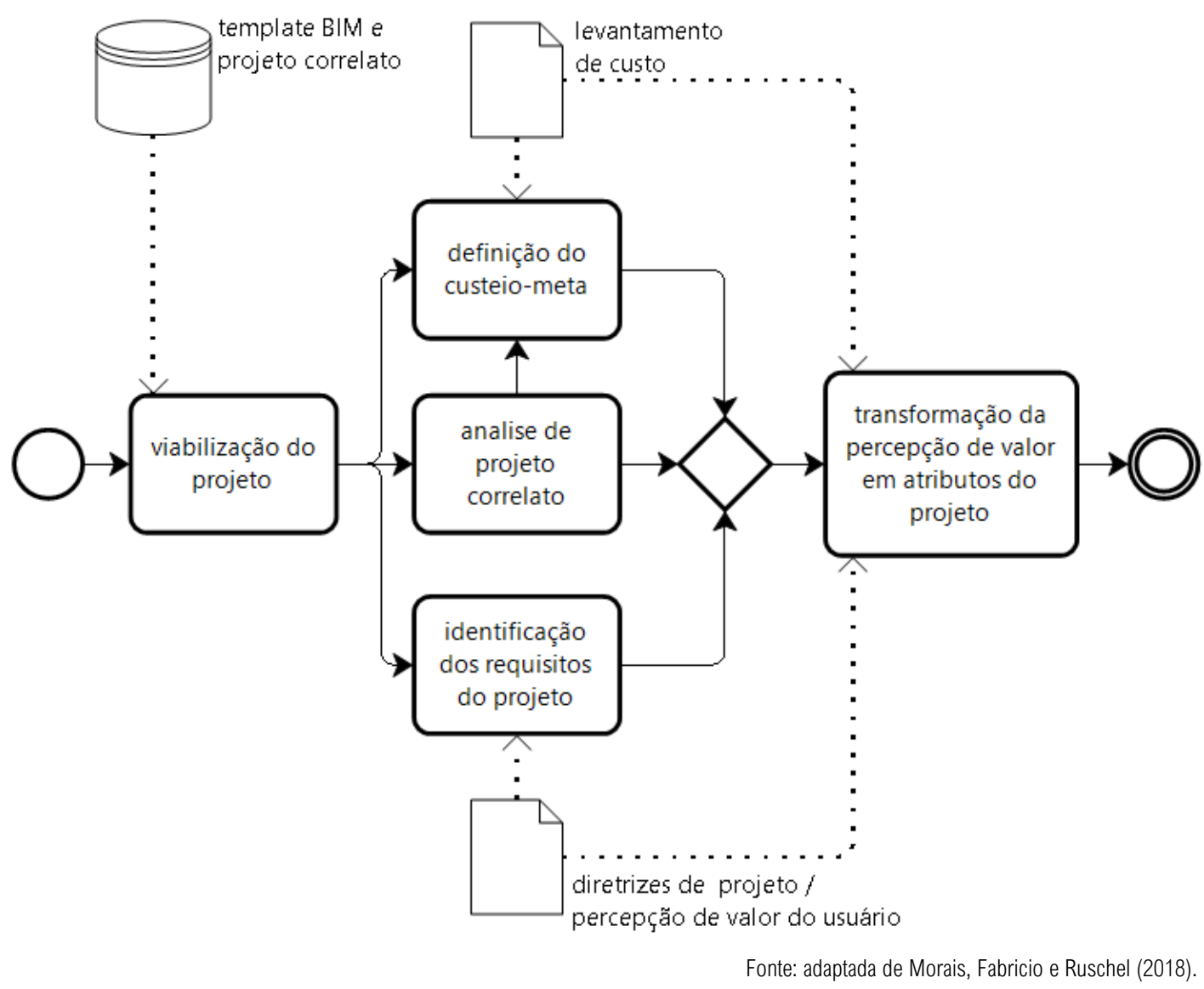

Como já observado, o levantamento de informações sobre o projeto se baseou em dados de um projeto de referência com programa igual à UBS projetada. No caso do custeiometa, o orçamento final da UBS construída forneceu dados consistentes de custo por sistemas. A modelagem das informações de custo foi um dado de entrada para a equipe, já incorporado aos instrumentos de apoio ao gerenciamento de valor utilizado. Outros dados de entrada, extraídos da UBS correlata, foram o programa de ambientes mínimos e a localização.

A captura de requisitos dos clientes não contou com um levantamento sistemático semelhante ao realizado para o $1^{\circ} \mathrm{EE}$, mas foi elencado pela equipe de projeto a partir dos relatos dos clientes participantes. Somaram-se a esses requisitos as diretrizes das normativas de saúde, ligadas à estrutura fisica (MINISTÉRIO DA SAÚDE, 2008), à vigilância sanitária (ANVISA, 2002) e à segurança contra incêndio em estabelecimentos assistenciais de saúde (ANVISA, 2014), entre outros, compondo o que a equipe de projeto chamou de requisitos do projeto. 
Os requisitos do projeto foram interpretados em termos de atributos do produto que potencialmente responderiam ao desempenho esperado. Esses atributos potenciais são o equivalente ao partido tecnológico do $1^{\circ} \mathrm{EE}$ e correspondem a um exercício de antecipação dos atributos funcionais definidos com a solução no nível dos sistemas.

\section{Análise funcional}

A análise funcional (Figura 19) envolve as atividades de decomposição do produto em funções, de classificação destas como funções básicas, necessárias ou secundárias (DELL'ISOLA, 1997; MORAIS; GRANJA; RUSCHEL, 2015). Essas relações funcionais são então hierarquizadas em razão de sua importância para o atendimento aos requisitos do projeto e relacionadas aos custeios-meta associados aos sistemas construtivos previstos na edificação, em um gráfico de comparação (RUIZ, 2011; MORAIS, 2016).

Figura 19 - Atividades da análise funcional - Segundo estudo exploratório

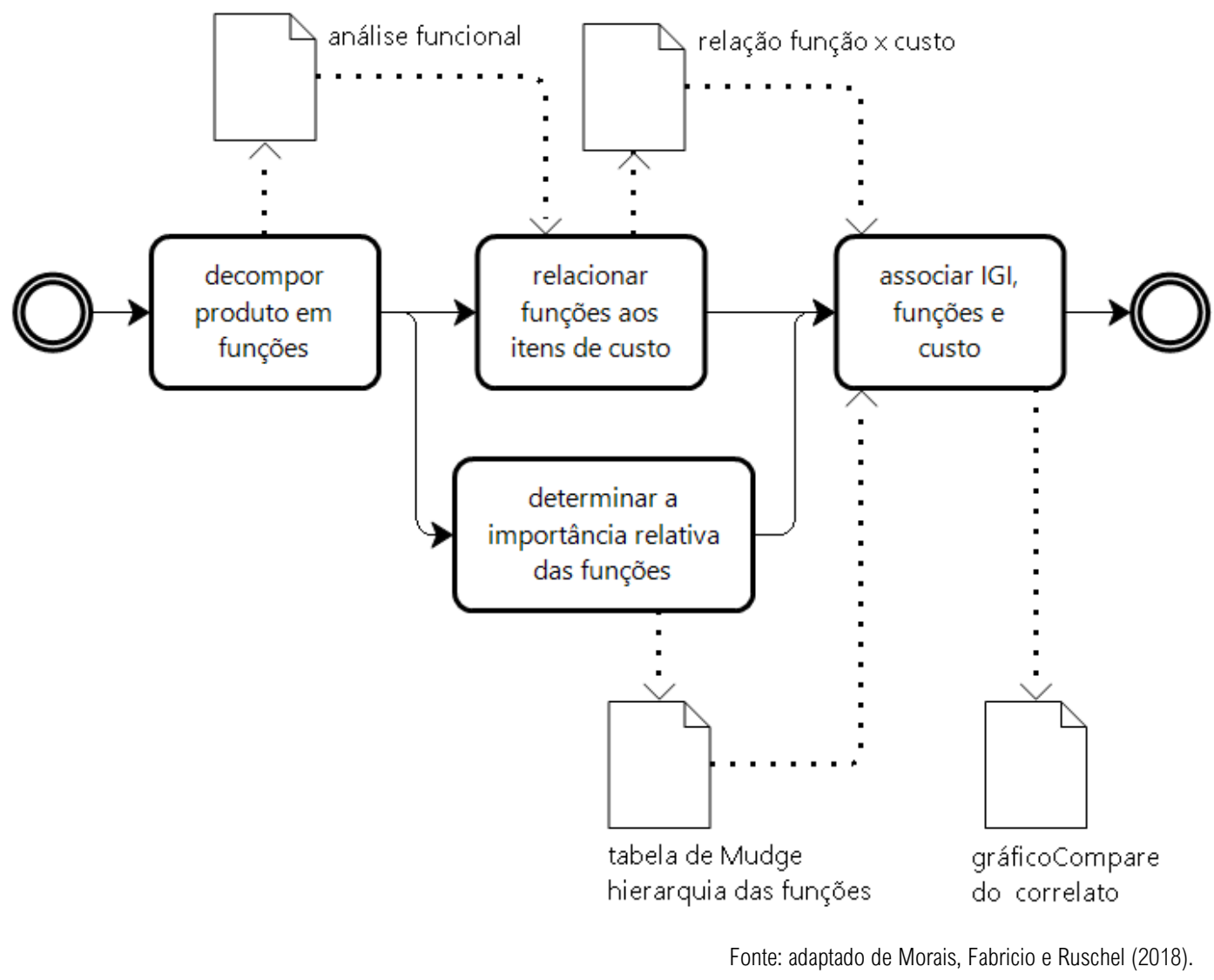


Na prática, a análise funcional do projeto foi realizada com a revisão da análise existente da UBS de referência. A equipe revisou a decomposição funcional existente, tendo alterado a classificação entre funções básicas, necessárias ou secundárias nos casos em que a função ganhava outro significado em decorrência dos atributos do produto predefinidos pela equipe na fase anterior.

Contudo, as mudanças com maior impacto sobre o resultado da análise foram realizadas na aplicação da Técnica de Mudge para identificar a importância das funções da UBS no atendimento dos requisitos do projeto (as mudanças foram indicadas em vermelho no Quadro 19). Os valores alterados implicaram uma mudança substancial entre a importância relativa ${ }^{2}$ dos sistemas observada na UBS de referência e a desenvolvida para a proposta (Figura 20).

Figura 20 - Diferença entre importância relativa da referência e do projeto

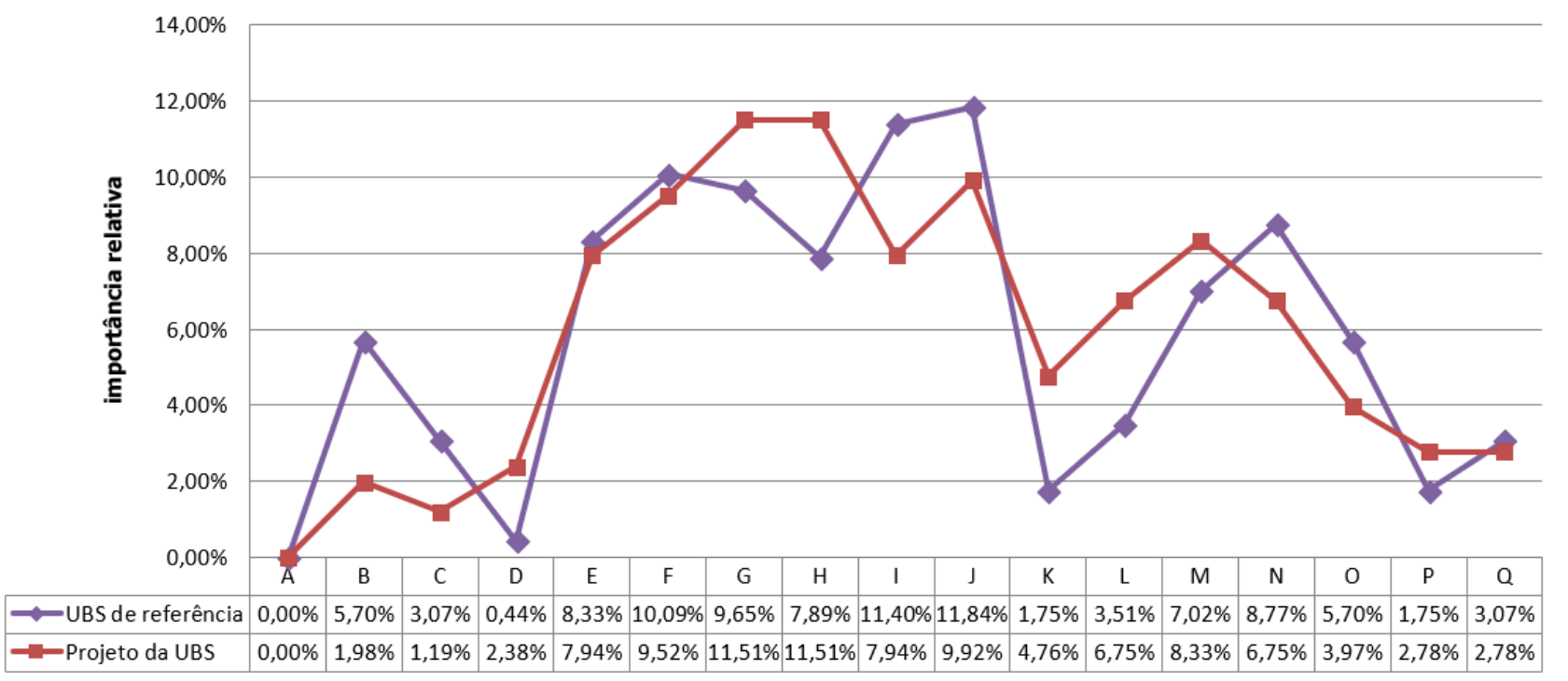

As diferenças mais expressivas entre as importâncias relativas foram observadas na redução dos pesos da fundação, das vigas e pilares e do sistema de cobertura (respectivamente funções B, C e I da Figura 20), e no aumento dos pesos de revestimentos internos, instalações elétricas, esquadrias e sistemas de ventilação (funções G, H, K, L e M da Figura 20).

\footnotetext{
20 termo "importância relativa" foi utilizado em substituição ao termo "necessidade relativa" para adequar a descrição à discussão geral da pesquisa.
} 


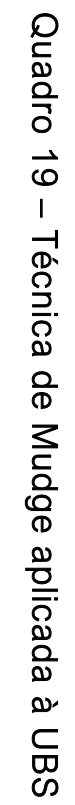
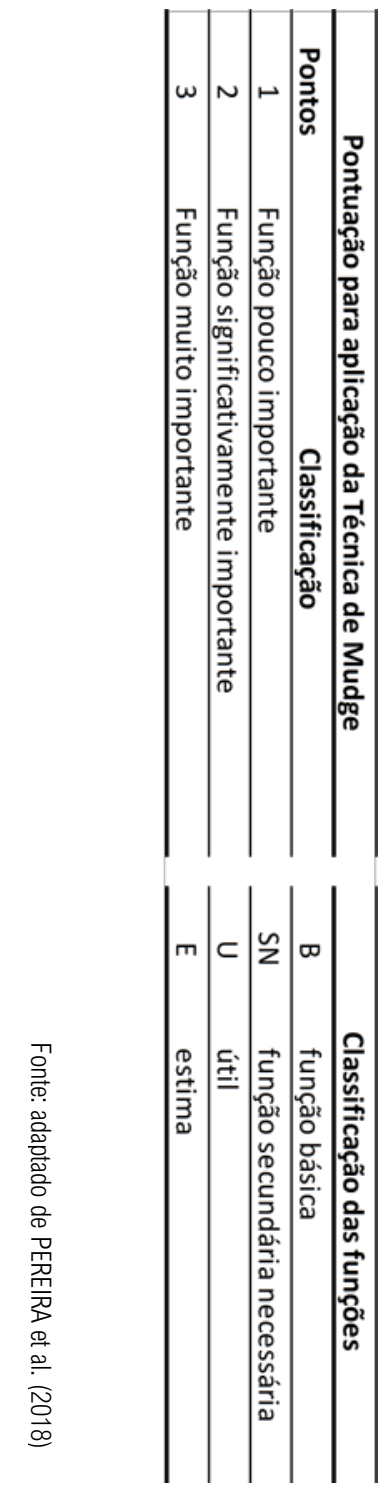
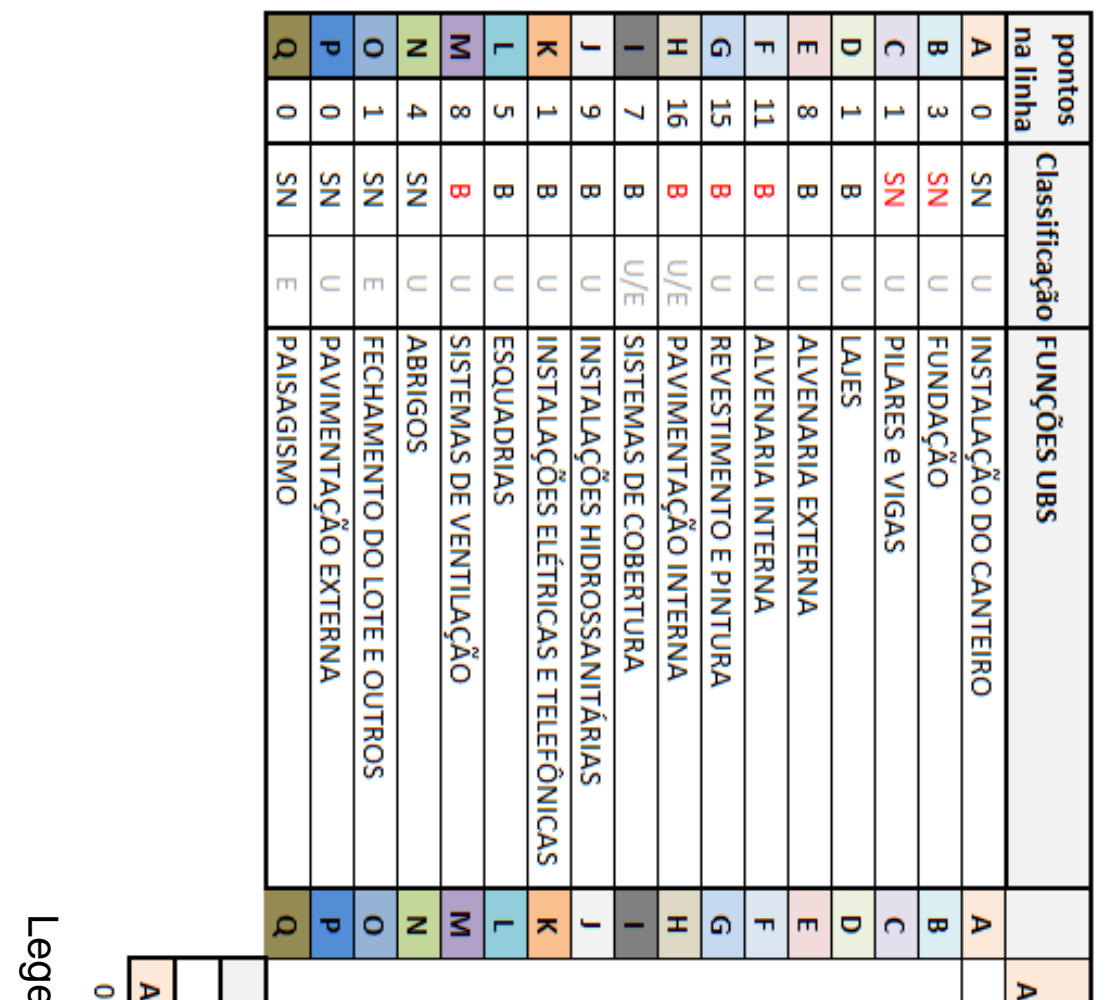

을

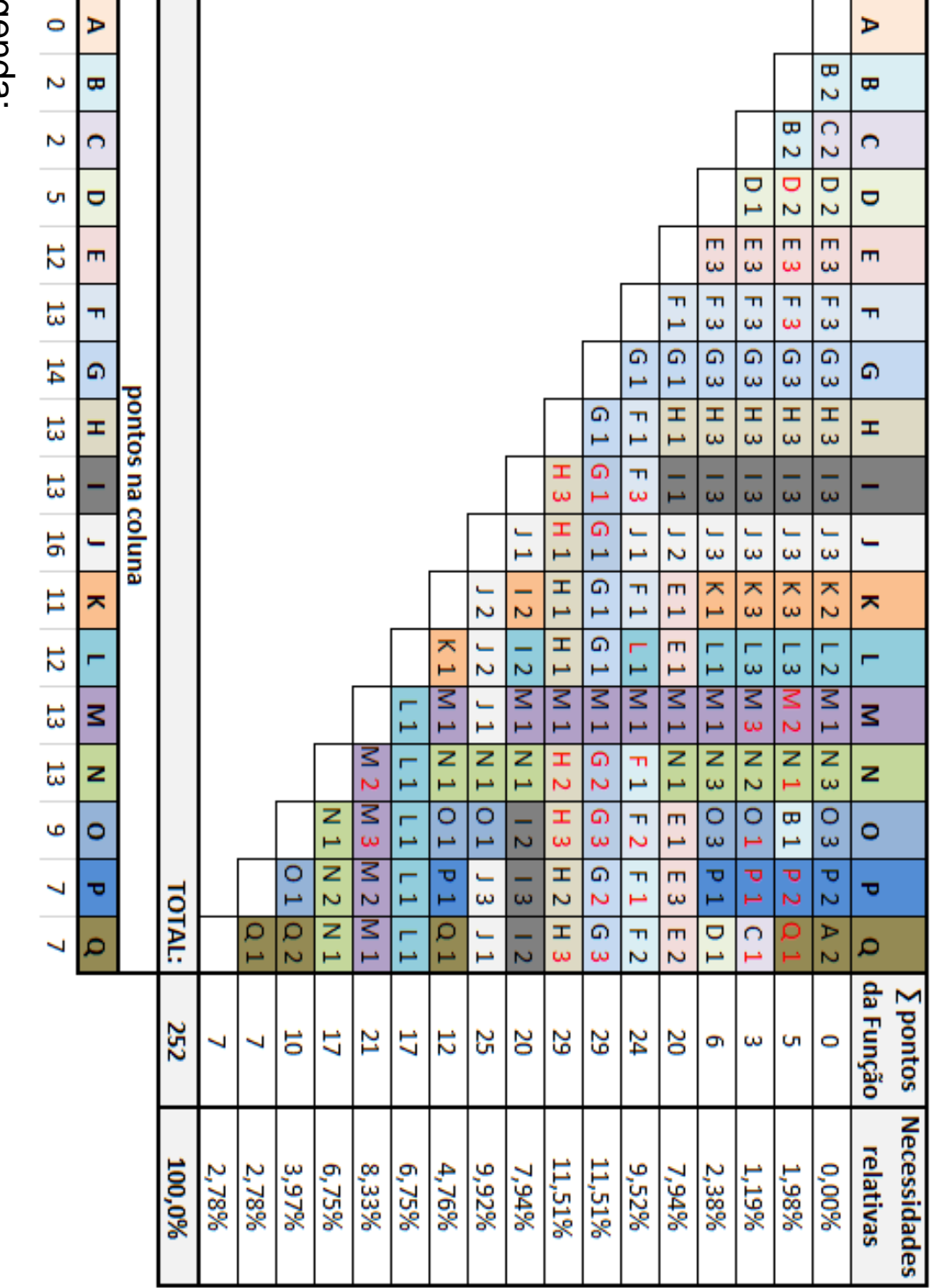


Tais mudanças foram realizadas pela equipe por entender que a valoração das funções deveria focar o atendimento dos requisitos do projeto, que estabelecem as expectativas a serem atendidas. A garantia de não apresentar defeitos associados, por exemplo, a uma fundação realizada adequadamente, não deveria ser considerada nessa análise, uma vez que o funcionamento dos sistemas é uma condição de uso, e não um valor agregado.

O índice de importância relativa das funções foi então comparado com o consumo relativo do custeio-meta da UBS de referência (Figura 21). Como não houve suporte para a negociação com a cadeia de suprimentos visando a soluções conjuntas que permitissem aproximar os custos relativos da importância relativa de cada função, o custeio-meta para o projeto foi definido como equivalente ao custo de referência.

Figura 21 - Consumo relativo de referência versus importância relativa

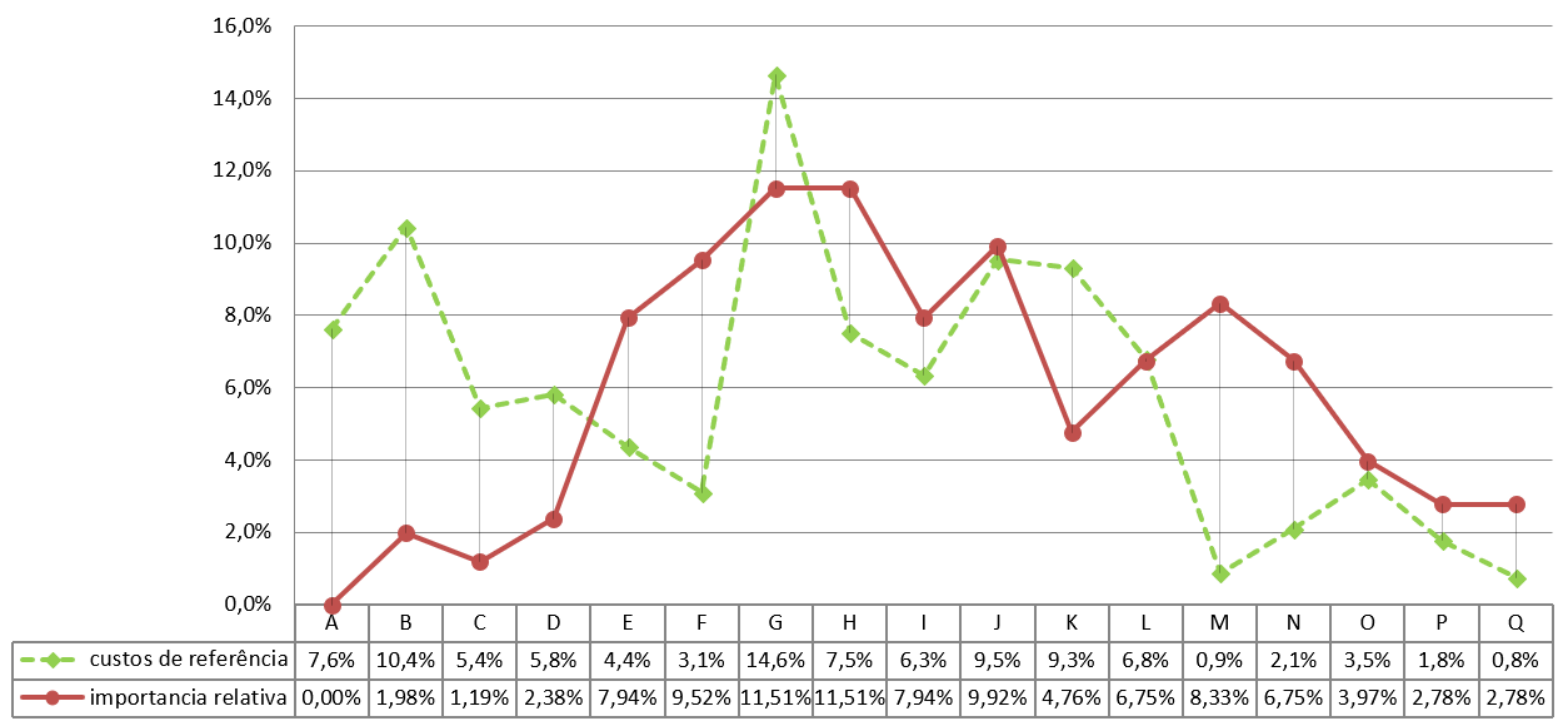

Sem o gerenciamento da cadeia de suprimentos, parte importante do custeio-meta não pode ser realizado para o estudo em questão, o que reduziu o potencial de ganho de valor possível ao condicionar a concepção da arquitetura apenas à utilização dos recursos disponíveis nas condições de execução e aquisição de mercado.

\section{Fase criativa}

Diante do desafio de melhoria na relação custo-beneficio representada no gráfico Compare inicial por meio das diferenças nas linhas de máximo e mínimo observadas entre a importância e o custo relativos de cada função (Figura 21), a equipe de projeto 
rediscutiu os atributos funcionais predefinidos, agora com o objetivo de propor “diretrizes para novas soluções” formais da UBS (Figura 22).

$\mathrm{Na}$ prática, o gerenciamento de atributos funcionais e a concepção da arquitetura ocorreram desde a fase de análise funcional (Figura 26). Tal simultaneidade foi reconhecida pela equipe de projeto e adotada como estratégia de atuação. As mudanças de peso realizadas durante a aplicação da Técnica de Mudge foram acompanhadas de estudos preliminares concorrentes, que respondiam circunstancialmente a um ou mais requisitos dos clientes (Figura 23).

Assim, por exemplo, a alocação de recursos para cobertura foi condicionada ao requisito de conforto, que se refletiu formalmente na opção por beirais que sombreavam as paredes, em vez de platibanda, e uso de telhas do tipo sanduiche, que, embora mais cara, exigem pouca estrutura. Como consequência, parte substancial do custo da cobertura ligado a calhas, platibanda e estrutura foi realocada para a aquisição dessa telha e sua estrutura, aumentando o desempenho térmico do edifício (Figura 24).

A opção por utilizar blocos estruturais para a execução de paredes, inicialmente proposta para reduzir a diferença entre o custo do sistema de pilares e vigas e de sua importância relativa, foi reavaliada em decorrência da decisão por sombrear as paredes com a cobertura para reduzir a insolação. Com as paredes menos expostas às intempéries, a exigência de proteção externa reduziu-se. A equipe então decidiu apenas impermeabilizar e pintar as paredes externas com tinta hidrofugante, incorporando a estética dos blocos aparentes como partido estético (Figura 24). Além disso, parte dos recursos economizados foi realocada para instalar revestimentos e acabamentos internos de maior qualidade.

A equipe de projeto observou no decorrer do processo de concepção que alguns atributos funcionais não associados diretamente a um sistema construtivo eram subrepresentados na análise de valor da forma como realizada. Por exemplo, a proposição de um pátio interno aumentou a possibilidade de iluminação e de ventilação cruzada, ou, ainda, a articulação dos fluxos e acessos livres e restritos, dois eixos de expansão e setorização dos serviços de saúde (Figura 25). Como foram decisões que não impactaram diretamente sobre os custos de um sistema, não tiveram a importância relativa mensurada na análise funcional, apesar de contribuírem para a flexibilidade de uma construção cujo programa está sujeito a constantes mudanças (GÓES, 2011). 
Figura 22 - Painel com as diretrizes para novas soluções

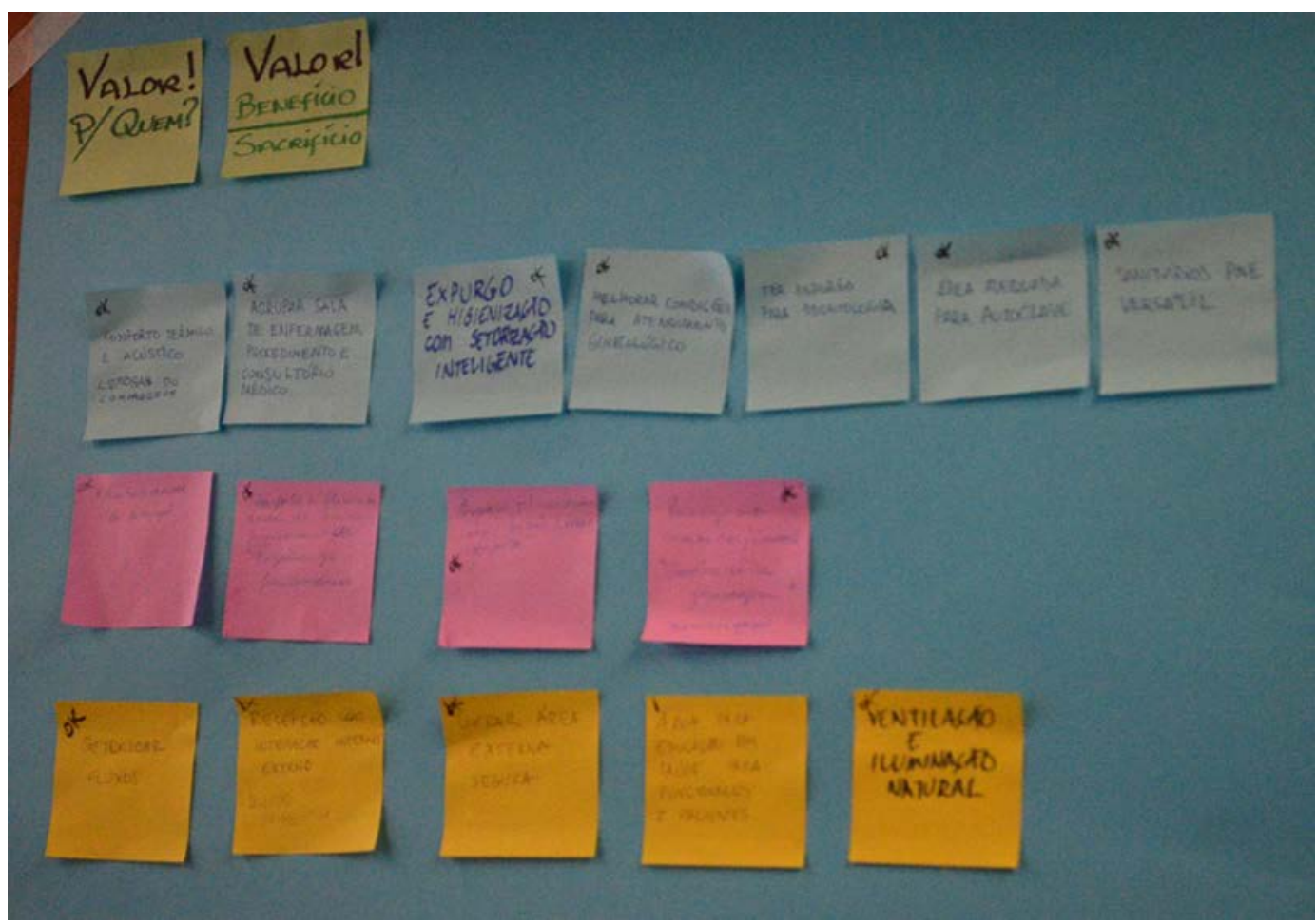

Fonte: Imagem do acervo da equipe

Figura 23 - Croqui de estudos preliminares realizado em mesa digital

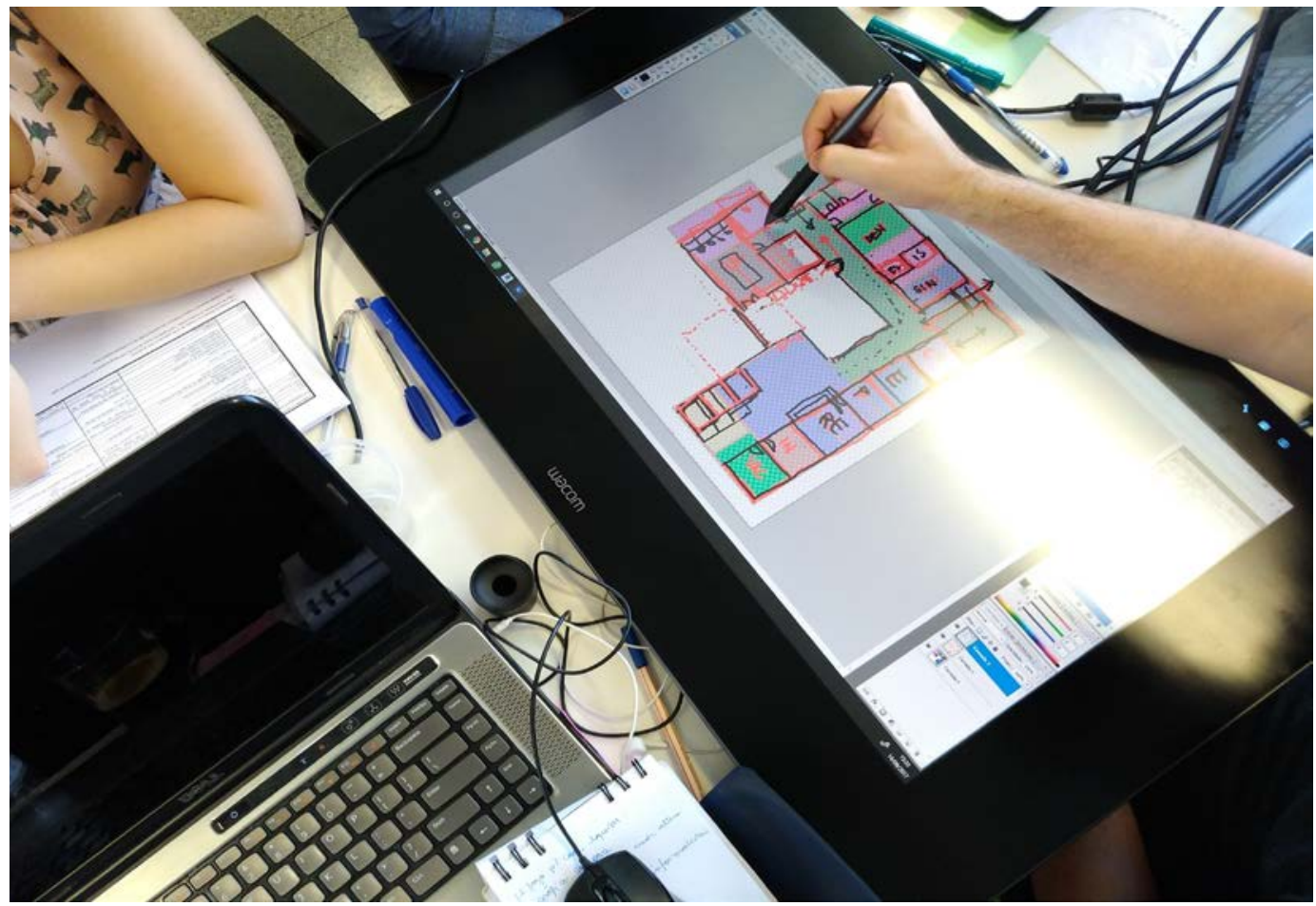

Fonte: Imagem do acervo da equipe. 
Figura 26 - Atividades da fase criativa - Segundo estudo exploratório
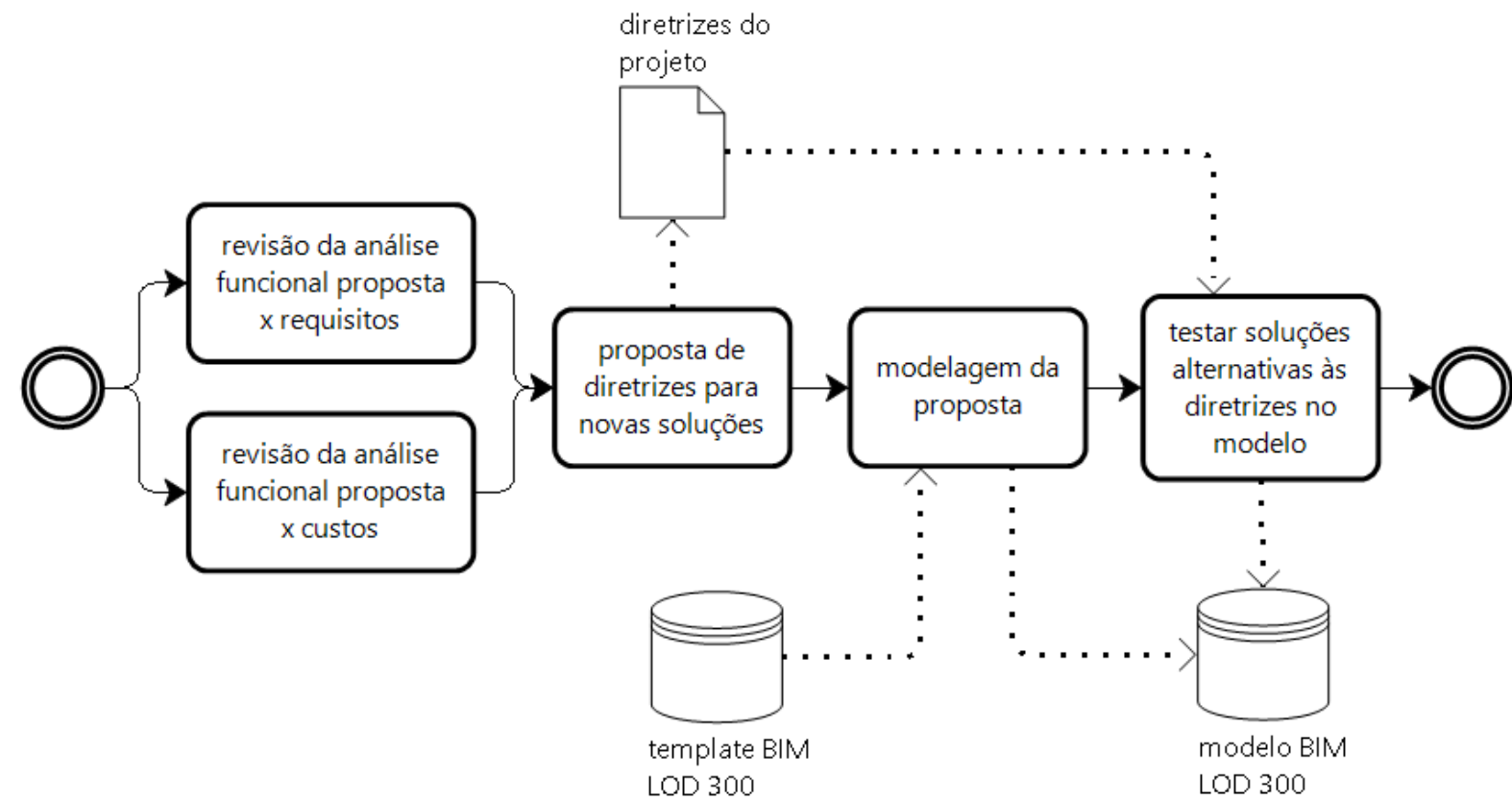

Fonte: adaptada de Morais, Fabricio e Ruschel (2018).

Sem antecipar a discussão sobre soluções possíveis, tais atributos não vinculados pela análise funcional seriam desfavorecidos pelo foco dado às funções previstas. Embora a equipe não tenha adicionado funções à análise para não descaracterizar a proposta do exercício, ficou claro que a eficácia da análise seria maior caso o gerenciamento dos itens, e não apenas o peso dos atributos funcionais, fosse instrumentalizado para ser realizado rapidamente, durante a iteração da análise e concepção. Diante dessa constatação, um integrante da equipe, especializado em custeio-meta, destacou que uma matriz da qualidade, como a utilizada no $1^{\circ} \mathrm{EE}$, ofereceria suporte para estabelecer essa relação indireta entre requisitos do projeto e atributos funcionais.

\section{Fase de avaliação}

As atividades de avaliação da concepção ocorrem quando um conjunto de soluções concorrentes é desenvolvido em resposta aos requisitos do projeto. A comparação entre essas soluções ocorre por meio da variação entre os itens de importância relativa e o consumo de recursos de cada possibilidade (MORAIS; FABRICIO; RUSCHEL, 2018). Para tanto, cada solução tem os custos de produção de seus componentes quantificados. Esses custos são então associados aos atributos funcionais e à importância relativa correspondente (Figura 27). 
Figura 27 - Atividades da fase de avaliação - Segundo estudo exploratório

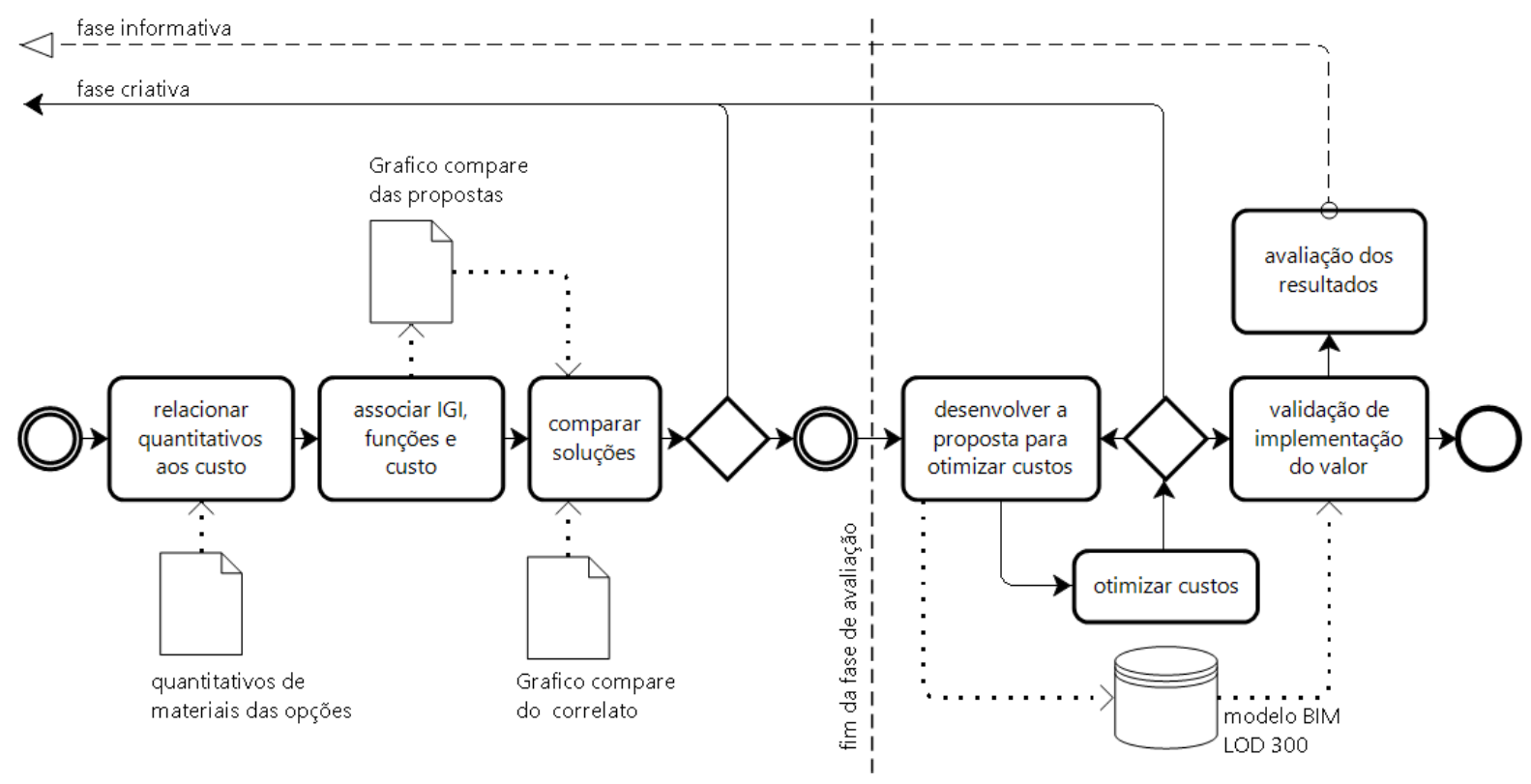

Fonte: adaptada de Morais, Fabricio e Ruschel (2018).

Assim como ocorreu com a análise funcional, a avaliação e a concepção das propostas concorrentes obtiveram melhor desempenho quando realizadas de forma paralela e iterativa, compreendidas não como fases, mas como atividades interdependentes do processo de concepção do projeto. A partir desse entendimento, a equipe pôde gerenciar o processo decisório, tendo reduzido o tempo entre as atividades de investigação e experimentação de soluções e de avaliação da aproximação do custo à importância relativa de cada função e da redução dos custos totais (Figura 28).

Figura 28 - Gráfico Compare da proposta de UBS

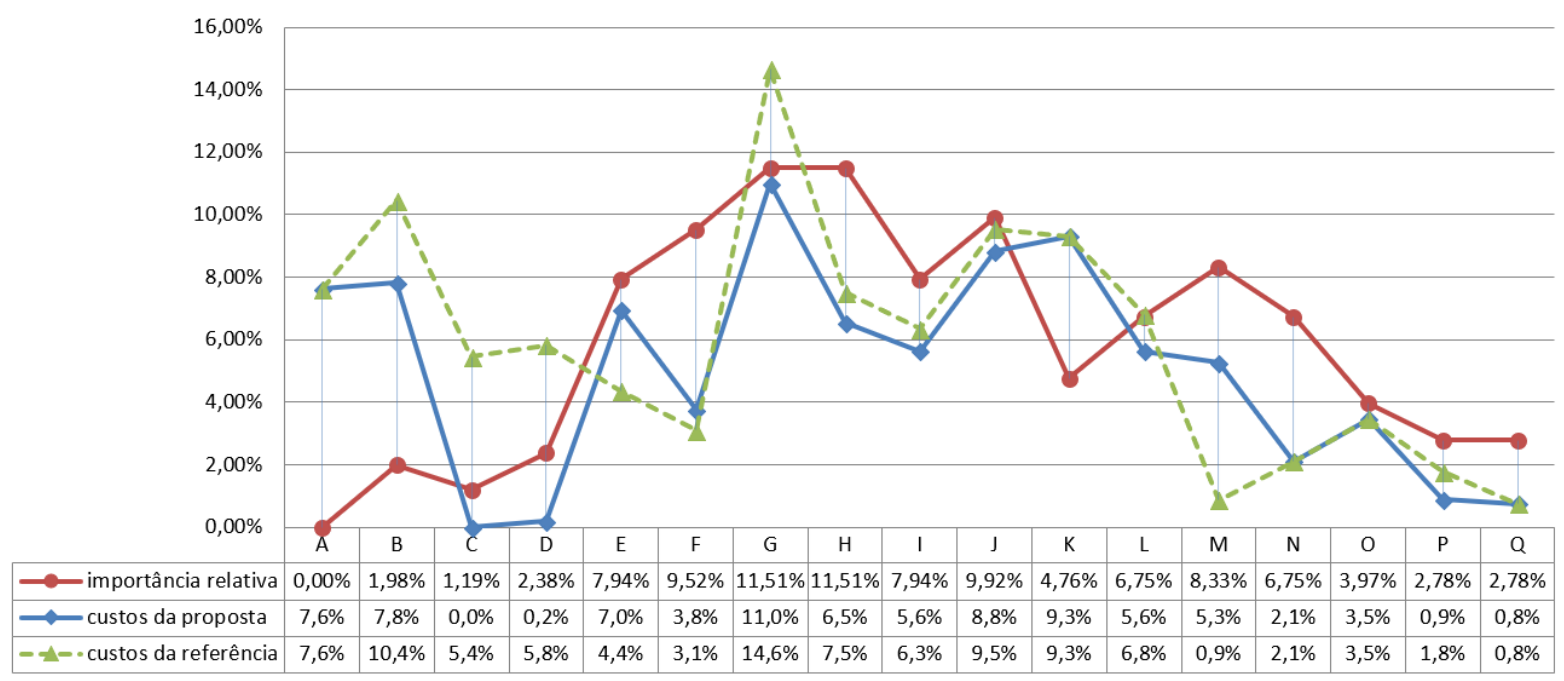




\begin{tabular}{|c|c|c|c|c|c|c|c|}
\hline \multicolumn{3}{|c|}{ Atributos funcionais dos sistemas da UBS } & \multirow{2}{*}{ 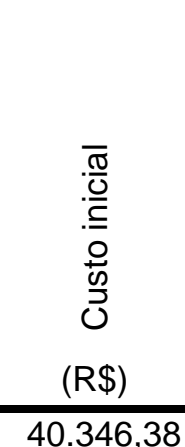 } & \multirow{2}{*}{ 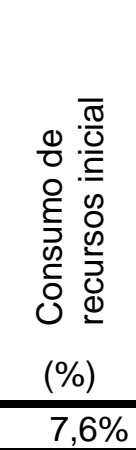 } & \multirow{2}{*}{$\begin{array}{c}\frac{\pi}{\omega} \\
0 \\
\frac{0}{0} \\
\frac{0}{0} \\
\frac{\pi}{0} \\
0 \\
\frac{0}{0} \\
0 \\
(R \$) \\
40.346,38\end{array}$} & \multirow{2}{*}{ 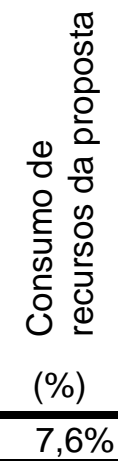 } & \multirow{2}{*}{ 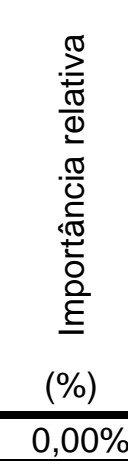 } \\
\hline Serviços preliminares & instalação de canteiro & $A$ & & & & & \\
\hline \multirow{3}{*}{ Superestruturas } & fundação & $\mathrm{B}$ & $55.232,35$ & $10,4 \%$ & $41.369,19$ & $7,8 \%$ & $1,98 \%$ \\
\hline & pilares e vigas & $\mathrm{C}$ & $28.810,94$ & $5,4 \%$ & - & $0,0 \%$ & $1,19 \%$ \\
\hline & lajes & $\mathrm{D}$ & $30.827,50$ & $5,8 \%$ & $1.060,00$ & $0,2 \%$ & $2,38 \%$ \\
\hline \multirow{2}{*}{ Paredes e painéis } & alvenaria externa & $\mathrm{E}$ & $23.073,31$ & $4,4 \%$ & $36.778,53$ & $7,0 \%$ & $7,94 \%$ \\
\hline & alvenaria interna & $\mathrm{F}$ & $16.424,07$ & $3,1 \%$ & $19.895,49$ & $3,8 \%$ & $9,52 \%$ \\
\hline \multirow{2}{*}{ Revestimentos } & revestimento e pintura & G & $77.442,21$ & $14,6 \%$ & $58.182,12$ & $11,0 \%$ & $11,51 \%$ \\
\hline & pavimentação interna & $\mathrm{H}$ & $39.734,68$ & $7,5 \%$ & $34.604,49$ & $6,5 \%$ & $11,51 \%$ \\
\hline Cobertura & telhamento, estrutura, etc. & 1 & $33.570,29$ & $6,3 \%$ & $29.741,41$ & $5,6 \%$ & $7,94 \%$ \\
\hline \multirow{2}{*}{ Sistemas MEP } & instalações hidrossanitárias & $\mathrm{J}$ & $50.484,19$ & $9,5 \%$ & $46.665,72$ & $8,8 \%$ & $9,92 \%$ \\
\hline & inst. elétricas e telemáticas & $\mathrm{K}$ & $49.278,85$ & $9,3 \%$ & $49.278,85$ & $9,3 \%$ & $4,76 \%$ \\
\hline \multirow{2}{*}{$\begin{array}{l}\text { Aberturas e } \\
\text { fechamento }\end{array}$} & esquadrias & $\mathrm{L}$ & $36.022,16$ & $6,8 \%$ & $29.745,68$ & $5,6 \%$ & $6,75 \%$ \\
\hline & sistemas de ventilação & M & $4.584,72$ & $0,9 \%$ & $27.800,06$ & $5,3 \%$ & $8,33 \%$ \\
\hline Instalações especiais & equipamento e resíduos & $\mathrm{N}$ & $11.119,76$ & $2,1 \%$ & $11.119,76$ & $2,1 \%$ & $6,75 \%$ \\
\hline \multirow{2}{*}{$\begin{array}{l}\text { Serviços } \\
\text { complementares }\end{array}$} & fechamento do lote e outros & $\mathrm{O}$ & $18.334,80$ & $3,5 \%$ & $18.334,80$ & $3,5 \%$ & $3,97 \%$ \\
\hline & pavimentação externa & $P$ & $9.413,49$ & $1,8 \%$ & $4.660,10$ & $0,9 \%$ & $2,78 \%$ \\
\hline \multirow[t]{2}{*}{ Paisagismo } & jardins, canteiros, etc. & Q & $4.025,38$ & $0,8 \%$ & $4.025,38$ & $0,8 \%$ & $2,78 \%$ \\
\hline & TOTAIS & & $528.725,09$ & $100,0 \%$ & $453.607,97$ & $85,8 \%$ & $100,0 \%$ \\
\hline
\end{tabular}

custeio-meta $\mathcal{Y}$ recursos alocados na concepção

A concepção avançou até o nível de anteprojeto, com especificações técnicas suficientes para realizar um orçamento completo. O preço calculado para o projeto da UBS foi de $\mathrm{R} \$ 453.607,97$, uma economia de $\mathrm{R} \$ 75.117,11$ em relação ao custeio-meta, de $\mathrm{R} \$$ 528.725,09 (Quadro 20). A economia foi conquistada por trabalho de investigação e experimentação de alternativas espaciais e construtivas, que impactaram principalmente na redução do custo de fundação e na eliminação de gastos com pilares e vigas de concreto in loco, e na adequação dos gastos à importância relativa dos revestimentos e pinturas, graças à economia com reboco externo (respectivamente os itens B, C e G da Figura 28). 
A adoção de sistema de blocos estruturais, além de eliminar os gastos em C, também equiparou os gastos da alvenaria externa com sua importância. Outro incremento de gastos, ligado aos sistemas de ventilação, ainda apresentava um saldo positivo com a importância relativa de sua função, a quinta mais relevante para os requisitos dos clientes (respectivamente os itens E e $M$ da Figura 28). Cabe notar que algumas funções não foram plenamente resolvidas na fase de concepção descritas até aqui. Trata-se de uma medida consciente, decorrente da estratégia de atuação adotada no início do projeto, em que algumas decisões foram postergadas para a fase de desenvolvimento do detalhamento e negociação com fornecedores e parceiros, em que se obteve benefício dessa iteração.

Foi para viabilizar o desenvolvimento iterativo do detalhamento do projeto com o gerenciamento da cadeia de suprimentos que o gerenciamento do processo decisório realizado durante a concepção da UBS buscou alocar menos recursos que o total disponibilizado pelo custeio-meta (Quadro 20), reservando parte desses recursos para ser alocados posteriormente, de forma a oferecer uma margem suficiente para negociar melhoras de custos e desempenho, bem como gerenciar os riscos decorrentes de variação das condições de aquisição de materiais, equipamentos e serviços de execução.

\subsubsection{Análise da prática reflexiva}

A definição de uma estratégia de atuação por parte da equipe de projeto, diferentemente daquela sugerida pelo padrão de processo empregado no workshop, foi motivada por uma postura reflexiva fomentada pelo pesquisador (ver seção 2.2.2).

Ainda no início do trabalho, em conversa da equipe sobre o modelo de processo para aquele projeto, o pesquisador questionou sobre a conveniência de tratar o gerenciamento de valor e o desenvolvimento do projeto como fases e funções distintas. A equipe formada por quatro integrantes contava com dois profissionais que já haviam participado de um ou mais processos de projeto orientados por gerenciamento de valor, incluindo o processo abordado no $1^{\circ}$ EE. Assim, a experiência adquirida com o projeto relatado no $1^{\circ}$ EE pôde ser apresentada e debatida com propriedade.

A equipe concordou em discutir e implementar mudanças no processo de projeto. Assim, a primeira medida foi adotada após um impasse diante da definição dos atributos funcionais e de suas importâncias relativas. A equipe decidiu então intercalar movimentos de investigação de tecnologia e experimentação formal para compreender 
como a relação entre atributos funcionais e a importância ocorriam de fato. A equipe constatou que essa iniciativa reduziu significativamente a incerteza quanto a que importância conferir aos atributos funcionais.

O que a equipe observou depois, durante a avaliação da concepção, foi que, caso a definição e a valoração dos atributos funcionais se restringissem à análise das relações preexistentes no caso correlato, o potencial para criar valor com a concepção se restringiria à promoção de melhorias incrementais a uma arquitetura existente. Por outro lado, o desenvolvimento iterativo da definição e valoração dos atributos baseados em propostas concorrentes e preliminares tornou todo o processo mais eficiente e direcionado, ao antecipar soluções provisórias para os requisitos dos clientes, que seriam posteriormente rediscutidas e combinadas em uma nova arquitetura.

Durante a análise funcional, as discussões sobre quais eram os atributos funcionais de cada solução e como eles atendiam aos requisitos dos clientes permitiram a combinação e a evolução de soluções integradas para conjuntos de requisitos. $\mathrm{Na}$ ocasião em que o custeio-meta foi estabelecido com base no custo de construção da UBS de referência, o pesquisador observou que, caso houvesse suporte para o gerenciamento da cadeia de suprimentos, a evolução iterativa da concepção durante a análise funcional ajudaria a atividade de custeio-meta a direcionar e diversificar a negociação de parcerias para o empreendimento.

Parte das atividades associadas à fase criativa já estava avançada, permitindo que a equipe se concentrasse na modelagem das soluções para confirmar se os custos levantados se confirmavam. Nesse ponto, foi possível identificar quais especificações poderiam ser definidas com segurança e quais dependeriam de um detalhamento desenvolvido iterativamente com o gerenciamento da cadeia de suprimentos, aproximando-se mais do conceito original de custeio-meta.

Ao analisar a experiência de prática reflexiva vivenciada pela equipe de projeto, é possível destacar uma característica comum entre as várias mudanças realizadas para melhorar a eficiência e eficácia do projeto, relacionadas à interdependência observada entre a análise funcional, a concepção de projeto e sua avaliação. Nesse sentido o movimento principal da equipe foi o de integrar essas atividades em um único processo, mudando o enfoque funcional, em que as responsabilidades e entregas de subprodutos são bem definidas, por um enfoque baseado em competências e colaboração. 


\section{ARQUITETURA DO PROCESSO DE PROJETO ORIENTADO AO VALOR}

A análise possível de ser realizada com os dois estudos exploratórios, somados à teoria consultada, ofereceu as bases para a elaboração de uma arquitetura do processo de projeto orientado ao valor. Para tanto, os casos estudados no capítulo 3 foram revisitados, agora com o objetivo de mapear o fluxo de atividades coerentes ao gerenciamento de valor aplicado em projetos de empreendimentos imobiliários.

A diagramação do fluxo do processo de projeto do primeiro estudo foi adotada como ponto de partida para a proposição do artefato. Após descrever as características desse processo de projeto, as críticas realizadas na análise da influência organizacional, relatadas na seção 4.1, foram recuperadas para justificar a proposição de mudanças no processo de projeto. A escolha desse caso como partido arquitetônico da proposição se sustenta pela maior abrangência e proximidade das condições reais de implementação do gerenciamento de valor no processo de projeto de empreendimentos imobiliários.

O segundo estudo exploratório, embora tenha como foco as atividades de concepção da solução, contribui na medida em que incorporou parte das críticas apontadas no primeiro estudo, avançando empiricamente no refinamento das interações sensíveis entre atividade criativa e gerencial. Assim, após a descrição das mudanças realizadas no processo pela equipe de projeto envolvida, as críticas decorrentes dessa segunda experiência foram incorporadas à construção do artefato.

Por fim, aspectos importantes para a promoção de um processo de projeto orientado ao valor que não foram abordados nem por um nem por outro estudo foram discutidos com base na teoria existente e introduzidos ao artefato. A descrição da arquitetura está separada em seções que abordam as fases tradicionais de projetos sob a perspectiva do gerenciamento de valor, intercalando o aprendizado adquirido com os dois estudos exploratórios. O fluxo orientado ao valor resultante é, assim, resultado da confrontação, combinação e evolução desses estudos e da teoria consultada. 


\subsection{ESTUDO PRELIMINAR}

A discussão feita sobre o $1^{\circ} \mathrm{EE}$ iniciou-se pela diagramação dos fluxos de atividades de projeto e a caracterização desse processo. Em seguida, apresentou-se uma análise das condições de realização do trabalho a partir da comparação entre os conteúdos das respostas dadas por profissionais envolvidos no projeto em entrevistas semiestruturadas. A discussão propriamente dita relacionou as pontuações levantadas com os profissionais ao processo descrito anteriormente, qualificando as condições organizacionais para a realização do trabalho com base na teoria levantada na revisão bibliográfica, com o objetivo de estabelecer orientações para a modelagem de uma arquitetura de processos condizente com o aprendido. Agora, um diagrama unificado das etapas de projeto, representadas separadamente na seção 4.1, foi elaborado para subsidiar a arquitetura do processo de projeto orientado ao valor (Figura 29). Esse diagrama conecta as atividades de viabilidade, estudo preliminar, anteprojeto, projeto executivo, etc., estabelecendo um fluxo contínuo de subprocessos e atividades ligadas ao projeto.

A fase relacionada à concepção do projeto, ou seja, o trabalho de negociação e de construção de um entendimento compartilhado a respeito dos termos de trabalho e dos objetivos do projeto, apresentou características bastante específicas, que não se refletem no diagrama, e por isso a contribuição possível precisa ser contextualizada. $\mathrm{O}$ desdobramento da atividade de identificação das condições de viabilização do projeto em viabilidade mercadológica, programática e institucional se caracterizou por ações de identificação e estruturação de variáveis de projeto e movimentos de negociação dos termos de parceria para colaboração. Uma vez estabelecido um alinhamento entre os objetivos acadêmicos, empresariais e institucionais para o projeto, um conjunto de três subprocessos paralelos perseguiu um entendimento inicial acerca dos contornos de atuação da equipe de projeto, colaboradores e clientes. Esses subprocessos resultaram em um conjunto de requisitos para o desenvolvimento do produto, acordados em reuniões e anteriores ao trabalho de elaboração de um estudo preliminar.

As atividades agrupadas no "ciclo 1" correspondem ao trabalho de elaboração de estudo preliminar, a partir da discriminação dos custos de cada subsistema do partido tecnológico e da análise dos requisitos dos clientes. Como o diagrama mostra, correspondem a um conjunto realizado depois da concepção do projeto. $\mathrm{Na}$ compreensão dos profissionais entrevistados, algumas definições da fase anterior 
restringiram demasiadamente a elaboração dos estudos. Sob outra perspectiva, a elaboração de estudos preliminares concorrentes poderia orientar o processo de negociação na concepção do projeto. Assim, na proposição do fluxo do processo de projeto orientado ao valor (Figura 31), tornam-se paralelas as atividades de negociação de contratos de parceria com a cadeia de suprimentos e o conjunto de atividades atrelado ao estudo preliminar.

A atividade de viabilidade indicada no fluxograma da proposta se restringe à viabilização financeira, que pode ser amparada por dados históricos de projetos anteriores, a exemplo do que ocorreu no $2^{\circ}$ EE. O processo de definição do custeio-meta e dos requisitos do cliente se daria junto com a elaboração do estudo preliminar, iterativamente, até o nível de maturidade necessário para a documentação adequada para aprovação por órgãos reguladores competentes. A aprovação dos clientes diretos, aqueles que têm voz de decisão no processo de concepção do projeto, indicada antes da atividade de documentação do edifício, é uma atividade formal de validação, contudo o cliente tem voz na elaboração do estudo preliminar, por meio da participação na definição dos requisitos do projeto e na análise do atendimento desses requisitos pelo estudo proposto.

A equipe de projeto, por meio da definição do custeio-meta, oferece subsídios para o gerenciamento da cadeia de suprimentos negociar os termos dos acordos de cooperação e de colaboração com as empresas fornecedoras de serviços e produtos da construção. $\mathrm{O}$ paralelismo entre as atividades de gerenciamento da cadeia de suprimentos e o conjunto de atividades do estudo preliminar visa, por um lado, evitar a imobilização de soluções alternativas apontadas pela equipe do $1^{\circ} \mathrm{EE}$ e, por outro, ampliar a relação de custobeneficio do custeio-meta, restrita no $2^{\circ}$ EE à análise da importância dos sistemas ante os custos praticados no mercado.

O modelo de processo proposto favorece a antecipação da consulta técnica e da contratação dos serviços de fornecimento dos principais sistemas construtivos, em regimes de contratação $\mathrm{DB}$ e $\mathrm{IPD}^{3}$, ou seja, de responsabilidade compartilhada do desenvolvimento e execução do projeto. Isso viabiliza uma modelagem de informação

\footnotetext{
${ }^{3}$ Ver definição de contratos do tipo DB e IPD na seção 3.4.2, Regimes contratuais.
} 
ao fim do estudo preliminar em nível de desenvolvimento LOD 200 ${ }^{4}$. Embora esse nível de desenvolvimento seja frequentemente relacionado ao anteprojeto, tal equivalência faz sentido apenas em um contexto de difusão de ferramentas BIM em processos convencionais, em que os ganhos possíveis com a modelagem da informação são reduzidos pela fragmentação do projeto em fases de concepção e análise de custos.

Em um processo de projeto orientado pelo gerenciamento de valor, a definição de custos é parte constituinte da concepção da solução. Assim, o nível de desenvolvimento realizado no anteprojeto do $1^{\circ}$ EE é adiantado para o estudo preliminar, evitando-se decisões sem informações de custo suficientes para estabelecer um custeio-meta coerente e desafiador para cada sistema. A definição das características fundamentais dos serviços ou componentes dos sistemas ainda no estudo preliminar viabiliza a antecipação de acordos comerciais, o que oferece oportunidade de antecipar o planejamento da alocação de recursos e a aquisição de insumos pelas empresas envolvidas.

Desta forma diminuiriam consideravelmente os riscos ligados às especificações técnicas ou orçamentárias inadequadas, como os ocorridos no estudo preliminar do $1^{\circ} \mathrm{EE}$, já que a colaboração de atores das empresas aumentaria a precisão das informações de projeto, por serem baseadas em informações pela cadeia de suprimento, e não em generalizações de práticas de mercado. Além disso, o entendimento construído no estudo preliminar sobre as condições de execução do projeto oferece suporte para orientar a negociação realizada com os colaboradores da cadeia de suprimento no anteprojeto com vistas a melhorar economias e ganhos, consolidados em um projeto executivo orientado para a produção.

\footnotetext{
${ }^{4}$ A sigla LOD é utilizada para abreviar tanto a expressão level of development como level of detail (CIRIBINI, 2013). Ambos os termos são usados de forma equivalente por diferentes guias BIM e correspondem ao nível de desenvolvimento, detalhe, definição ou maturidade de informações da construção que um modelo deve apresentar em cada fase do projeto. A definição de LOD aqui adotada se baseia em AIA e indica numericamente a evolução dos níveis em LOD 100, 200, 300, 400 e 500 (AIA, 2007; GARCIA; MOLLAOGLUKORKMAZ; MILLER, 2014; SOLIHIN, 2015; BIM FORUM, 2018; REZAEI; BULLE; LESAGE, 2019). As discussões acerca da evolução e diferenciação deste e de outros termos ligados à definição de níveis do modelo não são abordadas na tese, pois envolvem questões ligadas a regulações regionais ou definem os níveis, a disputa de mercado de software, etc. Havendo interesse, uma compilação histórica dos termos empregados é apresentada no seguinte link (último acesso em fevereiro de 2019): https://www.bimthinkspace.com/2016/07/the-many-faces-of-lod.html.
} 


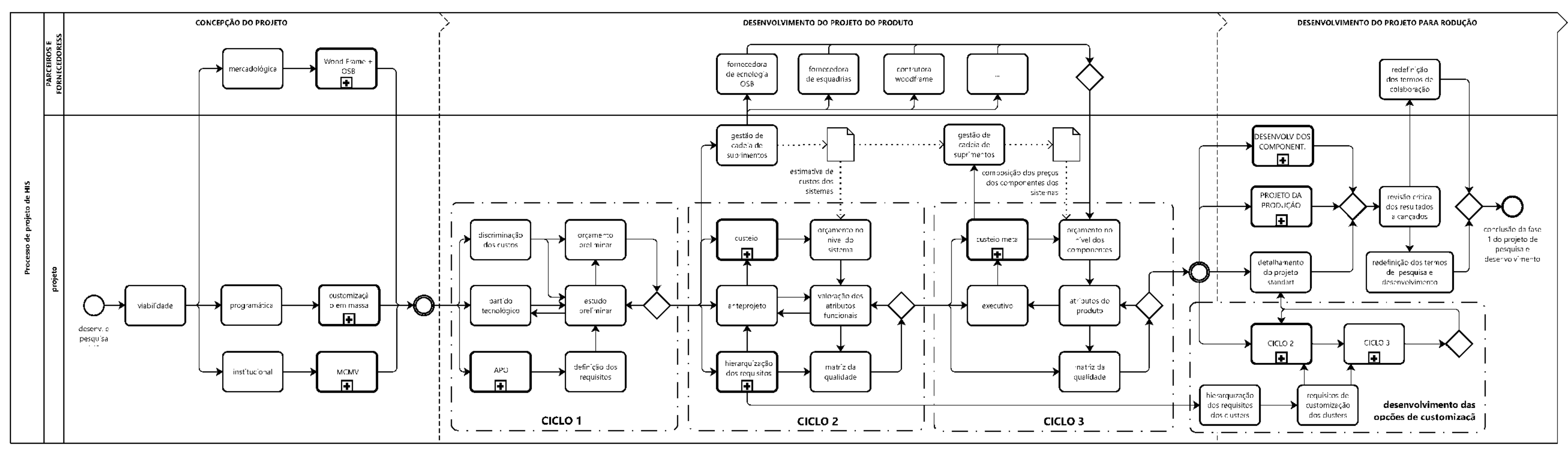

Figura 30 - Fluxo e processo de projeto do segundo estudo exploratório

(a)




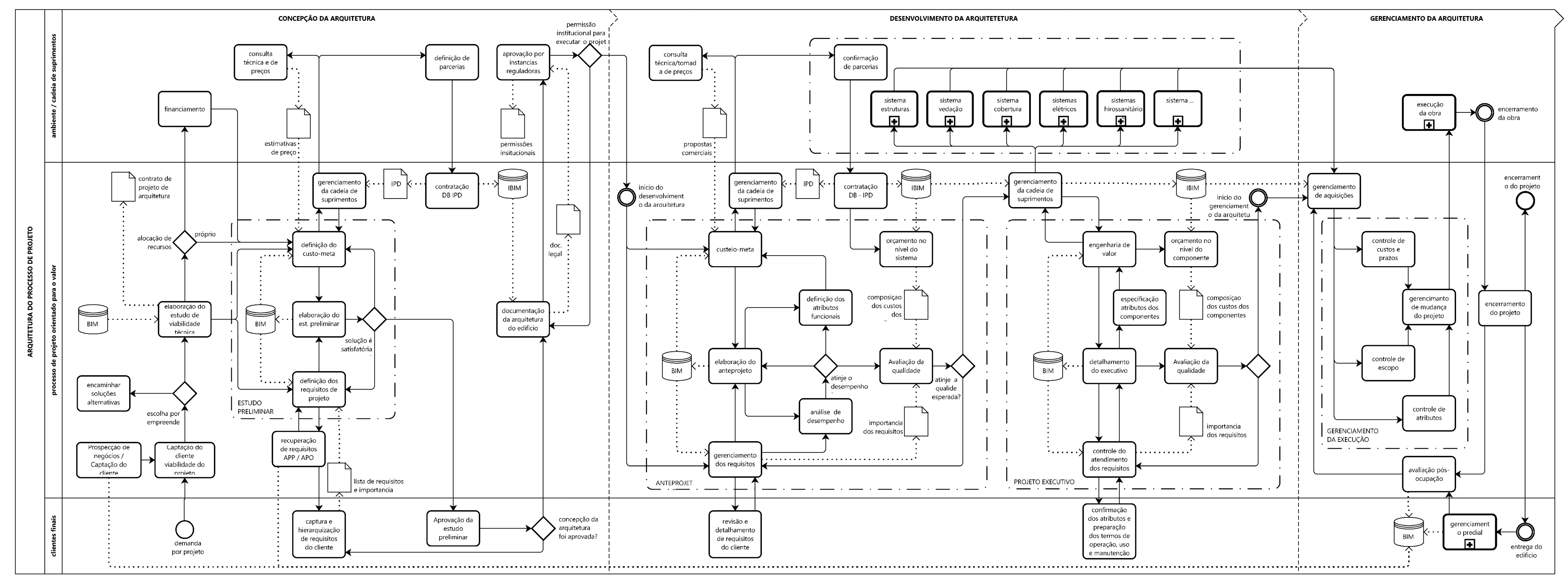


A maior proximidade com a cadeia de suprimentos pode representar um risco para o direcionamento da concepção, de ser direcionada por um viés excessivamente vinculado aos requisitos de produção. Para realinhar a concepção ao objetivo do projeto, a definição dos requisitos do projeto não está vinculada diretamente à definição do custeiometa. Preferencialmente, a atividade de captura e hierarquização dos requisitos do projeto deve contar com o envolvimento direto do cliente final. Esse envolvimento é mediado por instrumentos de captura e hierarquização das prioridades do cliente.

Entretanto, o envolvimento direto do cliente muitas vezes não é possível, seja porque ele responde a um perfil baseado em uma amostragem populacional, como no $1^{\circ} \mathrm{EE}$, seja porque não há condições de incorporar o cliente à equipe de projeto, como observado no $2^{\circ}$ EE. Nesses casos se mostrou importante elencar um representante da voz do cliente entre os integrantes da equipe para que o processo de análise funcional dos sistemas não tenha o viés dos requisitos da cadeia de suprimentos.

\subsection{ANTEPROJETO}

A aprovação do projeto pelos agentes competentes, seja pelos órgãos governamentais e associações profissionais, seja pelas vozes que representam os clientes finais, avaliza o início do desenvolvimento da arquitetura que foi concebida no estudo preliminar junto com a estrutura interorganizacional que a viabilize. Os atributos do projeto e as condições de execução são então confirmados no anteprojeto e no projeto executivo.

Embora seja recorrente relacionar o nível de desenvolvimento do anteprojeto às definições gerais de forma, tecnologia e estimativa de preço (LOD 200), foi observado no $1^{\circ} \mathrm{EE}$ que tais definições eram necessárias para a realização do gerenciamento de valor ainda na concepção do projeto, ainda no estudo preliminar. No anteprojeto os subsistemas são modelados até o nível dos componentes de forma a consolidar e a validar o orçamento em nível de sistema, e a viabilizar a quantificação de alguns componenteschave (LOD 300).

O nível de desenvolvimento de cada subsistema deve ser suficiente para estabelecer a causalidade entre o atendimento dos requisitos e os custos para atendê-los. Essa relação é estabelecida por meio da análise de desempenho da arquitetura e da definição de atributos funcionais para os sistemas que compõem a arquitetura em razão das contribuições dadas ao atendimento de requisitos do projeto. 
Como sugerido pelo fluxo de atividades do anteprojeto (Figura 31), trata-se de um ciclo iterativo em que as análises de desempenho cabíveis são definidas a partir da identificação de parâmetros de atendimento aos requisitos. A elaboração do anteprojeto é então detalhada até um nível de modelagem suficiente para fornecer informações relacionadas às especificações de materiais e detalhes construtivos que as simulações demandam para verificar o atendimento dos requisitos. A análise de desempenho pode se basear em simulações de eficiência energética, conforto ambiental, modularidade, fluxos de pessoas e materiais, entre outras variáveis mensuráveis segundo os parâmetros inicialmente identificados. Os resultados dessas análises justificam a definição dos atributos funcionais para determinados materiais e componentes dos sistemas, o que permite articular o gerenciamento dos requisitos e o custeio-meta por meio de uma avaliação da qualidade em que os requisitos e o consumo de recursos demandados pela arquitetura são balanceados de forma a alinhar o máximo de atributos desejáveis, possíveis com o custo permissível.

O gerenciamento do incremento de modelagem da informação do anteprojeto é parte constituinte da atividade de elaboração do anteprojeto descrita no parágrafo anterior. Enquanto a modelagem em si recebe demandas do custeio-meta e gerenciamento de requisitos, a iteração entre essas atividades é provocada pela demanda da modelagem por informações externas e internas. Internamente, os resultados da análise de desempenho são importantes entradas para atualizar qual é o problema de projeto a ser solucionado. Externamente, relaciona-se principalmente à captura de informações e compromissos junto à cadeia de suprimentos, o que estimula um ciclo externo de interação com os processos de empresas especializadas nos sistemas construtivos adotados no projeto.

O gerenciamento da cadeia de suprimentos é uma atividade de rotina associada ao custeio-meta, porém dissociada desta no fluxograma para diferenciar a natureza de seu envolvimento com o processo de projeto. É responsável por estabelecer e manter canais de comunicação e o relacionamento de confiança necessários para negociar e firmar os termos de contratação com fornecedores e parcerias comerciais. Trata-se, portanto, de uma atividade de suporte ao custeio-meta que não se relaciona diretamente ao processo de projeto. O custeio-meta, por outro lado, integra as atividades da equipe de projeto, pois se trata de um processo que realiza atividades intimamente ligadas à viabilização do desenvolvimento do projeto, tais como tomadas de preços, consultas técnicas e negociação dos termos de contratação IPD segundo os objetivos do projeto. Dessa 
forma, o custeio-meta influi na forma como a composição da organização do empreendimento é definida, contribuindo ou não para viabilizar a interação necessária entre as empresas envolvidas e assim realizar o entendimento sobre a arquitetura e as tecnologias envolvidas de maneira a viabilizar ajustes operacionais, materiais e tecnológicos, para ajustar o orçamento no nível do sistema ao custeio-meta.

O gerenciamento de requisitos apoia a elaboração do anteprojeto por meio da adequação dos requisitos de projeto a partir dos indicativos observados na análise de desempenho das soluções de projeto e da articulação da revisão e do detalhamento dos requisitos do cliente. Diferentemente das análises que possam ser simuladas no estudo preliminar, a análise de desempenho realizada durante o anteprojeto é instrumental para o gerenciamento de requisitos, porque, a partir dela, serão estabelecidos os critérios de controle de desempenho para o controle de qualidade da obra, relacionando o atendimento dos requisitos a métricas para verificação do escopo e da qualidade dos subprodutos gerados na execução.

Nesses termos, a revisão e o detalhamento dos requisitos do cliente permitem a participação da voz do cliente no desenvolvimento da arquitetura, o que reduz os riscos de desalinhamento entre o trabalho da equipe de projeto e os objetivos do empreendimento. $\mathrm{O}$ engajamento do cliente no direcionamento de detalhes construtivos relacionados ao uso e operação do edificio dificilmente é apreendido de forma consistente na captura e na hierarquização de requisitos feitas no estudo preliminar em razão da escala e da antecipação exigidas. Naquele momento apenas os aspectos mais relevantes são levantados; já no desenvolvimento do anteprojeto as preferências precisam ser identificadas sistematicamente para todas as especificações que impactam sobre o uso. Assim, conforme observado no $2^{\circ} \mathrm{EE}$, as decisões acerca de detalhes de acabamento e instalações que não impactam sobre a arquitetura, ou seja, sobre o sistema de integração dos subsistemas construtivos, são postergadas para reduzir os riscos decorrentes da variabilidade de disponibilidade de materiais e equipamentos.

A avaliação da qualidade é uma atividade instrumental para a equipe de projeto validar a maturidade do anteprojeto. Espera-se que a solução atenda aos principais requisitos do cliente dentro do custo permissível, com a perspectiva de alcançar o custeio-meta acordado com os parceiros do empreendimento por meio de termos de corresponsabilidade contratual. 


\subsection{PROJETO EXECUTIVO}

Assim como ocorreu no estudo preliminar e no anteprojeto, a necessidade de promover um processo iterativo antecipa o grau de desenvolvimento esperado para o projeto executivo. A engenharia de valor realizada no detalhamento do executivo é mediada pelo gerenciamento da cadeia de suprimentos, para ajustar o consumo de recursos, do custo permissível ao custeio-meta, operando no nível do componente. Para tanto, a equipe de projeto deve promover o entendimento compartilhado sobre o impacto de decisões de detalhes construtivos sobre a operacionalização dos processos de transformação na construção, de forma a negociar uma partilha de economia de custos decorrentes de ajustes formais que reduzam variabilidade e desperdícios ligados ao transporte e armazenamento de material e componentes, buffers, entre outros.

As negociações realizadas na engenharia de valor não podem ser alijadas da atividade de detalhamento do executivo, pois o sucesso da iteração depende da agilidade da modelagem da informação do edificio para mediar a avaliação da qualidade do detalhe desenvolvido para o atendimento aos requisitos do projeto. $\mathrm{O}$ distanciamento entre a equipe de projeto e a negociação de soluções com a cadeia de suprimentos foi observado no $1^{\circ} \mathrm{EE}$, em que um gerenciamento externo reduziu a capacidade de projetar e analisar alternativas com eficiência, o que reduziu a eficácia do custeio-meta.

O controle do atendimento aos requisitos visa garantir que a especificação de atributos dos componentes atenda ao desempenho projetado com os atributos funcionais. Como a equipe de projeto está comprometida com a resolução de questões ligadas à cadeia de suprimentos no detalhamento do executivo, é importante que os parâmetros de desempenho estabelecidos no anteprojeto sejam controlados no executivo, de forma a garantir que a qualidade da arquitetura modelada no anteprojeto se confirme na produção.

O desenvolvimento iterativo da modelagem integrada do projeto executivo deve atingir um nível de desenvolvimento suficiente para subsidiar o planejamento do cronograma fisico-financeiro da obra (LOD 400). Por outro lado, a modelagem integrada da informação da construção (Integrate Building Information Modeling - iBIM), representada como um banco de dados no fluxograma (Figura 31), incorpora ao modelo as especificações, custos e fornecedores de materiais e serviços da construção ligados ao LOD 500. Assim, em associação ao controle do atendimento aos requisitos, é possível 
preparar os termos de operação, uso e manutenção com o cliente final em resposta às demandas do gerenciamento predial, ainda pouco instrumentalizadas por BIM no Brasil, mas o que é central ao debate sobre sustentabilidade do ciclo de vida da edificação.

\subsection{GERENCIAMENTO DE MUDANÇAS}

Parte das atividades de projeto frequentemente negligenciadas por escritórios de projeto da arquitetura e dos demais sistemas está ligada ao gerenciamento de mudanças do projeto decorrentes da necessidade de adaptar o projeto desenvolvido à realidade da execução de forma a garantir a qualidade esperada em relação ao custo, prazo e desempenho da edificação projetada. A necessária articulação entre a equipe de desenvolvimento do projeto e a de gerenciamento da execução é frequentemente desconsiderada em processos do setor de AECO, o que torna o projeto suscetível a todas as variáveis de projeto que não podem ser antecipadas pelo planejamento.

Com considerável parte do orçamento comprometido por contratos firmados de execução e fornecimento de suprimentos, o gerenciamento de mudanças do projeto é parte fundamental do processo de gerenciamento de aquisições realizado durante a execução da obra junto a parceiros e fornecedores envolvidos no empreendimento. Essa atividade é complementar ao controle de prazos e custos da execução do projeto e ao controle de atributos do projeto, que juntas têm como objetivo verificar o atendimento do escopo das características fisicas, geométricas, estéticas e funcionais dos elementos de sistemas especificados em projeto, dentro das condições previstas contratualmente. Trata-se de um esforço criativo de gerenciamento de mudanças necessárias para viabilizar o atendimento dos requisitos do projeto.

Os procedimentos de encerramento do projeto se sucedem ao encerramento da obra com o objetivo de instrumentalizar a entrega do edificio aos responsáveis pelo gerenciamento predial, com a apresentação e o acompanhamento da aplicação dos termos de operação, uso e manutenção, realizada por meio de atividades de avaliação pós-ocupação, que, além de garantir a coleta de informações importantes para a prospecção de negócios e definição de requisitos de projetos futuros, estabelece um vínculo com o cliente final, potencializador da prospecção de novos negócios. A seta que conecta a avaliação pós-ocupação às atividades ligadas à concepção da arquitetura na Figura 31, bem como aos dados do BIM do gerenciamento predial, representa formalmente o estreitamento desse vínculo em um nível organizacional. 


\subsection{CARACTERÍSTICAS GERAIS DA ARQUITETURA DO PROCESSO}

As atividades vinculadas ao gerenciamento da arquitetura estão baseadas principalmente em contribuições da literatura, observação e reflexão de pesquisa, sendo, portanto, a parte do fluxograma menos elaborada, porém conceitualmente necessária para a promoção da integração dos processos visando maior eficiência do processo de projeto.

As atividades do processo de projeto orientado ao valor foram listadas no Quadro 21.

\section{Quadro 21 - Lista das atividades do processo de projeto orientado ao valor}

Estudo de viabilidade

01 - Prospecção de negócios/Captação do cliente

02 - Estudo de viabilidade do empreendimento

03 - Estudo de viabilidade técnica

04 - Financiamento

Estudo preliminar arquitetônico

05 - Definição do custeio-meta

06 - Captura e hierarquização de requisitos do cliente

07 - Recuperação de requisitos APP/APO

08 - Definição dos requisitos de projeto

09 - Elaboração do estudo preliminar

10 - Gerenciamento da cadeia de suprimentos

11 - Consulta técnica e de preços

12 - Definição de parcerias

13 - Aprovação do estudo preliminar

14 - Contratação DB-IPD

15 - Documentação da arquitetura do edifício

16 - Aprovação por instâncias reguladoras

Anteprojeto arquitetônico

17 - Custeio-meta

18 - Elaboração do anteprojeto

19 - Gerenciamento dos requisitos

20 - Revisão e detalhamento dos requisitos do cliente

21 - Análise de desempenho

22 - Definição dos atributos funcionais

23 - Gerenciamento da cadeia de suprimentos

24 - Consulta técnica e tomada de preços

25 - Confirmação de parcerias

26 - Contratação DB-IPD

27 - Orçamento no nível do sistema

28 - Avaliação da qualidade
Projeto executivo arquitetônico

29 - Gerenciamento da cadeia de suprimentos

30 - Engenharia de valor

31 - Elaboração do executivo

32 - Controle do atendimento dos requisitos

33 - Preparo dos termos de operação uso e manutenção

34 - Especificação de atributos dos componentes

35 - Orçamento no nível do componente

36 - Avaliação da qualidade

Gerenciamento da execução da arquitetura

37 - Gerenciamento de aquisições

38 - Controle de custos e tempo

39 - Controle de escopo

40 - Controle de atributos

41 - Gerenciamento de mudança do projeto

Execução dos sistemas da arquitetura

42 - Sistema estrutural

43 - Sistema de vedação

44 - Sistemas hidrossanitários

45 - Sistemas elétricos

46 - Sistema de cobertura

47 - Sistema de aberturas e fechamentos

48 - Gerenciamento da obra

Encerramento do projeto

49 - Encerramento do projeto

50 - Avaliação pós-ocupação

51 - Gerenciamento predial

Obs:: A numeração das atividades corresponde a uma sequência numérica simples, não incorporando nenhum modelo de classificação hierárquica ou facetada específico. 
A forma de registro linear dessas atividades é condizente com a forma de registro da lista das atividades levantada no mapeamento da congruência organizacional de um empreendimento imobiliários real. Assim, foi possível comparar e combinar ambas as listas para viabilizar a avaliação da congruência da arquitetura organizacional proposta. Essas etapas da pesquisa são relatadas a seguir. 


\section{MAPEAMENTO DA CONGRUÊNCIA ORGANIZACIONAL DE UM EMPREENDIMENTO IMOBILIÁRIO}

A percepção de qualidade de um empreendimento imobiliário relaciona-se à satisfação dos clientes, cujos interesses não estão necessariamente alinhados e podem ser conflitantes. Em decorrência dessas diferentes expectativas, as formas de análise da qualidade de empreendimentos apresentam abordagens distintas, cujo foco abrange aspectos do edifício ou do processo de projeto, execução, uso e manutenção do empreendimento. Assim, a qualidade do empreendimento pode ser compreendida em relação aos riscos assumidos, à satisfação do cliente final, à sustentabilidade da edificação, às condições de uso e manutenção, à modularidade, à eficiência de produção, etc.

Uma dessas abordagens reconhece as relações existentes entre qualidade do produto, do processo de projeto e da organização do empreendimento. Como as demais abordagens, o conceito de qualidade organizacional se traduz em um domínio disciplinar próprio, com conhecimentos, práticas e ferramentas particulares. Interessa para a pesquisa analisar uma organização segundo a capacidade de alcançar a qualidade do produto resultante do trabalho assim organizado. Em outras palavras, refere-se à capacidade de atender eficientemente aos requisitos e especificações descritos e a satisfazer efetivamente as necessidades das partes interessadas no empreendimento (PALANEESWARAN; NG; KUMARASWAMY, 2006).

A análise da congruência organizacional (SOSA; EPPINGER; ROWLES, 2004), cujo conceito foi apresentado na RSL, tem como objetivo identificar as interações potenciais de um processo de projeto que impactam sobre as características do edificio e, portanto, estão intimamente relacionadas à eficiência e eficácia com que a solução do projeto é concebida (AUSTIN et al., 2002). A realização de tal mapeamento oferece uma fotografia decodificada da organização do empreendimento, que instrumentaliza uma discussão sobre a reorganização do processo de projeto para viabilizar atividades de gerenciamento integrado do fluxo de informação e do valor do projeto. 


\subsection{O EMPREENDIMENTO ANALISADO}

O empreendimento utilizado para o estudo de caso foi construído na cidade de Londrina, Paraná, Brasil. Trata-se de um edificio residencial unifamiliar de três pavimentos localizado em um terreno de esquina, com 602,25 $\mathrm{m}^{2}$ construídos, sendo $284,5 \mathrm{~m}^{2}$ de pavimento térreo, $211 \mathrm{~m}^{2}$ de pavimento superior e 106,75 $\mathrm{m}^{2}$ de subsolo (Figura 32 e Figura 33).

Figura 32 - Perspectiva do empreendimento

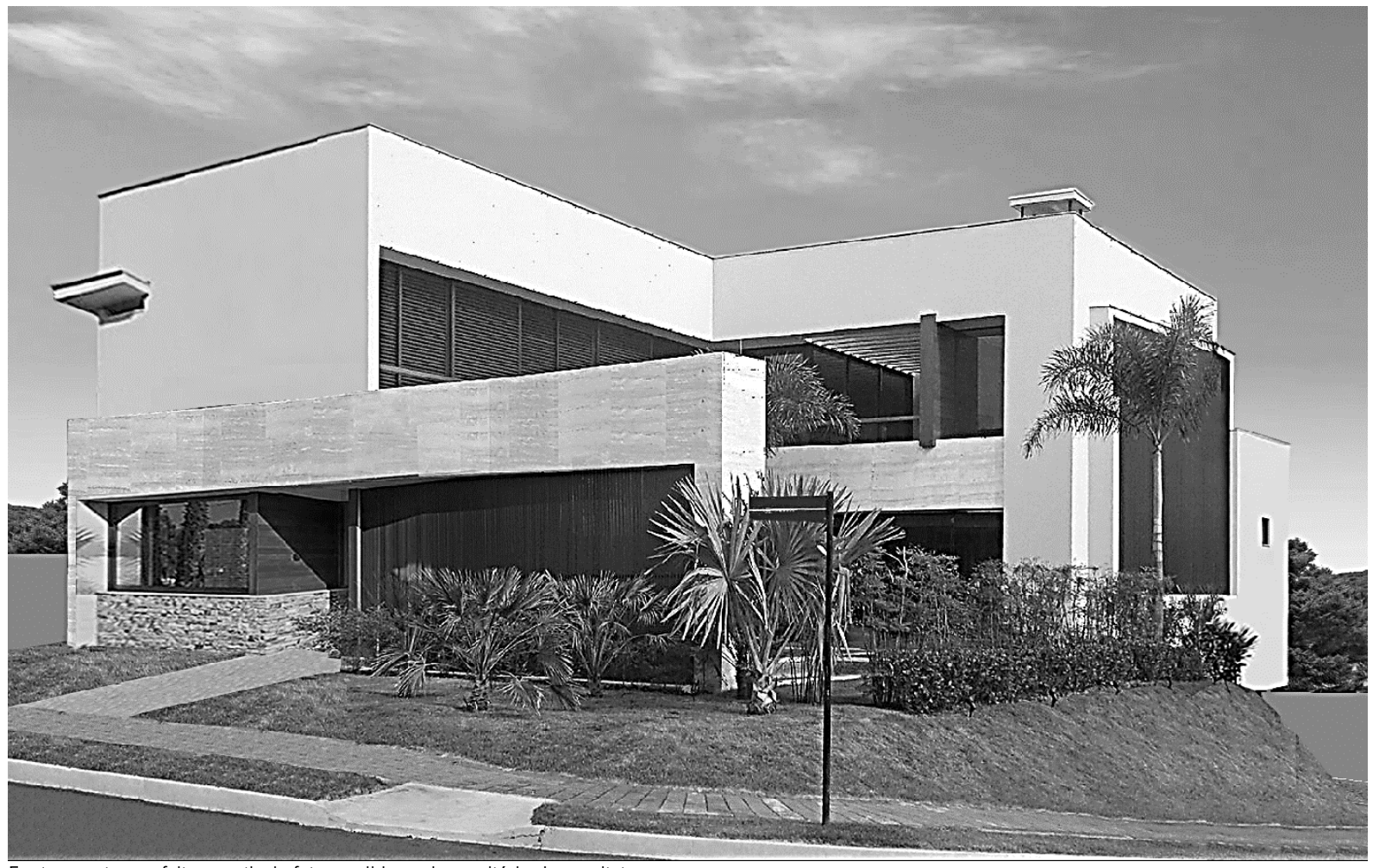

Fonte: montagem feita a partir de fotos cedidas pelo escritório de arquitetura.

O edificio compreende um sistema convencional de construção, com subsistema estrutural de concreto armado confeccionado in loco, alvenaria, esquadrias de madeira e alumínio, acabamentos como piso de madeira, porcelanato e mármore, etc. A lista de subsistemas e componentes do sistema apresentados no Quadro 22 é composta de elementos retirados diretamente dos desenhos técnicos cedidos pelas empresas envolvidas no empreendimento e ajustados segundo as orientações dos responsáveis pelos projetos. 
Figura 33 - Planta dos pavimentos do empreendimento

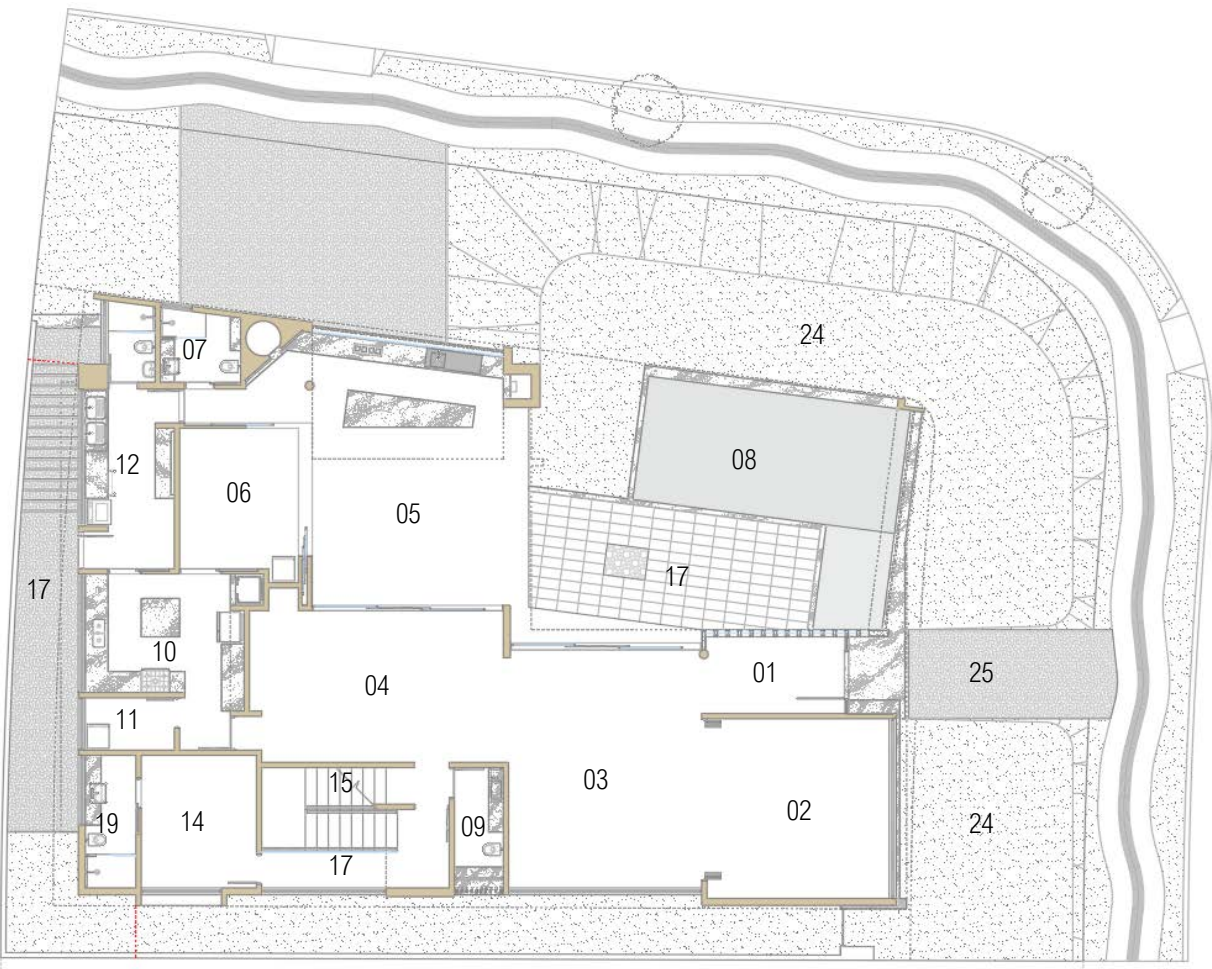

01 Hall

02 Sala de TV

03 Sala de estar

04 Sala de jantar

05 Varanda

06 Copa

07 Vestiários

08 Piscina

09 Lavabo

10 Cozinha

11 Despensa

12 Área de serviços

13 Garagem

14 Casa de máquinas

15 Escada interna

16 Escritório

17 Circulações

18 Dormitórios

19 Instalações sanitárias

20 Closet

$21 \mathrm{DML}$

22 Sacada

23 Terraço

24 Jardins

25 Acessos

Pavimento térreo

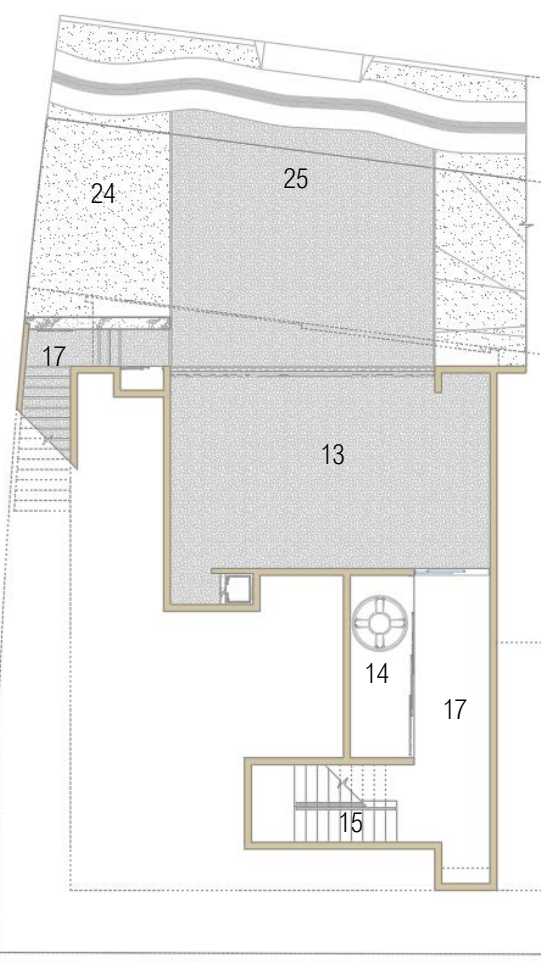

Pavimento subsolo

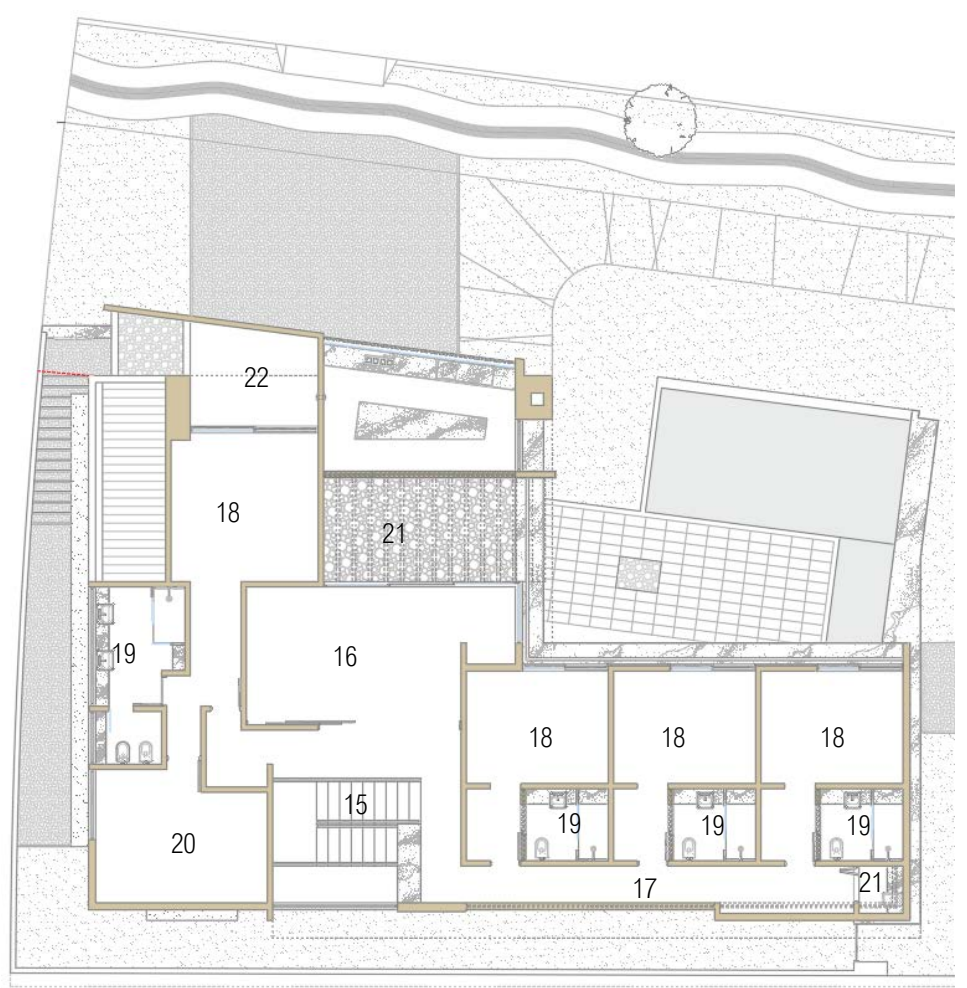

Primeiro pavimento

Fonte: adaptado do projeto original. 


\subsection{ANÁLISE DA CONGRUÊNCIA ORGANIZACIONAL DE UM EMPREENDIMENTO IMOBILIÁRIO EXISTENTE}

A análise do mapeamento da congruência organizacional realizada no empreendimento imobiliário de uma unidade residencial caracterizado na seção 2.4, do capítulo de métodos, é apresentada a seguir. A discussão se inicia com as seções sobre a "arquitetura da edificação" e sobre a "organização existente", em que se estabelece quais são as interfaces existentes entre as partes componentes da edificação, a interação reconhecidas entre as atividades realizadas na organização existente e quais dessas atividades estão envolvidas na definição de cada um daqueles componentes do edifício. A partir desses dados são deduzidas as interações potenciais por meio da interpolação entre os dados levantados nas três primeiras matrizes. As interações potenciais são então comparadas com a comunicação real observada na organização do empreendimento existente, ao combinar seus resultados em uma matriz de congruência, que oferece as bases para discutir a condição de congruência organizacional específica desse empreendimento.

\subsubsection{Arquitetura do sistema: o caso da edificação de uma unidade residencial}

Assim como o sistema estrutural é composto de vigas, pilares, lajes e demais componentes necessários para garantir a função de sustentação da edificação, cada subsistema de uma edificação é constituído por um conjunto de componentes interdependentes que desempenham determinada função, seja vedar vertical e horizontalmente, iluminar e ventilar, fornecer água, energia e conexão à internet, climatizar, etc. Porém, como a correlação entre sistema e função não é direta, uma vez que um componente ou sistema de componentes pode responder a mais de uma função, parte fundamental da funcionalidade depende da integração dos sistemas. Sob essa perspectiva, a arquitetura corresponde a um sistema de integração, que subordina o funcionamento dos subsistemas construtivos à função principal da edificação, ligada à atividade humana (Quadro 22).5

É por meio da arquitetura do edificio que os componentes são articulados espacial e funcionalmente para responder satisfatoriamente às demandas socioambientais que motivam um empreendimento.

\footnotetext{
5 A notação dos termos apresentados no Quadro 22 corresponde a uma sequência numérica simples, de progressão não linear. A redação dos termos é idêntica à levantada no mapeamento. 0 mesmo critério foi adotado para o Quadro 23. Quando a aplicação do mapeamento for feita em uma organização que tenha notação específica, pode-se utilizar a notação existente, de forma tornar a correlação imediata.
} 


\section{Quadro 22 - Lista de componentes da arquitetura de um edifício}

Terrapleno

001 - Platôs de implantação
002 - Aterros
003 - Taludes
004 - Ligação de luz, água e esgoto
005 - Drenagem
Infraestrutura (sistemas estruturais)
101 - Estacas
102 - Blocos
103 - Vigas baldrame
104 - Arrimos
110 - Impermeabilização

Superestrutura (sistemas estruturais)

105 - Vigas

106 - Pilares

107 - Lajes maciças e pré-moldadas

108 - Escadas

109 - Pergolado

\section{Coberturas}

201 - Impermeabilização

202 - Tesouras

203 - Platibandas

204 - Calhas

205 - Rufos

206 - Telhamento

207 - Terraço recoberto com argila expandida

Vedação

301 - Alvenaria convencional interna/externa

302 - Vergas

303 - Contravertas

304 - Alvenaria convencional interna/interna

305 - Janela com perfil de alumínio e vidro

307 - Janela com perfil e veneziana de alumínio e vidro

308 - Porta-janela com perfil de alumínio e vidro

309 - Porta-janela com perfil e veneziana de alumínio e vidro

310 - Porta com perfil e veneziana de alumínio

311 - Painel de veneziana de alumínio

312 - Brise de alumínio anodizado

313 - Impermeabilização

314 - Requadro

315 - Batente de madeira

316 - Porta de madeira
Revestimentos e acabamentos

501 - Contrapiso/cimentado

502 - Reboco das paredes

503 - Piso de madeira

504 - Piso de porcelanato

505 - Piso de mármore

506 - Piso de petit-pavet

507 - Piso de seixos

508 - Soleiras

509 - Pingadeiras

510 - Revestimento de pastilha

511 - Revestimento de mármore para parede

512 - Revestimento de réguas de madeira para parede

513 - Rodapé de mármore

514 - Rodapé de madeira

515 - Rodapé de granito

516 - Forro de gesso

517 - Reforço no forro de gesso

518 - Sanca de iluminação

519 - Pintura

531 - Revestimento de porcelanato

532 - Revestimento de granito

533 - Papel de parede

537 - Revestimento de pedra irregular assentada

538 - Hera

539 - Grama

540 - Vegetação ornamental

Equipamentos construtivos e acessórios

520 - Corrimão de metalon

521 - Corrimão e guarda corpo de madeira, vidro e aço inox

522 - Guarda corpo de madeira e alumínio

523 - Porta toalhas de rosto

524 - Porta toalhas de banho

525 - Papeleira

526 - Saboneteira

527 - Cabide

528 - Bancada de mármore

529 - Divisória de mármore

530 - Espelho

534 - Bancada de granito

535 - Sóculo

536 - Deck

Sistema elétrico

601 - Conduíte de parede e piso

602 - Eletrodutos 
603 - Caixas de passagem, tomada e interruptor

604 - Quadro(s) de distribuição

605 - Circuito(s) elétrico(s) de iluminação

606 - Interruptores

607 - Luminária de teto

608 - Luminária de parede

609 - Circuitos elétricos de tomadas de uso geral (TUG)

610 - Tomada de parede

611 - Tomada de teto

612 - Tomada de piso

613 - Circuitos elétricos de tomadas de uso específico (TUE)

614 - Tomadas especiais

615 - Sistema de segurança

616 - Monta-carga

617 - Medidor de energia elétrica

618 - Luminária de piso

\section{Sistema SPDA}

650 - Pontalete

651 - Condutor, ferragem embutida na estrutura

652 - Malha de aterramento, aproveitamento da fundação

\section{Sistemas hidrossanitários}

701 - Tubulação de água fria

702 - Tubulação de água quente

703 - Torneira

704 - Cuba

705 - Bacia sanitária

706 - Válvula de descarga

707 - Bidê

708 - Chuveiro

709 - Ducha higiênica

710 - Ducha manual

711 - Sifão

712 - Misturador

713 - Registro de gaveta

714 - Registro de pressão

715 - Tubulação de esgoto

716 - Ralos

717 - Saída de gás combustível

718 - Condutores de águas pluviais

719 - Combate a incêndio

720 - Tubulação de gás combustível

721 - Barrilete

722 - Caixa de inspeção

723 - Caixa de inspeção pluvial

724 - Hidrômetro

725 - Cisterna

726 - Filtro
727 - Eletrobomba da cisterna

728 - Poço de recalque da cisterna

729 - Sumidouro de águas pluviais

730 - Eletrobomba da piscina

731 - Reservatório de gás

732 - Retorno

734 - Caixa d'água

735 - Torneira de boia

736 - Boiler de aquecimento

737 - Painel solar

738 - Aquecedor de passagem a gás

739 - Tanque

740 - Retorno de água quente e fria

741 - Aspiração

Sistema de ar condicionado

801 - Evaporadoras

802 - Condensadoras split teto

803 - Condensadoras split parede

804 - Grelhas

805 - Tubulação flexível

806 - Tubulação frigorífera

Sistema de integração

901 - Hall
902 - Sala de TV
903 - Sala de estar
904 - Jantar
905 - Varanda
906 - Copa
907 - Vestiário
908 - Piscina
909 - Lavabo
910 - Cozinha
911 - Despensa
912 - Área de serviço
913 - Garagem
914 - Casa de máquinas
915 - Escadas internas
916 - Escritório
917 - Circulações
918 - Dormitórios
919 - Banhos
920 - Closet
921 - DML
922 - Sacada
923 - Terraço
924 - Jardins
925 - Acessos, rampas escadas externas
926 - Fachadas/Envoltória 
O caso de uma moradia unifamiliar cuja arquitetura do edificio foi decomposta em componentes dos sistemas (Quadro 22) ilustra como o sistema de integração, composto dos ambientes e elementos funcionais da arquitetura, apresenta maior incidência de interfaces com os componentes dos demais subsistemas (Figura 34). Cabe notar que o mapeamento da matriz da arquitetura do sistema $\left(\mathrm{S}_{\mathrm{nn}}\right)$ relaciona apenas as interfaces diretas entre os componentes dos sistemas listados. Por isso a influência indireta das especificações dos ambientes sobre as estruturas não está explicitada na matriz.

As interfaces do sistema estrutural com o sistema de integração são observadas quando se define detalhe da piscina e quando o arquitetônico atribui a geometria específica a um pilar aparente e ao pergolado no terraço. Observa-se outra particularidade desse mapeamento na definição de "equipamentos construtivos acessórios" como um sistema que não apresenta nenhuma interação interna. Essa conformação foi motivada pela preocupação dos profissionais em incluir inadequadamente os componentes acessórios a um ou outro sistema cuja função era bem definida. A função acessória desses componentes, contudo, leva a crer que eles se enquadrem ora dentro do sistema de vedação, ora do sistema de revestimento e acabamentos.

A análise geral da arquitetura da edificação captada pelo mapeamento indica a baixa modularidade dos sistemas. Essa característica está ligada à produção convencional do edificio. Parte da complexidade decorrente é reduzida em alguns sistemas com maior número de interfaces externas por meio de características compartilhadas (commonality) por famílias de componentes. É o caso dos sistemas hidráulico e sanitário, elétrico e telemático, de revestimentos e acabamento. Nesses sistemas as soluções de projeto vêm a reboque das especificações dos fornecedores de materiais, e eventuais inovações são impulsionadas principalmente pela cadeia de fornecimento, e não por aprendizado e melhorias do processo de projeto e construção.

\subsubsection{Organização existente do empreendimento analisado}

A organização do empreendimento estudado foi apreendida pela matriz de interações reconhecidas $\left(\mathrm{R}_{\mathrm{m}, \mathrm{m}}\right)$, que agrupa e relaciona as atividades de desenvolvimento do projeto e de construção do edificio listadas no Quadro 23, de forma a estabelecer as relações de precedência e as existentes (Figura 35). Não foram consideradas organizações de fornecedores que não prestassem alguns serviços associados à construção, e os que prestaram foram indicados como agentes da organização da obra. 


\section{Quadro 23 - Lista das atividades levantadas na organização do empreendimento}

Estudo preliminar arquitetônico

0001 - Contratação

0002 - Definição do programa de necessidades

0003 - Levantamento das regras da construção

0004 - Levantamento topográfico/planialtimétrico

Anteprojeto arquitetônico

0005 - Concepção da solução espacial dos pavimentos

0006 - Ajuste espacial ao leiaute do mobiliário

0007 - Checagem do atendimento ao programa

0008 - Checagem da movimentação do solo

0009 - Pré-lançamento estrutural

0010 - Estudo da cobertura

0011 - Modelagem tridimensional para ajustes e apresentação

0012 - Apresentação para aprovação do cliente

Projeto legal

0013 - Produção da documentação legal

0014 - Encaminhamento da documentação aos órgãos competentes

0015 - Aprovação do projeto legal

Pré-executivo arquitetônico

0016 - Escolha e contratação dos projetistas complementares

0017 - Desenvolvimento do pré-executivo arquitetônico (projeto técnico)

0018 - Encaminhamento do pré-executivo arquitetônico para análise estrutural

0019 - Discussão das soluções estruturais

0020 - Revisão do projeto pré-executivo arquitetônico/compatibilização com projeto estrutural

0021 - Lançamento das diretrizes hidráulicas (pontos hidráulicos, prumadas pluviais, poço artesiano, ar-condicionado, espaços técnicos)

0022 - Lançamento das diretrizes elétricas e automação (iluminação, tomadas, interruptores, telemática, etc.)

0023 - Lançamento das diretrizes de ar condicionado

0024 - Encaminhamento das diretrizes hidráulicas e de ar-condicionado para análise do projetista de hidráulica

0025 - Encaminhamento das diretrizes elétricas e de arcondicionado para análise do projetista eletricista

0026 - Compatibilização com o projeto das especialidades
Projeto executivo arquitetônico

0027 - Desenvolvimento do projeto executivo

0028 - Encaminhamento do projeto executivo para responsável pelo gerenciamento da obra

Detalhamento arquitetônico

0029 - Desenvolvimento das propostas dos ambientes

0030 - Lançamento dos tipos de revestimento

0031 - Apresentação das propostas de ambiente e revestimentos para aprovação do cliente

0032 - Detalhamento de ambientes: banheiro, cozinha, lavanderia, piscina, etc.

0033 - Paginação de pisos

0034 - Detalhamento de soleiras e pingadeiras

0035 - Detalhamento de esquadrias de alumínio

0036 - Detalhamento de esquadrias de madeira

0037 - Detalhamento do guarda-corpos e corrimãos

0038 - Projeto e detalhamento do forro

0039 - Projeto luminotécnico

0040 - Encaminhamento dos quantitativos a fornecedores (estimativa de preço)

0041 - Conferência de quantitativos de estimativa de preços recebidos dos fornecedores

0042 - Aprovação da contratação dos serviços e produtos dos fornecedores

0043 - Encaminhamento de detalhamento de ambientes e revestimentos para obra

0044 - Acompanhamento de obra

0045 - Lançamento paisagístico

0046 - Cotação dos serviços de paisagismo

0047 - Apresentação do projeto paisagístico para aprovação

0048 - Detalhamento de rodapés

0049 - Detalhamento de revestimento

Contratação de projeto estrutural

1001 - Proposta de honorários dos serviços de projeto estrutural

1002 - Contratação do projeto de estruturas

Projeto pré-executivo estrutural

1003 - Análise da arquitetura e lançamento de préforma estrutural

1004 - Reunião de validação do diagnóstico e pré-forma estrutural

1005 - Revisão do lançamento de pré-forma estrutural 
Projeto executivo estrutural

1006 - Modelagem da estrutura

1007 - Processamento da análise dos esforços, deformação, etc.

1008 - Detalhamento da estrutura

1009 - Liberação para das formas estruturais para projetos complementares

1010 - Desenvolvimento do projeto executivo estrutural para obra

1011 - Liberação do projeto estrutural para obra

Contratação de projeto hidráulico

2001 - Proposta comercial do serviço de projeto hidrossanitário

2002 - Contratação do projeto de sistemas hidrossanitários

Projeto executivo hidráulico

2003 - Lançamento hidráulico em planta (prumadas e dreno de ar-condicionado)

2004 - Discussão do lançamento hidráulico com arquiteto-coordenador de projeto

2005 - Lançamento da posição das prumadas pluviais e esgoto

2006 - Detalhamento isométrico dos sistemas de esgoto, água fria e quente

2007 - Detalhamento do sistema de aquecimento e caixa d'água na cobertura

2008 - Detalhamento do sistema hidrossanitário da piscina

2009 - Levantamento da relação de materiais

2010 - Controle de qualidade/Revisão dos projetos

2011 - Entrega dos arquivos de projeto ao arquitetocoordenador de projeto

Contratação de projeto elétrico

3001 - Proposta comercial do serviço de projeto elétrico (carta-proposta)

3002 - Contratação

Projeto executivo elétrico e SPDA

3003 - Reunião de levantamento dos requisitos de arquitetura

3004 - Lançamento de infraestrutura e circuitos elétricos

3005 - Detalhamento do Sistema de Proteção Contra Descargas Atmosféricas (SPDA)

3006 - Lançamento da infraestrutura de telefonia, TV e lógica

3007 - Revisão da documentação do projeto
3008 - Entrega dos arquivos de projeto ao arquitetocoordenador de projeto

Projeto de arquitetura de interiores

4001 - Contratação

4002 - Discussão do programa de interiores

4003 - Desenvolvimento da proposta para os ambientes

4004 - Apresentação dos ambientes (perspectivas) para aprovação

4005 - Detalhamento de marcenaria e tapeçaria

4006 - Especificação de papel de parede, cortinas e persianas, móveis avulsos, objetos de decoração

4007 - Encaminhamento do detalhamento para marcenaria para orçamento

4008 - Encaminhamento do detalhamento para tapeçaria para orçamento

4009 - Solicitação de orçamento de papel de parede, cortinas e persianas, móveis avulsos, objetos de decoração

4010 - Reunião de aprovação dos orçamentos e discussão de alternativas

4011 - Assessoria para compra de peças de decoração

Serviços preliminares à execução da obra

5001 - Reunião de negociação dos termos de contrato

5002 - Contratação

5003 - Aprovação do projeto e liberação do alvará

Execução da infraestrutura da obra

5004 - Ligação de água e padrão de luz

5005 - Terraplanagem

5006 - Montagem do canteiro de obras

5007 - Contratação e mobilização dos funcionários

Execução do subsolo da edificação

5008 - Marcação das estacas

5009 - Perfuração e concretagem das estacas

5010 - Execução dos blocos de fundação - subsolo

5011 - Execução das vigas baldrames e muros de arrimo - subsolo

5012 - Levantamento das alvenarias - subsolo

5013 - Forma, armação e concretagem dos pilares subsolo

5014 - Montagem da caixaria das lajes e vigas - subsolo

5015 - Forma, armação e concretagem das escadas subsolo

5016 - Locação de passagens hidráulicas e tubulações elétricas - subsolo

5017 - Concretagem das lajes e vigas - térreo

Execução do térreo da edificação 
5018 - Execução dos blocos de fundação - térreo

5019 - Execução das vigas baldrames e arrimos da piscina - térreo

5020 - Levantamento das alvenarias - térreo

5021 - Forma, armação e concretagem dos pilares térreo

5022 - Montagem da caixaria das lajes e vigas - térreo

5023 - Forma, armação e concretagem das escadas térreo

5024 - Locação de passagens hidráulicas e tubulações elétricas - térreo

5025 - Concretagem das lajes e vigas - $1^{0}$ pavimento

Execução do $1^{0}$ pavimento da edificação

5026 - Levantamento das alvenarias - $1^{\circ}$ pavimento

5027 - Forma, armação e concretagem dos pilares - $1^{\circ}$ pavimento

5028 - Montagem da caixaria das lajes e vigas - $1^{0}$ pavimento

5030 - Locação de passagens hidráulicas e tubulações elétricas - $1^{\circ}$ pavimento

5031 - Concretagem das lajes e vigas - cobertura

Execução da cobertura

5032 - Levantamento das platibandas

5033 - Levantamento das alvenarias de sala da caixa d'água

5034 - Instalação da serralheria da cobertura

5035 - Instalação da infraestrutura do ar-condicionado

5036 - Instalação dos barriletes

5037 - Telhamento

Execução das instalações e acabamentos
5038 - Instalação das tubulações hidráulicas internas

5039 - Instalação das tubulações elétricas internas

5040 - Instalação dos sistemas elétricos internos

5041 - Execução do reboco das paredes e cimentado nos pisos

5042 - Instalação dos requadros e batentes

5043 - Assentamento de soleiras e pingadeiras

5044 - Instalação de rodapés

5045 - Instalação dos forros de gesso

5046 - Assentamento de revestimentos de paredes

5047 - Execução dos sóculos

5048 - Assentamento de pisos de mármore

5049 - Assentamento de porcelanato

5050 - Assentamento de assoalho

5051 - Colocação das esquadrias de alumínio e vidros

5052 - Colocação das portas de madeira

5053 - Colocação de guarda-corpos e corrimãos

5054 - Pintura e envernizamento internos

5055 - Instalação de armários

5056 - Instalação de luminárias, lâmpadas e acabamentos elétricos

5057 - Instalação de louças e metais

5058 - Assentamento de revestimentos da piscina

5059 - Assentamento dos pisos de passagens e calçadas

5060 - Montagem do deck

5061 - Correção dos platôs e execução dos taludes

5062 - Instalação das tubulações hidráulicas externas

5063 - Instalação das tubulações elétricas externas

5064 - Instalação dos sistemas elétricos externos

Serviços finais à execução da obra

5065 - Desmontagem do canteiro de obra

5066 - Limpeza 
Figura 34 - Matriz da arquitetura do sistema $\left(S_{n n}\right)$ - Empreendimento existente

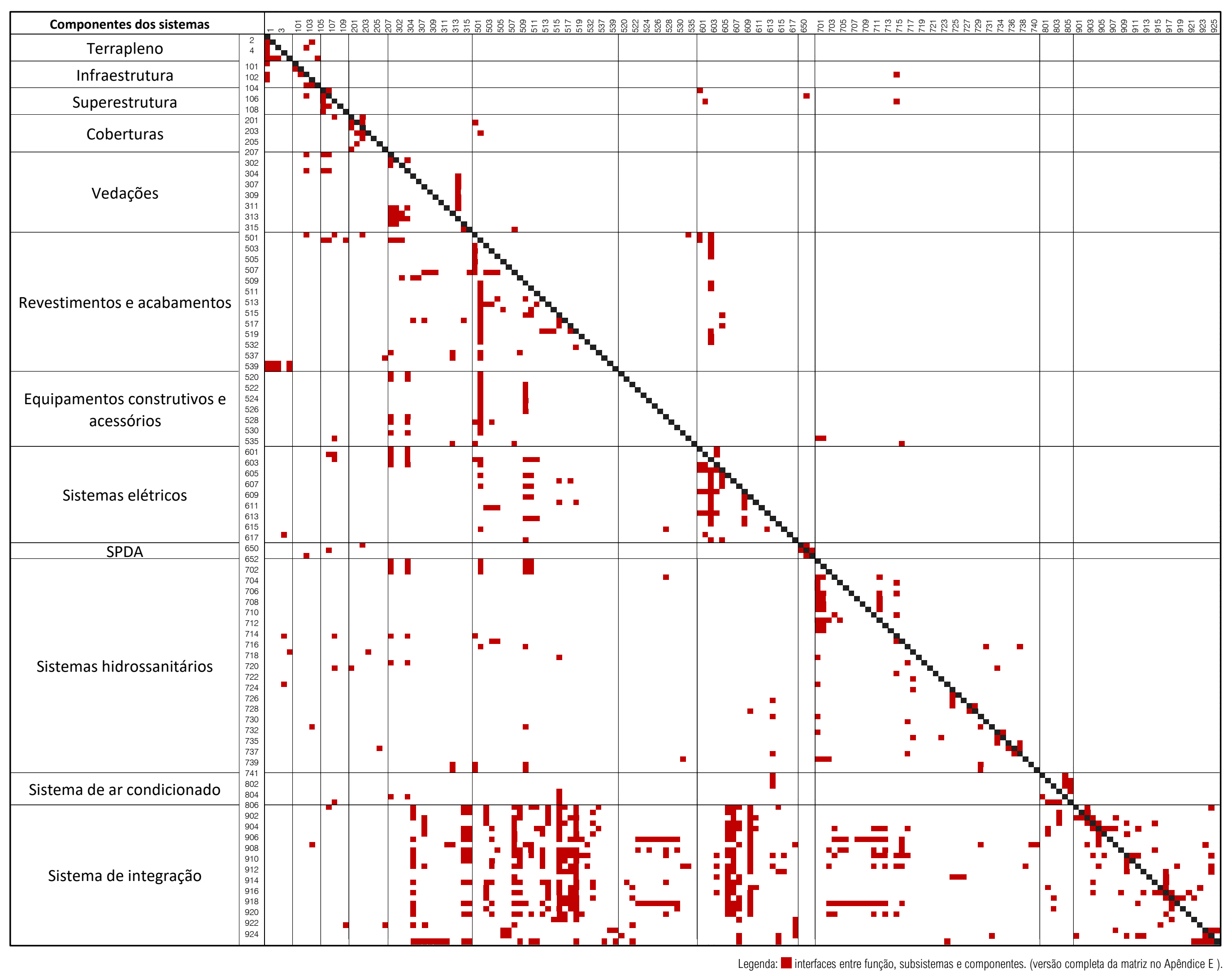


Figura 35 - Matriz das interações recinhecidas $\left(R_{m m}\right)$ - Empreendimento existente

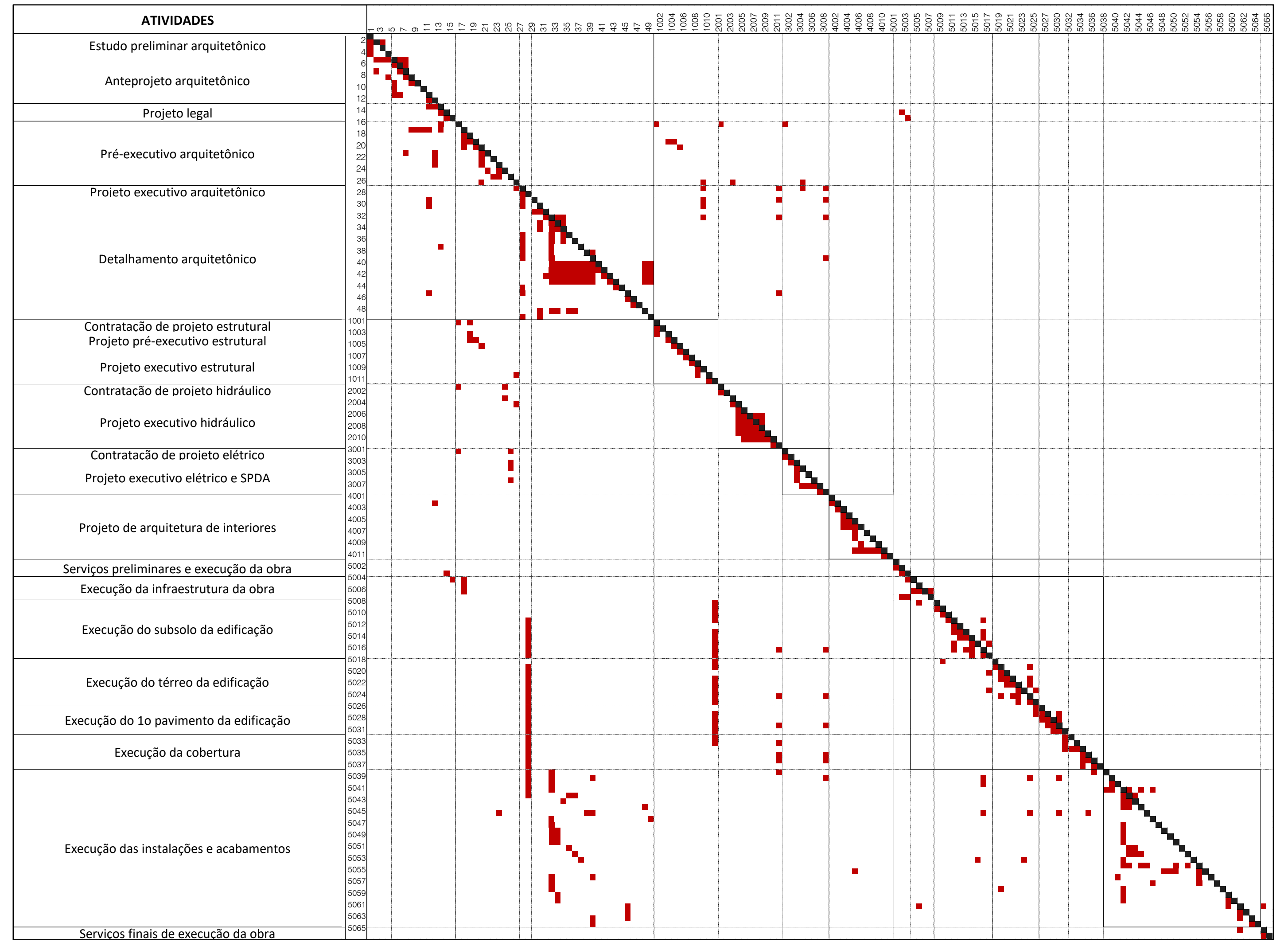

Legenda: i i solicita informaçōes relacionadas aj. (versão completa da matriz no Apêndice F). 
É notável a interação circular das atividades de projeto, que indicam uma característica iterativa e incremental da solução desenvolvida. Intraorganizacionalmente, tais iterações são observadas nas atividades de estudo preliminar, no anteprojeto, no detalhamento arquitetônico e no detalhamento hidráulico. Também interorganizacionalmente, as atividades de pré-executivo (ou projeto básico) e de detalhamento arquitetônico interagem com as demais especialidades de projeto. Neste último caso, parte considerável dos esforços de coordenação do projeto depende da cooperação entre os agentes responsáveis por cada especialidade para suprir as lacunas na definição e controle do escopo de projeto. Assim como no caso analisado, é recorrente que a contratação de um mesmo conjunto de empresas de projeto se repita em empreendimentos diferentes devido aos laços de confiança preestabelecidos.

Além disso, uma vez que o processo de projeto é predominantemente assíncrono e fragmentado, os esforços de coordenação são reduzidos com a adoção de soluções típicas, reconhecidas e difundidas no mercado. As soluções conservadoras conferem vantagens gerenciais ao empreendimento, pois reduzem problemas de compatibilização entre especialidades e os riscos da comunicação insuficiente ou de erros de interpretação das informações de projeto para a execução. Por outro lado, essa constatação corrobora apontamento realizado na análise da arquitetura da edificação: as incertezas decorrentes da assincronicidade e segmentação entre as atividades de projeto e de execução desestimulam o desenvolvimento de soluções inovadoras de projeto.

A matriz de filiação $\left(\mathrm{F}_{\mathrm{mn}}\right)$ relaciona o nível de envolvimento das atividades mapeadas na definição e implementação dos componentes da edificação edificio (Figura 36). Essa matriz mostra o grau de envolvimento das atividades do empreendimento para a realização dos componentes dos sistemas.

Durante o processo de projeto, o estudo preliminar, o anteprojeto arquitetônico e o projeto de interiores estão diretamente envolvidos na definição dos ambientes. Além disso, executivo e detalhamento arquitetônico estão envolvidos indiretamente na definição da maioria dos demais componentes, e o detalhamento arquitetônico está diretamente envolvido no sistema de revestimentos. Os projetos estruturais e hidráulicos estão diretamente envolvidos na definição do sistema estrutural, além do envolvimento direto óbvio do projeto hidráulico no sistema hidrossanitário, assim como do projeto elétrico sobre os sistemas SPDA e elétrico. 
Durante o processo de execução observa-se uma modularidade dos processos condizentes à arquitetura do sistema. As atividades diretamente envolvidas com a execução de determinados componentes se grupam de forma correspondente às atividades de projeto diretamente envolvidas em suas definições. Embora possa parecer óbvio que as atividades de definição e execução da estrutura estejam mais diretamente relacionadas ao sistema estrutural, a modularidade dos processos não foi organizada dessa forma. De modo mais ou menos evidente, é possível identificar uma correlação entre o grau de envolvimento de determinados conjuntos de atividades de projeto e de execução para cada sistema.

Distingue-se ainda o envolvimento das atividades de arquitetura sobre todos os sistemas, destacadamente o domínio sobre o sistema de integração. O envolvimento das atividades de execução das instalações e acabamento se justapõem às atividades de desenvolvimento da arquitetura, com maior envolvimento nos sistemas de vedação, de acabamentos, elétrico, hidrossanitário e de integração. Além disso, tanto as atividades de arquitetura, incluindo aqui a arquitetura de interiores, como as atividades de instalações e acabamento são os responsáveis diretos pela quase totalidade das decisões que envolvem sistemas de revestimento, de acabamento e de integração, sugerindo níveis mais altos de interação. Essa sugestão foi verificada na análise das interações potenciais, revelando ainda um conjunto de interações potenciais não previstas.

\subsubsection{Interações potenciais}

O resultado das matrizes de interações potenciais totais (Figura 37) e fortes (Figura 38) foi alcançado com a identificação do envolvimento direto, partilhado e indireto dos atores na decisão sobre os componentes do edificio.

A matriz de interações potenciais totais $\left(\mathrm{PT}_{\mathrm{mm}}\right)$ relaciona todas as interações potenciais possíveis para o desenvolvimento do produto, contudo não discrimina a importância de cada interação identificada, o que torna uma análise isolada pouco proveitosa. Por outro lado, a comparação entre os resultados da matriz de interações potenciais totais $\left(\mathrm{PT}_{\mathrm{mm}}\right)$ e os dados levantados com a matriz de interações reconhecidas $\left(\mathrm{R}_{\mathrm{mm}}\right)$, discutida na próxima seção, permite identificar quais interações reais são necessárias para a realização do edificio e quais decorrem de idiossincrasias da organização existente. 
Figura 36 - Matriz de filiação $\left(F_{m n}\right)$ - Empreendimento existente

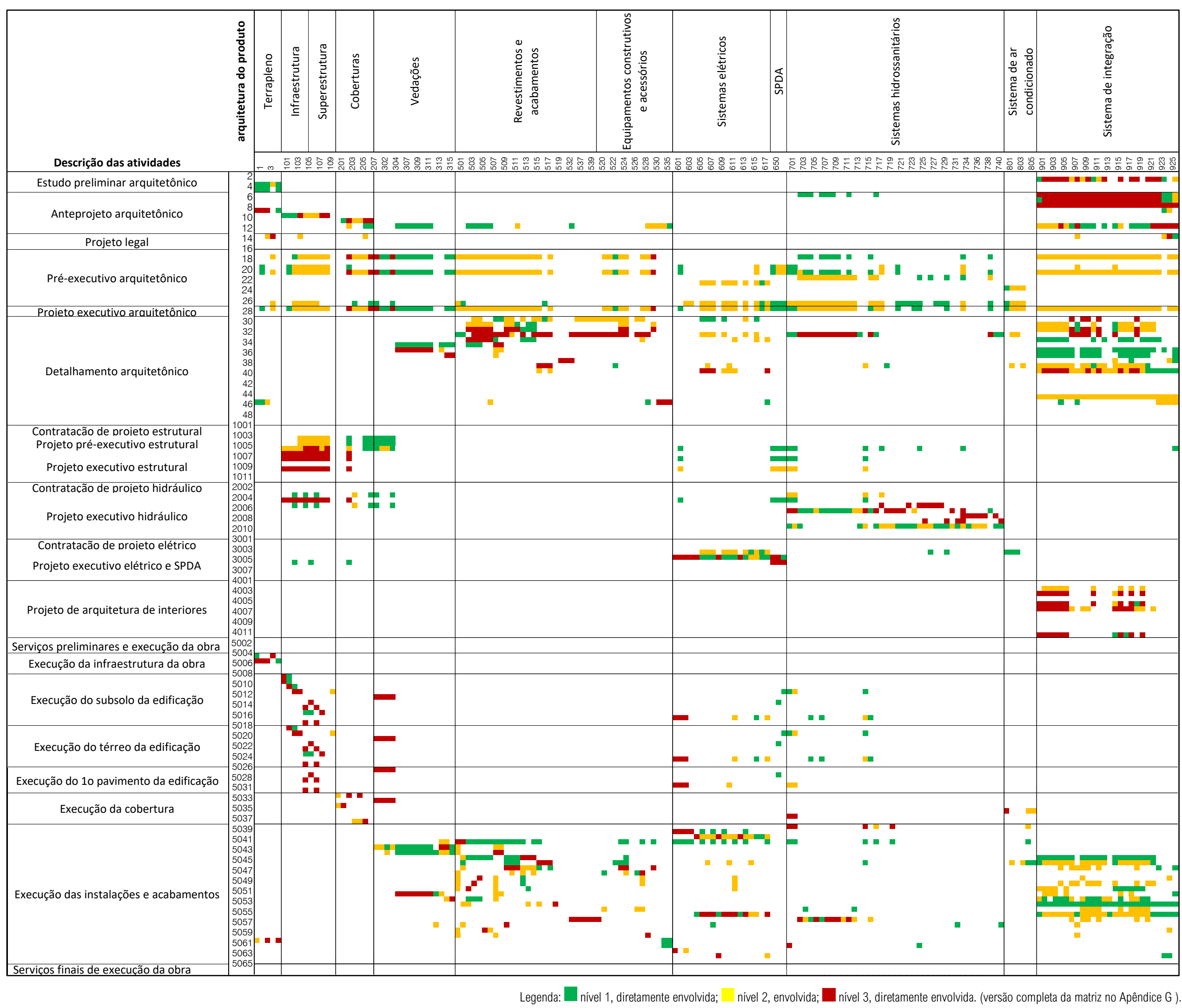


Figura 37 - Matriz de interações potenciais totais $\left(\mathrm{PT}_{\mathrm{mm}}\right)$ - Empreendimento existente

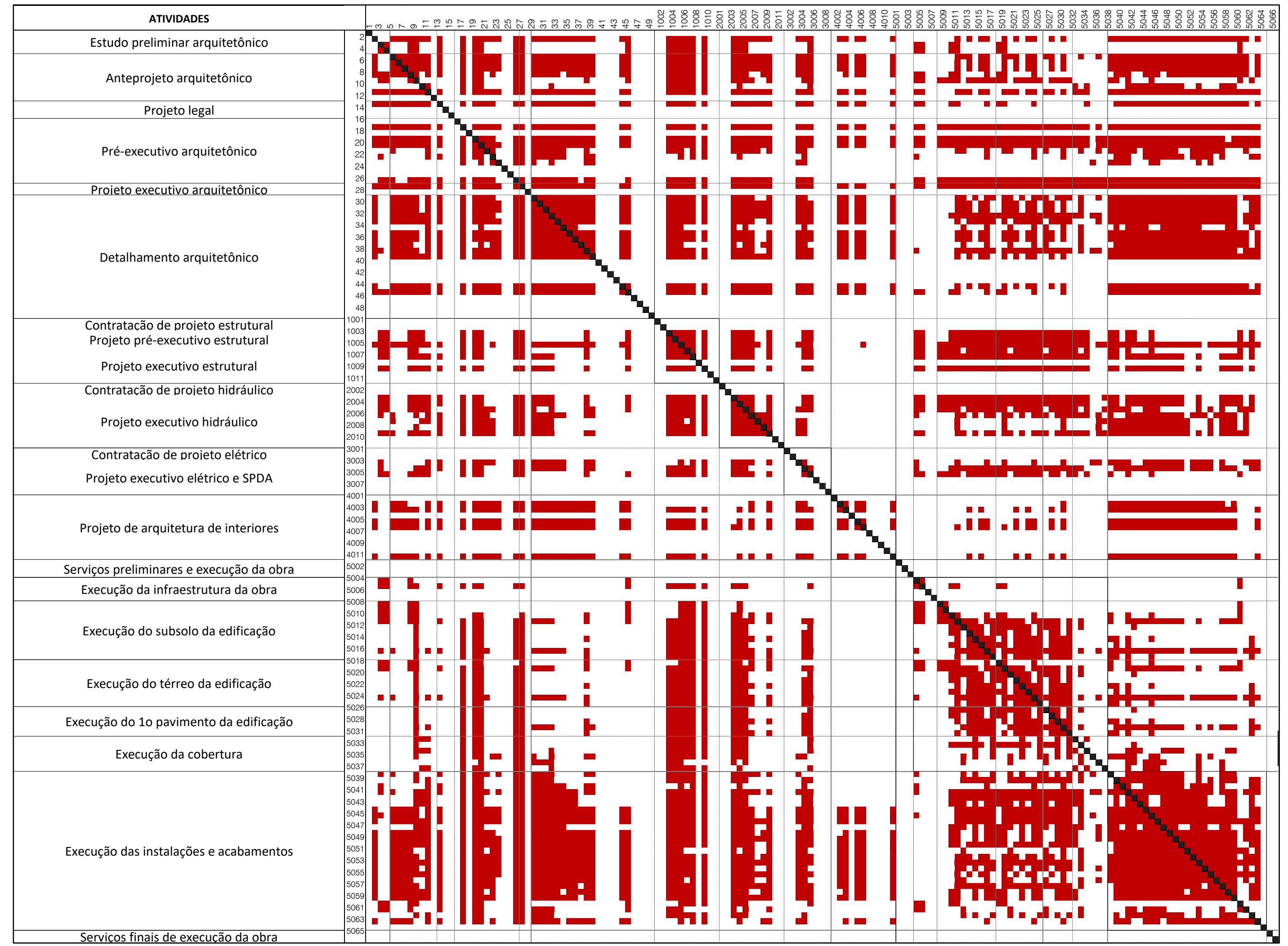

versão completa da matriz no Apêndice H 
Figura 38 - Matriz de interações potenciais fortes $\left(\mathrm{PF}_{\mathrm{mm}}\right)$ - Empreendimento existente

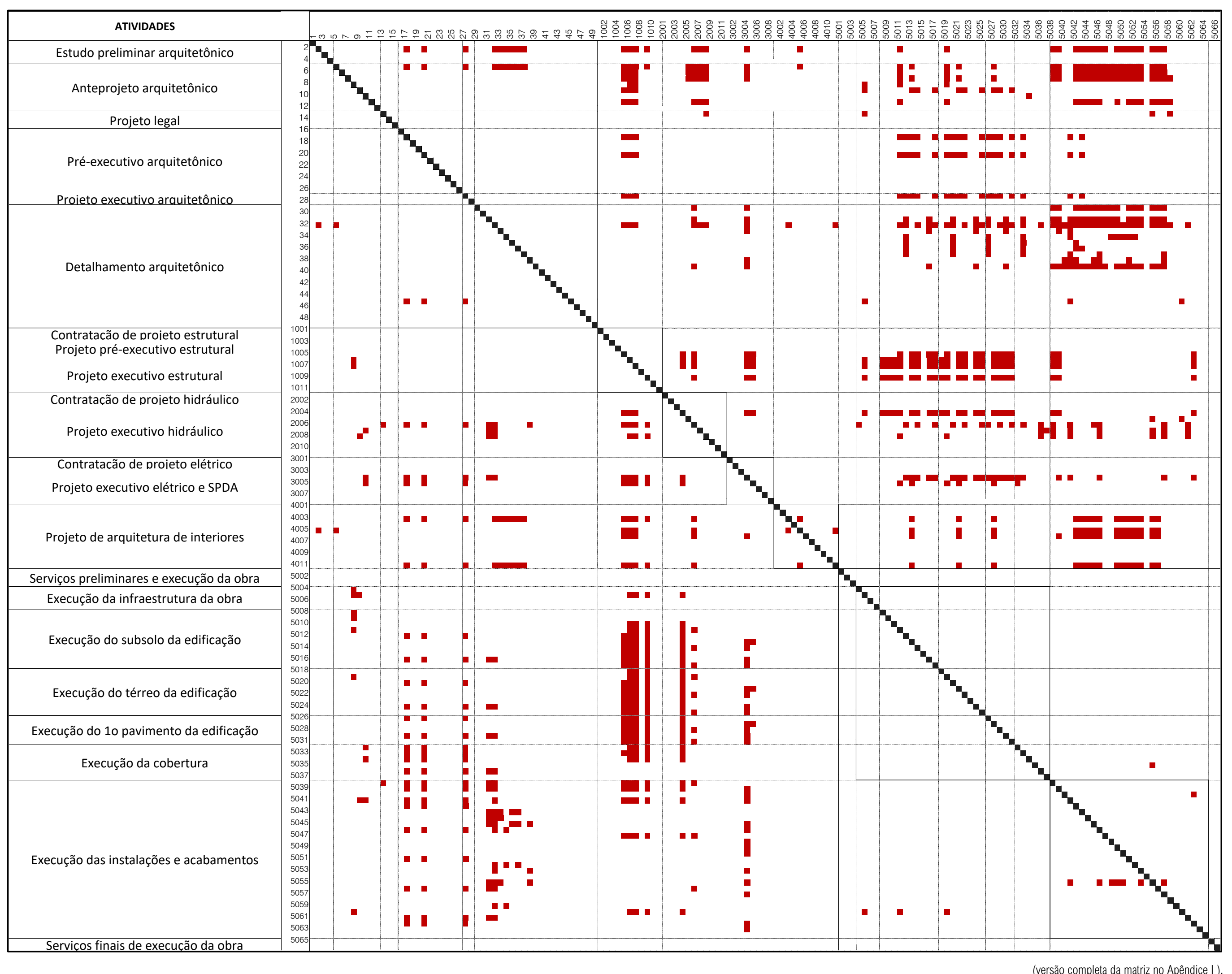


Figura 39 - Matriz de congruência $\left(C_{m m}\right)$ - Empreendimento existente

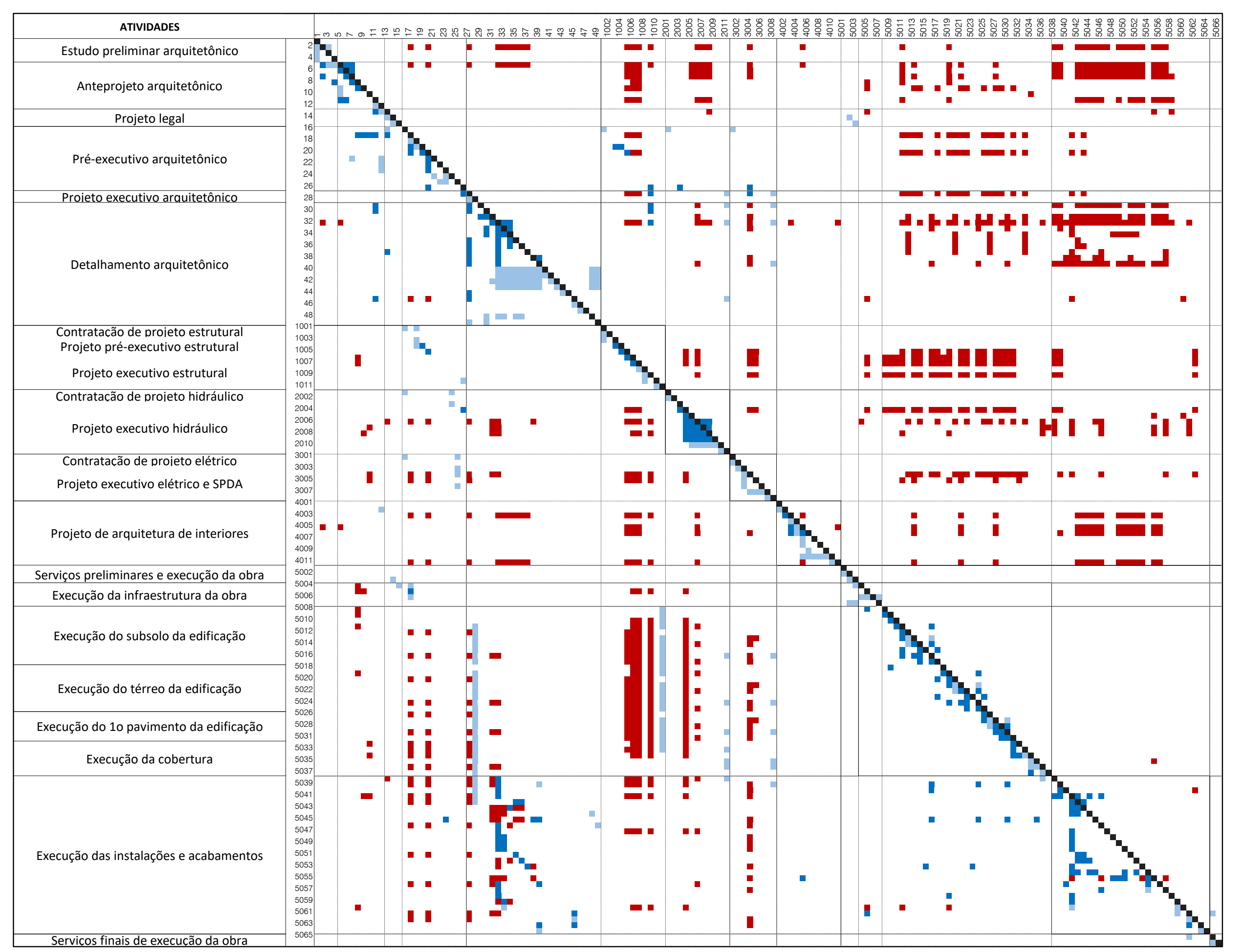

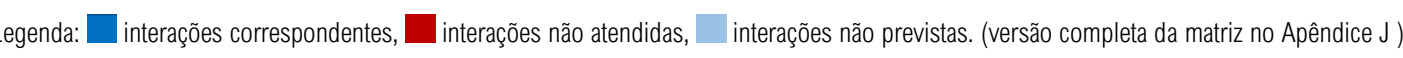


Já a matriz de interações potenciais fortes $\left(\mathrm{PF}_{\mathrm{mm}}\right)$ apresenta alguns padrões de interações que merecem atenção. Primeiramente, observa-se as interações interdisciplinares, que configuram os módulos tradicionais que originaram as divisões organizacionais entre as especialidades do projeto, em seu desenvolvimento e execução. Destacam-se a iteratividade das interações fortes das atividades no anteprojeto e no detalhamento arquitetônico, no executivo estrutural, hidráulico e elétrico.

Observa-se ainda grande quantidade de interações interdisciplinares entre o anteprojeto arquitetônico e as demais atividades subsequentes, marcadamente o executivo estrutural e hidráulico, além de atividades de execução de instalações e acabamento. O mesmo fenômeno se observa no projeto executivo estrutural com as atividades de execução da estrutura e, em menor número de situações, nas demais especialidades de projeto. As interações em questão relacionam-se ao processo de sucessivas aproximações, da concepção geral para a realidade construída, ou seja, de iteração problema-solução.

O não atendimento dessas iterações sugere que a solução no projeto eventualmente desconsiderou importantes variáveis, ligadas a atividades a jusante, ou adotou soluções conhecidas para diminuir os riscos de uma decisão não negociada, ou, ainda, reduziu o potencial de antecipação do projeto ao assumir as especificações genéricas e não detalhadas, delegando a decisão aos responsáveis pelas atividades de execução.

\subsubsection{Comparações entre as interações reconhecidas e potenciais}

A explicação inicialmente apontada para o predomínio de soluções conservadoras em projetos de edificio é ratificada pela matriz de congruência $\left(\mathrm{C}_{\mathrm{mm}}\right)$. As interações não atendidas delimitam quando a comunicação entre os responsáveis pelas atividades não possui suporte organizacional adequado. Os pontos correspondem às interações fortes, que influenciam o processo decisório no nível dos componentes. Várias dessas interações apontam a necessidade de receber informações de dada atividade, que é posterior ao desenvolvimento e à execução do projeto.

Contudo, contatou-se que nem todas as interações não atendidas realmente são desconsideradas; algumas estão deslocadas e subdimensionadas. Ao verificar a origem das interações não previstas, observou-se que elas correspondem a atividades de compatibilização, solicitação e entrega de informações de projeto. A maioria de tais 
atividades é programada contratualmente, seguindo o modelo tradicional de entregas, que pressupõe um desenvolvimento linear para o projeto, sem prever e dar suporte às interações cíclicas ou iterativas, demonstradas no mapeamento.

Outras interações não previstas são promovidas pela organização de arquitetura para suprir deficiências de um gerenciamento não integrado do desenvolvimento e execução de projeto. Esses casos foram identificados ao analisar o conjunto de atividades não previstas do detalhamento arquitetônico, em que as soluções de piso, rodapé, soleira, esquadras, etc., já decididas são discutidas com fornecedores e prestadores de serviço por ocasião da solicitação de orçamentos, em que se verifica a viabilidade de solução de componente para posterior contratação.

Embora não seja a organização responsável pela execução, não havendo um poder de controle efetivo das entregas contratadas, a antecipação da negociação e o entendimento entre arquitetura e parte dos prestadores de serviço e fornecedores da execução permite gerenciar as mudanças de projeto e contornar as barreiras organizacionais para iteração entre agentes de desenvolvimento e parte da execução. Contudo, esse esforço é subdimensionado na constituição da organização do empreendimento, que não oferece as condições adequadas para o gerenciamento da iteratividade e do entendimento compartilhado. As considerações deduzidas do mapeamento foram levadas aos profissionais envolvidos no projeto mapeado, com o objetivo de convergir e expandir o entendimento alcançado a partir da perspectiva dos agentes envolvidos no processo. Um breve relato das considerações é apresentado a seguir.

\subsection{DISCUSSÃO SOBRE A CONGRUÊNCIA ORGANIZACIONAL}

Esta subseção apresenta um resumo das considerações formuladas durante as discussões semiestruturadas, realizadas individualmente com os profissionais envolvidos no mapeamento. Os apontamentos principais estão organizados por especialidades, não se configurando como uma dedução estrita e estruturada dos dados, mas, sim, a prospecção de distintas perspectivas profissionais que eventualmente extrapolam considerações sobre o mapa da congruência organizacional.

Sob a perspectiva da arquitetura, foi levantado que o esforço para a integração e comunicação adequada das soluções de projeto é maior que os benefícios econômicos 
obtidos. Os profissionais, contudo, argumentam que o valor percebido de seu negócio está diretamente relacionado à qualidade da arquitetura do edifício, que parte da ordenação de uma coerência espacial e estética e engloba a resolução tectônica dos detalhes construtivos. Cabe destacar o histórico de atuação da empresa de arquitetura no mercado, que em diversas oportunidades integrou a responsabilidade sobre o projeto arquitetônico e o gerenciamento da execução de obras de edificio, instalações e interiores de vários projetos anteriores. A experiência de execução dos próprios projetos conferiu à empresa um domínio incomum sobre o detalhamento orientado para a construção, que permitiu aos profissionais articular soluções criativas para os requisitos de clientes e uma aplicação sofisticada de técnicas e acabamentos.

A forma de comunicação das informações do projeto se dá principalmente por meio de farta documentação dos detalhes arquitetônicos, estratificada segundo o interesse de a quem se destina esses registros, seja cliente, fornecedor ou executor. Essa atividade é bastante onerosa para a empresa, pois exige a resolução de problemas de projeto em escala e realismo adequados para antecipar a produção, o que confere beneficios para a execução com a diminuição de variabilidade e de retrabalhos decorrentes de soluções insuficientes. Assim, além de comunicar o desenho arquitetônico, também é o principal meio para conceber a solução arquitetônica, indicando um processo de tomada de decisão interno e fortemente iterativo.

Os responsáveis pela arquitetura, contudo, hesitam em considerar a integração entre os processos de projeto arquitetônico e o gerenciamento de obras uma estratégia de negócio vantajosa para um escritório de arquitetura. Inclusive, recentemente reduziram essa prática, de forma a ajustar o posicionamento da empresa como um escritório voltado para o desenvolvimento de projetos de arquitetura e, assim, se alinhar às formas de organização reconhecidas pelo mercado. Trata-se de um claro caso em que a forte influência de um isomorfismo institucional mimético se impõe à racionalidade organizacional.

Para o responsável pelo projeto estrutural o isomorfismo institucional mimético também observado em sua área de atuação decorre de características culturais do setor, que só são alteradas por pressões externas de governos, investidores e empresas de software, por meio de normas, escopo de entrega, tipos de contrato e burocracia. Aqueles que melhor compreendem e se ajustam à nova forma de organização obtêm vantagens competitivas 
evidentes durante o período de transição, mas, assim que essas mudanças se consolidam, ocorre uma tendência à homogeneização da atuação profissional, característica de isomorfismo institucional normativo e de legitimidade mercadológica ou governamental.

A não integração organizacionalmente das interações fortes e cíclicas observadas no mapeamento entre desenvolvimento e execução da estrutura impõe restrições à racionalização material da solução decorrentes de incertezas quanto ao controle rigoroso da operacionalização de procedimentos de execução mais precisos que tal racionalização exige. Como o projetista não pode garantir as condições para maior racionalidade, ele tende a adotar soluções conservadoras, que minimizam os riscos de tais variabilidades na construção. Além do esmero em documentar a solução estrutural, uma estratégia adotada pelo profissional é ser preditivo na relação com seus clientes e parceiros, estabelecendo uma agenda de antecipação de variáveis por meio de discussão e consultas, possível graças a sua grande experiência profissional e pragmatismo mercadológico.

Contudo, assim como no caso do escritório de arquitetura, tais estratégias para suprir a necessidade de interações fortes são iniciativas individuais, que sobrecarregam a atividade profissional porque não são facilitadas organizacionalmente. Se, por um lado, tais iniciativas informais configuram hoje uma vantagem mercadológica para esses profissionais, exprimem, por outro, a ineficiência da organização formal dominante no setor, que depende fortemente da cooperação das partes para o sucesso do projeto.

Como exemplo de uma organização contrastante foi apontado o caso de empresas que integram o projeto e execução de sistemas de estrutura e vedação para barracões e, assim, racionalizam produção, transporte e modularidade com maior eficácia e eficiência. Para os projetistas de arquitetura e de estrutura, a não adoção desse tipo de organização do trabalho por outros setores da construção civil, ao menos no contexto brasileiro, não se deve à inadequação de tal forma de trabalho para desenvolvimento e construção de edificios complexos, mas, sim, ao modo como o setor historicamente se organizou.

Os responsáveis pelo projeto hidrossanitário e elétrico se posicionaram de forma semelhante quanto à leitura do mapeamento da congruência organizacional, observando que, no caso específico, o lançamento de pontos hidráulicos e elétricos realizado no detalhamento arquitetônico reduziu consideravelmente a necessidade de envolvimento 
direto com a concepção do projeto, quando comparado a outros contratos em que a falta de especificações de terminais e equipamentos exige maior interação com clientes e obra. Além da relação com a arquitetura, as interações mais exigidas são ligadas ao projeto estrutural, principalmente para os sistemas hidrossanitários.

Nesse caso, o impacto das interações não atendidas entre as especialidades e a execução desse projeto são minimizados devido ao nível de previsibilidade decorrente da modularidade dos sistemas hidráulico e estrutural, da industrialização dos componentes e da melhor qualificação dos empreiteiros especialistas. Todavia, ao observar o mapeamento, o projetista hidráulico reconheceu um potencial de melhoria com uma integração entre a especificação e o levantamento do quantitativo de materiais, presente no projeto executivo hidráulico, e o processo de aquisição desses insumos, por acreditar ser o principal motivo para que as interações cíclicas identificadas ocorram.

O responsável pelo gerenciamento da obra destacou o envolvimento direto da arquitetura na negociação de conflitos decorrentes de demandas de fornecedores, por exemplo, ligadas à automação e aos acabamentos, que impuseram mudanças no desenho de gesso e instalações elétricas. Além disso, relatou mudança no procedimento de forma das estruturas de concreto, para se adequar à cultura construtiva da empresa, além de pequenas alterações nos projetos elétrico e hidráulico que não foram discutidas com os projetistas por serem compreendidas como mudanças com origem procedimental, que não alteravam a funcionalidade dos sistemas. Comentou que o projeto arquitetônico era muito detalhado, acima da média, o que, por um lado, facilitava a execução e, por outro, engessava o gerenciamento quando se exigia alguma mudança de material ou técnica para o ajuste do tempo, fornecimento de insumos e custos da obra.

\subsection{IMPLICAÇÕES PARA A PESQUISA}

A análise da congruência organizacional apresentada neste capítulo responde ao objetivo 3.1 da pesquisa e, portanto, é retomada na conclusão do trabalho para apresentar considerações sobre o isomorfismo setorial e a congruência organizacional. Além disso, são traçadas algumas considerações na conclusão sobre a perspectiva de aplicação do método de mapeamento da congruência organizacional adotado como um instrumento de gerenciamento estratégico de empreendimentos imobiliários. 
O mesmo procedimento de mapeamento utilizado neste capítulo também foi utilizado para avaliar a congruência da arquitetura organizacional descrita no capítulo 7, em que processo de projeto orientado ao valor é simulado e discutido. 


\section{ARQUITETURA ORGANIZACIONAL PARA O PROCESSO DE PROJETO ORIENTADO AO VALOR}

O mapeamento organizacional do empreendimento existente apresentado no capítulo 6 corresponde a um modelo codificado de um tipo de empreendimento recorrente em construções de empreendimento imobiliário. Sua forma contratual, baseada em modelos DBB (Design-Bid-Build), oferece maior controle ao cliente, porém impõe maior fragmentação ao fluxo de informações do projeto, o que traz maiores desafios de gestão e de liderança. O senso cooperativo e a competência dos profissionais envolvidos nesse tipo de empreendimento são fundamentais para superar tais desafios, o que se reflete no reconhecimento pelo mercado da qualidade nos serviços das empresas envolvidas. Por outro lado, a forma de organização temporária, com características menos hierárquicas e burocráticas, permite analisar um processo de projeto cujos sinais de incongruência organizacional não tenham sido gerencialmente reduzidos, a custo da normatização de atividades que não agregam valor ao resultado.

Foi neste contexto que a arquitetura do processo de projeto orientada ao valor proposta no capítulo 5 foi incorporada ao processo de projeto levantado no mapeamento do empreendimento existente. No presente capítulo as atividades da proposta de processo foram comparadas e combinadas com as atividades da organização existente; em seguida, a congruência organizacional do processo resultante dessa combinação foi simulada e analisada. A simulação foi repetida para avaliar o desempenho de dois arranjos organizacionais diferentes, de forma a subsidiar a discussão sobre a condição de congruência em cada caso.

Os diferentes arranjos apresentados não têm a pretensão de esgotar as possibilidades a serem exploradas, devendo ser compreendidos como resultados parciais de um exemplo de aplicação do método de análise da influência organizacional sobre a eficiência de novos processos de projeto. A eficiência com que novos processos são incorporados ao processo existente é avaliada por meio do nível de congruência organizacional observado. A fundamentação para tal relação foi apresentada na RSL, no capítulo 3. 


\subsection{CORRELAÇÃO ENTRE ATIVIDADES}

A correlação entre uma proposição de arquitetura de processos conceitual e a sequência de atividades de uma organização existente não é imediata. O trabalho de relacionar as tarefas deixa evidente as eventuais omissões decorrentes da limitação de um modelo teórico de processo. Tais limitações são muitas vezes ignoradas em pesquisas sobre processo de projeto, o que reduz a complexidade do trabalho; contudo, parte da relevância dos achados de pesquisas com características gerenciais decorre da verossimilhança dos modelos conceituais apresentados.

No caso estudado, em particular, as omissões observadas decorrem principalmente do recorte do processo realizado em torno das atividades de projeto da arquitetura do empreendimento e da compreensão distinta de que os processos de elaboração de uma solução são iterativos (no caso do processo proposto) em vez de sequenciais, como ocorre no caso analisado. As mudanças elaboradas para ajustar a arquitetura do processo e a arquitetura da organização são explicadas item a item a seguir.

As atividades do processo de projeto orientado ao valor, listadas no Quadro 21, foram relacionadas às atividades da organização do empreendimento existente, listadas no Quadro 23, conforme indicado na Figura 40. O primeiro aspecto a ser destacado a partir da simples análise entre as listas de atividades dos dois processos em questão se relaciona à baixa estruturação dada à captação, à análise e ao controle dos requisitos do cliente.

Enquanto o modelo conceitual formaliza as atividades que demandam a hierarquização dos requisitos associados à viabilidade técnica e financeira como parte do processo de projeto, o processo existente apresenta apenas duas atividades, a de "contratação" e a de definição do programa de necessidades, que são atividades de início, não iterativas. As iniciativas de verificação do atendimento das expectativas dos clientes não são formalizadas organizacionalmente, sendo resultado incidental de conversas e reuniões agendadas por demanda de outras atividades do projeto. Assim, não há recursos que instrumentalizem o gerenciamento de requisitos dos clientes na organização existente, o que implica que a qualidade da arquitetura resultante decorre unicamente do comprometimento dos profissionais envolvidos na concepção. 


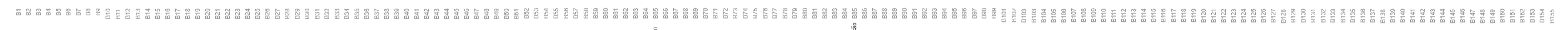
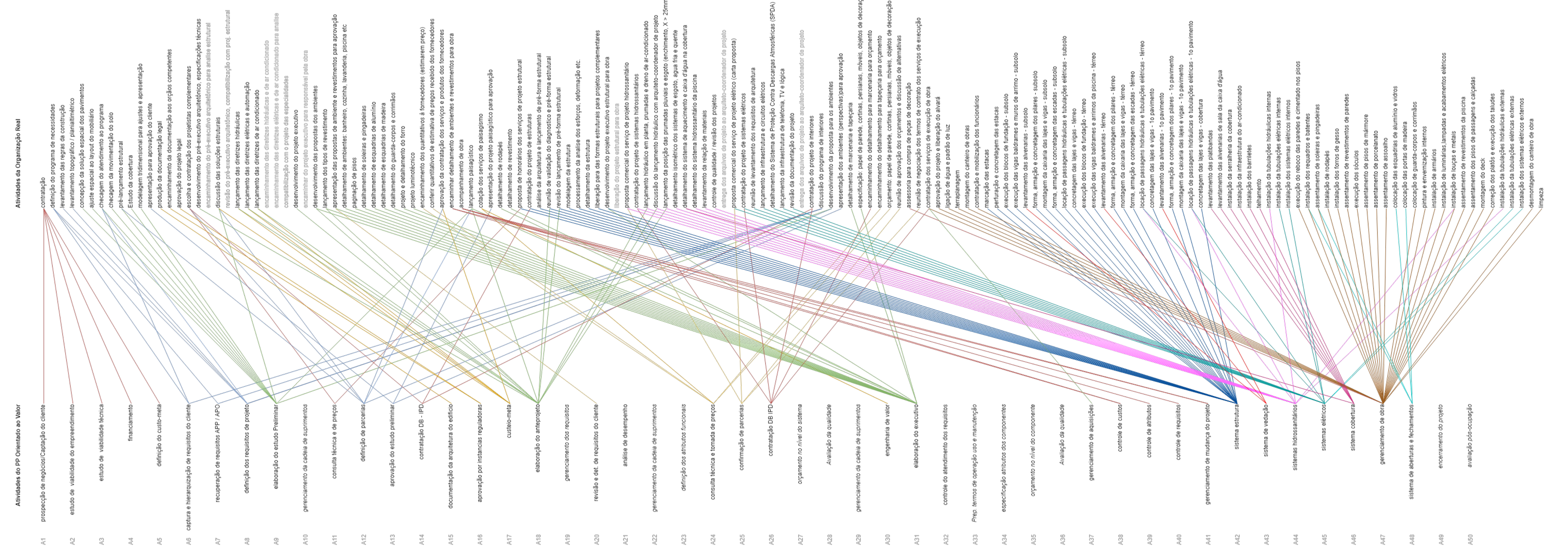


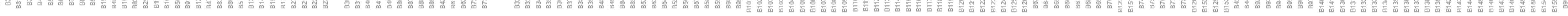

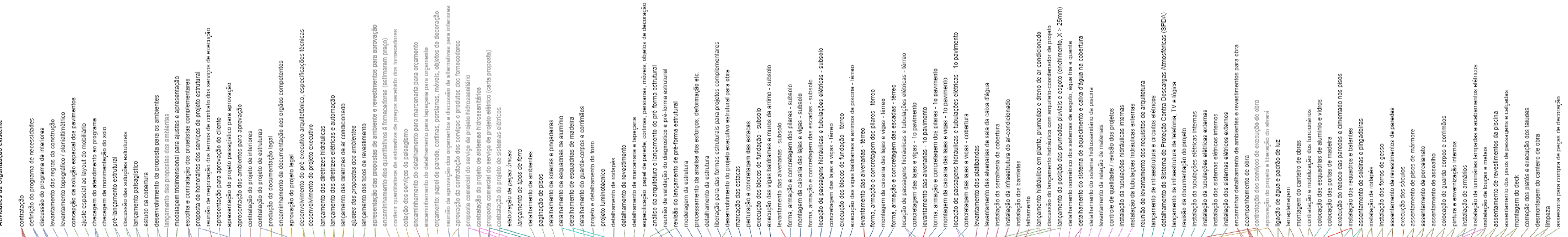


Além disso, as atividades de elaboração do projeto de arquitetura e dos demais sistemas são sequenciadas no processo existente, enquanto o modelo de processo prevê a flexibilidade de tais atividades, compreendidas como um subprocesso com característica colaborativa. O sequenciamento observado no caso existente é adequado às subdivisões funcionais, porém pouco eficiente e flexível para promover a interação entre especialidades durante a concepção e o desenvolvimento do projeto. Assim, as atividades dos projetos específicos - ligadas aos sistemas estrutural, hidrossanitário, etc. - foram relacionadas tanto à elaboração do projeto como aos correspondentes subprocessos.

As atividades de "gerenciamento da cadeia de suprimentos" não possuem paralelo na atividade da organização existente, e mesmo as atividades de "custeio-meta" e “engenharia de valor" indicadas na arquitetura do processo, embora tenham sido relacionadas Às atividades de "discussão das soluções estruturais" e do lançamento das diretrizes hidráulicas, das diretrizes elétricas e de automação, e das diretrizes de ar condicionado, não respondem às demandas esperadas do custeio-meta, nem possuem os meios para realizar o gerenciamento de custos no curso da elaboração dos projetos. Cabe salientar que essa correlação depende de uma mudança de escopo, com bases contratuais e instrumentais adequadas. Ou seja, o referido conjunto de atividades precisa ter condições de estimar os custos durante a elaboração da solução para garantir o alinhamento das soluções com o valor gerenciado pelas atividades de "definição dos requisitos de projeto", de "gerenciamento dos requisitos" e de "controle de requisitos", e precisa ter autonomia para negociar as adequações e mudanças necessárias no escopo da produção e de produto para consolidar esse alinhamento.

Algumas das atividades indicadas no processo existente com texto em cinza (Figura 40) não possuem correlato no modelo de processo e deixam de existir formalmente na reorganização das atividades (Figura 41). São atividades como de "encaminhamento das diretrizes hidráulicas e de ar condicionado", de "encaminhamento das diretrizes elétricas e de ar condicionado para análise" e de "compatibilização com o projeto das especialidades”. Além disso, uma série de atividades da organização existente mudou de lugar na lista. Por exemplo, a "discussão do programa de interiores" foi antecipada da octogésima primeira linha (Figura 40) para a terceira linha da atividade da organização existente (Figura 41). Essa conformação se justifica porque o escritório de arquitetura desenvolveu para o empreendimento existente tanto a arquitetura do edifício como a 
arquitetura dos interiores dos ambientes. Além disso, a discussão do uso dos ambientes é importante para a adequada definição dos requisitos do projeto acerca de sistemas de interação com o uso, como sistemas elétricos, telemáticos, hidráulicos, de revestimentos e acabamentos, etc.

\subsection{COMBINAÇÃO ENTRE ATIVIDADES}

A combinação entre as atividades correlacionadas anteriormente adotou alguns critérios gerais com o objetivo de não reduzir a complexidade do processo. Assim, sempre que uma atividade da organização existente corresponde a várias atividades da arquitetura de processo orientado ao valor, aquela foi substituída por estas, e quando mais de uma atividade da organização existente correspondeu a uma atividade ou subprocesso da arquitetura do processo, o conjunto de atividades foi mantido.

Tais critérios são exemplificados a seguir, com a descrição das correlações. Trata-se de um exercício de interpretação e proposição e, portanto, precisa ser compreendido circunstancialmente. A perspectiva de se realizarem diferentes combinações é parte da origem arbitral de qualquer arquitetura, contudo o que está em questão no exercício é o potencial de simulação da arquitetura resultante, de forma a subsidiar uma análise qualificada para a promoção de melhoria na qualidade do processo de projeto. Assim, arranjos diferentes destes poderão eventualmente ser realizados em outras circunstâncias, seja em outras pesquisas ou na aplicação do método em empresas, sem invalidar a contribuição da discussão dos resultados.

A explicação das combinações adotadas foi organizada segundo os ciclos estabelecidos na arquitetura do processo, iniciando-se com as atividades da concepção da arquitetura, realizadas em torno do "estudo preliminar". As atividades de desenvolvimento da arquitetura foram agrupadas em torno do "anteprojeto" e do "projeto executivo", e as atividades de gerenciamento da arquitetura, em torno do "gerenciamento de mudanças".

\subsubsection{Estudo preliminar arquitetônico}

Por exemplo, para a simulação da arquitetura organizacional, a atividade "contratação" existente foi substituída pelas atividades "prospecção de negócios/captação do cliente”, "estudo de viabilidade do empreendimento", "estudo de viabilidade técnica", 
"financiamento" e "definição do custeio-meta" para que as especificidades dessas atividades sejam organizacionalmente explicitadas, enquanto em um desenvolvimento da arquitetura organizacional com finalidade prática, mercadológica tais pontos seriam simplificados desde o início por meio de estratégias de mudança organizacional complementares, ligadas à cultura, à capacitação, etc. conforme indicado na RSL. Para o presente trabalho, a aceitação do aumento de complexidade tem como objetivo testar o falseamento do resultado esperado baseando-se apenas nos instrumentos de avaliação da congruência de mudanças no desenho organizacional do processo. Mudanças na cultura organizacional e na competência profissional, entre outras variáveis da organização de um processo de projeto, serão discutidos em outro momento, quando a simulação estiver consolidada.

Como já observado na seção anterior, a “discussão do programa de interiores” foi antecipada para a terceira linha, de forma a ser agrupada com a "discussão do programa de interiores" e relacionada à "captura e hierarquização de requisitos do cliente", "recuperação de requisitos APP/APO" e "definição dos requisitos de projeto". Esses itens substituíram as duas atividades originais, orientando o trabalho de identificação e hierarquia para as expectativas e necessidades do cliente, e não apenas se tratando de uma lista de ambientes e objetos.

Entre as atividades relacionadas ao subprocesso de "elaboração do estudo preliminar arquitetônico", a "checagem do atendimento ao programa" também apresenta correlação com a "captura e hierarquização de requisitos do cliente" e com a "definição dos requisitos de projeto", resultando em um arranjo cíclico e iterativo. Como já expresso na discussão sobre a proposição da arquitetura do processo (capítulo 5), tanto o tratamento dos requisitos como a definição do custeio-meta dependem da formalização de um ou mais partidos arquitetônicos para que se possa consolidar as metas do projeto a serem perseguidas por meio de criatividade e negociação.

A necessidade de iteração se deve porque a importância dada a um sistema em razão do potencial de atendimento a um requisito pode ser outra, dependendo das características formais, fisicas e materiais que o sistema apresenta. Assim, por exemplo, a importância dada ao sistema de cobertura de um edificio para atender aos requisitos de conforto térmico e insolação dependerá se o partido adotou platibandas ou beirais, telhas cerâmicas ou metálicas, etc. Conforme a contribuição do sistema, faz sentido atribuir mais recursos 
a sua execução, na definição do custeio-meta. Também os requisitos podem ser mais bem descritos, antecipando parâmetros de rápida verificação, como uma análise de sombreamento, a serem utilizados ainda no estudo preliminar, de forma a orientar o processo de concepção para a criação de valor sem restringir o potencial criativo com um conjunto de predefinições.

Algumas das atividades de projetos complementares foram antecipadas na lista para ser incorporadas ao subprocesso de "elaboração do estudo preliminar arquitetônico" em razão da influência das decisões para a definição da arquitetura. Foram elas o desenvolvimento da proposta para os ambientes, o lançamento paisagístico e a discussão das soluções estruturais. Essas atividades dependem da colaboração de profissionais especialistas, o que correlacionou tais atividades à "definição de parcerias" para o projeto, que, junto com a "consulta técnica e de preços", está vinculada ao "gerenciamento da cadeia de suprimentos".

A atividade "modelagem tridimensional para ajustes e apresentação" foi substituída por “preparação gráfica da apresentação do estudo preliminar para aprovação do cliente”, uma vez que a modelagem ocorreu desde o início do processo oferece uma base consistente para extrair e preparar a apresentação de informações espaciais, materiais, financeiras e procedimentais.

A “aprovação do estudo preliminar” é análoga à "apresentação para aprovação do cliente" e encerra o ciclo de concepção do projeto. Diferentemente da atividade da organização existente, além da arquitetura do edifico, ocorre aqui a aprovação da organização do empreendimento, isto é, do reconhecimento formal das relações de parceria e de aquisição até então iniciadas e da aprovação dos critérios de desempenho que regerão as negociações para as parcerias e aquisições que serão firmadas no desenvolvimento e gerenciamento da execução do projeto. Como um desdobramento da aprovação da arquitetura do edifício e da arquitetura do processo, são firmados contratos IPD entre as empresas que colaboraram para a elaboração da arquitetura, de forma a reduzir os riscos do negócio ao consolidar contratualmente os termos negociados. As atividades relacionadas às propostas de honorários, propostas comerciais, de negociação dos termos de contrato, etc., que dizem respeito à definição dos intervenientes do projeto, foram substituídas pelas tarefas de "tomada de preço", de “definição/consolidação de parcerias" e de "contratação IPD”. 
Com a aprovação da arquitetura do estudo preliminar, inicia-se um processo burocrático de aprovação do projeto a ser executado. Enquanto a organização existente identifica e separa as atividades de "produção da documentação legal", de "encaminhamento da documentação aos órgãos competentes" e de "aprovação do projeto legal" como uma etapa subsequente independente, a arquitetura do processo incorpora as atividades correspondentes, de "documentação da arquitetura do edificio" e de "aprovação por instâncias reguladoras", como atividades subsequentes, porém pertencentes à etapa de concepção da arquitetura. Assim, a concepção se encerra quando o conjunto de clientes com poder de veto e sem nenhuma responsabilidade técnica objetiva sobre o empreendimento avaliza a proposta.

Respeitando o critério de não simplificação do processo, após a atividade de "documentação da arquitetura do edificio" e antes da "aprovação por instâncias reguladoras", foi adicionado o "encaminhamento da documentação aos órgãos competentes". A adição também se justifica quanto à designação dos agentes envolvidos, que não coincidem nesses três casos, pois engloba trabalhos internos ao processo de projeto da concepção da arquitetura e processos externos, ligados às organizações reguladoras, que avaliam e homologam a arquitetura segundo regulamentação específica.

\subsubsection{Anteprojeto arquitetônico}

A etapa da organização existente denominada de "projeto pré-executivo" teve suas atividades correlacionadas às atividades ligadas ao ciclo de "anteprojeto arquitetônico" da arquitetura organizacional. O anteprojeto se inicia com o "custeio-meta", em que os sistemas concebidos são analisados e quantificados de forma a se iniciar o balanceamento do despendimento dos recursos disponíveis por meio do "desenvolvimento do anteprojeto arquitetônico", quando as soluções são tecnicamente detalhadas segundo as demandas de quantificação e análise de desempenho.

Por meio da colaboração com projetistas dos sistemas contratados, é realizado o "lançamento dos sistemas hidrossanitários", em que se definem os pontos hidráulicos, as prumadas pluviais, o poço artesiano, o ar-condicionado, os espaços técnicos, etc.; o "lançamento dos sistemas de energia elétrica, comunicação, aterro e automação", em que componentes como a iluminação, as tomadas, os interruptores, os terminais de telemática, entre outros, são locados e as principais informações das características 
materiais e de funcionamento são adicionadas; e soluções para sistemas mais específicos, como o lançamento de ar condicionado.

As atividades relacionadas ao "gerenciamento dos requisitos" não possuem correlatos na organização existente. Constituem parte fundamental da capacidade de gerenciamento de valor no processo de projeto, que visa orientar as decisões para atender às expectativas e às necessidades dos clientes do projeto.

A "revisão e detalhamento de requisitos do cliente" é um processo iterativo ao desenvolvimento do anteprojeto arquitetônico. Tem como objetivo atualizar os requisitos do cliente e complementá-los para corresponder ao nível de desenvolvimento do projeto, mais detalhado e específico. Para apoiar o gerenciamento do requisito, a “análise de desempenho" da arquitetura permite aferir as variáveis mensuráveis e arbitrar atributos do projeto que respondem às demandas expressas pelos requisitos do cliente. Com base nessas variáveis, alternativas de projeto podem ser comparadas, assim como a importância dos requisitos pode ser redefinida junto ao cliente, com repercussão para o balanceamento do custeio-meta por meio da "definição dos atributos funcionais" para os sistemas e componentes do edificio.

A “definição dos atributos funcionais" permite estruturar a orçamentação segundo unidades de valor, associando os custos de produção a determinados desempenhos esperados. Tal forma de estruturação orienta o custeio-meta para negociar melhores condições de realização, de forma a balancear os custos dispendidos com a importância dos requisitos atendidos. Essa avaliação é feita por meio de uma “avaliação da qualidade”, baseada em instrumentos de gestão de valor, que relacionam a importância dos requisitos e os custos dos atributos funcionais. Dois exemplos desses instrumentais foram apresentados nos dois estudos exploratórios da análise da influência organizacional sobre o gerenciamento de valor no processo de projeto (capítulo 3).

\section{Iteração em espiral}

O anteprojeto e o projeto executivo correspondem a dois ciclos de atividades iterativos em que as soluções de projeto são desenvolvidas e detalhadas de forma incremental, das especificações gerais para os subsistemas ao detalhamento material, tecnológico e produtivo de componentes dos sistemas. Isso significa que o projeto executivo 
construtivo de estruturas, vedações e cobertura demandam a realização do anteprojeto de detalhes construtivos de arquitetura específicos para os ambientes, como paginação de piso e revestimentos, soleiras e pingadeiras, etc. Por sua vez, o projeto executivo desses detalhes arquitetônicos depende de informações detalhadas do executivo dos outros subsistemas, principalmente aqueles que apresentam alguma interface de operação, como os sistemas elétricos, hidráulicos e de aberturas, para ajustar a execução de acabamento e garantir condições de uso, operação e manutenção adequadas, harmonia estética, etc. Assim, as atividades de "desenvolvimento das propostas dos ambientes" e de "lançamento dos tipos de revestimento" da organização existente correspondem ao conjunto de atividades de "desenvolvimento do anteprojeto arquitetônico", enquanto a "apresentação das propostas de ambiente e revestimentos para aprovação do cliente" é um desdobramento da "revisão e detalhamento dos requisitos do cliente".

No modelo de processo de projeto proposto, a interação entre a atividade de "controle do atendimento dos requisitos" do projeto executivo e a atividade de "gerenciamento dos requisitos" do anteprojeto indica a iteração entre os dois ciclos. Essa repetição de uma mesma atividade, agora orientada para a captação de preferências do cliente a respeito de detalhes de acabamento e de funcionalidade dos equipamentos da edificação, é mais adequada que a indicação de uma atividade nova, com escopo e tempo distintos, pois permite integrar e evoluir os requisitos já definidos por meio do "gerenciamento dos requisitos".

$\mathrm{Na}$ combinação desse modelo com a organização existente, as atividades de "ajustes das propostas dos ambientes" e de "lançamento dos tipos de revestimento" foram mantidas, pois apresentam iterações específicas, ligadas à revisão de concepção decorrente da demanda por ajustes do executivo. São atividades que se comportam, na prática, como a atividade da "elaboração do anteprojeto arquitetônico", iniciada posteriormente, a partir de uma demanda específica das atividades de detalhamento do projeto executivo arquitetônico. A indicação de tais atividades específicas deve ser compreendida como gatilhos que acionam a iteração em que o ciclo de elaboração do anteprojeto é acionado para apresentar uma solução específica para o detalhamento do executivo (Figura 42).

Como indicado na Figura 42, outras duas atividades ligadas à demanda de detalhamento foram criadas como gatilho: a "elaboração de peças únicas", para o detalhamento de 
guarda-corpos e corrimãos, e o "lançamento do forro". Tais atividades acionam mecanismos próprios da "elaboração do anteprojeto arquitetônico", o que permite um apuramento das especificações associadas ao "gerenciamento dos requisitos" aplicado ao detalhamento de acabamentos. Por fim, como sugerem as setas que retornam para a atividade gatilho, o processo de detalhamento é retomado uma vez balanceadas as relações de custos e séquitos, saltando as atividades já realizadas que não são impactadas com o novo ciclo de concepção.

Figura 42 - Iteração em espira entre anteprojeto e executivo arquitetônico

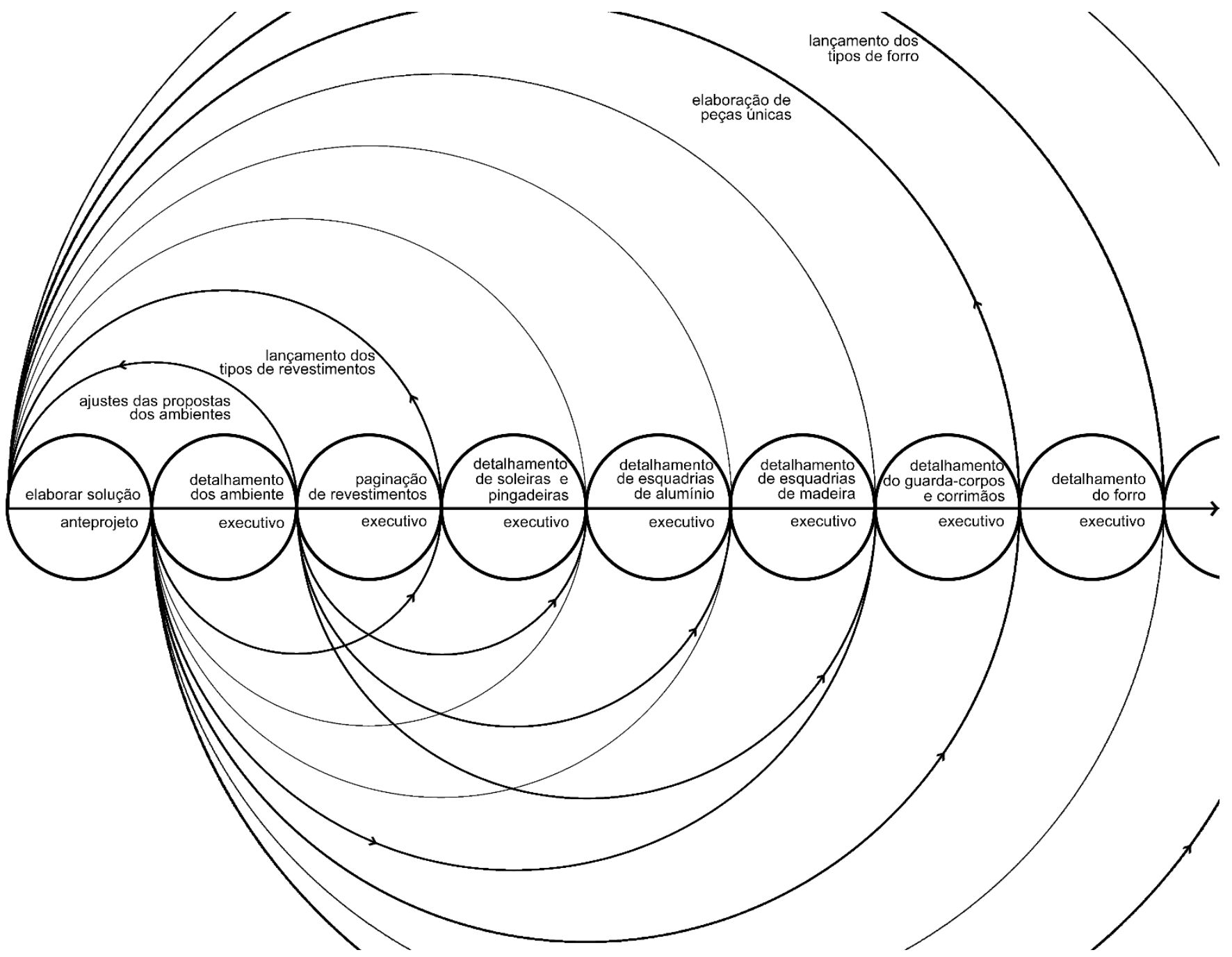


Associada a elaboração da solução em nível de anteprojeto, as atividades de gerenciamento de requisitos e de custeio-meta encadeiam a sequência de análises de desempenho, de atribuição de funcionalidade e de avaliação da qualidade. Assim, algumas atividades associadas aos gatilhos para a elaboração de uma solução foram identificadas como redundâncias às atividades pertencentes ao ciclo de elaboração do anteprojeto e por isso foram combinadas com elas, sendo suprimidas da lista. Por exemplo, a "apresentação das propostas de ambiente e revestimentos para aprovação do cliente" foi incorporada à "revisão e detalhamento de requisitos do cliente"; ou ainda, o "encaminhamento dos quantitativos aos fornecedores para estimarem um preço" e a atividade de "conferir quantitativos de estimativa de pregos recebidos dos fornecedores" foram incorporados à atividade de "consulta técnica e tomada de preços", que integra o "gerenciamento da cadeia de suprimentos".

Outras atividades ligadas ao projeto executivo e ao projeto de interiores também foram combinadas com as atividades que integram o ciclo de elaboração do anteprojeto. Algumas delas atividades são "apresentação das propostas de ambiente e revestimentos para aprovação", "encaminhamento dos quantitativos a fornecedores (estimarem preço)", "conferir quantitativos de estimativa de pregos recebidos dos fornecedores" e “cotação dos serviços de paisagismo". As combinações que reduziram atividades da organização existente estão destacadas em cinza, na segunda coluna da Figura 41. Nesses casos, a redução das atividades não significa a redução da complexidade, pois significa uma forma de interação cíclica impactante. Outros casos de combinação semelhantes foram observados entre as atividades do clico de anteprojeto e do projeto executivo. Esses casos são abordados na subseção seguinte.

Além dos gatilhos já mencionados, foram criadas algumas atividades sem paralelo no modelo de processo ou na organização existente. São atividades de elaboração de soluções de anteprojeto demandadas por atividades de detalhamento de subsistemas do executivo não suficientemente supridas pelas informações inicialmente modeladas. São atividades como "elaboração de peças únicas" para guarda-corpos, corrimões, etc., e "lançamento de tipos de forro". São atividades de desenvolvimento de anteprojeto que dependem de informações do executivo para serem realizadas. Estes casos também são retomados na subseção seguinte. 


\subsubsection{Projeto executivo arquitetônico}

Assim como observado no estudo preliminar e no anteprojeto, o projeto executivo possui a atividade de "gerenciamento da cadeia de suprimentos". Neste caso, porém, a atividade não se relaciona mais à "consulta técnica e tomada de preços", à "confirmação de parcerias” ou à “contratação IPD”, mas, sim, à coordenação dos subprocessos ligados aos sistemas especializados que compõem a arquitetura, de forma a viabilizar a negociação para a "engenharia de valor". As precedências dessa atividade estão relacionadas às tomadas de decisão do anteprojeto e é por meio dessas informações que o ciclo de desenvolvimento do projeto executivo tem início.

O "detalhamento de ambientes", como banheiros, cozinha, lavanderia, piscina, etc., a "paginação de pisos", o "detalhamento de soleiras e pingadeiras", o "detalhamento de esquadrias de alumínio", o "detalhamento de esquadrias de madeira”, o "detalhamento do guarda-corpos e corrimãos", o "detalhamento do forro" e o "detalhamento luminotécnico" são atividades relacionadas diretamente ao desenvolvimento do projeto executivo e aos gatilhos de iteração com o anteprojeto, mencionados na seção anterior. Como indicado na Figura 42, essas atividades dependem de informações sobre soluções de arquitetura devidamente valorizadas segundo procedimento modelado na arquitetura de processo.

Informalmente, o detalhamento do executivo realizado na organização existente já apresentava a interação com profissionais responsáveis pelos projetos específicos e execução de serviços especializados da obra, porém essa prática não era sistematizada, o que aumentava a variabilidade do processo e subdimensionava a complexidade interativa. $\mathrm{Na}$ arquitetura organizacional orientada ao gerenciamento de valor, a simulação do processo de projeto explicita essa interação, orientando o detalhamento para a negociação com os agentes da cadeia de suprimentos. Assim as atividades de detalhamento sempre apresentam o envolvimento direto de mais de um agente, mobilizado antecipadamente mediante consultas técnicas, tomada de preços, definição e confirmação de parcerias realizadas na elaboração do projeto.

$\mathrm{Na}$ arquitetura do processo orientada ao valor o projeto executivo assume definitivamente características de projeto orientado para a produção. Por meio da engenharia de valor, as definições de operação são alinhadas aos objetivos do projeto, de 
forma a equilibrar ganhos de qualidade do produto e melhorias da eficiência de produção. Nesse sentido, as atividades de "especificação de atributos dos componentes" e "orçamento no nível do componente" são instrumentais para balizar o "controle do atendimento dos requisitos" por meio da "avaliação da qualidade".

Esse ciclo de gerenciamento de valor no processo de projeto está diretamente ligado ao gerenciamento de processos complementares, ligados às especialidades de sistemas construtivos integrados na arquitetura. Estes não compõem o processo de projeto da arquitetura, mas têm influência sobre sua eficiência devido à interação existente. Embora tais processos não tenham sido detalhados na arquitetura de processos proposta, é possível organizar as atividades existentes analogamente, de forma a viabilizar a interação no empreendimento.

\section{Sistemas estruturais, sistemas hidrossanitários e sistemas elétricos}

A arquitetura do processo de projeto teve como foco as atividades ligadas diretamente ao sistema de integração, não estruturando uma arquitetura de processos específica para os demais sistemas funcionais que compõem a arquitetura do edificio. Todavia, a fim de realizar uma comparação entre uma organização tradicional de empreendimentos imobiliários, que segmenta o processo de projeto e de execução de cada sistema em razão da especialização funcional, com uma organização que segmenta modularmente o processo de projeto, integrando as competências e as informações de cada sistema, foram projetados dois cenários distintos por um escritório de projeto especializado para os sistemas que contam com um projeto específico.

No primeiro cenário, a segmentação interorganizacional das interações entre projeto e execução foi mantida da forma como foi mapeada no estudo de caso do empreendimento existente (Capítulo 6). Nesse arranjo, as atividades de projeto dos sistemas e de sua execução são realizadas por empresas diferentes, e os escritórios de projeto cooperam com o responsável pela execução, esclarecendo dúvidas, subsidiando tecnicamente e revisando as definições de projeto em face de incompatibilidades observadas em obra.

No segundo cenário, as atividades relacionadas aos processos de projeto e de construção do sistema construtivo foram reunidas de forma a integrar as responsabilidades e a interação de competências e de informações sobre o sistema. Assim, desde as atividades 
iniciais de proposta de honorários e de contratação de serviços de projeto estrutural até as atividades finais da execução do sistema construtivo, ou seja, todas as atividades ligadas diretamente a fundações e à estrutura identificadas junto aos profissionais envolvidos na organização existente foram rearranjadas organizacionalmente de forma a agrupá-las. Cabe observar que, como não se realizou um exercício de arquitetura de processo semelhante ao realizado para o sistema de integração, de responsabilidade da arquitetura do edifício, os resultados encontrados no segundo cenário refletem uma condição de aumento de congruência inferior ao possível de ser projetado. Ainda assim, os ganhos expressos por um alinhamento do arranjo ao princípio de integração de competências e informação foram significativos.

Algumas mudanças foram realizadas em ambos os cenários para adequar as relações de precedências e de responsabilidade dos agentes envolvidos na arquitetura do processo proposta para o sistema de integração. Por exemplo, o início do envolvimento do projetista estrutural foi antecipado para a concepção da arquitetura do edifício, e a cooperação deste foi formalizada, adicionando-o como um agente envolvido nas atividades de construção das fundações e da estrutura. Em outro ajuste o projetista da arquitetura passa a se envolver na atividade de "desenvolvimento do projeto executivo estrutural para obra" por meio da "gestão da cadeia de suprimentos", em que o grau de maturidade suficiente do modelo do projeto é negociado.

Além disso, em decorrência da reestruturação do sistema de comunicação da informação, com a adoção do iBIM, as atividades de liberação dos projetos estrutural, hidrossanitário e elétrico para a obra deixam de existir enquanto marco contratual de entrega de subproduto, passando a uma instância de decisão interna sobre a arquitetura, integrada à atividade de "desenvolvimento do projeto executivo estrutural para obra". No geral, a maioria das informações de precedência das atividades dos projetos específicos e de execução da obra foi mantida como levantada originalmente, o que permite uma leitura comparada entre os mapas da situação existente e da projetada.

\section{Sistema de vedação, de cobertura e de aberturas e fechamentos}

No empreendimento sobre o qual a arquitetura organizacional se baseia não houve um projeto de paginação de alvenaria ou qualquer cuidado semelhante. A execução das prumadas de vedação foram realizadas com as informações do projeto arquitetônico. Trata-se de um sistema cujas atividades estão distribuídas ao longo do processo de 
execução de outros sistemas, de tal forma que tem o maior número de interfaces com os demais sistemas, como os sistemas estrutural, de aberturas e fechamentos, hidrossanitários, elétricos, revestimentos, etc. Sob essa perspectiva, o envolvimento direto da equipe responsável pela arquitetura no sistema de vedação é, na arquitetura do edificio apresentada, coerente com a demanda por articulação dos demais sistemas. Por outro lado, como a arquitetura é responsável pelo gerenciamento do sistema de integração, orientado ao valor, oportunidades ligadas a melhorias orientadas à transformação podem ser desperdiçadas.

Os sistemas de cobertura e de aberturas e fechamentos possuem projetos para produção, porém as atividades não puderam ser mapeadas. De fato, ambos já são sistemas modularizados inseridos em uma organização de especialização funcional. Diferentemente dos sistemas elétricos e hidrossanitários, que utilizam a comunalidade de componentes industrializados, a produção das esquadrias e da cobertura oferece componentes prontos, projetados e executados considerando o planejamento da produção, o aproveitamento de material e a logística de transporte. O sequenciamento das atividades de execução da instalação desses sistemas no canteiro de obra, observado no caso existente, não foi alterado na proposta de arquitetura organizacional.

\subsubsection{Gerenciamento da execução da arquitetura}

Conforme observado na reorganização das atividades da organização existente (Figura 41), todo um conjunto de atividades ligadas à arquitetura foi adicionado ao processo de projeto do empreendimento imobiliário para promover o gerenciamento de valor na execução do edificio. As atividades de gerenciamento da execução da arquitetura compreendem o "controle dos custos e do tempo" de execução do projeto; o "controle do escopo" dos componentes e serviços associados à produção; e o "controle dos atributos" de atendimento aos requisitos de projeto. Compreendem ainda o "gerenciamento de aquisições", atividade responsável pelo fomento de insumos para a execução dos serviços finos de revestimento, acabamento e instalação de equipamentos.

No caso específico, os serviços de levantamento das empenas de vedação também são de responsabilidade da arquitetura, cabendo ao gerenciamento de aquisições subsidiar esse serviço. O "gerenciamento de mudanças do projeto" tem como finalidade promover mudanças discretas nas variáveis do projeto, seja balanceando os custos e o 
tempo despendido em cada atividade de transformação, seja revisando soluções formais da arquitetura para viabilizar a adequação da construção aos atributos de projeto, definidos no desenvolvimento da arquitetura.

Tanto as atividades de controle de tempo, custo e escopo quanto o gerenciamento de mudanças do projeto apresentam envolvimentos indiretos na definição dos atributos do edificio. Como mecanismos de controle da qualidade da arquitetura, essas atividades permitem que a organização responsável pela arquitetura promova a melhoria contínua dos processos decisórios, de comunicação da informação, de integração dos sistemas e da criação de valor para os clientes finais. Nesse sentido, associada ao "encerramento do projeto", a realização de uma "avaliação pós-ocupação" com o acompanhamento do gerenciamento predial retroalimenta as atividades iniciais de "prospecção de negócios e captação de clientes", a "recuperação de requisitos de APP/APO" e a "preparação dos termos de operação, uso e manutenção".

\subsubsection{Considerações sobre a combinação}

$\mathrm{O}$ arranjo resultante da combinação entre a arquitetura de processos proposta e a estrutura de processo do empreendimento existente é resultado de um trabalho analítico e criativo, que confere alguma arbitrariedade ao resultado. O objetivo de uma arquitetura de processo é induzir um estado projetado, não existente, visando ganhos às atividades humanas. Portanto, algumas decisões foram arbitradas pelo pesquisador e colaboradores.

A respeito da sequência de atividades dessa arquitetura, cabe destacar que sempre que possível o trabalho de correlação e combinação das atividades de ambos os processos buscou respeitar nomenclaturas reconhecidas pelo setor. Eventualmente, alguns termos foram substituídos para evitar uma interpretação equivocada em decorrência da ambiguidade. Por outro lado, alguns termos tradicionais assumiram contornos diferentes, como o entendimento dos resultados esperados do anteprojeto e projeto executivo. Descartadas eventuais idiossincrasias que tal lista de atividades pode conter, entendeu-se que as atividades do processo proposto foram suficientemente descritas de forma a mitigar as dúvidas gerais sobre a forma de organização.

A sequência das atividades combinadas resultante está listada no Quadro 24, nos mesmos moldes feitos no mapeamento da congruência organizacional realizada no empreendimento imobiliário existente. 


\section{Quadro 24 - Lista das atividades combinadas para a arquitetura organizacional}

Estudo preliminar arquitetônico

0001 - Prospecção de negócios/Captação do cliente

0002 - Estudo de viabilidade do empreendimento

0003 - Estudo de viabilidade técnica

0004 - Financiamento

0005 - Definição do custo-meta

0006 - Captura e hierarquização de requisitos do cliente

0007 - Recuperação de requisitos APP/APO

0008 - Definição dos requisitos de projeto

Elaboração do estudo preliminar arquitetônico

0009 - Concepção da solução espacial dos pavimentos

0010 - Ajuste espacial ao leiaute do mobiliário

0011 - Checagem do atendimento ao programa

0012 - Checagem da movimentação do solo

0013 - Lançamento estrutural

0014 - Estudo da cobertura

0015 - Desenvolvimento da proposta para os ambientes

0016 - Lançamento paisagístico

0017 - Preparação gráfica da apresentação do estudo preliminar para aprovação do cliente

0018 - Definição de parcerias

0019 - Consulta técnica e de preços

0020 - Aprovação do estudo preliminar

0021 - Contratação DB-IPD

0022 - Documentação da arquitetura do edifício

0023 - Encaminhamento da documentação aos órgãos competentes

0024 - Aprovação por instâncias reguladoras

\section{Anteprojeto arquitetônico}

0025 - Custeio-meta

0026 - Desenvolvimento do anteprojeto arquitetônico

0027 - Lançamento dos sistemas hidrossanitários

0028 - Lançamento dos sistemas de energia elétricas, comunicação, aterro e automação

0029 - Lançamento dos sistemas de ar condicionado

0030 - Gerenciamento dos requisitos

0031 - Revisão e detalhamento de requisitos do cliente

0032 - Análise de desempenho

0033 - Definição dos atributos funcionais

0034 - Gerenciamento da cadeia de suprimentos

0035 - Consulta técnica e tomada de preços

0036 - Definição e confirmação de parcerias

0037 - Contratação DB-IPD

0038 - Orçamento no nível do sistema

0039 - Avaliação da qualidade

0040 - Ajustes das propostas dos ambientes

0041 - Lançamento dos tipos de revestimento

0042 - Elaboração de peças únicas

0043 - Lançamento de tipos de forro

\author{
Projeto executivo arquitetônico
}

0050 - Gerenciamento da cadeia de suprimentos

0051 - Engenharia de valor

0052 - Detalhamento de ambientes

0053 - Paginação de pisos

0054 - Detalhamento de soleiras e pingadeiras

0055 - Detalhamento de esquadrias de alumínio

0056 - Detalhamento de esquadrias de madeira

0057 - Detalhamento do guarda-corpos e corrimãos

0058 - Detalhamento do forro

0059 - Detalhamento luminotécnico

0060 - Detalhamento de rodapés

0061 - Detalhamento de revestimento

0062 - Detalhamento de marcenaria e tapeçaria de móveis

0063 - Especificação de papel de parede, cortinas, persianas, móveis, objetos de decoração, etc.

0064 - Controle do atendimento dos requisitos

0065 - Preparação dos termos de operação uso e manutenção

0066 - Especificação de atributos dos componentes

0067 - Orçamento no nível do componente

0068 - Avaliação da qualidade

Projeto do sistema estrutural

1001 - Proposta de honorários dos serviços de projeto estrutural

1002 - Contratação do projeto de estruturas

1003 - Análise da arquitetura e lançamento de pré-forma estrutural

1004 - Reunião de validação do diagnóstico e pré-forma estrutural

1005 - Revisão do lançamento de pré-forma estrutural

1006 - Modelagem da estrutura

1007 - Processamento da análise dos esforços, deformação, etc.

1008 - Detalhamento da estrutura

1009 - Liberação para das formas estruturais para projetos complementares

1010 - Desenvolvimento do projeto executivo estrutural para obra

Execução do projeto estrutural

1101 - Marcação das estacas

1102 - Perfuração e concretagem das estacas

1103 - Execução dos blocos de fundação - subsolo

1104 - Execução das vigas baldrames e muros de arrimo - subsolo

1105 - Forma, armação e concretagem dos pilares - subsolo

1106 - Montagem da caixaria das lajes e vigas - subsolo

1107 - Forma, armação e concretagem das escadas - subsolo

1108 - Concretagem das lajes e vigas - térreo

1109 - Execução dos blocos de fundação - térreo

1110 - Execução das vigas baldrames e arrimos da piscina - térreo

1111 - Forma, armação e concretagem dos pilares - térreo

1112 - Montagem da caixaria das lajes e vigas - térreo

1113 - Forma, armação e concretagem das escadas - térreo

1114 - Concretagem das lajes e vigas - $1^{\circ}$ pavimento

1115 - Forma, armação e concretagem dos pilares - $1^{\circ}$ pavimento

1116 - Montagem da caixaria das lajes e vigas - $1^{\circ}$ pavimento

1117 - Concretagem das lajes e vigas - cobertura 
Execução do sistema de vedação

2101 - Levantamento das alvenarias - subsolo

2102 - Levantamento das alvenarias - térreo

2103 - Levantamento das alvenarias - $1^{0}$ pavimento

\section{Execução do sistema de cobertura}

3101 - Levantamento das platibandas

3102 - Levantamento das alvenarias de sala da caixa d'água

3104 - Instalação da serralheria da cobertura

3105 - Instalação da infraestrutura do ar-condicionado

3106 - Instalação dos barriletes

3107 - Telhamento

\section{Projeto dos sistemas hidrossanitários}

4001 - Proposta comercial do serviço de projeto hidrossanitário 4002 - Contratação do projeto de sistemas hidrossanitários

4003 - Lançamento hidráulico em planta, prumadas e dreno de ar-condicionado

4004 - Discussão do lançamento hidráulico com arquitetocoordenador de projeto

4005 - Lançamento da posição das prumadas pluviais e esgoto

4006 - Det. isométrico dos sistemas de esgoto, água fria e quente

4007 - Det. do sistema de aquecimento e caixa d'água na cobertura

4008 - Detalhamento do sistema hidrossanitário da piscina

4009 - Levantamento da relação de materiais

4010 - Controle de qualidade / revisão dos projetos

\section{Execução dos sistemas hidrossanitários}

4101 - Locação de passagens hidráulicas - subsolo

4102 - Locação de passagens hidráulicas - térreo

4103 - Locação de passagens hidráulicas - $1^{\circ}$ pavimento

4104 - Instalação das tubulações hidráulicas internas

4105 - Instalação das tubulações hidráulicas externas

\section{Projeto dos sistemas elétricos}

5001 - Proposta comercial do serviço de projeto elétrico (carta proposta)

5002 - Contratação do projeto de sistemas elétricos

5003 - Reunião de levantamento dos requisitos de arquitetura

5004 - Lançamento de infraestrutura e circuitos elétricos

5005 - Detalhamento do Sistema de Proteção Contra Descargas Atmosféricas (SPDA)

5006 - Lançamento da infraestrutura de telefonia, TV e lógica

5007 - Revisão da documentação do projeto

\section{Execução dos sistemas elétricos}

5101 - Locação de passagens elétricas - subsolo

5102 - Locação de passagens elétricas - térreo

5103 - Locação de passagens elétricas - $1^{0}$ pavimento

5104 - Instalação das tubulações elétricas internas
5105 - Instalação dos sistemas elétricos internos

5106 - Instalação das tubulações elétricas externas

5107 - Instalação dos sistemas elétricos externos

Sistemas de aberturas e fechamentos

6101 - Colocação das esquadrias de alumínio e vidros

6102 - Colocação das portas de madeira

\section{Gerenciamento de mudanças da arquitetura}

0100 - Gerenciamento de aquisições

0101 - Controle de custos e prazo

0102 - Controle de escopo

0103 - Controle de atributos

0104 - Gerenciamento de mudança do projeto

0105 - Encerramento do projeto

0106 - Avaliação pós-ocupação

Execução de serviços preliminares à execução

0201 - Ligação de água e padrão de luz

0202 - Terraplanagem

0203 - Montagem do canteiro de obras

0204 - Contratação e mobilização dos funcionários

Execução de instalações, revestimentos e acabamentos

7001 - Execução do reboco das paredes e cimentado nos pisos

7002 - Instalação dos requadros e batentes

7003 - Assentamento de soleiras e pingadeiras

7004 - Instalação de rodapés

7005 - Instalação dos forros de gesso

7006 - Assentamento de revestimentos de paredes

7007 - Execução dos sóculos

7008 - Assentamento de pisos de mármore

7009 - Assentamento de porcelanato

7010 - Assentamento de assoalho

7011 - Colocação de guarda-corpos e corrimãos

7012 - Pintura e envernizamento internos

7013 - Instalação de armários

7014 - Instalação de luminárias, lâmpadas e acabamentos elétricos

7015 - Instalação de louças e metais

7016 - Assentamento de revestimentos da piscina

7017 - Assentamento dos pisos de passagens e calçadas

7018 - Montagem do deck

7019 - Correção dos platôs e execução dos taludes

Serviços finais à execução da obra

7101 - Desmontagem do canteiro de obra

7102 - Limpeza

7103 - Assessoria para compra de peças de decoração

Operação, uso e manutenção

8001 - Gerenciamento predial 
As relações entre as atividades propostas, par a par, e o envolvimento dessas atividades com a arquitetura do edificio foram realizados em conformidade com o mapeamento da congruência feito no empreendimento imobiliário existente. O resultado desse trabalho é analisado a seguir.

\subsection{ANÁLISE DA CONGRUÊNCIA ORGANIZACIONAL DA ARQUITETURA ORGANIZACIONAL PROPOSTA}

A perspectiva de realizar uma simulação de desempenho, no caso, da congruência organizacional, permite antecipar as implicações de uma mudança organizacional e reduzir os impactos negativos da mudança. A arquitetura de processos proposta e combinada à estrutura organizacional existente pode ser simulada utilizando os recursos disponíveis de mapeamento da congruência organizacional. Para tanto, os procedimentos de alimentação dos dados primários foram realizados em semelhança ao feito no estudo de caso, e a congruência foi simulada.

\subsubsection{Organização projetada}

A organização projetada representada na matriz de interações reconhecidas $\left(R_{m m}\right)$ agrupa e relaciona as atividades de desenvolvimento do projeto e de construção do edifício combinadas no Quadro 24, de forma a estabelecer uma relação par a par que indique as relações de precedência identificadas (Figura 44). Assim como no caso do mapeamento da organização existente, não foram consideradas organizações de fornecedores que não prestassem alguns serviços associados à construção, e os que prestaram foram indicados como agentes da organização da obra.

Observou-se nesse mapeamento a existência de interações circulares bastante acentuadas entre as atividades do projeto arquitetônico, que reforçam as características comuns nas atividades de desenvolvimento de soluções de projeto, de serem iterativas e incrementais. Tais iterações são observadas tanto nas atividades que compõem o estudo preliminar, o anteprojeto e executivo arquitetônico, como notadamente ocorrem entre esses conjuntos de atividade, seja entre o estudo preliminar e o anteprojeto, seja entre o anteprojeto e o projeto executivo. As iterações curtas e longas confirmam a característica do processo ilustrado na Figura 42, em que os níveis de interações circulares nas 
atividades de arquitetura sugerem a instrumentalização do projeto colaborativo como estratégia de mitigação da complexidade de coordenação do processo decisório e do processo de comunicação.

A integração dos modelos de informação (iBIM) é possível em decorrência da relação contratual IPD centrada na organização de gerenciamento da arquitetura. Conforme as consultas por informações técnicas e mercadológicas ocorrem para se desenvolver a modelagem de lançamentos estruturais, hidrossanitários e elétricos, entre outros, o comprometimento com informações cada vez mais específicas condiciona em dado momento a definição de parcerias. Dessa forma, a demanda por informações para a modelagem da arquitetura provoca a negociação com organizações especializadas nos sistemas funcionais em razão da necessidade de estabelecer o escopo do sistema para mensurar adequadamente as projeções de custo e tempo de produção e fazê-las constar nos termos contratuais.

A antecipação de decisões sobre os sistemas funcionais reduz as interações circulares entre o projeto arquitetônico e os projetos estrutural, hidráulico, etc. Para tanto, é preciso condicionar a contratação dos projetos à execução dos sistemas projetados, sob o risco de demandar retrabalhos consideráveis decorrentes de não se considerarem as condições de execução reais na tomada de decisão. Tal condição de incerteza é um dos aspectos que prejudicam o modelo convencional de contratação separada dos projetos complementares e da execução.

Organizar as atividades em função da modularização dos sistemas funcionais diminui a complexidade dos esforços de coordenação do projeto. Ao agrupar em uma organização as competências complementares para realizar todas as atividades diretamente relacionadas ao sistema, a necessidade de transferência interorganizacional de informações é reduzida às informações de interface dos sistemas, isto é, informações que influenciam a geometria, a funcionalidade e o desempenho dos demais. Essa organização, destacada nos enquadramentos dos conjuntos de atividades na matriz $\mathrm{R}_{\mathrm{mm}}$ da arquitetura proposta, se traduz em modelos partilhados mais simples, adequados a padrões de interoperabilidade como o IFC.

Intraorganizacionalmente, a modelagem do sistema conta com todas as informações de geometria, material e produção precisas, possíveis graças a um template adequado às 
demandas específicas aos processos internos à organização. Nesse caso, o template pode ser gerenciado estrategicamente como um instrumento de consolidação do conhecimento organizacional, pois não precisa ser partilhado com outras organizações. Além disso, com o aprendizado obtido por meio do gerenciamento em ciclo fechado de projeto e produção, é possível promover a melhoria contínua desse conhecimento organizacional, com ganhos potenciais de eficiência dos processos e de desempenho do sistema.

As interações localizadas fora dos conjuntos indicados na matriz estão relacionadas em sua maioria às interfaces entre os sistemas funcionais e a arquitetura, isto é, o sistema de integração. Tais interações são recorrentes entre as atividades de anteprojeto e executivo arquitetônico com as atividades de execução de revestimentos, acabamentos e instalação de equipamentos. Assim, associar a responsabilização de gerenciamento da execução dessas atividades ao processo de gerenciamento de mudanças da arquitetura ofereceria vantagens de interação. Tal arranjo foi adotado na arquitetura organizacional e pôde ser confirmado, como se verá na análise das interações potenciais.

A matriz de filiação $\left(\mathrm{F}_{\mathrm{mn}}\right)$ estabelece qual é o grau de envolvimento de cada atividade do processo proposto para a definição dos componentes de sistemas do edifício identificados no mapeamento da congruência do empreendimento existente (Figura 43). A leitura da matriz $\mathrm{F}_{\mathrm{mn}}$ aponta para o quanto a organização responsável pela arquitetura tem um envolvimento direto, coadjuvante ou indireto sobre todo o processo decisório. A organização atua diretamente sobre as definições de utilização do edificio, indicadas nas colunas finais da Figura 43, em que estão listados os ambientes, os acessos e os elementos de composição da edificação. A matriz apresenta ainda um envolvimento coadjuvante ou indireto na definição dos demais sistemas, seja por meio das atividades associadas ao custeio-meta e ao gerenciamento da cadeia de suprimento, seja por meio do gerenciamento de mudanças da arquitetura, em que são controladas variáveis de tempo, custos e atributos do projeto.

Embora o volume de situações de envolvimento das atividades da arquitetura seja visualmente superior às atividades ligadas aos demais sistemas, cabe observar que a maioria desses envolvimentos é circunstancial, ligada à integração dos sistemas e ao gerenciamento de valor do projeto. Essa tendência de maior envolvimento das atividades ligadas à arquitetura já tinha sido detectada em menor grau no mapeamento do 
empreendimento existente. Entre as atividades de projeto estrutural, projeto hidrossanitário e projeto elétrico predominaram envolvimentos diretos sobre a decisão dos componentes relacionados aos sistemas funcionais correspondentes a cada especialidade. Já os casos pontuais de envolvimento coadjuvante ou indireto na definição de componentes de outros sistemas estão relacionados principalmente às resoluções de interface entre os sistemas.

A organização das atividades em função da modularidade dos sistemas alinha as atividades diretamente envolvidas às atividades de determinada especialidade de projeto com as atividades correspondentes a determinados componentes do sistema projetado. Tal alinhamento entre atividades complementares de projeto e execução, embora reduza a complexidade da gestão de informações interorganizacionais e seja condizente com a teoria das competências complementares, corresponde a uma estrutura organizacional diversa daquela dominantemente praticadas no âmbito dos empreendimentos imobiliários. A adequação da organização do processo de projeto integrada à execução dos sistemas é demonstrada de forma mais ou menos evidente na correlação imediata identificada na matriz de filiação, entre as atividades de definição da solução estrutural, hidrossanitária e elétrica e a execução delas.

\subsubsection{Interações potenciais}

Como observado no estudo sobre a congruência organizacional do empreendimento existente, não cabe uma interpretação independente para os resultados da matriz de interações potenciais totais $\left(\mathrm{PT}_{\mathrm{mm}}\right)$, pois esta apresenta dados de entrada para computar na matriz de congruência $\left(\mathrm{C}_{\mathrm{mm}}\right)$ : quais interações entre as atividades da organização são reconhecidas pela matriz $\mathrm{R}_{\mathrm{mm}}$, quais não são, e quais não apresentam nenhuma contribuição detectada para a definição de ao menos um componente do sistema projetado.

Assim como as interações potenciais totais, os dados indicados na matriz de interações potenciais fortes $\left(\mathrm{PF}_{\mathrm{mm}}\right)$ (Figura 45) foram alcançados com a identificação e a combinação dos casos de envolvimento direto, partilhado e indireto dos agentes na decisão sobre os componentes do edifício. Porém, neste caso, é possível identificar visualmente alguns padrões de interação que permitem iniciar uma discussão preliminar sobre os resultados alcançados. A matriz de interações potenciais fortes mapeou a demanda por comunicação 
entre agentes responsáveis pelo processo decisório de organizações diferentes, no caso das organizações responsáveis pelo sistema estrutural, sistemas hidrossanitários, sistema elétrico e sistema de integração.

A menor demanda por interações fortes evidencia uma vantagem da organização modular baseada em competências complementares adotadas na arquitetura organizacional discutida. O conjunto de interações demandada está alinhado aos principais sistemas funcionais em sua conexão com outros sistemas. Assim a complexidade decorrente da mediação entre organizações é reduzida à resolução de problemas de interfaces, não mais à comunicação detalhada de informações ligadas ao projeto do sistema, que ocorre entre agentes de uma mesma organização responsável pelo sistema, quando a iteração de relações cíclicas de comunicação e de tomada de decisões é facilitada.

As interações fortes mais acentuadas entre os sistemas funcionais e o sistema de integração foram observadas nas atividades ligadas ao estudo preliminar arquitetônico. Também foi identificada em menor volume a existência de interações cíclicas entre, de um lado, as atividades de projetos da estrutura, das instalações hidrossanitárias e das instalações elétricas e, de outro, as atividades de anteprojeto e projeto executivo arquitetônico, que integram o processo de sucessivas aproximações da solução.

Esse panorama apresenta um conjunto de interações fortes cíclicas nas atividades de concepção do projeto da arquitetura coerentes com a demanda por antecipação do processo decisório indicada na teoria para processos de BIM. A antecipação é particularmente interessante para reduzir o desafio de ajustar as soluções ao custeio-meta proposto, uma vez que os projetistas das especialidades envolvidas estão conscientes das variáveis e comprometidos com o desempenho da construção dos sistemas projetados.

\subsubsection{Congruência da organização projetada}

A composição da matriz de congruência $\left(\mathrm{C}_{\mathrm{mm}}\right)$ indica que as interações fortes ligadas às interfaces entre sistemas funcionais e de integração apontadas na seção anterior não são atendidas por meio da comunicação entre as atividades, conforme levantado na Figura 44. Dependendo do volume e da distribuição desses casos de não atendimento, podemse adotar duas diferentes estratégias. 
Em um contexto de revisão da estrutura organizacional proposta, a alteração da sequência de atividades e dos meios de comunicação necessários para suprir tais "não atendimentos" deve ser projetada e implementada. Essa estratégia é cabível em situações em que as interações não atendidas estão dispersas, resultando em uma complexidade gerencial acentuada. $\mathrm{O}$ risco decorrente de tal redesenho se relaciona à possibilidade de estabelecer novas e inesperadas relações de envolvimento das atividades com a definição da arquitetura do sistema.

Quando o grau de congruência é alto, isto é, quando as interações não atendidas são poucas e concentradas em interações interorganizacionais bem definidas, é possível concentrar esforços de gerenciamento de projeto para promover a coordenação entre os projetos de sistemas. Essa estratégia se baseia na cooperação entre agentes interessados na resolução das interfaces do projeto, uma vez que o desempenho de um sistema depende de variáveis de interface com os demais sistemas.

Foram observadas ainda "interações não previstas", isto é, casos de comunicação entre atividades que foram projetadas pela arquitetura organizacional, cujo impacto sobre a definição de componentes da arquitetura do edifício não foi detectado pelo mapeamento.

A existência de casos de interação não prevista indica os pontos de atenção para monitoramento durante a implementação da arquiteta do processo, de forma a verificar a possibilidade de combinação ou redução de tais comunicações, ou mesmo a supressão de uma ou mais atividades relacionadas a esses casos. A análise da simulação sugere que a ocorrência dessas comunicações excedentes está relacionada à manutenção de algumas atividades redundantes encontradas nas interações reconhecidas sobre a qual as mudanças organizacionais foram projetadas. Tal ocorrência residual era esperada diante da decisão de manutenção de maior complexidade do processo, conforme relatado na seção de “combinação entre atividades". 
Figura 43 - Matriz de filiação $\left(F_{m n}\right)$ - Arquitetura organizacional

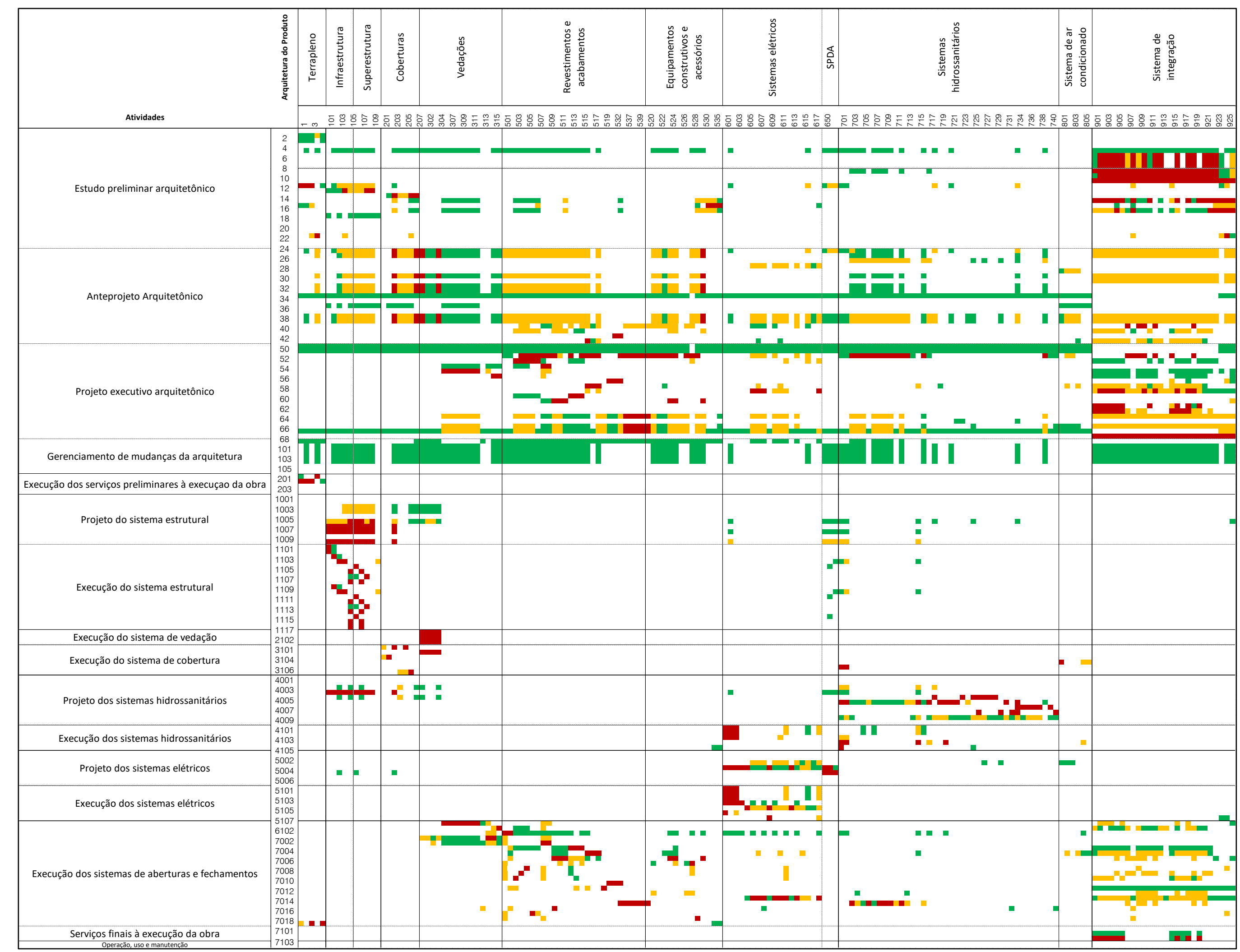

Legenda: $[$ indiretamente envolvido, $\square$ envolvido, $\square$ diretamente envolvido. 
Figura 44 - Matriz de interações reconhecidas $\left(R_{m m}\right)$ - Arquitetura organizacional

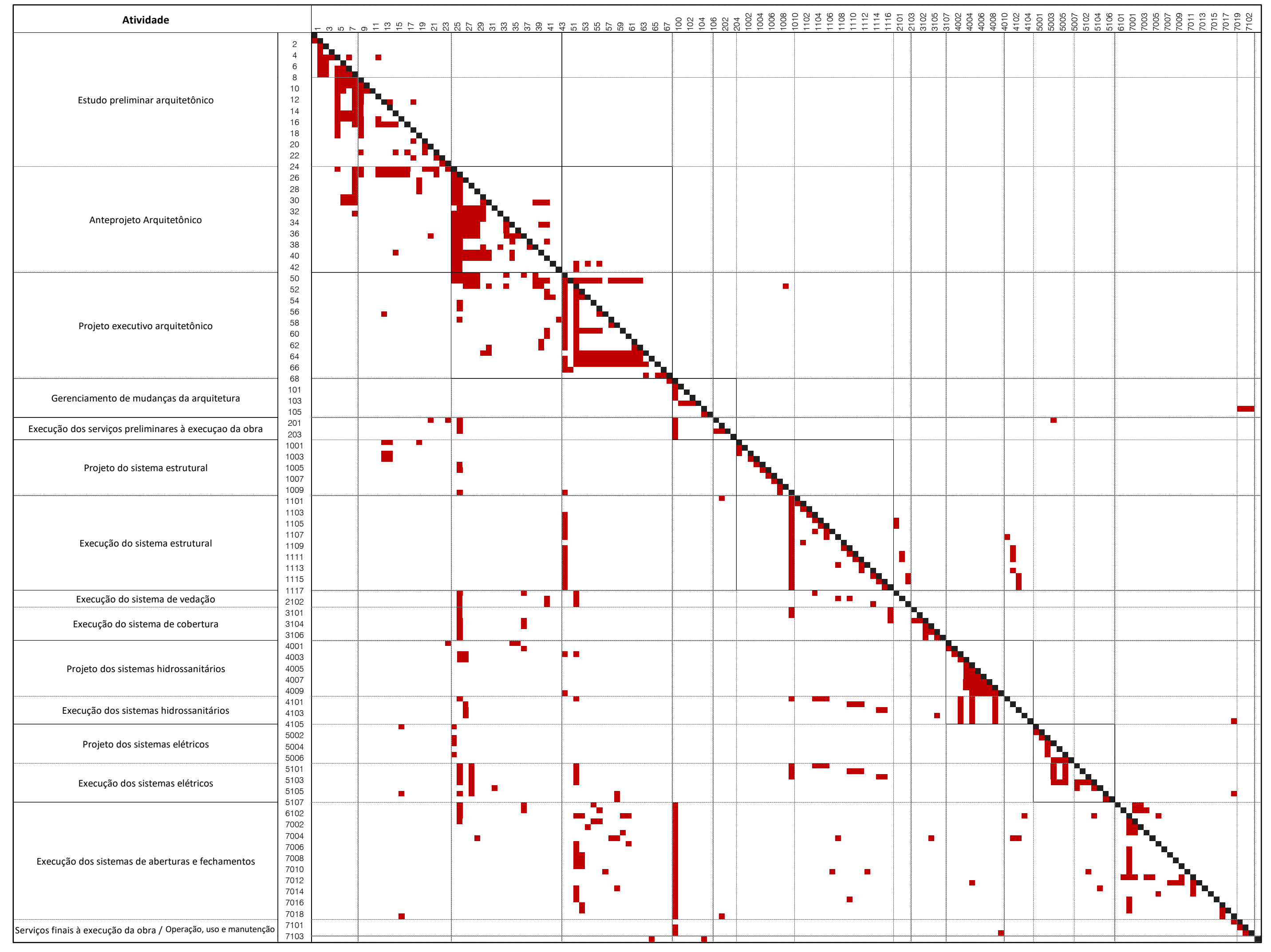

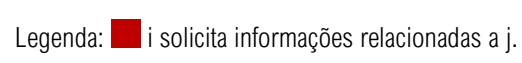


Figura 45 - Matriz de interações potenciais fortes $\left(\mathrm{PF}_{\mathrm{mm}}\right)$ - Arquitetura organizacional

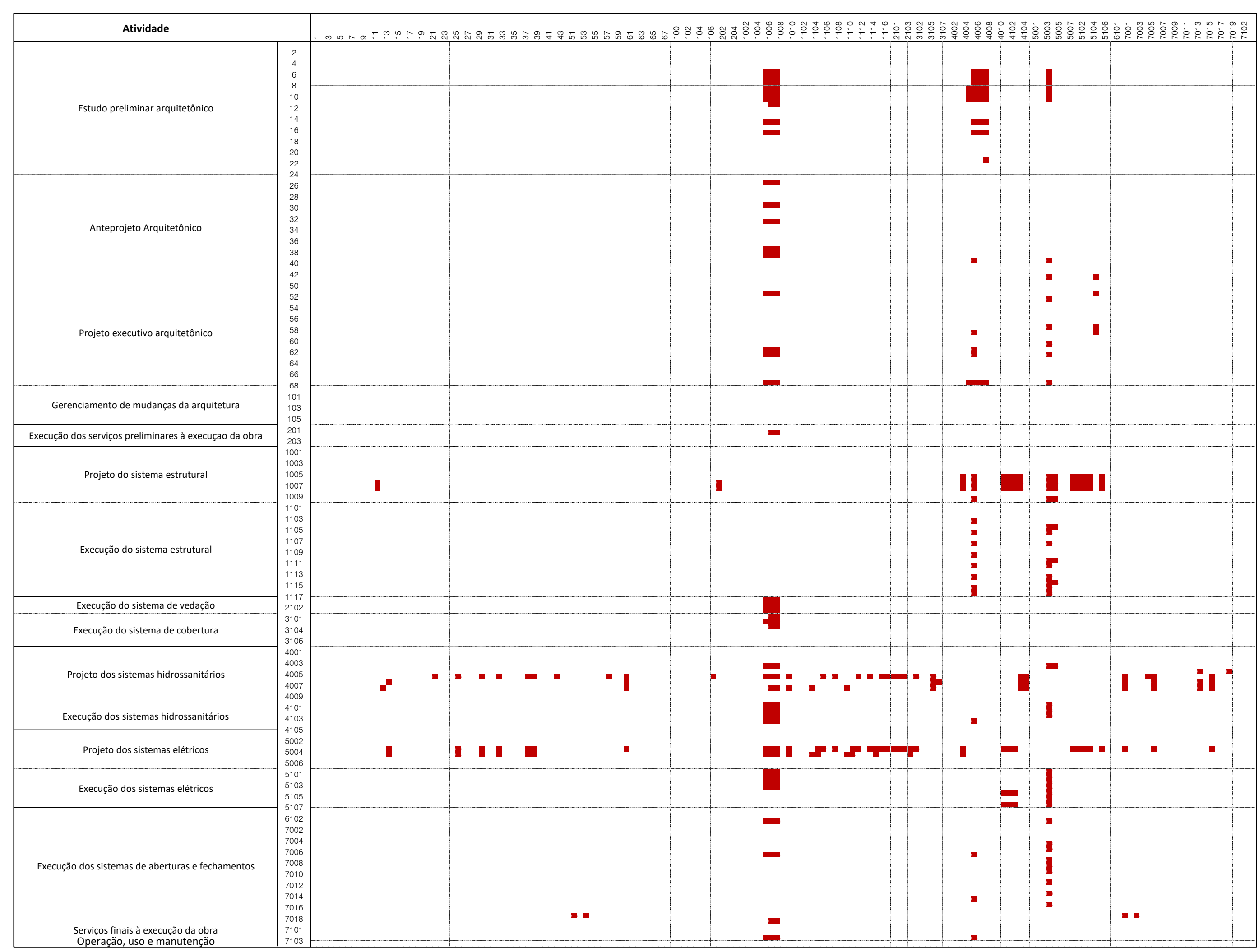


Figura 46 - Matriz de congruência $\left(\mathrm{C}_{\mathrm{mm}}\right)$ - Arquitetura organizacional

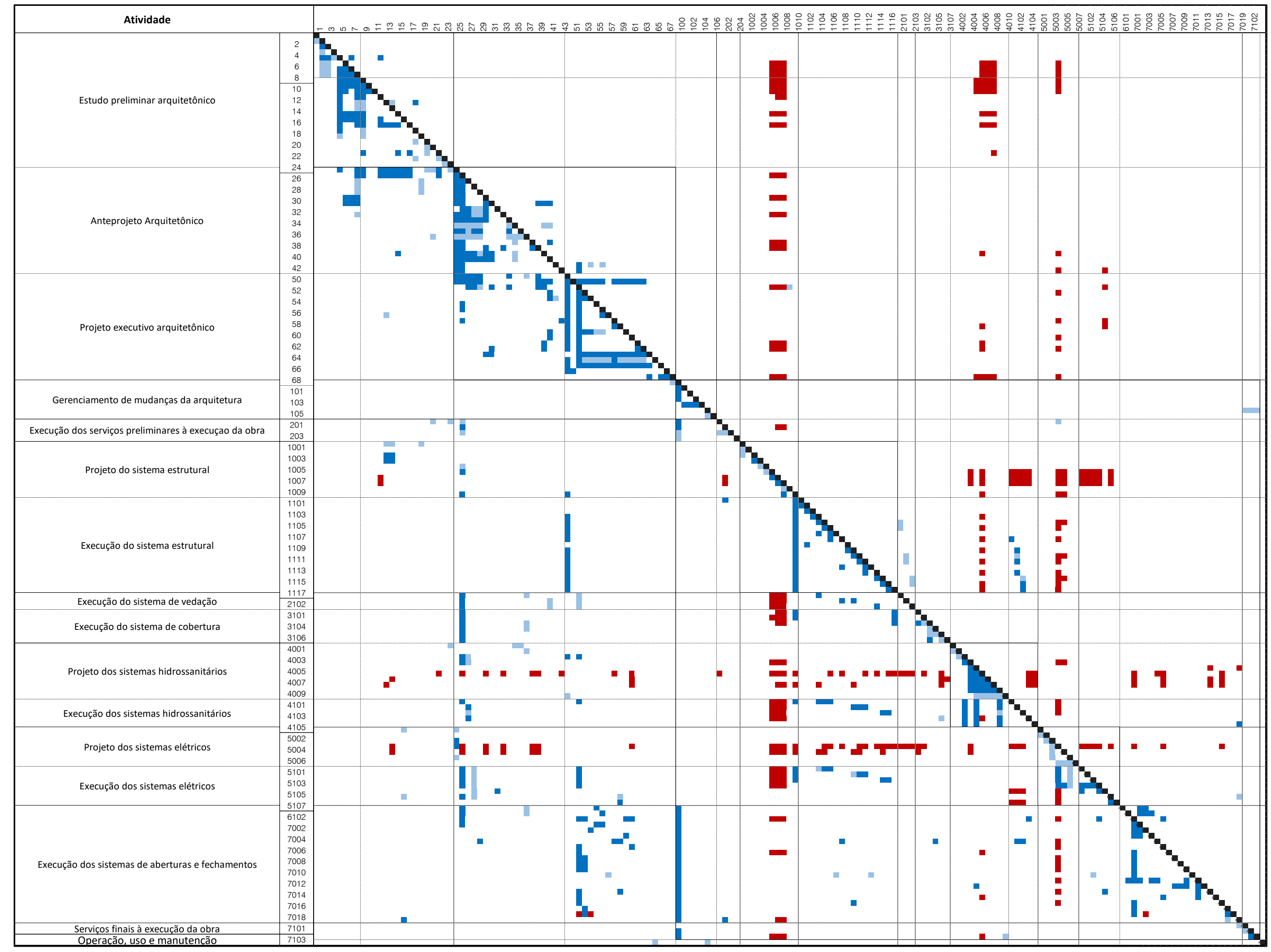


A despeito da motivação de testar essas melhorias, qualquer modificação fora de um cenário de gerenciamento da implementação da arquitetura organizacional em um empreendimento real faria dessa simulação um exercício especulativo, uma vez que variáveis não organizacionais presentes no caso real e abstraídas diante da ótica do instrumento de mapeamento poderiam ser suprimidas. O que é possível ser feito ainda para avançar na discussão sobre a qualidade da arquitetura proposta é realizar uma análise comparativa entre o mapeamento da congruência da organização existente e o da arquitetura proposta para essa organização, conforme realizado no capítulo 8 .

Antes, porém, foram delineadas algumas breves considerações sobre a aplicação do mapeamento da congruência organizacional como um instrumento de simulação da arquitetura organizacional na estrutura organizacional de um empreendimento existente.

\subsection{DISCUSSÃO SOBRE A APLICAÇÃO DO MAPEAMENTO DA CONGRUÊNCIA À ARQUITETURA ORGANIZACIONAL}

O mapeamento da congruência organizacional realizado para esta pesquisa pode ser reproduzido em uma situação de mudança organizacional real como um instrumento de gestão de mudanças do negócio. Nesse caso, porém, alguns critérios adotados para a realização do estudo, como a escolha pela manutenção de uma maior complexidade do processo, não teriam sentido prático. Por exemplo, a substituição da atividade de "escolha e contratação dos projetistas complementares" pelas atividades de "consulta técnica e de preços" e de "definição de parcerias" em vez de um item geral de "gerenciamento da cadeia de suprimentos" foi motivada pelo critério de complexidade adotado, para se testarem os limites da arquitetura do processo e tornar a comparação com o caso existente possível. Porém, uma simplificação poderia ser proposta e monitorada durante a implantação da arquitetura.

Em uma situação de aplicação prática desses mesmos instrumentos de arquitetura organizacional, é possível lançar mão de estratégias de mudança na cultura organizacional para viabilizar a simplificação do desenho organizacional. Esse procedimento, embora seja coerente e recomendável à prática administrativa, implicaria para o estudo a adição de variáveis não simuladas. A aplicação e o aperfeiçoamento de tais instrumentos à prática de negócios são um desdobramento possível para futuras pesquisas. 
Para o presente estudo, além de delinear um cenário aplicável da arquitetura do processo de projeto orientado ao valor, o método de mapeamento da congruência organizacional oferece uma métrica possível de ser comparada, o que amplifica a perspectiva de análise do fenômeno, assim como condições de rastreabilidade e contestação dos resultados relatados. A necessidade de leitura de dados codificados torna a atividade de análise organizacional, recorrentemente baseada em observação do pesquisador, um ganho para a discussão científica.

Por fim, o aperfeiçoamento dos instrumentos de aplicação e de manipulação dos dados, associado à reprodução da aplicação desse método de mapeamento ao contexto de AECO em quantidade suficiente, pode consolidar uma base de dados qualitativos e quantitativos para discussões organizacionais que extrapolem casos de observação individuais. 


\section{ANÁLISE COMPARATIVA ENTRE A CONGRUÊNCIA DA ORGANIZAÇÃO EXISTENTE E A DA ARQUITETURA ORGANIZACIONAL PROPOSTA}

A discussão da congruência entre a arquitetura do edifício, do processo e da organização depende de uma análise relacional que, devido à novidade do tema no campo de AECO, não conta com uma base de dados consolidada que permita confrontar dada arquitetura às parcelas representativas de formas de organização de empreendimentos imobiliários observadas em um cenário nacional ou mesmo internacional. Portanto, a análise possível foi a comparação entre a congruência organizacional levantada no empreendimento existente e a simulada para a arquitetura organizacional projetada sobre o caso mapeado.

A comparação foi possível porque o mapeamento do caso existente e a construção dos cenários seguiram o mesmo procedimento metodológico, conforme foi demonstrado nos capítulos 6 e 7. Na presente análise foi dado enfoque na distinção dos resultados alcançados e na discussão das implicações das mudanças observadas. A discussão na primeira subseção se concentra na interpretação estrita de cada mapa, sem a exposição de impressões externas. Contudo, assim como na interpretação individual dos mapeamentos do caso existente e das simulações, as subseções a seguir contaram com a valorosa cooperação de profissionais e acadêmicos das áreas de AECO, de administração e de computação, que contribuíram para a interpretação dos dados levantados por meio de discussões semiestruturadas, individuais e coletivas, documentadas por meio de notações do pesquisador e por e-mails.

A percepção dos especialistas é explicitada após os apontamentos iniciais, quando os resultados dos mapeamentos são confrontados com particularidades da organização existente. O texto está organizado por especialidades de modo a respeitar a integridade das reflexões coletadas. Tal estrutura não se configura, contudo, como um recorte disciplinar, pois as perspectivas explicitadas frequentemente extrapolaram os limites da atuação profissional dos agentes consultados. As conjecturas e projeções foram discutidas sob a perspectiva do mapeamento da congruência organizacional de forma a mitigar qualquer traço especulativo das considerações apresentadas. Os resultados dessas discussões foram confrontados com considerações levantadas na teoria, que complementam as condições de implementação da arquitetura proposta. 


\subsection{COMPARAÇÃO ENTRE OS MAPEAMENTOS DA CONGRUÊNCIA ORGANIZACIONAL}

Quando postos lado a lado, os mapeamentos do levantamento e da simulação final apresentam desenhos marcadamente distintos (Figura 47). Em comum, ambos apresentam a mesma decomposição da arquitetura do edificio e os mesmos procedimentos de depuração dos dados. Distinguem-se pelo número de atividades, que aumentou de 156 em 40 tempos no caso existente para 163 atividades em 54 tempos na proposta de arquitetura do processo.

As atividades adicionais estão relacionadas ao gerenciamento de valor incorporado ao processo de projeto da arquitetura levantado, e em um primeiro cenário não houve alteração significativa na sequência de trabalho (Figura 47, matriz 2). Enquanto a matriz de congruência da organização existente conta com um total de 452 interações atendidas, 494 interações não previstas e 2.062 interações não atendidas, o primeiro cenário apresentou um total de 1.058 interações atendidas, 356 interações não previstas e 2.052 interações não atendidas.

O aumento significativo de interações se deve ao reconhecimento e previsão da iteração entre atividades de arquitetura, que interagem circularmente com mais frequência que o observado nas atividades da organização existente. Tal fenômeno é identificado pelas marcações localizadas à direita da sequência de células em preto, que cortam a diagonal da matriz. Na prática, tal sinalização indica a promoção da colaboração entre os agentes envolvidos por meio da constituição de um ambiente organizacional adequado.

As interações não previsíveis pela relação de congruência entre produto, processo e organização diminuíram em 96 casos no primeiro cenário simulado. Embora se tenha reduzido significativamente entre as atividades de projeto arquitetônico, em que a arquitetura do processo se deu efetivamente, o número ainda alto de casos remanescentes pode ser analisado caso a caso para verificar possíveis redundâncias e oportunidade de remanejamento de atribuições de responsabilidade para alguma interação atendida ou não atendida, por meio da coordenação do projeto ou mesmo de uma mudança na arquitetura do processo proposta. 
A queda menos expressiva foi observada entre as interações não atendidas. Comparando a matriz 1 e a matriz 2 da Figura 47 é possível afirmar que a manutenção desse número elevado está relacionada principalmente às interações interorganizacionais (não agrupadas por nenhum dos quadros dentro de cada matriz). O predomínio da comunicação formal, nesses casos, promove um baixo entendimento compartilhado sobre as variáveis de projeto ao restringir e retardar as oportunidades de interação entre agentes responsáveis por atividades funcionalmente distintas.

Tanto na situação existente como no primeiro cenário, as interações não atendidas ocorrem entre atividades de uma mesma função, resultando em problemas de interação entre agentes com competências complementares à construção do sistema. As demandas identificadas à direita da diagonal das matrizes indicam grande paralelismo e interações cíclicas, em resposta à necessidade de informações de atividades a jusante no processo. Nesse contexto de segmentação organizacional regido contratualmente, as variantes de logística, de infraestrutura e de cultura organizacional distintas restringem a colaboração e exigem grande esforço de coordenação entre as atividades de desenvolvimento e a execução dos sistemas que compõem o projeto.

Um segundo cenário foi elaborado com a mesma arquitetura do processo adotada no primeiro cenário, reorganizando a sequência das atividades existentes em módulos de forma a agrupar atividades de projeto e execução de cada sistema e deixando, assim, apenas questões ligadas às interfaces de sistemas para serem gerenciadas entre as interações interorganizacionais. Neste segundo cenário, o desenvolvimento e a execução do projeto estrutural integrariam uma única empresa/organização, o mesmo valendo para as atividades de projeto e execução dos sistemas hidrossanitários e elétricos. Nos sistemas que não possuíam uma organização específica responsável pelo projeto, como ocorre com o sistema de vedação e cobertura, os projetos foram mantidos com a organização responsável pelo projeto de arquitetura, e a execução foi mantida com a organização responsável pelo gerenciamento da obra (Figura 47, matriz 3).

Nesse rearranjo se observou a manutenção das interações atendidas em 1.058 casos, o aumento das interações não previstas de 356 para 368, e a redução do total de interações não atendidas de 2.052 para 1.932 . 
As interações não atendidas não apenas diminuíram em quantidade como a distribuição delas foi alterada. Enquanto a matriz 2 da Figura 47 apresenta a quase totalidade das interações não atendidas entre os limites organizacionais, a matriz 3 apresenta casos de não atendimento dentro das organizações ligadas aos sistemas hidrossanitário e elétrico. São incongruências internas ao processo de uma organização empresarial decorrentes do simples acoplamento realizado entre projeto e construção. No caso, a adequação das incongruências é facilitada por se tratar de casos internos. Enquanto a promoção de mudanças substanciais em processos de organizações temporárias frequentemente oferece riscos inviabilizantes, no caso de uma estrutura organizacional empresarial projetar uma arquitetura organizacional congruente permite alcançar maior eficiência operacional. O mesmo raciocínio se aplica à organização responsável pelo gerenciamento da execução da obra.

O quadro que delimita a organização responsável pelo gerenciamento da execução da obra apresenta algumas características que a distinguem das demais. Da forma como foram sequenciados, os limites das atividades de gerenciamento englobam não apenas as atividades de execução de sistemas sem projeto especializado, como são os sistemas de vedação e de cobertura, mas também as atividades dos sistemas de estrutura, hidráulica e elétrica, que integram projeto e execução. Fora desse enquadramento, as atividades de arquitetura compõem um conjunto separado. Tal arranjo possui uma justificativa conceitual. Enquanto a arquitetura está orientada para as relações externas da edificação, que visam responder às demandas e expectativas sociais projetadas para a edificação, ou seja, as relações de valor, as atividades de projeto e execução dos sistemas funcionais são orientadas para resolver as relações internas, de transformação.

Como pode ser observado no quadrante superior esquerdo da matriz 3 (Figura 47), parte significativa das interações não atendidas está relacionada a problemas de interação a respeito do sistema de integração. Mais especificamente, a incongruência remanescente nesse cenário indica a falta ou a insuficiência de informações sobre as condições de execução de componentes dos sistemas, que subsidiam o processo decisório e, no caso da arquitetura do processo proposta, subsidiam o gerenciamento de valor. Trata-se de um problema decorrente das dificuldades organizacionais de retroalimentação, que campos ligados à APO, por exemplo, tentam suprir. 
Figura 47 - Comparação entre a matriz de congruência do empreendimento existente e a evolução da arquitetura organizacional proposta
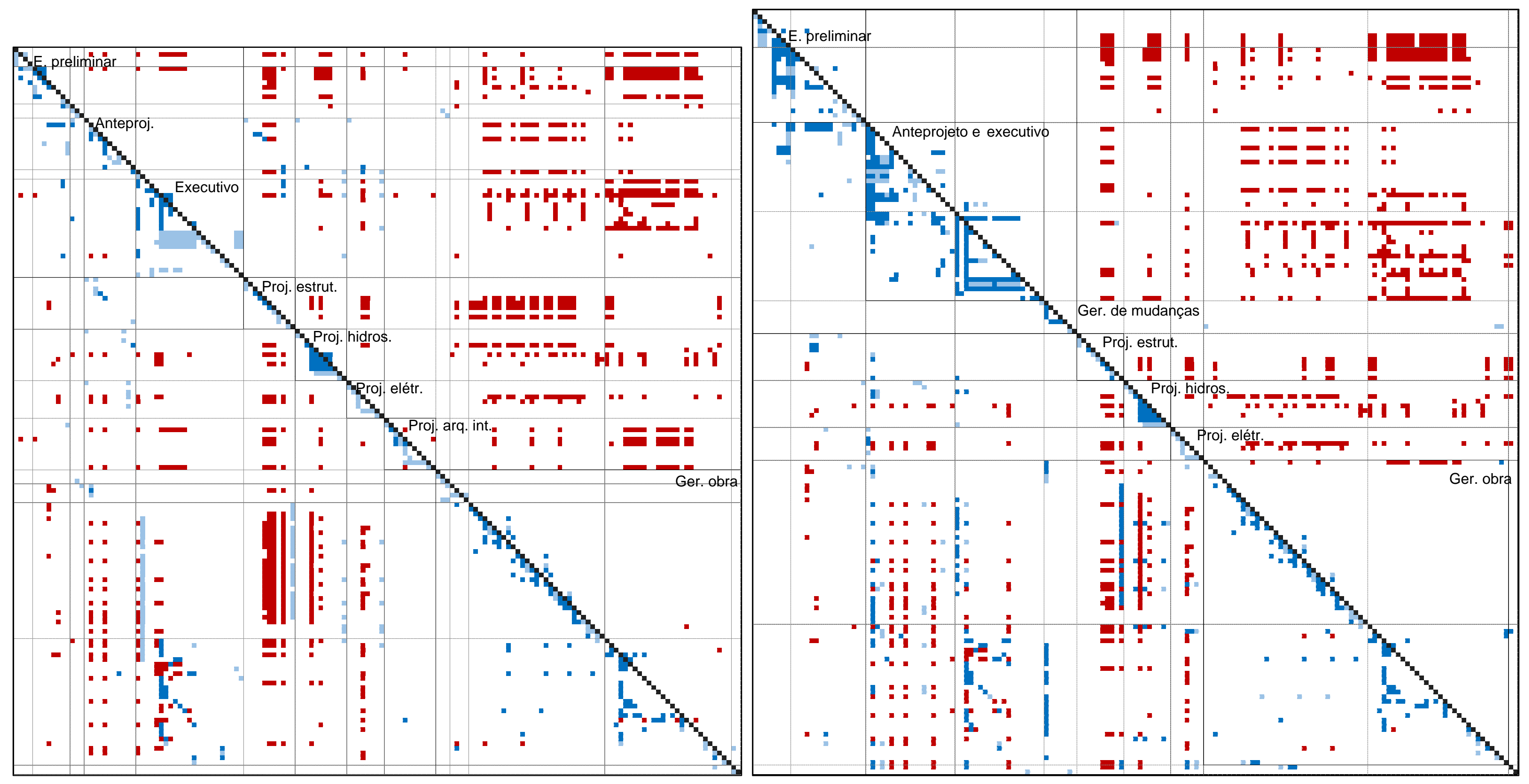

[1] Matriz $C_{m m}$ do empreendimento existente (Apêndice $J$ )

[2] Matriz $C_{m m}$ da combinação entre as atividades existentes e as atividades da arquitetura do processo

Legenda: $\square$ interaçōes correspondentes, $\square$ interacoōes näo atendidas, $\square$ interaçōes não previstas. 
[continuação da Figura 47]

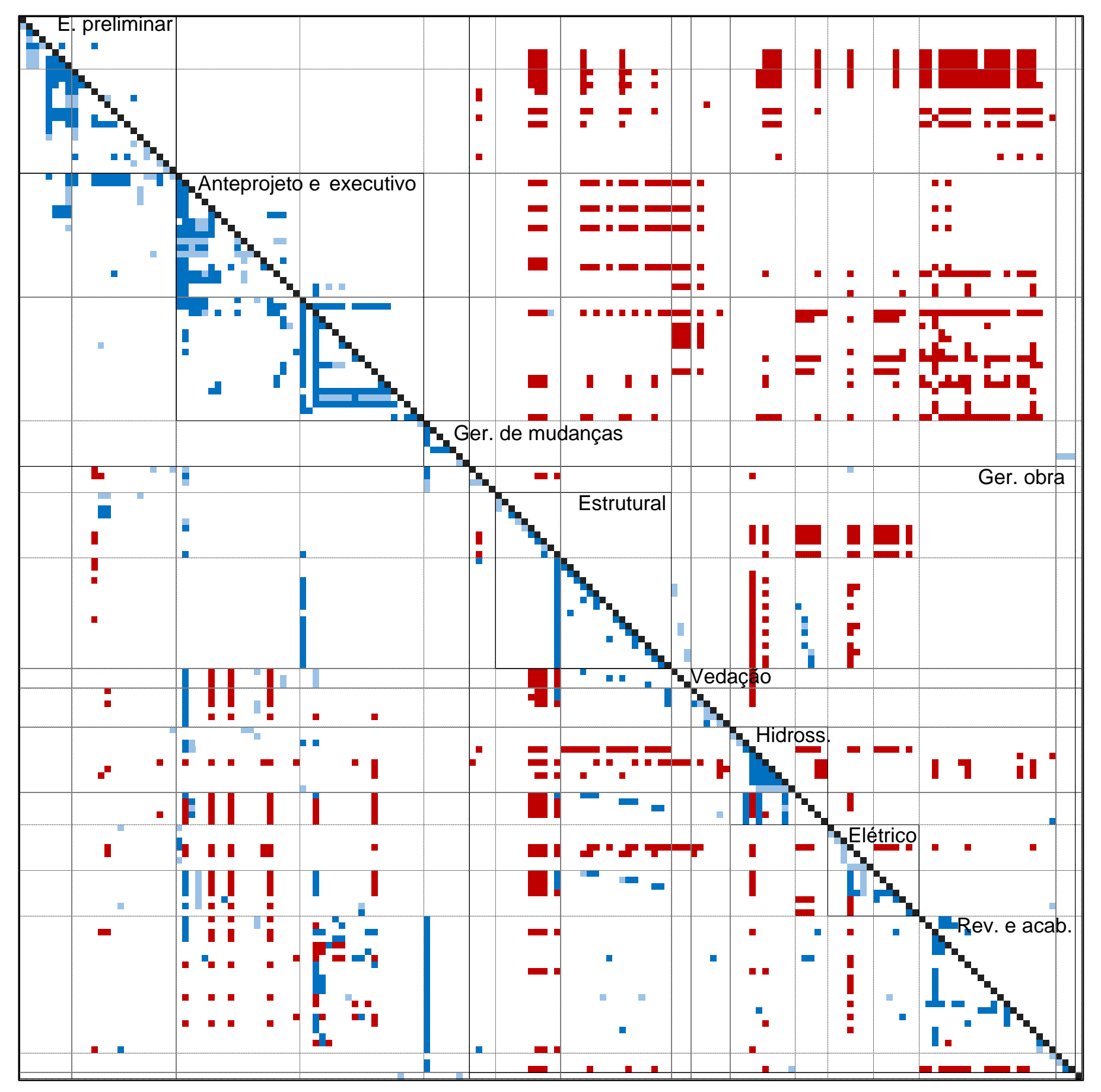

[3] Matriz $C_{m m}$ da arquitetura do organizacional com o gerenciamento das mudanças de projeto e o gerenciamento da execução independentes

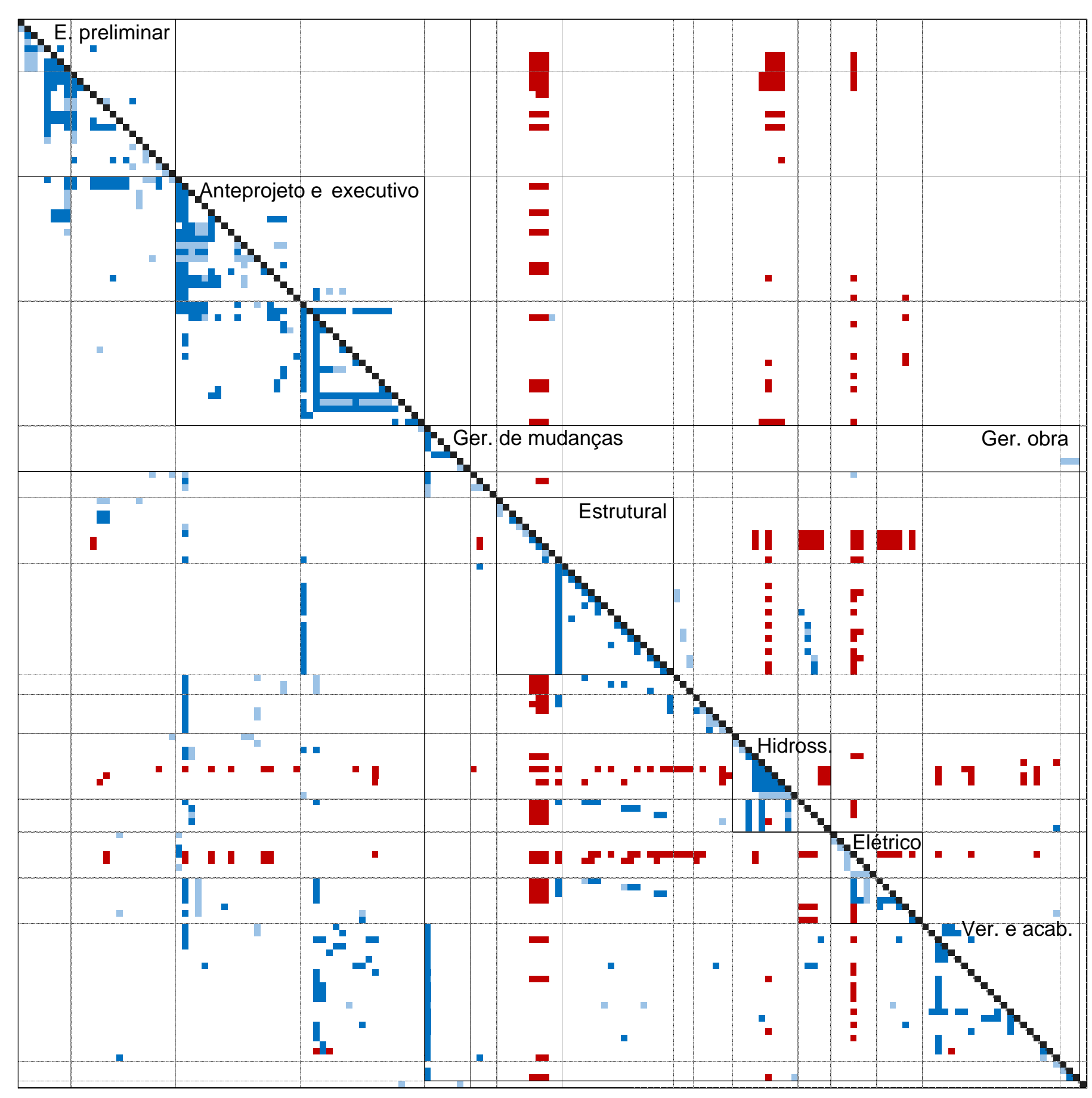

[4] Matriz $\mathrm{C}_{\mathrm{mm}}$ da arquitetura do organizacional com o gerenciamento das mudanças de projeto e o gerenciamento da execução integrados 
O terceiro cenário apresenta a simulação da implementação do projeto colaborativo como estratégia de integração das atribuições de gerenciamento de mudanças de projeto e de gerenciamento de obras de forma a reduzir a complexidade da comunicação interorganizacional. Com uma mesma equipe responsável pelo desenvolvimento e execução da arquitetura do edificio, comprometida com os objetivos de projeto, a necessidade de estruturar organizacionalmente as interações potenciais entre agentes reduziu consideravelmente. Enquanto as interações atendidas se mantiveram as mesmas e as interações não previstas tiveram uma baixa discreta para 354 casos, o total de interações não atendidas ficou reduzido a 738 casos de atenção para coordenação.

Como pode ser observado na matriz 3 da Figura 47 pela indicação de casos em eixos bem definidos em cruz, cujos eixos são as atividades de projetos dos sistemas funcionais, as interações não atendidas correspondem às interações de interface entre os sistemas funcionais modularizados e o sistema de integração. Com a perspectiva de modularizar os demais sistemas, como cobertura e vedação, tal padrão de interações potenciais fortes se repetirá. Contudo, diferentemente dos cenários anteriores, em que a demanda por coordenação das interações potenciais fortes é dispersa, no último cenário projetado os pontos de atenção seguem um padrão reconhecível, o que facilita a coordenação de projeto.

Com uma organização responsável pela arquitetura e o gerenciamento da execução, as interações potenciais não atendidas ligadas aos processos dos sistemas modularizados permaneceram, mas as demandas por interação das atividades de arquitetura foram dramaticamente reduzidas. Tal arranjo tanto permite que a arquitetura antecipe necessidades da execução quanto permite o gerenciamento de mudança do projeto visando à manutenção do valor projetado. Enquanto nos cenários anteriores o responsável pelo projeto do sistema de integração precisa de um instrumento contratual para obter informações da execução, e precisa ser acionado para oferecer uma resposta às mudanças de cenário inesperadas observadas durante a execução do projeto, no último cenário é a arquitetura que ativamente gerencia a execução do projeto e que controla as variáveis de qualidade, ligadas a custo, tempo e atributos do projeto. 
Quadro 25 - Comparação entre totais de interações observadas em cada cenário

\begin{tabular}{|l|c|c|c|c|}
\hline & Existente & Cenário 1 & Cenário 2 & Cenário 3 \\
\hline Total de interações atendidas & 452 & 1.058 & 1.058 & 1.058 \\
\hline Total de interações não previstas & 498 & 356 & 368 & 354 \\
\hline Total de interações não atendidas & 2.062 & 2.052 & 1.932 & 738 \\
\hline
\end{tabular}

O Quadro 25 apresenta um resumo da comparação geral entre o total de interações identificadas no cenário existente e nos cenários projetados da organização de arquitetura. Reflexões mais detalhadas desse resultado podem ser alcançadas com a confrontação do resultado observado com a comparação das matrizes e a percepção dos projetistas e gerentes especialistas envolvidos no processo.

\subsection{CONFRONTAÇÃO COM A PERSPECTIVA DAS ESPECIALIDADES}

As análises a seguir se baseiam na consulta aos especialistas envolvidos no empreendimento existente mapeado.

\subsubsection{Função da arquitetura}

Durante a análise do mapeamento da congruência do empreendimento existente foi observado que a organização então responsável pela arquitetura do edifício concentrava os maiores esforços de integração e comunicação das informações de projeto. Essa concentração da função de integração foi reconhecida pelo agente responsável pela execução da obra, que destacou os benefícios econômicos de tal envolvimento, com ressalva associada a casos de demora na resolução do problema.

Como os profissionais responsáveis pela arquitetura observaram, parte fundamental do valor percebido em seu negócio é constituída pela capacidade de ordenação de uma coerência espacial e estética e engloba a resolução tectônica dos detalhes construtivos. Garantir a concretização das soluções alcançadas é "fundamental” na constituição de seu portfólio. Por outro lado, reconhecem que os esforços da arquitetura para a integração e comunicação das soluções de projeto, associados aos esforços de gerenciamento de mudanças do projeto durante a execução, são maiores que os benefícios econômicos obtidos pela empresa. 
A empresa de arquitetura tem experiência em gerenciamento da execução, porém sem nunca ter estruturado tão fortemente a organização da execução como ocorreu com a organização do projeto. A experiência direta com execução é identificada pelos profissionais como uma das razões por possuírem detalhamentos orientados para a construção. A necessidade de comunicar informações de forma precisa e detalhada faz com que o escritório produza grande quantidade de documentos entre desenhos técnicos, tabelas, quadros, etc. Tais desenhos, além de mediar a comunicação entre o escritório de arquitetura e clientes, fornecedores e executores, são parte constituinte da formulação da solução em escala e nível de detalhamento suficiente para antecipar resoluções de construção, o que confere benefícios para as atividades de execução com a comunicação mais clara do escopo do trabalho e a diminuição de variabilidade. A demanda por redução de preço de projeto tem pressionado o escritório de arquitetura a se ajustar aos padrões de entrega comuns no mercado, o que entra em conflito direto com parte estrutural do valor construído pela empresa.

A análise realizada na seção 6 apontava as vantagens estratégicas vantajosas para o negócio da arquitetura integrar o projeto arquitetônico e o gerenciamento de obras, pois capitaliza os resultados de um projeto que tanto responde satisfatoriamente às expectativas e necessidades dos clientes como integra os sistemas de forma a não permitir desempenho insuficiente ou falho, além de permitir o aprendizado por meio da melhoria contínua, com a retroalimentação contínua e facilitada das informações a jusante de projetos realizados, o que, em última análise, permite à organização da arquitetura melhorar a tectônica de seu repertório arquitetônico. A matriz 3 (Figura 47) oferece uma simulação da arquitetura organizacional correspondente desse cenário, demonstrando os beneficios gerais para responder à demanda por interações entre processos e integração dos sistemas.

\subsubsection{Função estrutural}

A arquitetura organizacional simulada oferece respostas para as questões levantadas na seção 6 pelo profissional responsável pelo projeto estrutural. Este apontou a falta de interações fortes e cíclicas como um dos fatores que impõem restrições à racionalização material da solução porque essas medidas dependeriam de um controle suficientemente rigoroso de procedimentos de execução, cuja realização ele, como projetista, não poderia 
assegurar. Como não é possível assegurar as condições de execução para maior racionalidade, são adotadas soluções conservadoras, que minimizam os riscos de variabilidade da construção.

Com a integração do projeto e da execução da estrutura, os riscos de variabilidades podem ser controlados com maior eficácia, permitindo melhorias sistêmicas tanto nos processos como na tecnologia diretamente vinculada ao sistema. Assim como ocorre na arquitetura, a pressão por esforços individuais excepcionais para reduzir problemas de interação forte são reduzidos organizacionalmente. Trata-se de um modelo de negócio existente na construção civil em nichos específicos de atuação. Como lembrou o engenheiro estrutural durante a apresentação dos resultados parciais alcançados, são vários os exemplos de empresas que integram projeto e execução da estrutura e vedação de barracões.

Para o calculista, tal modelo não obtém o mesmo sucesso em outros tipos de construção em decorrência do modo como o setor historicamente se organizou. Outro aspecto a ser considerado está vinculado à dificuldade de gerenciar informações de arquitetura mais complexas, isto é, que envolvam mais interfaces de sistemas. Tal percepção se alinha aos achados do estudo, que apontam que, sem desempenhar um papel gerencial ativo durante a execução, a arquitetura, como um sistema de integração, não é capaz de assegurar que as variáveis não previsíveis no projeto signifiquem prejuízos ao valor da arquitetura.

\subsubsection{Funções hidrossanitárias e elétricas}

O sistema hidrossanitário e o sistema elétrico apresentam características semelhantes, destacadas pelos projetistas de cada especialidade. Estes argumentam que o impacto do não atendimento das interações fortes, como as identificadas no caso existente, são reduzidas consideravelmente graças ao nível de flexibilidade das instalações de ambos os sistemas, decorrente da comunalidade dos componentes industrializados e da melhor qualificação dos empreiteiros especialistas.

A indicação detalhada dos pontos hidrossanitários e elétricos realizada antecipadamente com a arquitetura, por outro lado, foi entendida como um ganho para os profissionais, ao reduzirem a necessidade de desenvolver uma proposta de locações de terminais e 
equipamentos sem o envolvimento da arquitetura. Diferentemente do que acontece em outras contratações, tal antecipação permite que as especialidades se concentrem na resolução das especificidades técnicas dos sistemas, o que implica menos tempo de desenvolvimento.

As interações fortes relacionadas à interface com a estrutura despertam atenções diferentes aos responsáveis pelas duas especialidades, especialmente a responsável pelo sistema hidrossanitário. As restrições impostas pelos sistemas de pilares, vigas e lajes frequentemente resultam em conflitos, retrabalho e atrasos para o empreendimento, com implicações negativas aos agentes envolvidos. A redução das interações não atendidas permite direcionar os esforços de coordenação para pontos de interfaces como esses.

Por fim, embora exista maior flexibilidade de instalação, ao menos a perspectiva de integrar o levantamento da relação de materiais do projeto executivo hidráulico e elétrico ao processo de aquisição desses insumos que a arquitetura propõe oferece ganhos potenciais para os subprocessos desses sistemas, uma vez que reduz o que os profissionais entendem ser a principal razão por que as demandas por interações cíclicas ocorrem. De fato, entre os ganhos potenciais observados até aqui, as mudanças para os sistemas hidrossanitários e elétricos parecem ser as que mais demandam uma arquitetura organizacional específica para serem projetadas e verificadas empiricamente.

\subsubsection{Demais funções}

O grau de modularização dos sistemas adequado a uma arquitetura depende da complexidade interna e da capacidade de identificação clara das interfaces com outros sistemas e componentes, de forma a caracterizar uma especialidade com escopo claro e suficientemente independente de trabalho no desenvolvimento e execução. Assim, a decisão por maior modularidade se inicia com a concepção da arquitetura, quando mobiliza sistemas e agentes específicos para a realização do empreendimento. No caso analisado, alguns sistemas, como a vedação e a cobertura, não foram tratados como sistemas modulares, mas, sim, como sistemas associados ao projeto de integração realizado pela arquitetura.

A função de integração da arquitetura no gerenciamento da execução, permite projetar o produto de forma a promover a modularização e a coordenar a execução especializada 
dos sistemas funcionais modularizados. Tal responsabilidade de planejamento da produção torna explícito os requisitos de projeto que impactam sobre as condições de construção e a qualidade do processo e da edificação.

\subsection{CONSIDERAÇÕES SOBRE A ARQUITETURA ORGANIZACONAL}

A congruência da arquitetura organizacional proposta para o processo de projeto orientado ao valor não depende apenas do modo como as relações de precedência de atividades, de atribuição de responsabilidade e de atendimento das demandas de interações entre os agentes são organizadas. $\mathrm{O}$ trabalho a ser realizado no decorrer desse processo é diretamente influenciado por condições específicas que condicionam a forma como os agentes interessados interagem com outros agentes, com a tecnologia e com as informações disponíveis para a construção de um entendimento compartilhado sobre os objetivos, meios e métricas de verificação do sucesso do projeto a serem alcançados.

Assim, algumas variáveis culturais e tecnológicas são premissas condicionantes que precisam ser consideradas dentro da arquitetura proposta.

\subsubsection{BIM e gerenciamento de valor}

Os dois estudos exploratórios que deram base empírica para a construção da arquitetura do processo de projeto orientado ao valor indicaram a importância da modelagem da informação do edificio para conferir celeridade aos instrumentos que dão o suporte necessário para que o gerenciamento de valor seja realizado sem onerar e atrasar significativamente o projeto, a ponto de prejudicar sua aplicação.

Verificou-se também que a realização do TVD como meio de gerenciamento de valor depende da antecipação do nível de desenvolvimento do modelo, o que significa alterar a convenção dominante sobre a equivalência das diferentes classificações de LOD e as fases do projeto (em particular, o arquitetônico), de forma a subsidiar com informações a "avaliação da qualidade" da proposta arquitetônica.

Tal antecipação dos LOD demanda não apenas o envolvimento de projetistas especialistas no desenvolvimento do estudo preliminar e do anteprojeto, mas também que estes sejam capazes de realizar uma projeção realista das condições de execução das 
soluções propostas, de forma a não ser possível que o projeto seja desvinculado do compromisso de atendimento das variáveis de execução então consideradas, o que reforça a defesa do agrupamento do projeto e da execução de cada sistema funcional em módulos.

Ao integrar parte substancial das interações fortes ligadas à comunicação entre o projeto e a execução de um sistema funcional, a organização modular apresentada acaba por favorecer a implementação do BIM ao minimizar o efeito deletério da perda de informação decorrente da demanda por interoperabilidade e de controle das informações disponibilizadas a outras empresas que cooperam em determinado empreendimento.

De fato, além das dificuldades tecnológicas de interoperabilidade entre softwares BIM, fica claro nos debates mais recentes que abordam o assunto que o principal dilema acerca do compartilhamento de modelos está vinculado ao risco de perder capital intelectual e tecnológico resultante do trabalho de modelagem de informações detalhadas sobre o sistema ou seu processo de execução, que precisa ser transferido a outras empresas que cooperam diretamente na definição desse mesmo sistema em um empreendimento cuja organização é temporária; ou então, no outro lado do espectro de preocupações desse dilema, preservar tal capital sob o risco de não transferir informações suficientes para que as empresas colaborem na realização do sistema, de forma a prejudicar o desempenho da arquitetura do edificio.

Ao tornar congruentes os limites das organizações das empresas que cooperam em um empreendimento com as interfaces dos sistemas funcionais, a comunicação interorganizacional de informações relacionadas ao conhecimento específico sobre o sistema é reduzida consideravelmente, o que facilita o alinhamento entre interesses das empresas e o objetivo do empreendimento. Reduz também as dificuldades tecnológicas que os softwares BIM enfrentam para operacionalizar a interoperabilidade de informações não geométricas detalhadas por meio de arquivos abertos baseados em sistemas de classificações como o IFC, uma vez que seriam reduzidas as informações de interface de sistemas. 


\subsubsection{Cooperação entre as organizações do empreendimento}

O alinhamento entre os objetivos do empreendimento e os das organizações que compõem o empreendimento estabelece as condições ambientais para se promover a cooperação interorganizacional nos níveis iniciais da concepção do projeto. Concepção aqui faz referência às fases de viabilidade e elaboração do estudo preliminar, quando os termos de atuação estão definidos apenas entre a arquitetura, o cliente e, eventualmente, mais alguém interveniente cuja particularidade do projeto demande, seja um agente financiador ou mesmo uma empresa-chave para execução.

$\mathrm{Na}$ concepção do projeto, organizações responsáveis pelos sistemas funcionais são consultadas pelo gerenciamento de cadeia de suprimentos para saber do interesse e negociar as condições de ingresso no empreendimento. Parte dessa negociação envolve definir o custeio-meta e para tal é preciso definir com suficiente nível de detalhamento o estudo preliminar. Esse processo demanda a cooperação de agentes dessas organizações, que devem subsidiar a equipe de projeto com informações do sistema. Além disso, um agente da empresa eventualmente colabora com a equipe de projeto e compartilha recursos da organização, como componentes BIM e uso de softwares e equipamentos especializados.

A cooperação tem como objetivo antecipar soluções de arquitetura com especificações mais detalhadas do sistema e assim, indiretamente, vincular a solução aos termos e condições de trabalho das organizações comprometidas com o desenvolvimento do projeto. Nesse sentido, o nível de eficiência com que uma organização comunica as informações de interfaces do sistema é estratégico para o negócio, estimulando o atendimento não estruturado das interações fortes nas fases iniciais. Além disso, a cooperação na concepção é estimulada por haver repercussão de ganhos futuros com a confirmação da participação no empreendimento.

Com a contratação dos serviços associados ao sistema funcional, e não mais a uma atividade específica para uma fase qualquer do empreendimento, o sucesso do trabalho está vinculado ao sucesso do projeto. Pode-se sugerir que se trata de uma forma de organização do empreendimento em que valores pregados em sistemas contratuais do tipo IPD, ligados ao comprometimento e à confiança, deixam de ser protocolares e passam a ser empregados dentro de um regime de gestão de cadeia de suprimentos. 


\subsubsection{Colaboração entre competências complementares}

Projetos de empreendimento imobiliários possuem organizações complexas que dependem do trabalho de vários agentes com diferentes competências para ser bemsucedidos. Muitas vezes não é possível ou conveniente decompor em atividades individuais determinado trabalho, a ponto de exigir a colaboração de parte considerável dos agentes em algum momento do processo de desenvolvimento e execução do projeto.

A arquitetura organizacional proposta estabelece dois direcionamentos à colaboração como alternativa à demanda por instrumentalização organizacional para promover as interações fortes entre agentes (Figura 48). Dentro dos processos internos ao desenvolvimento e à construção de um sistema, a colaboração ocorre principalmente entre projetistas e gerentes da execução, que coordenam as operações de aquisição de insumos, estoque, transporte, produção, etc. Os projetistas, ao integrarem as diferentes equipes de gerenciamento, têm um meio de comunicação direto, facilitado, com os interlocutores da execução interessados nas informações produzidas sobre o projeto. Isso permite trânsito para que a execução esclareça dúvidas de projeto e para que o projeto colete informações para tornar-se mais preciso e inteligível.

Mais do que facilitar a comunicação objetiva de informações de projeto, as interações fortes sobre o conhecimento explícito e tácitos de profissionais de uma mesma organização com competências distintas - de desenhista, de calculista, de negociador, de operador de equipamentos, de gerenciador de pessoas, dos mais diversos trabalhos de ofício - estimula o aprendizado e a criação de conhecimento. Como um ciclo, a perspectiva de integrar o gerenciamento do processo de concepção, desenvolvimento, execução e pós-ocupação permite melhorar e consolidar processos, tecnologias ou negócios e pode ser organizacionalmente capitalizada. 
Figura 48 - Dimensões da colaboração

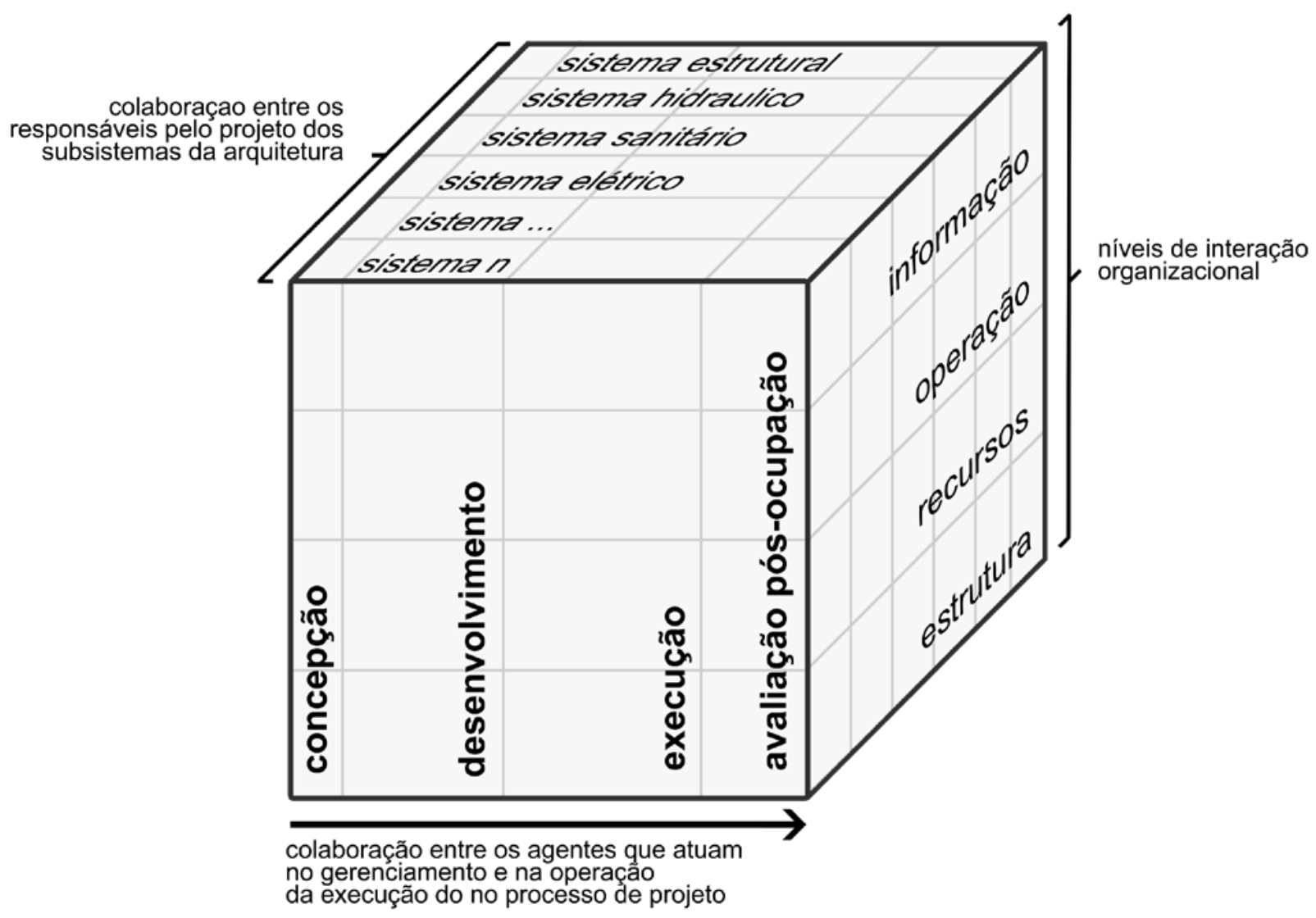

Outro direcionamento da colaboração acontece entre os projetistas dos sistemas funcionais e os projetistas do sistema de integração. A organização responsável pela arquitetura apresentada oferece o ambiente organizacional adequado para integrar o trabalho de projetistas de cada especialidade envolvida, deslocado temporariamente para realizar o desenvolvimento da arquitetura, colaborando nos ciclos de estudo preliminar e no anteprojeto apresentados. A colaboração permite que se construa rapidamente um entendimento compartilhado não apenas sobre os objetivos do projeto, mas também sobre os desafios e estruturas compartilhadas, disponíveis para sua realização.

Ambas as dimensões da colaboração apresentadas têm como objetivo tornar mais eficiente a interação necessária para realizar o trabalho com eficácia. A interação pode ocorrer em relação ao compartilhamento de informações, de operações, de recursos e de estruturas organizacionais disponíveis (Figura 48). Sem o subsídio organizacional necessário, o dinamismo do projeto colaborativo é comprometido com a demanda por estruturar as condições de trabalho para o qual foi iniciado. 


\subsubsection{Organização matricial e orientada ao projeto}

O projeto colaborativo compreende uma forma específica e estruturada de trabalho que demanda a interação forte entre agentes com competências complementares que atuam tanto entre os agentes responsáveis pelo desenvolvimento do projeto como entre os responsáveis pelas atividades de gerenciamento e operação da execução de cada sistema. Assim, agentes realizam atividades de rotina, vinculadas a determinada competência dentro de uma estrutura de trabalho e integram uma equipe responsável pelo desenvolvimento e gerenciamento da execução de determinado projeto.

As informações, operações, recursos e estrutura organizacional comum, que oferecem sustentação e padronização às atividades de rotina, são compartilhadas entre integrantes das equipes de projeto. Cada especialidade possui uma burocracia própria associada a essa rotina, o que assegura previsibilidade aos processos. Como as organizações são congruentes à modularidade dos sistemas que compõem a arquitetura do edificio, tais processos de rotina podem ser harmonizados entre as diferentes etapas que compõem o desenvolvimento e a execução. Por exemplo, a planilha atualizada de fornecedores de determinado serviço contratado durante a atividade "gerenciamento de aquisições" pode ser vinculada à família de objetos utilizada no estudo preliminar, instrumentalizando o "gerenciamento da cadeia de suprimentos", ou, ainda, objetos de determinado componente construtivo podem ser retirados desse template por apresentar problemas associados à aquisição, como atraso, defeito, etc.

A equipe de projeto constituída por profissionais que operam essa burocracia tem em mãos dados consistentes sobre as condições de execução e, por pertencerem à organização que executará o projetado, tem antecipação suficiente para promover ajustes nas operações de suporte e de execução necessárias para realizar o trabalho como planejado. Como é possível antever nesse cenário, o conflito entre o objetivo do projeto e a inércia burocrática de uma organização é transferido para dentro dos processos do sistema, pois o projetista do sistema que integra a equipe de projeto busca dentro da organização a que pertence os meios de realizar os interesses alinhados do empreendimento. 


\subsubsection{Equipe de projeto autônoma e gerenciamento de mudanças}

As atividades da arquitetura organizacional apresentadas no fluxograma (Figura 31) não devem ser entendidas como subdivisões ou segmentações funcionais. O fluxo entre atividades demanda intensa articulação entre competências, característica de um projeto colaborativo. Particularmente, as atividades consideradas eminentemente criativas, circunscritas nos grupos de atividades identificados por estudo preliminar, anteprojeto e projeto executivo, dependem de autonomia para articular movimentos de negociação, modelagem e avaliação durante o processo decisório.

Um dos problemas observados no desenvolvimento $1^{\circ} \mathrm{EE}$ está relacionado ao nível de desenvolvimento esperado de um anteprojeto. Embora faça sentido caracterizar a entrega do anteprojeto no nível de subsistema em um regime contratual baseado na entrega de informações como subprodutos por meio da terceirização de serviços de desenvolvimento de soluções técnicas e arquitetônicas, cabe observar que o nível de detalhe da entrega e o nível de desenvolvimento real da arquitetura são diferentes, sendo necessário projetar soluções além do escopo do anteprojeto para consolidar a validade das decisões. Essa antecipação é potencializada pela necessidade de explicitar o valor da arquitetura, uma vez que depende de uma definição antecipada dos componentes dos sistemas, de maneira que estipule uma previsão de custos realista.

Os movimentos iterativos de exploração e consolidação das definições de projeto em um ambiente colaborativo dificilmente são gerenciados externamente e por isso são muitas vezes ignorados nas discussões sobre o gerenciamento de projeto. Mesmo em discussões sobre a maturidade de modelos BIM, que, em princípio, partem de uma lógica incremental e colaborativa para o desenvolvimento do processo de projeto, frequentemente se busca arbitrar com pouco sucesso critérios para relacionar o nível de desenvolvimento do modelo ao escopo de entrega dos projetos. Tal dificuldade decorre da inadequação de se enquadrar a informação do projeto como um subproduto e, consequentemente, de assumir que a eficiência e a eficácia de um serviço de arquitetura são passíveis de ser gerenciadas externamente por meio do controle do escopo desse subproduto, pois tal orientação gerencial leva os projetistas a priorizarem tempo e esforços ao entendimento das formalidades de entrega, individualmente cobradas segundo o escopo de cada disciplina. 
Como se observou nos estudos empíricos, a associação entre arquitetura e gerenciamento do projeto influencia o engajamento e o alinhamento da equipe de projeto com os objetivos do empreendimento. $\mathrm{O}$ atraso em uma avaliação negativa de determinada proposta causa frustração à equipe e volume de retrabalho maior que o observado em uma situação em que o desenvolvimento tem incorporados os meios de avaliação de resultados tangíveis e a liberdade de gerenciar mudanças para que o projeto atinja o desempenho esperado. Tal autonomia precisa ser garantida organizacionalmente, por meio da constituição da equipe multidisciplinar de projeto e gestão.

A autonomia da equipe de projeto permite o gerenciamento preditivo das mudanças de projeto. Diferentemente do gerenciamento convencional, o desenvolvimento do projeto é realizado apenas com base na experiência dos projetistas, sem dados que balizem a decisão. Com o gerenciamento de valor alimentado com dados das organizações que integram o empreendimento e a perspectiva de embasar a avaliação das decisões em curso, os riscos ligados ao projeto são menores. Os dados são orientados aos custos do desempenho de função dos sistemas. As características tecnológicas e procedimentais ligadas a cada sistema são de responsabilidade do projetista oriundo da organização especialista, e assim ele pode negociar ajustes de custeio-meta sem expor informações de interesse de mercado.

\subsubsection{Ciclos de melhoria contínua orientados à diferenciação, APO e gerenciamento predial}

As oportunidades de melhoria já foram mencionadas com a integração do ciclo de vida do projeto nas organizações modularizadas. Os dados empíricos observados respondem à relação de projeto e execução. Porém, a confirmação do valor construído é avaliada de fato, durante o uso, operação e manutenção do edificio. Como é obrigação legal o acompanhamento técnico após a entrega do edificio, é possível incorporar a APO aos processos de gerenciamento e controle para identificar requisitos de projeto correlatos para subsidiar outros projetos. Além do produto, soluções inovadoras em sistemas funcionais podem ter seu desempenho acompanhado sob a perspectiva do gerenciamento predial. 
Tais implicações, contudo, não foram verificadas no estudo, cabendo pesquisas complementares a serem realizadas com foco no ciclo de vida do edifício, e não apenas no ciclo de vida do projeto.

Nesse sentido, pesquisas que relacionam o projeto ao gerenciamento predial por meio de métodos consistentes como a APO se apresentam como um direcionamento proficuo tanto para aproximar os instrumentos de APO de outros ambientes de aplicação que não o institucional acadêmico, como também para expandir os limites de atuação dos campos do conhecimento associados à arquitetura organizacional. Tais considerações serão pontuadas a seguir, na conclusão, mais especificamente nas recomendações para pesquisas futuras. 


\section{CONCLUSÃo}

O presente trabalho apresentou em sua introdução um conjunto de objetivos a serem respondidos por meio de uma investigação multimétodos orientada não apenas a "analisar as condições organizacionais que influenciam a qualidade no projeto de empreendimentos imobiliários", por meio de estudos exploratórios (objetivo 1), mas também a "propor uma arquitetura organizacional para integrar do processo de projeto por meio do gerenciamento de valor como forma de promover maior qualidade arquitetônica a empreendimentos imobiliários" (objetivo 2).

O enunciado desses objetivos indica a existência de algumas premissas de pesquisa que foram apontadas na introdução e cuja adoção é justificada com a revisão bibliográfica. Assim, o trabalho parte do reconhecimento de um conjunto de teorias consolidadas acerca de alguns temas sobre valor, sobre o processo de projeto e sobre a influência que a forma de organização do trabalho impacta sobre o resultado do projeto.

Entre as principais premissas adotadas, cabe destacar que se assumiu uma correlação direta entre valor e qualidade, tomando como base uma definição já clássica de que a qualidade de um artefato está vinculada à condição de não apresentar defeito e de atender às necessidades e expectativas para o qual ele existe. $\mathrm{O}$ valor, no caso, corresponde à relação de balanceamento entre a qualidade almejada e as condições de aquisição, realização ou uso do artefato.

Outra premissa aceita tem base na teoria das organizações, que aponta uma relação de isomorfismo racional, em que a arquitetura do artefato, a arquitetura do processo e a arquitetura da organização são congruentes e, em razão disso, apresentam a forma mais eficiente e eficaz de realizar a produção do artefato. Esse princípio taylorista foi largamente aplicado em indústrias avançadas de manufatura ao longo de todo o período industrial, inclusive sendo revisitado em discussões sobre a existência de outras formas de isomorfismo, algumas prejudiciais à produção, que são institucionalizadas por constrangimento legal, legitimidade de mercado e mimetismo de experiências de sucesso, entre outras formas não racionais de organização do trabalho. 
No caso de empreendimentos imobiliários, e do ambiente construído em geral, o artefato apresenta particularidades de escala, localização e contexto que o caracterizam como prototípico, realizado em condições ambientais únicas e, portanto, não reproduzível em sua totalidade. Ao confrontar tal característica às condições de isomorfismo, pareceu evidente que, diferentemente de outros setores da manufatura, o desenvolvimento do projeto se justapõe a sua execução, restringindo os benefícios na adoção de estratégias de separar o gerenciamento do projeto e o gerenciamento da produção em razão das diferenças existentes entre uma forma de organização temporária típica do desenvolvimento de projetos e uma organização permanente associada à rotina do chão de fábrica (Figura 49).

Figura 49 - Organização temporária do projeto e da obra versus organização permanente do chão de fábrica
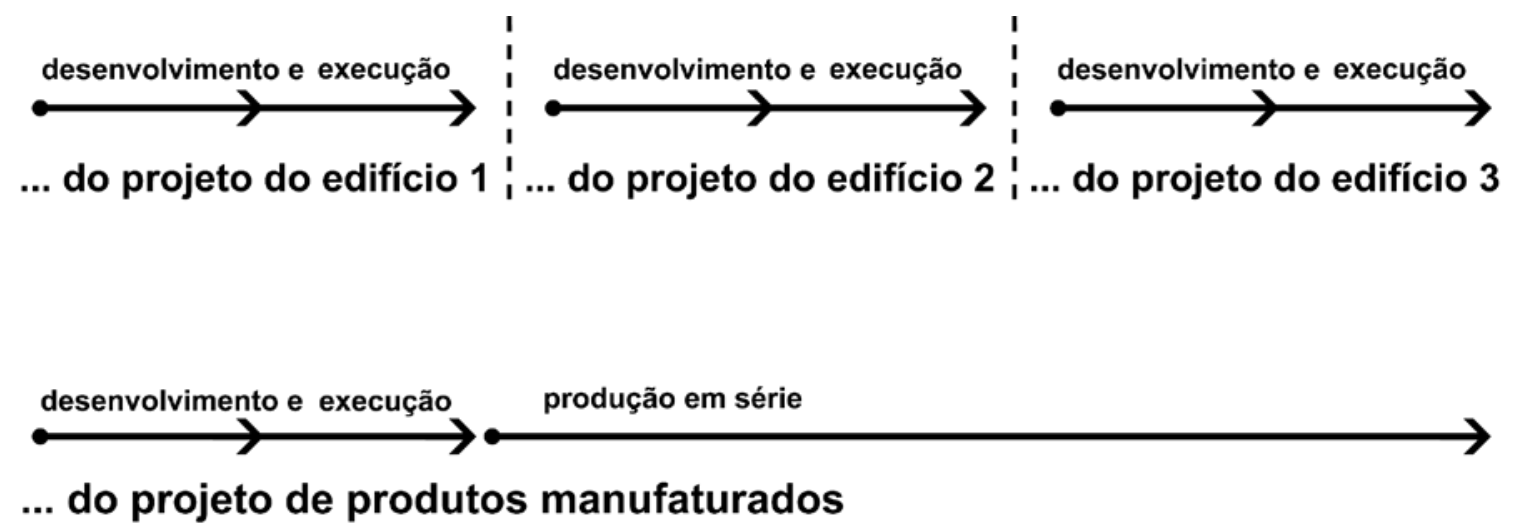

A organização temporária de um canteiro de obra, diferentemente do que sugere a analogia com o chão de fábrica em uma planta industrial permanente, confere ao gerenciamento da execução atribuições que não são suficientemente atendidas por procedimentos e instrumentos de gerenciamento de operações. Tomando como exemplo a indústria automotiva, a produção de protótipos completos de um automóvel para teste de funcionalidade ou mesmo a realização de estudos de montagem no chão de fábrica (First-Run Studies) para ajustar os parâmetros de rotina a serem gerenciados são atividades vinculadas ao processo de projeto. Ao mesmo tempo, a adoção de procedimentos semelhantes, adaptados à AECO, são limitados a aplicações pontuais, de menor impacto para a diminuição das variabilidades da construção, vez que uma aplicação equivalente significaria, em última análise, a construção integral do edifício. 
Reflexões como a exemplificada no parágrafo anterior sugerem um problema de racionalidade na organização isomórfica de setores ligados à $\mathrm{AECO}$, que historicamente mimetizaram as formas de organização de setores mais industrializados da manufatura e reproduziram aproximações nas formas de especialização e de segmentação do trabalho. A persistência da variabilidade nas operações de transformação decorrente do caráter prototípico da construção aponta para a necessidade de identificar outra forma de organização para os empreendimentos imobiliários.

A confrontação entre a teoria organizacional e a situação observada no setor de AECO resultou na hipótese da pesquisa, de que uma organização modular para o trabalho a ser realizado em um empreendimento imobiliário é mais eficiente do que uma organização funcional, uma vez que, em vez de segmentar o trabalho segundo critérios de similaridade e sequencialidade da tarefa, mantém a integridade das interações fortes entre as atividades de projeto e as de construção de cada sistema funcional da arquitetura, segmentando as interações associadas às interfaces entre os sistemas.

A verificação dessa hipótese, bem como o atendimento aos dois objetivos inicialmente apresentados, foi obtida por meio dos procedimentos multimétodos indicados no capítulo 2. Para tornar a tarefa mensurável, os dois objetivos foram subdivididos e sequenciados em oito atividades inter-relacionadas.

A discussão sobre as bases teóricas que abordam a influência organizacional sobre o processo do projeto de empreendimentos imobiliários e sobre sua relação com o gerenciamento de valor e a qualidade do ambiente construído (atividade 1.1) foi iniciada no capítulo 1, de introdução, e detalhada no capítulo 3. O capítulo de RSL abordou o conhecimento, técnicas, práticas e ferramentas de criação de valor, bem como de gerenciamento das informações e outros temas relacionados ao projeto (atividade 1.2) a partir de uma perspectiva organizacional, ao discutir sobre as formas de organizações orientadas ao projeto, sobre o conceito de isomorfismo organizacional e sobre o projeto de uma arquitetura organizacional congruente, entre outros conceitos pertinentes à realização da arquitetura (atividade 1.3). Além da redação deste capítulo, a revisão associada às três primeiras atividades permearam todo o trabalho, ao aperfeiçoarem os métodos empregados, indicados no capítulo 2, e ao subsidiarem teoricamente os apontamentos realizados nos demais capítulos. 
O capítulo 4 apresentou a análise das condições para a adoção do gerenciamento de valor identificado na atividade 1.2, que foram incorporados ao processo de projeto em dois estudos exploratórios (atividade 2.1), oferecendo subsídios empíricos para a elaboração de uma arquitetura para o processo de projeto orientado ao valor (atividade 2.2), descrita no capítulo 5. O mapeamento da congruência organizacional de um empreendimento imobiliário típico foi apresentado no capítulo 6. Esse mapeamento (atividade 2.3), além de oferecer contribuições diretas à discussão da tese, apresentou os dados da estrutura organizacional existente utilizados como base para a construção da arquitetura organizacional apresentada no capítulo 7 , em que o processo de projeto orientado ao valor proposto foi combinado às tarefas do empreendimento existente, e então foi possível simular a congruência da arquitetura organizacional (atividade 2.4). Por fim, como o mapeamento e a simulação partilhavam as mesmas bases de cálculo e estrutura de dados, foi possível apresentar no capítulo 8 uma avaliação comparativa entre o desempenho do empreendimento existente e os desempenhos dos diferentes cenários projetados na arquitetura organizacional (atividade 2.5).

Os resultados alcançados permitiram "discutir as contribuições teóricas da pesquisa sobre a influência organizacional para a qualidade de empreendimentos imobiliários e as implicações práticas da proposição de uma arquitetura organizacional para promover a congruência organizacional em um empreendimento existente" (objetivo 3). Assim como os dois objetivos apresentados inicialmente, este foi decomposto em três atividades de pesquisa, que abordaram a discussão sobre a contribuição da tese para a prática profissional e acadêmica em AECO sob as perspectivas teórica, metodológica e política.

A conclusão apresenta uma discussão dos achados sobre a organização do projeto de empreendimentos imobiliários (atividade 3.1), discute o potencial de adotar o mapeamento da congruência organizacional como um procedimento de pesquisa e de gerenciamento estratégico de empreendimentos e empresas de AECO, mediante alguns ajustes, aperfeiçoamentos e automatização necessários (atividade 3.2), e propõe um debate sobre as condições de disseminação do gerenciamento de valor na prática do projeto e qual é a contribuição potencial dessa disseminação para a qualidade do ambiente construído e valorização dos serviços de AECO, ao aumentar a eficiência do projeto em empreendimentos imobiliários. 


\subsection{IMPLICAÇÕES TEÓRICAS DOS ACHADOS SOBRE A ORGANIZAÇÃO DO PROJETO}

A breve explanação sobre as relações existentes entre os objetivos, as atividades de pesquisa e os capítulos da tese visou explicitar as relações teóricas e experimentais que alimentaram as conclusões ora apresentadas.

Os casos estudados foram abordados segundo procedimentos específicos orientados aos objetivos da pesquisa. Os estudos exploratórios foram realizados para entender empiricamente as condições de aplicação dos procedimentos e ferramentas de TVD por equipes de projeto e, assim, balizar a elaboração de uma arquitetura do processo orientada ao valor. $\mathrm{O}$ mapeamento da congruência organizacional realizado em um empreendimento imobiliário existente permitiu compreender como essa forma de organização, recorrente em AECO, influencia o trabalho dos agentes envolvidos ao não subsidiar as interações e ao restringir a colaboração. Com base nesse diagnóstico, foi desenvolvida uma arquitetura organizacional para o empreendimento existente, orientada à integração do processo de desenvolvimento e de gerenciamento de valor por meio da arquitetura.

A simulação da congruência da arquitetura organizacional demonstrou virtualmente os ganhos de eficiência de uma organização modular, orientada à integração das competências complementares para o desenvolvimento e a execução do projeto dos sistemas funcionais e de integração. As razões para esse desempenho são explicadas com base na teoria sobre a organização do processo de projeto levantada na literatura científica disponível.

\subsubsection{O empreendimento estudado e outras formas de organização em AECO}

O empreendimento analisado apresentou baixa modularidade na arquitetura da edificação e uma segmentação organizacional que acompanha a subdivisão por especialização do trabalho. O regime de entregas de subprodutos é utilizado desde a concepção como meio de regular a prestação de serviços. Assim, o gerenciamento do escopo das entregas define o progresso do empreendimento. 
Um conjunto significativo das atividades mapeadas está vinculado ao atendimento do escopo de entrega de informações do projeto. São atividades orientadas a especificidades normativas e formais de entrega não orientadas ao atendimento dos requisitos do cliente, isto é, são atividades que não agregam valor ao projeto. Embora tenham sido naturalizadas entre profissionais de AECO, tais atividades acrescentam complexidade ao desenvolvimento e ao gerenciamento da execução do projeto sem beneficiar o fluxo de valor.

Problemas de iteração observados por meio das interações cíclicas não atendidas, mapeadas no empreendimento analisado, são reflexo do gerenciamento do projeto orientado ao escopo de entregas de informação como subprodutos, e não como fluxo de informações. Mais do que informação, as barreiras interorganizacionais dificultam a interação cíclica entre agentes cuja função especializada é complementar, comprometendo a eficiência e mesmo a eficácia do gerenciamento de mudanças, que depende da antecipação na detecção de inconformidades da execução, do poder de negociação dos termos de ajuste do escopo do projeto e do envolvimento direto para promover e manter o entendimento compartilhado sobre os objetivos do projeto e o engajamento dos envolvidos.

O levantamento confirmou que problemas de interação causados pela segmentação das atividades do empreendimento com base na especialização e no sequenciamento do fluxo de transformação se acentuavam entre os limites interorganizacionais, e que esses limites reproduziam a lógica de especialização e do sequenciamento, reduzindo o potencial de integração dos fluxos de informação e de valor do projeto por meio de uma organização permanente das tarefas.

Contudo, tal forma de organização não foi deliberada pelos agentes envolvidos. Variações da conformação do empreendimento analisado são recorrentes no setor de AECO. Como foi apontado na discussão sobre o mapeamento feito, os arquitetos responsáveis pelo escritório de arquitetura atribuíam a qualidade apontada por outros profissionais em seus projetos à experiência adquirida por meio do gerenciamento de obras de arquitetura. Todavia, consideravam que esse modelo de negócio não era percebido pelo mercado, o que os motivou a se especializarem no desenvolvimento da arquitetura. Como consequência dessa decisão, sentiram que os detalhamentos construtivos têm perdido consistência por falta de experiência tectônica dos profissionais recentemente associados ao escritório. 


\subsubsection{Isomorfismo institucional e congruência organizacional}

Quando questionados do porquê da aceitação de algumas características organizacionais onerosas ao trabalho, os agentes argumentam sobre a necessidade de se ajustar a um modelo de negócio reconhecido pelo mercado e regulamentado por instituições corporativas e governamentais. Adequações semelhantes motivadas pela busca por reconhecimento, pressão mercadológica ou constrangimento legal e normativo são exemplos de isomorfismos institucionais recorrentes no setor.

No exemplo estudado, o escritório de arquitetura tem diminuído sistematicamente seu envolvimento com o gerenciamento da execução de seus projetos, pressionado a se se ajustar a um modelo em que projeto de arquitetura é uma especialidade contratada como um serviço independente. Contudo, foi levantado que tal segmentação desconsidera que parte substancial do valor nos projetos decorre da tectônica apreendida tacitamente e aperfeiçoada com a iteração contínua entre atividades de desenvolvimento e de gerenciamento da execução do projeto.

A qualidade auferida pelo escritório de arquitetura sugere uma organização diferente da conformação isomórfica observada no mercado. Enquanto dominava todo o processo de desenvolvimento e execução do projeto, o escritório atendeu à integridade das interações fortes por meio do esforço profissional de seus integrantes. Com a perspectiva de galgar projetos maiores, o escritório é pressionado a abandonar tal integridade nas interações para se especializar, mimetizando outros escritórios de arquitetura reconhecidos mercadologicamente.

Contudo, o que a análise comparativa dos mapeamentos demonstrou é que uma organização congruente para empreendimentos para edificações deve respeitar os conjuntos de interações fortes por meio da modularização dos processos de desenvolvimento e gerenciamento da execução dos sistemas funcionais e de sistemas de integração. O grau de modularização depende da complexidade dos sistemas que compõem a arquitetura da edificação, e a forma de modularização deve preservar a integridade e a fluidez do fluxo de informação e valor, permitindo um processo decisório iterativo e incremental, simplificando o gerenciamento de mudanças do projeto e instrumentalizando o aprendizado organizacional para capitalizar o aperfeiçoamento de uma tectônica própria, eventualmente inovadora, capaz de promover uma diferenciação de mercado consistente. 


\subsubsection{Organização de rede de multiempresas orientada à criação de valor}

A modularização dos processos de acordo com as interações entre atividades complementares não adjacentes e a complexidade dos sistemas permite a segmentação e a especialização das tarefas de desenvolvimento e execução, ao mesmo tempo em que mantém a integridade dos fluxos de informação sobre a transformação e a criação de valor. As condições de criação de valor são promovidas por uma estrutura de organizações permanentes, com ambientes, recursos e competências adequados para subsidiar as interações fortes.

Por outro lado, os limites interorganizacionais são coincidentes com as interações de interface dos sistemas e demandam a coordenação da arquitetura do edificio, do processo e da organização do empreendimento por meio da definição de regras e interfaces de acoplamento claras. Esse tipo de regras já é bastante desenvolvido em razão de as disciplinas de conhecimento serem funcionalmente divididas. Ao situar corretamente a função da arquitetura como sistema de integração, é possível coordenar as atividades de transformação para alcançar os objetivos do projeto, gerenciando os fluxos de informação e de valor da arquitetura. O princípio por trás dessa proposição é agrupar em determinada organização as competências necessárias para integrar o fluxo de transformação e de criação de valor ligado ao funcionamento interno de cada sistema, e atribuir à organização da arquitetura as competências necessárias para coordenar o fluxo de transformação e de valor ligado ao funcionamento externo dos sistemas que compõem a arquitetura, de forma a atender às expectativas, necessidades e condições do projeto.

A análise comparativa da congruência organizacional entre o mapeamento do empreendimento existente e a simulação da arquitetura organizacional demonstrou ganhos de congruência com a proposição de uma organização em rede orientada à criação de valor do projeto. A teoria existente associa esse modelo a melhores condições para ganhos de capacidade organizacional ao clarificar quais são as competências centrais ao negócio que precisam ser desenvolvidas e melhoradas. A confirmação dos ganhos, contudo, depende do atendimento de algumas condições de trabalho, que garantam meios de comunicação síncrona e assíncrona, e uma estrutura de governança para mediar conflitos, fomentar o desenvolvimento de competências e promover o comprometimento por meio do senso de ganho mútuo. Algumas dessas condições foram 
tratadas de forma concreta na discussão sobre colaboração, gerenciamento de valor e BIM, retomadas a seguir.

\subsubsection{Autonomia para colaborar}

A atribuição de autonomia à equipe de projeto para alcançar maior eficiência e eficácia é uma decisão organizacional orientada para a colaboração incompatível com as tentativas de controle por meio do escopo de entrega, principalmente na concepção da arquitetura.

A escolha por autonomia se justifica pelo reconhecimento da característica não estável dos conhecimentos de projeto, uma vez que este se consolida conforme o trabalho se desenvolve na construção de uma realidade ainda não existente (NONAKA; TAKEUCHI, 1997; NONAKA; TOYAMA, 2003). Na prática do projeto, uma gestão bem coordenada não é suficiente para garantir resultados criativos bem-sucedidos (GERWIN; BARROWMAN, 2002). Como observado no caso, a demanda por uma nova solução, principalmente devido à novidade da inserção dos custos desde o início do processo, impede a simples repetição de um comportamento passado, o que suscita incerteza sobre o que precisa ser feito (HOOPES; POSTREL, 1999).

Os fatos são construídos iterativamente com o trabalho e só podem existir quando os conceitos e ideias anteriores formam a base para trabalhar novos conceitos, que respondem especificamente à relação existente entre problema e solução do projeto, recontextualizada e reavaliada por meio do entendimento compartilhado galgado com a prática reflexiva (VALKENBURG; DORST, 1998; KLEINSMANN; VALKENBURG, 2008; STEEN, 2013). A prática reflexiva, por sua vez, ocorre quando a equipe de projeto reflete e intervém sobre a ação em andamento, propiciando o amadurecimento articulado do artefato e do processo do projeto visando atender ao objetivo principal (VALKENBURG, 2000; PEREIRA et al., 2018).

Como as variáveis não previsíveis em um processo de projeto são significativas, modelos de gestão externos são pouco eficazes em promover valor. A resistência em migrar do modelo de projeto linear para um modelo baseado em projeto colaborativo tem se mostrado mais evidente ante a dificuldade de adaptação do setor para explorar todo o potencial que plataformas BIM oferecem (KENT; BECERIK-GERBER, 2010). 


\subsubsection{Gerenciamento de valor e BIM}

A associação entre as ferramentas de TVD e BIM para promover o gerenciamento de valor durante o desenvolvimento do projeto, conforme foi observado no segundo estudo exploratório, foi crucial para viabilizar o resultado com a rapidez e a precisão alcançadas.

A modelagem de informação beneficiou a comunicação e a validação das alternativas apresentadas pelos projetistas durante a concepção. Essa validação foi possível graças à automatização parcial da extração de informações paramétricas do projeto que subsidiaram com quantitativos uma estimativa orçamentária em nível do sistema. $\mathrm{O}$ trabalho exigiu intensa atividade presencial da equipe de projeto, e não é possível afirmar que o mesmo resultado seria alcançado com o trabalho remoto dos projetistas, como é recorrente em projetos de AECO.

O estudo indicou que a definição do TVD como um processo anterior à concepção do projeto pode ser uma compreensão inadequada, pois não contempla a dimensão iterativa do processo decisório nas fases iniciais do projeto. Como a colaboração entre projetistas e clientes em projetos complexos é fundamental para construir um entendimento compartilhado sobre as características espaciais e os critérios de desempenho esperados, entre os quais o custo projetado, parece adequado compreender o TVD como parte da atividade integrada à concepção do valor do projeto, aproximando-o de uma dimensão estratégica e gerencial do empreendimento.

Observou-se que soluções mais criativas dependem da negociação direta entre projetistas e a cadeia de suprimentos, já que, do contrário, as resoluções ficam limitadas à manipulação de resoluções tradicionais similares às existentes no mercado. Sem essa autonomia, constatou-se que algumas soluções foram evitadas por não serem convencionais, devido aos riscos decorrentes da falta de suporte. A falta de um envolvimento direto no gerenciamento da execução sujeita a equipe de projeto a um entendimento reduzido das condições de construção.

O aumento da eficiência na alocação de recursos ocorre por meio do entendimento compartilhado sobre a relação entre problema e soluções possíveis, cujas relações de custo-beneficio foram mensuradas por meio das ferramentas de valor. Sem a colaboração assistida pelo BIM, as atividades de modelagem e avaliação das propostas seriam morosas. $\mathrm{O}$ engajamento da equipe ao transitar entre perspectivas técnicas, do cliente e dos custos 
foi fundamental para aprofundar a negociação sobre qual solução era a mais eficaz. A possibilidade de transitar livremente entre as diferentes perspectivas permitiu realizar o trabalho em tempo hábil, o que seria inviável caso atividades de dependência iterativa fossem segmentadas organizacionalmente.

O potencial observado na pesquisa apontou para a importância de aperfeiçoar e interoperabilidade das ferramentas de GV e BIM, mas evidenciou a necessidade de promover uma arquitetura organizacional orientada ao gerenciamento de valor e, por consequência, que a equipe de projeto apresente competências sociais de negociação em projeto colaborativo, adequadas às demandas de gerenciamento da cadeia de suprimentos.

\subsection{MAPEAMENTO DA CONGRUÊNCIA ORGANIZACIONAL PARA PESQUISA E GESTÃO}

Além dos achados relacionados à discussão sobre a organização do projeto, a pesquisa apresentou resultados interessantes quanto à adequação e aplicação do método de mapeamento da congruência organizacional em empreendimentos imobiliários. Identificado como um desdobramento de trabalhos que discutem ferramentas de Design Structure Matrix e Domain Mapping Matrix (BONJOUR; MICAELLI, 2010), o mapeamento da congruência agrega e relaciona as informações levantadas sobre o artefato e sobre o processo de projeto, de forma a identificar as interações potenciais entre as atividades do projeto que influenciam a construção do valor de projeto.

O estudo apresenta duas contribuições para a análise de organizações em AECO. Primeiro, descreve os procedimentos metodológicos e apresenta um exemplo de aplicação do mapeamento, com sua consequente análise. Segundo, introduz o mapeamento ao processo de proposição da arquitetura organizacional, adotando-o como um instrumento de simulação da congruência entre produto, processo e organização. A comparação entre a congruência do mapeamento da organização existente e a das simulações de arquitetura enriqueceu a discussão ao estabelecer parâmetros e métricas à avaliação do cenário existente e os cenários projetados. 


\subsubsection{Um instrumento de pesquisa}

A utilização de um método estruturado de levantamento, tratamento e apresentação de dados como o mapeamento da congruência organizacional oferece vantagens à análise baseada na observação do pesquisador ao reduzir o viés de confirmação das crenças prévias do observador, que inconscientemente direciona sua percepção aos fenômenos que pretende demonstrar, ainda durante a coleta de dados, o que reduz significativamente a oportunidade de se estabelecer o contraditório.

O mapeamento da congruência estabelece um cenário codificado e explícito em um conjunto de matrizes que podem ser lidas e interpretadas independentemente da análise que o acompanha. Apesar de trabalhosa, a coleta dos dados é de simples apreensão, pois envolve orientações objetivas, o que facilita o engajamento e o esclarecimento dos colaboradores em relação aos objetivos e aos procedimentos para o levantamento. $\mathrm{O}$ tratamento dos dados relaciona as interfaces entre componentes, a afiliação dos componentes às tarefas e a comunicação entre tarefas, o que é informado por meio de matrizes com dados secundários qualificados. Particularmente, os cenários apreendidos nas matrizes de interação potencial e a matriz de congruência dependem do processamento dos dados primários, apresentando relações não evidentes com a simples observação em campo.

Em última análise, o que a relação de congruência apresentada faz é converter todas as formas de interação em uma informação unidimensional, um marcador, que permite homogeneizar e relacionar os dados levantados. Assim, o mapeamento não distingue se a interação entre as tarefas é um dado do projeto ou a construção de um componente, pois este último é convertido na informação da transformação da atividade que interage com a atividade dependente. Essa conversão não pressupõe um achatamento das condições reais de realização das atividades, mas, sim, um ajuste de escala adequado para o gerenciamento estratégico.

Embora não tenha sido testada, a estrutura baseada em domínio permite justapor esse mapeamento a outras matrizes ligadas à designação de recursos e competências. Essa possibilidade oferece um campo de expansão de novas pesquisas promissor a ser considerado. 


\subsubsection{Um instrumento gerencial}

O mapeamento da congruência organizacional se mostrou um instrumento adequado para realizar um diagnóstico de suporte ao gerenciamento estratégico do processo de projeto. Por meio do mapeamento da situação existente é possível identificar pontos de interação forte não atendidos e, após propor uma estratégia de mitigação dos casos observados, simular a congruência organizacional da modificação. Aferir a congruência de uma proposta reduz os riscos de mudanças que visam a maior eficiência dos processos existentes.

A utilização do mapeamento da situação existente e a simulação da congruência de mudanças podem ser realizadas para estudar como incorporar de forma bem-sucedida novas atividades, práticas e ferramentas aos processos de projeto. Todavia, os meios de processamento dos dados ainda não estão consolidados em um sistema de informação operacional automatizado, acessível aos usuários. Essa tarefa, assim como a ampliação da variedade de índices de desempenho e de formas de visualização dos dados, é importante para estabelecer o método de mapeamento da congruência como um produto de suporte ao gerenciamento utilizável.

A consolidação de instrumentos que subsidiem a discussão de mudanças em empreendimentos imobiliários assume relevância diante das pressões ambientais inauditas por mudanças estruturais significativas experimentadas no setor de AECO. Assim, a análise da congruência organizacional é instrumental para responder aos desafios estratégicos de integrar racionalmente as mudanças de tecnologias e os métodos de projetos disruptivos que impactam sobre a cadeia produtiva e o ciclo de vida de construção, tais como a modelagem de informação da construção (BIM), o Target Value Design (TVD) e a análise de ciclo de vida (ACV).

\subsubsection{Diretrizes gerais da proposição de uma arquitetura organizacional}

A proposição de uma arquitetura organizacional conforme realizada no presente estudo pode ser descrita como um conjunto de diretrizes ou passos elementares que buscam relacionar a arquitetura do edificio e a arquitetura do processo para promover a congruência organizacional entre as atividades do projeto, com vistas a uma maior eficiência na projeção de uma arquitetura de qualidade. 
Os dois primeiros passos correspondem ao levantamento dos dados básicos sobre a arquitetura do edifício e a arquitetura do processo do projeto. São atividades utilizadas tanto para estruturar uma organização nova, como para modificar uma organização existente.

1. A proposição de uma arquitetura organizacional congruente se inicia com a análise da estrutura da arquitetura do edificio, distinguindo cada sistema funcional e relacionando as interfaces diretas entre cada componente dos sistemas. A arquitetura do edificio corresponde ao sistema de integração e é determinada por ambientes e demais elementos arquitetônicos como acessos, volumetria, etc., que estão vinculados à percepção e à utilização do edificio.

2. O trabalho de desenvolvimento e execução do projeto precisa ser decomposto em atividades cujas competências necessárias para a realização possam ser bem definidas e compatíveis com as competências de domínio dos agentes mobilizados.

Desse ponto em diante os passos para a realização da arquitetura organizacional se dividem entre a promoção de uma arquitetura nova e a modificação de uma organização existente. Os passos ligados à primeira situação são listados a seguir, porém precisam ser compreendidos como uma orientação geral, dado que foram tratados apenas operacionalmente nos testes preliminares da aplicação do mapeamento para tese. Portanto, não foram acompanhados do mesmo nível de análise dos resultados observados no segundo caso.

3.a. Em uma situação de elaboração de uma organização nova, os dois conjuntos de dados são suficientes para gerar a matriz de interações potenciais fortes.

4.a. A definição das precedências, o planejamento da comunicação entre agentes responsáveis pelas atividades e a combinação ou a decomposição das atividades inicialmente previstas são propostos a partir da análise detalhada dos dados da matriz $\mathrm{PF}_{\mathrm{mm}}$.

5.a. Definidas as comunicações entre as atividades, é possível gerar a matriz de congruência da proposta de arquitetura e realizar um aperfeiçoamento da proposta, ou mesmo comparar propostas concorrentes de arquitetura, de forma a subsidiar a decisão pela implantação de um arranjo organizacional mais conveniente aos objetivos da nova organização. 
Os passos a seguir são referentes à generalização do trabalho apresentado na tese. Portanto, as condições de realização e os resultados alcançados podem ser tomados como exemplos ou parâmetros de aplicação mais detalhados. Todavia, cabe o registro-síntese:

3.b. Em uma arquitetura realizada sobre uma organização existente (assim como foi realizada no estudo), em que o objetivo é promover modificações no processo para inserir novas atividades ou racionalizar sua congruência, é preciso identificar a comunicação na organização existente, de forma a estabelecer as relações de precedências e paralelismo preexistentes e orientar mudanças a partir dessa realidade.

4.b. Com a indicação da decomposição da arquitetura do edificio, a relação de afiliação desta com as atividades existentes, mais o levantamento da comunicação existente é possível gerar a matriz de congruência, que relaciona a matriz das atividades e as matrizes das interações potenciais.

5.b. A partir da análise detalhada da matriz $\mathrm{C}_{\mathrm{mm}}$ são propostas mudanças de adição de atividades desejadas na redefinição das precedências, no planejamento da comunicação entre agentes responsáveis pelas atividades, na combinação ou decomposição das atividades inicialmente previstas ou, ainda, no remanejamento de atribuições de responsabilidade entre os agentes.

6.b. A congruência da proposta de arquitetura é comparada à congruência existente, de forma a subsidiar a construção de outros cenários, segundo a conveniência dos objetivos da arquitetura organizacional.

A sugestão de passos tanto para arquiteturas organizacionais novas (ramificação "a") como para mudanças em arquiteturas organizacionais existentes (ramificação "b”) oferece as condições básicas para estabelecer a congruência entre sistema, processo e organização. Embora esses elementos sejam baseados na análise de um caso único, são a evolução de procedimentos existentes, levantados na literatura sobre arquitetura organizacional, o que significa que a novidade da contribuição apresentada é circunstancial e cumulativa, destinada à difusão e adequação do conhecimento geral às condições particulares observadas em projetos de empreendimentos imobiliários compostos por uma rede de empresas.

Por fim, como observado anteriormente, a relação de congruência do mapeamento apresentado converte todas as formas de interação em um marcador único, o que implica a abstração de dimensões da interação a uma escala adequada para o gerenciamento 
estratégico da arquitetura organizacional. Assim, a elaboração de uma arquitetura organizacional congruente depende da interpretação adequada das informações mapeadas para que as condições de interações sejam adequadas.

Com o conhecimento apreendido com a RSL foi possível identificar as condições de modularização dos processos a serem consideradas durante o desenvolvimento de uma arquitetura organizacional. Essas condições foram traduzidas em postulados propositivos que consideram (1) promover a colaboração entre as atividades com competências complementares não adjacentes responsáveis por um módulo funcional da arquitetura do sistema por meio da modularização de recursos e processos compartilhados; (2) promover a cooperação entre as atividades adjacentes e interdependentes por meio de interfaces organizacionais que estimulem a autonomia e o comprometimento entre agentes para interagir; (3) promover a coordenação do acoplamento entre módulos da arquitetura do sistema por meio da interoperabilidade digital de informações, disponibilizando os recursos para garantir as condições de interoperabilidade das informações; e (4) conferir autonomia para que a equipe multidisciplinar de projeto possa coordenar com eficiência e eficácia a integração da arquitetura, orientada pelo gerenciamento de valor.

Os quatro pontos levantados orientam a aplicação dos procedimentos de arquitetura organizacional descritos de forma a reduzir as barreiras organizacionais e os problemas de comunicação assíncrona que dificultam o entendimento compartilhado sobre o conteúdo e o valor do sistema.

\subsection{CONDIÇÕES DE DISSEMINAÇÃO DE MUDANÇAS ORGANIZACIONAIS}

Os impactos das conclusões apresentadas até aqui precisam ser compreendidos dentro das características do setor de AECO, com baixos índices de inovação, principalmente nas áreas associadas ao gerenciamento de valor e à interação entre desenvolvimento e execução do projeto, em que mudanças culturais, tecnológicas e organizacionais enfrentam resistência.

O empreendimento mapeado ilustra a hesitação de profissionais do setor em adotar formas de atuação que difiram das organizações tradicionais, reconhecidas pelo mercado. 
No caso da arquitetura, embora apresente um histórico de atuação no desenvolvimento e no gerenciamento da execução dos projetos que lhes conferiram diferenciação de mercado, em vez de estruturar organizacionalmente tais práticas em ganhos para o negócio, o escritório vem reduzindo tais práticas para ajustar o posicionamento da empresa como um escritório voltado para o desenvolvimento de projetos de arquitetura e, assim, se alinhar a formas de organização reconhecidas pelo mercado.

O isomorfismo institucional, também observado em outras áreas de atuação da AECO, decorre de características culturais, normativas e corporativas do setor. A manutenção dessa realidade está diretamente vinculada à ação de agências reguladoras, sejam governamentais ou de representações profissionais. Os casos esporádicos de mudança disruptiva normalmente são promovidos por pressão de grandes empresas e empresas de software ou materiais da construção, que possuem capacidade de investimento suficiente para se articular politicamente para tanto. Nesse contexto, as empresas que melhor compreendem e se ajustam às novas formas de organização obtêm vantagens competitivas durante o período de transição, mas assim que essas mudanças se consolidam ocorre uma tendência à homogeneização da atuação profissional, característica de isomorfismo institucional normativo e de legitimidade mercadológica e governamental.

Dentro de um cenário como o observado em AECO, as contribuiçõoes da pesquisa para a prática profissional precisam ser colocadas em perspectiva. Em um ambiente favorável, a implantação de uma arquitetura organizacional congruente tem repercussões positivas para toda a cadeia de negócios indiretamente envolvida; porém, em um ambiente avesso a mudanças disruptivas, tais mudanças podem resultar em deslegitimação mercadológica da empresa que implantou a arquitetura. A promoção de um ambiente favorável para que o potencial da modularização de arquiteturas congruentes se concretize depende da mobilização dos agentes que promovem o isomorfismo institucional no setor, por meio da conscientização dos ganhos potenciais de aumentar o campo de atuação do projeto, de forma a viabilizar a iteratividade adequada para o gerenciamento de mudanças do projeto, o aprendizado e a melhoria contínua.

O entendimento de uma organização orientada ao projeto aproxima estrategicamente o conceito de projeto do edificio ao conceito de gerenciamento do empreendimento imobiliário e confere um duplo desafio ao setor, de superar o isomorfismo institucional 
que aliena o potencial inovador do processo de projeto e de promover arquitetura organizacional de empreendimentos imobiliários orientadas para o gerenciamento de valor. Como é de se esperar, tais mudanças setoriais têm repercussões significativas sobre a qualidade do ambiente construído, tanto na valorização dos profissionais ligados ao projeto como no alinhamento do setor aos interesses da sociedade, ao "puxar" as inovações mediante a construção de valor para os habitantes dos imóveis construídos, em vez de se apropriar de ganhos oriundos de inovações ligadas aos interesses dos setores de fomento de material e tecnologia da construção.

\subsection{CONSIDERAÇÕES FINAIS}

O presente trabalho tem como base a formulação de modelos de sistema, de processo e de organização. Por definição, modelos são utilizados para descrever uma síntese de determinadas características da realidade e a partir dessa lente permitir uma leitura adequada para discutir como o sistema deveria/poderia ser (CHAGAS JR.; CAMPANÁRIO, 2014). Embora sejam uma simplificação, modelos devem representar a realidade com informações suficientes para descrever uma situação e elucidar satisfatoriamente o funcionamento do sistema na obtenção dos fins previstos. Isso significa que existe um nível de arbitrariedade na definição das variáveis isoladas, mesmo que tais variáveis tenham sido subordinadas ao escrutínio da teoria existente.

Além disso, devido à tendência dos estudos empíricos da tese de se concentrarem em empreendimentos de habitação e saúde, pode-se entender que o conceito desenvolvido deve se aplicar diretamente a esses tipos de empreendimentos. No entanto, uma vez que as bases de elaboração do modelo e dos métodos de estudo empregados sejam originados na teoria organizacional geral, argumenta-se que os achados podem ser aplicáveis a outros tipos de empreendimento imobiliários, com o cuidado de se estabelecerem aplicações complementares que ratifiquem ou retifiquem os achados, total ou parcialmente. As consequências dessa replicação permitirão um debate adicional sobre as diferenças contextuais entre os setores da indústria, por exemplo, no que diz respeito às possibilidades e ao nível viável de repetição, integração e centralização nesses setores, e eventualmente estabelecerão generalizações possíveis (VRIJHOEF, 2011). 


\subsubsection{Direcionamento para futuras pesquisas}

Os desafios apresentados pela discussão da influência organizacional sobre a qualidade no processo de projeto abrem perspectivas para um vasto campo de pesquisas, ligadas à compreensão das diferentes formas como o isomorfismo organizacional impacta o setor e influencia a qualidade do ambiente construído.

Entre os campos de pesquisa possíveis, destacam-se três perspectivas consideradas desdobramentos diretos da tese: (1) a aplicação do método de análise para situações específicas, como mudanças de processos decorrentes de implementação de novas tecnologias, atuação em novos mercados, com novos produtos; (2) a elaboração de instrumentos de arquitetura organizacional mais sofisticados, associando outras variáveis organizacionais que impactam o desempenho de um negócio à discussão da congruência organizacional, de forma a adicionar a discussão da influência organizacional a outras variáveis não consideradas; e (3) uma análise da congruência focada nas interações potenciais entre gerenciamento de valor, negócios imobiliários, gerenciamento predial e projeto, de forma a promover a integração do fluxo de valor não apenas do empreendimento imobiliário, mas de todo o ciclo de vida do edifício. 


\section{REFERÊNCIAS}

ABAURRE, M. W. Modelos de contrato colaborativo e projeto integrado para modelagem da informação da construção. 2014.

ABNT. NBR ISO 14040 Gestão ambiental - Avaliação do ciclo de vida - Princípios e estrutura. Rio de Janeiro: Associação Brasileira de Normas Técnicas, 2001.

ABNT. NBR ISO 14004 Sistemas de gestão ambiental - Diretrizes gerais sobre princípios, sistemas e técnicas de apoio. Rio de Janeiro: Associação Brasileira de Normas Técnicas, 2005.

ABNT. NBR ISO 14044 Gestão ambiental - Avaliação do ciclo de vida - Requisitos e orientações. Rio de Janeiro: Associação Brasileira de Normas Técnicas, 2009. v. 46

ABNT. NBR ISO 14001 Sistemas de gestão ambiental - Requisitos com orientações para uso. Rio de Janeiro: Associação Brasileira de Normas Técnicas, 2015.

AHUJA, R. et al. Adoption of BIM by architectural firms in India: technology-organizationenvironment perspective. Architectural Engineering and Design Management, v. 12, n. 4, p. 311-330, 3 jul. 2016. Disponível em: http://dx.doi.org/10.1080/17452007.2016.1186589. Acesso em: 5 out. 2018.

AHUJA, R.; SAWHNEY, A.; ARIF, M. Developing organizational capabilities to deliver lean and green project outcomes using BIM. Engineering, Construction and Architectural Management, v. 25, n. 10, p. 1255-1276, 2018.

AIA. Integrated Project Delivery : A Guidelntegrated Project Delivery: A Guide. [s.l: s.n.].

AIER, S.; FISCHER, C. Criteria of progress for information systems design theories. Information Systems and e-Business Management, v. 9, n. 1, p. 133-172, 27 mar. 2011. Disponível em: http://link.springer.com/10.1007/s10257-010-0130-8.

AKAO, Y. QFD : Past, Present, and Future. Quality Progress, n. 2, p. 1-12, 1997.

AKINTOYE, A. S. Factors Influencing the Project Cost Estimating Decision. (P. Bowen, R. Hindle, Eds.) In: CIB W55 \& W65 Joint Triennial Symposium Customer Satisfaction : A focus for research \& practice, September, Anais [...]1999.

AKINTOYE, A. S.; MACLEOD, M. J. Risk analysis and management in construction. v. 15, n. 1, p. 31-38, 1997.

ALDRICH, H. E.; RUEF, M. Organizations evolving. 2. ed. London: SAGE Publications Ltd, 2006.

AMMETER, A. P.; DUKERICH, J. M. Leadership, team building, and team member characteristics in high performance project teams. EMJ - Engineering Management Journal, v. 14, n. 4, p. 3-10, 2002. 
ANCHIETA, C. C. Regression models to assess the thermal performance of Brazilian low-cost houses: consideration of solar incidence and shading devices. 2016.

Universidade de São Paulo, São Carlos, 2016. Disponível em:

http://www.teses.usp.br/teses/disponiveis/102/102131/tde-10102016-105601/. Acesso em: 22 ago. 2018.

ANDERSON, A. et al. Construction to operations exchange: Challenges of implementing COBie and BIM in a large owner organization. In: Construction Research Congress 2012: Construction Challenges in a Flat World, Proceedings of the 2012 Construction Research Congress, Cic 2011, West Lafayette, IN, United states. Anais [...] West Lafayette, IN, United states: 2012. Disponível em: http://dx.doi.org/10.1061/9780784412329.070. Acesso em: 5 out. 2018.

ANDRADE, C. D. de. Rosa do povo. São Paulo: Companhia das Letras, 2012.

ANDRADE, M. L. V. X. de; RUSCHEL, R. C. Interoperabilidade de aplicativos BIM usados em arquitetura por meio do formato IFC. Gestão \& Tecnologia de Projetos, v. 4, n. 2, p. 76-111, 15 dez. 2009. Disponível em: http://www.revistas.usp.br/gestaodeprojetos/article/view/50960. Acesso em: 5 out. 2018.

ANKER JENSEN, P. et al. In search for the added value of FM: what we know and what we need to learn. Facilities, v. 30, n. 5/6, p. 199-217, 30 mar. 2012. Disponível em:

https://www.emeraldinsight.com/doi/10.1108/02632771211208486. Acesso em: 22 ago. 2018

ANVISA. Regulamento Técnico para planejamento, programação, elaboração e avaliação de projetos físicos de estabelecimentos assistenciais de saúde. Brasil: Agência Nacional de Vigilância Sanitária. Resolução - RDC nº 50, 2002.

ANVISA. Segurança contra Incêndio em Estabelecimentos Assistenciais de Saúde. $1^{a}$ ed. Brasília: Agência Nacional de Vigilância Sanitária, 2014.

ARAGÃO, D. L. L. J. Subsídios Para Aplicação do Custeio-Meta na Etapa de Concepção de Unidades Habitacionais de Interesse Social no Âmbito do PMCMV. 2014.

Universidade Estadual de Londrina - UEL, 2014.

ARAGÃO, D. L. L. J. de et al. Sistematização de requisitos do usuário com o uso da Casa da Qualidade do QFD na etapa de concepção de unidades habitacionais de interesse social no âmbito do Programa Minha Casa, Minha Vida. Ambiente Construído, v. 16, n. 4, p. 271-291, 2016. Disponível em: http://www.scielo.br/scielo.php?script=sci_arttext\&pid=S1678$86212016000400271 \&$ Ing=pt\&tlng=pt. Acesso em: 12 ago. 2017

ARAUJO, L. C. G. de. Organização, Sistemas e Métodos - e as Tecnologias de Gestão Organizacional - Vol. 1. 5ª ed. São Paulo: Atlas, 2011.

ARGOTE, L. Organizational Learning: Creating, Retaining and Transferring Knowledge. 2. ed. Boston, MA: Springer US, 2013.

ARGYRIS, C. Organizational Traps. [s.I.] Oxford University Press, 2010.

ASHWORTH, A. Contractual Procedures in the Construction Industry. 6. ed. [s.I.] 
Routledge, 2012.

ASQ. The Global Voice of Quality | ASQ. Disponível em: https://asq.org/. Acesso em: 3 mar. 2016.

AUSTIN, S. et al. Modelling and managing project complexity. v. 20, p. 191-198, 2002.

AUSTIN, S. A. et al. Integrated collaborative design. Journal of Engineering, Design and Technology, v. 5, n. 1, p. 7-22, 2007. Disponível em:

http://dx.doi.org/10.1108/17260530710746579.

AVISON, D. et al. Action research. Communications of the ACM, v. 42, n. 1, p. 94-97, 1999.

AZAMBUJA, M. M. B.; FORMOSO, C. T. Aplicação de conceitos da gestão da cadeia de suprimentos na indústria da construção civil: um estudo dos processos de projeto, aquisição, pré-instalação e instalação de elevadores em edifícios. In: ENEGEP 2003 - XXIII Encontro Nacional de Engenharia de Produção, 1999, Ouro Preto, MG. Anais [...] Ouro Preto, MG: ABEPRO, 2003.

AZAMBUJA, M.; O'BRIEN, W. J. Construction supply chain modeling: issues and perspectives. In: O'BRIEN, W. J. et al. (Ed.). Construction Supply Chain Management Handbook. [s.l.] Taylor \& Francis Group, 2009. p. 2:1-31.

AZUMA, M. H. Customização em massa de projeto de Habitação de Interesse Social por meio de modelos físicos paramétricos. 2016. Universidade de São Paulo, 2016.

BADKE-SCHAUB, P.; FRANKENBERGER, E. Analysis of design projects. Design Studies, v. 20, n. 5, p. 465-480, 1999.

BALDWIN, C. Y.; CLARK, K. B. Managing in an Age of Modularity. Harvard Business Review, n. September-October, 1997. Disponível em: https://hbr.org/1997/09/managing-inan-age-of-modularity.

BALDWIN, C. Y.; CLARK, K. B. Design Rules, Vol. 1: The Power of Modularity. Cambridge: The MIT Press, 2000.

BALLARD, G. Target Value Design. International Design Conference, v. DS70, p. 11-22, 2012.

BALLARD, G.; KOSKELA, L. J. On the agenda of design management research. In: IGLC 1998 - $6^{\circ}$ Annual Conference of the International Group for Lean Construction, Guarujá. Anais [...] Guarujá: IGLC, 1998. Disponível em: http://www.iglc.net/Papers/Conference/8. Acesso em: 25 maio 2016

BALLARD, G.; REISER, P. The St. Olaf College Fieldhouse Project: A Case Study in designing to Target cost. In: IGLC $200412^{\circ}$ Annual Conference of the International Group for Lean Construction., Høgskoleringen. Anais [...] Høgskoleringen: IGLC, 2004.

BARLOW, J. et al. Choice and delivery in housebuilding : lessons from Japan for UK housebuilders. n. January 2014, p. 37-41, [s.d.] 
BARNEY, J. B.; HANSEN, M. H. Trustworthiness as a Source of Competitive Advantage. Strategic Management Journal, v. 15, n. Special Issue: Competitive Organizational, p. 175190, 2016. Disponível em: https://www.jstor.org/stable/2486817 Acesso em: 22 ago. 2018.

BECERIK-GERBER, B. et al. Application Areas and Data Requirements for BIM-Enabled Facilities Management. Journal of Construction Engineering and Management, v. 138, n. 3, p. 431-442, 2011.

BEHAM, B.; STRAUB, C.; SCHWALBACH, J. Managing Diversity in Organizations. Wiesbaden: Gabler Verlag, 2012.

BETHA, A. Enterprise Integration for Value Creation in an Organization. In: LOUREIRO, G AND CURRAN, R. (Ed.). Complex Systems Concurrent Engineering. London: Springer London, 2007. p. 649-656.

BHAKOO, $\mathrm{V}$; $\mathrm{CHOI}, \mathrm{T}$. The iron cage exposed: Institutional pressures and heterogeneity across the healthcare supply chain. Journal of Operations Management, v. 31, n. 6, p. 432449, 2013.

BIM FORUM. LOD Specification 2018 Part I: For Building Information Models and Data. [S.l: s.n.], 2018. Disponível em: <www.bimforum.org/lod>. Acesso em: 2 fev. 2019.

BLYTH, A.; WORTHINGTON, J. Managing the Brief for Better Design. 2. ed. Abingdon, UK: Taylor \& Francis, 2001.

BØLVIKEN, T.; GULLBREKKEN, B.; NYSETH, K. Collaborative Design Management. In: 18 Annual Conference of the International Group for Lean Construction, Anais [...]Routledge, 12 abr. 2013. Disponível em: https://www.taylorfrancis.com/books/9780203819128. Acesso em: 10 abr. 2017.

BONJOUR, E. et al. A Fuzzy Method for Propagating Functional Architecture Constraints to Physical Architecture. Journal of Mechanical Design, v. 131, n. 6, p. 061002, 2009.

BONJOUR, E.; MICAELLI, J.-P. Design Core Competence Diagnosis: A Case From the Automotive Industry. IEEE Transactions on Engineering Management, v. 57, n. 2, p. 323337, maio 2010. Disponível em: https://www.scopus.com/inward/record.uri?eid=2-s2.077951620006\&partner ID=40\&md5=433dacb521b8d755412e19b1589a8340. Acesso em: 12 jan. 2019

BOSSINK, B. A. G. Managing Drivers of Innovation in Construction Networks. Journal of Construction Engineering and Management, v. 130, n. 3, p. 337-345, 2004.

BROWNING, T. R. Applying the Design Structure Matrix To System Decomposition and Integration Problems: A Review and New Directions. IEEE Transactions on Engineering Management, v. 48, n. 3, p. 292-306, 2001.

BRUGNERA, R. R. Potencial de economia de energia em edifícios de escritórios com estratégias de ventilação híbrida. 2014. Universidade de São Paulo, São Carlos, 2014. Disponível em: http://www.teses.usp.br/teses/disponiveis/102/102131/tde-30102014-152311/. Acesso em: 25 set. 2017. 
BRUSONI, S.; PRENCIPE, A. Making design rules: a multidomain perspective. Organization Science, v. 17, n. 2, p. 179-189, 2006.

BUENO, C. Avaliação de ciclo de vida na construção civil: análise de sensibilidade. 2014. Universidade de São Paulo, São Carlos, 2014. Disponível em:

http://www.teses.usp.br/teses/disponiveis/102/102131/tde-10112014-144911/. Acesso em: 25 out. 2018.

BUENO, C.; PEREIRA, L. M.; FABRICIO, M. M. Life cycle assessment and environmentalbased choices at the early design stages: an application using building information modelling. Architectural Engineering and Design Management, v. 14, n. 5, p. 332-346, 3 set. 2018. Disponível em: https://www.tandfonline.com/doi/full/10.1080/17452007.2018.1458593. Acesso em: 9 set. 2018.

BUILDING SMART. IFC Introduction. Disponível em: https://www.buildingsmart.org/about/what-is-openbim/ifc-introduction/. Acesso em: 13 jul. 2018. Acesso em: 2 fev. 2019.

BURT, R. S. Structural holes: the social structure of competition. Cambridge: Harvard University Press, 1992.

CAO, D.; LI, H.; WANG, G. Impacts of isomorphic pressures on BIM adoption in construction projects. Journal of Construction Engineering and Management, v. 140, n. 12, p. 1-9, 2014. Disponível em: http://dx.doi.org/10.1061/(ASCE)CO.1943-7862.0000903. Acesso em: 5 out. 2018.

CARTER, M. Z. et al. Transformational leadership, relationship quality, and employee performance during continuous incremental organizational change. Journal of

Organizational Behavior, v. 34, p. 942-958, 2013.

CASTAÑO, H. F. M. Impacto de dispositivos de sombreamento externos e muro na ventilação natural e no desempenho térmico de uma habitação de interesse social térrea. 2017. Universidade de São Paulo, São Carlos, 2017. Disponível em: http://www.teses.usp.br/teses/disponiveis/102/102131/tde-04092017-125132/. Acesso em: 25 jan. 2019.

CHAGAS JR., M. de F.; CAMPANÁRIO, M. de A. Systems architecture, procedural knowledge and learning by using: Implications on systems integration capabilities. BAR - Brazilian Administration Review, v. 11, n. 1, p. 1-21, 2014. Disponível em:

https://www.scopus.com/inward/record.uri?eid=2-s2.084893304895\&partnerID=40\&md5=a36ead7e616d2cfc172d47ac739a210e. Acesso em: 25 set. 2017. Acesso em: 15 ago. 2018.

CHEN, K.; LI, H. AHP based weighting system for BIM implementation \& assessment framework. In: IEEE International Conference on Industrial Engineering and Engineering Management, Anais [...] IEEE Computer Society, 2016. Disponível em:

https://www.scopus.com/inward/record.uri?eid=2-s2.084962040377\&doi=10.1109\%2FIEEM.2015.7385943\&partnerID=40\&md5=1fd53edb7fe2457 a341ddd7f314e7052. Acesso em: 6 out. 2018. 
CHEN, P. B.; CLOTHIER, J. C. D. Advancing systems engineering for systems-of-systems challenges. Systems Engineering, v. 6, n. 3, p. 170-183, 2003. Disponível em:

https://www.scopus.com/inward/record.uri?eid=2-s2.0-

2942598109\&partnerID=40\&md5=7a85eeed5814dba7f77707d7fc685048. Acesso em: 15 ago. 2018.

CHIAVENATO, I. Princípios da administração. Rio de Janeiro: Campus, 2006.

CHIAVENATO, I. Iniciação a Sistemas, Organização e Métodos - SO\&M. $1^{\text {a }}$ ed. [s.l: s.n.]

CHINOWSKY, P.; MOLENAAR, K.; REALPH, A. Learning Organizations in Construction. Journal of Management in Engineering, v. 23, n. 1, p. 27-34, jan. 2007. Disponível em: http://ascelibrary.org/doi/10.1061/\%28ASCE\%290742-

$597 X \% 282007 \% 2923 \% 3 A 1 \% 2827 \% 29$.

CHIU, M.-L. An organizational view of design communication in design collaboration. Design Studies, v. 23, n. 2, p. 187-210, mar. 2002. Disponível em:

https://www.scopus.com/inward/record.uri?eid=2-s2.0-

0036498384\&partnerlD=40\&md5=9d9afa2e0d7404d27cdf2dd49da58f55. Acesso em: 2 ago. 2018.

CHO, S.; FISCHER, M. Real-Time Supply Chain Management Using Virtual Design and Construction. Proceedings for the 18th Annual Conference of the International Group for Lean Construction, n. July, p. 212-221, 2010.

CIRIBINI, Angelo Luigi Camillo. Level of detail e level of development: commissioning processes and information modelling. Techne, v. 6, p. 90-99, 2013.

ÇIDIK, M. S. et al. Ordering in disguise: digital integration in built-environment practices. Building Research and Information, v. 45, n. 6, p. 665-680, 2017. Disponível em: http://dx.doi.org/10.1080/09613218.2017.1309767.

CLARK, K. B.; WHEELWRIGHT, S. C. Organizing and Leading "Heavyweight" Development Teams. California Management Review, v. 34, n. 3, p. 9-28, 1992.

CLEVEN, A.; GUBLER, P.; HÜNER, K. M. Design alternatives for the evaluation of design science research artifacts. Proceedings of the 4th International Conference on Design Science Research in Information Systems and Technology - DESRIST '09, n. May, p. 1, 2009.

CONCEIÇÃO, P. A.; IMAI, C.; URBANO, M. R. Captura e hierarquização de requisitos do cliente de habitação de interesse social a partir da avaliação pós-ocupação e da técnica de preferência declarada. Gestão e Tecnologia de Projetos, v. 10, n. 1, p. 79-98, 2015.

CONCEIÇÃO, P. de A. Método para classificação de famílias visando à adoção da Customização em massa por segmentos na Habitação de Interesse Social. 2015. Universidade Estadual de Londrina-UEL e e Universidade Estadual de Maringá-UEM, 2015.

COOK, S. D. N.; BROWN, J. S. Bridging Epistemologies: The Generative Dance Between Organizational Knowledge and Organizational Knowing. Organization Science, v. 10, n. 4, p. 
381-400, 2008.

CORMEN, T. H. et al. Introduction to algorithms. 3. ed. Cambridge: MIT Press, 2009. v. 254

CORRÊA, M. V. G.; RUSCHEL, R. C. Tendências da colaboração em Arquitetura, Engenharia, Construção. In: FABRICIO, M. M.; ORNSTEIN, S. W. (Ed.). Qualidade no Projeto de Edíficios. 1. ed. São Carlos: Rima/ANTAC, 2010. p. 119-136.

CRESWELL, J. W. Research design: qualitative, quantitative, and mixed methods approaches. 4. ed. Londres: SAGE Publications Inc., 2013.

DANILOVIC, M.; BROWNING, T. R. Managing complex product development projects with design structure matrices and domain mapping matrices. International Journal of Project Management, v. 25, n. 3, p. 300-314, abr. 2007. Disponível em: https://linkinghub.elsevier.com/retrieve/pii/S0263786306001645.

DANILOVIC, M.; LEISNER, P. Analyzing core competence and core products for developing agile and adaptable corporation. DSM 2007: Proceedings of the 9th International Design Structure Matrix Conference, n. October, p. 49-59, 2007. Disponível em: http://www.designsociety.org/downloadpublication/27692/analyzing_core_competence_and_core_products_for_developing_agile_an d_adaptable_corporation. Acesso em: 15 ago. 2018.

DAVIES, A.; HOBDAY, M. The business of projects: managing innovation in complex products and systems. Cambridge: Cambridge University Press, 2005.

DAVIS, G. F.; SCOTT, W. R. Organizations and organizing: Rational, natural, and open system perspectives. 5. ed. Nova York: Routledge - Taylor \& Francis, 2007.

DAVISON, R. M.; MARTINSONS, M. G.; KOCK, N. Principles of canonical action research. Information Systems Jounal, v. 14, p. 65-86, jul. 2004.

DE OLIVEIRA, J. S.; CAVEDON, N. R. Micropolicies of day-to-day practices: Conducting ethnography in a circus organization [Micropolíticas das práticas cotidianas: Etnografando uma organização circense]. RAE Revista de Administracao de Empresas, v. 53, n. 2, p. 156-168, 2013. Disponível em: https://www.scopus.com/inward/record.uri?eid=2-s2.084877118205\&partnerID=40\&md5=78936db02cb3fb19f6c7a1371a62dfa0. Acesso em: 15 ago. 2018.

DELL'ISOLA, A. J. Value engineering : practical applications --for design, construction, maintenance \&amp; operations. [s.I.] R.S. Means Co, 1997.

DEN OTTER, A.; EMMITT, S. Design team communication and design task complexity: The preference for dialogues. Architectural Engineering and Design Management, v. 4, n. 2, p. 121-129, 2008.

DIKMEN, I.; TALAT BIRGONUL, M.; KIZILTAS, S. Strategic use of quality function deployment (QFD) in the construction industry. Building and Environment, v. 40, n. 2, p. 245-255, fev. 2005. Disponível em: https://linkinghub.elsevier.com/retrieve/pii/S0360132304001660. 
DIMAGGIO, P. J.; POWELL, W. W. A gaiola de ferro revisitada: isomorfismo institucional e racionalidade coletiva nos campos organizacionais. RAE - Revista de Administração de Empresas, v. 45, n. 2, p. 74-89, 2005.

DO, D.; BALLARD, G.; TOMMELEIN, I. D. An Analysis of Potential Misalignment of Commercial Incentives in Integrated Project Delivery and Target Value Design. In: IGLC 2015 - 23 Annual Conference of the International Group for Lean Construction: Global Knowledge - Global Solutions, Perth, Australia. Anais [...] Perth, Australia: IGLC, 2015.

DONG, A.; KLEINSMANN, M. S.; DEKEN, F. Investigating design cognition in the construction and enactment of team mental models. Design Studies, v. 34, n. 1, p. 1-33, 2013. Disponível em: http://dx.doi.org/10.1016/j.destud.2012.05.003.

DOSSICK, C. S.; NEFF, G. Organizational Divisions in BIM-Enabled Commercial Construction. Journal of Construction Engineering and Management, v. 136, n. 4, p. 459-467, abr. 2010. Disponível em: http://ascelibrary.org/doi/10.1061/\%28ASCE\%29C0.1943-7862.0000109. Acesso em: 6 out. 2018. Acesso em: 15 out. 2018.

DOSSICK, C. S.; NEFF, G. Messy talk and clean technology: communication, problem-solving and collaboration using Building Information Modelling. Engineering Project Organization Journal, v. 1, n. 2, p. 83-93, 2011.

DOWSETT, R. M.; HARTY, C. F. The wider implementation issues of BIM within a multifaceted property and real estate consultancy. (A.-N. E. Raiden A., Ed.) In: Proceedings 30th Annual Association of Researchers in Construction Management Conference, ARCOM, September, Anais [...] Association of Researchers in Construction Management, 2014. Disponível em: https://www.scopus.com/inward/record.uri?eid=2-s2.084911439224\&partnerID=40\&md5=c6c58a756ae6e04d512de1465b19fb9f. Acesso em: 15 out. 2018.

DRUSKAT, V. U.; PESCOSOLIDO, A. T. The context of effective teamwork mental models in self-managing ... Human Relations, v. 55, n. 3, p. 283-314, 2002.

DUBOIS, A.; GADDE, L.-E. The construction industry as a loosely coupled system: implications for productivity and innovation. Construction Management and Economics, $v$. 20, n. 7, p. 621-631, out. 2002. Disponível em:

http://www.tandfonline.com/doi/abs/10.1080/01446190210163543. Acesso em: 3 ago. 2018.

DYER, J. H.; NOBEOKA, K. Creating and managing a high-performance knowledge-sharing network: the Toyota case. Strategic Management Journal, v. 21, n. 3, p. 345-367, mar. 2000. Disponível em: http://doi.wiley.com/10.1002/\%28SICI\%2910970266\%28200003\%2921\%3A3\%3C345\%3A\%3AAID-SMJ96\%3E3.0.CO\%3B2-N. Acesso em: 15 out. 2018.

EADIE, R. et al. BIM implementation throughout the UK construction project lifecycle: An analysis. Automation in Construction, v. 36, p. 145-151, 2013. Disponível em: http://dx.doi.org/10.1016/j.autcon.2013.09.001. Acesso em: 5 out. 2018.

EASTMAN, C. et al. Manual de BIM: um guia de modelagem da informação da construção 
para arquitetos, engenheiros, gerentes, construtores e incorporadores. Porto Alegre: Bookman, 2014. Acesso em: 6 out. 2018.

ECCLES, R. G. Bureaucratic versus Craft Administration : The Relationship of Market Structure to the Construction Firm Author ( $s$ ): Robert G . Eccles Source: Administrative Science Quarterly, v. 26, n. 3, Sep. 1981, p . 449-469 Published by Sage Public. Administrative Science Quarterly, v. 26, n. 3, p. 449-469, 1981. Disponível em: https://www.jstor.org/stable/2392517. Acesso em: 12 jun. 2018.

EDEN, C.; ACKERMANN, F. Mapping distinctive competencies: a systemic approach. Journal of the Operational Research Society, v. 51, n. 1, p. 12-20, 21 jan. 2000. Disponível em: https://www.tandfonline.com/doi/full/10.1057/palgrave.jors.2600909. Acesso em: 15 out. 2018.

EDEN, C.; ACKERMANN, F. Competences, distinctive competences, and core competences. Research in Competence-Based Management, v. 5, n. March 2017, p. 3-33, 2010.

EISNER, H. Essentials of project and systems engineerion management. 3. ed. [s.I.] John Wiley \& Sons, 2008.

EL. REIFI, M. H.; EMMITT, S. Perceptions of lean design management. Architectural Engineering and Design Management, v. 9, n. 3, p. 195-208, ago. 2013. Disponível em: http://www.tandfonline.com/doi/abs/10.1080/17452007.2013.802979. Acesso em: 11 jun. 2018.

EL ASMAR, M.; HANNA, A. S.; LOH, W.-Y. Quantifying Performance for the Integrated Project Delivery System as Compared to Established Delivery Systems. Journal of Construction Engineering and Management, v. 139, n. 11, p. 04013012, 2013.

EOM, J. Modularity and technological change: A primer and synthesis. Asian Journal of Technology Innovation, v. 16, n. 2, p. 1-24, jan. 2008. Disponível em: http://www.tandfonline.com/doi/abs/10.1080/19761597.2008.9668654. Acesso em: 15 jun. 2018.

EPPINGER, S. D.; SALMINEN, V. Patterns of Product Development Interactions. 13th International Conference on Engineering Design, ICED 01, p. 283-290, 2001.

ERBIL, Y.; AKINCITÜRK, N.; ACAR, E. Inter-organizational context of the innovation process and the role of architectural designers as system integrators: case evidence from Turkey. Architectural Engineering and Design Management, v. 9, n. 2, p. 77-94, maio 2013. Disponível em: http://dx.doi.org/10.1080/17452007.2012.738038.

FABIAN, J. Anthropology with an attitude : critical essays. [s.I.] Stanford University Press, 2001.

FABRICIO, M. M.; MESQUITA, M. J. M.; MELHADO, S. B. Colaboração simultânea em diferentes tipos de empreendimentos de construção de edifícios. In: ENTAC 2002 - IX Encontro Nacional de Tecnologia do Ambiente Construído, Foz do Iguaçú. Anais [...] Foz do Iguaçú: ANTAC - Associação Nacional de Tecnologia do Ambiente Construído, 2002. 
FAVRETTO, A. P. O. Regression models to assess the thermal performance of Brazilian low-cost houses: consideration of opaque envelope. 2016. Universidade de São Paulo, São Carlos, 2016. Disponível em: http://www.teses.usp.br/teses/disponiveis/102/102131/tde10102016-132422/. Acesso em: 10 dez. 2018.

FEIL, P.; YOOK, K.; KIM, I. Japanese Target Costing: A Historical Perspective. International Journal of Strategic Cost Management, p. 10-19, 2004.

FELIN, T.; FOSS, N. J. Organizational routines and capabilities: Historical drift and a coursecorrection toward microfoundations. Scandinavian Journal of Management, v. 25, n. 2, p. 157-167, 2009.

FIXSON, S. K. Product architecture assessment: a tool to link product, process, and supply chain design decisions. v. 23, p. 345-369, 2005.

FJELDSTAD, Ø. D. et al. The architecture of collaboration. Strategic Management Journal, v. 33, n. 6, p. 734-750, 2012. Disponível em: http://dx.doi.org/10.1002/smj.1968.

FORD, R. C.; RANDOLPH, W. A. Cross-Functional Structures: A Review and Integration of Matrix Organization and Project Management. Journal of Management, v. 18, n. 2, p. 267294, 30 jun. 1992. Disponível em: http://journals.sagepub.com/doi/10.1177/014920639201800204.

FORGUES, D.; LEJEUNE, A. BIM: In search of the organisational architect. International Journal of Project Organisation and Management, v. 7, n. 3, p. 270-283, 2015. Disponível em: https://www.scopus.com/inward/record.uri?eid=2-s2.0-

84944385186\&partnerID=40\&md5=a600f240a62a214723df87f008ce02f6. Acesso em: 6 out. 2018.

FORMOSO, C. T. et al. Material Waste in Building Industry: Main Causes and Prevention. Journal of Construction Engineering and Management, v. 128, n. 4, p. 316-325, 2002.

FRANZ, B. et al. Impact of Team Integration and Group Cohesion on Project Delivery Performance. Journal of Construction Engineering and Management, v. 143, n. 1, p. 04016088, jan. 2017. Disponível em:

http://ascelibrary.org/doi/10.1061/\%28ASCE\%29CO.1943-7862.0001219.

FULFORD, R.; STANDING, C. Construction industry productivity and the potential for collaborative practice. JPMA, 2013. Disponível em:

http://dx.doi.org/10.1016/j.ijproman.2013.05.007.

FUNDLI, I. S.; DREVLAND, F. Collaborative Design Management - A case study. In: 22 Annual Conference of the International Group for Lean Construction, June, Oslo. Anais [...] Oslo: Routledge, abr. 2014. Disponível em: https://www.taylorfrancis.com/books/9780203819128. Acesso em: 10 ago. 2017.

GAL, U.; LYYTINEN, K.; YOO, Y. The dynamics of IT boundary objects, information infrastructures, and organisational identities: The introduction of 3D modelling technologies into the architecture, engineering, and construction industry. European Journal of Information Systems, v. 17, n. 3, p. 290-304, 2008. 
GALBRAITH, J. R. et al. Organization Design : an information processing view. Interfaces, v. 4, n. 3, p. 28-36, 1974. Disponível em: http://www.jstor.org/stable/25059090.

GALBRAITH, J. R. The Future of Organization Design. v. 1, n. 1962, p. 3-6, 2012.

GAMZAZADE, A. I. et al. The thermolysis of a polyarylate based on terephthalic and phenolphthalen at relatively low temperatures. Polymer Science U.S.S.R., v. 17, n. 8, p. 2015-2023, 1975.

GARAVAN, T. The learning organization: a review and evaluation. The Learning Organization, v. 4, n. 1, p. 18-29, mar. 1997. Disponivel em:

http://www.emeraldinsight.com/doi/10.1108/09696479710156442. Acesso em: 15 ago. 2018.

GARCIA, A. J.; MOLLAOGLU-KORKMAZ, S.; MILLER, V. D. Progress loops in interorganizational project teams: An IPD case. In: Construction Research Congress 2014: Construction in a Global Network - Proceedings of the 2014 Construction Research Congress, Atlanta, GA, United states. Anais [...] Atlanta, GA, United states: 2014. Disponível em: http://dx.doi.org/10.1061/9780784413517.0205.

GARUD, R.; JAIN, S.; TUERTSCHER, P. Incomplete by Design and Designing for Incompleteness. 1996.

GARVIN, D. Building a learning organization. Harvard business review, v. 71 (4), n. julyaugust, p. 78-91, 1993.

GERWIN, D.; BARROWMAN, N. J. An Evaluation of Research on Integrated Product Development. Management Science, v. 48, n. 7, p. 938-953, jul. 2002.

GHOZ, H. B. C. El. diretrizes para projeto de subsistemas de cobertura modulares visando a customização em massa de habitações unifamiliares. 2017. Universidade Estadual de Londrina-UEL e e Universidade Estadual de Maringá-UEM, 2017.

GIBSON, J. L. et al. Organizações: Comportamentos, Estrutura e Processos. $12^{\mathrm{a}}$ ed. Porto Alegre: AMGH, 2006.

GIEL, B. K.; ISSA, R. R. A. Return on Investment Analysis of Using Building Information Modeling in Construction. Journal of Computing in Civil Engineering, v. 27, n. 5, p. 511521, set. 2013. Disponível em: http://www.teizer.com.

GÓES, R. de. Manual Prático de Arquitetura Hospitalar. 2. ed. São Paulo: Edgard Blücher, 2011.

GOMES, P. J.; DAHAB, S. Bundling resources across supply chain dyads: The role of modularity and coordination capabilities. International Journal of Operations and Production Management, v. 30, n. 1, p. 57-74, 12 jan. 2010. Disponível em: https://www.scopus.com/inward/record.uri?eid=2-s2.074349131176\&partnerID=40\&md5=9f1f2ee10bc2281764bf439ddd51422d. Acesso em: 14 abr. 2018.

GOUGH, D.; OLIVER, S.; THOMAS, J. An Introduction to Systematic Reviews. 1. ed. 
London: SAGE PUBLICATIONS LTD, 2012.

GOURLAY, S. Conceptualizing knowledge creation: A critique of Nonaka's theory. Journal of Management Studies, v. 43, n. 7, p. 1415-1436, 2006.

GREEN, S. D. Towards an integrated script for risk and value management: insights from the dramaturgical metaphor. In: CIB W55 \& W65 Joint Triennial Symposium Customer Satisfaction : A focus for research \& practice, September, Anais [...] 1999. Disponível em: http://www.irbnet.de/daten/iconda/CIB3340.pdf. Acesso em: 27 set. 2015.

GRILO, L.; MELHADO, S. B. Novas Formas De Contratação E Organização Dos Empreendimentos No Segmento De ... n. May 2014, p. 683-692, 2002.

GUADANHIM, S. J. et al. A design process proposal to brazilian government's social housing program. In: ALTAN, H.; TEGOLA, A. LA; NICHILO, E. DE (Ed.). Zemch 2015 - International Conference. Lecce: Ordine degli Architetti Pianificatori Paesaggistici e Conservatori della Provincia di Bari, 2015. p. 543-561.

GUADANHIM, S. J.; HIROTA, E. H.; LEAL, J. G. Análise da aplicabilidade do custeio-meta na etapa de concepção de empreendimentos habitacionais de interesse social. Ambiente Construído, v. 11, n. 2, p. 39-56, 2011.

GULATI, R. Managing Network Resources: Alliances, Affiliations and Other Relational Assets. New York: Oxford University Press, 2007.

GULATI, R. K.; EPPINGER, S. D. The Coupling of Product Architecture and Organizational Structure Decisions. MIT - Sloan School of Management, v. no.3906, n. Working Paper, p. 1-31, 1996.

GULATI, R.; PURANAM, P.; TUSHMAN, M. Meta-organization design: Rethinking design in interorganizational and community contexts. Strategic Management Journal, v. 33, n. 6, p. 571-586, jun. 2012. Disponível em: http://doi.wiley.com/10.1002/smj.1975.

GULATI, R.; SINGH, H. The Architecture of Cooperation: Managing Coordination Costs and Appropriation Concerns in Strategic Alliances. Administrative Science Quarterly, v. 43, n. 4, p. 781, dez. 1998. Disponível em: https://www.jstor.org/stable/2393616. Acesso em: 18 mar. 2018.

GUNN, W.; LØGSTRUP, L. B. Participant observation, anthropology methodology and design anthropology research inquiry. Arts and Humanities in Higher Education, v. 13, n. 4, p. 428-442, 29 out. 2014. Disponível em:

http://journals.sagepub.com/doi/10.1177/1474022214543874. Acesso em: 4 jul. 2018.

HALL, D. et al. The Role of Integrated Project Delivery Elements in Adoption of Integral Innovations. In: EPOC 2014, Anais [...]2014.

HAMZEH, F.; BALLARD, G.; TOMMELEIN, I. D. Is the Last Planner System applicable to design? A case study. 17th Annual Conf. of the Internation Lean Construction Group, n. July, p. 165-176, 2009. Disponível em: http://www.prosjektnorge.no/files/pages/364/hamzehballard-tommelein-2009-is-the-last-planner-system-applicable-to-design-a-case-study-ballard- 
et-al-2009.pdf.

HAN, S. B. et al. A conceptual QFD planning model. International Journal of Quality \& Reliability Management, v. 18, n. 8, p. 796-812, 2001.

HANDLEY, H. A. H. . b; LEVIS, A. H. . c d. Organizational architectures and mission requirements: A model to determine congruence. Systems Engineering, v. 6, n. 3, p. 184194, 2003. Disponível em: https://www.scopus.com/inward/record.uri?eid=2-s2.0-

24744434347\&partnerlD=40\&md5=e31b07e7a1f19e85c0829f17940114ed. Acesso em: 15 ago. 2018.

HANNAN, M. T.; PÓLOS, L.; CARROLL, G. R. Cascading Organizational Change.

Organization Science, v. 14, n. 5, p. 463-482, out. 2003. Disponível em:

http://pubsonline.informs.org/doi/abs/10.1287/orsc.14.5.463.16763.

HANSEN, G. K.; OLSSON, N. O. E. Layered project-layered process: Lean thinking and flexible solutions. Architectural Engineering and Design Management, v. 7, n. 2, p. 70-84, 2011.

HARNESS, B. S. H. 2008 AIA Documents Advance the Use of BIM and Integrated Project Delivery. p. 1-4, 2008.

HARTMANN, A. The role of organizational culture in motivating innovative behaviour in construction firms. Construction Innovation, v. 6, n. 3, p. 159-172, set. 2006. Disponível em: http://www.emeraldinsight.com/doi/10.1108/14714170610710712.

HARTY, C. Innovation in construction: a sociology of technology approach. Building Research \& Information, v. 33, n. 6, p. 512-522, nov. 2005. Disponível em: http://www.tandfonline.com/doi/abs/10.1080/09613210500288605. Acesso em: 15 ago. 2018.

HASTJARJO et al. Strategic real estate development: Developing dynamic core competence as competitive strategic flexibility and competitive advantage resources for anticipating environment risk and increasing organization performance on real estate industry in Indonesia. International Journal of Applied Business and Economic Research, v. 13, n. 7, p. 6243-6270, 2015. Disponível em: https://www.scopus.com/inward/record.uri?eid=2-s2.084964388877\&partnerID=40\&md5=cbc52b8c72381a36109fde67cccaffe9. Acesso em: 15 nov. 2018.

HATTAB, M. Al; HAMZEH, F. Modeling design workflow: Integrating process and organization. In: IGLC 2016 - 24th Annual Conference of the International Group for Lean Construction, Boston, MA, United states. Anais [...] Boston, MA, United states: 2016.

HAUSER, J. The House of Quality. n. November 1987, 2015.

HAUSER, J. R.; CLAUSING, D. The house of quality. Harvard Business Review, v. 66, n. 3, p. 63-73, 1988.

HEDLUND, G. A model of knowledge management and the N-Form corporation, Vol . 15, : Search for New Published by: Stable URL : https://www.jstor.org/stable/2486877 THE.

Strategic Management Journal, v. 15, n. Special Issue: Strategy, p. 73-90, 1994. Disponível 
em: https://www.jstor.org/stable/2486877. Acesso em: 3 abr. 2016.

HENDERSON, R. M.; CLARK, K. B. Architectural innovation: the reconfiguration of existing. Administrative Science Quarterly, v. 35, n. 1, p. 9-30, 1990.

HESS, C.; OSTROM, E. (ed.). Understanding Knowledge as a Commons - From Theory to Practice. Cambridge: The MIT Press, 2007.

HOBDAY, M. Product complexity, innovation and industrial organisation. Research Policy, v. 26, p. 689-710, 1998.

HOBDAY, M. The project-based organisation: an ideal form for managing complex products and systems? Research Policy, v. 29, n. 7-8, p. 871-893, ago. 2000. Disponível em: http://linkinghub.elsevier.com/retrieve/pii/S0048733300001104.

HOETKER, G. Do modular products lead to modular organizations? Strategic Management Journal, v. 27, n. 6, p. 501-518, 2006.

HOOPES, D. G.; POSTREL, S. Shared knowledge, "glitches," and product development performance. Strategic Management Journal, v. 20, p. 837-865, 1999.

IBUSUKI, U.; KAMINSKI, P. C. Product development process with focus on value engineering and target-costing: A case study in an automotive company. International Journal of Production Economics, v. 105, n. 2, p. 459-474, 2007.

ILOZOR, B. D.; KELLY, D. J. Building Information Modeling and Integrated Project Delivery in the Commercial Construction Industry: A Conceptual Study. Journal of Engineering, Project, and Production Management, v. 2012, n. 1, p. 23-36, 2011.

IVANCEVICH, J. M.; MATTESON, M. T.; KONOPASKE, R. Organizational Behavior and Management. 13. ed. [s.l.] McGraw-Hill Irvwin, 2013.

JACOBIDES, M. G.; BILLINGER, S. Designing the Boundaries of the Firm: From "Make, Buy, or Ally" to the Dynamic Benefits of Vertical Architecture. Organization Science, v. 17, n. 2, p. 249-261, abr. 2006. Disponível em: http://pubsonline.informs.org/doi/abs/10.1287/orsc.1050.0167.

JACOBSSON, M.; LINDEROTH, H. C. J. The influence of contextual elements, actors' frames of reference, and technology on the adoption and use of ICT in construction projects: A swedish case study. Construction Management and Economics, v. 28, n. 1, p. 13-23, 2010.

JACOMIT, A. M. Modelo para incorporação do custeio-meta ao processo de desenvolvimento de produtos em edificações. 2010. Universidade Estadual de Campinas, 2010.

JACOMIT, A. M.; GRANJA, A. D. An investigation into the adoption of target costing on Brazilian public social housing projects. Architectural Engineering and Design Management, v. 7, n. 2, p. 113-127, 2011.

JÄRVINEN, P. Action research is similar to design science. Quality and Quantity, v. 41, n. 1, 
p. 37-54, 2007.

JAVERNICK-WILL, A.; LEVITT, R. E. Mobilizing Institutional Knowledge for International Projects. Journal of Construction Engineering and Management, v. 136, n. 4, p. 430-441, abr. 2010. Disponível em: http://ascelibrary.org/doi/10.1061/\%28ASCE\%29CO.19437862.0000110.

JAY, B. Firm resources and sustained competitive advantage.pdfJournal of Management, 1991. .

JENSEN, P. A. et al. How can facilities management add value to organisationsas well as to society? CIB World Building Congress, v. 5, n. May, p. 5-9, 2013.

JIAO, J.; SIMPSON, T. W.; SIDDIQUE, Z. Product family design and platform-based product development: A state-of-the-art review. Journal of Intelligent Manufacturing, v. 18, n. 1, p. 5-29, 2007.

JOCHEM, R.; MENRATH, M.; LANDGRAF, K. Implementing a quality-based performance measurement system. The TQM Journal, v. 22, n. 4, p. 410-422, 2010.

KANTER, R. M.; STEIN, B. A.; JICK, T. D. The challenge of organizational change: how companies experience it and leaders guide it. [s.l: s.n.]

KARIM, S. Modularity in organizational structure: the reconfiguration of internally developed and acquired business units. Strategic Management Journal, v. 27, n. 9, p. 799-823, set. 2006. Disponível em: http://doi.wiley.com/10.1002/smj.769.

KATZENBACH, J. R.; SMITH, D. K. The Discipline of Teams. Administrative Science Quarterly, v. 43, n. Best of EST OF HBR 1993, p. 406-469, 2005.

KELLY, J.; MALE, S.; GRAHAM, D. Value Management of Construction Projects. 2. ed. [s.I.] Wiley Blackwell, 2015.

KENT, D. C.; BECERIK-GERBER, B. Understanding Construction Industry Experience and Attitudes toward Integrated Project Delivery. Journal of Construction Engineering and Management, v. 136, n. 8, p. 815-825, 2010.

KERZNER, H. Project management a systems approach to planning, scheduling, and controlling. 12. ed. New Jersey: Wiley, 2017.

KESTLE, L.; POTANGAROA, R.; STOREY, B. Integration of lean design and design management and its influence on the development of a multidisciplinary design management model for remote site projects. Architectural Engineering and Design Management, v. 7, n. 2, p. 139-153, 2011.

KLEINSMANN, M. S. Understanding collaborative design. 2006. Technische Universiteit Delft, 2006.

KLEINSMANN, M.; VALKENBURG, R. Barriers and enablers for creating shared understanding in co-design projects. Design Studies, v. 29, n. 4, p. 369-386, 2008. 
Disponível em: http://dx.doi.org/10.1016/j.destud.2008.03.003.

KNIGHTS, D.; VURDUBAKIS, T. Information technology as organization/disorganization. Information and Organization, v. 15, n. 3, p. 181-184, jul. 2005. Disponível em: https://linkinghub.elsevier.com/retrieve/pii/S1471772705000357.

KNOTTEN, V. et al. Organizational power in building design management. In: IGLC $2015-23^{\circ}$ Annual Conference of the International Group for Lean Construction: Global Knowledge Global Solutions, Julho, Perth, WA, Australia. Anais [...] Perth, WA, Australia: IGLC, 2015. Disponível em: http://iglc.net/Papers/Conference/25.

KOHLER, N.; LÜTZKENDORF, T. Integrated life-cycle analysis. Building Research and Information, v. 30, n. 5, p. 338-348, 2002.

KOSKELA, L. An exploration towards a production theory and its application to construction. 2000. Technical Research Centre of Finland, 2000.

KOSKELA, L.; HUOVILA, P.; LEINONEN, J. Design management in building construction: From theory to practice. Journal of Construction Research, v. 3, n. 1, p. 1-16, mar. 2002. Disponível em: http://www.worldscientific.com/doi/abs/10.1142/S1609945102000035. Acesso em: 12 ago. 2018.

KOTHANDARAMAN, P.; WILSON, D. T. The future of competition: Value-creating networks. Industrial Marketing Management, v. 30, p. 379-389, 2001.

KOWALTOWSKI, D. C. C. K.; GRANJA, A. D. The concept of desired value as a stimulus for change in social housing in Brazil. Habitat International, v. 35, n. 3, p. 435-446, 2011. Disponível em: http://dx.doi.org/10.1016/j.habitatint.2010.12.002. Acesso em: 11 set. 2017.

KREIMEYER, M.; EICHINGER, M.; LINDEMANN, U. Aligning Multiple Domains of Design. In: ICED 2007 - INTERNATIONAL CONFERENCE ON ENGINEERING DESIGN, August, Paris. Anais [...] Paris: ICED, 2007.

KÜHLMANN, T. M.; HEINZ, R. Managing Cultural Diversity in Small and Medium-Sized Organizations. Wiesbaden: Springer Fachmedien Wiesbaden, 2017.

KULATUNGA, U.; AMARATUNGA, R.; HAIGH, R. Construction innovation: a literature review on current research. INTERNATIONAL POSTGRADUATE RESEARCH CONFERENCE IN THE BUILT AND HUMAN ENVIRONMENT, 6., Proceedings [...] 2006. p. 654-662.

KUNZ, J.; FISCHER, M. Virtual design and construction: themes, case studies and implementation suggestions CIFE Working Paper-97. Stanford: Stanford University Press, 2012. Disponível em: https://cife.stanford.edu/sites/default/files/WP097_0.pdf.

KUSUNOKI, K.; NONAKA, I.; NAGATA, A. Organizational Capabilities in Product Development of Japanese Firms: A Conceptual Framework and Empirical Findings. Organization Science, v. 9, n. 6, p. 699-718, 2008.

KYNG, M. Designing for cooperation: cooperating in design. Communications of the ACM, v. 34, n. 12, p. 65-73, 1 dez. 1991. Disponível em: http://doi.acm.org/10.1145/125319.125323. 
LAMMING, R. et al. An initial classification of supply networks. International Journal of Operations and Production Management, v. 20, n. 6, p. 675-691, 2000.

LAURENT, J.; LEICHT, R. M. Practices for Designing Cross-Functional Teams for Integrated Project Delivery. Journal of Construction Engineering and Management, v. 145, n. 3, p. 05019001-11, mar. 2019. Disponível em:

http://ascelibrary.org/doi/10.1061/\%28ASCE\%29C0.1943-7862.0001605.

LEONARD, D.; SENSIPER, S. The Role of Tacit Knowledge in Group Innovation. California Management Review, v. 40, n. 3, p. 112-132, abr. 1998. Disponível em: http://journals.sagepub.com/doi/10.2307/41165946.

LESTER, R. K.; PIORE, M. J. Innovation - The Missing Dimension. Cambridge, MA, United states: Harvard University Press paperback, 2006. v. 223

LEVENSON, A. Talent management: challenges of building cross-functional capability in highperformance work systems environments. Asia Pacific Journal of Human Resources, v. 50, n. 2, p. 187-204, abr. 2012. Disponível em: http://doi.wiley.com/10.1111/j.1744-

7941.2011.00022.x.

LEVITT, R. E. Towards project management 2.0. Engineering Project Organization Journal, v. 1, n. 3, p. 197-210, set. 2011. Disponível em:

http://www.tandfonline.com/doi/abs/10.1080/21573727.2011.609558. Acesso em: 10 fev. 2018.

LICHTIG, W. A. Sutter Health : Developing a Contracting Model to Support Lean Project Delivery. Lean Construction Journal, v. 2, n. April, p. 105-112, 2005. Disponível em: www.leanconstructionjournal.org. Acesso em: 15 ago. 2017.

LIMA, K. M. de; CARAM, R. M. Avaliação de sistemas de janela para suporte a decisões de projeto quanto ao equilíbrio de ganhos de luz e calor. Ambiente Construído, v. 15, n. 3, p. 117-133, set. 2015. Disponível em:

http://www.scielo.br/scielo.php?script=sci_arttext\&pid=S1678-

$86212015000300117 \&$ Ing=pt\&tlng=pt. Acesso em: 7 set. 2017.

LINDGREN, J. Diffusing systemic innovations: influencing factors, approaches and further research. Architectural Engineering and Design Management, v. 12, n. 1, p. 19-28, 2016. Disponível em: http://dx.doi.org/10.1080/17452007.2015.1092942.

LINDHOLM, A.-L.; GIBLER, K. M.; LEVAINEN, K. I. Modelling the Value Adding Attributes of Real Estate to the Wealth Maximization of the Firm. Journal of Real Estate Research, v. 28, n. 4, p. 445-476, 2006. Disponível em:

http://ares.metapress.com/index/w1558474p1902t31.pdf.

LING, F. Y. Y. et al. Influences on Innovation Benefits during Implementation: Client's Perspective. Journal of Construction Engineering and Management, v. 133, n. 4, p. 306315, abr. 2007. Disponível em: http://ascelibrary.org/doi/10.1061/\%28ASCE\%2907339364\%282007\%29133\%3A4\%28306\%29.

LIU, J. Y.; ZOU, P. X. W.; GONG, W. Managing Project Risk at the Enterprise Level : 
Exploratory Case Studies in China. n. September, p. 1268-1274, 2013.

LONDRINA, U. E. D. E.; TAUBE, J. No Processo De Provisão De Habitações De Interesse Social : estudo de caso na Cohab de Londrina-PR no processo de provisão de habitações de interesse social : estudo de caso na Cohab de Londrina-PR. 2015.

LOVE, P. E. D. et al. Nurturing a learning organization in construction: a focus on strategic shift, organizational transformation, customer orientation and quality centered learning. Construction Innovation, v. 4, n. 2, p. 113-126, 12 jun. 2004. Disponível em: http://www.emeraldinsight.com/doi/10.1108/MRR-09-2015-0216. Acesso em: 15 ago. 2018.

LOVE, P. E. D. et al. A benefits realization management building information modeling framework for asset owners. Automation in Construction, v. 37, p. 1-10, 2014. Disponível em: http://dx.doi.org/10.1016/j.autcon.2013.09.007.

LU, S. C. Y. et al. a Scientific Foundation of Collaborative Engineering. CIRP Annals Manufacturing Technology, v. 56, n. 2, p. 605-634, 2007.

LUKKA, K. The constructive research approach. In: OJALA, L.; HILMOLA, O.-P. (Ed.). Case study research in logistics. [s.l.] Publications of the Turku School of Economics and Business Administration, 2003. p. 83-101.

LUO, L.; MAO, W.; FU, S. Grasping the Complexity of Organizational Behavior for MegaConstruction Projects. In: ICCREM 2016: BIM Application and Offsite Construction Proceedings of the 2016 International Conference on Construction and Real Estate Management, Edmonton, AB, Canada. Anais [...] Edmonton, AB, Canada: 2016. Disponível em: http://dx.doi.org/10.1061/9780784480274.048. Acesso em: 12 out. 2018.

MACAL, C. M.; NORTH, M. J. Agent-based modeling and simulation. In: WSC 2009 - Winter Simulation Conference, December 2009, Anais [...] IEEE, dez. 2009. Disponível em: http://ieeexplore.ieee.org/document/6147864/.

MACCORMACK, A.; BALDWIN, C.; RUSNAK, J. Exploring the duality between product and organizational architectures: A test of the "mirroring" hypothesis. Research Policy, v. 41, n. 8, p. 1309-1324, 2012. Disponível em: https://www.scopus.com/inward/record.uri?eid=2-s2.084865237253\&partnerID=40\&md5=71336e606e2008f93f3a4540eb9012a9. Acesso em: 15 nov. 2018.

MACHADO, F. A.; RUSCHEL, R. C.; SCHEER, S. Análise da produção científica brasileira sobre a Modelagem da Informação da Construção. Ambiente Construído, v. 17, n. 4, p. 359384, dez. 2017. Disponível em: http://www.scielo.br/scielo.php?script=sci_arttext\&pid=S1678$86212017000400359 \&$ Ing=pt\&tlng=pt. Acesso em: 2 fev. 2018.

MACKAY, B. R.; CHIA, R. Choice, chance, and unintended consequences in strategic change: A process understanding of the rise and fall of northco automotive. Academy of Management Journal, v. 56, n. 1, p. 208-230, 2013.

MACLEAMY, P. Collaboration, Integrated Information, and the Project Lifecycle in Building Design, Construction and OperationThe construction users roundtable - CURT. [s.l: s.n.]. 
MACOMBER, H.; HOWELL, G.; BARBERIO, J. Target-Value Design: Nine Foundational and Six Advanced Practices For Delivering Surprising Client Value. [s.l: s.n.].

MAGENT, C. S. et al. A design process evaluation method for sustainable buildings. Architectural Engineering and Design Management, v. 5, n. 1-2, p. 62-74, 2009.

MAHONY, S. O.; FERRARO, F. The Emergence of Governance in an Open Source Community. Academy of Management Executive, v. 50, n. 5, p. 1079-1106, 2016.

MAJCHRZAK, A.; JARVENPAA, S. L.; HOLLINGSHEAD, A. B. Coordinating Expertise Among Emergent Groups Responding to Disasters. Organization Science, v. 18, n. 1, p. 147-161, 2007.

MARQUES, N. R.; BORGES, R. M. Utilizando a APO para qualificar o processo de projeto e o ambiente construído. XIV Encontro Nacional de Tecnologia do Ambiente Construído, n. 1, p. 1642-1651, 2012.

MARTIN, M. V.; ISHII, K. Design for variety: developing standardized and modularized product platform architectures. Research in Engineering Design, v. 13, n. 4, p. 213-235, 2016.

MCCARTHY, I. P.; GORDON, B. R. Achieving contextual ambidexterity in R \& D organizations : a management control system approach. 2011.

MCCARTY, T. D.; GOTTSCHALK, D. Capabilities of the new strategic organization. Journal of Corporate Real Estate, v. 16, n. 4, p. 290-298, 2014. Disponível em:

https://www.scopus.com/inward/record.uri?eid=2-s2.084913530512\&partnerID=40\&md5=58af5015095e14417454d6964f4dddb8. Acesso em: 15 ago. 2017.

MCDERMOTT, C.; COATES, T. Managing Competencies in Breakthrough Product Development: A Comparative Study of Two Material Processing Projects. IEEE Transactions on Engineering Management, v. 54, n. 2, p. 340-350, maio 2007. Disponível em: http://ieeexplore.ieee.org/document/4160171/.

MCGRAW HILL CONSTRUCTION. Project Delivery Systems: How They Impact Efficiency and Profitability in the Buildings Sector. [s.l: s.n.].

MCGREGOR, D. Human Side of EnterpriseThe Management Review, 1957. .

MELHADO, S. B. Qualidade do projeto na construção de edifícios: aplicação ao caso das empresas de incorporação e construção. 1994. Universidade de São Paulo, 1994.

MENTZER, J. T. et al. Defining supply chain management. Journal of Business Logistics, v. 22, n. 2, p. 109-128, 2001.

MERSCHBROCK, C. Collaboration in multi-actor BIM design: A configuration analysis view. In: GUDNASON; SCHERER (Ed.). eWork and eBusiness in Architecture, Engineering and Construction - Proceedings of the European Conference on Product and Process Modelling 2012, ECPPM 2012. Londres: Taylor \& Francis Group, 2012a. p. 793-799. 
MERSCHBROCK, C. Unorchestrated symphony: The case of inter-organizational collaboration in digital construction design. Electronic Journal of Information Technology in Construction, v. 17, n. April, p. 333-350, 2012b.

MIETTINEN, R.; PAAVOLA, S. Beyond the BIM utopia: Approaches to the development and implementation of building information modeling. Automation in Construction, v. 43, p. 8491, 2014. Disponível em: http://dx.doi.org/10.1016/j.autcon.2014.03.009. Acesso em: 5 out. 2018.

MILLS, F. T.; GLASS, J. The Construction Design Manager's Role in Delivering Sustainable Buildings. Architectural Engineering and Design Management, v. 5, n. 1-2, p. 75-90, 6 jan. 2009. Disponível em: https://www.tandfonline.com/doi/full/10.3763/aedm.2009.0908. Acesso em: 15 ago. 2017.

MINISTÉRIO DA SAÚDE. Manual de estrutura física das unidades básicas de saúde: saúde da família. $2^{\mathrm{a}}$ ed. [s.l.] Secretária de Atenção à Saúde Departamento de Atenção Básica, 2008. v. 2

MINTZBERG, H. Structure in Fives: Designing Effective Organizations. [s.I.] Prentice Hall, 1992.

MIRON, L. I. G. Gerenciamento dos requisitos dos clientes de empreendimentos habitacionais de interesse social: proposta para Programa Integrado Entrada da Cidade em Porto Alegre/RS. n. January, p. 351, 2008.

MITROPOULOS, P.; TATUM, C. B. Forces Driving Adoption of New Information Technologies. Journal of Construction Engineering and Management, v. 126, n. 5, p. 340-348, out. 2000. Disponível em: https://academic.oup.com/ajae/article-lookup/doi/10.1093/ajae/aaw076.

MOODY, D. L.; SHANKS, G. G. Improving the quality of data models: Empirical validation of a quality management framework. Information Systems, v. 28, n. 6, p. 619-650, 2003.

MORAIS, M. de. Método para implementação de BIM e custeio-meta em Habitação de Interesse Social. 2016. Universidade Estadual de Campinas, 2016.

MORAIS, M. de; FABRICIO, M. M.; RUSCHEL, R. C. Target Value Design Aplicado Ao Projeto E Modelagem De Estabelecimentos Assistenciais De Saúde: Uma Experiência Didática Avançada. Revista Projetar - Projeto e Percepção do Ambiente, v. 3, n. 1, p. 08-28, 2018. Disponível em: http://revistaprojetar.ct.ufrn.br/index.php/revprojetar/article/view/241/86.

MORAIS, M. De; GRANJA, A. D.; RUSCHEL, R. C. Restrições orçamentárias e entrega de valor: sinergias entre BIM e custeio-meta. Gestão \& Tecnologia de Projetos, v. 10, n. 1, p. 7, 13 ago. 2015. Disponível em: http://www.revistas.usp.br/gestaodeprojetos/article/view/81141. Acesso em: 15 out. 2018.

MOREIRA, D. de C.; KOWALTOWSKI, D. C. C. K. Discussão sobre a importância do programa de necessidades no processo de projeto em arquitetura. Ambiente Construído, n. 19, p. 31-45, 2009.

MORGAN, G. Images of organization. 2. ed. Thousand Oaks, Londres, Nova Delhi: SAGE 
Publications Inc., 2006.

MORRIS, P. W. G. Managing Project Interfaces- Key Points for Project Success. In:

CLELAND, D. I.; KING, W. R. (Ed.). Project Management Handbook. [s.I: s.n.]p. 408-446.

MUIANGA, E. A. D. Modelo evolutivo para aplicação do IPD (integrated project delivery) em ambientes de produção de empreendimentos onde há pouca difusão de práticas colaborativas. 2018. Universidade Estadual de Campinas - UNICAMP, 2018.

NBS. BIM Object Standard. Nbs, n. January, p. 44, 2014.

NEFF, G.; FIORE-SILFVAST, B.; DOSSICK, C. S. A case study of the failure of digital communication to cross knowledge boundaries in virtual construction. Information, Communication \& Society, v. 13, n. 4, p. 556-573, jun. 2010. Disponível em: http://www.tandfonline.com/doi/abs/10.1080/13691181003645970. Acesso em: 11 nov. 2017.

NEIVA, S.; FARIA, B. L. De; BIZELLO, S. A. Implantação de bim em uma construtora de médio porte: caso prático, da modelagem a quantificação. PARC: Pesquisa em Arquitetura e Construção, v. 5, n. 1, p. 45-51, 2014.

NELSON, S. A.; PARKINSON, M. B.; PAPALAMBROS, P. Y. Multicriteria Optimization in Product Platform Design. Journal of Mechanical Design, v. 123, n. 2, p. 199, 2002.

NICOLINI, D. et al. Can Target Costing and Whole Life Costing be Applied in the Construction Industry ?: Evidence from Two Case Studies 1. v. 11, p. 303-324, 2000.

NOGUEIRA, C. F. B. Diretrizes de projeto para a redução de perdas na produção em massa de painéis de vedação pré-fabricados em sistemas de construção a seco. 2016. Universidade Estadual de Londrina - UEL, 2016.

NONAKA, I.; TAKEUCHI, H. Criação de Conhecimento na Empresa - como empresas japonesas geram a dinâmica da inovação. Rio de Janeiro: Campus - Elsevier, 1997.

NONAKA, I.; TOYAMA, R. The knowledge-creating theory revisited: knowledge creation as a synthesizing process. Knowledge Management Research \& Practice, v. 1, n. 1, p. 2-10, 2003.

NOVAK, V. M. Design management of sustainability values: a learning organization perspective. Architectural Engineering and Design Management, v. 10, n. 3-4, p. 218-232, 3 jul. 2014. Disponível em:

http://www.tandfonline.com/doi/abs/10.1080/17452007.2014.896782. Acesso em: 12 nov. 2017.

ONO, R. et al. (ed.). Avaliação pós-ocupação: na arquitetura, no urbanismo e no design: da teoria à prática. 1. ed. São Carlos, SP: Oficina de Textos, 2018.

OPARAOCHA, G. O. B. G. O. Towards building internal social network architecture that drives innovation: a social exchange theory perspective. Journal of Knowledge

Management, v. 20, n. 3, p. 534-556, 2016. Disponível em:

https://www.scopus.com/inward/record.uri?eid=2-s2.0- 
84977513231\&partnerID=40\&md5=1d64121e9f3faf27d7472901786ccecc. Acesso em: 12 nov. 2017.

ORNSTEIN, S. W.; ROMÉRO, M. Avaliação pós-ocupação (APO) do ambiente construído. São Paulo: Studio Nobel: Editora da Universidade de São Paulo, 1992.

ÖRTENBLAD, A. On differences between organizational learning and learning organization. The Learning Organization, v. 8, n. 3, p. 125-133, ago. 2001. Disponível em: https://doi.org/10.1108/09696470110391211.

ORTON, J. D.; WEICK, K. E. Loosely Coupled Systems: A Reconceptualization. Academy of Management Review, v. 15, n. 2, p. 203-223, 1990.

OWEN, R. et al. Challenges for Integrated Design and Delivery Solutions. Architectural Engineering and Design Management, v. 6, n. 4, p. 232-240, 6 jan. 2010. Disponível em: https://www.tandfonline.com/doi/full/10.3763/aedm.2010.IDDS1. Acesso em: 13 nov. 2017.

ÖZTAŞ, A.; ÖKMEN, Ö. Risk analysis in fixed-price design-build construction projects. Building and Environment, v. 39, n. 2, p. 229-237, fev. 2004. Disponível em: https://linkinghub.elsevier.com/retrieve/pii/S0360132303002026.

ÖZTAŞ, A.; ÖKMEN, Ö. Judgmental risk analysis process development in construction projects. Building and Environment, v. 40, n. 9, p. 1244-1254, set. 2005. Disponível em: https://linkinghub.elsevier.com/retrieve/pii/S0360132304003191.

PAHL, G.; BADKE-SCHAUB, P.; FRANKENBERGER, E. Résumé of 12 years interdisciplinary empirical studies of engineering design in Germany. Design Studies, v. 20, p. 481-494, 1999. Disponível em: http://www.elsevier.com. Acesso em: 10 nov. 2017.

PALANEESWARAN, E.; NG, T.; KUMARASWAMY, M. Client satisfaction and quality management systems in contractor organizations. Building and Environment, v. 41, n. 11, p. 1557-1570, nov. 2006. Disponível em:

http://linkinghub.elsevier.com/retrieve/pii/S0360132305002374.

PAMMER, W. J.; KILLIAN, J. Handbook of Conflict Management. [s.l: s.n.]

PAN, S. L. et al. The dynamics of implementing and managing modularity of organizational routines during capability development: Insights from a process model. IEEE Transactions on Engineering Management, v. 54, n. 4, p. 800-813, 2007.

PAPADONIKOLAKI, E.; VERBRAECK, A.; WAMELINK, H. Formal and informal relations within BIM-enabled supply chain partnerships. Construction Management and Economics, v. 35, n. 8-9, p. 531-552, 2017. Disponível em: https://doi.org/10.1080/01446193.2017.1311020. Acesso em: 7 nov. 2018.

PAPADONIKOLAKI, E.; VRIJHOEF, R.; WAMELINK, H. Supply chain integration with BIM: a graph-based model. Structural Survey, v. 33, n. 3, p. 257-277, 2015. Disponível em: http://dx.doi.org/10.1108/SS-01-2015-0001. Acesso em: 6 out. 2018.

PAPADONIKOLAKI, E.; WAMELINK, H. Inter- and intra-organizational conditions for supply 
chain integration with BIM. Building Research \& Information, v. 45, n. 6, p. 649-664, 18 ago. 2017. Disponível em: http://dx.doi.org/10.1080/09613218.2017.1301718. Acesso em: 5 out. 2018.

PARMIGIANI, A.; MITCHELL, W. Complementarity, capabilities, and the boundaries of the firm: the impact of within-firm and interfirm expertise on concurrent sourcing of complementary components. Strategic Management Journal, v. 30, n. 10, p. 1065-1091, out. 2009. Disponível em: http://doi.wiley.com/10.1002/smj.769.

PASQUIRE, C.; SALVATIERRA-GARRIDO, J. Introducing the Concept of First and Last Value to Aid Lean Design: Learning from Social Housing Projects in Chile. Architectural

Engineering and Design Management, v. 7, n. 2, p. 128-138, maio 2011. Disponível em: http://www.tandfonline.com/doi/abs/10.1080/17452007.2011.582335. Acesso em: 18 nov. 2017.

PAVITT, K. Specialization and systems integration where manufacture and services still meet. In: PRENCIPE, A.; DAVIES, A.; HOBDAY, M. (Ed.). The Business of Systems Integration. Nova York: Oxford University Press, 2003. p. 78-94.

PENG, C. Exploring communication in collaborative design: co-operative architectural modelling. Design Studies, v. 15, n. 1, p. 19-44, 1994.

PENNANEN, A.; BALLARD, G.; HAAHTELA, Y. Target costing and designing to targets in construction. Journal of Financial Management of Property and Construction, v. 16, n. 1, p. 52-63, 2011.

PEREIRA, L. M. Desenho Organizacional para a Integração de Projetos através da Modelagem da Informação em Processos Colaborativos. 2014. Universidade Estadual de Londrina - UEL, Londrina, 2014. Disponível em:

https://www.researchgate.net/publication/315803571_Desenho_organizacional_para_a_integr acao_de_projetos_atraves_da_modelagem_da_informacao_em_processos_colaborativos_dis sertacao_de_mestrado. Acesso em: 10 nov. 2015.

PEREIRA, L. M. et al. Aplicação do TVD assistido por BIM na fase inicial de um projeto colaborativo. In: XVII ENTAC - Encontro Nacional de Tecnologia do Ambiente Construído, Foz do Iguaçu. Anais [...] Foz do Iguaçu: ANTAC, 2018.

PEREIRA, L. M.; HIROTA, E. H.; FABRICIO, M. M. Organização das atividades de Custeio Meta e Gestão de Requisitos no Processo de Projeto de Habitação de Interesse Social. In: 4o Congresso Internacional da Habitação no Espaço Lusófono, Porto - Covilhã. Anais [...] Porto Covilhã: 2017. Disponível em:

https://www.researchgate.net/publication/317673969_Organizacao_das_atividades_de_custei o_meta_e_gestao_de_requisitos_no_processo_de_projeto_de_Habitacao_de_Interesse_Soci al. Acesso em: 18 abr. 2017.

PERROW, C. A Framework for the Comparative Analysis of Organizations. American Sociological Review, v. 32, n. 2, p. 194-208, 1967. Disponível em: https://www.jstor.org/stable/2091. Acesso em: 1 fev. 2018. 
PMI. Guia do conhecimento em gerenciamento de projetos (PMBOK). 6a edição ed. [s.l: S.n.]

PRAHALAD, C. K.; HAMEL, G. The Core Competence of the Corporation. Harvard Business Review, v. 68, n. 3, p. 79-91, 1990. Disponível em:

http://www.springerlink.com/index/v1774282g031q747.pdf. Acesso em: 22 nov. 2017.

PRASAD, B. Review of QFD and related deployment techniques. Journal of Manufacturing Systems, v. 17, n. 3, p. 221-234, 1998.

PURANAM, P. A Future for the Science of Organization Design. v. 1, n. 1, p. 18-19, 2012.

REICHARDT, T. et al. Creating dynamic organizational modularity in lean construction design - Combining MDM and DSM methodology systematically. In: Gain Competitive Advantage by Managing Complexity - Proceedings of the 14th International Dependency and Structure Modelling Conference, DSM 2012, Kyoto, Japan. Anais [...] Kyoto, Japan: 2012.

REZAEI, F.; BULLE, C.; LESAGE, P. Integrating building information modeling and life cycle assessment in the early and detailed building design stages. Building and Environment, v. 153, n. January, p. 158-167, 2019. Disponível em:

https://doi.org/10.1016/j.buildenv.2019.01.034.

ROBERT, G. R. T.; GRANJA, A. D. Target and kaizen costing implementation in construction. Understanding and Managing the Construction Process: Theory and Practice - 14th Annual Conference of the International Group for Lean Construction, IGLC-14, n. July 2006, p. 91-105, 2006.

ROBIN, P.; SLAGMULDER, R. Redução de custos com inteligência. 2003.

ROMCY, N.; SANTIAGO, Z. A Avaliação Pós-Ocupação como instrumento na busca da acessibilidade. In: ENTAC 2010 - XIII Encontro Nacional de Tecnologia da Ambinente Construído, Canelas, RS. Anais [...] Canelas, RS: ANTAC - Associação Nacional de Tecnologia do Ambiente Construído, 2010.

ROOKE, J. et al. Developing production theory: what issues need to be taken into consideration? In: Proceedings for the 20th Annual Conference of the International Group for Lean Construction, 0, Anais [...]IGLC, 2012. Disponível em: http://usir.salford.ac.uk/28842/.

ROPER, K. O.; LEED, A. P. Future Trends Impact Construction, Real Estate and Facility Management. CIB W107 Construction in Developing Countries International Symposium, n. January, 2006.

ROSEMANN; VESSEY. Toward Improving the Relevance of Information Systems Research to Practice: The Role of Applicability Checks. MIS Quarterly, v. 32, n. 1, p. 1, 2008.

ROSENBERG, N. Inside the black box: Technology and economics. Cambridge: Cambridge University Press, 1982.

ROSSI, M. M. Regression models to assess the thermal performance of Brazilian lowcost houses: consideration of natural ventilation. 2016. Universidade de São Paulo, São 
Carlos, 2016. Disponível em: http://www.teses.usp.br/teses/disponiveis/102/102131/tde13102016-163056/. Acesso em: 22 nov. 2018.

ROZENFELD, H. et al. Gestão de Desenvolvimento de Produtos: uma Referência para a Melhoria do Processo. São Paulo: Saraiva, 2006.

RUIZ, J. D. A. et al. Valor agregado ao produto sob a perspectiva do cliente: desdobramento da função qualidade e diagrama Fast. In: ENTAC 2010 - XIII Encontro Nacional de Tecnologia da Ambinente Construído, Canela, RS. Anais [...] Canela, RS: ANTAC - Associação Nacional de Tecnologia do Ambiente Construído, 2010.

RUIZ, J. de A. Engenharia De Valor Na Construção De Edifícios: Simulação De Aplicações. 2011. Universidade Estadual de Campinas - UNICAMP, 2011.

RUTTEN, M. E. j.; DORÉE, A. G.; HALMAN, J. I. m. Innovation and interorganizational cooperation: A synthesis of literature. Construction Innovation, v. 9, n. 3, p. 285-297, 2009.

SAAD, M.; MAHER, M. Lou. Shared understanding in computer-supported collaborative design. Computer-Aided Design, v. 28, n. 3, p. 183-192, 1996.

SAAD, M.; MAHER, M. Lou. Shared understanding in collaborative design. v. 28, n. 3, 2006.

SAFFARO, F. A.; SANTOS, D. de G.; HEINECK, L. F. Uma proposta para a Classificação de decisões voltadas a melhoria da construtibilidade. In: ENEGEP 2004 - XXIV Encontro Nacional de Engenharia de Produção, Florianópolis, SC. Anais [...] Florianópolis, SC: ABEPRO, 2004.

SAITO, C. Estudo para a determinação dos Custos-meta em Empreendimentos Habitacionais de Interesse Social no Programa Minha Casa Minha Vida. 2016. Universidade Estadual de Londrina-UEL e Universidade Estadual de Maringá-UEM, 2016.

SANCHEZ, R. Modular architectures, knowledge assets and organizational learning: new management processes for product creation. International Journal of Technology Management, v. 19, n. 6, p. 610-629, 2000.

SANCHEZ, R. Architecting organizations: A dynamic strategic contingency perspective. Research in Competence-Based Management, v. 6, p. 7-48, jan. 2012. Disponível em: https://www.scopus.com/inward/record.uri?eid=2-s2.0-

84879664795\&partnerID=40\&md5=8ea035d0245fbcfaaad9a7b38ab3cf1a. Acesso em: 12 nov. 2017.

SANCHEZ, R.; MAHONEY, J. T. Modularity, flexibility, and knowledge management in product and organization design. Strategic Management Journal, v. 17, n. S2, p. 63-76, dez. 1996. Disponível em: http://doi.wiley.com/10.1002/smj.4250171107. Acesso em: 12 nov. 2017.

SANDBERG, J.; TSOUKAS, H. Grasping the Logic of Practice: Theorizing through Practical Rationality. Academy of Management Review, v. 36, n. 2, p. 338-360, 2011.

SARAH SLAUGHTER, E.; SHIMIZU, H. "Clusters" of innovations in recent long span and multi-segmental bridges. Construction Management and Economics, v. 18, n. 3, p. 269- 
280, 21 abr. 2000. Disponível em:

https://www.tandfonline.com/doi/full/10.1080/014461900370645. Acesso em: 14 set. 2016.

SATO, C. E. Y.; DERGINT, D. E. A. a Organização Baseada Em Projetos (Obp) Como Um Sistema Adaptativo Complexo (Sac). In: XXIII Simpósio de Gestão da Inovação Tecnológica, XXIII, Anais [...]2014.

SAVE. Introduction to the Value Methodology. Disponível em: https://www.value-eng.org/. Acesso em: 4 jul. 2018.

SCHILLING, M. A. Toward a general modular systems theory and its application to interfirm product modularity. Academy of Management Review, v. 25, n. 2, p. 312-334, 2000.

SCHÖN, D. A. Designing: Rules, types and words. Design Studies, v. 9, n. 3, p. 181-190, 1988.

SCOTT, W. R. Institutions and Organizations: Foundations for Organizational Science.

Thousand Oaks, Londres, Nova Delhi: SAGE Publications Inc., 1995.

SEBASTIAN, R. Changing roles of the clients, architects and contractors through BIM.

Engineering, Construction and Architectural Management, v. 18, n. 2, p. 176-187, mar.

2011. Disponível em: http://www.emeraldinsight.com/doi/10.1108/09699981111111148.

Acesso em: 2 ago. 2017.

SEIN et al. Action Design Research. MIS Quarterly, v. 35, n. 1, p. 37, 2011.

SHARMAN, D. M.; YASSINE, A. A. Characterizing complex product architectures. Systems Engineering, v. 7, n. 1, p. 35-60, 2004.

SHOU, Y.; WANG, W. Multidimensional competences of supply chain managers: an empirical study. Enterprise Information Systems, v. 11, n. 1, p. 58-74, 2017. Disponível em:

http://dx.doi.org/10.1080/17517575.2015.1080303.

SINHA, K. et al. Interplay between product architecture and organizational structure. In: Gain Competitive Advantage by Managing Complexity - Proceedings of the 14th International DSM Conference, DSM 2012, Kyoto, Japan. Anais [...] Kyoto, Japan: 2012.

SINHA, K. K.; VAN DE VEN, A. H. Designing Work Within and Between Organizations. Organization Science, v. 16, n. 4, p. 389-408, 2005.

SLAUGHTER, S. E.; SLAUGHTER, E. . S. Models of Construction Innovation. Journal of Construction Engineering and Management, v. 124, n. 3, p. 226-231, 1998. Disponível em: http://ascelibrary.org/doi/abs/10.1061/(ASCE)0733-9364(1998)124:3(226).

SMYTH, H. J.; THOMPSON, N. J. Partnering and conditions of trust. n. September 1999, p. 510, 1999.

SNOWDEN, D. Complex acts of knowing: Paradox and descriptive self-awareness. Journal of Knowledge Management, v. 6, n. 2, p. 100-111, 2002. 
SOKAL, A.; BRICMONT, J. Imposturas Intelectuais. 1. ed. São Paulo: Record, 1999.

SOLIHIN, W.; EASTMAN, C. Classification of rules for automated BIM rule checking development. Automation in Construction, v. 53, p. 69-82, May 2015. Disponível em: http://dx.doi.org/10.1016/j.autcon.2015.03.003. Acesso em: 3 mar. 2018.

SONNENBERG, C.; VOM BROCKE, J. Evaluation Patterns for Design Science Research Artefacts BT - Practical Aspects of Design Science. Practical Aspects of Design Science, v. 286, Chapter 7, p. 71-83, 2012.

SOSA, M. E. Aligning process, product, and organizational architectures in software development. In: Proceedings of ICED 2007, the 16th International Conference on Engineering Design, August, Anais [...]2007. Disponível em: https://www.scopus.com/inward/record.uri?eid=2-s2.084862592271\&partnerID=40\&md5=392d0b786dd507406ddc97432d84e79c. Acesso em: 12 nov. 2017.

SOSA, M. E.; EPPINGER, S. D.; ROWLES, C. M. Designing Modular and Integrative Systems. In: DETC2000 / ASME 2000: International Design Engineering Technical Conferences and Computers and Information in Engineering Conference, Baltimore. Anais [...] Baltimore: ASME, 2000.

SOSA, M. E.; EPPINGER, S. D.; ROWLES, C. M. The Misalignment of Product Architecture and Organizational Structure in Complex Product Development. Management Science, v. 50, n. 12, p. 1674-1689, dez. 2004. Disponível em: http://dx.doi.org/10.1287/mnsc.1040.0289.

SOSA, M. E.; ROWLES, C. M. Identifying Modular and Integrative Systems and Their Impact on Design Team. v. 125, n. June, 2003.

STARY, C. et al. Towards Stakeholder-Centered Design of Open Systems: Learning from Organizational Learning. In: Proceedings of the European Conference on Cognitive Ergonomics 2015, New York, NY, USA. Anais [...] New York, NY, USA: ACM, 2007. Disponível em: http://doi.acm.org/10.1145/2788412.2788440.

STEEN, M. Co-Design as a Process of Joint Inquiry and Imagination. v. 29, n. 2, 2013.

STEWART, G. L.; COURTRIGHT, S. H.; MANZ, C. C. Self-leadership: A multilevel review. Journal of Management, v. 37, n. 1, p. 185-222, 2011.

SUCCAR, B. Building Information Modelling Maturity Matrix. In: Handbook of Research on Building Information Modeling and Construction Informatics: Concepts and Technologies. [s.I.] Information Science Publishing, 2009. p. 65-103.

SUCCAR, B.; SHER, W.; WILLIAMS, A. Measuring BIM performance: Five metrics. Architectural Engineering and Design Management, v. 8, n. 2, p. 120-142, 2012. Disponível em: http://dx.doi.org/10.1080/17452007.2012.659506. Acesso em: 8 mar. 2018.

SUCCAR, B.; SHER, W.; WILLIAMS, A. An integrated approach to BIM competency assessment, acquisition and application. Automation in Construction, v. 35, p. 174-189, 2013. Disponível em: https://www.scopus.com/inward/record.uri?eid=2-s2.0- 
84884498619\&partner|D=40\&md5=312687fbec 1 b6ddd4b25e37d3643c22b. Acesso em: 5 out. 2018.

SULLIVAN, L. H. The Tall Office Building Artistically Conidered. Lippincott's Magazine, v. March, n. 1896, p. 403-409, 1896. Disponível em: https://ocw.mit.edu/courses/architecture/4205-analysis-of-contemporary-architecture-fall-2009/readings/MIT4_205F09_Sullivan.pdf.

TAYLOR, F. W. The principles of scientific management. Nova York: Harper \& Brothers, 1919.

TAYLOR, J. E. Antecedents of Successful Three-Dimensional Computer-Aided Design Implementation in Design and Construction Networks. Journal of Construction Engineering and Management, v. 133, n. 12, p. 993-1002, 2007.

TAYLOR, J. E.; LEVITT, R. Innovation Alignment and Project Network Dynamics: An Integrative Model for Change. Project Management Journal, v. 38, n. 3, p. 22-35, set. 2007. Disponível em: http://journals.sagepub.com/doi/10.1002/pmj.20003.

TEECE, DAVID JPISANO, G.; SHUEN, A. Dynamic Capabilities and Strategic Management David. Strategic Management Journal, v. 18, n. 71, p. 509-533, 1997.

TEO, H. H.; WE, K. K.; BENBASAT, I. Predicting Intention to Adopt Interorganizational Linkages: An Institutional Perspective. MIS Quarterly, v. 27, n. 1, p. 19-49, 2003. Disponível em: https://www.jstor.org/stable/30036518. Acesso em: 16 jun. 2017.

THIA, C. W. et al. An exploratory study of the use of quality tools and techniques in product development. 2006.

THOMSON, D. S. et al. Managing value and quality in design. Building Research \& Information, v. 31, n. 5, p. 334-345, 15 jan. 2003. Disponível em:

http://www.tandfonline.com/doi/full/10.1080/0961321032000087981. Acesso em: 24 abr. 2017.

TIWANA, A. Does technological modularity substitute for control? A study of alliance performance in software outsourcing. Strategic Management Journal, v. 29, n. 7, p. 769780, jul. 2008. Disponível em: http://doi.wiley.com/10.1002/smj.673.

TOLEDO, J. C. De. Gestão da mudança da qualidade de produto. Gestão \& Produção, v. 1, n. 2, p. 104-124, 1994. Disponível em:

https://s3.amazonaws.com/academia.edu.documents/32764472/Gestao_da_Mudanca_da_Qu alidade_de_Produto.pdf?AWSAccessKeyld=AKIAIWOWYYGZ2Y53UL3A\&Expires $=15380650$ 36\&Signature=mGBVSWO25jd8ZMaWPAJaXeZXmN8\%3D\&response-contentdisposition=inline\%3B filename\%3D04_GES.

TOSI, H.; ALDAG, R.; STOREY, R. On the Measurement of the Environment: An Assessment of the Lawrence and Lorsch Environmental Uncertainty. Administrative Science Quarterly, v. 18, n. 1 , p. $27-36,1973$.

TRIPP, D. Pesquisa-ação: uma introdução metodológica. Educação e Pesquisa, v. 31, n. 3, p. 443-466, 2005. 
TSOUKAS, H.; CHIA, R. On Organizational Becoming: Rethinking Organizational Change. Organization Science, v. 13, n. 5, p. 567-582, 2003.

TUMELERO, G. Estanqueidade na interface de conexão entre esquadrias de alumínio e painéis do sistema construtivo wood frame. 2016. Universidade Estadual de Londrina, Universidade Estadual de Maringá, Londrina/Maringá, 2016.

UFRGS, R. D. Á. Modelagem de processos organizacionais utilizando a matriz de estrutura baseada em atividades. p. 1-8, 2006.

ULRICH, D.; SMALLWOOD, N. Capitalizing on capabilities. Harvard Business Review, v. 82, n. 6, p. 1-10, 2004. Disponível em: https://hbr.org/2004/06/capitalizing-on-capabilities.

ULRICH, K. The role of product architecture in the manufacturing firm. Research Policy, v. 24, p. 419-441, 1995.

USDIKEN, B. et al. Strategies and Boundaries: Subcontracting in Construction. Strategic Management Journal, v. 9, n. 6, p. 633-637, 1988. Disponível em:

https://www.jstor.org/stable/2486695. Acesso em: 25 ago. 2016.

UZZI, B.; SPIRO, J. Collaboration and Creativity: The Small World Problem. American Journal of Sociology, v. 111, n. 2, p. 447-504, 2005.

VALKENBURG, A. C. The reflective practice in product design teams, 2000. .

VALKENBURG, R. C. Shared understanding as a condition for team design. v. 7, 1998.

VALKENBURG, R.; DORST, K. The reflective practice of design teams. Design Studies, v. 19, n. 1998, p. 249-271, 1998.

VAN DER LUGT, D. R. Sketching in idea generation meetings. 2001. Industrial Design Engineering, 2001. Disponível em: http://resolver.tudelft.nl/uuid:7bd2639b-26ef-4550-867594bda367a102.

VAN DER VOORDT, T. Facilities management and corporate real estate management: FM/CREM or FREM? Journal of Facilities Management, v. 15, n. 3, p. 244-261, 3 jul. 2017. Disponível em: https://www.scopus.com/inward/record.uri?eid=2-s2.085023632222\&doi=10.1108\%2FJFM-05-20160018\&partnerID=40\&md5=b55dc85c30c7f325eaeae37835e71db1. Acesso em: 12 jan. 2018.

VAN DER VOORDT, T. J. M. Adding value by health care real estate: parameters, priorities, and interventions. Journal of Corporate Real Estate, v. 18, n. 2, p. 145-159, 9 maio 2016. Disponível em: http://www.emeraldinsight.com/doi/10.1108/JCRE-11-2015-0037. Acesso em: 2 abr. 2017.

VASS, S.; KARRBOM GUSTAVSSON, T. The perceived business value of BIM. In: eWork and eBusiness in Architecture, Engineering and Construction - Proceedings of the 10th European Conference on Product and Process Modelling, ECPPM 2014, Vienna, Austria. Anais [...] Vienna, Austria: 2015. Acesso em: 2 set. 2017. 
VENKATRAMAN, A. N.; CAMILLUS, J. C. Exploring the Concept of "Fit" in Strategic Management. The Academy of Management Review, v. 9, n. 3, p. 513-525, 1984. Disponivel em: https://www.jstor.org/stable/258291. Acesso em: 10 jan. 2017.

VICTOR, B.; BOYNTON, A. C. Invented Here: maximizing your organization's internal growth and profitability. [s.I.] Harvard Business School Press, 1998.

VIVANCOS, adriano gameiro; CARDOSO, francisco ferreira. A implantação de sistemas de gestão da qualidade e a descentralização do poder em empresas construtoras. In: ENEGEP Encontro Nacional de Engenharia de Producao, Anais [...]1999.

VIVANCOS, A. Estruturas Organizacionais de Empresas Construtoras de Edifícios em Processo de Implementação de Sistemas de Gestão da Qualidade. p. 183, 2001.

VRIJHOEF, R. Supply chain integration in the building industry. 2011. Delft University of Technology, Delft, 2011.

WAKS, L. J. Donald Schon's Philosophy of Design and Design Education. International Journal of Technology and Design Education, v. 11, p. 37-51, 2001.

WALBE ORNSTEIN, S. et al. Avaliação Pós-Ocupação em Sistemas Construtivos Inovadores: Considerações Finais. In: Avaliação de Desempenho de Tecnologias Construtivas Inovadoras: Conforto Ambiental, Durabilidade e Pós-Ocupação. [s.I.] Editora Scienza, 2017. p. 293-304.

WANG, X. et al. Augmented Reality in built environment: classification and implications for future research. 2013.

WEBER, M. Introduction Theory of Social and Economic Organization.pdf. 1a (traduz ed. Nova York: Oxford University Press, 1947.

WEYTJENS, L.; ATTIA, S.; OTHERS. A comparative study of the ' architect-friendliness ' of six building performance simulation tools. Sustainable Buildings CIB, 2010. Disponível em: http://scholar.google.com/scholar?hl=en\&btnG=Search\&q=intitle:A+comparative+study+of+t he+'+architect-friendliness+'+of+six+building+performance+simulation+tools\#0.

WHYTE, J.; LOBO, S. Coordination and control in project-based work: Digital objects and infrastructures for delivery. Construction Management and Economics, v. 28, n. 6, p. 557567, 2010.

WINCH, G. M. Managing Construction Projects. 2. ed. Chichester: Wiley-Blackwell, 2010.

WOODRUFF, R. B. Customer Value: The Next Source for Competitive Advantage. Journal of the Academy of Marketing Science, v. 25, n. 2, p. 139-153, 1997.

YASSINE, A. A.; WISSMANN, L. A. The implications of product architecture on the firm. Systems Engineering, v. 10, n. 2, p. 118-137, 2007. Disponível em: https://www.scopus.com/inward/record.uri?eid=2-s2.034249860524\&partnerlD=40\&md5=ab883a59bdbf36517dc41029734b4738. Acesso em: 3 set. 2016. 
YIN, X.; ZAJAC, E. J. The strategy/governance structure fit relationship: theory and evidence in franchising arrangements. Strategic Management Journal, v. 25, n. 4, p. 365-383, 2004.

ZAGER, D. Collaboration as an activity coordinating with pseudo-collective objects.

Computer Supported Cooperative Work, v. 11, n. 1-2, p. 181-204, 2002.

ZHENG, L. et al. Benefit sharing for BIM implementation: Tackling the moral hazard dilemma in inter-firm cooperation. International Journal of Project Management, v. 35, n. 3, p. 393405, 2017. Disponível em: http://dx.doi.org/10.1016/j.ijproman.2017.01.006. Acesso em: 15 out. 2018. 
APÊNDICES 


\section{Apêndice A Acrônimos e glossário}

Além da indicação das siglas utilizadas no texto, a seguir é disponibilizado um glossário contendo a definição de alguns termos abordados na tese, mas não aprofundados. Assim, as definições devem ser interpretadas a partir da perspectiva da pesquisa, uma vez que não abordam significados que extrapolem a explicação suficiente para apoiar a compreensão e para complementar a discussão da tese. Por essa razão, algumas descrições são menos detalhadas e outras são bem detalhadas, portanto algumas podem apenas indicar uma acepção do termo ou combinar dois verbetes em uma única explicação, enquanto outras podem abranger uma discussão complementar ao corpo da tese sobre as implicações dos achados para a definição dos termos empregados.

ACV: Avaliação do Ciclo de Vida

AECO: Arquitetura, Engenharia, Construção e Operação

APO: Avaliação Pós-Ocupação

BIM: Build Information Modelling/Model

Cohab-LD: Companhia de Habitação de Londrina

CM: Custeio-meta

CVE: Ciclo de Vida do Edificio/da Edificação

CVP: Ciclo de Vida do Projeto

DSR: Design Science Research

iBIM: Integrate Building Information Modeling

IGI: Índice Geral de Importância

LCA: Life Cycle Assessment

MCMV: Programa Habitacional Minha Casa, Minha Vida

QFD: Quality Function Deployment

RSL: Revisão Sistemática da Literatura

TC: Target Costing

TVD: Target Value Design 


\section{Glossário}

Avaliação do Ciclo de Vida (ACV); Life Cycle Assessment (LCA): é um método de avaliação do impacto ambiental dos resíduos, materiais, componentes e subsistemas consumidos e descartados ao longo do ciclo de vida do edificio (CVE). É aplicável a todos os níveis do sistema construtivo, desde a seleção de materiais a uma avaliação global para a melhoria da arquitetura. Sua finalidade principal é apoiar o desenvolvimento de projetos com baixo impacto ambiental, o que subsidia a consecução de valores de sustentabilidade para AECO. No Brasil, os procedimentos de ACV são normatizados pela NBR ISO 14040 e pela NBR ISO 14044, e estipulam que um estudo de AVC deve ser composto de quatro fases fundamentais, ligadas à definição do objetivo, à análise de inventário, à avaliação dos impactos e à interpretação do ciclo de vida (ABNT, 2001, 2009; KOHLER; LÜTZKENDORF, 2002; EADIE et al., 2013; BUENO, 2014; BUENO; PEREIRA; FABRICIO, 2018).

Avaliação Pós-Ocupação (APO): é uma metodologia que busca diagnosticar aspectos positivos e negativos da edificação durante a operação, uso e manutenção, a partir da avaliação de fatores técnicos, funcionais, econômicos e comportamentais identificados por meio da opinião de técnicos, projetistas e usuários, da observação direta do edifício em uso e da análise das especificações dos projetos técnicos e arquitetônicos. A APO corresponde a um tipo de sistema de retroalimentação em looping fechado, de curto prazo, que busca realimentar novos projetos com informações capturadas em edificios em operação com programa e tipologia semelhantes. Trata-se de um método versátil, aplicável a diferentes objetos e objetivos específicos, tais como a avaliação de acessibilidade, de manutenção predial, de tecnologias construtivas inovadoras, etc. (ORNSTEIN; ROMÉRO, 1992; ROMCY; SANTIAGO, 2010; MARQUES; BORGES, 2012; CONCEIÇÃO; IMAI; URBANO, 2015; WALBE ORNSTEIN et al., 2017; ONO et al., 2018).

\section{Build Information Modelling (BIM); Integração digital; Sistemas de Informaçãa da}

Construção: com o passar do tempo, o significado de BIM tem mudado de um sistema de informação da construção para um paradigma de integração digital do ciclo de vida do projeto (CVP) e do CVE. O paradigma atual de BIM engloba ferramentas de modelagem digital da construção e processo de projeto colaborativo, que permitem integrar as informações e antecipar decisões nas fases iniciais de desenvolvimento do 
projeto, potencialmente reduzindo os riscos de perdas para o empreendimento. Para tanto, é preciso o desenvolvimento de novas competências técnicas e sociais de profissionais ligados ao projeto e uma reestruturação da organização do projeto como a discutida na tese (ANDRADE; RUSCHEL, 2009; CORRÊA; RUSCHEL, 2010; SUCCAR; SHER; WILLIAMS, 2012, 2013; EASTMAN et al., 2014; VASS; KARRBOM GUSTAVSSON，2015; CHEN; LI，2016; LINDGREN，2016; ZHENG et al., 2017; ÇIDIK et al., 2017; MACHADO; RUSCHEL; SCHEER, 2017).

Cadeia de Suprimentos: [ver "gerenciamento da cadeia de suprimentos"]

Captura e Hierarquização de Requisitos dos Clientes: para que o projeto seja orientado à criação de valor é preciso adotar algum método de identificação das preferências dos clientes/usuários. A captura e a hierarquização do valor dos requisitos para o cliente podem se basear em técnicas de preferência declarada, em que uma análise de escolhas (trade-off) é feita com o usuário entre ganhos financeiros, de desempenho energético, de conforto e funcionalidade, de qualidades socioespaciais e valores culturais, etc. Podese utilizar também instrumentos adaptados de APO para identificar aspectos positivos e negativos percebidos em casos existentes dificeis de ser ponderados por meio da preferência declarada. A hierarquia dos requisitos capturados é dada pelo índice geral de importância (IGI). O IGI é uma variável de medição da importância de cada item de uma lista de requisitos capturados com o objetivo de ajustar eventuais intensões residuais, dispersas entre as múltiplas opções de prioridades explicitadas. Esse índice corresponde a uma taxa percentual alcançada por meio da frequência ponderada com que cada requisito é preferido quando comparado aos demais dividida pela soma de todas as taxas de preferências levantadas (KOWALTOWSKI; GRANJA, 2011; CONCEIÇÃO; IMAI; URBANO, 2015; ARAGÃO et al., 2016).

Ciclo de Vida do Edifício (CVE): compreende todas as interações que ocorrem entre um edifício e o ambiente, bem como o impacto dessas interações, que se inicia com o planejamento do empreendimento imobiliário e sua construção. Inclui a produção de materiais e de equipamentos, se estende por todo o período de operação, uso e manutenção, e conclui-se com a demolição, reúso ou reciclagem de partes ou da totalidade do edificio, quando outro ciclo pode se iniciar. $\mathrm{O}$ impacto ambiental se refere às alterações que ocorrem no meio ambiente por causa do edificio e pode ser benéfico ou adverso (ABNT, 2005, 2015; BUENO, 2014). 
Ciclo de Vida do Projeto (CVP): para atividades do setor produtivo, o ciclo de vida de um projeto compreende o conjunto de processos necessários para realizar um resultado único, sem uma solução já disponível no mercado. Uma das descrições mais difundidas do CVP é apresentada pelo Project Management Institute (PMI), que divide o ciclo em quatro processos genéricos fundamentais relacionados à iniciação, ao planejamento, à execução e ao encerramento. Uma interpretação do CVP da construção civil foi apresentada por Morris em 1988 e adotada desde então como um modelo corrente para o setor. Nesse modelo os quatro estágios do PMI são adaptados como uma sequência de processos de viabilidade; planejamento e design; produção e adaptação; e lançamento. $\mathrm{O}$ design corresponde às atividades arquitetônicas e técnicas ligadas ao projeto básico. Todavia, entende-se que manter a alocação do design como uma fase do projeto é anacrônico, incompatível com as condições de criação de valor e o processo de integração da arquitetura discutido na RSL (capítulo 3). Sob essa perspectiva, o que se entende por processo de projeto não está circunscrito aos estágios de viabilidade, planejamento e design, mas se estende ativamente sobre todo o CVP, de forma a capacitar a equipe de projeto a promover o gerenciamento da integração. Uma adaptação feita no modelo clássico de CVP de empreendimentos imobiliários (Figura 50) ajuda a explicar a diferença entre as duas interpretações. Considere os segmentos de linha azul e verde que juntos representam a curva esquemática do ciclo de vida de um projeto integrado. $\mathrm{Na}$ interpretação recorrente, o limite entre essas cores estabelece a transição entre o projeto, em azul, e a execução da construção, em verde. Os estágios de "produção" e "adaptação e lançamento" corresponderiam, nesse caso, a etapas posteriores ao projeto, de execução de obra e entrega do imóvel. Já uma segunda interpretação para o CVP argumenta que existe uma aproximação inexata entre a atividade de gerenciamento da execução do projeto e o gerenciamento das rotinas de produção, realizadas na fabricação, instalação e execução de serviços no canteiro de obra. Enquanto setores de manufatura realizam um CVP completo antes do início da produção, com a prototipagem do produto e da produção (ver First-Run Study), empreendimentos imobiliários são prototípicos, com condições de execução não replicáveis ou parcialmente replicáveis. As propriedades emergentes das condições não replicáveis implicam maior variabilidade e indefinição das especificações de projeto, que não podem ser completas e adequadamente resolvidas antes do início da obra. Como consequência, as condições de gerenciamento de rotinas de produção são prejudicadas, resultando em desperdício e imprevisibilidade. 
Figura 50 - Ciclo de vida do projeto de empreendimentos imobiliários

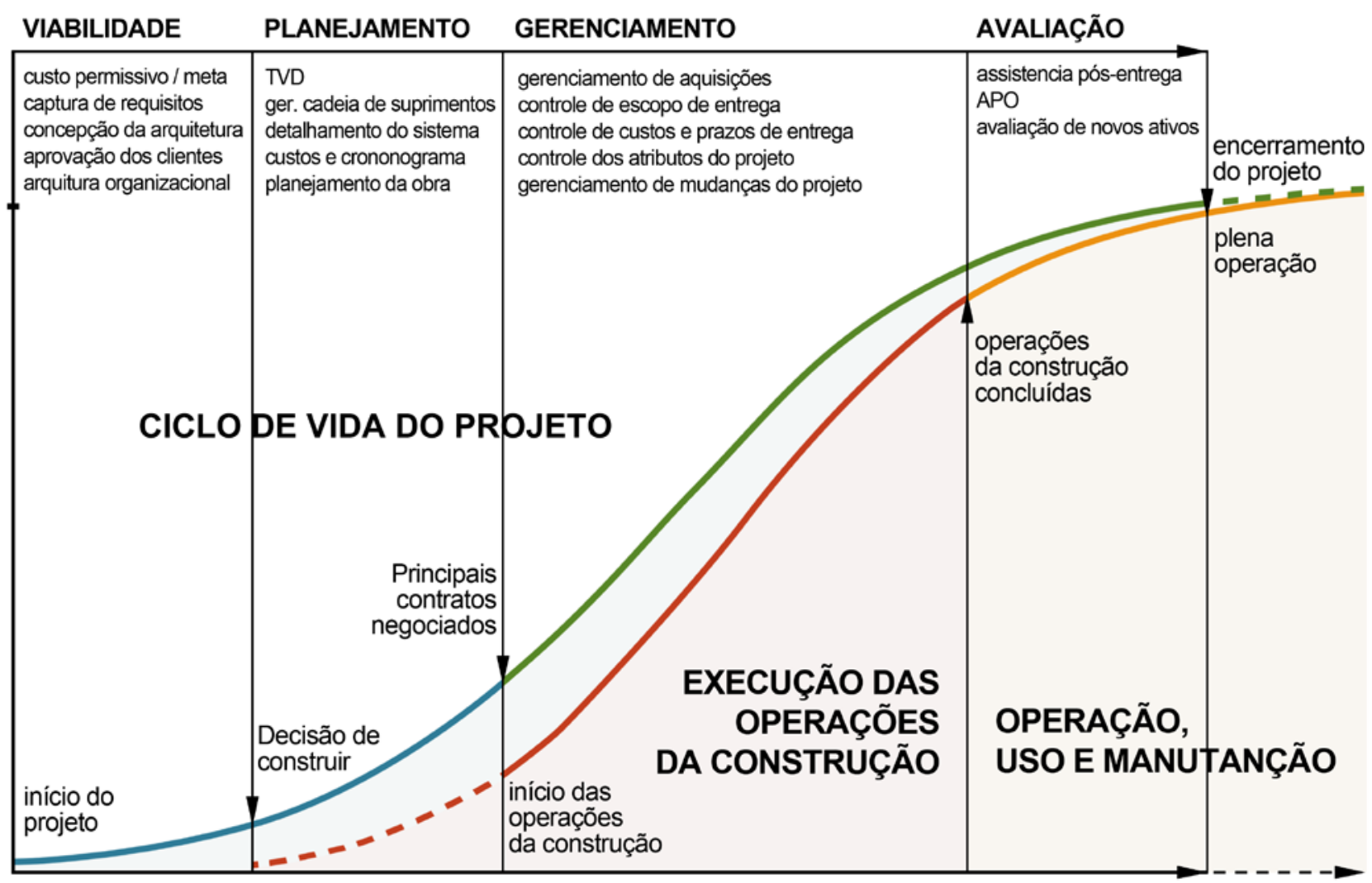

Fonte: adaptada de Pereira (2014) e Morris (1988).

A falta de recursos para simular e avaliar o desempenho do projeto com a rapidez e a confiabilidade necessárias fez com que a parte das atividades de gerenciamento de mudanças do projeto historicamente migrasse para o gerenciamento de operações da construção, o que justifica a aproximação inexata, mas acarreta perdas na capacidade de mudanças. Com a integração digital de procedimentos e sistemas de BIM e de simulações de desempenho, existe a perspectiva de recuperar a continuidade entre desenvolvimento e gerenciamento do projeto. Nesse cenário, o gerenciamento de mudanças (linha verde) e o gerenciamento das operações de rotina da construção (linha vermelha) são simultâneos e iterativos. O segundo responde pelo trabalho de execução, e o primeiro gerencia a adequação da execução aos requisitos funcionais da arquitetura para a persecução do valor projetado. Uma interpretação análoga estabelece a simultaneidade entre gerenciamento predial e a APO. Como discutido na RSL, uma integração organizacional dos processos de projeto permite o compartilhamento de recursos de gerenciamento e reduz a complexidade da coordenação de atividades interdependentes não adjacentes e problemas de interoperabilidade, o que contribui para a formação das 
condições de criação de valor, aprendizado organizacional e inovação em organizações de rede multiempresas (MORRIS, 1988; KOSKELA, 2000; SAFFARO; SANTOS; HEINECK, 2004; MCCARTHY; GORDON, 2011; PEREIRA, 2014; PMI, 2017).

Colaboração; Cooperação; Projeto Colaborativo: conceitualmente existe uma diferença fundamental entre cooperação e colaboração que muitas vezes é negligenciada nos âmbitos acadêmico e gerencial. Em um sistema cooperativo de trabalho, o comprometimento é construído ante a percepção de interdependência entre as tarefas e os objetivos individuais de projetistas compromissados com seu próprio negócio; já na colaboração promove-se um objetivo final comum, e este objetivo só é possível dentro de um arranjo organizacional adequado que viabilize o trabalho coordenado de uma equipe. Por exemplo, em um arranjo típico das relações de interação de uma equipe de projeto em AECO, cada empresa ou profissional é responsável contratualmente por uma área específica do desenvolvimento do projeto e compromete-se a cooperar com os demais envolvidos, pois entende que assim obterá as condições necessárias para realizar o trabalho e para alcançar os resultados esperados em sua competência. Nessa configuração cada disciplina específica possui um interesse particular e é exercida por uma pessoa ou empresa cuja equipe está comprometida com o escopo restrito a essa especialidade. Os interesses particulares alinham-se indiretamente ao sucesso do projeto, pois objetivam atingir os parâmetros de desempenho definidos antecipadamente, mediante contrato, com a empresa promotora do projeto e assim faturar o pagamento combinado. Mas se os problemas de projeto permanecem em aberto, como definir antecipadamente os critérios de desempenho para a contratação de forma a garantir que os objetivos do projeto sejam atendidos da melhor forma possível? A resposta apresentada pelo projeto colaborativo é "não definir", e para isso seus defensores propõem um arranjo organizacional diferente, em que profissionais escalados para o desenvolvimento de um projeto também atuam nos departamentos ou organizações responsáveis pelo gerenciamento da execução das etapas projetadas. Eles se deslocam temporariamente de suas posições de rotina e interagem pessoalmente buscando uma solução integrada para o projeto. Nessa configuração cada interveniente estaria comprometido com os objetivos do projeto, pois o sucesso individual das especialidades se torna indissociável do sucesso global. A equipe teria autonomia para gerenciar da melhor forma possível todas as variáveis do projeto com base nas limitações de produção e nos objetivos do projeto, de forma a intensificar prática interativa de socialização de conceitos e experiências para criar um entendimento compartilhado sobre o problema de projeto (KYNG, 1991; 
KLEINSMANN, 2006; LU et al., 2007; FULFORD; STANDING, 2013; PEREIRA, 2014; PEREIRA; HIROTA; FABRICIO, 2017).

Comunicação Assíncrona: corresponde às formas de comunicação mediadas por representações de objetos definidas organizacional, semântica e graficamente, destinadas ao compartilhamento e ao registro de informações de projeto. Essas representações são registradas em uma linguagem específica, explícita ou codificada, podendo ser difundidas e armazenadas por meio analógicos e digitais, tais como e-mails, contratos, formulários, memoriais descritivos, desenhos técnicos, croquis, SAP e BIM (PENG, 1994; SAAD; MAHER, 1996, 2006; VAN DER LUGT, 2001).

Comunicação Síncrona: corresponde às formas de comunicação ocorridas por meio da interação interpessoal, para consulta e reflexão, compartilhamento de impressões, informações, conhecimentos tácitos e valores, negociação e criação de entendimento compartilhado. Embora a comunicação assíncrona seja o meio principal de difusão e registro das informações de projeto, a comunicação síncrona é fundamental ao projeto colaborativo porque permite superar problemas de semântica, média, desempenho e organização que ocorrem na comunicação assíncrona (BADKE-SCHAUB; FRANKENBERGER，1999; CHIU，2002; KLEINSMANN，2006; PEREIRA, 2014).

Cooperação: : [ver colaboração]

Desempenho do Edifício; Análise de Desempenho do Edifício: elementos de desempenho do edificio e de conforto ambiental apresentam grande influência sobre o valor percebido em projetos imobiliários, pois impactam diretamente o bem-estar humano e a economia de recursos. São múltiplas variáveis, relacionadas ao desempenho térmico, ergonômico, visual, acústico, etc., que precisam ser consideradas nas fases iniciais do projeto. Diante de tantos parâmetros importantes, não é razoável depender apenas da experiência projetiva. Assim, a adoção de diferentes ferramentas de simulações de desempenho pode oferecer suporte para superar essa crescente complexidade, se integrada no início do processo de projeto arquitetônico. A maioria das ferramentas disponíveis para uso de projetistas ainda não está ajustada às abordagens práticas do projeto, o que tem limitado o uso extensivo de métodos e ferramentas de análise e simulação de desempenho. Todavia, é possível destacar algumas pesquisas importantes 
sobre o tema relacionadas ao desempenho térmico em edificios envelopados, sombreamento de paredes e edificios com ventilação natural, economia de energia e ventilação hídrica, equilíbrio de ganhos de luz e calor por meio de janelas, impacto de dispositivos de sombreamento externos e muro na ventilação natural, etc. (WEYTJENS; ATTIA; OTHERS, 2010; BRUGNERA, 2014; LIMA; CARAM, 2015; ANCHIETA, 2016; FAVRETTO, 2016; ROSSI, 2016; CASTAÑO, 2017).

Entendimento Compartilhado: corresponde ao alinhamento entre os modelos mentais e valores individuais dos integrantes de uma equipe de projeto, que abrange conhecimentos sobre elementos ligados ao conteúdo e ao processo do projeto em curso. A criação do entendimento compartilhado é um processo social e cognitivo em que os integrantes de uma equipe desenvolvem novos modelos mentais e valores em comum. Diferentemente de uma interação simples, em que alguma informação é compartilhada, o entendimento compartilhado permite integrar domínios de atividade e de conhecimento distintos. Pessoas com domínios de conhecimento diferentes têm dificuldade de compartilhar ideias e frequentemente consideram com preconceito as questões centrais apresentadas por seus interlocutores. Todavia, quando trabalham efetivamente juntas, essas pessoas constroem um novo modelo mental com um sistema de significados dirigidos a procedimentos, métodos e avaliações comuns. A literatura aponta que a criação de entendimento compartilhado é necessária para a colaboração efetiva, influencia a qualidade da solução e constitui uma parte do processo de inovação (LEONARD; SENSIPER, 1998; VALKENBURG, 2000; KLEINSMANN, 2006; KLEINSMANN; VALKENBURG, 2008).

First-Run Study: Produção Piloto: é um tipo de planejamento detalhado da execução de determinada tarefa de rotina da produção, seguido pela realização do primeiro ciclo de repetição, o First Run, que é estudado com o intuito de testar e revisar o processo em questão, definindo um padrão para a produção. Dessa forma, a tarefa estaria associada à atividade de gerenciamento de obra, e não ao desenvolvimento do projeto. Todavia, diante da variabilidade e da indefinição das especificações de projeto, mesmo durante a execução, o First-Run Study detecta também problemas de competência da equipe de projeto, o que reforça a natureza iterativa do gerenciamento de mudanças de projeto e de operações da construção (GAMZAZADE et al., 1975; SAFFARO; SANTOS; HEINECK, 2004; PEREIRA, 2014). 
Gerenciamento da Cadeia de Suprimentos: uma cadeia de suprimentos corresponde ao conjunto de processos de transformação e de fluxo de bens e de serviços, incluindo o fluxo de informações, que se conectam ao ciclo de CVP do fornecimento de matériaprima até a operação, uso e manutenção. Também pode ser compreendida como uma rede multiempresas que compõe um empreendimento, o que resulta em um sistema complexo de processos associados temporariamente que precisam ser gerenciados para a obtenção dos objetivos do empreendimento. O cenário atual é marcado pelo desequilíbrio de poder, pela falta de confiança e de autonomia, e pelo desalinhamento entre os interesses particulares de empresas e o objetivo global do projeto, que oferecem obstáculos para alcançar a governança integrada da cadeia de suprimento de empreendimentos imobiliários. Uma perspectiva para lidar com tamanha fragmentação está na definição de um controle centralizado, capaz de articular níveis mais altos de sincronização, de transferência de conhecimento e de feedback sistemático entre as empresas; uma organização alinhada com os interesses dos clientes finais, orientada para a criação de valor final, visando à capacidade de resposta às demandas do mercado e à melhoria do desempenho global da rede de empresas. A integração da cadeia de suprimentos precisaria, portanto, de novos arranjos organizacionais que combinem a capacidade de integração da arquitetura do sistema e a modularidade funcional. Essas condições foram tangenciadas e são compatíveis com a discussão realizada na tese, que aponta problemas da falta de gerência do projeto sobre a cadeia de fornecimento, ao menos no que tange ao fluxo de informação do projeto (AZAMBUJA; FORMOSO, 2003; GOMES; DAHAB, 2010; VRIJHOEF, 2011; PAPADONIKOLAKI; VRIJHOEF; WAMELINK, 2015; PAPADONIKOLAKI; VERBRAECK; WAMELINK, 2017; PAPADONIKOLAKI; WAMELINK, 2017).

Gerenciamento de Mudanças de Projeto: corresponde ao processo proposição e controle de integração das mudanças necessárias para adequar a realidade da construção aos atributos funcionais que correspondem ao valor projetado para o empreendimento. Pressupõe a revisão da mudança sobre as projeções de custos, prazos e escopo do projeto, e uma avaliação do impacto dessas mudanças sobre o valor do projeto, bem como sobre a confiança e o comprometimento das pessoas e a rede de empresas que atuam na organização do projeto. A sugestão de integração do gerenciamento de riscos e de valor, bem como a discussão sobre a extensão do CVP, impacta diretamente a percepção da competência necessária para realizar as mudanças de projeto, como uma atividade com componentes criativos e sociais, iterativa à concepção da solução (FULFORD; STANDING, 2013; PMI, 2017). 
Gerenciamento dos Riscos do Projeto; Risco: o risco corresponde à qualificação de uma ou mais situações em que haja indeterminação e possibilidade de perda. Trata-se de uma qualidade potencial, probabilística, que pode ser determinada ou intuída com base em registros e experiências passadas a fim de antecipar sua existência e permitir o planejamento de alguma ação. Para que o risco seja calculado, deve haver ao menos dois cenários possíveis, um que apresente resultados indesejados. Isto é, a perda é certa, não há riscos. Assim, o gerenciamento de riscos é um procedimento de controle sistemático e evolutivo da imprevisibilidade dos riscos de perda de valor em um investimento ou projeto. A necessidade de realizar a gestão de riscos em projetos de empreendimento imobiliários tem crescido junto com o crescimento da complexidade dos processos. A revisão relata grande dificuldade em implementar sistemas de gerenciamento de riscos no setor de AECO para a realização de projetos dentro do cronograma e do orçamento planejados. Argumenta-se a falta de um contexto apropriado para definir metas e objetivos realistas, identificar e analisar riscos durante o processo decisório, monitorá-los ao longo do CVP e promover as mudanças de projeto necessárias. De fato, raramente as técnicas formais de gerenciamento de risco são usadas no setor em decorrência da falta de informações confiáveis sobre as variáveis tecnológicas e ambientais a serem consideradas. Parte dessa literatura argumenta, ainda, que a distinção atual existente entre o gerenciamento de risco e o gerenciamento de valor do projeto é mais retórica do que substancial, derivada de origem em duas tradições admirativas distintas. Ambos os gerenciamentos têm como objetivo a redução das incertezas de projeto por meio da determinação e do controle de valores de desempenho. Ambos têm em comum também que o surgimento de propriedades emergentes ao longo do processo de projeto exige um gerenciamento continuado durante todo o projeto de forma a identificar as incertezas o mais cedo possível e gerenciar os riscos de perder valor criado pelo projeto. Assim, a integração do gerenciamento de riscos ao gerenciamento de valor do projeto é apontada como um meio de superar as limitações das técnicas formais de gerenciamento de risco para lidar com a excessiva variabilidade técnica e ambiental de cada novo empreendimento. A discussão sobre a criação e o gerenciamento de valor no projeto da arquitetura do sistema, do processo e da organização realizada na pesquisa oferece algum insight para essa integração, que abre um campo promissor para novas pesquisas (AKINTOYE; MACLEOD, 1997; AKINTOYE, 1999; GREEN, 1999; ÖZTAŞ; ÖKMEN, 2004, 2005; LIU; ZOU; GONG, 2013). 
Gerenciamento de Valor no Projeto: na gestão de desenvolvimento de projeto, a gestão do valor se caracteriza como um projeto informacional realizado no início do projeto de produtos, que parte da captura de informações de requisitos do produto e especificaçõesmetas. Analogamente, a elaboração do programa de necessidades do projeto corresponde à coleta de informações relacionadas aos requisitos dos clientes, requisitos ambientais e especificações-metas. Contudo, da forma como é entendido na AECO, o programa de necessidades não se caracteriza como um processo realizado no início do projeto, mas, sim, como um subproduto de uma fase anterior à do início do projeto. Sob a ótica da gestão de valor, o projeto e a construção correspondem às fases de definição e de concretização dos atributos do produto, que são percebidas e hierarquizadas pelo usuário a partir de seus atributos preferenciais, do desempenho dos atributos e da avaliação de um produto em uso. É também nessas fases que se concretiza outra variável do valor: os custos associados aos atributos, ou seja, os custos que decorrem do trabalho realizado e dos insumos empregados para alcançar os objetivos do projeto. Diferentemente de uma visão de CVP focada na transformação, não são os custos de produção que determinam o preço do edifício, mas, sim, as expectativas do cliente individual ou do mercado que estabelecem um preço total adequado, em que os custos precisam se adequar. Em uma visão de CVP voltada para o valor, os custos não são consequência de um projeto técnico, mas um instrumento para tomada de decisão no projeto. A relação entre sacrificios e beneficios se torna evidente em HIS, em que os custos totais são preestabelecidos: a relação entre o benefício recebido e o sacrificio exigido corresponde à definição dos requisitos prioritários possíveis de ser atendidos ante a restrição orçamentária imposta, o que exige um trabalho consistente de hierarquização dos requisitos do projeto. Contudo, a construção do valor percebido sob essa perspectiva não se restringe à HIS; ela continua relevante em outros segmentos e tipologias construtivas que estejam sujeitas a restrições orçamentárias significativas. Pode-se argumentar inclusive que a exceção são os projetos em que o controle ativo dessa variável não é importante ou essencial. A possibilidade de antecipar e gerenciar os custos com a confiabilidade necessária para balancear os recursos financeiros limitados corresponde a algumas estratégias de desenvolvimento de produtos conhecidas por Target Costing e Target Value Design (ORNSTEIN; ROMÉRO, 1992; WOODRUFF, 1997; GREEN, 1999; ROBIN; SLAGMULDER, 2003; ROZENFELD et al., 2006; MOREIRA; KOWALTOWSKI, 2009; BALLARD, 2012; FULFORD; 
STANDING, 2013; CONCEIÇÃO; IMAI; URBANO, 2015; KELLY; MALE; GRAHAM, 2015; MORAIS; GRANJA; RUSCHEL, 2015).

\section{Gerenciamento Predial; Facility Management (FM); Negócios Imobiliários; Real Estate:}

os conceitos de gerenciamento predial e negócios imobiliários têm se alterado dramaticamente com a crescentes exigências do mercado e da sociedade. Originalmente impulsionado pela necessidade de controlar e reduzir custos das várias atividades de operação e manutenção, o gerenciamento predial ou o gerenciamento de instalações (eventualmente a expressão "facility management" foi transliterada como “gerenciamento de facilidades”) tem gradativamente assumido preocupações ligadas ao valor percebido do imóvel, seja ao proporcionar locais de trabalho, permanência e convívio atraentes, equipados com excelentes serviços ou para atender às demandas de sustentabilidade energética e de responsabilidade social. Um fenômeno semelhante é observado em negócios imobiliários, que têm migrado de uma forma de gestão voltada apenas a transações lucrativas de curto prazo para um gerenciamento baseado em relacionamentos de longo prazo com os clientes, incorporando necessidades e expectativas de diferentes partes interessadas no imóvel. Trata-se de um novo contexto de gerenciamento em que as atividades e responsabilidades são delegadas cada vez mais a profissionais especializados, que centralizam e integram serviços e recursos compartilhados de gerenciamento predial e imobiliário. As relações com os clientes ganham assim cada vez mais importância e atenção, aproximando-se das práticas e da teoria de marketing de relacionamento e de gerenciamento de valor. A evolução observada no mercado imobiliário aponta uma mudança de foco, de uma operação incidental, visando reduzir custos de manutenção, para um processo contínuo de gerenciamento da operação, uso e manutenção do imóvel; e, então, um processo integrado de gerenciamento de recursos da cadeia de suprimentos associados à operação, uso e manutenção, até atingir o nível de gerenciamento estratégico de reconhecimento das instalações como ativo organizacional de suporte para os processos principais que ocorrem no imóvel. Semelhantes demandas estabelecem uma crescente atenção do impacto das decisões de projeto sobre o desempenho dos processos subsequentes durante a construção e ao longo de todo o CVE. Assim, apesar das barreiras existentes, é cada vez mais aceito que o gerenciamento predial deve se envolver nos estágios iniciais do CVP. O envolvimento entre projeto, gerenciamento predial e imobiliário já é uma 
realidade em alguns empreendimentos corporativos, de hospitais e universidades, todavia possui potencial de ser difundido em outros tipos, conforme se observará a consolidação das práticas bem-sucedidas (ROPER; LEED, 2006; ANKER JENSEN et al., 2012; JENSEN et al., 2013; NEIVA; FARIA; BIZELLO, 2014; VAN DER VOORDT, 2017).

Índice Geral de Importância: [ver "Captura e Hierarquização de Requisitos dos Clientes"]

Life Cycle Assessment (LCA): [ver "Avaliação do Ciclo de Vida"]

Matriz da Qualidade: [ver "Quality Function Deployment (QFD)"]

Produção Piloto: [ver “First-Run Study”]

Projeto Colaborativo [ver "Colaboração"]: é uma estratégia de resolução de problemas complexos que envolvem componentes lógicos e criativos em um contexto ambíguo de iteração e integração do trabalho de múltiplos agentes de áreas de conhecimento distintas e uma grande cadeia de suprimentos (VALKENBURG, 2000). As duas principais estratégias de implementação de projetos colaborativos são: (1) por meio de uma organização matricial, em que a equipe de projeto coexiste com uma estrutura funcional, partilhando atores e recursos mobilizados temporariamente para o projeto; ou (2) a constituição de uma equipe autônoma composta de atores deslocados da estrutura funcional que oferece sustentação ao projeto (OTTUM; MOORE, 1997).

Qualidade: em uma acepção abrangente, qualidade corresponde às propriedades distintivas de algo, normalmente associada a uma condição de valoração. A qualidade pode ser percebida de forma subjetiva, por meio da estima, ou compreendida de forma objetiva, por meio de propriedades e atributos distinguíveis e mensuráveis. Assim, para os sistemas produtivos, a percepção de qualidade é interpretada como um valor de satisfação de clientes que pode ser parcialmente mensurado e controlado. Sob essa perspectiva, a qualidade de um serviço, objeto ou mesmo edifício está relacionada, por um lado, à capacidade de satisfazer as expectativas declaradas e implícitas dos clientes, e, por outro lado, de não apresentar defeitos que frustrem essas expectativas (ASQ, 1993; TOLEDO, 1994). 
Quality Function Deployment (QFD); Matriz da Qualidade: foi criado para captar a voz do cliente e traduzi-la na forma de demandas ou características de qualidade e funcionalidade incrementais para um produto, compreendidas como parâmetros ou requisitos de projeto. O QFD é composto de um conjunto de matrizes, sendo uma mais comumente utilizada. Sozinha, a Casa da Qualidade (Figura 51) é entendida como um poderoso instrumento capaz de beneficiar o projeto ao relacionar as funções técnicas de um produto, seus atributos e os requisitos dos usuários.

Figura 51 - Estrutura básica da Casa da Qualidade

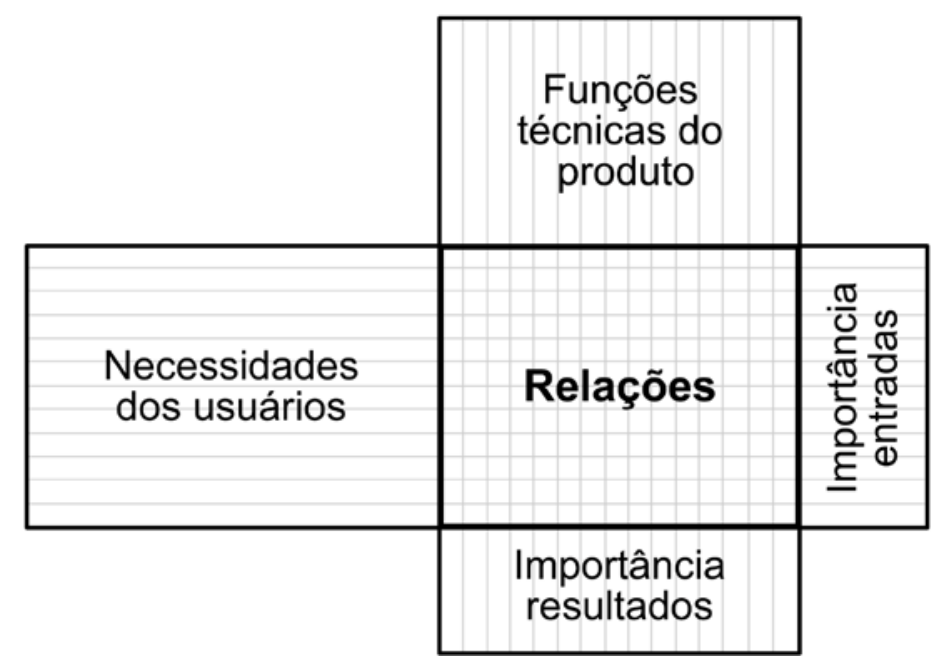

Fonte: baseada em Aragão (2014)

A aplicação da Casa da Qualidade acontece em seis etapas: (1) identificação e hierarquização dos requisitos do cliente; (2) especificação dos requisitos mensuráveis de projeto com base nas solicitações do cliente captadas na etapa anterior; (3) definição das relações entre os requisitos do cliente e os requisitos de projeto nos níveis forte, moderado e fraco; (4) análise competitiva, pela qual se realiza o benchmarking competitivo com o objetivo de identificar o nível de satisfação do cliente ou usuários de produtos similares ao em desenvolvimento; (5) definição das correlações positivas ou negativas entre os atributos de projeto em níveis forte, médio ou neutro, com o objetivo de auxiliar a equipe técnica na tomada de decisões sobre possíveis trade-off, e (7) especificações-metas de projeto e dificuldade técnica, esta última consistente na definição de algarismos de 1 a 5 usados para indicar o nível de dificuldade técnica envolvida para cumprir determinado requisito de projeto. Com aplicação incipiente em empreendimentos imobiliários, o método QFD ainda precisa ser adequado a um contexto com características ímpares como o observado no setor de AECO. Nesse 
sentido, alguns estudos apontam para a necessidade instrumental de incorporar ao processo de projeto a identificação de demanda para o produto, a definição dos recursos financeiros disponíveis para sua produção e a identificação das necessidades do usuário, para então determinar a qualidade dos atributos do produto desenvolvido (HAUSER; CLAUSING, 1988; AKAO, 1997; PRASAD, 1998; NICOLINI et al., 2000; HAN et al., 2001; BALLARD; REISER, 2004; DIKMEN; TALAT BIRGONUL; KIZILTAS, 2005; ROBERT; GRANJA, 2006; THIA et al., 2006; JACOMIT, 2010; GUADANHIM; HIROTA; LEAL, 2011; HAUSER, 2015; ARAGÃO et al., 2016).

Regulação Baseada em Antecipação: é uma estratégia de gerenciamento de valor do projeto que se inicia antes da concepção de uma arquitetura do sistema, com a captura e a análise dos requisitos do usuário e o balanceamento dos recursos financeiros disponíveis. Balizada por essas variáveis, a equipe de projeto teria como objetivo perseguir os requisitos do cliente dentro dos limites de custo permissível previamente estabelecidos. O custeio-meta emprega a estratégia de regulação do projeto baseada em antecipação associada à negociação de melhores condições de produção junto à cadeia de fornecimento. Estudos que aplicaram o CM em projetos de empreendimentos imobiliários apontam, contudo, que as particularidades do setor de AECO tornam particularmente dificil estimar antecipadamente custos condizentes com aqueles realizados de fato, o que compromete o potencial de ganhos originalmente alcançados com o TC (RUIZ et al., 2010; JACOMIT; GRANJA, 2011).

Requisitos dos Clientes: [ver "Captura e Hierarquização de Requisitos dos Clientes”].

Retroalimentação em Looping Fechado: é uma estratégia alternativa ao sistema de regulação baseada em antecipação, em que o responsável pela integração da arquitetura do sistema mede os efeitos positivos e negativos das decisões de projeto sobre o resultado esperado a partir de um modelo analítico capaz de representar a realidade com a verossimilhança progressiva. Assim, é fundamental que o fluxo de informações de retroalimentação do sistema de integração seja adequado para que o responsável pela arquitetura do sistema promova as ações para ajustar o projeto aos requisitos do cliente sem prejuízos ao projeto. Se a retroalimentação for lenta, o detalhamento da solução inadequada será perdido, resultando em retrabalho; e caso existam restrições para o fluxo de informações de retroalimentação, o processo pode mesmo ser inviabilizado (PENNANEN; BALLARD; HAAHTELA, 2011). 
Risco: [ver "Gerenciamento de Riscos do Projeto"]

Target Costing (TC); Custeio-Meta (CM): é uma estratégia de regulação do projeto baseada em antecipação, oriunda do setor automobilístico, que visa estabelecer uma vantagem econômica à indústria ao negociar melhores condições de produção junto à cadeia de fornecimento, para viabilizar maiores taxas de lucro em um preço de mercado competitivo. Para realizar tal propósito, o custeio-meta busca identificar e eliminar sistematicamente custos desnecessários e incorporar melhorias ao produto, visando agregar o máximo de valor a ele. Com o custeio-meta, parâmetros como custo, qualidade e funcionalidade são entendidos como entradas para o processo de projeto, deixando de ser consequências deste. Portanto, o custeio-meta é aplicado de forma integrada ao processo de desenvolvimento de produtos, determinando metas de custo, funcionalidade e qualidade que irão nortear o processo criativo. Contudo, para compreender com precisão o conceito de custeio-meta e suas abordagens, é fundamental definir o conceito de valor, pois este termo é bastante explorado nessa metodologia, extrapolando a dimensão meramente econômica (FEIL; YOOK; KIM, 2004; IBUSUKI; KAMINSKI, 2007; ARAGÃO et al., 2016).

Target Value Design (TVD); Valor-Meta do Projeto: é uma revisão crítica do CM para a indústria da $\mathrm{AECO}$, que reconhece as particularidades ligadas à previsão do custo em produtos complexos com produção individualizada, com potencial limitado para a automatização e a fabricação em série devido a seus atributos estarem intimamente relacionados às condições únicas de uso e do lugar em que é construído. Por isso, diferentemente do enfoque do CM sobre a negociação com a cadeia de fornecedores, essa estratégia tem como foco a integração e o gerenciamento da fase de definição e concepção do projeto. O método ainda se baseia no custeio-meta, que estabelece uma margem superior de custos, em que os limites de investimento são aceitáveis, chamado custo permissível. A observação desses limites indica a adequação da solução proposta. Assim, a definição do projeto se inicia com a validação de um plano de negócio, que estabelece a partir de dados típicos uma estimativa do custo permissível (CP) para os atributos fisicos e espaciais que respondem aos requisitos do cliente. Assim que a decisão de financiamento do projeto se viabiliza, o custo permissível é confrontado com preço de mercado (PM), quantificado a partir da concepção de uma proposta que responda aos atributos do projeto, definidos no plano de negócio. Dessa confrontação podem resultar três variáveis: $\mathrm{CP}=\mathrm{PM}$, em que o orçamento para a construção corresponde ao CP; 
$\mathrm{CP}>\mathrm{PM}$, em que o orçamento para a construção corresponde ao PM, e a diferença é partilhada pelos atores que partilham os riscos do negócio; $\mathrm{CP}<\mathrm{PM}$, em que a diferença entre o CP e o PM precisa ser superada por meio de parcerias e gerenciamento do escopo e prazos de projeto ou o negócio se mostra inviável (MACOMBER; HOWELL; BARBERIO, 2007; BALLARD, 2012; MORAIS; FABRICIO; RUSCHEL, 2018; PEREIRA et al., 2018).

Valor; Criação de Valor: em sua definição elementar, valor é a resultante da ponderação entre os benefícios percebidos e os sacrifícios exigidos para se alcançar algo. Vinculado intimamente ao conceito de qualidade, o valor atribuído a um serviço, produto ou resultado alcançado não depende diretamente das variáveis técnicas e processuais de um sistema produtivo, mas, sim, evolui com a percepção de beneficio do cliente que o adquire. A criação de valor em um projeto pressupõe, portanto, que os requisitos do cliente não sejam mais abordados como um dado de entrada para o projeto, mas, sim, geridos como uma variável interdependente que muda ao longo do CVP, o que demanda a interlocução contínua com o cliente, seja diretamente ou por meio de algum representante para a "voz do cliente". Por fim, o conceito e exemplos de duas estratégias de gerenciamento à criação de valor foram apresentadas no glossário. São elas a regulação baseada em antecipação, exemplificada pelo TC, e a retroalimentação em looping fechado, parcialmente representada pelo TVD e pela perspectiva de evolução da APO (MACOMBER; HOWELL; BARBERIO, 2007; MIRON, 2008).

Voz do Cliente: a definição do interlocutor é determinante para se definir valor, pois a percepção do valor pode variar dependendo da perspectiva de quem o avalia. Como os profissionais envolvidos no projeto normalmente estão imbuídos de preocupações funcionais e construtivas específicas, suas perspectivas de valor podem não coincidir com a perspectiva do cliente final. Assim, a inserção de uma voz que represente o ponto de vista do cliente ajuda a controlar qualquer tendência entrópica durante o processo decisório (ROBIN; SLAGMULDER, 2003). 


\section{Apêndice B Revisão sistemática da literatura \\ (RSL)}

Os dados e procedimentos da RSL foram registrados e tratados em um software específico e gratuito chamado StArt, desenvolvido pelo Laboratório de Pesquisa em Engenharia de Software (LaPES), da Universidade Federal de São Carlos (UFSCar). O arquivo de instalação está disponível para download no endereço http://lapes.dc.ufscar.br/tools/start_tool.

A versão utilizada na RSL foi a 2.3.4. Trata-se de uma versão antiga, que não subsidia a colaboração entre pesquisadores. Novas versões oferecem recursos de assistência à colaboração, porém não foram testadas para a tese. O protocolo de pesquisa da RSL (Quadro 2), o formulário de avaliação da qualidade (Quadro 3) e o formulário de extração de dados (Quadro 4) são, na verdade, uma transcrição dos protocolos informatizados do sistema StArt.

Após o processo de identificação das publicações científicas indexadas nos principais bancos de dados de revistas, teses e congressos acadêmicos, e de seleção dos trabalhos adequados, foram classificados para o processo de extração e sumarização 199 trabalhos, dos quais 67 foram considerados muito relevantes ou relevantes. A lista a seguir relaciona estes trabalhos. 


\section{Quadro 26 - Lista de artigos muito importantes e importantes da TSL}

Title

Authors

Year

\section{MUITO RELEVANTES}

1. Critical analysis of key determinants and barriers to digital innovation adoption among architectural organizations

Ramilo, R.; Embi, M.R.B.

2014

2. Systems architecture, procedural knowledge and learning by using: Implications on systems integration capabilities

Chagas Jr., M.F.; Campanário, M.A.

3. Architecting organizations: A dynamic strategic contingency perspective

Sanchez, R.

4. The architecture of collaboration

Fjeldstad, Oystein D.; Snow, Charles C.; Miles, Raymond E.; Lettl, Christopher

5. Design core competence diagnosis: A case from the automotive industry

Bonjour, Eric; Micaelli, Jean-Pierre

6. The implications of product architecture on the firm

Yassine, A.A.; Wissmann, L.A.

7. Organizational power in building design management

Knotten, V.; Svalestuen, F.; Lædre, O.;

8. Inter-organizational context of the innovation process and the role of architectural designers as system integrators: Case evidence from Turkey

9. Organizational divisions in BIM-enabled commercial construction

Dossick, C.S.; Neff, G.

10. Talent management: challenges of building cross-functional capability in high-performance work systems environments

Levenson, Alec

11. Supply chain integration with BIM: a graph-based model

Papadonikolaki, E.; Vrijhoef, R.; Wamelink, $\mathrm{H}$

12. Impacts of isomorphic pressures on BIM adoption in construction projects

Cao, Dongping; Li, Heng; Wang, Guangbin 2014

13. Ordering in disguise: digital integration in built-environment practices

Cidik, Mustafa Selcuk; Boyd, David;

Thurairajah, Niraj

14. Practices for Designing Cross-Functional Teams for Integrated Project Delivery

15. Adding value by health care real estate: parameters, priorities, and interventions

16. Design management of sustainability values: A learning organization perspective

Novak, V.M.

17. Developing organizational capabilities to deliver lean and green project outcomes using BIM

Ahuja, Ritu; Sawhney, Anil; Arif, Mohammed

\section{RELEVANTES:}

18. A systems approach to assessing organisational viability in project based organisations

19. Assessing the functional alignment of a business process

Karni, Reuven

20. Organizing interindustry architectural innovations: Evidence from mobile communication applications

Jaspers, F.; Prencipe, A.; Van Den Ende, J.

2012

21. Exploring organizational architecture and space: A case for heterodox research 
22. Negotiating through boundary objects in global design project networks

23. Multi perspective framework to improve the knowledge flow

Yoo, Choon-Bae; Hawryszkiewycz, Igor; Kang, Kyeong-Soon

24. Unified modelling in support of organization design and change

Rashid, S.; Masood, T.; Weston, R.H. 2009

25. Systematic approach to superior innovation structures Boutellier, R.; Deplazes, U.; Deplazes, W. 2008

26. The role of climate for innovation in enhancing business performance: The case of design firms

Panuwatwanich, K.; Stewart, R.A.;

Mohamed, S.

2008

27. Aligning process, product, and organizational architectures in software development

Sosa, M.E.

2007

28. A critical systems perspective on the design of organizational space

Mobach, Mark P.

2007

29. The wider implementation issues of BIM within a multifaceted property and real estate consultancy

Dowsett, R.M.; Harty, C.F.

30. A classification framework for facilities and real estate management: The Built Environment Management Model (BEM2)

31. BIM: In search of the organisational architect

Ebinger, M.; Madritsch, T.

32. Construction of a conceptual model for knowledge management in an organization

Forgues, D.; Lejeune, A.

De Moraes, C.R.B.

2012

33. Mimetic behavior in the abandonment of ERP systems: The case of a Brazilian organization

Dos Santos, A.M.; Maçada, A.C.G.

34. Identifying design development factors in Australian PPP projects using an AHP framework

Raisbeck, Peter; Tang, Llewellyn C. M.

35. Integrated collaborative design

Austin, Simon A.; Thorpe, Anthony; Root, David; Thomson, Derek; Hammond, Jamie

36. Collaboration environments for construction: Management of organizational changes

Erdogan, Bilge; Anumba, Chimay J.; Bouchlaghem, Dino; Nielsen, Yasemin

37. Modelling organizations' structural adjustment to BIM adoption: A pilot study on estimating organizations

Olatunji, Oluwole Alfred

38. Improving Collaborative Decision Making in New Product Development Projects Using Clustering Algorithms

Jaber, Hadi; Marle, Franck; Jankovic, Marija

39. Needs and technology adoption: observation from BIM experience

Singh, Vishal; Holmstrom, Jan 2015

40. Managing complexity in lean construction design - using the MDM methodology to create organizational modularity

Krinner, Michael; Elezi, Fatos; Tommelein, Iris D.; Lindemann, Udo

41. Knowledge sharing among architects in a project design team - An empirical test of theory of reasoned action in China

42. Organizational Learning, knowledge creation, problem formulation and innovation in messy problems

43. Investigating the effects of social and organizational structures on information spread: A simulation-based approach

44. Inter- and intra-organizational conditions for supply chain integration with BIM

45. The research of the interaction mechanism between BIM and organizational integration 
46. Dynamics of Project-Based Collaborative Networks for BIM Implementation: Analysis Based on Stochastic Actor-Oriented Models

47. Implementation of Building Information Modeling (BIM) - A process perspective

48. Beyond the BIM utopia: Approaches to the development and implementation of building information modeling

49. Factors influencing BIM adoption in small and medium sized construction organizations

50. A session-based collaboration environment for BIM-based Project Life-cycle Management

51. Construction to operations exchange: Challenges of implementing COBie and BIM in a large owner organization

52. Theoretical categories of successful collaboration and BIM implementation within the AEC industry

53. BIM-based commercial real estate operations flatten structure Research

54. Origins and probabilities of MEP and structural design clashes within a federated BIM model

55. Innovative Capability of Building Information Modeling in Construction Design

56. The Impact of Institutional Context on Organizational Evolution: The Case of a Project-Based Enterprise

57. Contractors' Transformation Strategies for Adopting Building Information Modeling

58. Modeling design workflow: Integrating process and organization

59. Information delivery manuals to integrate building product information into design

60. The realities of building information modeling for collaboration in the AEC industry

61. Diffusing systemic innovations: influencing factors, approaches and further research

62. TBIM: A language for modeling and reasoning about business plans

63. Using effort distribution analysis to evaluate the performance of building information modeling process

64. A Study on the Cooperative Behavior of Engineering Technical Service Based on Quasi-Market Organization: A Theoretical Analysis Framework

65. A social network perspective of building information modelling in Greek construction projects

66. Implementing a quality-based performance measurement system A case study approach

67. Key issues and challenges of risk management and insurance in China's construction industry: An empirical study
Cao, Dongping; Li, Heng; Wang, Guangbin;

Luo, Xiaochun; Yang, Xincong; Tan, Dan

Maunula, Antti; Smeds, Riitta; Hirvensalo, 2008 Antero

Miettinen, Reijo; Paavola, Sami

2014

Hong, Ying; Sepasgozar, Samad M.E.; Ahmadian, A.F.F.; Akbarnezhad, Ali

2016

Chin, Sangyoon; Shin, Tae-Hong; Choi,

Cheolho; Yoon, Su-Won; Lee, Ghang;

Kwon, Soon-Wook

Anderson, Anne; Marsters,;rew; Dossick, Carrie Sturts; Neff, Gina

Homayouni, Hoda; Neff, Gina; Dossick, Carrie Sturts

Xu, Yong Ge; Zhang, Zhen

2013

Parn, E.A.; Edwards, D.J.; Sing, Michael C.P. 2018

Selcuk Cldlk, Mustafa; Boyd, David;

Thurairajah, Niraj

2017

Zhai, Zhao; Le, Yun; Xie, Jianxun; Dong, Shuang

2016

Ahn, Yong Han; Kwak, Young Hoon; Suk, Sung Joon

2016

Hattab, Malak Al; Hamzeh, Farook

2016

Berard, Ole; Karlshoej, Jan

2012

Dossick, Carrie S.; Neff, Gina; Homayouni, Hoda

2009

Lindgren, John

2016

Francesconi, Fabiano; Dalpiaz, Fabiano;

Mylopoulos, John

2013

Aibinu, A.A.; De Jong, P.; Wamelink, H.; Koutamanis, A.

2014

Peng, Xinyan; Zhou, Guohua

Badi, Sulafa; Diamantidou, Dimitra

2017

Jochem, Roland; Menrath, Martin; 


\section{Apêndice C Modelos de "Termo de consentimento informado" e de "Solicitação de informações documentais e entrevista"}

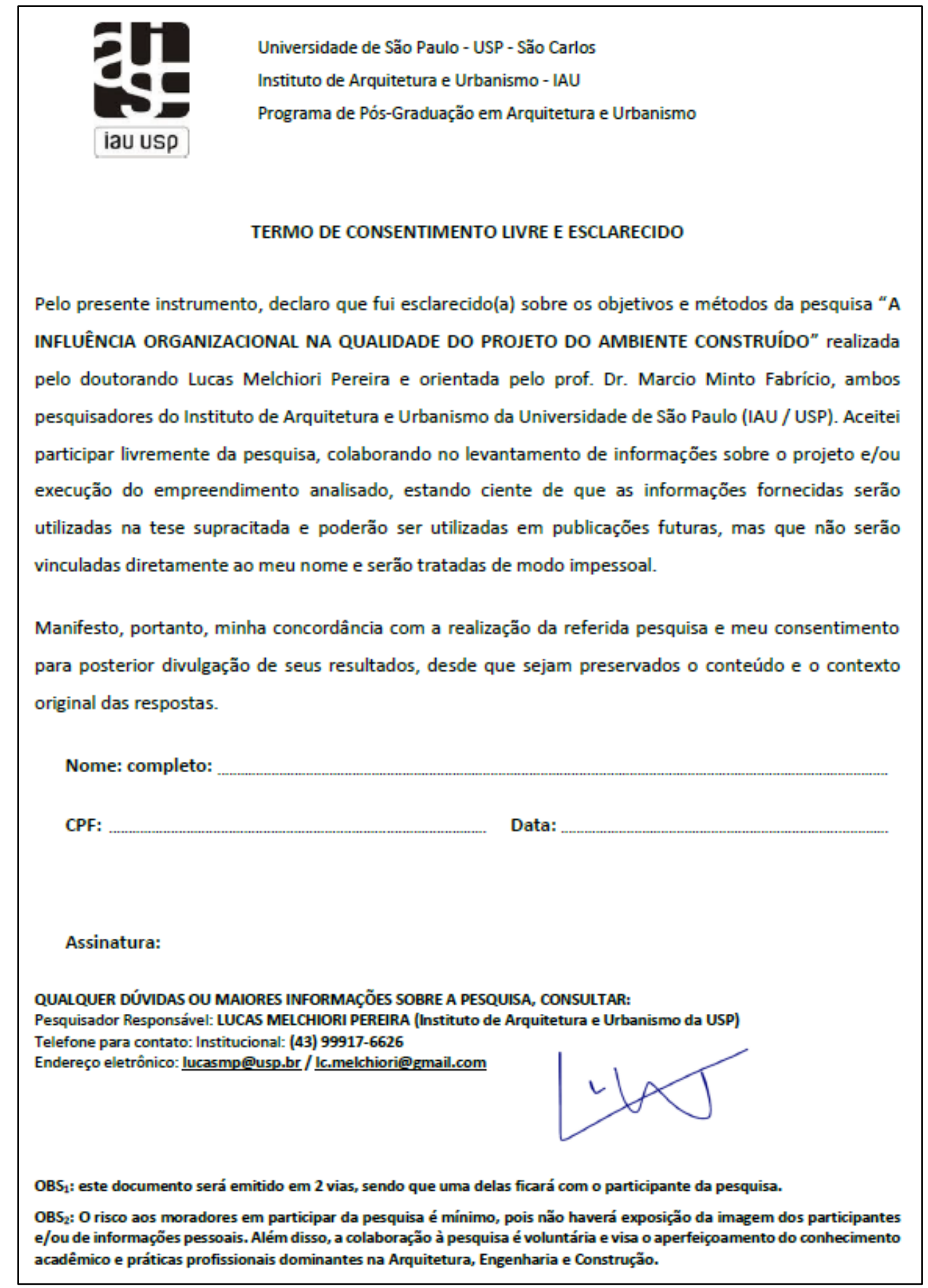


Solicitação de informações documentais e entrevista.

São Carlos, 29 de setembro de 2016.

Aos responsáveis pela comunicação institucional - [nome da instituição].

Eu, Lucas Melchiori Pereira RG 8.772.738-6, doutorando regularmente matriculado no Programa de Pós-Graduação em Arquitetura e Urbanismo - IAU-USP. grupo de concentração em arquitetura, inovação e tecnologia (ARQUITEC) ${ }^{1}$ e orientado pelo professor Dr. Márcio Minto Fabricio, solicito por esta carta $\circ$ acesso a informações documentais e / ou entrevista, para pesquisa acadêmica relacionada a inovação no processo de projeto referentes ao perfil empresarial de escritórios de projeto, com a finalidade de identificar total ou parcialmente os desenhos organizacionais mais expressivos no mercado.

Os dados podem abordar dados, informações e referências sobre os subtemas indicados a seguir:

\section{Desenho organizacional:}

- Pessoas e competências; recursos humanos; comunicação

- Organização formal; estrutura organizacional,

- Organização da informação; cultura organizacional,

- Fluxos de Processos do negócio; projeto,

- Estratégia do negócio; objetivo; visão; papel da organização.

Com objetivo de fomentar a inovação e melhoria contínua dos negócios ligados a AEC, contamos com a cooperação institucional da [nome da instituição], bem como o apoio e interesse dos profissionais envolvido nesta instituição.

De acordo,

Assinatura do orientador

Dr. Márcio Minto Fabricio
Assinatura do aluno

Lucas Melchiori Pereira

${ }^{1}$ Para mais informações acessar https://arquitec.iau.usp.br/ e https://www.iau.usp.br/ 


\section{Apêndice D Orientações para a realização do mapeamento da congruência organizacional}

O mapeamento da congruência organizacional foi realizado para a tese orientado por alguns cuidados procedimentais descritos a seguir. As orientações estão estruturadas segundo a sequência de procedimentos realizada no estudo.

\section{Procedimentos preliminares}

Como a atividade de mapeamento da congruência envolve a participação de pessoas de dada organização, é importante atentar para alguns procedimentos preliminares, de preparação do trabalho. São cuidados ligados à comunicação e ao aceite dos termos da pesquisa, com o recolhimento de assinaturas que comprovem o aceite do "Termo de consentimento informado" pelas pessoas envolvidas no levantamento, e do atendimento a "Solicitação de informações documentais e entrevista", concedida pela organização, na pessoa do responsável legal pela empresa, unidade ou departamento em que o mapeamento será realizado (o Apêndice C apresenta os modelos para esses termos empregados na pesquisa).

Em especial, quando o trabalho visa à publicização dos resultados, é importante garantir antecipadamente a aprovação do estudo por parte do comitê de ética em pesquisa com seres humanos, realizado pelo Conselho Nacional de Saúde do Ministério da Saúde. Até 2019, o processo de aprovação do projeto de pesquisa é realizado por meio do sistema on-line denominado "Plataforma Brasil", acessível em http://plataformabrasil.saude.gov.br/.

Na ocasião da submissão do projeto, o sistema solicitará o preenchimento de um formulário, que requer a indicação de um conjunto de informações sobre a pesquisa, que abrange identificação do pesquisador principal, assistentes e equipe de pesquisa, quando houver; instituição proponente; indicar se é um estudo internacional; área temática especial; grandes áreas do conhecimento; propósito principal do estudo; título público da pesquisa/título principal da pesquisa; contato público/contato científico; desenho/delineamento da pesquisa; financiamento; palavras-chave; resumo; introdução; hipótese; objetivo primário; objetivo secundário (campo não obrigatório; método de pesquisa; critério de inclusão e de exclusão (se houver); riscos; benefícios; método de análise de dados; desfecho primário; desfecho secundário; tamanho da amostra; data do primeiro recrutamento (se houver); países de recrutamento; se haverá uso de fontes secundárias de dados; número da amostragem; grupos em que serão divididos os participantes da pesquisa; se o estudo é multicêntrico; instituição coparticipante; se propõe dispensa do TCLE; se haverá a retenção de amostras para armazenamento em banco; cronograma de execução; orçamento financeiro; outras informações; e bibliografia. 
Além do formulário, a plataforma exige que sejam apresentados ao menos três documentos principais para protocolar uma solicitação de avaliação para pesquisa. São eles:

- folha de rosto disponibilizada pela Conep;

- $\quad$ projeto de pesquisa, em português; e

- termo de consentimento livre e esclarecido - TCLE.

Detalhes de como preencher o formulário e de como conseguir a folha de rosto ou as orientações para a formulação do TCLE devem ser levantados no site da Plataforma Brasil, com especial atenção aos termos da Resolução CNS 196/96-VI.3.e. A aprovação no conselho de ética para pesquisas com seres humanos, embora ainda não seja uma prática recorrente em campos de pesquisa das ciências sociais aplicadas e de pesquisas tecnológicas, na qual pesquisas em AECO se enquadram, deve ser feita sob risco de os resultados não serem aceitos para divulgação em revistas científicas.

\section{Levantamento e registro dos dados}

Uma vez que os participantes foram devidamente informados e consentiram formalmente em participar da pesquisa, inicia-se a etapa de levantamento de dados. Esse levantamento é feito por meio de análise de documentos e entrevistas. Dependendo do grau e do formato dos registros disponíveis sobre os processos da organização, o grau de envolvimento direto dos participantes é diferente, podendo se resumir apenas ao esclarecimento de dúvidas e à confirmação da adequação dos registros em uma situação em que os processos são documentados, até o envolvimento no levantamento desses dados por meio de entrevistas, quando o processo apresenta grau significativo de informalidade.

Como o objetivo do mapeamento é identificar as condições de congruência real, é recomendado que a análise seja feita sobre um empreendimento existente, cuidando que, nos casos em que exista documentação prévia, seja verificado que as informações existentes sejam condizentes com a prática real. Ao realizar o mapeamento em um caso real, evita-se que os envolvidos projetem relações ideais, não existentes, o que prejudicaria a realidade do mapeamento. Os dados levantados são objetivos e relacionais, isto é, não consideram observações e justificativas que não possam ser computadas.

O primeiro levantamento envolve a decomposição do sistema do edifício por meio da análise dos projetos executivos e detalhamentos arquitetônico, estrutural, hidrossanitário, etc. Os componentes são listados em um documento txt, conforme indicado no Quadro 1D. Por definição, os subsistemas são designados sem um código específico, uma vez que não são considerados na definição das relações, mas, sim, indicam um agrupamento dos componentes, o que auxilia o levantamento feito com os participantes. As relações são efetivamente registradas entre os componentes, e, para isso, são relacionados logo abaixo do nome dos componentes os códigos atribuídos a cada componente com quem apresenta interface. Como a relação entre interfaces não considera um sentido, a indicação da interface em apenas um dos componentes é suficiente. 
Quadro 1D - Estrutura de notação e exemplo de decomposição do sistema do edifício

\section{Estrutura de notação dos componentes do sistema do edifício}

[Subsistema]

[código de identificação do componente] - [nome do componente] [código do componente com interface]

\section{Exemplo}

\section{Terrapleno}

001 - Platôs de implantação

002 - Aterros

001

104

003 - Taludes

001

103

004 - Ligação de luz, água e esgoto 001

005 - Drenagem

001

002

003

110

\section{Fundações / sistema estrutural}

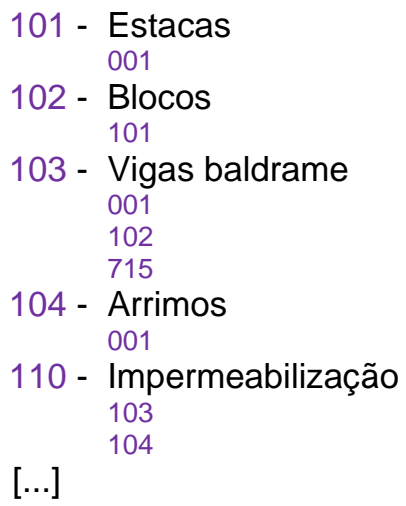

No exemplo indicado no Quadro 1D é suficiente que a indicação de interface do "001 - Platôs de implantação" com os "002 - Aterros", "003 - Taludes" e "101 - Estacas" seja apenas em um dos casos, sem prejuízo para a determinação de relação.

O segundo levantamento mapeia as interações reconhecidas entre atividades da organização analisada. As atividades são listadas em um documento txt, conforme indicado no Quadro 2D. Assim como definido no levantamento anterior, os subprocessos são designados sem numeração, não sendo considerados na definição das relações, servindo para delimitar os agrupamentos de atividade existentes e, assim, auxiliar o trabalho dos participantes. Cada atividade recebe um código e um nome. Após a indicação de código e a descrição de cada atividade são listadas as indicações dos agentes que são corresponsáveis pela realização da atividade. Nessa fase não é observada nenhuma indicação de protagonismo. A indicação dos agentes é feita por meio de um código específico, que remete a outra lista auxiliar de identificação dos agentes. 
Quadro 2D - Estrutura de notação e exemplo de registro das atividades

\section{Estrutura de notação dos componentes do sistema do edifício}

[Subprocesso]

[código de identificação da atividade] - [descrição da atividade]

[código dos agentes envolvidos] [indicação da precedência: indicar apenas o código da atividade]

\section{Exemplo}

Anteprojeto arquitetônico

[...]

0030 - Gerenciamento dos requisitos

$$
\begin{aligned}
& 0006 \\
& 0007 \\
& 0008 \\
& 0025 \\
& 0026
\end{aligned}
$$

0031 - Revisão e detalhamento de requisitos do cliente 6
0030
0039
0040
0041

0032 - Análise de desempenho

8

$[\ldots]$

12

14

$$
\begin{aligned}
& 0026 \\
& 0027 \\
& 0028 \\
& 0029 \\
& 0030 \\
& 0031
\end{aligned}
$$

0033 - Definição dos atributos funcionais

6

$$
\begin{aligned}
& 0008 \\
& 0025 \\
& 0026 \\
& 0027 \\
& 0028 \\
& 0029 \\
& 0030 \\
& 0031
\end{aligned}
$$

$[\cdots]$

0038 - Orçamento no nível do sistema

14

0025

0026

0035

0041

0039 - Avaliação da qualidade

$$
\begin{aligned}
& 0025 \\
& 0026 \\
& 0033 \\
& 0038
\end{aligned}
$$

$[\ldots]$ 
As relações entre as atividades são registradas após a sequência de códigos de identificação dos agentes, por meio da indicação dos códigos atribuídos a cada outra atividade com quem os agentes apresentem alguma interação durante a realização. Diferentemente do que foi observado na explicação do levantamento sobre interfaces dos componentes do edifício, as interações entre agentes responsáveis pelas atividades possuem um sentido determinado, que é considerado pelo mapeamento. Assim, quando a precedência de uma tarefa em relação a outra é indicada ao relacionar seu código logo abaixo dos códigos dos agentes, a relação no sentido inverso não é verdadeira. Para que essa relação de ciclicidade entre atividades seja capturada pelo mapeamento, é preciso que a atividade cujo código foi reportado também reporte o código daquela de que é precedente.

No exemplo indicado pelo Quadro 2D são apresentados dois trechos da sequência de atividades do subprocesso de "Anteprojeto arquitetônico". Indicada no primeiro trecho do exemplo, a atividade "0030 - Gerenciamento dos requisitos" é citada pelas atividades "0031 Revisão e detalhamento de requisitos do cliente", "0032 - Análise de desempenho", "0033 Definição dos atributos funcionais" e "0039 - Avaliação da qualidade". Esta última, indicada no segundo trecho, é referenciada como uma antecedência pela atividade "0031", o que indica uma relação de ciclicidade e, no caso, de iteração.

O terceiro levantamento mapeia as relações de filiação entre as atividades e sua influência sobre a definição dos componentes. Nesse levantamento as atividades são novamente listadas em um documento txt, conforme indicado no Quadro 3D, seguindo a mesma sequência do levantamento anterior. Para cada atividade são relacionados os componentes cuja definição é impactada pelas decisões a ela ligadas. Em seguida, é indicado após uma virgula qual o grau de envolvimento da atividade na definição do componente.

A graduação apresenta três variáveis, sendo que o grau 1 corresponde a um envolvimento indireto sobre o componente, o grau 2 apresenta um envolvimento solidário, e o grau 3 indica um envolvimento direto sobre o componente. Como se pode observar, o levantamento desses dados apresenta maior margem para subjetividade no estudo. Todavia, como o levantamento é realizado sobre um caso existente, e não sobre uma situação ideal, é possível cruzar as informações levantadas com mais de um participante e acareá -las com base em fatos vivenciados, de forma a estabelecer um entendimento consensual. 
Quadro 3D - Estrutura de notação e exemplo de registro das filiações

\section{Estrutura de notação dos componentes do sistema do edifício}

\section{[Subprocesso]}

[código de identificação da atividade] - [descrição da atividade]

[código do componente com interface], [grau de envolvimento]

\section{Exemplo}

[...]

Execução do projeto estrutural

1101 - Marcação das estacas

101,3

102,1

1102 - Perfuração e concretagem das estacas

101,3

102,1

1103 - Execução dos blocos de fundação - subsolo

102,3

103,1

1104 - Execução das vigas baldrames e muros de arrimo - subsolo

103,3

104,3

110,1

701,2

702,1

715,1

652,1

1105 - Forma, armação e concretagem dos pilares - subsolo 106,3

651,1

1106 - Montagem da caixaria das lajes e vigas - subsolo

105,3

107,3

1107 - Forma, armação e concretagem das escadas - subsolo

108,3

105,1

106,1

1108 - Concretagem das lajes e vigas - térreo

105,3

107,3

1109 - Execução dos blocos de fundação - térreo

102,3

103,1

1110 - Execução das vigas baldrames e arrimos da piscina - térreo

103,3

104,3

110,2

701,1

702,2

715,1

$[\ldots]$

652,1 
Além disso, para apoiar a definição do envolvimento e qual é o grau desse envolvimento, foram consideradas as respostas afirmativas para três perguntas indicadas a seguir:

- para o grau 1, "a atividade influência de alguma forma a execução do componente?". Por exemplo, o tamanho de um vão definido na concepção da arquitetura influencia a adoção de uma viga metálica pelo projeto estrutural, mas não há uma indicação nesse sentido;

- para o grau 2, "o componente sofre influência direta por alguma mudança provocada na atividade?". Por exemplo, a superfície da parede e demais elementos muda com o aumento do pé-direito; e

- para o grau 3, "a atividade incorre diretamente sobre o componente?". Por exemplo, o detalhamento de esquadrias determina que tipo de abertura cada porta e janela terá.

Considerando especificamente um exemplo de filiação apresentado pelo Quadro 3D, em que são apresentadas algumas filiações ligadas à execução do projeto estrutural, pode-se observar que foi atribuído a "1104 - Execução das vigas baldrames e muros de arrimo - subsolo" um envolvimento de nível 3 para os componentes vigas baldrame e arrimos; de nível 2 para as estacas e tubulação de esgoto; e de nível 1 para impermeabilização, malha de aterramento e tubulação de água quente e fria.

Nos três levantamento os códigos de identificação dos elementos não possuem formatação rígida, podendo se ajustar a qualquer sistema de codificação preexistente. A única condição é que cada código faça referência a um único elemento de cada conjunto de dados levantados. Os critérios para determinar a relação entre elementos também são flexíveis, podendo ser adequados a objetivos e escalas relacionadas à aplicação do mapeamento.

\section{Tratamento dos resultados}

A partir dos dados obtidos com os três levantamentos registrados, conforme indicado na seção anterior, é possível gerar as representações matriciais dos dados e determinar as relações potenciais de interação total e fortes, assim como as relações de congruência. Para tanto, são empregados recursos computacionais.

O programa de análise organizacional foi programado conforme descrito no método de pesquisa e tem como resultado seis matrizes.

1. $\mathrm{S}_{\mathrm{nn}} \quad$ - Matriz das interfaces dos componentes da arquitetura do edifício

2. $\mathrm{R}_{\mathrm{mm}}$ - Matriz das interações entre as atividades reconhecidas pela organização existente

3. Fmn - Matriz de afiliação dos componentes as atividades

4. $P t_{m m}$ - Matriz com todas as interações potenciais

5. $\mathrm{Pf}_{\mathrm{mm}}$ - Matriz com as interações potenciais fortes

6. $\mathrm{C}_{\mathrm{mm}} \quad$ - Matriz de congruência organizacional 
Além disso, gera dois relatórios, um que apresenta uma lista dos paralelismos e prioridades, e outro que apresenta individualmente as interações previstas, atendidas e não atendidas de cada atividade, bem como quantifica os totais de interação diagnosticados no mapeamento.

As matrizes $S_{n n}$ e $R_{m m}$ interpretam os dados do primeiro e segundo levantamento, indicados binariamente por 0 ou 1 , sendo que 1 indica a existência da relação. A matriz $F_{m n}$ também interpreta o terceiro levantamento, apresentando como retorno a indicação dos níveis 1, 2 e 3. As matrizes Ptmm e $\mathrm{Pf}_{\mathrm{mm}}$ são resultado da equação $<\mathrm{P}_{\mathrm{mm}}=\mathrm{F}_{\mathrm{mn}}$. $\mathrm{S}_{\mathrm{nn}}$. $\mathrm{F}_{\mathrm{nm}}>$, sendo que a primeira considera todas as relações de filiação em $\mathrm{F}_{\mathrm{nm}}$, enquanto a segunda considera apenas as relações de nível 3 de filiação em Fnm. Os números resultantes são diversos, resultados da multiplicação, mas para fim de interpretação são reduzidos a uma relação binária, em que a interação potencial existe ou não. A matriz $\mathrm{C}_{\mathrm{mm}}$ é resultado da sobreposição da matriz $\mathrm{Rmm}$ com as matrizes $\mathrm{Ptmm}_{\mathrm{m}}$ e $\mathrm{Pf}_{\mathrm{mm}}$. Assim como $\mathrm{F}_{\mathrm{mn}}, \mathrm{C}_{\mathrm{mm}}$ também retorna a sequência numérica 1,2 e 3, porém neste caso o significado é outro: o numeral 1 indica as interações fortes não atendidas pelas interações reconhecidas, o número 2 indica as interações totais atendidas, e o número 3 indica as interações reconhecidas não previstas na computação das interações potenciais totais.

A representação das matrizes com indicações coloridas corresponde apenas a uma interface amigável para a interpretação visual dos dados.

\section{Formas de análise dos resultados}

As matrizes e os relatórios compõem a base informacional dos resultados do mapeamento da congruência organizacional. A interpretação desses dados pode ser realizada de diferentes formas, uma vez que tanto os objetos como a escala e abrangência da análise muda são ajustáveis a especificidades de cada organização e dos objetivos do mapeamento. Todavia, algumas orientações básicas podem ser apresentadas para apoiar a leitura e a interpretação das matrizes.

A matriz $\mathrm{S}_{\mathrm{nn}}$ apresenta as interfaces entre componentes do sistema construtivo, o que permite identificar a possibilidade de modulação de subsistemas independentes, associado a um gerenciamento de acoplamentos nas interfaces limites, que estão fora dos quadrantes dos subsistemas, conforme destacado na Figura 1D. No caso, a delimitação transversal definida pelo cruzamento da linha e coluna de um mesmo componente não possui implicações analíticas predefinidas, uma vez que a interface não tem sentido, todavia a programação pode ser adaptada para incorporar uma relação de conter/contido não considerada no presente método de mapeamento. 
Figura 1D - Trecho de um exemplo de matriz $S_{n n}$

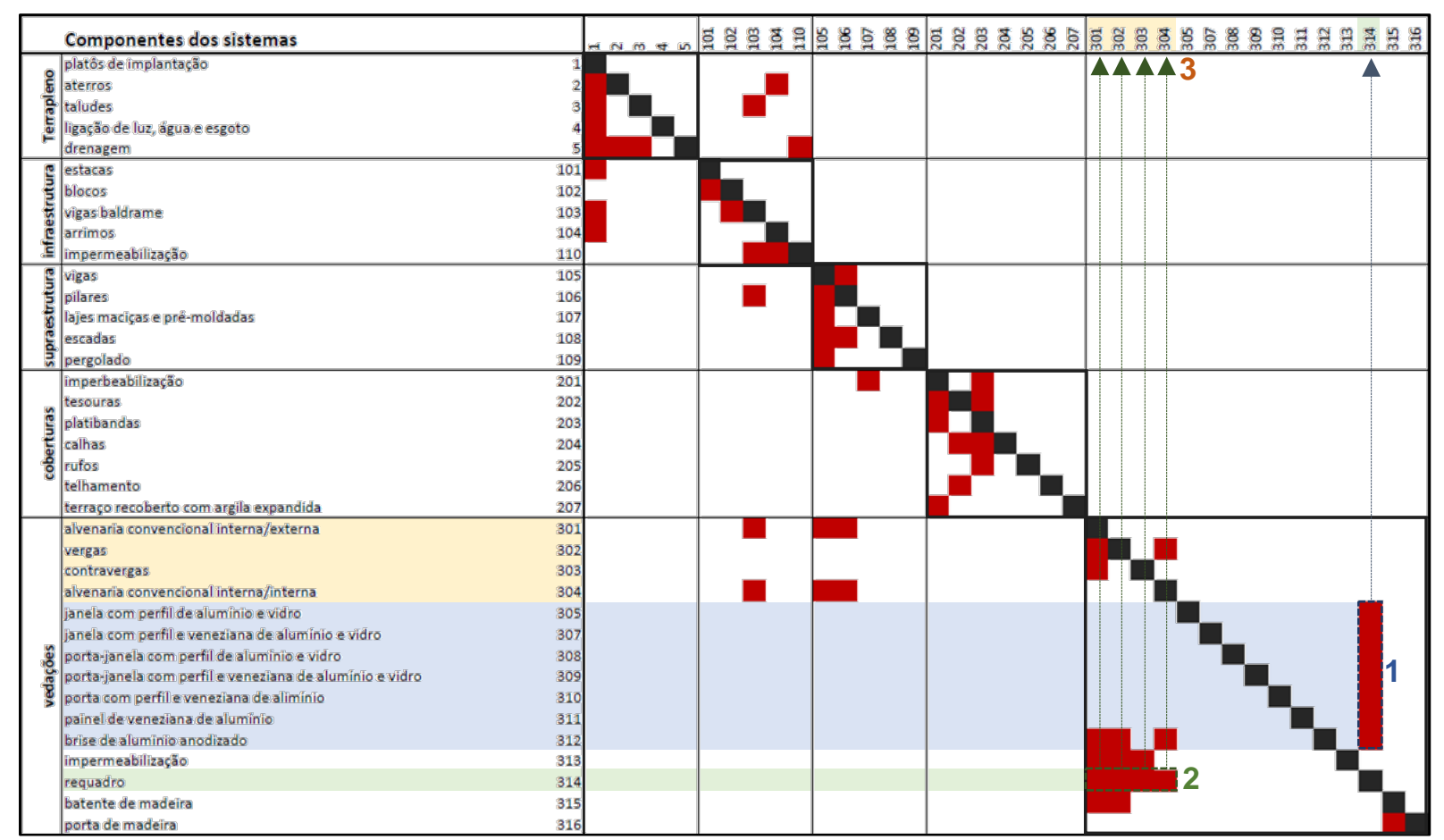

Em um sistema integrado, com um sistema construtivo convencional de estrutura de concreto moldada in loco e alvenaria cerâmica executada sobre vigas, a relevância da definição dos acoplamentos de subsistemas é menos relevante do que em sistemas industrializados, em que a predefinição das regras de acoplamento deve ser definida sob o risco de incompatibilidade. É o caso da necessidade de requadros adequados para esquadrias de alumínio (ver 1 na Figura 1D), que delimitam as condições de acoplamento com a precisão da abertura (2) na vedação que as esquadrias não produzidas no local demandam das vergas, contravergas, alvenarias internas e externas (3).

A matriz $\mathrm{R}_{\mathrm{mm}}$ apresenta as interações existentes entre as atividades do processo, bem como os agentes responsáveis por cada atividade e os subprocessos que agrupam essas atividades em dada unidade organizacional (Figura 2D). A delimitação transversal observada na matriz $R_{\mathrm{mm}}$ é definida pelo cruzamento da linha e da coluna de uma mesma atividade. Diferentemente do que se observa no caso anterior, essa transversal é fundamental para a análise, uma vez que estabelece o limite que distingue as atividades identificadas como sequenciais e cíclicas em dado processo. Como as atividades estão agrupadas de acordo com os subprocessos existentes na organização mapeada, as interações além desses limites merecem especial atenção gerencial, principalmente quando cíclicas. 
Figura 2D - Trecho de um exemplo de matriz $R_{m m}$

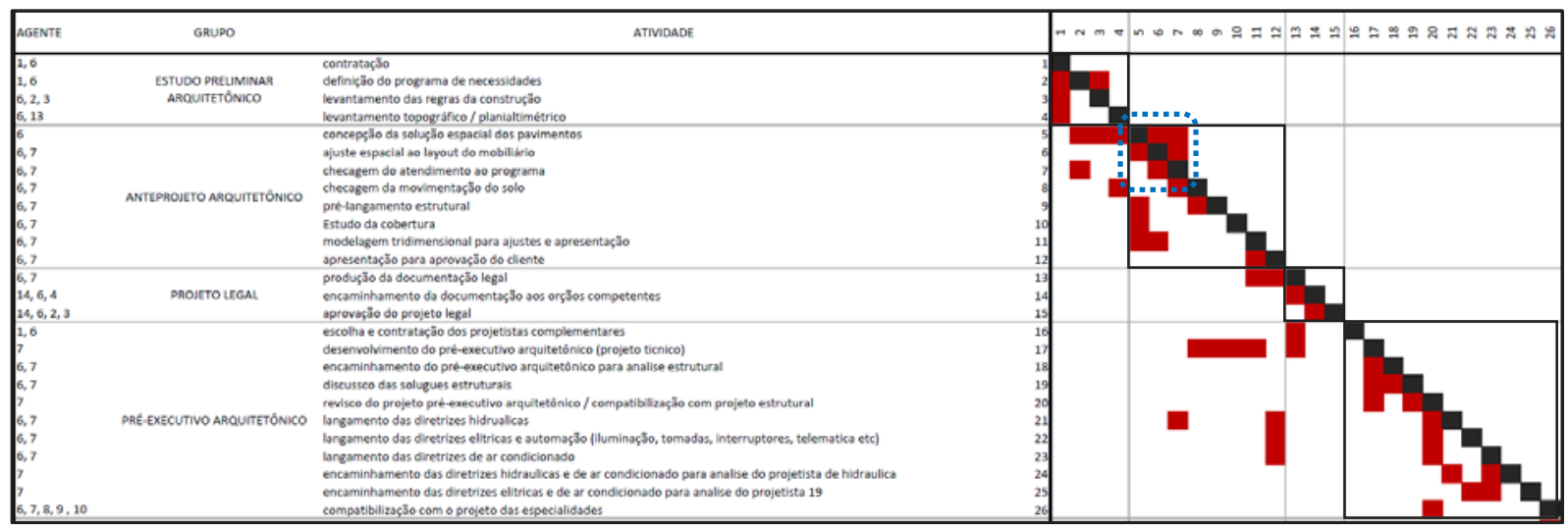

Casos de interações cíclicas, como no destaque em pontilhado da Figura 2D, que não pertençam a um único subprocesso implicam problemas de iteratividade, isto é, problemas de se confirmar a adequação dos resultados por interrupção no ciclo das atividades. O exemplo apresenta uma situação adequada, em que os agentes responsáveis pelas atividades podem avançar e retomar as atividades de forma a incrementar o conteúdo necessário para obter o resultado esperado. Caso contrário, algum ajuste organizacional deve ser realizado para viabilizar a iteração entre atividades com interação cíclica. O exemplo ainda mostra as relações de interação entre atividades sequenciais que estão em dois subprocessos distintos, o que demanda atenção do gerenciamento do projeto.

A matriz $\mathrm{F}_{\mathrm{mn}}$ apresenta as relações de filiação entre os componentes do sistema e as atividades do processo que os desenvolvem e produzem, estabelecendo uma hierarquia dessa filiação, considerando diferentes graus de correlação entre a atividade feita e os resultados obtidos, caso a caso. A leitura dessa matriz permite compreender quais atividades são as principais responsáveis por cada subsistema e confirmar a concentração delas em um subprocesso, como indicam os destaques na Figura 3D. A indicação 1 relaciona o sistema de integração ao estudo preliminar e anteprojeto arquitetônico. A indicação 2 relaciona parte dos sistemas de vedação, de revestimentos e acabamento, e de equipamentos construtivos e acessórios ao detalhamento arquitetônico. A indicação 3 relaciona os sistemas de infraestrutura, superestrutura e cobertura ao projeto pré-executivo e executivo estrutural.

Tanto a matriz $\mathrm{Pt}_{\mathrm{mm}}$ como a matriz $\mathrm{Pf}_{\mathrm{mm}}$ não possuem uma leitura visual específica, sendo utilizadas para o processamento da matriz $\mathrm{C}_{\mathrm{mm}}$. 
Figura 3D - Trecho de um exemplo de matriz $F_{m n}$

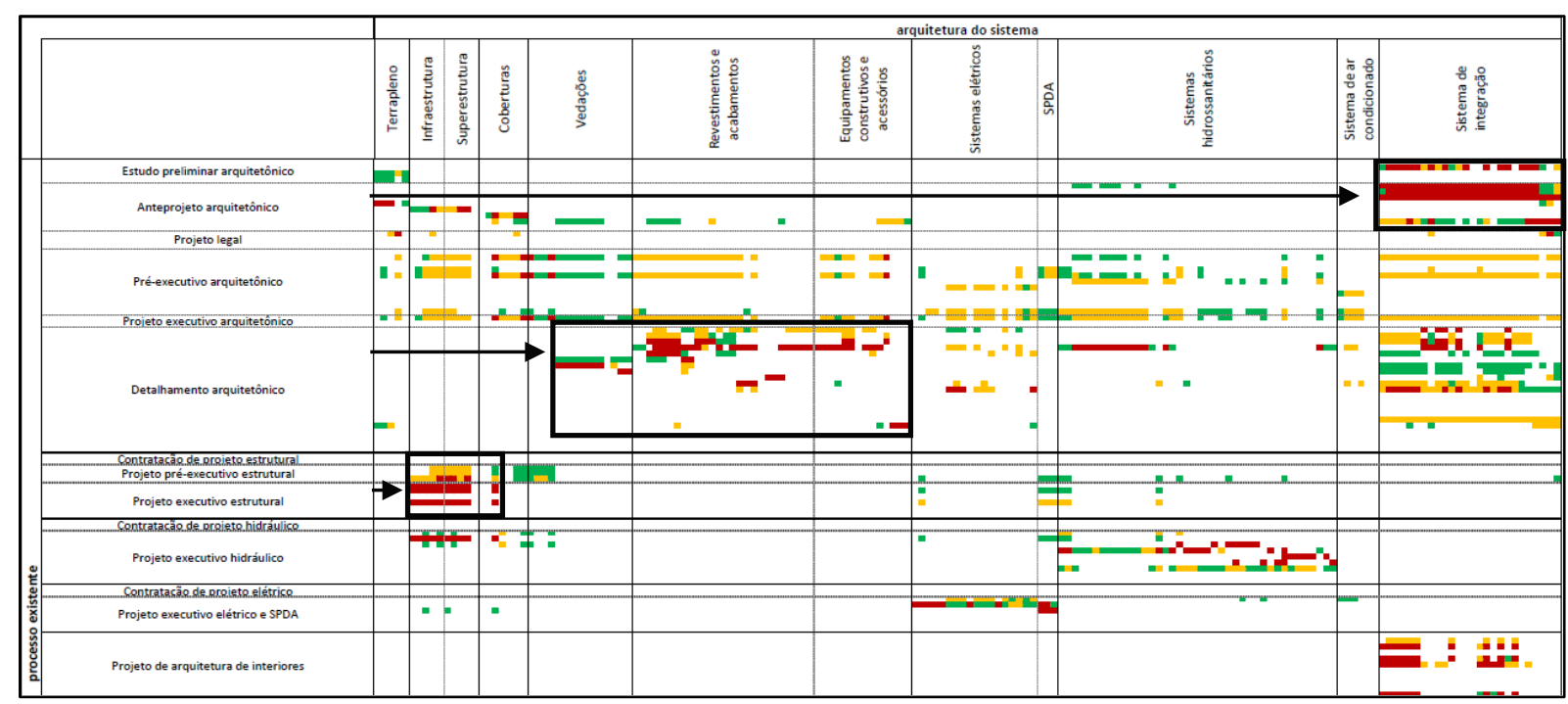

Nível de envolvimento:

1

Quando o impacto de das definições de uma atividade influencia características do componente, sem atribuição responsabilidade

\section{2}

Quando a responsabilidade sobre a definição do componente é compartilhada I negociada por duas ou mais atividades

\section{3}

Quando a atividade detém a responsabilidade exclusiva de concepção, execução ou instalação do componente

A matriz $\mathrm{C}_{\mathrm{mm}}$ apresenta o resultado da sobreposição da matriz $\mathrm{R}_{\mathrm{mm}}$, e a matriz $\mathrm{Pt}_{\mathrm{mm}}$ com a matriz $\mathrm{Pf}_{\mathrm{mm}}$. Por meio dessa sobreposição a matriz evidencia a congruência entre o sistema e o processo, apontando as interações potenciais que são e não são atendidas pelas interações previstas, bem como as interações que não foram previstas pela computação de todas as interações potenciais (Figura 4D).

Por definição, as interações atendidas indicam congruência organizacional entre sistema e produto. As interações não previstas devem ser investigadas e podem significar que as relações de filiação indicadas não são condizentes com a realidade da organização, ou que as interações previstas são atividades que não agregam valor, cabendo um estudo de como assimilar seu escopo por outras atividades congruentes. As interações não atendidas correspondem àquelas não previstas pelo levantamento e são potencialmente importantes para a realização das atividades.

Assim como foi observado na matriz $\mathrm{R}_{\mathrm{mm}}$, as interações de atividades localizadas à direita/superior da transversal são tipificadas como interações cíclicas, que dependem de informação de atividades a jusante do processo de projeto, o que demanda o reconhecimento dessa relação e definição de estratégias de coordenação, como promover as condições de colaboração entre agentes responsáveis pelas atividades. O esforço inicial é reduzir ao mínimo as atividades cíclicas não atendidas para reduzir a complexidade do processo e direcionar a atenção do gerenciamento para os casos de interação não atendidos reminiscentes. 
Figura 4D - Trecho de um exemplo de matriz $\mathrm{C}_{\mathrm{mm}}$

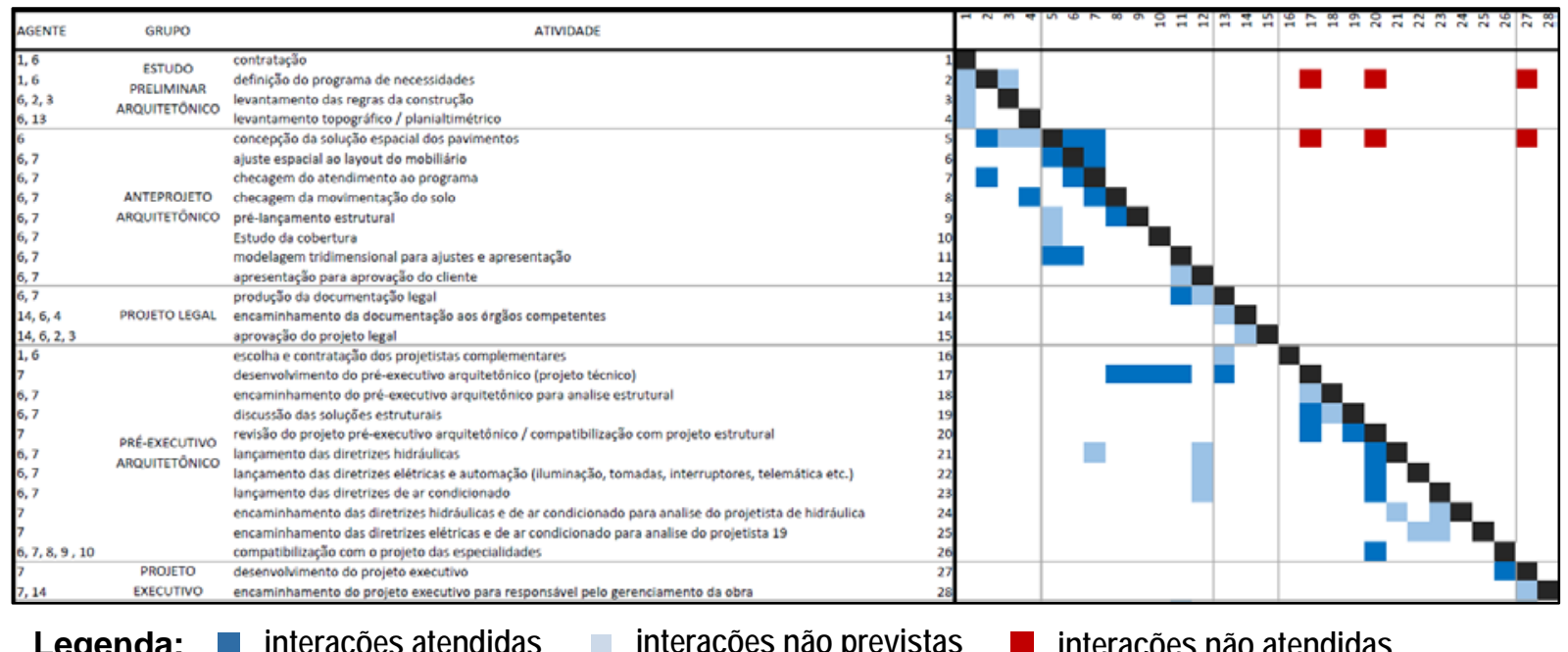

Diante de um quadro de impossibilidade de reduzir interações não atendidas por meio de ajustes na organização existente e mantendo-se um nível entendido como alto de incongruência, cabe ao responsável pela gestão estratégica da organização do empreendimento decidir por uma alteração estrutural.

A proposição de uma nova arquitetura pode apresentar diferentes motivações e objetivos, cabendo um estudo individual. Também é importante ressaltar que como ainda não existe uma métrica geral que balize a determinação de um alto nível de incongruência, esta definição também é arbitrada estrategicamente, com base no levantamento do desempenho da organização existente. Caso a utilização deste sistema de análise organizacional seja utilizado suficientemente e tais incursões sejam documentadas de forma adequada, é possível consolidar métricas a partir de um histórico de mapeamentos.

Acredita-se que os procedimentos para o mapeamento da congruência organizacional descritos, foram adequados para serem utilizados em empreendimentos imobiliários. A descrição de tais procedimentos, embora sucinta, apresentou os principais aspectos levantados pela pesquisa, do levantamento a análise dos resultados. Espera-se que com esta contribuição novos estudos sejam estimulados, para o aperfeiçoamento e identificação de novas aplicações do método, e que a aplicação profissional do mapeamento seja profícua em diagnosticar a situação existente e servir de suporte à decisões em nível estratégico visando o aperfeiçoamento e inovação de processos em AEC. 
Apêndice E Matriz da Arquitetura do Sistema (Snn) - edifício

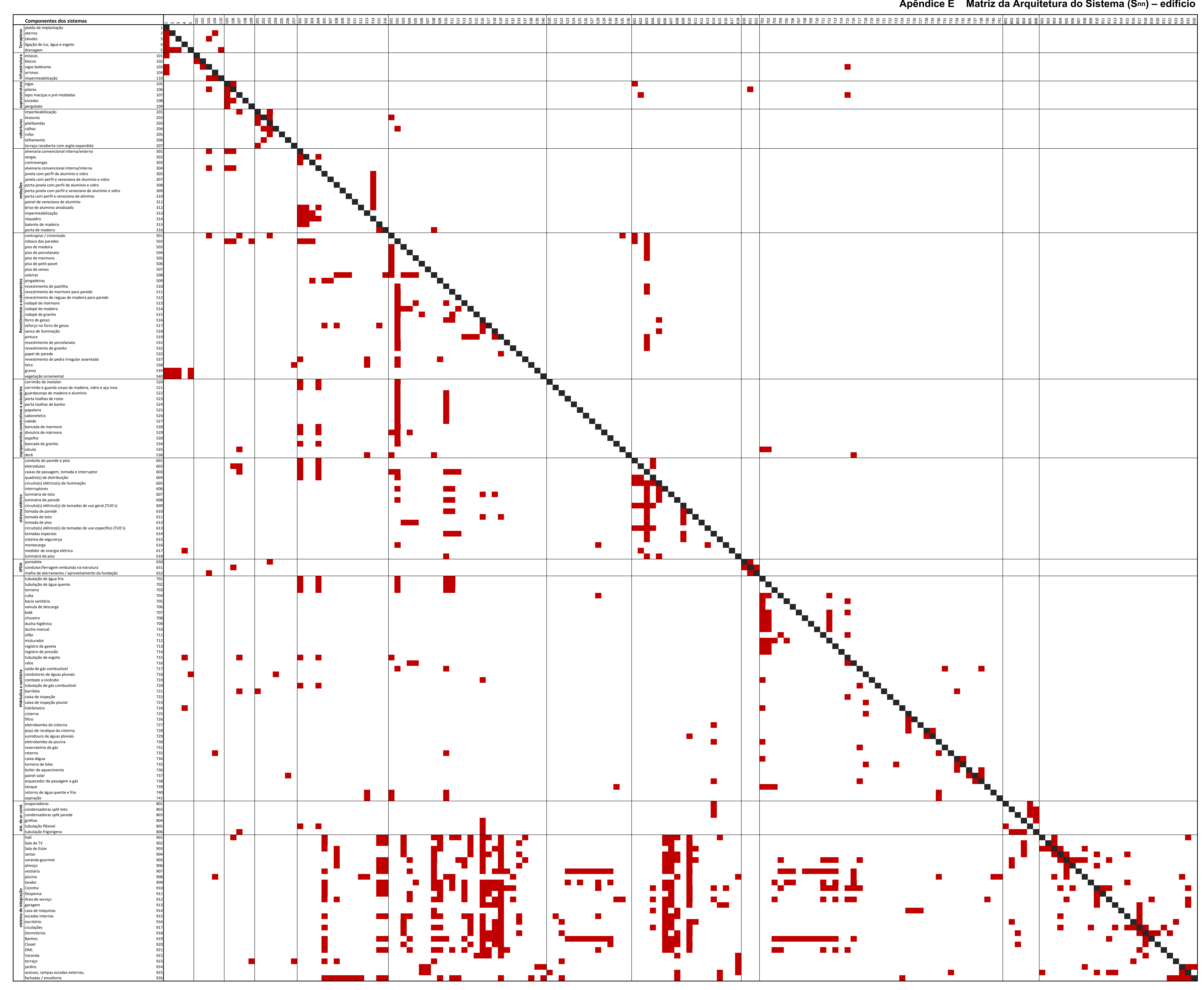


Apêndice $F$ Matriz de interações reconhecidas $\left(\boldsymbol{R}_{m m}\right)$ - empreendimento existente

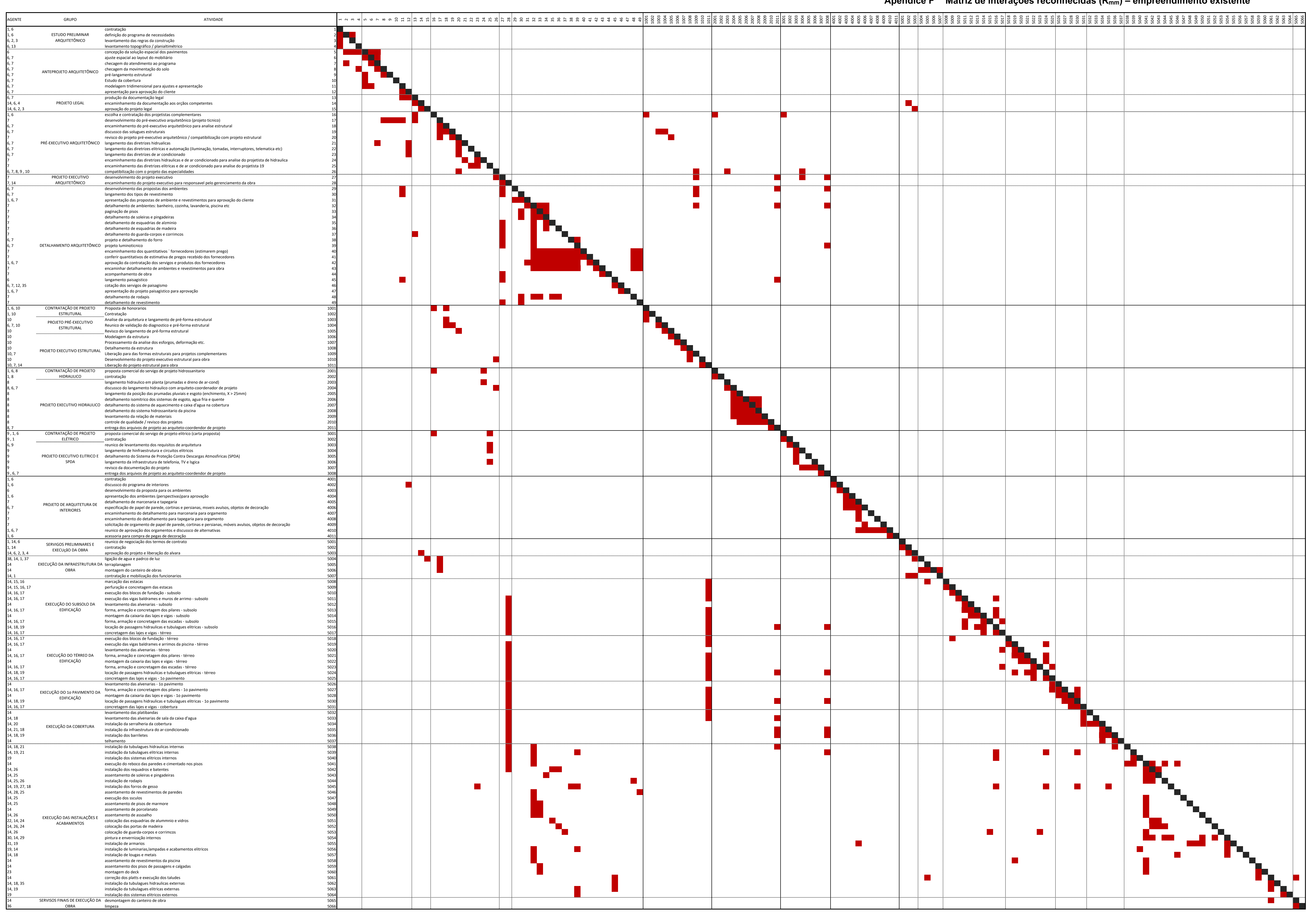




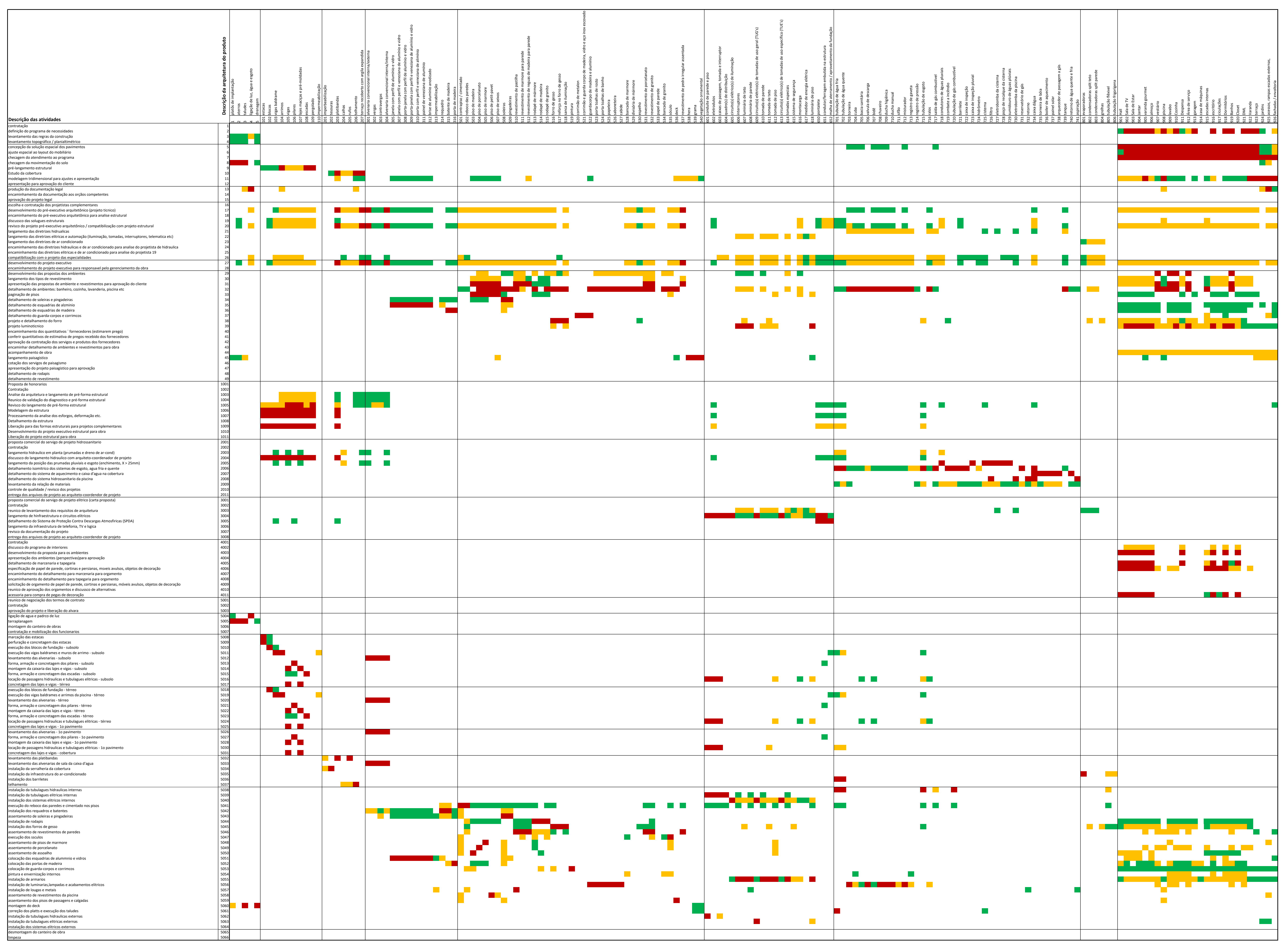




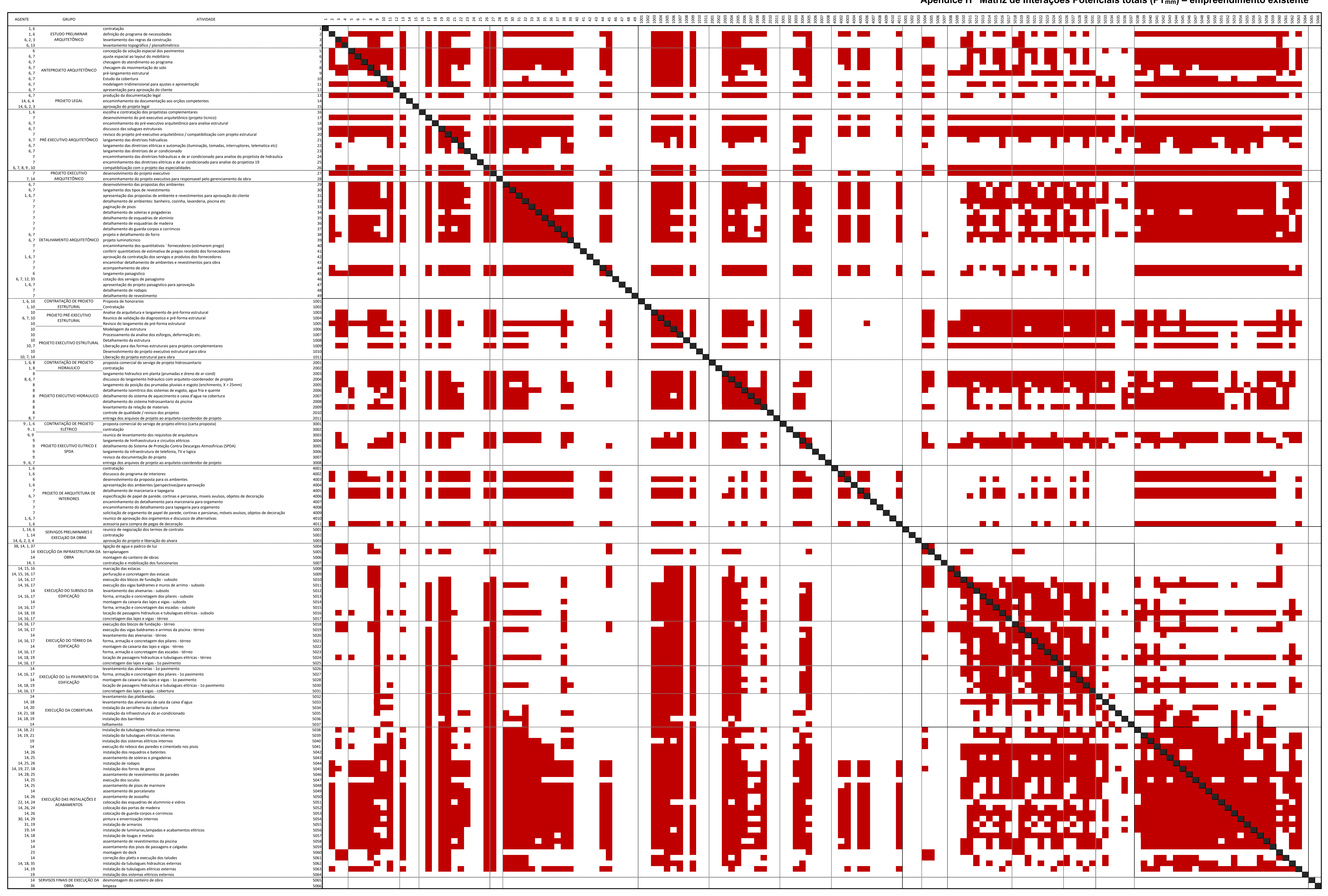


Apêndice I Matriz de Interaçōes Potenciais fortes $\left(\mathrm{PF}_{\mathrm{mm}}\right)$ - empreendimento existente

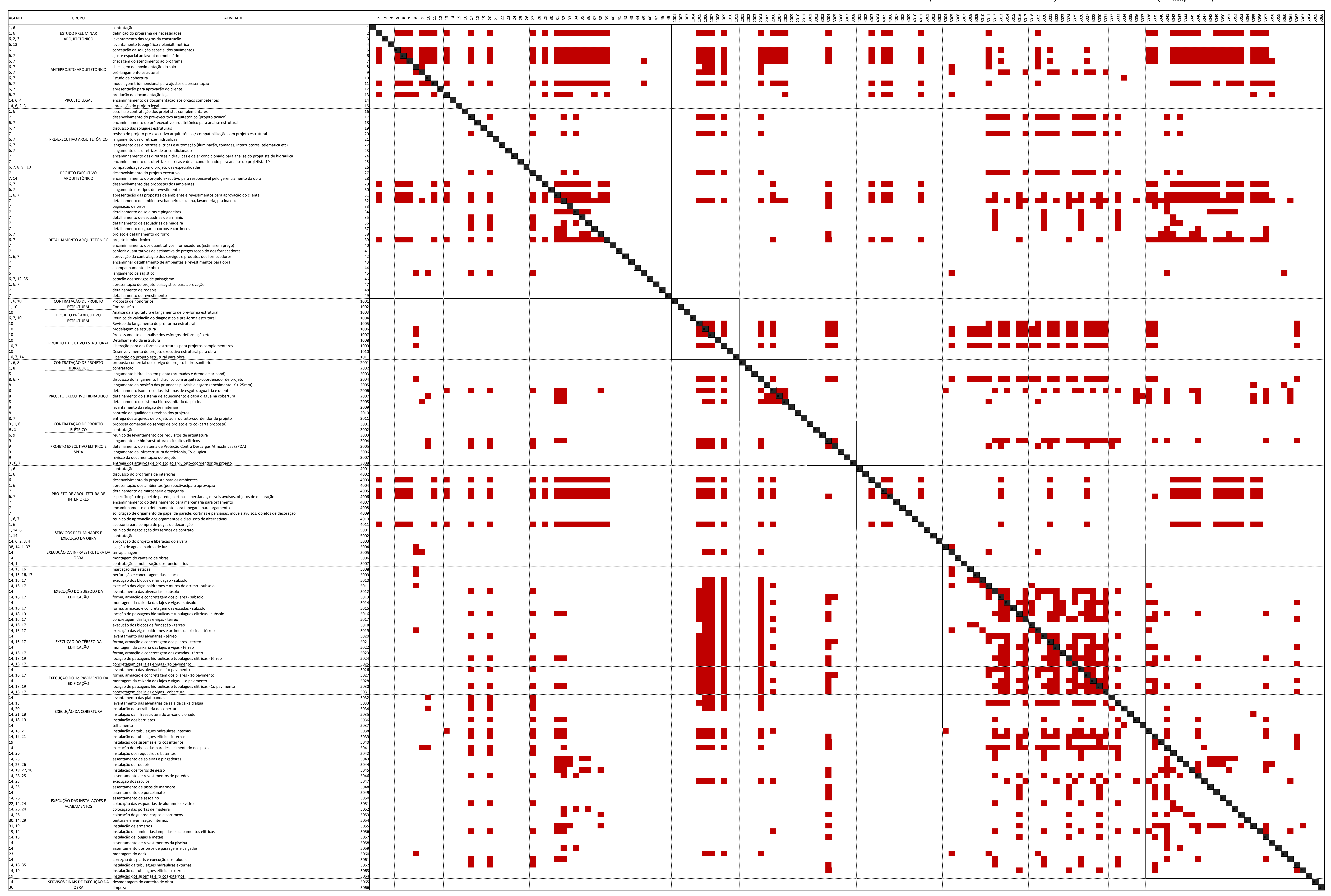




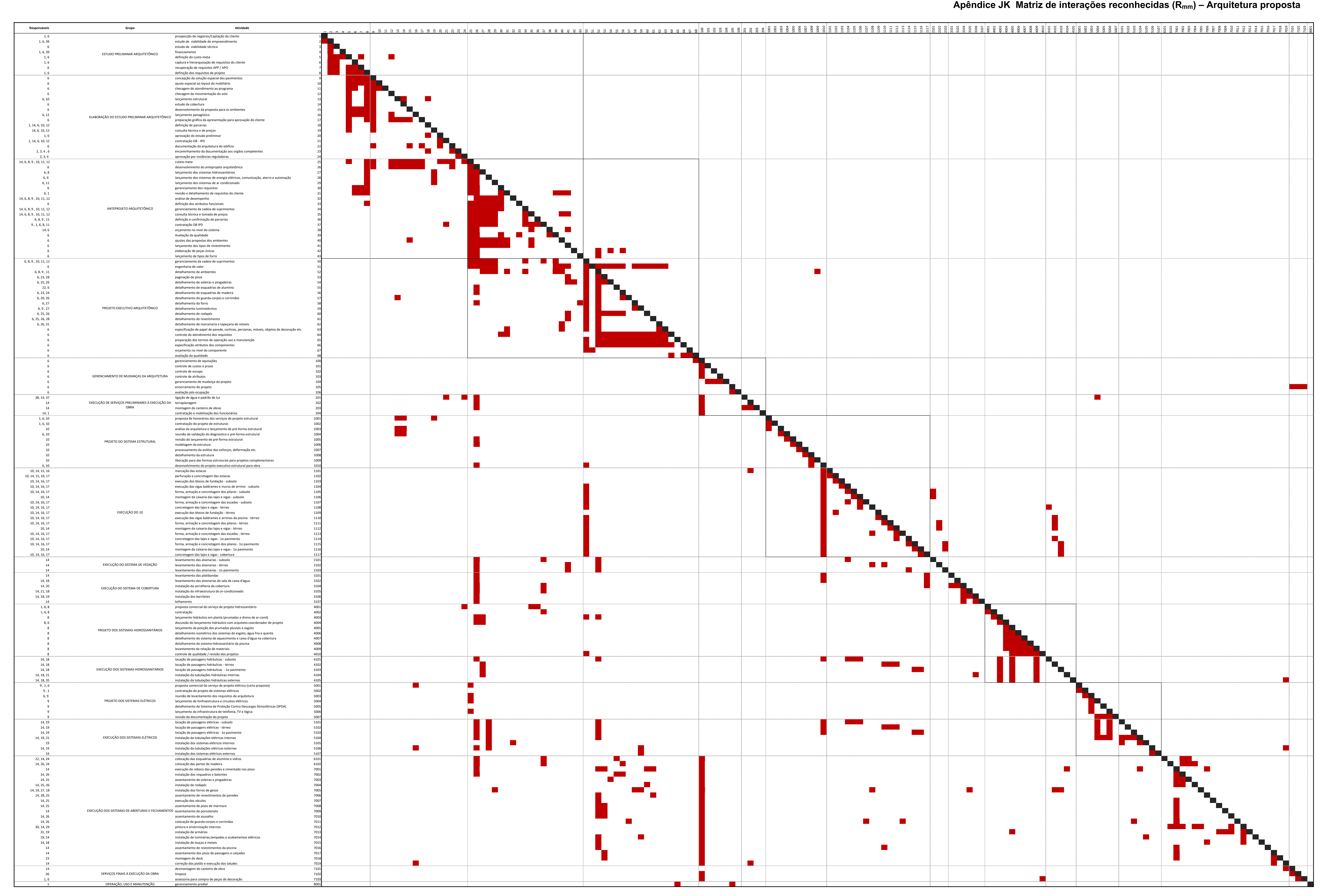




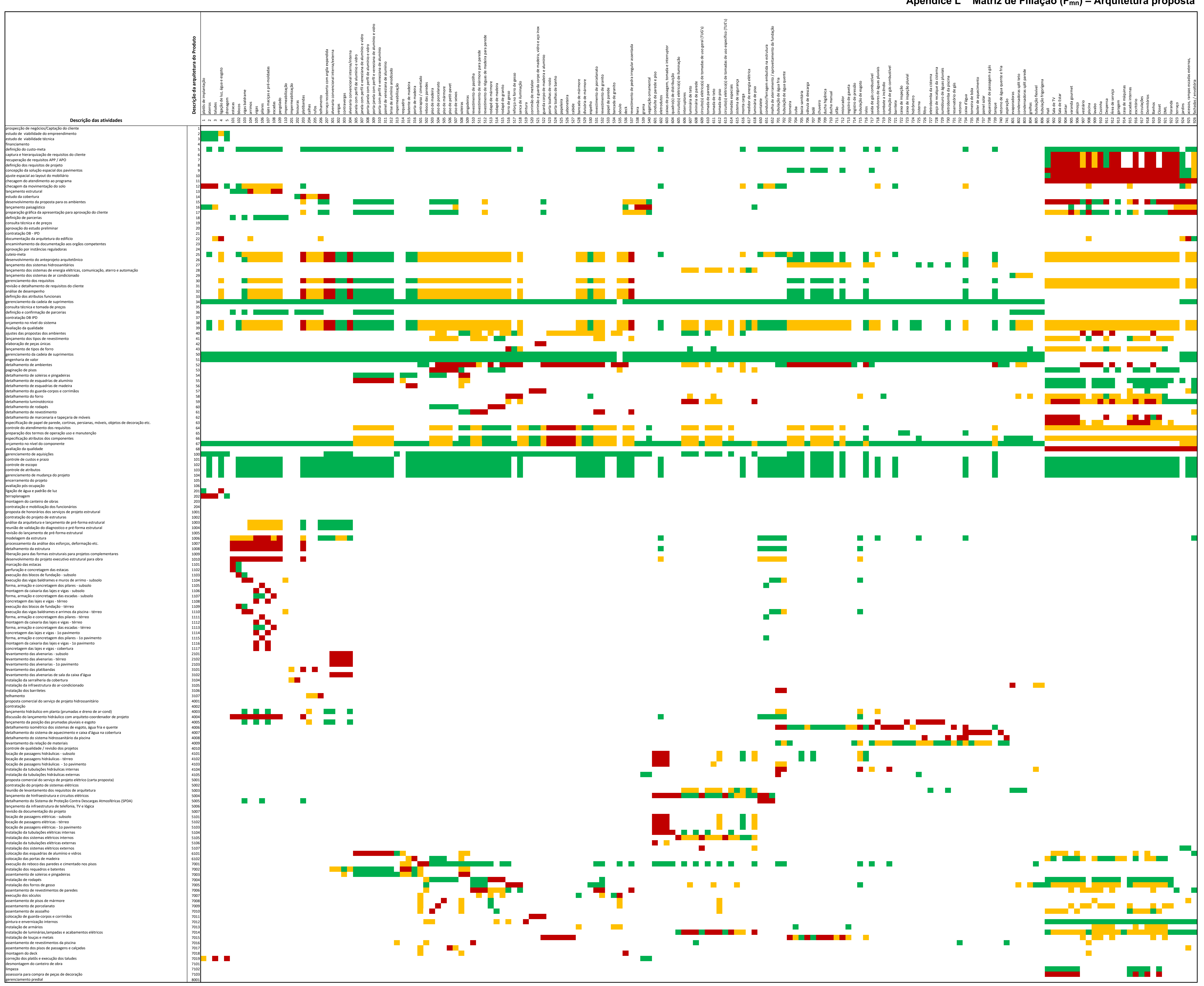




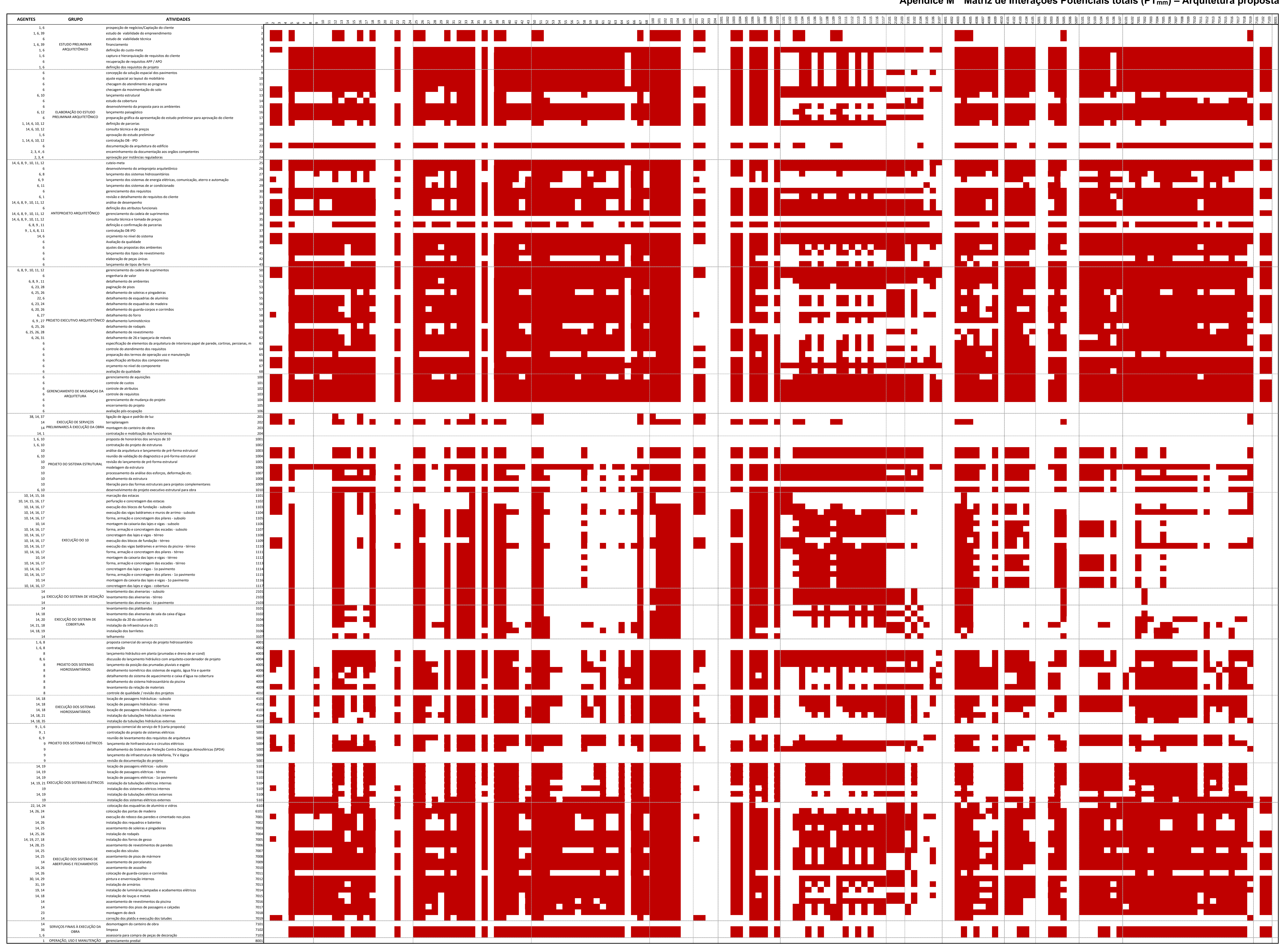


Apêndice $\mathbf{N}$ Matriz de Interações Potenciais fortes $\left(\mathrm{PF}_{\mathrm{mm}}\right)$ - Arquitetura proposta

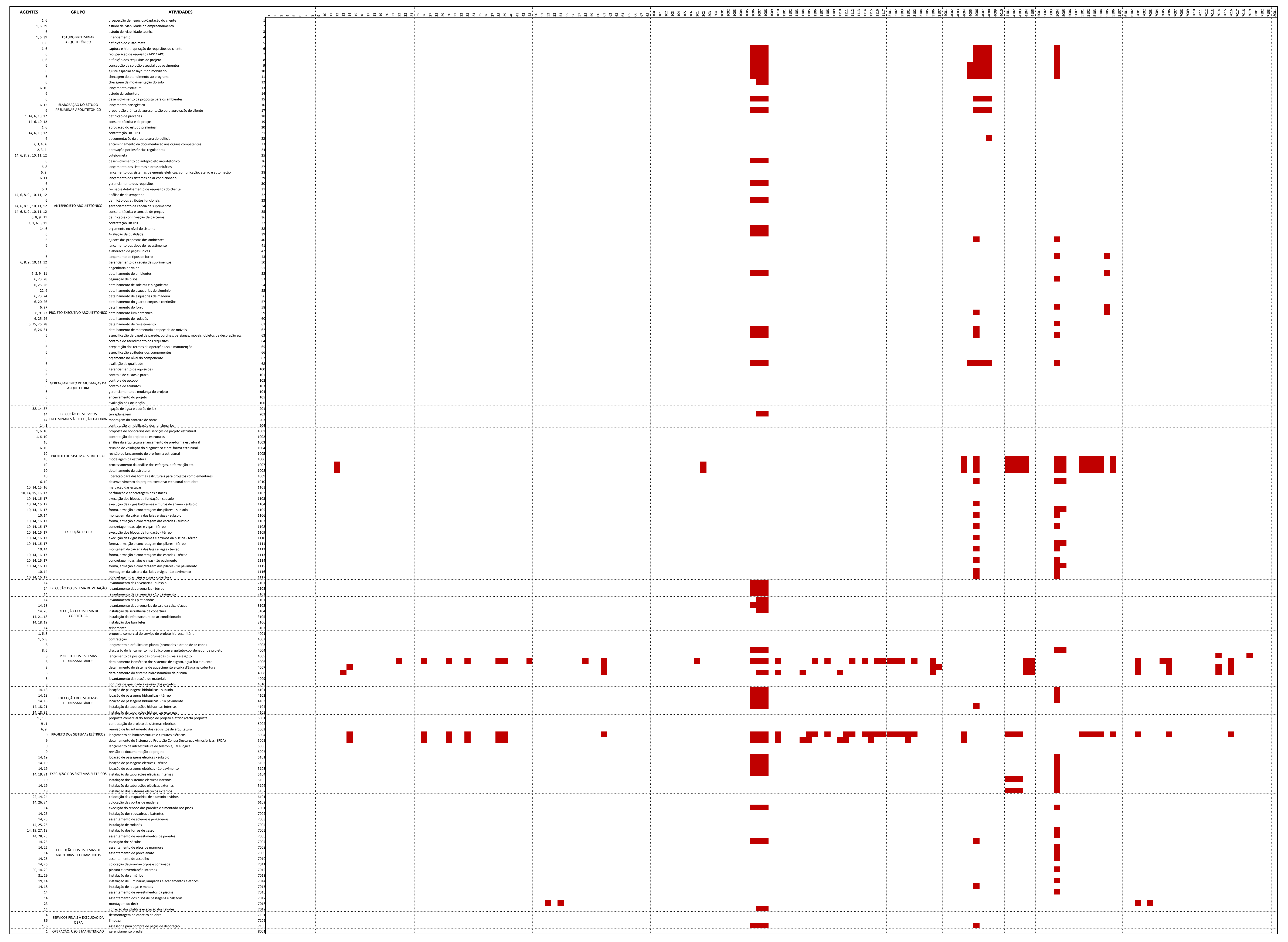


Apêndice $O$ Matriz de Congruência $\left(C_{m m}\right)$ - Arquitetura proposta

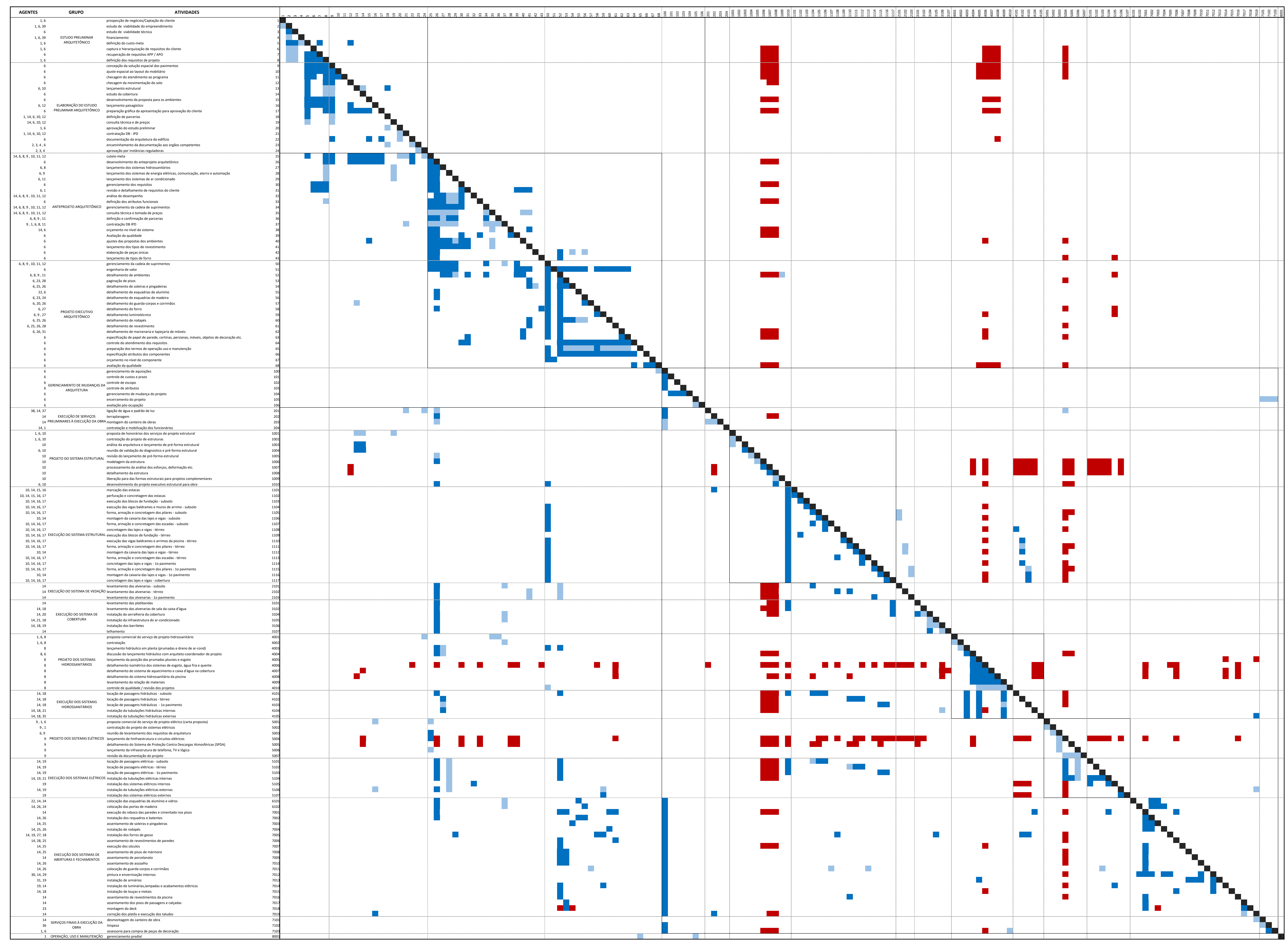

